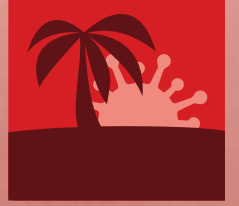

\title{
Tropical Medicine and
} Infectious Disease

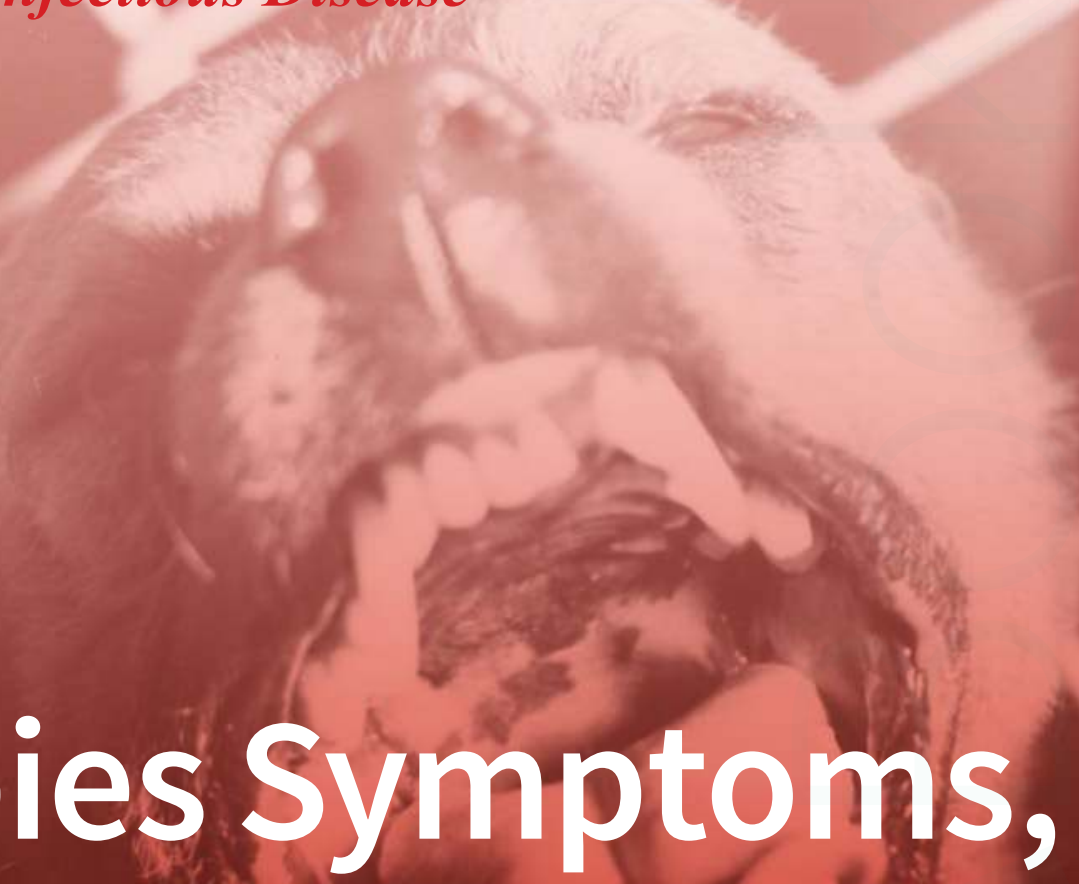

Rabies Syn

Prophylaxis and

\section{Treatment}

Edited by Charles Rupprecht, Bernhard Dietzschold Printed Edition of the Special Issue Published in Tropical Medicine and Infectious Disease 


\section{Rabies Symptoms, Diagnosis, Prophylaxis and Treatment}

Special Issue Editors

Charles Rupprecht

Bernhard Dietzschold

MDPI • Basel • Beijing • Wuhan • Barcelona $\bullet$ Belgrade

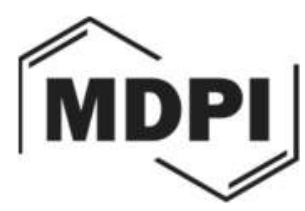


Special Issue Editors

Charles Rupprecht

Bernhard Dietzschold

The Wistar Institute Thomas Jefferson University

USA USA

Editorial Office

MDPI AG

St. Alban-Anlage 66

Basel, Switzerland

This edition is a reprint of the Special Issue published online in the open access journal Tropical Medicine and Infectious Disease (ISSN 2414-6366) in 2017

(available at: http://www.mdpi.com/journal/tropicalmed/special_issues/rabies).

For citation purposes, cite each article independently as indicated on the article page online and as indicated below:

Lastname, F.M.; Lastname, F.M. Article title. Journal Name. Year. Article number, page range.

First Edition 2018

ISBN 978-3-03842-682-0 (Pbk)

ISBN 978-3-03842-683-7 (PDF)

Articles in this volume are Open Access and distributed under the Creative Commons Attribution license (CC BY), which allows users to download, copy and build upon published articles even for commercial purposes, as long as the author and publisher are properly credited, which ensures maximum dissemination and a wider impact of our publications. The book taken as a whole is (C) 2018 MDPI, Basel, Switzerland, distributed under the terms and conditions of the Creative Commons license CC BY-NC-ND (http://creativecommons.org/licenses/by-nc-nd/4.0/). 


\section{Table of Contents}

About the Special Issue Editors vii

Charles E. Rupprecht and Bernhard Dietzschold

Special Issue: Rabies Symptoms, Diagnosis, Prophylaxis, and Treatment

Reprinted from: Trop. Med. Infect. Dis. 2017, 2(4), 59; doi: 10.3390/tropicalmed2040059 .1

\section{Arnaud Tarantola}

Four Thousand Years of Concepts Relating to Rabies in Animals and Humans, Its Prevention and Its Cure

Reprinted from: Trop. Med. Infect. Dis. 2017, 2(2), 5; doi: 10.3390/tropicalmed2020005. .5

David Durrheim

Childhood Rabies Deaths and the Rule of Rescue

Reprinted from: Trop. Med. Infect. Dis. 2017, 2(2), 9; doi: 10.3390/tropicalmed2020009. .26

Emily G Pieracci, Terence P Scott, Andre Coetzer, Mwatondo Athman, Arithi Mutembei, Abraham Haile Kidane, Meseret Bekele, Girma Ayalew, Samson Ntegeyibizaza, Justine Assenga, Godson Markalio, Peninah Munyua, Louis H Nel and Jesse Blanton The Formation of the Eastern Africa Rabies Network: A Sub-Regional Approach to Rabies Elimination

Reprinted from: Trop. Med. Infect. Dis. 2017, 2(3), 29; doi: 10.3390/tropicalmed2030029 . .30

Andre Coetzer, Jessica Coertse, Mabusetsa Joseph Makalo, Marosi Molomo, Wanda Markotter and Louis Hendrik Nel

Epidemiology of Rabies in Lesotho: The Importance of Routine Surveillance and Virus Characterization

Reprinted from: Trop. Med. Infect. Dis. 2017, 2(3), 30; doi: 10.3390/tropicalmed2030030 .35

Monique Lechenne, Rolande Mindekem, Séraphin Madjadinan, Assandi Oussiguéré, Daugla Doumagoum Moto, Kemdongarti Naissengar and Jakob Zinsstag The Importance of a Participatory and Integrated One Health Approach for Rabies Control: The Case of N'Djaména, Chad

Reprinted from: Trop. Med. Infect. Dis. 2017, 2(3), 43; doi: 10.3390/tropicalmed2030043 . .49

Alexandra M. Medley, Max Francois Millien, Jesse D. Blanton, Xiaoyue Ma, Pierre Augustin, Kelly Crowdis and Ryan M. Wallace

Retrospective Cohort Study to Assess the Risk of Rabies in Biting Dogs, 2013-2015,

Republic of Haiti

Reprinted from: Trop. Med. Infect. Dis. 2017, 2(2), 14; doi: 10.3390/tropicalmed2020014

Janine F. R. Seetahal, Alexandra Vokaty, Christine V.F. Carrington, Abiodun A. Adesiyun, Ron Mahabir, Avery Q. J. Hinds and Charles E. Rupprecht The History of Rabies in Trinidad: Epidemiology and Control Measures Reprinted from: Trop. Med. Infect. Dis. 2017, 2(3), 27; doi: 10.3390/tropicalmed2030027 .78

Ricardo Castillo-Neyra, Edith Zegarra, Ynes Monroy, Reyno F. Bernedo, Ismael Cornejo-Rosello, Valerie A. Paz-Soldan and Michael Z. Levy Spatial Association of Canine Rabies Outbreak and Ecological Urban Corridors, Arequipa, Peru Reprinted from: Trop. Med. Infect. Dis. 2017, 2(3), 38; doi: 10.3390/tropicalmed2030038 
Philippe Buchy, Scott Preiss, Ved Singh and Piyali Mukherjee

Heterogeneity of Rabies Vaccination Recommendations across Asia

Reprinted from: Trop. Med. Infect. Dis. 2017, 2(3), 23; doi: 10.3390/tropicalmed2030023

Maria B. Palamar, Maria T. Correa, Nils M. Peterson and Christopher S. DePerno

Public Preference for Pet-Rabies Prophylaxis: Opportunities and Information Dissemination

Reprinted from: Trop. Med. Infect. Dis. 2017, 2(3), 46; doi: 10.3390/tropicalmed2030046 .120

Scott Bender, David Bergman, Adrian Vos, Ashlee Martin and Richard Chipman

Field Studies Evaluating Bait Acceptance and Handling by Dogs in Navajo Nation, USA

Reprinted from: Trop. Med. Infect. Dis. 2017, 2(2), 17; doi: 10.3390/tropicalmed2020017

Timothy P. Algeo, Dennis Slate, Rosemary M. Caron, Todd Atwood, Sergio Recuenco,

Mark J. Ducey, Richard B. Chipman and Michael Palace

Modeling Raccoon (Procyon lotor) Habitat Connectivity to Identify Potential Corridors for

Rabies Spread

Reprinted from: Trop. Med. Infect. Dis. 2017, 2(3), 44; doi: 10.3390/tropicalmed2030044 .140

Kevin Middel, Christine Fehlner-Gardiner, Natalie Pulham and Tore Buchanan

Incorporating Direct Rapid Immunohistochemical Testing into Large-Scale Wildlife

Rabies Surveillance

Reprinted from: Trop. Med. Infect. Dis. 2017, 2(3), 21; doi: 10.3390/tropicalmed2030021

Brian M. Bjorklund, Betsy S. Haley, Ryan J. Bevilacqua, Monte D. Chandler, Anthony G. Duffiney, Karl W. von Hone, Dennis Slate, Richard B. Chipman, Ashlee Martin and Timothy P. Algeo

Progress towards Bait Station Integration into Oral Rabies Vaccination Programs in the

United States: Field Trials in Massachusetts and Florida

Reprinted from: Trop. Med. Infect. Dis. 2017, 2(3), 40; doi: 10.3390/tropicalmed2030040

Betsy S. Haley, Timothy P. Algeo, Brian Bjorklund, Anthony G. Duffiney, Robert Edwin Hartin, Ashlee Martin, Kathleen M. Nelson, Richard B. Chipman and Dennis Slate

Evaluation of Bait Station Density for Oral Rabies Vaccination of Raccoons in Urban and Rural

Habitats in Florida

Reprinted from: Trop. Med. Infect. Dis. 2017, 2(3), 41; doi: 10.3390/tropicalmed2030041

Dennis Slate, Jordona D. Kirby, Daniel P. Morgan, Timothy P. Algeo, Charles V. Trimarchi, Kathleen M. Nelson, Robert J. Rudd, Adam R. Randall, Mark S. Carrara and Richard B. Chipman

Cost and Relative Value of Road Kill Surveys for Enhanced Rabies Surveillance in Raccoon

Rabies Management

Reprinted from: Trop. Med. Infect. Dis. 2017, 2(2), 13; doi: 10.3390/tropicalmed2020013

Jordona D. Kirby, Richard B. Chipman, Kathleen M. Nelson, Charles E. Rupprecht, Jesse D. Blanton, Timothy P. Algeo and Dennis Slate

Enhanced Rabies Surveillance to Support Effective Oral Rabies Vaccination of Raccoons in the Eastern United States

Reprinted from: Trop. Med. Infect. Dis. 2017, 2(3), 34; doi: 10.3390/tropicalmed2030034 .197 
Susan M. Moore, Amy Gilbert, Ad Vos, Conrad M. Freuling, Christine Ellis, Jeannette Kliemt and Thomas Müller

Rabies Virus Antibodies from Oral Vaccination as a Correlate of Protection against Lethal Infection in Wildlife

Reprinted from: Trop. Med. Infect. Dis. 2017, 2(3), 31; doi: 10.3390/tropicalmed2030031

Todd G. Smith and Amy T. Gilbert

Comparison of a Micro-Neutralization Test with the Rapid Fluorescent Focus Inhibition Test for Measuring Rabies Virus Neutralizing Antibodies

Reprinted from: Trop. Med. Infect. Dis. 2017, 2(3), 24; doi: 10.3390/tropicalmed2030024 .235

Dinchi A. Tyem, Banenat B. Dogonyaro, Timothy A. Woma, Ernest Chuene Ngoepe and Claude Taurai Sabeta

Sero-Surveillance of Lyssavirus Specific Antibodies in Nigerian Fruit Bats (Eidolon helvum)

Reprinted from: Trop. Med. Infect. Dis. 2017, 2(3), 26; doi: 10.3390/tropicalmed2030026

Richard D. Suu-Ire, Anthony R. Fooks, Ashley C. Banyard, David Selden, Kofi Amponsah-Mensah, Silke Riesle, Meyir Y. Ziekah, Yaa Ntiamoa-Baidu, James L. N. Wood and Andrew A. Cunningham

Lagos Bat Virus Infection Dynamics in Free-Ranging Straw-Colored Fruit Bats (Eidolon helvum)

Reprinted from: Trop. Med. Infect. Dis. 2017, 2(3), 25; doi: 10.3390/tropicalmed2030025 .245

Joe Kgaladi, Milosz Faber, Bernhard Dietzschold, Louis H. Nel and Wanda Markotter Pathogenicity and Immunogenicity of Recombinant Rabies Viruses Expressing the Lagos Bat Virus Matrix and Glycoprotein: Perspectives for a Pan-Lyssavirus Vaccine Reprinted from: Trop. Med. Infect. Dis. 2017, 2(3), 37; doi: 10.3390/tropicalmed2030037

Aurore Lebrun, Samantha Garcia, Jianwei Li, Rhonda B. Kean and D. Craig Hooper

Protection Against CNS-Targeted Rabies Virus Infection is Dependent upon Type-1 Immune Mechanisms Induced by Live-Attenuated Rabies Vaccines

Reprinted from: Trop. Med. Infect. Dis. 2017, 2(3), 22; doi: 10.3390/tropicalmed2030022

Richard Franka, William C. Carson, James A. Ellison, Steven T. Taylor, Todd G. Smith, Natalia A. Kuzmina, Ivan V. Kuzmin, Wilfred E. Marissen and Charles E. Rupprecht In Vivo Efficacy of a Cocktail of Human Monoclonal Antibodies (CL184) Against Diverse North American Bat Rabies Virus Variants

Reprinted from: Trop. Med. Infect. Dis. 2017, 2(3), 48; doi: 10.3390/tropicalmed2030048 .282

Mary Warrell, David A. Warrell and Arnaud Tarantola

The Imperative of Palliation in the Management of Rabies Encephalomyelitis Reprinted from: Trop. Med. Infect. Dis. 2017, 2(4), 52; doi: 10.3390/tropicalmed2040052 


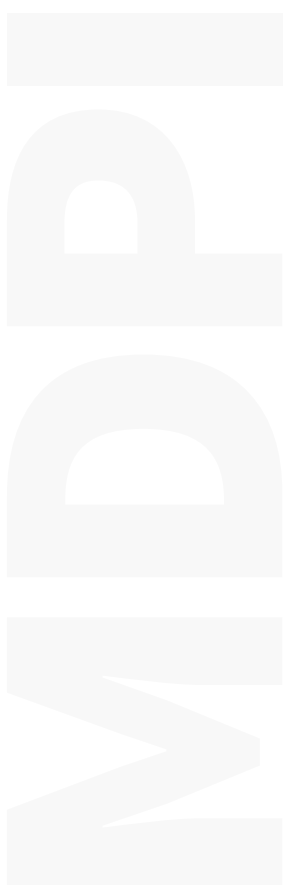




\section{About the Special Issue Editors}

Charles Rupprecht received his under graduate degree at Rutgers University, his MS and PhD from the University of Wisconsin and his VMD from the University of Pennsylvania. He remains active in the field as a biomedical consultant with over 35 years of research experience in rabies and other infectious diseases with academia, government, industry and NGOs, with more than 350 peer-reviewed publications to date.

Bernhard Dietzschold is an alumnus of the Wistar Institute and a distinguished Professor Emeritus, retired from Thomas Jefferson University, with more than 200 peer-reviewed publications spanning in excess of 50 years of research experience in working on rabies and other infectious diseases. 

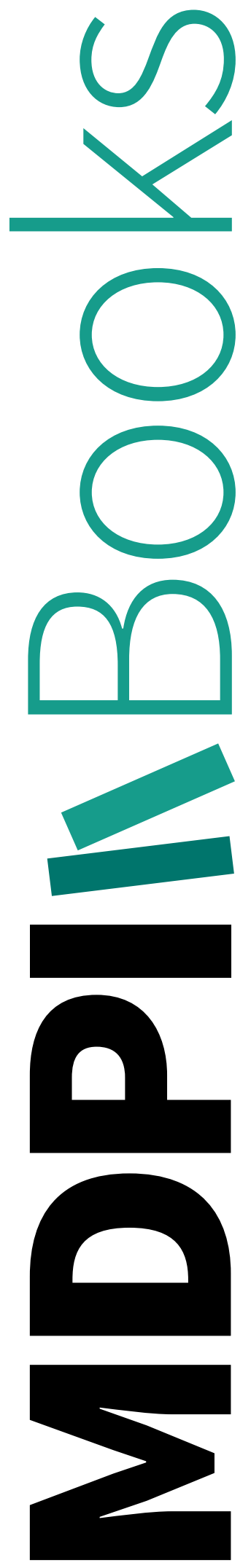


\title{
Special Issue: Rabies Symptoms, Diagnosis, Prophylaxis, and Treatment
}

\author{
Charles E. Rupprecht ${ }^{1, *}$ and Bernhard Dietzschold ${ }^{2}$ \\ 1 LYSSA LLC, Cumming, GA 30040, USA \\ 2 Department of Microbiology and Immunology, Thomas Jefferson University, Philadelphia, PA 19107, USA; \\ Bernhard.Dietzschold@jefferson.edu \\ * Correspondence: charles_rupprecht@yahoo.com; Tel.: +1-770-736-0217
}

Received: 6 November 2017; Accepted: 8 November 2017; Published: 14 November 2017

Rabies is an acute, progressive, incurable viral encephalitis found throughout the world. Despite being one of the oldest recognized pathogens, its impact remains substantial in public health, veterinary medicine, and conservation biology. Thus, it is essential to apply existing tools and to seek new methods to improve upon prevention, control, selective variant elimination, and treatment efforts. Advances in diagnosis, vaccinology, pathobiology, and related research techniques continue to afford enhanced insights on rabies. Although rabies is not a candidate for eradication, the results of these innovative communications provide further knowledge to define a more optimal approach to understanding and managing this complex infectious disease of nature on a global basis in a One Health context.

More than 24 papers have been published upon peer review acceptance in this special issue (20 original papers, 1 perspectives piece, and 4 review papers are included). They each contribute to a much better understanding of this disease and to advances concerning the improvements for rabies management. These topics can be summarized as follows:

The clarion call for action was sounded in a perspective by David Durrheim that provides an ideal framework for the ongoing tragedy exemplified by childhood deaths from rabies and application of the necessary steps to end this situation now [1]. Such a thoughtful piece is made all the more enigmatic considering the breakthroughs that have occurred over the millennia, as reviewed by Tarantola [2] and which appear to remain somewhat complicated in practice or ignored in diverse and disparate regions, such as across Asia and in the Caribbean, as reviewed by Buchy et al. [3] at a continental focus, and Seetahal et al. [4] locally for Trinidad (where the unique appreciation of rabies in vampire bats was one of the first examples to be documented and investigated in the New World), respectively.

One underlying theme is paramount: the key to reducing human rabies deaths is the mass vaccination of dogs, which serve as the major global reservoir responsible for the substantial public health burden today. A much better appreciation of the human animal bond, with a focus upon pet prophylaxis as the primary strategy to overcome many public health impacts of rabies, is supported by the work of Palamar et al. [5]. All developed countries have eliminated canine-transmitted rabies. Increasingly, developing countries have also achieved this success, especially in the New World. However, even in North America, reintroduction from abroad or via wildlife is a concern, with a feasible solution for free-ranging dogs in distinct communities such as the Navajo nation, as described by Bender et al. [6]. Additionally, uncontrolled foci at affected borders remain a threat as long as rabies remains in a region, as evidenced in the account from Peru by Castillo-Neyra et al. [7]. Foci remain within Central and South America, as well as the Caribbean. In Haiti, the country most affected by rabies in the New World, Medley et al. [8] present a concept of applied risk assessments combined with a laboratory-based diagnostics focus upon protocols to ensure that exposed individuals receive the needed prophylaxis in a resource-limited environment. In the same vein in the Old World, Lechenne et al. [9] for Chad and Coetzer et al. [10] for Lesotho, discuss the utility of surveillance 
and control by mass vaccination of dogs as a critical component for relief of the human rabies burden. Such focal projects there and elsewhere demonstrate the need for a pan-African approach, as championed by Pieracci et al. [11].

As described in the above communications, human rabies may be prevented and dog rabies can be eliminated. However, cross-species transmission complicates what appears to be a somewhat simple system. All warm-blooded vertebrates are susceptible to infection. Beyond dogs, meso-carnivores also act to perpetuate the disease in the Americas, Eurasia, and Africa. Perhaps uniquely among the zoonoses, vaccination against rabies can be applied to such free-ranging populations. In fact, western Europe is largely free of rabies by oral vaccination of red foxes and raccoon dogs. Similar successful programs are operative in North America against gray foxes and coyotes. Subjectively, the meso-carnivore species of greatest concern in Canada and the USA is the raccoon (Procyon lotor), as discussed by the following series of related papers. Kirby et al. [12] describe a system for enhanced surveillance of raccoon rabies in the eastern USA. Slate et al. [13] present the data on the use of a tiered system of suspect animals and index of activity centered upon road-killed raccoons. In concert, the use of a decentralized enhanced laboratory-surveillance system using a direct rapid immuno-histochemical test contributes not only to a highly sensitive and specific method concentrated on suspect wildlife in the USA, but also in Canada, as described for a new focus of raccoon rabies in southern Ontario, by Middel et al. [14]. Using the information from public health and wildlife rabies detection, Algeo et al. [15] formulated a model to track raccoon rabies spread over landscape corridors, as an approach to understanding its epizootiology and management from the aerial distribution of vaccine-laden baits. This method is efficient across broad areas but cannot be used easily in urban and suburban ecosystems. Hence, bait stations may prove useful in reaching these distinct raccoon populations, as described in Massachusetts and Florida by Bjorkland et al. [16] and Haley et al. [17].

Besides rabies virus, at least 15 other lyssaviruses cause this disease and more are expected for additional pathogen discovery. Cross-reactivity for all veterinary and human rabies vaccines may be limited against some of these lyssavirus species. To this effect, Kgaladi et al. describe an experimental approach to develop a panlyssavirus vaccine [18]. In addition to prevention or control concerns, relatively little is understood about the pathobiology of these diverse lyssaviruses in their various hosts, such as bats. Suu-Ire et al. describe the results from experimental infection of bats to one major lyssavirus, Lagos bat virus [19]. Similarly, when routine surveillance of wildlife is lacking, enhanced detection may be needed to augment a description of regional lyssavirus reservoirs. Virus neutralizing antibodies are one of the most critical immune effector products in vaccine-mediated immunity in all studied species, regardless of administration route, as well as in abortive infection, but the dilemma in drawing firm conclusions about absolute sero-protection dynamics among wildlife from investigations to date is summarized by Moore et al. [20]. Regarding serology, Tyem et al. utilized sero-surveillance in bat populations to fill in such gaps [21]. However, because many bats are small-bodied, limits to blood volume collection may be a liability for such surveys. Smith and Gilbert [22] describe a micro-neutralization test that can help overcome such issues for focal serological work in laboratory and field applications.

The blood-brain barrier is a formidable concern when trying to deliver certain biologics to the CNS, especially in the treatment of encephalitis. To this end, data on further technological improvement for the use of a highly attenuated rabies virus recombinant vaccine in disease prevention and potential treatment is offered by Lebrun et al. [23]. Needs for improved passive immunity via alternative methods to polyclonal immune globulins, such as monoclonal antibodies (MAb), were first described at the end of the 1970s. Since then, numerous studies have shown the utility of these products as a potential replacement for rabies immune globulin. To this effect, another example of some of the epidemiological complexities posed by bat rabies virus variants, for a broadly reactive MAb candidate is discussed by Franka et al. [24].

Finally, Warrell et al. [25] can be understood in a similar context as the issue discussion began-rabies can be prevented by rapid and appropriate postexposure prophylaxis, but retains 
the title as the entity with the highest case fatality. As such, once clinical signs manifest, frustration and futility ensue for all involved. Rather than be treated as a pariah, at a very minimum, modern medicine offers palliation to the victim afflicted with this heinous affliction, as attempts for treatment continue. Towards this latter point, a challenge is presented to veterinarians at large to use their considerable time, talent and treasure to vaccinate all companion animals at risk and begin to develop safe and effective measures to treat clinical rabies as it presents in the domestic animals under their charge, given their oath and the biomedical tools at hand now, first by palliation at the very least and predictably by intervention. All veterinarians and their staff should be vaccinated, reliving a major concern from the unvaccinated physicians and nurses that care for rabies patients now. In this manner, a better collective approach will evolve for all species at hand, including Homo sapiens. Please recall that Pasteur, a biochemist, embarked on this controversial path from animal models to Joseph Meister and, at one time, canine vaccination was viewed as an unrealistic fantasy-it is far time the veterinary profession accepted the same responsibility towards the 'incurable wound' as true One Health demands.

In retrospect, the comparative number and the diversity of papers, the depth of the topics and the geographical reach of the authors from the Americas, Africa, Eurasia, and Australia in this special issue on rabies confirm the continued collective major interest in this area. This eclectic open access collection contributes to a much better understanding on the detection, prevention, control, selective elimination, and eventual therapy of this ancient zoonosis. We hope that you may enjoy digesting their content as much as we were pleased to share them with an international audience and look forward to future opportunities to broaden such success to the field at large. Optimistically, if even a single individual is inspired by a new thought in one of these manuscripts, then our objective is accomplished.

Conflicts of Interest: The authors declare no conflict of interest.

\section{References}

1. Durrheim, D. Childhood rabies deaths and the rule of rescue. Trop. Med. Infect. Dis. 2017, 2, 9. [CrossRef]

2. Tarantola, A. Four thousand years of concepts relating to rabies in animals and humans, its prevention and its cure. Trop. Med. Infect. Dis. 2017, 2, 5. [CrossRef]

3. Buchy, P.; Preiss, S.; Singh, V.; Mukherjee, P. Heterogeneity of rabies vaccination recommendations across Asia. Trop. Med. Infect. Dis. 2017, 2, 23. [CrossRef]

4. Seetahal, J.F.R.; Vokaty, A.; Carrington, C.V.; Adesiyun, A.A.; Mahabir, R.; Hinds, A.Q.J.; Rupprecht, C.E. The history of rabies in Trinidad: Epidemiology and control measures. Trop. Med. Infect. Dis. 2017, 2, 27. [CrossRef]

5. Palamar, M.B.; Correa, M.T.; Peterson, N.M.; DePerno, C.S. Public preference for pet-rabies prophylaxis: Opportunities and information dissemination. Trop. Med. Infect. Dis. 2017, 2, 46. [CrossRef]

6. Bender, S.; Bergman, D.; Vos, A.; Martin, A.; Chipman, R. Field studies evaluating bait acceptance and handling by dogs in Navajo Nation, USA. Trop. Med. Infect. Dis. 2017, 2, 17. [CrossRef]

7. Castillo-Neyra, R.; Zegarra, E.; Monroy, Y.; Bernedo, R.F.; Cornejo-Rosello, I.; Paz-Soldan, V.A.; Levy, M.Z. Spatial association of canine rabies outbreak and ecological urban corridors, Arequipa, Peru. Trop. Med. Infect. Dis. 2017, 2, 38. [CrossRef]

8. Medley, A.M.; Millien, M.F.; Blanton, J.D.; Ma, X.; Augustin, P.; Crowdis, K.; Wallace, R.M. Retrospective cohort study to assess the risk of rabies in biting dogs, 2013-2015, Republic of Haiti. Trop. Med. Infect. Dis. 2017, 2, 14. [CrossRef]

9. Lechenne, M.; Mindekem, R.; Madjadinan, S.; Oussiguéré, A.; Moto, D.D.; Naissengar, K.; Zinsstag, J. The importance of a participatory and integrated One Health approach for rabies control: The case of N’Djaména, Chad. Trop. Med. Infect. Dis. 2017, 2, 43. [CrossRef]

10. Coetzer, A.; Coertse, J.; Makalo, M.J.; Molomo, M.; Markotter, W.; Nel, L.H. Epidemiology of rabies in Lesotho: The importance of routine surveillance and virus characterization. Trop. Med. Infect. Dis. 2017, 2, 30. [CrossRef] 
11. Pieracci, E.G.; Scott, T.P.; Coetzer, A.; Athman, M.; Mutembei, A.; Kidane, A.H.; Bekele, M.; Ayalew, G.; Ntegeyibizaza, S.; Assenga, J.; et al. The formation of the Eastern Africa Rabies Network: A sub-regional approach to rabies elimination. Trop. Med. Infect. Dis. 2017, 2, 29. [CrossRef] [PubMed]

12. Kirby, J.D.; Chipman, R.B.; Nelson, K.M.; Rupprecht, C.E.; Blanton, J.D.; Algeo, T.P.; Slate, D. Enhanced rabies surveillance to support effective oral rabies vaccination of raccoons in the eastern United States. Trop. Med. Infect. Dis. 2017, 2, 34. [CrossRef]

13. Slate, D.; Kirby, J.D.; Morgan, D.P.; Algeo, T.P.; Trimarchi, C.V.; Nelson, K.M.; Rudd, R.J.; Randall, A.R.; Carrara, M.S.; Chipman, R.B. Cost and relative value of road kill surveys for enhanced rabies surveillance in raccoon rabies management. Trop. Med. Infect. Dis. 2017, 2, 13. [CrossRef]

14. Middel, K.; Fehlner-Gardiner, C.; Pulham, N.; Buchanan, T. Incorporating direct rapid immunohistochemical testing into large-scale wildlife rabies surveillance. Trop. Med. Infect. Dis. 2017, 2, 21. [CrossRef]

15. Algeo, T.P.; Slate, D.; Caron, R.M.; Atwood, T.; Recuenco, S.; Ducey, M.J.; Chipman, R.B.; Palace, M. Modeling raccoon (Procyon lotor) habitat connectivity to identify potential corridors for rabies spread. Trop. Med. Infect. Dis. 2017, 2, 44. [CrossRef]

16. Bjorklund, B.M.; Haley, B.S.; Bevilacqua, R.J.; Chandler, M.D.; Duffiney, A.G.; von Hone, K.W.; Slate, D.; Chipman, R.B.; Martin, A.; Algeo, T.P. Progress towards bait station integration into oral rabies vaccination programs in the United States: Field trials in Massachusetts and Florida. Trop. Med. Infect. Dis. 2017, 2, 40. [CrossRef]

17. Haley, B.S.; Algeo, T.P.; Bjorklund, B.; Duffiney, A.G.; Hartin, R.E.; Martin, A.; Nelson, K.M.; Chipman, R.B.; Slate, D. Evaluation of bait station density for oral rabies vaccination of raccoons in urban and rural habitats in Florida. Trop. Med. Infect. Dis. 2017, 2, 41. [CrossRef]

18. Kgaladi, J.; Faber, M.; Dietzschold, B.; Nel, L.H.; Markotter, W. Pathogenicity and immunogenicity of recombinant rabies viruses expressing the Lagos bat virus matrix and glycoprotein: Perspectives for a pan-lyssavirus vaccine. Trop. Med. Infect. Dis. 2017, 2, 37. [CrossRef]

19. Suu-Ire, R.D.; Fooks, A.R.; Banyard, A.C.; Selden, D.; Amponsah-Mensah, K.; Riesle, S.; Ziekah, M.Y.; Ntiamoa-Baidu, Y.; Wood, J.L.N.; Cunningham, A.A. Lagos bat virus infection dynamics in free-ranging straw-colored fruit bats (Eidolon helvum). Trop. Med. Infect. Dis. 2017, 2, 25. [CrossRef]

20. Moore, S.M.; Gilbert, A.; Vos, A.; Freuling, C.M.; Ellis, C.; Kliemt, J.; Müller, T. Rabies virus antibodies from oral vaccination as a correlate of protection against lethal infection in wildlife. Trop. Med. Infect. Dis. 2017, 2, 31. [CrossRef]

21. Tyem, D.A.; Dogonyaro, B.B.; Woma, T.A.; Ngoepe, E.C.; Sabeta, C.T. Sero-surveillance of lyssavirus specific antibodies in Nigerian fruit bats (Eidolon helvum). Trop. Med. Infect. Dis. 2017, 2, 26. [CrossRef]

22. Smith, T.G.; Gilbert, A.T. Comparison of a micro-neutralization test with the rapid fluorescent focus inhibition test for measuring rabies virus neutralizing antibodies. Trop. Med. Infect. Dis. 2017, 2, 24. [CrossRef] [PubMed]

23. Lebrun, A.; Garcia, S.; Li, J.; Kean, R.B.; Hooper, D.C. Protection against CNS-targeted rabies virus infection is dependent upon type-1 immune mechanisms induced by live-attenuated rabies vaccines. Trop. Med. Infect. Dis. 2017, 2, 22. [CrossRef]

24. Franka, R.; Carson, W.C.; Ellison, J.A.; Taylor, S.T.; Smith, T.G.; Kuzmina, N.A.; Kuzmin, I.V.; Marissen, W.E.; Rupprecht, C.E. In vivo efficacy of a cocktail of human monoclonal antibodies (cl184) against diverse North American bat rabies virus variants. Trop. Med. Infect. Dis. 2017, 2, 48. [CrossRef]

25. Warrell, M.; Warrell, D.A.; Tarantola, A. The imperative of palliation in the management of rabies encephalomyelitis. Trop. Med. Infect. Dis. 2017, 2, 52. [CrossRef]

(C) 2017 by the authors. Licensee MDPI, Basel, Switzerland. This article is an open access article distributed under the terms and conditions of the Creative Commons Attribution (CC BY) license (http:/ / creativecommons.org/licenses/by/4.0/). 
Review

\title{
Four Thousand Years of Concepts Relating to Rabies in Animals and Humans, Its Prevention and Its Cure
}

\author{
Arnaud Tarantola ${ }^{1,2}$ \\ 1 Epidemiology \& Public Health Unit, Institut Pasteur du Cambodge, BP983 Phnom Penh, Cambodia; \\ atarantola@pasteur-kh.org or atarantola@pasteur.nc; Tel.: +687-50-78-88 \\ 2 Unité de Recherche et d'Expertise en Maladies Infectieuses (UREMI), Institut Pasteur de \\ Nouvelle-Calédonie, 9800 Nouméa, New Caledonia
}

Academic Editors: Charles Rupprecht and Bernhard Dietzschold

Received: 20 February 2017; Accepted: 17 March 2017; Published: 24 March 2017

\begin{abstract}
The epitome of the One Health paradigm—and of its shortcomings—rabies has been known to humankind for at least 4000 years. We review the evolution through history of concepts leading to our current understanding of rabies in dogs and humans and its prevention, as transmitted by accessible and surviving written texts. The tools and concepts currently available to control rabies were developed at the end of the 19th Century, including the first live, attenuated vaccine ever developed for humans and the first post-exposure prophylaxis (PEP) regimen. No progress, however, has been made in etiological treatment, leaving clinicians who provide care to animals or patients with symptomatic rabies as powerless today as their colleagues in Mesopotamia, 40 centuries ago. Rabies remains to date the most lethal infectious disease known to humans. Widespread access to timely, effective, and affordable PEP in rural areas of developing countries is urgently needed.
\end{abstract}

Keywords: rabies; vaccine; history; One Health; post-exposure prophylaxis; Galtier; Roux; Pasteur; Semple; dog

\section{Preamble}

Rabies is an ancient and much-feared disease. Over the centuries, many different authors-clinicians, veterinarians, surgeons, pharmacists but also writers, philosophers, and poets - have mentioned rabies in their writings. The sequence of research and surviving writings on rabies described below is far from exhaustive. Rather, it aims to identify the work of those who made remarkable contributions to the current stage of knowledge on dog-mediated rabies, its cause and its prevention, control or management. Sources that conducted research on rabies but proposed alternate views of causation now considered misleading (such as spontaneous generation) have purposefully been left aside. Furthermore, no further potential sources from Ancient China, India, pre-Columbian America, or Africa could be identified or accessed.

\section{Rabies in Sumerian and Akkadian Civilizations}

Humans have lived alongside domesticated dogs for 14,000 years at least, with estimates reaching back to 32,000 years $[1,2]$. They have also long been familiar with their diseases, which became more prevalent as populations and their animals congregated in the cities that arose in Mesopotamia [3-6]. Two cuneiform tablets (Figure 1) discovered at Tell Abū Harmal, Baghdad Governorate, Iraq in 1945 and 1947, recount the Laws of Eshnunna, a Sumerian and later Akkadian city-state located in present Tell Asmar, Iraq [7]. This city was most prominent during the Isin-Larsa period, ca. 1950-1850 BCE and the tablet is dated ca. 1770 BCE [8]. Distinct copies of another source date back to ca. 1930 BCE. These describe Sumerian rules and regulations attesting to the fact that a causal link between the bite of a rabid animal and a human death from rabies was well recognized almost 4000 years ago [9]: 


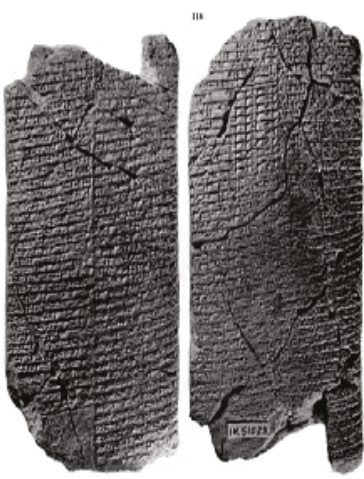

(a)
"If a dog becomes rabid and the ward authority makes that known to its owner, but he does not watch over his dog so that it bites a man and causes his death, the owner of the dog shall pay forty shekels of silver; if it bites a slave and causes his death, he shall pay fifteen shekels of silver."

(b)

Figure 1. Excerpts from the Sumerian Laws of Eshnunna, Northern Babylonia ca. 1930 BCE. (a) Tablets of the Laws of Eshnunna; (b) One possible translation of Paragraphs 56-57 of the Laws of Eshnunna (A iv 20-24) [10]. Another possible translation speaks of a dog becoming "furious" or "vicious" [8,9]. Even 15 shekels was a considerable sum: The Hammurabi code mentions the cost of a boat of sixty "gur" at two shekels. (Source: http://legacy.fordham.edu/halsall/ancient/hamcode.asp). Acknowledgement: Dr. Mark Weeden, Lecturer in Ancient Near Eastern Studies, School of Oriental and African Studies, London, UK.

At least five old Mesopotamian "dog incantations" (ca. 1900-1600 BCE) such as the one below (Figure 2) clearly reflect the notion of rabies being caused by something present in the saliva of the afflicted animal, akin to the poison transmitted by a snakebite or scorpion sting [9-12]. An herb seems to have been used after a dog bite and the biting dog's movement was restricted [12]. Dogs were thought more likely to become rabid when a lunar eclipse occurred at year's end [9].

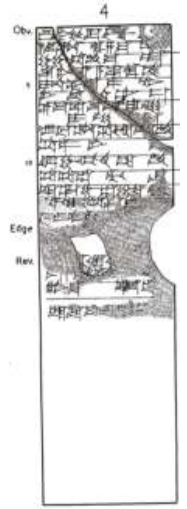

(a)
"Its [seed] coagulates on its [dogs'] teeth.

Where it has bitten it has left its [consequence]." (b)

Figure 2. "Dog incantation", ca. 1900-1600 BCE (a) Tablet; (b) Translation, adapted from [11].

Finally, clay tablets (Figure 3) unearthed by H.V. Hilprecht in 1889 at the Nippur site (3rd dynasty of Ur III, 21st- 20th-century BCE) of what is now Nuffar in Iraq display Akkadian incantations, to which healers resorted when medicine failed $[9,13,14]$. This dialogue between Marduk, the God of Healing, and his father Enki was recited by priests over (thus blessed) water which was then administered orally. 
These incantations are striking, marked as they are by the caveat of likely-however divine-failure, and certain death should rabies develop.

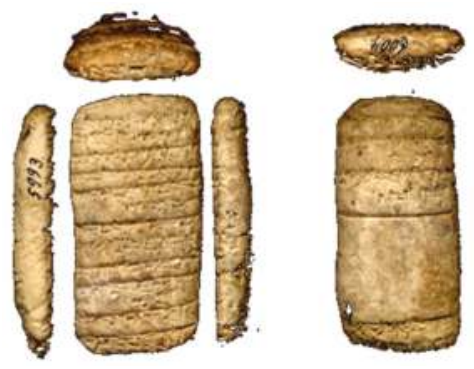

(a)
“Oh! my Father! Concerning a man whom a [...] rabid dog attacks, and to whom it passes (lit. "gives") its venom [...], I do not know what shall I do for that man."

"Oh! my son! For what you do not know, what can I add for him?"

(b)

Figure 3. Ur incantations. (a) Tablets of the Ur III incantations (http://cdli.ucla.edu/P142047); (b) Translation. Acknowledgement: Prof. N. Veldhuis, Professor of Assyriology, University of California, Berkeley, CA, USA.

Just like Yama, a Hindu god of death, the Babylonian Goddess Gula, patroness of doctors and a healing deity, was represented in the 14 th-7thC BCE with a dog at her feet $[15,16]$ (Figure 4). In one ancient tale, a Nippur man bitten by a dog, self-referred for treatment to a temple in Isin, the city of Gula [9]. As ancient deities of the Near East were shown mounting or otherwise dominating animals to demonstrate their power, it can be hypothesized that this association represented dogs both positively (the dog as a protector) and negatively (the dog as a source of danger, including rabies) (Prof. T. Ornan, personal communication, 11 December 2015).

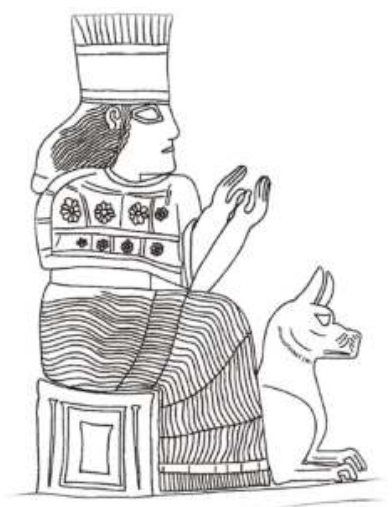

Figure 4. Goddess Gula represented on her throne, a dog at her feet on a kudurru of Nebuchadnezzar I (12th Century, BCE) [16]. Acknowledgement: Prof. Tallay Ornan, Hebrew University of Jerusalem, Department of Archaeology \& the Ancient Near East Department.

Although this remains disputed [17], the origin of "rabias", the Latin word for rabies, may originate from "rabhas" or "rabhasa" (रभस) in Sanskrit (http:/ /www.webcitation.org/6os2XRrN8), perhaps crossing Indo-European cultures and centuries [18]. Indeed, rabies is mentioned in many ancient texts, from the Vedic period (in ancient India ca. 1750-500 BCE) [19-21], to ancient China [22-25], Egypt [26] and the Middle East [27] as well as Greece and Rome [19,28]. Attempts at prevention or treatment of clinical rabies, however, remained faith-based, magical or otherwise exotic [19,29-31]. 


\section{Rabies in Classical Antiquity}

Aristotle, Hippocrates, Pliny, Ovid, Cicero... a great many texts by physicians and other authors of classical antiquity attest to a progressively improved comprehension of rabies. They-and especially Caelius Aurelianus, who also wrote an early description of palliative care in rabies patients [32]-provide accurate and detailed descriptions of symptoms, whether in dogs or in humans [19,28,31,33,34]. Galen noted the absence of symptoms in bite victims before the onset of rabies [34]. Both Dioscorides (ca. 4-90 CE) and Philomenos (1stC CE) discuss a latency period of varying duration after an infective bite, generally lasting six weeks but sometimes lasting up to several years [32]. In his "Emergency Formulas to Keep up One's Sleeves" (Zhŏu Hòu Jiù Zú Fān, 肘後備急方), Ge Hong (葛洪) of the Jin Dynasty (around $300 \mathrm{CE}$ ) also described prolonged incubation periods in humans (but unfortunately recommended the application of the biting dog's brain tissue to the bite wound to prevent rabies) [35].

Primary prevention of rabies through the prevention of bites by suspected rabid dogs was recommended in the Persian Avesta, composed in 200-400 CE, perhaps from much more ancient texts [36]. Around 60 CE, Columella's De Re Rustica described shepherds' habit of cutting puppies' tails when they are 40 days old, as a preventive measure against rabies in dogs should they be bitten, perhaps one of the earliest known example of One Health, or at least One Medicine, which sees disease prevention in humans as intimately linked with the health of the animals to which they are exposed [32,37-39]. Many different treatments were on offer to prevent rabies in dogs after they had been bitten [40].

Rabies prevention after a bite in humans made few advances. Similar incantations to that found at Nippur/Nuffar were spoken in Greek-speaking Egypt around the 3rdC CE [41]. Along with Aulus Cornelius Celsus in his De Medicina (published between 18 and 39 CE in Rome) [42,43], the only author who may have had some impact on the replication of viral inocula in wounds made by rabid animals, was Pedianus Dioscorides (ca. 40-90 A.D.), of Anazarba in Cilicia, founded by the Assyrians but a then Roman city, now in Adana Province of southern Turkey. A physician and a pharmacologist, he is said to have described rabies accurately and like Celsus, proposed cauterization of the bitten part as prevention [28]. But all attempts at treatment of clinically-declared rabies cases remained based on hopeful conjecture [44] or were denounced as unnecessarily brutal, as by Asclepiades of Bithynia in the mid-2ndC CE [45].

\section{The Middle Ages}

The list continues with great mediaeval practitioners of medicine and botany, in Europe and elsewhere $[19,28,31,33]$. Despite religious antagonism against dogs, considered unclean, and recommendations for their containment [40] the mediaeval Middle East was rife with stray dogs [26,27,46]. Works by Mohammad-e Zakariā-ye Rāzi (Rhazes) [47,48], Ibn-Sīnā (Avicenna) [47,49], Moshe ben Maimon a.k.a. Mūsā ibn Maymūn (Maimonides) [27,29] and many others [32], all discuss or refer to dog-mediated rabies (Figure 5). Authors continued to accurately describe the disease in animals or humans, including the notion of paralytic rabies [40], the absence of hydrophobia in rabid dogs [40], or of a-in some cases considerable-delay [29] before symptoms onset of rabies in humans and its lamentable prognosis. No further remedy to clinically-declared rabies was identified.

At the end of the 13thC, Arnaldus de Villanova insisted on the importance of careful and thorough wound cleansing as prevention of rabies after a dog bite [50]. Bartholomew Glanville (mid-13thC) is said to have referred to a poison, "growing" and "multiplying" in bite wounds although this author found no primary source [40]. Prevention and treatment otherwise made no significant progress. Medical or surgical management delineated in Ancient Greece or Rome became increasingly tinted with religion. In Europe a miracle cure was deemed to be found at several specialized religious sites [51], such as the church of the village of Andage, renamed Saint-Hubert, where Louis I the Pious, one of Charlemagne's sons and his successor, authorized the transfer of the eponymous saint's thighbones in $826 \mathrm{CE}$. This abbey located near Liège, Belgium became a specialized center for rabies prevention. At the time, prevention before a bite took the form of applying a white-hot Key of 
Saint Hubert to dogs so they would not contract the disease [52,53]. An example of this amulet can be seen at http://www.webcitation.org/6os1x82Ty. Contrary to what was practiced in other reputed sites such as San Bellino [17], near present-day Rovigo in Italy, or in Saint-Tügen's chapel in Primelin, France, this method must have been considered too cruel or too unreliable in humans bitten by suspected rabid animals. In humans, the preferred method of rabies prevention after a bite was based on incision of the forehead and implantation of threads from the Saint's supposedly miraculous stole, accompanied by prayers and fasting [19,25,52-54]. In spite of Ambroise Paré-who after the siege of Turin in 1536 discontinued the practice of cauterization to heal wounds [55,56]—Dioscorides' and Celsus' cauterization approach remained widespread in the management of rabies risks well into the 19thC [31,57]. This may be because cauterization was performed to inactivate a "poison" and perhaps also because their work was never lost to practitioners in Europe in spite of the fall of the Roman Empire [58,59]. Patients, however, found little recourse should prevention fail: at Saint-Tügen chapel, patients with declared rabies were stifled between mattresses until the beginning of the 19thC.

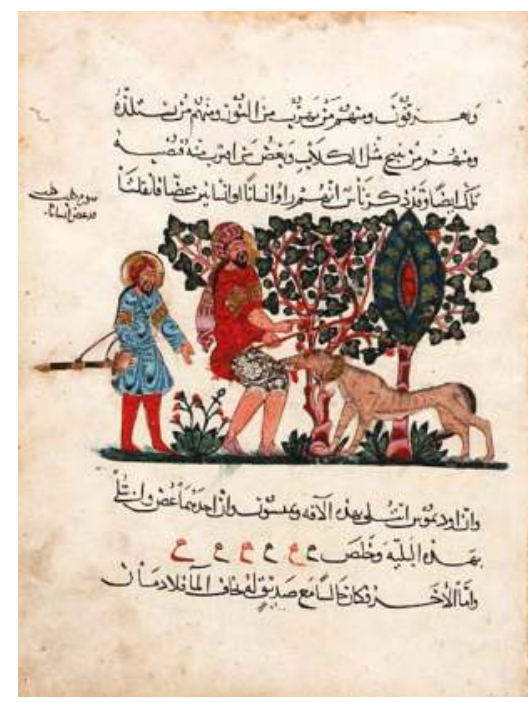

Figure 5. Outdoor scene with a mad dog biting a man. Folio from the 'Kitab al-Hashaish', an Arabic translation of the Materia medica by Dioscorides (ca. 40-90 C.E.) copied by Abdallah ibn al-Fadl, Baghdad, A.H.621/1224 A.D. Freer Gallery of Art and Arthur M. Sackler Gallery, Smithsonian Institution, Washington, D.C.: Purchase-Charles Lang Freer Endowment, F 1953.91.

\section{After 1492: Emergence and Control}

Rabies continued to concern populations and medical writers of the Renaissance. Julien Le Paulmier (1520-1588) wrote seven medical textbooks in all, one specifically on rabies [60,61].

The preventive practices at Saint-Hubert were condemned by the Sorbonne as superstitious in June 1671 [28] but remained in use in the Ardennes well into the 19thC [19,28,31,54]. The protective effect of thorough wound washing, and described anew in a publication dated 1796 cited by C. Ménécier, was by now well established among clinicians $[62,63]$. The converse was also true: the potentially deadly role of saliva was put to use by Polish-Lithuanian artillery general Kazimierz Siemienowicz (c. 1600-c. 1651), who in an early attempt at biological warfare, is said to have fired hollow shells containing saliva of rabid dogs in $1650[64,65]$.

"Madstones"- -bezoars or gallstones-thought to absorb or otherwise neutralize the agent of rabies were used extensively as amulets in mediaeval Europe and well into the 19thC by early European 
settlers in North America [31,66,67]. Dog-mediated rabies circulated in Europe, in Africa and in Asia $[26,31,68]$. Human deaths associated with bat bites were already identified in the mid-1500s in Latin America [69]. Although there were Nahuatl (Aztec) words for rabies and rabid dogs in what is now central Mexico, canine rabies was noticeably rare if not entirely absent from Central and South America $[25,31,66,69]$. Dog-mediated rabies, however, seems to have circulated more intensely and widely in both the Old and the New World after the landings of seafaring European conquerors and their dogs $[19,25,68,70,71]$. The $18^{\text {th }} \mathrm{C}$ was marked by intense rabies epizootics in the Americas and by the emergence of rabies on many islands of the Caribbean and the Indian Ocean $[25,28,68,72]$. Rabies became rampant among mongooses introduced in the Caribbean to eliminate rats pillaging sugar fields [73-76]. Colonial powers increasingly documented animal and human rabies cases in southern Africa in the 18th-19th Centuries [77].

Although circulation of rabies had reportedly increased, especially in Europe, great progress was being made in the prevention of dog bites in European cities [28,40]. Regulations for keeping dogs or for the containment of domestic dogs and elimination of stray dogs were passed in a city (Utrecht, Netherlands) in 1446 [78], in a Dutch province (Friesland) in 1714 [61], and in a country (Prussia) in 1787 [72,79,80]. A similar approach led to the successful elimination of dog-mediated rabies from Denmark, Norway and Sweden by 1826 [81]. Other long-known approaches including muzzling were implemented in other cities or territories [28,40,72]. In a 1793 communication, Samuel Bardsley proposed to quarantine local and imported dogs to "eradicate rabies from the British Isles" [40,82]. The decision to implement an international plan to control canine rabies was made at the 2nd International Veterinary Conference in Vienna on 21-27 August 1865. Cities and states legislated, integrating and applying early forms of what are now termed One Health principles [20,53].

The understanding of the physiopathology of rabies also evolved: in 1546, Girolamo Fracastoro hypothesized that rabies was transmitted by semina ("seeds") present in the saliva $[64,72,83,84]$. Edward Topsell, translating Conrad Gessner's work dated ca. 1555, mentions that rabies transmission is inconstant after the bite of a rabid dog [17]. Martin Lister added in 1698 that the risk of transmission varies according to the anatomical site of the bite [32], a notion comprehensively described by John Hunter in 1793 [85]. Joseph-Ignace Guillotin proposed in 1766 that biting dogs remain in 15-day observation to ascertain the risk of rabies transmission to a bite victim [40]. Van Swieten in 1775 declared saliva to be the source of rabies transmission and provides a clinical description in humans that remains relevant to date [86]. Hunter also spoke of many animals being, like humans, susceptible to rabies without being capable of transmitting the virus, and of that susceptibility being variable among species [85]. In 1776 and 1793, respectively, both Guillotin and Hunter proposed (dog bite) inoculation experiments to better understand the physiopathology of rabies, including in prisoners awaiting capital punishment $[24,85,87]$. Like Pasteur's similar considerations plainly laid out in a letter to the Emperor of Brazil dated September 22, 1884, ten months before the post-exposure vaccination of Joseph Meister, these fortunately were never put into effect [87,88].

The understanding of post-bite rabies prevention in animals or in humans, however, still made no progress. Published on 17 June 1684, the first edition of Medicina Curiosa, the first English-language journal wholly dedicated to medicine, describes post-exposure prevention failure in a suspected human case of rabies acquired from a cat [89]. "Treatment" after a bite remained faith-based [90] or otherwise fanciful, based for example on applying hair of the biting dog ("hair of the dog") to the wound $[28,66]$ or omelets flavored with "dog-rose root" (Rosa canina or cynorrhodon, as already suggested by Pliny the Elder in the 1stC CE) [91-95]. The same was true outside Europe [96]. Suggested therapies-some even based on homeopathic approaches-were rightly criticized as ineffective [97]. The fact that rabies is not transmitted in all cases even after the bite of an evidently rabid dog or wolf contributed to the illusion that each of the many preventive "treatments" had been effective.

These are all too easily disparaged as ludicrous recommendations made by self-assured and pompous clinicians, steeped from old-wives' remedies. They are, however, sure signs of desperate and all-out efforts by health providers of the time to save their patients from what to this day remains 
an intractable disease. Vigorous approaches continued to be used well into the mid-19thC: In 1830s London, children bitten by potentially rabid dogs still underwent surgery or cauterization of the wound [57] (still discussed by Babes in 1912 [72]). Patients with clinically declared rabies were plunged into cold water or hot oil as recommended by Celsus [31,86], or were later euthanized by being stifled between mattresses or made to bleed to death $[17,90,98,99]$.

\section{Pasteur and His Time}

Around the turn of the 19thC, the scientific approach improved the understanding of the physiopathology and clinical epidemiology of rabies, which was remarkably summarized by Samuel Cooper in 1823 [100].

Much experimental work was done on the transmission of rabies [26,101-103] —and its prevention through the amputation (Helmann, cited in [72]) or immunization of animals [28,72,102,104]. In 1804 in Jena (in present-day Germany), Georg Zinke transmitted rabies experimentally (without a bite) by applying the saliva of rabid dogs to animals' tissues $[28,31,101-103,105]$. The same was demonstrated in 1813 by Hugo Altgraf zu Salm-Reifferscheidt [106] and prior to 1814 by François Magendie and Gilbert Breschet, this time using saliva from a human rabies patient [107-109]. In 1805 in Turin, Francesco Rossi reported having experimentally transmitted rabies to dogs by inserting sciatic nerve segments of rabid cats into a fresh wound [110]. Clinicians progressively identified the seat of rabies infection in the midbrain $[28,102]$ and nerve ending density was positively correlated with risks of infection and migration $[72,111]$.

In the struggle pitting the microbial theory against spontaneous generation, subsequent experiments provided solid scientific evidence to support the long-suspected transmission of rabies by "filterable" infectious agents present in the saliva [101,102,104]: Magendie in 1842 suspected that the agent was not a poison but a "virus" capable of multiplying and developing in the host $[112,113]$. Magendie, then Casimir Davaine in 1872, experimented on virulence, increased by serial passage (but these were with septicemia and anthrax bacteria, not with viruses) [114-116]. In 1880, Edmond Nocard succeeded in separating saliva into two components, one non-infective and the other infective [117]. These agents were now considered to progressively ascend from the infected wound to the brain not through the blood but through the nerves-as initially hypothesized in 1879 but not established by Paul-Henri Duboué [118]—before diffusing centrifugally [31,72,102,112].

Resorting to nerve section as a means of prevention had been contemplated by George Hicks in 1807 [119]. Duboué—who communicated his findings to Louis Pasteur on 12 January 1881 [117]—also postulated that the rabies "virus" could be destroyed in situ or prevented from reaching the medulla oblongata [111]. This paved the way for the advent of post-exposure prophylaxis, based on the notion of taking advantage of the latency period and rapidly building the patient's immunity through timely and adequate vaccination [102].

Variolation-the use of dried-out scabs containing attenuated smallpox virus to directly immunize against and prevent more severe smallpox-had been performed by intranasal insufflation in China since the 10thC, and inoculation was later extensively used in the Ottoman Empire [120,121]. This hazardous procedure was described by Emanuele Timoni in 1714 and subsequently experimented by Hans Sloane in English prisoners in 1722, after being championed by Mary Wortley Montagu [120-126]. Vaccination - the inoculation of virus causing much milder cowpox-to provide cross-immunization against smallpox had been pioneered by Benjamin Jesty in 1774, Peter Plett in 1790-1792 and Edward Jenner in 1796, perhaps based on John Fewster's earlier work [121,127,128]. Putting John Hunter's recommendations into practice, Eusebio Valli, an Italian physician, claimed to have carried out experimental infections and successfully immunized dogs by injecting the saliva of other dogs after submitting it to gastric juices of frogs in 1799 . He claimed to have inoculated this mixture to at least two people in Pisa bitten by a suspected rabid dog and who did not contract rabies $[24,129,130]$. If confirmed, this would make Valli the initiator of the first attenuated vaccine and rabies vaccine, although the small numbers discussed and the absence of laboratory confirmation would not prove 
preventive effectiveness. Valli in 1816 made a fatal attempt at self-inoculation, not with rabies virus but with yellow fever, a few days after landing in Cuba to assist in an epidemic [26,131-133]. Although this author was unable to access original sources, Apollinaire Bouchardat, a pharmacist of the Veterinary Faculty in Lyons, is cited as having postulated in the 1850s that dogs could be immunized against rabies as a public health measure [134]. Available sources from 1882-1884 show Bouchardat discussing vaccination against infectious diseases, citing Pasteur's work. In 1879, at the Veterinary school also in Lyons, rabies pioneer Pierre-Victor Galtier inoculated rabies to a rabbit through cutaneous injection, administered rabid dog saliva intravenously to a sheep which did not contract rabies but became immunized, theorized post-exposure prophylaxis and began experimenting on vaccination of dogs [102,135-144]. Henry Toussaint-another veterinarian-conducted research in Lyons on heatand subsequently carbolic acid-attenuated anthrax vaccine in 1880 [144,145]. Paul Gibier from the Faculty of Medicine and the Muséum d'Histoire Naturelle de Paris, showed in 1883-1884 that the rabies virus lost virulence after dessication and that this approach could be used in humans [146,147].

It is in this already extremely rich and advanced research context that Louis Pasteur and his colleagues at the Ecole Normale Supérieure in Paris began to apply their systematic, rigorous and data-driven scientific methods to the study of rabies in December of $1880[92,118,146]$. Pasteur and his team had already developed an effective attenuated fowl cholera vaccine [148], were working on an attenuated anthrax vaccine and strove to apply their techniques to rabies-a much-feared and highly symbolic disease, albeit known to be controllable by veterinary measures alone [117,149]. An experimental model of rabies was developed by Paul Emilio (Emile) Roux in dogs inoculated after trepanation, and later in the noticeably more manageable rabbit [92,102]. A "fixed", adapted, rabies virus strain of "exalted virulence" with shorter incubation times and unfailing transmission could then be selected through successive passage in the rabbit, thereby paving the way for an experimental and methodical approach. After discussing it in 1881 [150], Pasteur and his team endeavored in 1882 to develop a canine "vaccine" (thus named in honor of Jenner), using after 1884 the desiccation technique also developed by Emile Roux to attenuate this live, highly virulent virus [151-154]. Rabies virus attenuation was first validated by experiments which Pasteur and his team reported in 1884, documenting survival of dogs vaccinated by live, attenuated vaccine before viral challenge. The prototypal vaccine against rabies was first used as salvage therapy in humans presenting signs of declared clinical rabies, with rapid documented failure in at least one instance: that of the child Antoinette Poughon in late June 1885 [92,155]. The vaccine, however, was to meet resounding success in patients exposed to rabies virus but with yet no signs of declared infection.

History remembers a 9-year-old schoolboy, Joseph Meister (Figure 6), attacked and bitten 14 times by Mr. Théodore Vonné's dog while on an errand in Maisonsgoutte (Meissengott), in then German-occupied Alsace, on 4 July 1885 [152]. Joseph Meister suffered deep bites to the right hand and to the thighs and leg. The owner of the dog, Mr. Théodore Vonné (or Vone) also received one bite to the arm by the same dog before it was shot by the police; the bite being delivered through cloth (untorn) and leaving no wound, Mr. Vonné received no prophylaxis and survived [72,154,156,157]. Dr. Eugène Weber, a local medical doctor with a practice in nearby Villé, made a call to the Meister home that evening and cleansed the wound thoroughly with carbolic acid, $12 \mathrm{~h}$ after the attack [158]. As he waited in a café for the coach to return home, Vonné spoke of the event with clients and was told that Pasteur had developed prevention against rabies [158]. He went back to the Meister home to inform the family and Meister, accompanied by his mother and Vonné left the next morning by train and arrived in Paris on 6 July. Although a medical doctor, Emile Roux did not inject the vaccine into Meister. This may be because he was not regularly working in the laboratory at the time or had not practiced medicine for too long, but published sources agree it clearly was because Roux had unequivocally stated his concern that the rabies vaccination procedure developed in dogs was insufficiently tested and too risky to be used in humans $[92,131,159,160]$. Jacques-Joseph Grancher therefore administered subcutaneously the first doses of live attenuated rabies vaccine on 6 July 1885, at 8:00 PM in the presence of Louis Pasteur-who, as a chemist, was not authorized to perform injections-and Alfred 
Vulpian. The first injection was derived from the chord of an inoculated rabbit which died of rabies on 21 June (15 days earlier) [92]. Over the 10 following days, Joseph Meister received 12 additional doses of attenuated and progressively more virulent virus to quickly generate an immune response, in an attempt to beat the virus in a deadly race against time [19,33,72]. Meister survived.

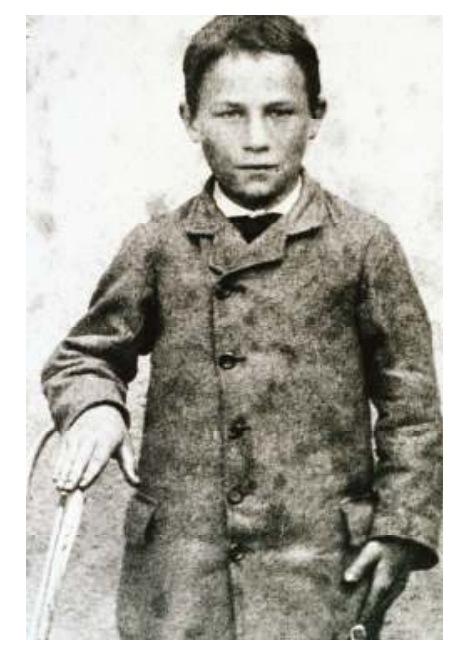

Figure 6. Joseph Meister in 1885, the first human to have received Pasteur's live, attenuated rabies vaccine on July 6, 1885 (@ Institut Pasteur-Musée Pasteur).

This successful attempt was repeated in late October 1885 in a second case, that of a 15-year-old shepherd, Jean-Baptiste Jupille from Villers-Farlay, Jura, who sustained on October 14 a deep bite to the left and right hands after an attack by a furious dog [92,152]. Jupille was referred to Pasteur by the town mayor and received rabies post-exposure prophylaxis (PEP) in Paris from 20 to 30 October, 1885. Following Grancher's accidental exposure to the attenuated vaccine during Jupille's PEP, Adrien Loir and Eugène Viala became the two first humans to receive pre-exposure rabies vaccination [134]. Having become a laboratory assistant in the Pasteur team, Meister was also the first to receive rabies vaccine boosters when he underwent a-reportedly less well-tolerated-second PEP in 1890 after being bitten by a guinea pig with experimental rabies (M-T. Meister, personal communication, 16 May 2016).

For the very first time since its first recorded description 3800 years earlier, and despite some failures due mostly to delayed referral [92,154], clinicians now had a proven and effective means of rabies prevention in humans. This led to Louis Pasteur's laboratory at École Normale Supérieure, Paris routinely offering PEP services. Around one year after the first PEP, L. Pasteur in August 1886 reported $3(0.2 \%)$ deaths (whether the case of Louise Pelletier is included among these deaths is unclear) among 1235 PEP recipients [92], while another source speaks of 21 (1.0\%) deaths among 1986 recipients (including one from Bombay, India) by 22 August of that same year [161]. In 1887, Vulpian documented $12(0.7 \%)$ deaths among 1726 PEP recipients, for an expected number of approximately $264(15.3 \%)$ rabies deaths if PEP had not been administered [162].

The rabbit cord used in the Pasteur vaccination protocol was known to preserve its virulence despite preservation in carbolic acid [152]. It was, however, not stabilized and therefore not usable outside Paris unless "transported" by/in inoculated rabbits. Patients therefore had to travel to access PEP, in some cases across continents or oceans [163,164]. After PEP spared the lives of 16 of 19 Russian patients who came to Paris from Smolensk after being attacked by a rabid wolf [165], Elie Metchnikoff was named director of the first center established specifically to produce rabies vaccine (which benefited from Louis Pasteur's support) and implemented the "Pasteur treatment" in 
Odessa in June 1886, [166-168]. The not-for-profit, non-governmental Institut Pasteur Foundation was incorporated in France by a decree on 4 June 1887. The Institut Pasteur itself was built and inaugurated on 14 November 1888, after an unprecedented national and international movement and fundraising campaign to further disseminate the technique and to pursue research $[19,118,163]$.

\section{Modern Developments}

Over the decades that followed the development of PEP by Pasteur and his team, many rabies prevention centers or "Pasteur institutes"- -some affiliated with the Institut Pasteur in Paris, most not [167] — appeared across the Old and the New World. In 1909 there were 75 such centers worldwide, including in then Indochina [72,169]. These centers cultured in vivo then attenuated highly virulent rabies virus (RABV) locally. In Saigon, animal bite victims received PEP as early as 1891, becoming the first to receive rabies PEP in Asia, Africa or Latin America (Figure 7) [170-174]. This was facilitated by RABV preservation techniques in glycerin, also developed by Emile Roux and Albert Calmette [30,118], which no longer made uninterrupted sequences of RABV inoculation to successive unfortunate rabbits every ten days a requirement to preserve live virus.

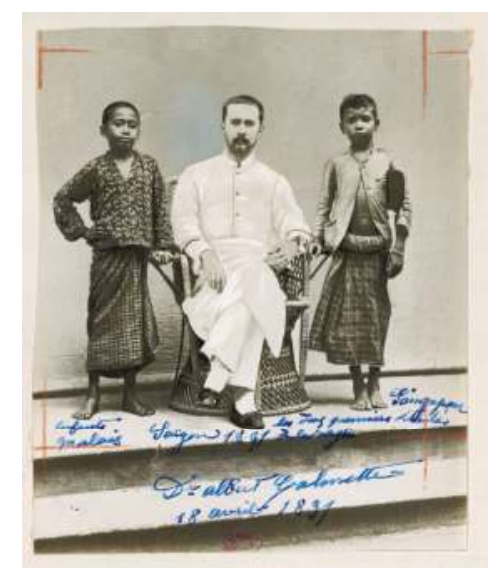

Figure 7. Albert Calmette and the first two patients to receive rabies PEP in Asia (excluding the Russian Empire), Africa or Latin America, 18 April 1891. The handwritten legend indicates that these were Malay children referred from Singapore (@ Institut Pasteur-Musée Pasteur).

Post-exposure prophylaxis biologicals and procedures were improved in the ensuing decades. The rabies vaccine was further refined by Emile Roux [170,175], Victor Babes [72], Follen Cabot [176], Claudio Fermi, Endre Högyes [177] and especially David Semple [177-179]. Babes and M. Lepp in 1889 first described immunity as a correlate of vaccine response and protection, discussed inactivated rabies vaccines and experimentally demonstrated protection of animals by antiserum in 1891 [72,177,180]. Solutions of attenuated virus mixed with serum immunoglobulin were experimented at the Pasteur Institute as early as 1902 [169]. Rabies antiserum was administered in humans to interrupt replication of the virus in bite wounds by Fermi in 1911 and the use of rabies-specific immunoglobulin was generalized in the 1950s [31,181-186]. Monoclonal antibodies (produced either in animals or by yeasts or plants) are now being developed to replace unaffordable equine-let alone human—rabies immunoglobulin (RIG), so far with mixed but promising results [187-194].

Semple's killed-virus vaccine, developed in 1911 at the Pasteur Institute in Kasauli, India, using sheep brain tissue, remained the most used worldwide into the 2000s. Although the vaccine had limited immunogenicity and required a tedious protocol (and was painful, as experienced first-hand by the author in West Africa as a child in the 1970s) it was affordable and for decades saved countless 
human lives, especially in the developing world. The League of Nations' health organization's bulletin reported 115,859 PEP worldwide recipients in 1932-May 1934 among whom $439(0.4 \%)$ were considered to have died of rabies [195]. After initial attempts at the Institut Pasteur in 1913 [196], the rabies virus was successfully cultured in vitro through several passages in 1936 [197]. In the 1960s, harvests of RABV grown in tissue cultures became increasingly pure [198] and normative methods were developed to standardize the potency of the various vaccines $[31,199,200]$. Vaccines were developed on suckling mouse brains [201] or on duck or chicken embryos [202], until the advent of new, highly antigenic, better-tolerated cell-culture vaccines [33,203-206]. This allowed for the tedious Pasteur then Semple protocols to be progressively replaced by the shorter Essen and Zagreb protocols [207]. An oral vaccine was developed for wildlife in 1971 [208]. Through canine population regulations and control, rabies was eliminated from cities in the industrialized world and elsewhere, including Shanghai in 1949 and Malaya in the early 1950s [25,209].

Research on the rabies virus itself made rapid advances. In 1903, Adelchi Negri described the first RABV-neuron interaction and Lina Luzzani-Negri described its diagnostic value in infection with "street" rabies virus [210-212]. The rabies virus itself was first observed by electron microscope in the early 1960s [213-215]. The molecules produced by RABV (transcriptional mapping) were described in 1978 [216] and the viral genes which code for them were sequenced in their entirety in 1988 [217]. Direct and indirect diagnostic methods were developed to reliably confirm infection and antibody protection $[200,218,219]$.

These advances led to the validation of rabies vaccine effectiveness, of shorter and dose-sparing regimens and of the equivalence of the intradermal vaccination route [220-222]. It also enabled the identification of nonfatal cases of RABV infection in animals [223-226] and in humans [227-229]. Human survivors of clinical rabies were first documented, mostly in the New World following bat exposure [230-236].

Whether or not these survived thanks to attempted treatment remains hotly debated [33,237-239]. Despite our dramatic advancements in the knowledge and prevention of rabies, and with a handful of exceptions to date [229], all documented patients with clinically-declared rabies have died within a few hours or days. Efforts to test some traditional medicines, in Ethiopia for example, have failed [240]. Antivirals are currently being explored as a therapeutic resource, so far with little success [241].

\section{Conclusions}

Our understanding of the mechanisms and primary and secondary prevention of rabies in animals and in humans has profoundly changed since the Laws of Eshnunna were introduced by one of the earliest known civilizations. Yet despite this, and great progress in symptomatic management of encephalitic patients, clinicians caring for animals or patients with symptomatic rabies remain as powerless today as they were 4000 years ago. Rabies remains today the most lethal disease known to man and this author is not aware of any other disease for which—once the disease is declared-modern medicine has offered no tangible improvement. We wait in hope for researchers to identify antiviral agents capable of controlling progression of clinically-declared rabies.

Rabies became a neglected disease when it was eliminated from Europe and North America. It is emerging in some island territories and remains uncontrolled in most of the developing world, where surveillance of dog bites, rabies exposures (syndromic or laboratory-confirmed) or rabies deaths, is poor $[242,243]$. The prevention of human rabies deaths in the $21 \mathrm{stC}$ still rests on tools and strategies developed in the 19thC: Effective primary prevention of animal bites and responsible dog ownership as delineated by Fleming (in 1872) [28]; canine vaccination as proposed by H. Bouley (in 1884) [72] and timely and effective rabies post-exposure prophylaxis (developed by Pasteur and his team and first administered in 1885).

An estimated total of 59,000 humans die of rabies each year, more than twice the estimated 28,600 deaths caused by the tragic 2014-2016 Ebola outbreak in West Africa [244,245]. The World Health Organization, the World Organization for Animal Health and the Food and Agriculture 
Organization of the United Nations are currently spearheading an effort to eliminate dog-transmitted rabies worldwide by 2030 [246]. While we strive for all dogs to be vaccinated, a major effort is urgently needed to make the time-proven and well-tolerated vaccine (and immunoglobulin) geographically and financially accessible in a timely way to those people who remain the most vulnerable to rabies: the rural populations of developing countries $[247,248]$.

Acknowledgments: The author is deeply indebted to the libraries (and librarians) that digitize rare and old texts before making them freely accessible on the internet. The author also wishes to gratefully acknowledge Mina Bui-Jones, Emma Quilliam and Jean-Yves Mary for their editorial assistance, Jean-François Meister for discussions on the case of his grandfather, Marie-France Estadieu from the Société d'Histoire du Val de Villé for a comprehensive document on Joseph Meister's case (now accessible at http://www.webcitation.org/6oOwdJq7l), Nick Veldhuis, Tallay Ornan, Mark Weeden and Mirjam Duijvestijn for their help in accessing historical material, Hervé Bourhy and Anne-Marie Moulin for sharing their extensive knowledge of rabies and its history and providing much-needed guidance, and Daniel Tarantola for discussions on variolation and smallpox vaccination (and for providing half of the author's genome).

Conflicts of Interest: The author declares no conflict of interest, no funding or sponsorship.

\section{References}

1. Dayan, T. Early domesticated dogs of the Near East. J. Archaeol. Sci. 1994, 21, 633-640. [CrossRef]

2. Thalmann, O.; Shapiro, B.; Cui, P.; Schuenemann, V.J.; Sawyer, S.K.; Greenfield, D.L.; Germonpré, M.B.; Sablin, M.V.; López-Giráldez, F.; Domingo-Roura, X.; et al. Complete mitochondrial genomes of ancient canids suggest a European origin of domestic dogs. Science 2013, 342, 871-874. [CrossRef] [PubMed]

3. Armelagos, G. Disease, Darwin, and medicine in the third epidemiological transition. Evol. Anthropol. Issues News Rev. 1997, 5, 212-220. [CrossRef]

4. Zuckerman, M.K.; Harper, K.N.; Barrett, R.; Armelagos, G.J. The evolution of disease: Anthropological perspectives on epidemiologic transitions. Glob. Health Action 2014. [CrossRef] [PubMed]

5. Greger, M. The human/animal interface: Emergence and resurgence of zoonotic infectious diseases. Crit. Rev. Microbiol. 2007, 33, 243-299. [CrossRef] [PubMed]

6. Rashidi, J.S. Paleoepidemiology of Mesopotamia and the ancient Near East: The impact of zoonotic diseases and population demographics on infectious disease patterns. Ph.D. Thesis, University of California, Los Angeles, CA, USA, 2011.

7. Eshnunna. Wikipedia Free Encycl. 2014.

8. Roth, M.T.; Hoffner, H.A.; Michalowski, P. Law collections from Mesopotamia and Asia Minor: Writings from the Ancient World, 2nd ed.; Scholars Press: Atlanta, GA, USA, 1997.

9. Yuhong, W. Rabies and rabid dogs in Sumerian and Akkadian literature. J. Am. Orient. Soc. 2001, 121, 32. [CrossRef]

10. Goetze, A. The laws of Eshnunna. Annu. Am. Sch. Orient. Res. 1965, 31, 133. [CrossRef]

11. Abusch, I.T.; Toorn, K.V.D. Mesopotamian Magic: Textual, Historical, and Interpretative Perspectives; BRILL: Leiden, The Netherlands, 1999.

12. Sigrist, M. On the bite of a dog. In Love and Death in the Ancient near East: Essays in Honor of Marvin H. Pope; Marks, J.H., Good, R.M., Eds.; Four Quarters Pub Co: Guilford, CT, USA, 1987.

13. Veldhuis, N. An Ur III Incantation against the bite of a snake, a scorpion, or a dog. Zeitschrift für Assyriologie und Vorderasiatische Archäologie 1993, 83, 161-169. [CrossRef]

14. Geller, M.J. Ur III Incantations from the Frau Professor Hilprecht-Collection, Jena; Otto Harrassowitz Verlag: Wiesbaden-Erbenheim, Germany, 2003.

15. Black, J.; Green, A. Gods, Demons and Symbols of Ancient Mesopotamia: An Illustrated Dictionary: Jeremy Black, Anthony Green: 9780292707948: Amazon.com: Books; University of Texas Press: Austin, TX, USA, 2004.

16. Ornan, T. The Goddess Gula and her dog. IMSA 2004, 3, 13-30.

17. Swabe, J. Chapter 22: Folklore, perceptions, science and rabies prevention and control. In Historical Perspective of Rabies in Europe and the Mediterranean Basin; King, A.A., Fooks, A.R., Aubert, M., Wandeler, A.I., Eds.; World Organization for Animal Health: Paris, France; Weybridge, UK, 2004; pp. 311-323.

18. Fustel de Coulanges. La cité antique; Flammarion: Paris, France, 2009. 
19. Wasik, B.; Murphy, M. In the beginning. In Rabid: A Cultural History of the World's Most Diabolical Virus; Penguin Books: New York, NY, USA, 2013; pp. 17-36.

20. Menezes, R. Rabies in India. CMAJ Can. Med. Assoc. J. 2008, 178, 564-566. [CrossRef] [PubMed]

21. Bhishagratna, K.K.L. Chapter VI. In An English Translation of the Sushruta Samhita, Based on Original Sanskrit Text by Susruta; Kaviraj Kunja Lal Bhishagratna: Calcutta, India, 1907; Volume 1, pp. 728-736.

22. Zhang, Y.-Z.; Xiong, C.-L.; Xiao, D.-L.; Jiang, R.-J.; Wang, Z.-X.; Zhang, L.-Z.; Fu, Z.F. Human rabies in China. Emerg. Infect. Dis. 2005, 11, 1983-1984. [CrossRef] [PubMed]

23. Adedeji, A.O.; Okonko, I.O.; Eyarefe, O.D.; Adedeji, O.B.; Babalola, E.T.; Ojezele, M.O.; Nwanze, J.C.; Amusan, T.A. An overview of rabies-History, epidemiology, control and possible elimination. Afr. J. Microbiol. Res. 2010, 4, 2327-2338.

24. Bellini, F.; Fossati, P.; Liverini, A. L'evoluzione della rabbia attraverso i secoli. Rassegna Dirit. Legis. E Med. Leg. Vet. 2009, 8, 27-41.

25. Baer, G.M. The history of rabies. In Rabies: Scientific Basis of the Disease and Its Management; Wunner, W.H., Jackson, A.C., Eds.; Academic Press: London, UK, 2010.

26. Blancou, J. Chapter 2: Rabies in Europe and the Mediterranean Basin: From Antiquity to the 19th Century. In Historical Perspective of Rabies in Europe and the Mediterranean Basin; King, A.A., Fooks, A.R., Aubert, M., Wandeler, A.I., Eds.; World Organization for Animal Health: Paris, France; Weybridge, UK, 2004; pp. $15-46$.

27. Yakobson, B.A.; David, D.; Aldomy, F. Chapter 13: Rabies in Israel and Jordan. In Historical Perspective of Rabies in Europe and the Mediterranean Basin; King, A.A., Fooks, A.R., Aubert, M., Wandeler, A.I., Eds.; World Organization for Animal Health: Paris, France; Weybridge, UK, 2004; pp. 171-183.

28. Fleming, G. Rabies and Hydrophobia: Their History, Nature, Causes, Symptoms, and Prevention; Chapman and Hall: London, UK, 1872.

29. Rosner, F. Rabies in the Talmud. Med. Hist. 1974, 18, 198-200. [CrossRef] [PubMed]

30. Schneider, M.C.; Santos-Burgoa, C. Treatment of human rabies: A summary of its history. Rev. Saúde Pública 1994, 28, 454-463. [CrossRef] [PubMed]

31. Steele, J.H.; Fernandez, P.J. The Natural History of Rabies, 2nd Edition. In The Natural History of Rabies; Baer, G.M., Ed.; CRC Press: Boca Raton, FL, USA, 1991.

32. Moreau, R. La rage de l'Antiquité au Siècle des Lumières. In Pasteur et la Rage; Rosset, R., Ed.; Informations Techniques des Services Vétérinaires-Ministère de l'Agriculture; Services Vétérinaires: Paris, France, 1985; pp. $19-28$.

33. Jackson, A.C. Chapter 1-History of rabies research. In Rabies, 3rd ed.; Jackson, A.C., Ed.; Academic Press: Boston, MA, USA, 2013; pp. 1-15.

34. Neville, J. Chapter 1: Rabies in the Ancient World. In Historical Perspective of Rabies in Europe and the Mediterranean Basin; King, A.A., Fooks, A.R., Aubert, M., Wandeler, A.I., Eds.; World Organization for Animal Health: Paris, France; Weybridge, UK, 2004.

35. Wang, Z.G.; Chen, P.; Xie, P. History and Development in Traditional Chinese Medicine; Advanced Traditional Chinese Medicine Series; Science Press/IOS Press/Ohmsha: Beijing, China; Amsterdam, The Netherlands; Tokyo, Japan, 1999.

36. On the mad dog and the dog diseased; how they are to be kept, and cured. Available online: http:/ / www.avesta.org/vendidad/vd13sbe.htm (accessed on 21 March 2017).

37. Cardiff, R.D.; Ward, J.M.; Barthold, S.W. "One medicine—one pathology": Are veterinary and human pathology prepared? Lab. Investig. J. Tech. Methods Pathol. 2008, 88, 18-26. [CrossRef] [PubMed]

38. Schwabe, C.W. History of the scientific relationships of veterinary public health. Rev. Sci. Tech. Int. Off. Epizoot. 1991, 10, 933-949. [CrossRef]

39. Lucius Junius Moderatus Columella Book. In On Agriculture, with a Recension of the Text and an English Translation; Harvard University Press: Cambridge, MA, USA, 1941; Volume 2, p. 503.

40. Blancou, J. Early methods for the surveillance and control of rabies in animals. Rev. Sci. Tech. Int. Off. Epizoot. 1994, 13, 361-372. [CrossRef]

41. Griffith, F.L. The Demotic Magical Papyrus of London and Leiden; Griffith, F.L., Thompson, H., Eds.; H. Grevel \& Co.: London, UK, 1904.

42. Aulus Cornelius Celsius Book V-Chapter 27. In De Medicina; Loeb Classical Library: London, UK; W. Heinemann Ltd.: Cambridge, MA, USA; Harvard University Press: Cambridge, MA, USA, 1935; Volume 2, p. 368. 
43. Köckerling, F.; Köckerling, D.; Lomas, C. Cornelius Celsus-Ancient encyclopedist, surgeon-scientist, or master of surgery? Langenbecks Arch. Surg. 2013, 398, 609-616. [CrossRef] [PubMed]

44. Claudius Aelianus (Aelian) XIV. In On the Characteristics of Animals; Scholfield AF: Cambridge, MA, USA, 1959; Volume III.

45. Allbutt, T.C. Greek Medicine in Rome: The Fitzpatrick Lectures on the History of Medicine Delivered at the Royal College of Physicians of London in 1909-1910, with Other Essays; Special Edition; MacMillan \& Co.: London, UK, 1921.

46. Menache, S. Dogs: God's worst enemies? Soc. Anim. 1997, 5, 23-44. [CrossRef]

47. Hatami, H. History of rabies in traditional medicine's resources and Iranian research studies: On the occasion of the World Rabies Day (28 September 2012). Int. J. Prev. Med. 2012, 3, 593-595. [PubMed]

48. Tadjbakhsh, H. Traditional methods used for controlling animal diseases in Iran. Rev. Sci. Tech. Int. Off. Epizoot. 1994, 13, 599-614. [CrossRef]

49. Dalfardi, B.; Esnaashary, M.H.; Yarmohammadi, H. Rabies in medieval Persian literature-The Canon of Avicenna (980-1037 AD). Infect. Dis. Poverty 2014, 3, 7. [CrossRef] [PubMed]

50. Arnaldi de Villanova Capitulum. XIII. De morsu canis rabidi. In Breviariuz pratice; Antonius Carcanus: Pavia, Italy, 1485.

51. Théodoridès, J.; Lépine, P. Histoire de la Rage: Cave Canem; Fondation Singer-Polignac: Masson/Paris, France, 1986.

52. Guitard, E.-H.; Amblard, É. L'histoire merveilleuse de la clef de saint Hubert. Rev. Hist. Pharm. 1960, 48, 369-371.

53. Bazin, H. Saint Hubert, guérisseur de la rage de l’homme et des animaux. Bull. Soc. Hist. Méd. Sci. Vét. 2007, 104-126.

54. Schayes, A.-G.-B. Essai Historique sur les Usages, les Croyances, les Traditions, les Cérémonies et Pratiques Religieuses et Civiles des Belges Anciens et Modernes; Chez L'auteur: 1834

55. Donaldson, I. Ambroise Paré's accounts of new methods for treating gunshot wounds and burns. Available online: http://www.jameslindlibrary.org/articles/ambroise-pares-accounts-of-new-methodsfor-treating-gunshot-wounds-and-burns/ (accessed on 26 March 2015).

56. Paré, A. Les oeuvres d'Ambroise Paré; Chez Pierre Rigaud: Lyon, France, 1652.

57. Pemberton, N.; Worboys, M. Mad Dogs and Englishmen: Rabies in Britain 1830-2000: Rabies in Britain, 1830-2000; Palgrave Macmillan: Basingstoke, UK, 2007.

58. Pedanius Dioscorides. Wikipedia Free Encycl. 2015.

59. De Vos, P. European Materia Medica in historical texts: Longevity of a tradition and implications for future use. J. Ethnopharmacol. 2010, 132, 28-47. [CrossRef] [PubMed]

60. Le Paulmier de Grantmesnil, J.I. Palmarii Constantini de morsu caninis rabidi et hydrophobia, liber. In Iulii Palmarii, Constantini, medici Parisiensis, De Morbis Contagiosis Libri Septem: Ad Amplissimum Senatum Parisiensem; Cum Indice Gemino; Apud Claudium Marnium, [et] heredes Ioannis Aubrii: Parisiis, France, 1578; pp. 265-279.

61. Nutton, V. Understanding contagious diseases: Baillou's notes on Julien Le Paulmier's De morbis contagiosis. Med. Storia 2011, 11, 141-151.

62. Allan Observations sur la rage. Recl. Périodique Société Santé Paris Vendémiaire Brum. V 1796.

63. Ménécier, C. Notice sur la rage: avec un projet nouveau de police sanitaire sur la race canine: présenté à Son Excellence M. le ministre de l'agriculture et du commerce/par le docteur Charles Ménécier,...; Ad. Delahaye, Paris, Camoin, Marseille, France, 1864.

64. DiMarco, V. The Bearer of Crazed and Venomous Fangs; iUniverse: Bloomington, Indiana, 2014.

65. Ramasamy, S.; Liu, C.; Tran, H.; Gubala, A.; Gauci, P.; McAllister, J.; Vo, T. Principles of antidote pharmacology: an update on prophylaxis, post-exposure treatment recommendations and research initiatives for biological agents. Br. J. Pharmacol. 2010, 161, 721-748. [CrossRef] [PubMed]

66. Kumar, P.D. Rabies; Biographies of Disease; Greenwood Press: Westport, CT, USA, 2009

67. Mike Nichols Nineteenth-Century Medicine: "Sir, the Madstone Will See You Now". Available online: http:/ / www.webcitation.org/6os1vFBQS (accessed on 12 March 2017).

68. Nadin-Davis, S.A.; Bingham, J. Chapter 19: Europe as a source of rabies for the rest of the world. In Historical Perspective of Rabies in Europe and the Mediterranean Basin; King, A.A., Fooks, A.R., Aubert, M., Wandeler, A.I., Eds.; World Organization for Animal Health: Paris, France; Weybridge, UK, 2004; pp. 259-280. 
69. Vos, A.; Nunan, C.; Bolles, D.; Müller, T.; Fooks, A.R.; Tordo, N.; Baer, G.M. The occurrence of rabies in pre-Columbian Central America: an historical search. Epidemiol. Infect. 2011, 139, 1445-1452. [CrossRef] [PubMed]

70. Troupin, C.; Dacheux, L.; Tanguy, M.; Sabeta, C.; Blanc, H.; Bouchier, C.; Vignuzzi, M.; Duchene, S.; Holmes, E.C.; Bourhy, H. Large-scale phylogenomic analysis reveals the complex evolutionary history of rabies virus in multiple carnivore hosts. PLOS Pathog. 2016, 12, e1006041. [CrossRef] [PubMed]

71. Schwartz, G.R. The History and Development of Caravels. Master's Thesis, Texas A\&M University, College Station, TX, USA, 2008.

72. Babes, V. Traité de la Rage; Ballière: Paris, France, 1912.

73. Barun, A.; Hanson, C.C.; Campell, K.J.; Simberloff, D. A review of small Indian mongoose management and eradications on islands. In IUCN, 2011; pp. 17-25.

74. World Health Organization. WHO Expert Consultation on Rabies (First Report); WHO Technical Report Series; World Health Organization: Geneva, Switzerland, 2004.

75. Tierkel, E.S.; Arbona, G.; Rivera, A.; de Juan, A. Mongoose rabies in Puerto Rico. Public Health Rep. 1952, 67, 274-278. [CrossRef] [PubMed]

76. Styczynski, A. Human Rabies-Puerto Rico, 2015. MMWR Morb. Mortal. Wkly. Rep. 2017, 65, 1474-1476. [CrossRef] [PubMed]

77. Brown, K. Travelers and Doctors. The mystery of rabies in colonial South Africa. In Mad Dogs and Meerkats: A History of Resurgent Rabies in Southern Africa; Ohio University Press Series in Ecology and History; Ohio University Press: Athens, Greece, 2011; pp. 20-37.

78. Van der Monde, N. Bepaling op Het Houden van Honden, Binnen Utrecht, in Het Jaar 1446, Des Woensdags na St. Michielsavont. In Tijdschrift voor Geschiedenis, Oudheden en Statistiek van Utrecht: Met Naamlijst der Geborenen, Ondertrouwden en Overledenen Binnen Utrecht en Voorsteden; Utrecht, The Netherlands, 1839; Volume 5, p. 603.

79. Germany, P. Extrakt aus dem Edict wegen des Tollwerdens der Hunde vom 20 Februar 1787; 1787; p. 2.

80. Müller, W.; Cox, J.; Müller, T. Rabies in Germany, Denmark and Austria. In Historical Perspective of Rabies in Europe and the Mediterranean Basin-A Testament to Rabies by Dr Arthur A. King; OIE-World Organisation for Animal Health: Paris, France; Weybridge, UK, 2004.

81. Evans, A.S.; Kaslow, R.A. Viral Infections of Humans: Epidemiology and Control; Springer: 1997.

82. Brockbank, E.M.; Edward, M. Sketches of the Lives and Work of the Honorary Medical Staff of the Manchester Infirmary, from Its Foundation in 1752 to 1830 When It Became the Royal Infirmary; Manchester University Press: Manchester, UK, 1904.

83. Riddell, W.R. Hydrophobia: Four Centuries Ago. Public Health J. 1923, 14, 155-167.

84. Meunier, L. Chapitre X-De la Rage (Caput X-De Rabie). In Les Trois Livres de Jérôme Fracastor sur la Contagion, les Maladies Contagieuses et Leur Traitement; Société D'éditions Scientifiques: Paris, France, 1893; p. 408.

85. Hunter, J. Observations, and Heads of Inquiry, on Canine Madness, drawn from the Cases and Materials collected by the Society, reflecting that Disease. In Transactions of a Society for the Improvement of Medical and Chirurgical Knowledge; J. Johnson: London, UK, 1793; pp. 294-329.

86. Swieten, G.V. An Abridgement of Baron Van Swieten's Commentaries upon the Aphorisms of ... Herman Boerhaave Concerning the Knowledge and Cure of Diseases; printed for Robert Horsfield ... and Thomas Longman; London, UK, 1774.

87. Soubiran, A.; Théodoridès, J. Guillotin et la rage: Un Mémoire inédit. Hist. Sci. Medicales 1982, 16, $227-236$.

88. Arboleda-Flórez, J. The ethics of biomedical research on prisoners. Curr. Opin. Psychiatry 2005, 18, 514-517. [CrossRef] [PubMed]

89. Colman, E. The first English medical journal: Medicina Curiosa. Lancet 1999, 354, 324-326. [CrossRef]

90. Les protecteurs contre la rage. In Oeuvres Complètes de Mgr. X. Barbier de Montault, Prélat de la Maison de Sa Sainteté; Blais, Roy et Cie.: Poitiers, France, 1895; Volume X, pp. 169-226.

91. Andry, C.L.F. Recherches sur la Rage; Chez Didot le Jeune: Paris, France, 1780.

92. Debré, P. Louis Pasteur; Flammarion: Paris, France, 1997.

93. Withey, D.A. Mad dog (bites) and Englishmen: early-modern remedies for hydrophobia. Dr Alun Withey.

94. Diderot, D.; le Rond d'Alembert, J.R. Encycl. Ou Dict. Raison. Sci. Arts Métiers Etc 1765, 13, 758.

95. Berkenhout, J. An Essay on the Bite a Mad Dog: In Which the Claim to Infallibility of the Principal Preservative Remedies against the Hydrophobia Is Examined; R. Baldwin: London, UK, 1783. 
96. Pankhurst, R. The history and traditional treatment of rabies in Ethiopia. Med. Hist. 1970, 14, 378-389. [CrossRef] [PubMed]

97. Bouchardat, A. Rapport général (...) sur divers remèdes proposés pour prévenir ou pour combattre la rage. Bull. Acad. Natl. Méd. 1852, 18, 6-30.

98. Magendie, F. Course of the lectures on the blood and on the changes which it undergoes during disease, delivered at the College de France in 1837-8-Lecture IX. Lancet 1838, 1, 361-370.

99. Buisson, F. Traité sur L'hydrophobie ou Rage. Moyen de Prévenir et de Guérir Cette Maladie par BUISSON; Impr. d'Herban: Paris, France, 1836.

100. Cooper, S. A Dictionary of Practical Surgery: Comprehending All the Most Interesting Improvements, from the Earliest Times down to the Present Period; an Account of the Instruments, Remedies and Applications Employed in Surgery; the Etymology and Signification of the Principal Terms; ... Forming Together a "catalogue Raisonné" of Surgical Literature ...; Collins and Hannay: New York, 1823; Vol. II.

101. Hertwig, K.H. Contribution towards a better knowledge of rabies canina [Beiträge zur nähern Kentniss der Wuthkrankheit, etc.]. In The Edinburgh Medical and Surgical Journal ...; Arch. Constable \& Comp.: Edinburgh, 1829; pp. 378-389.

102. Roux, E.P.P. Des Nouvelles Acquisitions sur la Rage. Thèse de Médecine, Paris, France, 1883.

103. Pearce, J.M.S. Louis Pasteur and rabies: A brief note. J. Neurol. Neurosurg. Psychiatry 2002, 73, 82. [CrossRef] [PubMed]

104. Rosset, R. Pasteur et les vétérinaires. Bull. Soc. Fr. Hist. Méd. Sci. Vét 2003, 2, 1-25.

105. Zinke, G.G. Neue Ansichten der Hundswuth; ihrer Ursachen und Folgen, nebst einer sichern Behandlungsart der von tollen Thieren gebissenen Mensch ...; C.E. Gabler: Jena, 1804.

106. Baer, G.M. The natural history of rabies; Academic Press: New York, 1975.

107. Théodoridès, J. Dupuytren et la rage. Hist. Sci. Médicales 1978, 3, 241-248.

108. Breschet, $\mathrm{G}$. Recherches expérimentales relatives au mode de transmission de la rage. In Archives générales de médecine; IIe et nouvelle série; Béchet jeune et Labet: Paris, 1840; Vol. IX, pp. 229-231.

109. Wright, S. The physiology and pathology of the saliva. The Lancet 1842, 38, 737-742. [CrossRef]

110. Vassali-Eandi, A.M. Notice des ravaux de la classe des sciences physiques et mathématiques. In Mémoires de l'Académie Impériale des Sciences, Littérature et Beaux-Arts de Turin pour les Années 1805-1808. Sciences Physiques et Mathématiques; Imprimerie de l'Académie Imépriale des Sciences: Turin, Italy, 1809; p. 678.

111. Duboué, P.H.; Royal College of Physicians of Edinburgh. De la Physiologie Pathologique et du Traitement Rationnel de la Rage: Suite D'études de Pathogénie; V. Adrien Delahaye: Paris, France, 1879.

112. Théodoridès, J. Magendie et la pathologie infectieuse. Hist. Sci. Medicales 1983, 17, 367-380.

113. Magendie, F. Leçons faites au Collège de France pendant le semestre d'hiver (1851-1852) par M. Magendie, Recueillies et Analysées par le Dr V.A. Fauconneau Dufresne; Union Médicale: Paris, France, 1862.

114. Davaine, C. Recherches sur quelques questions relatives à la septicémie. Bull. Acad. Natl. Méd. 1872, A36, 907-929.

115. Théodoridès, J. Casimir Davaine (1812-1882): A precursor of Pasteur. Med. Hist. 1966, 10, 155-165. [CrossRef] [PubMed]

116. Wrotnowska, D. Pasteur et Davaine d'après des documents inédits. Hist Sci. Med. 1976, 9, 213-230.

117. Moreau, R. Notes sur Pasteur et la rage: A propos de quelques lettres ou documents inédits. In Pasteur et la Rage; Rosset, R., Ed.; Informations Techniques des Services Vétérinaires-Ministère de l'Agriculture; Services Vétérinaires: Paris, France, 1985; pp. 69-85.

118. Perrot, A.; Schwartz, M. Pasteur et ses Lieutenants: Roux, Yersin et les autres; Odile Jacob: Paris, France, 2013.

119. Hicks, G. Mr. Hicks, on hydrophobia. Lond. Med. Phys. J. 1807, 18, 272-278.

120. Weiss, R.A.; Esparza, J. The prevention and eradication of smallpox: A commentary on Sloane (1755) "An account of inoculation". Philos. Trans. R. Soc. B Biol. Sci. 2015. [CrossRef] [PubMed]

121. Early Efforts at Control: Variolation, Vaccination, and Isolation and Quarantine. In Smallpox and Its Eradication; Fenner, F.; Henderson, D.A.; Arita, I.; Jezek, Z.; Ladnyi, I.D. (Eds.) History of International Public Health; World Health Organization: Geneva, Switzerland, 1988; pp. 245-276.

122. Gross, C.P.; Sepkowitz, K.A. The myth of the medical breakthrough: smallpox, vaccination, and Jenner reconsidered. Int. J. Infect. Dis. IJID Off. Publ. Int. Soc. Infect. Dis. 1998, 3, 54-60. [CrossRef]

123. Pead, P.J. Benjamin Jesty: New light in the dawn of vaccination. Lancet 2003, 362, 2104-2109. [CrossRef]

124. Pead, P.J. Benjamin Jesty: The first vaccinator revealed. Lancet 2006, 368, 2202. [CrossRef] 
125. Boylston, A. The origins of inoculation. J.R. Soc. Med. 2012, 105, 309-313. [CrossRef] [PubMed]

126. Hawkins, S.A. Sir Hans Sloane (1660-1735): His life and legacy. Ulster Med. J. 2010, 79, 25-29. [PubMed]

127. Plett, P.C. Peter Plett and other discoverers of cowpox vaccination before Edward Jenner. Sudhoffs Arch. 2006, 90, 219-232. [PubMed]

128. Thurston, L.; Williams, G. An examination of John Fewster's role in the discovery of smallpox vaccination. J.R. Coll. Physicians Edinb. 2015, 45, 173-179. [CrossRef] [PubMed]

129. Valli, E. Sulla peste di Costantinopoli del 1803 giornale del dottore Eusebio Valli cittadino fiorentino...; Presso la Società Tipografica all'Apollo: Mantova, Italy, 1805.

130. Castiglioni, A. VALLI, Eusebio. Encicl. Ital. Sci. Lett. Ed Arti 1937.

131. Bazin, H. L'Histoire des Vaccinations; John Libbey Eurotext: Esher (Surrey), UK, 2008.

132. Denis, A.L. Disease and Society in Colonial Cuba, 1790-1840. P.h.D. Thesis, University of California, Los Angeles, CA, USA, 2007.

133. Frank, J. Encyclopédie des Sciences Médicales: Ou Traité Général, Méthodique et Complet des Diverses Branches de L'art de Guérir. Médecine. Pathologie Médicale/Par Joseph Frank. Deuxième Division; Imp. de Béthune et Plon: Paris, France, 1835; Volume 1.

134. Rotivel, Y.; Goudal, M.; Perrin, P.; Tordo, N. Une histoire de la vaccination contre la rage. Virologie 2002, 6, 89-104.

135. Galtier, P. Etudes sur la rage. Note de M. Galtier, présentée par M. Bouley. C. R. L'Académie Sci. 1879, 89, 444-446.

136. Galtier, P. Les injections de virus rabique dans le torrent circulatoire ne provoquent pas l'éclosion de la rage et semblent conférer l'immunité. La rage peut être transmise par l'ingestion de la matière rabique (Note présentée par M. Bouley). Rev. Anal. Sociétés Savantes Fr. Létranger Académie Sci. 1881, 93, 180-181.

137. Smith, K.A. Louis Pasteur, the father of immunology? Immunol. Mem. 2012, 3, 68. [CrossRef] [PubMed]

138. Théodoridès, J. Quelques grands précurseurs de Pasteur. Hist Sci Med 1973, 336-343.

139. Rosset, R. Pierre Victor Galtier: Professeur à l'Ecole Vétérinaire de Lyon, précurseur de la vaccination antirabique. In Pasteur et la Rage; Rosset, R., Ed.; Informations Techniques des Services Vétérinaires-Ministère de l'Agriculture; Services Vétérinaires: Paris, France, 1985; pp. 41-50.

140. Galtier, P. Transmission du virus rabique (Observations à l'occasion du procès-verbal). Bull Acad Méd 1881, 90-94.

141. Lombard, M.; Pastoret, P.P.; Moulin, A.M. A brief history of vaccines and vaccination. Rev. Sci. Tech. Int. Off. Epizoot. 2007, 26, 29-48. [CrossRef]

142. Lepine, P. Galtier and research on rabies. Bull. Acad. Natl. Med. 1969, 153, 78-81. [PubMed]

143. Mérieux, C. [1879-1979. It is now one hundred years since Victor Galtier, a professor of Veterinary School in Lyon, presented a paper on the prophylaxis of rabies to the Academy of Sciences]. Bull. Acad. Natl. Med. 1979, 163, 125-127; discussion 127-128.

144. Williams, E. The forgotten giants behind Louis Pasteur: Contributions by the veterinarians Toussaint and Galtier. Vet. Herit. Bull. Am. Vet. Hist. Soc. 2010, 33, 33-39.

145. Toussaint, $\mathrm{H}$. Note contenue dans un pli cacheté et relative à un procédé pour la vaccination du mouton et du jeune chien (Note de Toussaint présentée par M. Bouley). C. R. Acad. Sci. 1880, 91, 303-304.

146. Vignal, M.W. Report on M, Pasteur's Researches on Rabies and the Treatment of Hydrophobia by Preventive Inoculation. Br. Med. J. 1886, 1, 671-673. [CrossRef] [PubMed]

147. Gibier, P. Recherches Expérimentales sur la Rage et sur son Traitement/Par Paul Gibier,...; avec Une Préface de M.H. Bouley, ...; Asselin et Houzeau: Paris, France, 1884.

148. Pasteur, L. De l'atténuation du virus du choléra des poules. C. R. Acad. Sci. 1880, XCI, 673-680.

149. Pasteur, L.; Chamberland, C.E.; Roux, E.P.P. Sur la vaccination charbonneuse. C. R. Acad. Sci. 1881, 92, 1378-1383.

150. Pasteur, L. Note sur la maladie nouvelle provoquée par la salive d'un enfant mort de la rage. Bull. Acad. Natl. Méd. 1881.

151. Rappuoli, R. Inner Workings: 1885 , the first rabies vaccination in humans. Proc. Natl. Acad. Sci. USA 2014, 111, 12273-12273. [CrossRef] [PubMed]

152. Pasteur, L. Méthode pour prévenir la rage après morsure. C. R. Acad. Sci. 1885, 101, 765-774.

153. Pasteur, L.; Chamberland, C.E.; Roux, E.P.P. Sur la rage. Bull. Acad. Natl. Méd. 1884, 661-664. 
154. Suzor, J.-R. Exposé pratique du traitement de la rage par la méthode Pasteur: historique et description de la rage, collection complète des communications de M. Pasteur, technique de sa méthode, resultats statistiques, etc.; Maloine: Paris, 1888.

155. Plotkin, S. History of Vaccine Development; Springer Science \& Business Media, 2011.

156. Joseph Meister (1876-1940). Commune de Steige.

157. Rupprecht, C.E.; Plotkin, S.A. 29-Rabies vaccines. In Vaccines, 6th ed.; W.B. Saunders: London, UK, 2013; pp. 646-668.

158. Dubail, A. Joseph Meister, le premier être humain sauvé de la rage. Annu. Société Hist. Val Villé 1985, 10, 93-148.

159. Wolpert, L. Experiments in Deceit. New York Times, 1995.

160. Geison, G.L. The Private Science of Louis Pasteur; Princeton University Press: Princeton, NJ, USA, 2014.

161. Académie de Versailles Louis Pasteur: Quelques Textes. Available online: http://www.histoire.ac-versailles. $\mathrm{fr} /$ old/pedagogie/pasteur/pasteur_ressources.htm (accessed on 4 May 2016).

162. Brunet, J.-P. La rage envers Pasteur-Ou le révisionnisme en Sciences médicales. Bull. Assoc. Anc. Elèves Inst. Pasteur 2012, 54, 112-115.

163. Hansen, B. America's first medical breakthrough: How popular excitement about a French rabies cure in 1885 raised new expectations for medical progress. Am. Hist. Rev. 1998, 103, 373-418. [CrossRef] [PubMed]

164. Bazin, H. Rabies or hydrophobia vaccine. In Vaccination: A History; John Libbey Eurotext: Montrouge/France; Esher (Surrey)/UK, 2011; p. 600.

165. Schwartz, M. Histoire et actualité du réseau international des Instituts Pasteur. Ann. Mines Responsab. Environ. 2008, 3, 42-48. [CrossRef]

166. Ilya Mechnikov—Biographical. Available online: http://www.nobelprize.org/nobel_prizes/medicine/ laureates/1908/mechnikov-bio.html (accessed on 1 April 2015).

167. Botvinkin, A.; Kosenko, M. Chapter 5: Rabies in the European parts of Russia, Belarus and Ukraine; King, A.A., Fooks, A.R., Aubert, M., Wandeler, A.I., Eds.; World Organization for Animal Health: Paris, France; Weybridge, UK, 2004; pp. 47-63.

168. Ulyankina, T. The Pasteur Institute and the advent of immunology in Russia (1880-1917). In ImmunologyPasteur's Heritage; Cazenave, P.-A., Talwar, G., Eds.; Wiley Eastern Limited: New Delhi, India, 1991.

169. Marie, A.A. L'étude Experimentale de la Rage; O. Doin: Paris, France, 1909.

170. Bernard, P.-N. Les Instituts Pasteur d'Indochine; Saigon: Ho Hi Minh City, Vietnam, 1922; p. 249.

171. Dedet, J.-P. Les Instituts Pasteurs D'outre-Mer. Cent Vingt Ansde Microbiologie Français; Editions L'Harmattan: Paris, France, 2001.

172. Guénel, A. The creation of the first overseas Pasteur Institute, or the beginning of Albert Calmette's Pastorian career. Med. Hist. 1999, 43, 1-25. [CrossRef] [PubMed]

173. Calmette, A. Notes sur la rage en Indo-Chine et sur les vaccinations antirabiques pratiquées à Saïgon du 15 Avril au 1er Août 1891. Ann. Inst. Pasteur 1891, 5, 633-641.

174. Sun, B.Z. Medicine as Colonial Enterprise: The Founding of the Pasteur Institute in Saigon, 1891; Columbia University Academic Commons: New York, NY, USA, 2014.

175. Smith, T.G.; Wu, X.; Franka, R.; Rupprecht, C.E. Design of future rabies biologics and antiviral drugs. Adv. Virus Res. 2011, 79, 345-363. [PubMed]

176. Cabot, F. Report of experimental work on the dilution method of immunization from rabies. J. Exp. Med. 1899, 4, 181-188. [CrossRef] [PubMed]

177. Semple, D. The Preparation of a Safe and Efficient Antirabic Vaccine; Scientific Memoirs by the Officers of the Medical and Sanitary Departments of the Government of India, Sanitary Commission with the Government of India, Simla: Calcutta, India, 1911; pp. 1-32.

178. Chakrabarti, P. "Living versus dead": The Pasteurian paradigm and imperial vaccine research. Bull. Hist. Med. 2010, 84, 387-423. [CrossRef] [PubMed]

179. Wu, X.; Smith, T.G.; Rupprecht, C.E. From brain passage to cell adaptation: The road of human rabies vaccine development. Expert Rev. Vaccines 2011, 10, 1597-1608. [CrossRef] [PubMed]

180. Babes, V.; Lepp, V. Recherches sur la vaccination antirabique. 1889, 3, 384-390.

181. Hosty, T.S.; Kissling, R.E.; Schaeffer, M.; Wallace, G.A.; Dibble, E.H. Human antirabies gamma globulin. Bull. World Health Organ. 1959, 20, 1111-1119. [PubMed]

182. Habel, K. Rabies prophylaxis in man. Public Health Rep. 1957, 72, 667-674. [CrossRef] [PubMed] 
183. Habel, K. Seroprophylaxis in experimental rabies. Public Health Rep. 1945, 60, 545-576. [CrossRef]

184. Anderson, D.A. WHO guidelines dealing with immunoglobulin use impede rabies prevention. Asian Biomed. 2007, 1, 103-107.

185. Expert Committee on Rabies. Third Session; Technical Report Series; World Health Organization: Geneva, Switzerland, 1957.

186. Koprowski, H.; Cox, H.R. Recent developments in the prophylaxis of rabies. Am. J. Public Health Nations Health 1951, 41, 1483-1489. [CrossRef] [PubMed]

187. Nagarajan, T.; Rupprecht, C.E.; Dessain, S.K.; Rangarajan, P.N.; Thiagarajan, D.; Srinivasan, V.A. Human monoclonal antibody and vaccine approaches to prevent human rabies. Curr. Top. Microbiol. Immunol. 2008, 317, 67-101. [PubMed]

188. Hanlon, C.A.; Niezgoda, M.; Morrill, P.A.; Rupprecht, C.E. The incurable wound revisited: Progress in human rabies prevention? Vaccine 2001, 19, 2273-2279. [CrossRef]

189. Gogtay, N.; Thatte, U.; Kshirsagar, N.; Leav, B.; Molrine, D.; Cheslock, P.; Kapre, S.V.; Kulkarni, P.S.; SII RMab Author Group. Safety and pharmacokinetics of a human monoclonal antibody to rabies virus: A randomized, dose-escalation phase 1 study in adults. Vaccine 2012, 30, 7315-7320. [CrossRef] [PubMed]

190. Muhamuda, K.; Madhusudana, S.N.; Ravi, V. Use of neutralizing murine monoclonal antibodies to rabies glycoprotein in passive immunotherapy against rabies. Hum. Vaccin. 2007, 3, 192-195. [CrossRef] [PubMed]

191. De Kruif, J.; Bakker, A.B.H.; Marissen, W.E.; Kramer, R.A.; Throsby, M.; Rupprecht, C.E.; Goudsmit, J. A human monoclonal antibody cocktail as a novel component of rabies postexposure prophylaxis. Annu. Rev. Med. 2007, 58, 359-368. [CrossRef] [PubMed]

192. Van Dolleweerd, C.J.; Teh, A.Y.-H.; Banyard, A.C.; Both, L.; Lotter-Stark, H.C.T.; Tsekoa, T.; Phahladira, B.; Shumba, W.; Chakauya, E.; Sabeta, C.T.; et al. Engineering, expression in transgenic plants and characterisation of E559, a rabies virus-neutralising monoclonal antibody. J. Infect. Dis. 2014, 210, 200-208. [CrossRef] [PubMed]

193. Both, L.; van Dolleweerd, C.; Wright, E.; Banyard, A.C.; Bulmer-Thomas, B.; Selden, D.; Altmann, F.; Fooks, A.R.; Ma, J.K.-C. Production, characterization, and antigen specificity of recombinant 62-71-3, a candidate monoclonal antibody for rabies prophylaxis in humans. FASEB J. Off. Publ. Fed. Am. Soc. Exp. Biol. 2013, 27, 2055-2065. [CrossRef] [PubMed]

194. Müller, T.; Dietzschold, B.; Ertl, H.; Fooks, A.R.; Freuling, C.; Fehlner-Gardiner, C.; Kliemt, J.; Meslin, F.X.; Rupprecht, C.E.; Tordo, N.; et al. Development of a mouse monoclonal antibody cocktail for post-exposure rabies prophylaxis in humans. PLoS Negl. Trop. Dis. 2009, 3, e542. [CrossRef]

195. Anonymous. Antirabies Treatment. Am. J. Public Health Nations Health 1935, 25, 857-858.

196. Levaditi, C. Virus rabique et culture des cellules "in vitro". C. R. Soc. Biol. 1913, 75, 505.

197. Webster, L.T.; Clow, A.D. Propagation of rabies virus in tissue culture. J. Exp. Med. 1937, 66, 125-131. [CrossRef] [PubMed]

198. Sokol, F.; Kuwert, E.; Wiktor, T.J.; Hummeler, K.; Koprowski, H. Purification of rabies virus grown in tissue culture. J. Virol. 1968, 2, 836-849. [PubMed]

199. Habel, K. Laboratory techniques in rabies. Habel test for potency. Monogr. Ser. World Health Organ. 1966, 23, 140-143. [PubMed]

200. Laboratory Techniques in Rabies, 3rd ed.; Kaplan, M.M., Koprowski, H., Eds.; World Health Organization: Geneva, Switzerland; Philadelphia, PA, USA, 1973.

201. Fuenzalida, E.; Palacios, R.; Borgono, J.M. Antirabies antibody response in man to vaccine made from infected suckling-mouse brains. Bull. World Health Organ. 1964, 30, 431-436. [PubMed]

202. Molner, J.G.; Willson, R.F.; Kalish, S. Rabies control in Detroit. Am. J. Public Health Nations Health 1955, 45, 998-1004. [CrossRef] [PubMed]

203. Schnurrenberger, P.R.; Anderson, G.R.; Russell, J.H. Rapidity and magnitude of antibody response to duck-embryo rabies vaccine administered as a pre-exposure regimen. Bull. World Health Organ. 1967, 37, 547-551. [PubMed]

204. Kaur, M.; Garg, R.; Singh, S.; Bhatnagar, R. Rabies vaccines: Where do we stand, where are we heading? Expert Rev. Vaccines 2015, 14, 369-381. [CrossRef] [PubMed]

205. Wiktor, T.J.; Sokol, F.; Kuwert, E.; Koprowski, H. Immunogenicity of concentrated and purified rabies vaccine of tissue culture origin. Proc. Soc. Exp. Biol. Med. Soc. Exp. Biol. Med. N.Y. N. 1969, 131, 799-805. [CrossRef] 
206. Sikes, R.K.; Cleary, W.F.; Koprowski, H.; Wiktor, T.J.; Kaplan, M.M. Effective protection of monkeys against death from street virus by post-exposure administration of tissue-culture rabies vaccine. Bull. World Health Organ. 1971, 45, 1-11. [PubMed]

207. Expert Consultation on Rabies Post-Exposure Prophylaxis; European Centre for Disease Prevention and Control (ECDC): Stockholm, Sweden, 2009.

208. Baer, G.M.; Abelseth, M.K.; Debbie, J.G. Oral vaccination of foxes against rabies. Am. J. Epidemiol. 1971, 93, 487-490. [CrossRef] [PubMed]

209. Wells, C.W. The control of rabies in Malaya through compulsory mass vaccination of dogs. Bull. World Health Organ. 1954, 10, 731-742. [PubMed]

210. Kristensson, K.; Dastur, D.K.; Manghani, D.K.; Tsiang, H.; Bentivoglio, M. Rabies: Interactions between neurons and viruses. A review of the history of Negri inclusion bodies. Neuropathol. Appl. Neurobiol. 1996, 22, 179-187. [CrossRef] [PubMed]

211. Negri Luzzani, L. Le diagnostic de la Rage par la Démonstration du Parasite Spécifique—Résultat de Dix Ans d'Expérience (Première Partie). Ann. Inst. Pasteur J. Microbiol. Publiées Sous Patronage M Pasteur Par E Duclaux 1913, 27, 907-923.

212. Negri Luzzani, L. Le diagnostic de la Rage par la Démonstration du Parasite Spécifique—Résultat de Dix Ans d'Expérience (Deuxième Partie). Ann. Inst. Pasteur J. Microbiol. Publiées Sous Patronage M Pasteur Par E Duclaux 1913, 27, 1039-1062.

213. Almeida, J.D.; Howatson, A.F.; Pinteric, L.; Fenje, P. Electron microscope observations on rabies virus by negative staining. Virology 1962, 18, 147-151. [CrossRef]

214. Matsumoto, S. Electron microscope studies of rabies virus in mouse brain. J. Cell Biol. 1963, 19, 565-591. [CrossRef] [PubMed]

215. Matsumoto, S. Electron microscopy of nerve cells infected with street rabies virus. Virology 1962, 17, 198-202. [CrossRef]

216. Flamand, A.; Delagneau, J.F. Transcriptional mapping of rabies virus in vivo. J. Virol. 1978, 28, 518-523. [PubMed]

217. Tordo, N.; Poch, O.; Ermine, A.; Keith, G.; Rougeon, F. Completion of the rabies virus genome sequence determination: Highly conserved domains among the $\mathrm{L}$ (polymerase) proteins of unsegmented negative-strand RNA viruses. Virology 1988, 165, 565-576. [CrossRef]

218. Laboratory Techniques in Rabies, 4th ed.; Meslin, F.-X.; Kaplan, M.M.; Koprowski, H.; World Health Organization, Eds.; World Health Organization: Geneva, Switzerland, 1996.

219. Duong, V.; Tarantola, A.; Ong, S.; Mey, C.; Bourhy, H.; Dussart, P.; Buchy, P. Laboratory diagnostics in dog-mediated rabies-An overview of performance and a proposed strategy in various settings. Int. J. Infect. Dis. 2016, 46, 107-114. [CrossRef] [PubMed]

220. Briggs, D.J.; Banzhoff, A.; Nicolay, U.; Sirikwin, S.; Dumavibhat, B.; Tongswas, S.; Wasi, C. Antibody response of patients after postexposure rabies vaccination with small intradermal doses of purified chick embryo cell vaccine or purified Vero cell rabies vaccine. Bull. World Health Organ. 2000, 78, 693-698. [PubMed]

221. Jaiiaroensup, W.; Lang, J.; Thipkong, P.; Wimalaratne, O.; Samranwataya, P.; Saikasem, A.; Chareonwai, S.; Yenmuang, W.; Prakongsri, S.; Sitprija, V.; et al. Safety and efficacy of purified Vero cell rabies vaccine given intramuscularly and intradermally. (Results of a prospective randomized trial). Vaccine 1998, 16, 1559-1562. [CrossRef]

222. Quiambao, B.P.; Dimaano, E.M.; Ambas, C.; Davis, R.; Banzhoff, A.; Malerczyk, C. Reducing the cost of post-exposure rabies prophylaxis: Efficacy of $0.1 \mathrm{~mL}$ PCEC rabies vaccine administered intradermally using the Thai Red Cross post-exposure regimen in patients severely exposed to laboratory-confirmed rabid animals. Vaccine 2005, 23, 1709-1714. [CrossRef] [PubMed]

223. Fekadu, M.; Shaddock, J.H.; Baer, G.M. Intermittent excretion of rabies virus in the saliva of a dog two and six months after it had recovered from experimental rabies. Am. J. Trop. Med. Hyg. 1981, 30, 1113-1115. [PubMed]

224. Starr, L.E.; Sellers, T.F.; Sunkes, E.J. Apparent recovery of a dog from rabies. J. Am. Vet. Med. Assoc. 1952, 121, 296. [PubMed]

225. Mshelbwala, P.P.; Ogunkoya, A.B.; Maikai, B.V. Detection of rabies antigen in the saliva and brains of apparently healthy dogs slaughtered for human consumption and its public health implications in abia state, Nigeria. ISRN Vet. Sci. 2013, 2013, 468043. [CrossRef] [PubMed] 
226. Cleaveland, S.; Barrat, J.; Barrat, M.J.; Selve, M.; Kaare, M.; Esterhuysen, J. A rabies serosurvey of domestic dogs in rural Tanzania: Results of a rapid fluorescent focus inhibition test (RFFIT) and a liquid-phase blocking ELISA used in parallel. Epidemiol. Infect. 1999, 123, 157-164. [CrossRef] [PubMed]

227. Follmann, E.H.; Ritter, D.G.; Beller, M. Survey of fox trappers in northern Alaska for rabies antibody. Epidemiol. Infect. 1994, 113, 137-141. [CrossRef] [PubMed]

228. Gilbert, A.T.; Petersen, B.W.; Recuenco, S.; Niezgoda, M.; Gómez, J.; Laguna-Torres, V.A.; Rupprecht, C. Evidence of rabies virus exposure among humans in the Peruvian Amazon. Am. J. Trop. Med. Hyg. 2012, 87, 206-215. [CrossRef] [PubMed]

229. Weyer, J.; Msimang-Dermaux, V.; Paweska, J.T.; le Roux, K.; Govender, P.; Coertse, J.; Markotter, W.; Nel, L.H.; Blumberg, L.H. A case of human survival of rabies, South Africa. South. Afr. J. Infect. Dis. 2016, 31, 1-3. [CrossRef]

230. Hattwick, M.A.; Weis, T.T.; Stechschulte, C.J.; Baer, G.M.; Gregg, M.B. Recovery from rabies. A case report. Ann. Intern. Med. 1972, 76, 931-942. [CrossRef] [PubMed]

231. Willoughby, R.E., Jr.; Tieves, K.S.; Hoffman, G.M.; Ghanayem, N.S.; Amlie-Lefond, C.M.; Schwabe, M.J.; Chusid, M.J.; Rupprecht, C.E. Survival after treatment of rabies with induction of coma. N. Engl. J. Med. 2005, 352, 2508-2514. [CrossRef] [PubMed]

232. Madhusudana, S.N.; Nagaraj, D.; Uday, M.; Ratnavalli, E.; Kumar, M.V. Partial recovery from rabies in a six-year-old girl. Int. J. Infect. Dis. IJID Off. Publ. Int. Soc. Infect. Dis. 2002, 6, 85-86. [CrossRef]

233. Presumptive abortive human rabies-Texas, 2009. MMWR Morb. Mortal. Wkly. Rep. 2010, 59, 185-190.

234. Porras, C.; Barboza, J.J.; Fuenzalida, E.; Adaros, H.L.; Oviedo, A.M.; Furst, J. Recovery from rabies in man. Ann. Intern. Med. 1976, 85, 44-48. [CrossRef] [PubMed]

235. Recovery of a patient from clinical rabies-Wisconsin, 2004. MMWR Morb. Mortal. Wkly. Rep. 2004, 53, 1171-1173.

236. Recovery of a patient from clinical rabies-California, 2011. MMWR Morb. Mortal. Wkly. Rep. 2012, 61, 61-65.

237. Jackson, A.C.; Warrell, M.J.; Rupprecht, C.E.; Ertl, H.C. J.; Dietzschold, B.; O’Reilly, M.; Leach, R.P.; Fu, Z.F.; Wunner, W.H.; Bleck, T.P.; et al. Management of rabies in humans. Clin. Infect. Dis. Off. Publ. Infect. Dis. Soc. Am. 2003, 36, 60-63. [CrossRef] [PubMed]

238. Jackson, A.C. Recovery from rabies. N. Engl. J. Med. 2005, 352, 2549-2550. [CrossRef] [PubMed]

239. Wilde, H.; Hemachudha, T.; Jackson, A.C. Viewpoint: Management of human rabies. Trans. R. Soc. Trop. Med. Hyg. 2008, 102, 979-982. [CrossRef] [PubMed]

240. Deressa, A.; Hussen, K.; Abebe, D.; Gera, D. Evaluation of the Efficacy of Crude Extracts of Salix subserrata and Silene macroselen for the treatment of rabies in Ethiopia. Ethiop. Vet. J. 2010, 14, 1-16. [CrossRef]

241. Yamada, K.; Noguchi, K.; Komeno, T.; Furuta, Y.; Nishizono, A. Efficacy of favipiravir (T-705) in rabies postexposure prophylaxis. J. Infect. Dis. 2016, 213, 1253-1261. [CrossRef] [PubMed]

242. Taylor, L.H.; Hampson, K.; Fahrion, A.; Abela-Ridder, B.; Nel, L.H. Difficulties in estimating the human burden of canine rabies. Acta Trop. 2017, 165, 133-140. [CrossRef] [PubMed]

243. World Health Organization. Recommended Standards and Strategies for Surveillance, Prevention and Control of Communicable Diseases. A82: Rabies; World Health Organization: Geneva, Switzerland, 1999; pp. 101-103.

244. Hampson, K.; Coudeville, L.; Lembo, T.; Sambo, M.; Kieffer, A.; Attlan, M.; Barrat, J.; Blanton, J.D.; Briggs, D.J.; Cleaveland, S.; et al. On behalf of the global alliance for rabies control partners for rabies prevention estimating the global burden of endemic canine rabies. PLoS Negl. Trop. Dis. 2015, 9, e0003709.

245. World Health Organization. Ebola Situation Report-30 March 2016; World Health Organization: Geneva, Switzerland, 2016; p. 12.

246. Abela-Ridder, B.; Knopf, L.; Martin, S.; Taylor, L.; Torres, G.; De Balogh, K. 2016: The beginning of the end of rabies? Lancet Glob. Health 2016, 4, e780-e781. [CrossRef]

247. Tarantola, A.; Ly, S.; In, S.; Ong, S.; Peng, Y.; Heng, N.Y.; Buchy, P. Rabies vaccine and rabies immunoglobulin in Cambodia: Use and obstacles to use. J. Travel. Med. 2015, 22, 348-352. [CrossRef] [PubMed]

248. Tarantola, A.; Blanchi, S.; Cappelle, J.; Ly, S.; Chan, M.; In, S.; Peng, Y.; Hing, C.; Taing, C.N.; Ly, S.; Bourhy, H.; Buchy, P.; Dussart, P.; Mary, J.-Y. Rabies postexposure prophylaxis (PEP) noncompletion after dog bites: estimating the unseen to meet the needs of the underserved. Am. J. Epidemiol 2017. (Accepted for publication).

(C) 2017 by the author. Licensee MDPI, Basel, Switzerland. This article is an open access article distributed under the terms and conditions of the Creative Commons Attribution (CC BY) license (http:/ / creativecommons.org/licenses/by/4.0/). 


\title{
Childhood Rabies Deaths and the Rule of Rescue
}

\author{
David Durrheim ${ }^{1,2}$ \\ 1 School of Medicine and Public Health, University of Newcastle, \\ Callaghan, New South Wales 2387, Australia; David.Durrheim@newcastle.edu.au; Tel.: +61-2-49246395 \\ 2 College of Public Health, Medical and Veterinary Sciences, James Cook University, \\ Queensland 4814, Australia
}

Academic Editors: Charles Rupprecht and Bernhard Dietzschold Received: 6 January 2017; Accepted: 11 April 2017; Published: 17 April 2017

\begin{abstract}
Every childhood rabies death is potentially preventable. The vaccine that prevents rabies disease has a formidable safety and efficacy track record. Rabies vaccination of dogs and timely pre-and post-exposure vaccine administration are life-saving and cost-effective, and yet nearly 60,000 people, mainly children, die unnecessarily each year. Poor performance by many veterinary and public health systems, and neglect by complicit authorities is in stark contravention of the Convention on the Rights of the Child. The ethical principle of beneficence and the rule of rescue demand re-energised commitment to eradicating childhood rabies deaths.
\end{abstract}

Keywords: rabies; child; death; vaccination; immunization; ethics; rights; beneficence; rescue

\section{Introduction}

The burden of human rabies falls heavily on young children in developing countries with most of the approximately 59,000 annual deaths due to rabies occurring in children younger than 15 years of age in Africa and Asia with virus transmission largely from rabid dogs [1,2]. Almost every one of these deaths reflects a failure of the public health and veterinary systems as the vaccine that is available is highly effective in preventing disease in dogs and humans [3]. However, in addition to the primary failure of not reaching all dogs with vaccine by weak veterinary programs, and the secondary failure in not providing ready access to post-exposure treatment with rabies vaccine and immunoglobulin by deficient health systems, either through inability to secure stock or to follow guidelines, there is a potential third failure, that of not administering pre-emptive protective vaccination to children in high-risk rabies-endemic areas where the perpetual weakness of the public health and veterinary systems in delivering education and vaccination is well recognised [4]. A recent systematic review of the safety and immunogenicity of pre-exposure rabies prophylaxis found that it is safe, effective and should be considered in areas "where access to post-exposure prophylaxis is limited or delayed, where the risk of exposure is high and may go unrecognised, and where controlling rabies in the animal reservoir is difficult" [5]. However, only two countries, Peru and the Philippines, have thus far implemented this strategy.

In addition, accelerated regimens (all vaccine doses administered within a week) and administration by intradermal rather than intramuscular route were found to be highly immunoprotective. Thus we have at our disposal effective tools to eliminate childhood rabies deaths but to date the will to fully embrace this challenge in many endemic countries and the international community has been lacking.

\section{Convention of the Rights of the Child}

It is timely to remind ourselves of our shared obligations under the Convention of the Rights of the Child (http://www.unicef.org/crc/). This international legally binding instrument enjoys remarkable acceptance with all United Nations states, excepting Somalia and the United States of 
America, having ratified the Convention [6]. Article 6 (Survival and Development) is particularly pertinent to the childhood rabies death sentence: "Children have the right to live. Governments should ensure that children survive and develop healthily". Thus individual governments in rabies endemic areas should not tolerate poor performance of their veterinary or public health sectors in achieving high dog rabies vaccination or ensuring the availability of post-exposure rabies vaccination, respectively. Each rabies death should prompt an enquiry to identify preventable system failures. Confidential enquiries into maternal deaths, infant deaths, peri-operative deaths, and malaria and cholera deaths have proven immensely valuable for correcting system weaknesses. Identifying the system root causes of deaths would allow targeting of resources to limit the likelihood of recurrence. Governments may argue that this will come at an opportunity cost as there are many competing priorities for finances. Sustainable development requires investment in many areas including clean water, adequate sanitation, quality education and secure food supply. However, immunisation is a wonderful public good, in that a single intervention can provide long-lived benefits to the individual. Further, dog rabies vaccination programs are a basic indicator of the coverage and quality of veterinary public health initiatives. Recent case studies from Bhutan and Tanzania demonstrated the effectiveness of programs implemented to achieve at least $70 \%$ canine coverage [7].

A health service that does not effectively reach communities with education messages about stray canine and wild life avoidance, and appropriate first aid measures, or cannot provide a reliable timely supply of potent rabies vaccine, will likely be failing to provide other primary health care services. Both dog rabies vaccination and human pre-exposure (in certain high risk settings) and post-exposure rabies vaccination have been shown to be cost-effective in developing countries, and for canine rabies vaccination, cost-saving (if the estimated $\$ 2.7$ billion wasted with post-exposure prophylaxis annually is included), so it is time for individual governments to demonstrate appropriate accountability and deliver on their human rights commitment [5,7].

A true commitment to the rights of children demands that every country's government implements carefully monitored strategies for guaranteeing all children protection against rabies through equal access to effective vaccines based on local rabies epidemiology [8].

But impoverished endemic countries should not shoulder this responsibility alone. Article 24 (Health and Health Services) states: "Children have the right to good quality health care- the best health care possible- to safe drinking water, nutritious food, a clean and safe environment, and information to help them stay healthy. Rich countries should help poorer countries achieve this". This places a specific legal obligation on developed countries to support less-developed countries to ensure social justice in the delivery of preventive and curative health care, including rabies prevention. These developed countries have already experienced the benefit of eradication of canine rabies through well organized and funded veterinary vaccination campaigns. GAVI, the global alliance for vaccines and immunization, has provided a dependable and accountable mechanism for raising and administering funds from donors and wealthy countries for critical vaccine introductions and immunisation program strengthening in developing countries. It is time that GAVI carefully reviewed the evidence supporting expanding access to rabies vaccine and immunoglobulin, including the childhood mortality burden, the cost-effectiveness data and the opportunity for strengthening immunisation programs.

\section{Principle of Beneficence}

This legally binding prerogative for eliminating childhood rabies deaths is supported by important ethical considerations. The principle of beneficence is succinctly summarised by the Golden Rule: "Do unto others, as you would have them do unto you". This ethical principle dictates that national governments and the international community have a duty of care to ensure that all children enjoy the protection offered by effective vaccines [9]. The strength of the duty of care depends on the availability of effective and affordable measures [10]. This requirement is clearly satisfied by rabies vaccines, which enjoy a proven track record if administered correctly without delay. 


\section{Rule of Rescue}

The rule of rescue places a compelling obligation on those that are able, in this case governments and health personnel, to "rescue identifiable individuals facing avoidable death" if personal sacrifice is not excessive [11]. This duty is influenced by the urgency of the situation, the consequences of doing nothing, the feasibility of preventing serious consequences and the sacrifice required [12]. Rabies vaccination for all children who are at high risk of exposure or have been exposed to a bite or scratch from an infected animal easily meets each one of these criteria: "urgency"—-delayed vaccination can result in preventable death; "consequence of doing nothing"- death is almost inevitable once clinical symptoms have occurred [2]; "feasibility of preventing serious consequences"—vaccine and immunoglobulin are highly effective and cost-effective in preventing disease; and "sacrifice required" - surely the opportunity costs of providing vaccine in these circumstances are morally defensible! [13]

\section{Conclusions}

The principle of Justice obligates those who are better off to assist those who are worse off and to allocate resources accordingly [14]. A global Convention considers the lives of children as precious and demands that governments ensure child health and survival. We have effective tools to rescue children from agonising preventable deaths due to lyssavirus 1. Rabies deaths in children are a true measure of our generation's commitment to children's rights and social justice.

Conflicts of Interest: The author declares no conflict of interest.

\section{References}

1. World Health Organization. Human rabies: 2016 updates and call of data. Wkly. Epidemiol. Rec. 2017, $92,77-86$.

2. Crowcroft, N.S.; Thampi, N. The prevention and management of rabies. BMJ 2015, 350, g7827. [CrossRef] [PubMed]

3. Durrheim, D.N. Every rabies death is a veterinary and health system failure until proven otherwise. Vaccine 2016, 34, 2294-2295. [CrossRef] [PubMed]

4. Durrheim, D.N.; Rees, H.; Briggs, D.J.; Blumberg, L.H. Mass vaccination of dogs, control of canine populations and post-exposure vaccination-Necessary but not sufficient for achieving childhood rabies elimination. Trop. Med. Int. Health 2015, 20, 682-684. [CrossRef] [PubMed]

5. Kessels, J.A.; Recuenco, S.; Navarro-Vela, A.; Deray, R.; Vigilato, M.; Ertl, H.; Durrheim, D.N.; Rees, H.; Nel, L.H.; Abela-Ridder, B.; et al. Pre-exposure rabies prophylaxis: A systematic review. Bull. WHO 2017, 95 , 210-219. [CrossRef] [PubMed]

6. The United Nations Children's Fund. Convention on the Rights of the Child. Frequently Asked Questions. Available online: https://www.unicef.org/crc/index_30229.html (accessed on 6 January 2017).

7. Lavan, R.P.; King, A.I.M.; Sutton, D.J.; Tunceli, K. Rationale and support for a One Health program for canine vaccination as the most cost-effective means for controlling zoonotic rabies in endemic settings. Vaccine 2017, 35, 1668-1674. [CrossRef] [PubMed]

8. Hinman, A.R. Immunization, equity and human rights. Am. J. Prev. Med. 2004, 26, 84-88. [CrossRef] [PubMed]

9. Murphy, L. Beneficence. Georget. Law J. 2001, 3, 605-665.

10. Hurst, S.A.; Mezger, N.; Mauron, A. Allocating resources in humanitarian medicine. Public Health Ethics 2009, 2, 89-99. [CrossRef]

11. Jonsen, A.R. Bentham in a box: Technology assessment and health care allocation. Law Med. Health Care 1986, 14, 172-174. [CrossRef] [PubMed]

12. Murphy, L. Beneficence, law and liberty; the case of required rescue. Georget. Law J. 2001, 3, 605-665. 
13. Kenny, C. Disaster risk reduction in developing countries: Costs, benefits and institutions. Disasters 2012, 36, 559-588. [CrossRef] [PubMed]

14. Rawls, J. A Theory of Justice; Harvard University Press: Cambridge, MA, USA, 1971.

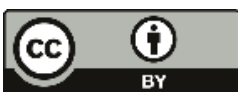

(c) 2017 by the author. Licensee MDPI, Basel, Switzerland. This article is an open access article distributed under the terms and conditions of the Creative Commons Attribution (CC BY) license (http:/ / creativecommons.org/licenses/by/4.0/). 


\title{
The Formation of the Eastern Africa Rabies Network: A Sub-Regional Approach to Rabies Elimination
}

\author{
Emily G. Pieracci ${ }^{1, *}$ Terence P. Scott ${ }^{2,3, *}$, Andre Coetzer ${ }^{2,3}$, Mwatondo Athman ${ }^{4}$, \\ Arithi Mutembei ${ }^{4}$, Abraham Haile Kidane ${ }^{5}$, Meseret Bekele ${ }^{6}$, Girma Ayalew ${ }^{7}$, \\ Samson Ntegeyibizaza ${ }^{8}$, Justine Assenga ${ }^{9}$, Godson Markalio ${ }^{10}$, Peninah Munyua ${ }^{11}$, \\ Louis H. Nel ${ }^{2,3}$ and Jesse Blanton ${ }^{1}$
}

1 National Center for Emerging and Zoonotic Infectious Diseases, Centers for Disease Control and Prevention, Atlanta, GA 30329, USA; JBlanton@cdc.gov

2 Department of Microbiology and Plant Pathology, Faculty of Natural and Agricultural Sciences, University of Pretoria, 0028 Pretoria, South Africa; andre.coetzer@rabiesalliance.org (A.C.); louis.nel@rabiesalliance.org (L.H.N.)

3 Global Alliance for Rabies Control SA NPC, Erasmus Forum A434, South Erasmus Rand, 0181 Pretoria, South Africa

4 Zoonotic Disease Unit, Kenya Ministry of Health, Nairobi, Kenya; amwatondo@yahoo.com (M.A.); drmutembei@gmail.com (A.M.)

5 Ethiopian Public Health Institute, Addis Ababa, Ethiopia; abrahamhaile21@gmail.com

6 Ethiopian Ministry of Livestock and Fisheries, Addis Ababa, Ethiopia; yohanan14sm@gmail.com

7 Ethiopian Ministry of Wildlife and Conservation, Addis Ababa, Ethiopia; girmasas@gmail.com

8 Rwandan Ministry of Agriculture, Kigali, Rwanda; ntegsam@yahoo.fr

9 Tanzania Directorate of Veterinary Services, Ministry of Agriculture, Dar es Salam, Tanzania; assengakanda@yahoo.com

10 Tanzania Ministry of Health, Dar es Salam, Tanzania; markalio@yahoo.com

11 Division of Global Health Protection, Centers for Disease Control and Prevention, Nairobi, Kenya; ikg2@cdc.gov

* Correspondence: EPieracci@cdc.gov (E.G.P.); terence.scott@rabiesalliance.org (T.P.S); Tel.: +1-404-639-2603 (E.G.P.)

Received: 30 June 2017; Accepted: 13 July 2017; Published: 18 July 2017

\begin{abstract}
International rabies networks have been formed in many of the canine-rabies endemic regions around the world to create unified and directed regional approaches towards elimination. The aim of the first sub-regional Eastern Africa rabies network meeting, which included Kenya, Ethiopia, Tanzania, Rwanda, and Uganda, was to discuss how individual country strategies could be coordinated to address the unique challenges that are faced within the network. The Stepwise Approach towards Rabies Elimination and the Global Dog Rabies Elimination Pathway tool were used to stimulate discussion and planning to achieve the elimination of canine-mediated human rabies by 2030. Our analysis estimated a total dog population of 18.3 million dogs in the Eastern Africa region. The current dog vaccination coverage was estimated to be approximately 5\% (915,000 dogs), with an estimated 4910 vaccinators available. Assuming that every vaccinator performs rabies vaccination, this equated to each vaccinator currently vaccinating 186 dogs per year, whilst the target would be to vaccinate 2609 dogs every year for the community to reach $70 \%$ coverage. In order to achieve the World Health Organization-recommended $70 \%$ vaccination coverage, an additional 11 million dogs need to be vaccinated each year, pointing to an average annual shortfall of $\$ 23$ million USD in current spending to achieve elimination by 2030 across the region. Improved vaccination efficiency within the region could be achieved by improving logistics and/or incorporating multiple vaccination methods to increase vaccinator efficiency, and could serve to reduce the financial burden associated with rabies elimination. Regional approaches to rabies control are of value, as neighboring countries can share their unique challenges while, at the same time, common approaches can be developed and resource-saving strategies can be implemented.
\end{abstract}


Keywords: rabies surveillance; rabies network; Africa; rabies elimination

\section{Introduction}

Rabies is a neglected disease that kills an estimated 59,000 people every year, with more than 21,000 of those deaths (36\%) occurring in Africa [1,2]. As rabies is preventable, every death should be considered a public health failure. However, one human still dies from rabies every 9 minutes, with the majority of these deaths occurring in low- and middle-income countries (LMICs) in Africa and Asia [1].

In line with the Sustainable Development Goals (SDGs) [3], a preponderance of African governments seeks to emulate other continents that have drastically reduced the number of human deaths from rabies and controlled or eliminated the disease from the domestic dog, e.g., the Americas and Europe $[4,5]$. The vast majority of human rabies deaths are attributed to bites from rabid dogs, with children and individuals in poor communities being disproportionately affected $[1,2,5,6]$. Despite effective preventive measures and available post-exposure prophylaxis in humans, the most cost-effective control measure to eliminate canine-mediated human rabies remains the routine vaccination of dogs [4,7]. Across Africa, however, canine mass vaccination efforts are primarily still in the developmental stages. The global community, led by the World Health Organization (WHO), World Organisation for Animal Health (OIE), the Food and Agricultural Organization (FAO), and the Global Alliance for Rabies Control (GARC), has set a globally agreed upon goal to eliminate canine-mediated human rabies deaths by 2030 [8].

International rabies networks have been formed in many of the canine-rabies endemic regions to create unified and directed approaches towards elimination within the given regions. The Meeting of Directors of Rabies Programs in the Americas (REDIPRA) structure acted as a regional network, encompassing 27 countries in the Americas [9]. Additionally, smaller multi-national strategic planning groups were implemented to drive rabies elimination efforts; for example the North American Rabies Management Plan (NARMP) was created with a focus on wildlife rabies elimination between Canada, Mexico, and the United States [10]. In Africa, the Pan-African Rabies Control Network (PARACON), under the secretariat of GARC, was recently established as the regional network for sub-Saharan African countries [11], but smaller, community-based, sub-regional planning structures have not been implemented. For this reason, the United States Centers for Disease Control and Prevention (CDC) and GARC worked with regional leaders to establish an Eastern African rabies control planning commission. The aim of this group is to discuss how individual country strategies could be coordinated to address the unique challenges that are faced in terms of rabies control efforts within the region.

The first Eastern African regional rabies control group meeting was held from 7-9 February 2017 in Nairobi, Kenya, and was hosted collaboratively by GARC, CDC, and the Kenya Zoonotic Disease Unit (Kenya ZDU). Representatives from four Eastern African countries, along with regional and international rabies partners, attended the meeting to assess the sub-region's current rabies control strategies, develop sub-regional targets for the future, and showcase a needs assessment analysis to approximate the cost of rabies elimination within the sub-regional network. One Eastern African country was unable to attend, but provided its data the following week. All five countries' data were included in the model for projecting resource needs for canine rabies vaccination.

\section{The Stepwise Approach towards Rabies Elimination}

In a detailed workshop focused on the Stepwise Approach towards Rabies Elimination (SARE), and its linkage to the Rabies Blueprint (http:/ / rabiesblueprint.org/), country representatives identified the current status of rabies control within their country. The SARE assessment provided countries with measurable steps to progress from canine rabies endemic to a canine rabies free status [12]. Representatives outlined these steps to prioritize short- and medium-term activities for each country 
towards a dynamic and ongoing development and implementation of national rabies control plans. Common priority activities from each of the countries were compiled into a sub-regional assessment to provide a basis for the development of a comprehensive sub-regional roadmap for the network. The development of this roadmap is focused on facilitating partnerships and coordination between countries in an effort to address the transboundary nature of canine rabies.

\section{Regional Business Plan and Estimated Needs for Rabies Mass Vaccination}

Country representatives used the Global Dog Rabies Elimination Pathway (GDREP) model for projecting resource needs for canine rabies vaccination (e.g., vaccines, vaccinator resources, and funds) [13]. The GDREP model accounts for resources needed to achieve elimination of canine-mediated human rabies, accommodating varied inputs for cost of dog vaccination, availability of vaccine, and existing workforce available for vaccinating animals to generate outputs of estimated resources needed to achieve vaccination goals. The analysis estimated a total dog population of 18.3 million dogs, based upon the Human to Dog Ratio (HDR) method [6,14-16], for the region (Kenya, Ethiopia, Tanzania, Rwanda, and Uganda). The current dog vaccination coverage in the region was estimated to be approximately 5\% (915,000 dogs), with an estimated 4910 vaccinators available to be mobilized for vaccination campaigns [1]. This is likely to be sufficient personnel to achieve $70 \%$ vaccination of dog populations in the region, based on projections made by the GDREP tool. The estimated cost of the current 2017 level of 5\% vaccination coverage $(915,000 \mathrm{dogs})$ was approximately $\$ 3.2$ million USD per year, equating to an average of \$3.50 USD per vaccinated dog. In order to achieve the recommended $70 \%$ vaccination coverage necessary to eliminate canine rabies [5], an additional 11 million dogs will need to be vaccinated each year, equating to an approximately \$23 million USD annual shortfall in current spending across the region.

The total cost of vaccinating a single dog encompasses supplies and personnel, not just the cost of the vaccine alone. Improving the efficiency of vaccination programs by improving logistics and/or incorporating multiple vaccination methods (e.g., central point vaccination, capture-vaccinate-release), could reduce overall costs [13]. Considering the range of vaccination costs reported in the GDREP [13], from $\$ 1.50 / \mathrm{dog}$ to $\$ 7.00 / \mathrm{dog}$, the estimated average annual shortfall in current spending is likely between \$ 8.5 million USD and \$ 49.8 million USD. Improvements in the planning and efficiency of national canine rabies vaccination campaigns coupled with frequent refinements of national strategies will be critical to ensure that the expected shortfall is reduced and additional funds can be secured. Sharing of resources and technical experience between regional countries will help to facilitate these improvements and more efficiently identify and secure support from national and international partners.

\section{Data Sharing Within the Eastern African Rabies Region}

The PARACON epidemiological bulletin, a web-based surveillance database, is a useful tool for the collection, collation, analysis, and dissemination of rabies surveillance data [17]. To encourage the use of the bulletin, sub-regional country-specific data were collected from meeting participants, and collated data were summarized on a single viewable page. This 'Eastern Africa Dashboard' was made available to all of the participating countries within the network and is envisaged to encourage international collaboration and communication. With increased transparency, a stronger case can be made for transboundary control effort by the participating countries, drawing global interest and raising awareness and advocacy for rabies control within the region. It is also important to engage other Eastern African countries (Burundi and South Sudan) in the Eastern Africa rabies network to achieve a unified regional approach.

\section{Conclusions}

Rabies prevention should be considered a free public good globally. Despite the presence of an effective vaccine for the prevention of rabies for more than a hundred years, rabies continues to 
kill thousands of people across the globe each year $[1,18]$. Some countries have achieved success in eliminating rabies through effective, organized, and coordinated control efforts, but many LMICs remain rabies endemic.

Across Africa, rabies control and elimination efforts are primarily still in the developmental stages. A concerted and carefully conceived approach will need to be created and undertaken to ensure that the goal of elimination by 2030 is reached. The overarching PARACON network guides African countries and provides exposure to new and innovative tools and approaches, while facilitating the development and revision of their national control strategies [11]. Although each country within the PARACON network has access to the same tools, the implementation and use of these tools will often need to be adapted to sub-regions that experience different or additional challenges to those faced by Africa as a whole. Thus, the establishment of the Eastern Africa rabies network has addressed this issue by providing a close-knit working group within the PARACON network for strategic planning and cooperation.

These tools, in conjunction with the increased transparency between the participating countries, and leveraging on existing regional economic and technical bodies promoting the One Health approach, will enable this network to develop their own sustainable roadmap towards rabies control and elimination, with a focus on addressing the transboundary nature of the disease throughout the region. It is envisaged that this roadmap will provide detailed priority activities, steps, and plans directed to the mobilization and unification of the community towards the common goal of canine-mediated human rabies elimination. For the Eastern Africa rabies network, Kenya was nominated to act as the chair on a two-year rotational basis and will be the leading country in the development of such a roadmap for presentation, review, and discussion at the next PARACON meeting (2017). By sharing the roadmap and presenting the concept of the smaller focused communities within the PARACON network, the Eastern Africa rabies network will act as a flagship for other communities with common challenges to unite and tailor the foundational basis of the roadmap to their specific needs.

Acknowledgments: We would like to thank Kim Doyle, Marco Antonio Natal Vigilato and Eduardo Undurraga for their assistance.

Author Contributions: J.B., L.H.N., A.C., P.M., E.G.P. and T.P.S. conceived and designed the experiments; A.C., T.P.S., M.A., A.M., A.H.K., M.B., G.A., S.N., J.A., G.M. performed the experiments; J.B., E.G.P., A.C., T.P.S., L.H.S. analyzed the data; E.G.P., T.P.S., A.C., L.H.N., and J.B. wrote the paper.

Conflicts of Interest: The authors declare no conflict of interest.

Disclosures: The findings and conclusions in this report are those of the authors and do not necessarily represent the views of the Centers for Disease Control and Prevention.

\section{References}

1. Hampson, K.; Coudeville, L.; Lembo, T.; Sambo, M.; Kieffer, A.; Attlan, M.; Barrat, J.; Blanton, J.D.; Briggs, D.J.; Cleaveland, S.; et al. Estimating the global burden of endemic canine rabies. PLoS Negl. Trop. Dis. 2015, 9, $1-20$.

2. Dodet, B.; Adjogoua, E.V.; Aguemon, A.R.; Amadou, O.H.; Atipo, A.L.; Baba, B.A.; Ada, S.B.; Boumandouki, P.; Bourhy, H.; Diallo, M.K.; et al. Fighting rabies in Africa: The Africa Rabies Expert Bureau (AfroREB). Vaccine 2008, 26, 6295-6298. [CrossRef] [PubMed]

3. United Nations. Transforming Our World: the 2030 Agenda for Sustainable Development; United Nations General Assembly: New York, NY, USA, 2015; Available online: http://www.un.org/ga/search/view_doc.asp? symbol=A/RES/70/1\&Lang=E (accessed on 14 July 2017).

4. Belotto, A.; Leanes, L.F.; Schneider, M.C.; Tamayo, H.; Correa, E. Overview of rabies in the Americas. Virus Res. 2005, 111, 5-12. [CrossRef] [PubMed]

5. World Health Organization. WHO Expert Consultation on Rabies: Second Report; WHO: Geneva, Switzerland, 2013; pp. 1-141. 
6. Knobel, D.L.; Cleaveland, S.; Coleman, P.G.; Fèvre, E.M.; Meltzer, M.I.; Miranda, M.E.G.; Shaw, A.; Zinsstag, J.; Meslin, F.-X. Re-evaluating the burden of rabies in Africa and Asia. Bull. World Health Organ. 2005, 83, 360-368. [PubMed]

7. Schneider, M.C.; Belotto, A.; Adé, M.P.; Hendrickx, S.; Leanes, L.F.; Rodrigues, M.J.D.F.; Medina, G.; Correa, E. Current status of human rabies transmitted by dogs in Latin America. Cad. Saude Publica 2007, 23, 2049-2063. [CrossRef] [PubMed]

8. Jarvis, S. Aiming for elimination of dog-mediated human rabies cases by 2030. Vet. Rec. 2016, 178, 86-87.

9. Clavijo, A.; Del Rio Vilas, V.J.; Mayen, F.L.; Yadon, Z.E.; Beloto, A.J.; Vigilato, M.A.N.; Schneider, M.C.; Cosivi, O. Gains and future road map for the elimination of dog-transmitted rabies in the Americas. Am. J. Trop. Med. Hyg. 2013, 89, 1040-1042. [CrossRef] [PubMed]

10. Slate, D.; Algeo, T.P.; Nelson, K.M.; Chipman, R.B.; Donovan, D.; Blanton, J.D.; Niezgoda, M.; Rupprecht, C.E. Oral rabies vaccination in North America: Opportunities, complexities, and challenges. PLoS Negl. Trop. Dis. 2009, 3, 1-9. [CrossRef] [PubMed]

11. Scott, T.P.; Coetzer, A.; de Balogh, K.; Wright, N.; Nel, L.H. The Pan-African Rabies Control Network (PARACON): A unified approach to eliminating canine rabies in Africa. Antiviral Res. 2015, 124, 93-100. [CrossRef] [PubMed]

12. Coetzer, A.; Kidane, A.H.; Bekele, M.; Hundera, A.D.; Pieracci, E.G.; Shiferaw, M.L.; Wallace, R.; Nel, L.H. The SARE tool for rabies control: Current experience in Ethiopia. Antiviral Res. 2016, 135, 74-80. [CrossRef] [PubMed]

13. Wallace, R.M.; Undurraga, E.A.; Blanton, J.D.; Cleaton, J.; Franka, R. Elimination of dog-mediated human rabies deaths by 2030: Needs assessmnet and alternatives for progress based on dog vaccination. Front. Vet. Sci. 2017, 4, 9. [CrossRef] [PubMed]

14. Davlin, S.L.; VonVille, H.M. Canine rabies vaccination and domestic dog population characteristics in the developing world: A systematic review. Vaccine 2012, 30, 3492-3502. [CrossRef] [PubMed]

15. Knobel, D.L.; Laurenson, M.K.; Kazwala, R.R.; Boden, L.A.; Cleaveland, S. A cross-sectional study of factors associated with dog ownership in Tanzania. Bmc Vet. Res. 2008, 4, 5. [CrossRef] [PubMed]

16. Cleaveland, S.; Beyer, H.; Hampson, K.; Haydon, D.; Lankester, F.; Lembo, T.; Meslin, F.-X.; Morters, M.; Mtema, Z.; Sambo, M.; Townsend, S. The changing landscape of rabies epidemiology and control. Onderstepoort J. Vet. Res. 2014, 81, 1-8. [CrossRef] [PubMed]

17. Scott, T.P.; Coetzer, A.; Fahrion, A.S.; Nel, L.H. Addressing the disconnect between the estimated, reported and true rabies data: The development of a regional African rabies bulletin. Front. Vet. Sci. 2017, 4, 4-9. [CrossRef] [PubMed]

18. Pasteur, M.L. Méthode pour prévenir la rage après morsure. Comptes Rendus des Seances L'academie des Sci. $1885,17,765-772$.

(C) 2017 by the authors. Licensee MDPI, Basel, Switzerland. This article is an open access article distributed under the terms and conditions of the Creative Commons Attribution (CC BY) license (http:/ / creativecommons.org/licenses/by/4.0/). 
Article

\title{
Epidemiology of Rabies in Lesotho: The Importance of Routine Surveillance and Virus Characterization
}

\author{
Andre Coetzer ${ }^{1,2}$, Jessica Coertse ${ }^{3}$, Mabusetsa Joseph Makalo ${ }^{4}$, Marosi Molomo ${ }^{4}$, \\ Wanda Markotter ${ }^{3}$ and Louis Hendrik Nel ${ }^{1,2, *}$ \\ 1 Department of Microbiology and Plant Pathology, Faculty of Natural and Agricultural Sciences, \\ University of Pretoria, 0001 Pretoria, South Africa; andre.coetzer@up.ac.za \\ 2 Global Alliance for Rabies Control SA NPC, Erasmus Forum A434, South Erasmus Rand, \\ 0181 Pretoria, South Africa \\ 3 Centre for Viral Zoonoses, Department of Medical Virology, Faculty of Health Sciences, \\ University of Pretoria, 0001 Pretoria, South Africa; jessica.coertse@up.ac.za (J.C.); \\ Wanda.Markotter@up.ac.za (W.M.) \\ 4 Department of Livestock Services, Ministry of Agriculture and Food Security, Private Bag A82, \\ 100 Maseru, Lesotho; mabusetsa1930@gmail.com (M.J.M.); molomomarosi@gmail.com (M.M.) \\ * Correspondence: louis.nel@rabiesalliance.org; Tel.: +27-12-420-3622
}

Received: 27 June 2017; Accepted: 16 July 2017; Published: 19 July 2017

\begin{abstract}
Rabies is widespread throughout Africa and Asia, despite the fact that the control and elimination of this disease has been proven to be feasible. Lesotho, a small landlocked country surrounded by South Africa, has been known to be endemic for rabies since the 1980s but the epidemiology of the disease remains poorly understood due to limited sample submission, constrained diagnostic capabilities, and a lack of molecular epidemiological data. Considering the existing challenges experienced in Lesotho, we aimed to evaluate the direct, rapid immunohistochemical test (DRIT) as an alternative to the direct fluorescent antibody (DFA) test for rabies diagnosis in Lesotho. Towards this aim, extensive training on the implementation and interpretation of the DRIT was hosted in Lesotho in April 2016 before both tests were applied to all samples subjected to routine rabies diagnosis at the Central Veterinary Laboratory (CVL). We found agreement between the DFA and DRIT assays in 90/96 samples (93.75\%). The samples that produced inconsistent results $(n=6)$ were re-tested a further two times with both assays before being subjected to a real-time qPCR to confirm the diagnosis. Additionally, a statistically significant three-fold increase in the average number of samples submitted per month was observed after the DRIT implementation started, following continuous rabies awareness initiatives amongst the animal health professionals in the country over a 12-month period $(p=0.0279)$. Partial G-L intergenic regions of selected rabies-positive samples $(n=21)$ were amplified, sequenced, and subjected to phylogenetic analyses. Molecular epidemiological analyses, which included viruses from neighbouring provinces in South Africa, suggested that at least three independent rabies cycles within Lesotho were implicated in instances of cross-border transmission. This study has evaluated alternative methods for diagnosing and improving rabies surveillance in Lesotho, as well as providing new information that would be of importance in the planning of future disease intervention campaigns, not only in Lesotho, but also in neighbouring South Africa.
\end{abstract}

Keywords: surveillance; rabies; diagnosis; southern Africa

\section{Introduction}

Canine-mediated rabies, caused by rabies virus (RABV), is a neglected tropical disease that has the highest case-fatality rate of any known infectious disease, accounting for an estimated 
59,000 human deaths every year globally [1]. The burden associated with the disease is highest in developing countries and is typically a scourge on the poorest people in low and middle income countries (LMICs) [1-3]. On the African continent, rabies causes an estimated 21,000 (36\% of the global canine-mediated human rabies cases) deaths annually, with the number of infected animals being several magnitudes higher [1]. While the availability of post-exposure prophylaxis (PEP) prevents the onset of human rabies after an exposure, the most cost-effective control measure is the routine vaccination of the domestic dog populations [3]. Unfortunately, various social, economic, and political factors contribute to the inadequate control of canine-mediated rabies in endemic areas, with human rabies cases occurring as a result thereof $[1,3,4]$.

Rabies was first recorded in Lesotho in the 1980s when the disease was introduced into the northeastern part of the country from the KwaZulu-Natal (KZN) province of South Africa [5]. Subsequent to the introduction, rabies spread throughout the country within two years and has remained endemic ever since [5-8]. Despite annual dog vaccination campaigns undertaken throughout the country, the control and elimination of rabies in the country is complicated by a low estimated vaccination coverage [8] and the fact that Lesotho is bordered by three rabies-endemic South African provinces, viz. the Free State (FS), Eastern Cape (EC), and KZN provinces. These provinces have historically been shown to contribute to the cross-border transmission of rabies between the two countries [5,9-11].

The transboundary spread of rabies between South Africa and Lesotho was first confirmed during a molecular epidemiological investigation of canine rabies in the FS province [9]. During that study, 13 sequences originating from Lesotho were included in the molecular epidemiological analyses. It was not only shown that the FS province and Lesotho shared the same epidemiological cycle, but historical surveillance data also indicated that canine rabies was most likely introduced into the FS province after crossing the border from Lesotho [9]. Since then, no further molecular epidemiological studies had been performed in either the FS province or Lesotho, limiting the contemporary information needed to guide disease intervention campaigns within the two countries.

One of the main limitations to the improved epidemiological understanding of rabies in Lesotho is limited surveillance data. Although rabies is a notifiable disease in Lesotho, the surveillance network has historically been constrained by a lack of samples subjected to routine rabies diagnosis at the only laboratory capable of diagnosing rabies in the country, the Central Veterinary Laboratory (CVL) in Maseru (Figure 1). The limited surveillance data and molecular epidemiological information directly contributed to the underestimated burden of the disease [8], as well as the subsequently low prioritisation and lack of rabies control activities.

In an effort to enhance the rabies diagnostic capabilities and capacity in Lesotho, we implemented the direct, rapid immunohistochemical test (DRIT) in a twinning approach to the gold standard direct fluorescent antibody (DFA) test at the CVL in Maseru. Throughout this project, the routine submission of samples was continuously encouraged amongst the animal health professionals operating within the country. The awareness activities not only facilitated the submission of samples to be tested with the DFA and DRIT assays, but also enabled us to investigate whether stimulating the members of the expert network into collecting and submitting samples would result in a statistically-significant increase in sample submission over a 12-month period. To improve molecular epidemiological information within Lesotho, a sub-set of the samples-including viruses from the neighbouring provinces of South Africa-was analysed by targeting the G-L intergenic region of RABV cDNA. 


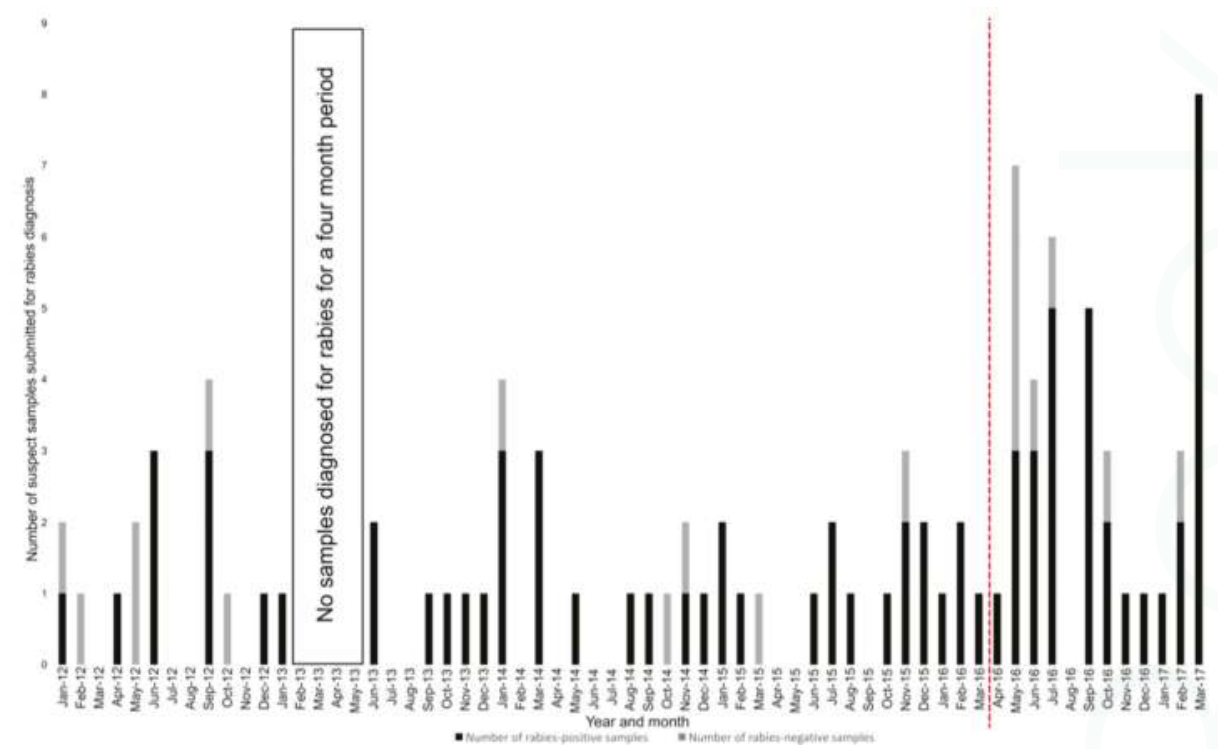

Figure 1. The number of positive and negative samples submitted per month for rabies diagnosis at the Central Veterinary Laboratory in Maseru, Lesotho (2012-2016). The number of samples subjected to rabies diagnosis per month between January 2012 and March 2017 are depicted as vertical bars. The number of rabies-positive samples are depicted as the black-filled bars, while the number of rabies-negative samples are depicted as the grey-filled bars. Months where no vertical bars are present indicate a month where no samples were subjected to rabies diagnosis. The vertical dashed line represents the start of the twelve-month study period during which the DRIT was actively promoted in the country.

\section{Materials and Methods}

\subsection{Diagnostic Training and Sample Cohort}

Before the routine implementation of the DRIT assay in Lesotho, a workshop on the implementation and interpretation of the assay was presented in April 2016 by a South African diagnostician experienced in the use and interpretation of the assay [12]. Over the course of the five-day workshop held at the CVL in Maseru, four local diagnosticians were introduced to the DRIT assay and its use in a diagnostic setting by applying the assay blindly to a cohort of archival samples $(n=57)$ that had been found to be either rabies-positive or -negative with the gold standard DFA test. The DFA test applied at the CVL in Lesotho relied on a FITC-labelled polyclonal antibody (PAb) preparation prepared by the Agricultural Research Council-Onderstepoort Veterinary Institute (ARC-OVI, Rabies Division) prior to the samples being stored in a 50\% glycerol-saline solution at ambient temperature (Table 1) $[13,14]$. While all of the diagnosticians were familiar with the DFA, the samples in this study were the first DRIT-diagnosed samples that the local diagnosticians had interpreted.

After the diagnostic training programme had been completed in April 2016, the DRIT and DFA assays were routinely applied concurrently to newly-submitted brain tissue samples $(n=39)$ that were collected by the trained technicians without further supervision from the DRIT trainer (Table 1). Additionally, the expert network of trained animal technicians and veterinarians (both state and private) operating within Lesotho were continuously contacted via short messages service (SMS), emails or telephonic calls and encouraged to collect samples for diagnostic confirmation within their communities. The aforementioned messages were sent on a monthly basis to the animal health 
technicians responsible for each of the ten districts, who subsequently disseminated the information to all of relevant stakeholders operating in the specific resource centres. Suspect samples were subsequently collected, submitted, and diagnosed in support of the project which, in turn, increased the level of surveillance data generated for the country.

Table 1. Neuronal tissue sample cohort from Lesotho depicting the initial diagnostic results from the CVL in Maseru, Lesotho, the diagnostic discrepancies and their independent molecular confirmation at the laboratory in South Africa.

\begin{tabular}{|c|c|c|c|c|c|c|}
\hline & Sample Number & Species & Town & DRIT Result & DFA Result & Real-Time PCR Result \\
\hline $1 *$ & $15 / 09 / 11$ & Bovine & Maseru & Positive & Positive &.- \\
\hline $2 *$ & $254 / 09 / 11$ & Bovine & Mokhotlong & Negative & Negative & -.- \\
\hline $3 *$ & $11 / 01 / 12$ & Bovine & Berea & Positive & Positive & -- \\
\hline $4^{*}$ & $24 / 01 / 12$ & Bovine & Maseru & Negative & Negative & $\ldots$ \\
\hline $5 *$ & $04 / 02 / 12$ & Bovine & Maseru & Negative & Negative &.- \\
\hline $6^{*}$ & $106 / 04 / 12$ & Bovine & Maseru & Negative & Negative &.- \\
\hline $7^{*}$ & $113 / 05 / 12$ & Bovine & Maseru & Negative & Negative &.- \\
\hline $8 *$ & $123 / 05 / 12$ & Canine & Maseru & Negative & Negative & -- \\
\hline $9 *$ & $14 / 06 / 12$ & Canine & Maseru & Positive & Positive & $\ldots$ \\
\hline $10 * \#$ & $145 / 06 / 12$ & Bovine & Maseru & Positive & Positive & $-\ldots$ \\
\hline $11 *$ *\# & $136 / 06 / 12$ & Canine & Maseru & Positive & Positive &.- \\
\hline $12 *$ & $12 / 09 / 12$ & Bovine & Maseru & Negative & Negative &.- \\
\hline $13 * \#$ & $151 / 09 / 12$ & Bovine & Quthing & Positive & Positive & -- \\
\hline 14 *\# & $190 / 09 / 12$ & Canine & Maseru & Positive & Positive &.- \\
\hline $15 *$ *\# & $201 / 09 / 12$ & Caprine & Maseru & Positive & Positive &.- \\
\hline 16 * & $211 / 10 / 12$ & Canine & Maseru & Positive & Positive &.- \\
\hline 17 * & $276 / 12 / 12$ & Bovine & Maseru & Positive & Positive & -- \\
\hline $18^{*}$ \# & $07 / 01 / 13$ & Bovine & Mokhotlong & Positive & Positive &.-- \\
\hline 19 *\# & $136 / 06 / 13$ & Bovine & Maseru & Positive & Positive &.- \\
\hline 20 *\# & $137 / 06 / 13$ & Canine & Qacha's Nek & Positive & Positive &.- \\
\hline $21 * \#$ & $164 / 09 / 13$ & Canine & Maseru & Positive & Positive &.- \\
\hline $22 *$ & $10 / 10 / 13$ & Bovine & Berea & Positive & Positive &.- \\
\hline $23 *$ & $05 / 11 / 13$ & Bovine & Berea & Positive & Positive & $-\ldots$ \\
\hline 24 *\# & $194 / 12 / 13$ & Canine & Maseru & Positive & Positive & $\ldots$ \\
\hline 25 *\# & $08 / 01 / 14$ & Bovine & Maseru & Positive & Positive & $\ldots$ \\
\hline $26 *$ & $10 / 01 / 14$ & Bovine & Maseru & Negative & Negative & $\ldots$ \\
\hline $27 *$,\# & $13 / 01 / 14$ & Bovine & Maseru & Positive & Positive & -.. \\
\hline $28 *$ & $23 / 01 / 14$ & Canine & Maseru & Positive & Positive &.- \\
\hline $29 *$ & $20 / 03 / 14$ & Bovine & Maseru & Positive & Positive &.- \\
\hline $30 * \#$ & $45 \mathrm{a} / 03 / 14$ & Bovine & Maseru & Positive & Positive &.- \\
\hline 31 *\# & $45 \mathrm{~b} / 03 / 14$ & Bovine & Maseru & Positive & Positive &.- \\
\hline $32 * \#$ & $60 / 05 / 14$ & Canine & Qacha's Nek & Positive & Positive & -.. \\
\hline $33 *$ & $26 / 08 / 14$ & Bovine & Maseru & Positive & Positive & -.. \\
\hline $34 *$ *\# & $99 / 09 / 14$ & Bovine & Maseru & Positive & Positive & $\ldots$ \\
\hline $35 *$ & $21 / 10 / 14$ & Canine & Maseru & Negative & Negative &.- \\
\hline $36 *$ & $192 / 11 / 14$ & Bovine & Berea & Negative & Negative &.- \\
\hline $37 *$ & $193 / 11 / 14$ & Canine & Qacha's Nek & Positive & Positive & -.- \\
\hline $38 *$ & $10 / 12 / 14$ & Equine & Berea & Negative $^{\circ}$ & Positive $^{\circ}$ & Negative \\
\hline $39 *$ & $07 / 01 / 15$ & Canine & Maseru & Positive & Positive & -. \\
\hline $40 *$ \# & $30 / 01 / 15$ & Ovine & Maseru & Positive & Positive & - - \\
\hline 41 *\# & $17 / 02 / 15$ & Canine & Maseru & Positive & Positive & -.. \\
\hline $42 *$ & $18 / 03 / 15$ & Feline & Maseru & Negative & Negative & -.. \\
\hline $43 *$ & $18 / 06 / 15$ & Ovine & Qacha's Nek & Positive & Positive &.- \\
\hline $44 *$ & $150 / 11 / 15$ & Canine & Maseru & Positive & Positive &.- \\
\hline $45^{*} \#$ & $21 / 07 / 15$ & Bovine & Maseru & Positive & Positive & $-\ldots$ \\
\hline $46 *$ & $23 / 07 / 15$ & Bovine & Maseru & Positive & Positive &.- \\
\hline $47 *$,\# & $24 / 08 / 15$ & Canine & Maseru & Positive & Positive & -.. \\
\hline $48 *$ & $06 / 10 / 15$ & Canine & Maseru & Positive & Positive & - - \\
\hline 49 * & $10 / 11 / 15$ & Caprine & Maseru & Positive & Positive & -- \\
\hline $50 *$ & $26 / 11 / 15$ & Bovine & Mohales Hoek & Negative $^{\circ}$ & Positive ${ }^{\circ}$ & Negative \\
\hline 51 * & $149 / 11 / 15$ & Caprine & Maseru & Positive & Positive & - \\
\hline $52 *$ & $29 / 12 / 15$ & Canine & Maseru & Negative $^{\circ}$ & Positive $^{\circ}$ & Negative \\
\hline $53 *$ & $161 / 12 / 15$ & Canine & Berea & Positive & Positive & -. \\
\hline $54 *$ & $14 / 01 / 16$ & Canine & Maseru & Negative $^{\circ}$ & Positive ${ }^{\circ}$ & Negative \\
\hline $55 * \#$ & $22 / 02 / 16$ & Bovine & Maseru & Positive & Positive & -- \\
\hline $56 *$ & $26 / 02 / 16$ & Bovine & Berea & Negative $^{\circ}$ & Positive $^{\circ}$ & Negative \\
\hline $57 *$ & $03 / 03 / 16$ & Canine & Maseru & Negative $^{\circ}$ & Positive $^{\circ}$ & Negative \\
\hline $58+$ & $95 / 04 / 16$ & Bovine & Berea & Positive & Positive & --. \\
\hline $59+$ & $100 / 05 / 2016$ & Canine & Maseru & Negative & Negative &.- \\
\hline $60+$ & $105 / 05 / 2016$ & Canine & Berea & Negative & Negative &.- \\
\hline
\end{tabular}


Table 1. Cont.

\begin{tabular}{|c|c|c|c|c|c|c|}
\hline & Sample Number & Species & Town & DRIT Result & DFA Result & Real-Time PCR Result \\
\hline $61+$ & $109 / 05 / 2016$ & Canine & Maseru & Positive & Positive & $\ldots$ \\
\hline $62+$ & $110 / 05 / 2016$ & Canine & Berea & Positive & Positive & $-\ldots$ \\
\hline $63+$ & $113 / 05 / 2016$ & Ovine & Berea & Negative & Negative & -- \\
\hline $64+$ & $115 / 05 / 2016$ & Bovine & Berea & Positive & Positive & $\ldots$ \\
\hline $65+$ & $123 / 6 / 2016$ & Canine & Maseru & Positive & Positive & $-\ldots$ \\
\hline $66+$ & $125 / 6 / 2016$ & Ovine & Maseru & Positive & Positive & $\ldots$ \\
\hline $67+$ & $127 / 06 / 2016$ & Porcine & Mohales Hoek & Negative & Negative &.- \\
\hline $68+$ & $128 / 06 / 2016$ & Canine & Mohales Hoek & Positive & Positive & -- \\
\hline $69+$ & $131 / 07 / 2016$ & Canine & Berea & Positive & Positive & $\ldots$ \\
\hline $70+$ & $132 / 07 / 2016$ & Canine & Maseru & Positive & Positive &.- \\
\hline $71+$ & $133 / 07 / 2016$ & Canine & Maseru & Positive & Positive & -. \\
\hline $72+$ & $136 / 07 / 2016$ & equine & Maseru & Negative & Negative &.- \\
\hline $73+$ & $137 / 07 / 2016$ & Canine & Mohales Hoek & Positive & Positive & - - \\
\hline $74+$ & $138 / 07 / 2016$ & Bovine & Mohales Hoek & Positive & Positive & $\ldots$ \\
\hline $75+$ & $163 / 09 / 2016$ & Ovine & Maseru & Positive & Positive &.- \\
\hline $76+$ & $179 / 09 / 2016$ & Bovine & Maseru & Positive & Positive &.- \\
\hline $77+$ & $182 / 09 / 2016$ & Canine & Mohales Hoek & Positive & Positive &.- \\
\hline $78+$ & $184 / 09 / 2016$ & Canine & Maseru & Positive & Positive & $\ldots$ \\
\hline $79+$ & $185 / 09 / 2016$ & Canine & Maseru & Positive & Positive & - - \\
\hline $80+$ & $196 / 10 / 2016$ & Canine & Berea & Positive & Positive & - - \\
\hline $81+$ & $198 / 10 / 2016$ & Ovine & Maseru & Negative & Negative & -.. \\
\hline $82+$ & $199 / 10 / 2016$ & Bovine & Maseru & Positive & Positive &.- \\
\hline $83+$ & $210 / 11 / 2016$ & Canine & Berea & Positive & Positive &.- \\
\hline $84+$ & $234 / 12 / 2016$ & Canine & Maseru & Positive & Positive & -- \\
\hline $85+$ & $30 / 01 / 2017$ & Bovine & Mafeteng & Positive & Positive & $\ldots$ \\
\hline $86+$ & $62 / 02 / 2017$ & Bovine & Maseru & Positive & Positive &.-- \\
\hline $87+$ & $63 / 02 / 2017$ & Canine & Maseru & Positive & Positive & $\ldots$ \\
\hline $88+$ & $71 / 02 / 2017$ & Bovine & Quthing & Negative & Negative & -- \\
\hline $89+$ & $63 / 03 / 2017$ & Ovine & Maseru & Positive & Positive & -- \\
\hline $90+$ & $69 / 03 / 2017$ & Bovine & Maseru & Positive & Positive &.- \\
\hline $91+$ & $70 / 03 / 2017$ & Equine & Maseru & Positive & Positive &.- \\
\hline $92+$ & $72 / 03 / 2017$ & Canine & Maseru & Positive & Positive & -. \\
\hline $93+$ & $88 / 03 / 2017$ & Canine & Mokhotlong & Positive & Positive & -- \\
\hline $94+$ & $89 / 03 / 2017$ & Bovine & Mokhotlong & Positive & Positive & $\ldots$ \\
\hline $95+$ & $90 / 03 / 2017$ & Canine & Mokhotlong & Positive & Positive & $-\ldots$ \\
\hline $96+$ & $91 / 03 / 2017$ & Ovine & Mokhotlong & Positive & Positive &.- \\
\hline
\end{tabular}

* denotes archival samples subjected to DRIT diagnosis during the diagnostic training programme; + denotes samples subjected to routine rabies diagnosis by both the DFA and DRIT assays; \# denotes samples included in the molecular epidemiological analysis; The DFA and DRIT assays were repeated twice on samples that produced inconsistent results and the diagnostic outcomes of the two assays remained unchanged; - - - Real-time PCR not performed on samples without diagnostic incongruities.

\subsection{Direct, Rapid Immunohistochemical Test (DRIT)}

All of the suspect rabies samples diagnosed in this study $(n=96)$ were subjected to the DRIT diagnostic assay according to the standard operating procedure $[15,16]$. The DRIT assay used a biotinylated anti-ribonucleoprotein PAb preparation prepared by the ARC-OVI, Rabies Division, and both positive and negative controls, consisting of homogenized brain material that had been confirmed as rabies-positive and -negative, respectively, by the OIE Rabies Reference Laboratory in South Africa, were included in every run.

Briefly, the brain material was homogenised prior to diagnostic confirmation to prevent viral tissue tropism from influencing the outcome of the DRIT test. A single touch impression was made from the brain tissues by placing a small amount of homogenised material on clean tissue paper. Touch impressions of the samples were allowed to air dry for five minutes before being submerged in $10 \%$ neutral buffered formalin (Sigma-Aldrich, Missouri, MO, USA) for ten minutes. After fixation, the touch impressions were re-hydrated by dip-rinsing the slides in TRIS phosphate-buffered saline (TPBS) buffer (phosphate-buffered saline (PBS), pH of 7.5 (Whitehead Scientific, Stikland, South Africa) containing $1 \%$ Tween 80 (Merck, Kenilworth, NJ, USA) and, thereafter, were submerged in 3\% hydrogen peroxide (Merck) for ten minutes at room temperature in order to halt all endogenous peroxidase activity. Subsequent to the hydrogen peroxide flooding, the slides were dip-rinsed in fresh TPBS buffer and the excess buffer was shaken from the slides. The areas surrounding the smear impressions were 
blotted using a fresh paper towel. Anti-ribonucleoprotein biotinylated polyclonal antibody (PAb) preparation (1:300 working concentration) was applied dropwise until the impression was completely covered. After the application of the antibody, the slides were placed in a humidity chamber and incubated at room temperature for ten minutes, and subsequently dip-rinsed in fresh TPBS buffer. The excess buffer was shaken from the slides, and the areas surrounding the smear impressions were blotted using a fresh paper towel. All of the touch impressions were covered in a ready-to-use solution of $2 \mu \mathrm{g} / \mathrm{mL}$ streptavidin-peroxidase (Kirkegaard and Perry Laboratories, Gaithersburg, MD, USA), after which the slides were transferred to a humidity chamber. The humidity chamber was incubated at room temperature for ten minutes, and the slides were dip-rinsed in fresh TPBS buffer. The excess buffer was shaken from the slides and the areas surrounding the smear impressions were blotted using a fresh paper towel. The impressions were covered in a working solution of the 3-amino-9-ethylcarbazole (AEC) chromogen (Sigma-Aldrich), and the slides were transferred to a humidity chamber and incubated at room temperature for five minutes. After sufficient staining had occurred, the slides were submerged in distilled water. The touch impressions were counterstained with a 1:2 dilution of Gill's formulation \#2 (Sigma-Aldrich) for two minutes before they were dip-rinsed in distilled water in order to wash away the residual counterstain. Finally, the slides were mounted with a water-soluble mounting medium $(1 \times$ PBS (Whitehead Scientific)/glycerol (Sigma-Aldrich) prepared 1:1) and examined by light microscopy (Olympus, CX21) at both $200 \times$ and $400 \times$ magnification in order to score the respective immunoreactivity based on both the presence and staining intensity of the visible red inclusions present on the blue cellular background [16].

\subsection{Direct Fluorescent Antibody (DFA) Test}

The DFA diagnostic assay was repeated on all the archival samples that produced discrepant results from those obtained after performing the DRIT assay during the training programme and, thereafter, in parallel to the DRIT assay on all of the samples that arrived for routine rabies diagnosis. The DFA test was performed according to the standard operating procedure $[13,17]$ and relied on treating homogenised tissue impressions with a 1:1000 working dilution of FITC-labelled anti-ribonucleoprotein PAb preparation (ARC-OVI, Rabies Division, Pretoria, South Africa) in order to confirm any false results. Two microscopists based at the CVL interpreted the results on a Zeiss Axiovert 25 (Axiolab) fluorescent microscope at a magnification of $400 \times$ (excitation: $490 \mathrm{~nm}$; Emission: $525 \mathrm{~nm}$ ) in a blind reading in order to eliminate reader bias.

\subsection{Resolving Diagnostic Incongruities}

Samples that produced diagnostic incongruities observed between the DFA and DRIT assays $(n=6)$ were first re-tested a further two times with both assays at the CVL to confirm the relevant diagnostic results. Continued discrepancies were resolved by the attempted amplification of viral nucleic acid from the total RNA extracted from each sample (Table 1). Briefly, the total RNA of the homogenised brain tissue samples $(n=6)$ was extracted using the Direct-Zol ${ }^{\mathrm{TM}}$ RNA MiniPrep Kit (Zymo Research, Irvine, CA, USA) as per the manufacturer's instructions. An established "one-step" quantification real-time PCR (qRT-PCR) assay targeting the partial nucleoprotein gene was applied to amplify any lyssavirus RNA present in the brain material [18].

\subsection{Data Analysis}

The determination of the diagnostic sensitivity, specificity and respective confidence intervals of the DFA and DRIT diagnostic assays was determined using an exact binomial distribution (MedCalc 12.2.1.0, Ostend, Belgium). In order to determine whether the increase in sample submissions observed during the study period was statistically significant, a one-way analysis of variation (ANOVA) analysis was performed using the Epi Info ${ }^{\mathrm{TM}}$ software (version 7.2). The one-way ANOVA analysis was used across differences in mean sample submissions per month prior to the onset of the study (January 2012-March 2016) and within the study period (April 2016-March 2017). 


\subsection{Molecular Epidemiology of Rabies in LESOTHO}

\subsubsection{Sample Cohort}

Twenty-one rabies-positive brain samples, collected and stored at the CVL in Maseru, were selected and used for molecular epidemiological characterization and phylogenetic analysis (Table S1). The representative panel of samples from across the country was chosen based on both the location where the samples were originally collected within Lesotho and the amount of available brain material stored at the CVL.

\subsubsection{Viral RNA Extractions, PCR, and Sequencing}

The total RNA of all of the brain tissue samples $(n=21)$ was extracted using the Direct-Zol ${ }^{\mathrm{TM}}$ RNA MiniPrep Kit (Zymo Research). A reverse transcription PCR was performed on the rabies-positive samples using the $\mathrm{G}(+)$ and $\mathrm{L}(-)$ primers $[19,20]$, which amplifies the cytoplasmic domain of the glycoprotein gene and the adjacent G-L intergenic region of the RABV genome.

The PCR-positive products obtained from the 21 samples were electrophoresed on a standard $1 \%$ agarose gel and subsequently gel-extracted and purified using the Zymocelan ${ }^{\mathrm{TM}}$ Gel DNA Recovery kit per the manufacturer's instructions (Zymo Research). Both the forward and reverse strands of the purified PCR amplicons were sequenced using the respective PCR primers and the BigDye ${ }^{\circledR}$ Terminator v3.1 sequencing reaction kit per the manufacturer's instructions (Applied Biosystems). The Sanger sequencing was performed using an ABI 3100 automated capillary sequencer situated at the University of Pretoria, RSA. Consensus sequences were generated and trimmed to 592 nucleotides (nt), representing the cytoplasmic domain of the glycoprotein gene and the adjacent G-L intergenic region of the RABV genome using the CLC Main Workbench software (CLC Bio, Version 7.7.2). The final sequences were subsequently submitted to the NCBI GenBank and allocated unique accession numbers (MF197287-MF197307) (Table S1).

\subsubsection{Phylogenetic Analysis}

The phylogenetic analysis included a total of 100 G-L intergenic region sequences obtained from Lesotho and selected neighbouring South African provinces (Table S1). An alignment of the collection of sequences was created using the ClustalW subroutine of the BioEdit software [21] and the phylogenetic analysis was performed using a Bayesian Markov Chain Monte Carlo (MCMC) method in the BEAST software package (version 1.8.1) [22]. The best fitting DNA substitution model (TVMef+G) was selected using the Akaike's information criterion (AIC) determined using the JModel software (version 2.1.3). For the purpose of the phylogenetic analysis, three independent Markov chains were sampled for 50 million states and a sampling frequency of 50,000 was combined after discarding at least 10 per cent burn. The posterior distributions were inspected using Tracer (version 1.6) to ensure adequate mixing and convergence. The associated statistics were summarised as a maximum clade credibility tree and visualised using the FigTree software (version 1.4.2).

\section{Results}

\subsection{Statistical Analysis of DRIT Diagnostic Efficacy}

The number of true-positive $(n=72)$ and negative $(n=24)$ samples (determined by either agreeing DRIT and DFA assays or qRT-PCR amplification of nucleic acid) were used to determine the diagnostic efficacy of the DFA and DRIT assays (Table 2). Based on the confirmatory results provided by the "one-step" quantification qRT-PCR assay, the DFA test had produced an inaccurate result in six archival brain samples (DFA-positive but DRIT- and qRT-PCR-negative), indicating a reduced diagnostic specificity of $75 \%$ (Table 2 ). In contrast, the DRIT and qRT-PCR produced identical results for the samples in question and the DRIT was considered to have an overall diagnostic sensitivity and specificity of $100 \%$ (Table 2 ). 
Table 2. Diagnostic sensitivity, specificity of the direct rapid immunohistochemical test applied to a cohort of samples stored at the central veterinary laboratory in Lesotho.

\begin{tabular}{ccccccc}
\hline & $\begin{array}{c}\text { True } \\
\text { Positive }\end{array}$ & $\begin{array}{c}\text { False } \\
\text { Positive }\end{array}$ & $\begin{array}{c}\text { True } \\
\text { Negative }\end{array}$ & $\begin{array}{c}\text { False } \\
\text { Negative }\end{array}$ & $\begin{array}{c}\text { Diagnostic } \\
\text { Sensitivity * }\end{array}$ & $\begin{array}{c}\text { Diagnostic } \\
\text { Specificity * }\end{array}$ \\
\hline DFA & 72 & 6 & 18 & 0 & $100 \%$ & $\left.\begin{array}{c}75.00 \% \\
(95.01-100 \%) \\
(53.29-90.23 \%) \\
100 \%\end{array}\right)$ \\
DRIT & 72 & 0 & 24 & 0 & $(95.01-100 \%)$ & $(85.75-100 \%)$ \\
\hline
\end{tabular}

* Values in brackets represented the $95 \%$ confidence interval (CI).

\subsection{Increased Sample Submission and Distribution Analysis}

Over a 51-month period prior to the start of the DRIT implementation in Lesotho (January 2012-March 2016), the CVL had intermittently received and diagnosed an average of one sample per month. Over the same 51-month period, a total of 17 months (33\%) had passed without any samples being submitted for rabies diagnosis (Figure 1). During the first 12 months of DRIT implementation in Lesotho (April 2016-March 2017), the average number of samples had increased to three samples per month, primarily due to the continued encouragement of the trained animal health professionals, resulting in a statistically significant three-fold increase in the monthly sample submission for rabies diagnosis ( $p=0.0279,95 \%$ CI: 0.2449 to 3.4556) (Figure 1 ). The significance of the increase is further appreciated when considering that samples were submitted regularly for every month of the year, with the exception of August 2016.

\subsection{Molecular Epidemiology}

The RABV sequences included in this study could, phylogenetically, be divided into three clades (Clade A-C), with each clade comprising separate lineages with posterior probability scores of 0.99 , 0.96 and 1, respectively, (Figure 2). Clade A consisted largely of canid rabies viruses $(n=79)$ from Lesotho and two provinces of South Africa (the FS province and the northern region of the EC province) (Figure 3). Clade B consisted primarily of rabies-positive samples collected from the north-eastern region of the KZN province where a sylvatic outbreak is currently ongoing (2012-2017) [23] (Figure 3). The sequences that form part of Clade B clustered independently from Clade A as the cross-border spread of rabies between Lesotho and the KZN province is limited to a large extent by geographical barriers such as the Drakensberg and Maloti mountain ranges, which limit the movement of people and animals between Lesotho and the neighbouring South African province to the south [9]. Clade C was comprised of rabies-positive samples collected from the southeastern and central regions of the EC province bordering the KZN province (Figure 3).

Clade A could be further divided into three separate sub-clades (sub-clade AI-AIII) with each sub-clade representing independent endemic cycles that are both geographically defined and shared with its immediate regional neighbour (Figure 2). Sub-clade AI consisted exclusively of RABV sequences obtained from the FS province and Lesotho (Figure 3). The clustering observed in this sub-clade is similar to the cross-border spread that was observed in an earlier study investigating the increased number of dog-rabies cases in the FS province [9]. The branching clusters observed within the sub-clade illustrated that the viruses in this clade were closely related, which suggests that a single RABV strain historically circulated between Lesotho and the FS province. This finding was also in line with the previous findings where the authors concluded that canine rabies most likely spread from Lesotho to the FS prior to becoming an established active cycle spanning the entire region [9].

Sub-clade AII comprised of a single RABV sequence (146/98) collected from a dog in the FS province in 1998 and RABV sequences obtained from Lesotho and the northern region of the EC province (Figure 3). Evidence of an endemic cycle between the FS and northern region of the EC province had previously been suggested, but our study provides evidence that rabies virus-positive samples, identified in Lesotho between 2012 and 2013, can also be linked to this cycle [9]. 


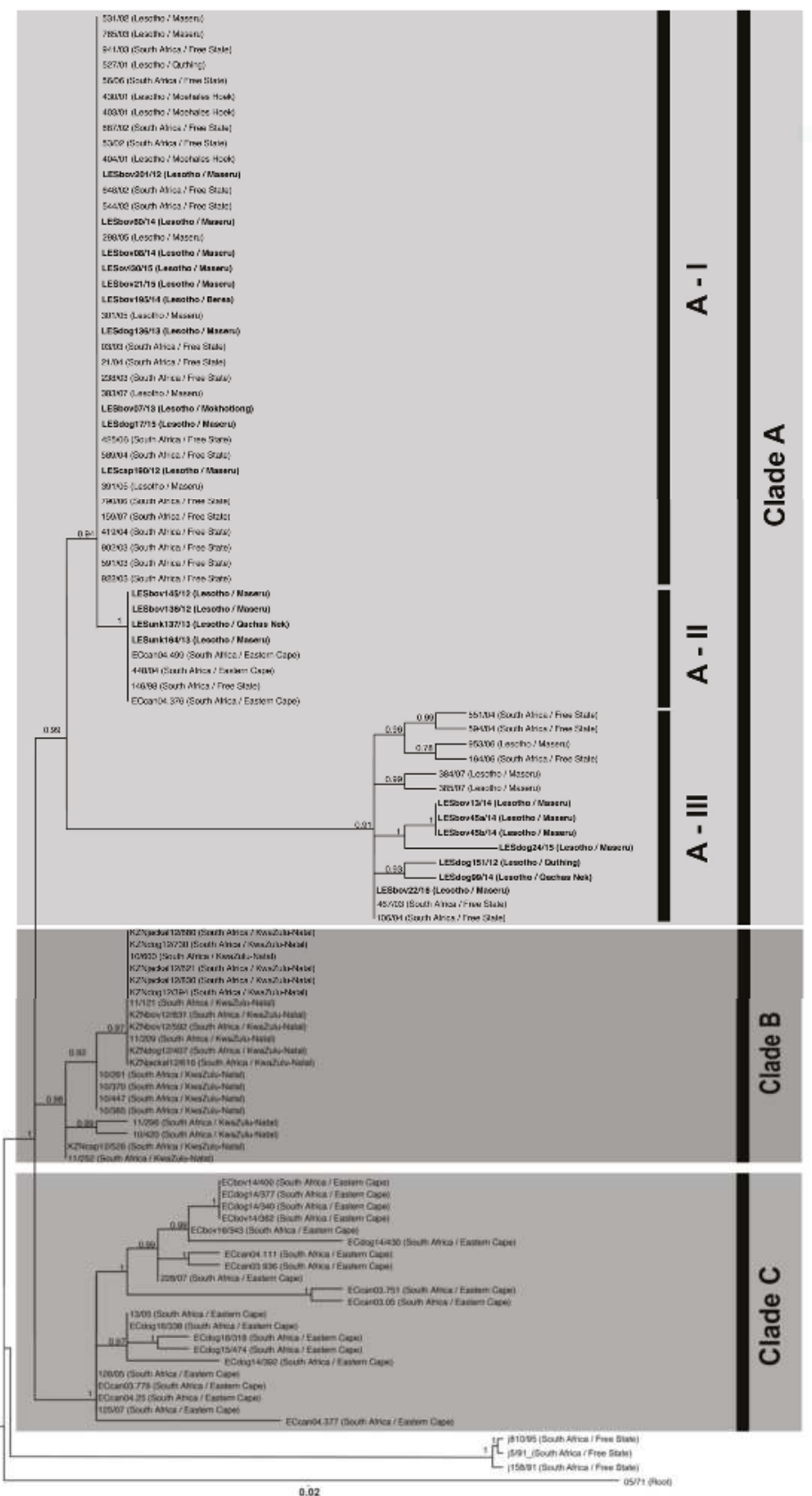

Figure 2. Maximum clade credibility tree of the cytoplasmic domain of the G-L intergenic region of RABV sequences originating from selected sub-Saharan African countries (Table S1). The horizontal branch lengths are proportional to the similarity of the sequences within and between groups and all branches with a posterior probability of 0.75 or less were collapsed. A bat-eared fox sequence from the Western Cape Province (isolate 05/71) was used to root the tree. The new sequences generated in this study have been indicated in a bold font (Table S1). 
The third clade, sub-clade AIII, highlighted genetic relatedness between isolates originating from the capital, Maseru, the rural areas in the southernmost district of Lesotho (Quthing) and the FS province of South Africa (Figure 3). To our knowledge, this is the first report of an independent phylogenetic relationship between rabies viruses from the FS province and this specific region of Lesotho.

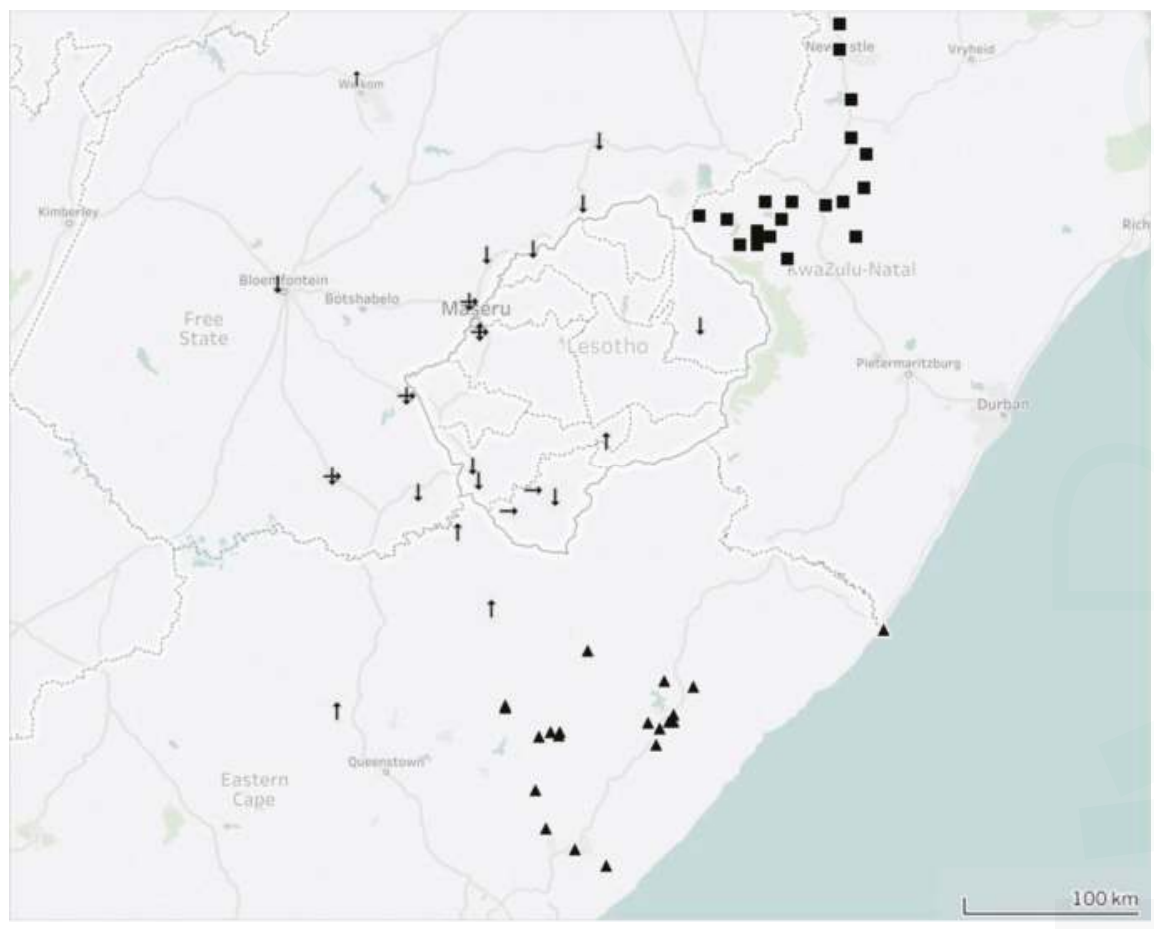

Figure 3. Illustrated map showing the inferred cross-border spread of endemic dog rabies between Lesotho and South Africa. Samples forming part of Clade A have been indicated with arrows, Clade B with squares, and Clade $\mathrm{C}$ with triangles. The three sub-clades have been indicated as follows: arrows facing downwards (sub-clade AI), arrows facing upwards (sub-clade AII) and arrows facing to the right (sub-clade AIII).

\section{Discussion}

In this study, we analysed 96 samples and found that $93.75 \%$ had correctly been diagnosed as either rabies-positive or -negative using the DFA assay when compared with qRT-PCR results. Several reasons could explain the occurrence of the false-positive results associated solely with the archival samples, especially when considering that the DFA test had been implemented in a resource-limited laboratory, where the maintenance of equipment is often lacking $[24,25]$. The most common possible reasons for incongruent results, viz. antigen degradation/putrefaction and the misinterpretation of fluorescence when performing the DFA test, were all considered [12,26-30]. However, sample degradation should be discussed in more detail. During our investigation, the archival samples had been placed in $50 \%$ glycerol-saline solution upon collection, before being stored at ambient temperature for extended periods of times (collected between 2011 and 2016). Despite relying on the glycerol-saline solution to preserve the samples, some of the samples had visible and olfactory signs of putrefaction (varying between samples) when tested with the DRIT assay. 
Samples that have undergone putrefaction due to inadequate sample storage could contain bacterial or fungal contamination, which could, in turn, produce a large amount of non-specific fluorescence [27]. The presence of non-specific fluorescence could be misinterpreted as positive signals in the hands of an inexperienced reader or a reader relying on an improperly calibrated fluorescence microscope, leading to false-positive results being recorded [12]. The use of sub-optimal equipment while relying on an inadequate infrastructure in developing countries, is commonplace and a genuine concern [12]. Regardless of the cause of the incorrect diagnostic outcomes, the results reported here do not reflect negatively on the competency of the CVL staff. Instead, the technical challenges and difficulties associated with equipment, cold storage and the shipment of samples in developing countries, are highlighted.

This study adds to the realization of the versatility of the DRIT assay. In our view, this test should be considered for routine rabies diagnosis as it has been shown to be advantageous to resource-limited settings such as the one described here. Apart from having a diagnostic efficacy that is comparable to that of the DFA test, the DRIT is less sensitive to potential misinterpretations of results by not relying on fluorescent signals [12,24,31-33]. By reducing the visible interfering background staining (especially in samples that have undergone putrefaction), and simplifying the differentiation between a positive and negative result, the DRIT provides accurate diagnostic results by adequately-trained personnel.

In this study, 62/96 (65\%) of the samples diagnosed as rabies-positive originated from the Maseru district where the CVL is located, with the number of samples dissipating as the districts locate further away from the CVL (Table 1). The positive correlation between the number of samples submitted for routine rabies diagnosis and the distance from the CVL indicates that the surveillance network could be enhanced even further by decreasing the distance samples must travel before reaching a laboratory. Considering the financial benefits associated with starting and routinely implementing the DRIT test at new diagnostic facilities, the assay could be used for decentralised rabies diagnosis without incurring a large capital investment [15]. In recognition of this fact, two decentralised diagnostic facilities in the Mokhotlong and Moehale's Hoek districts of Lesotho have already been identified as possible locations for decentralised routine rabies diagnosis in the future.

The submission and diagnosis of suspect samples provide a basic burden indicator for rabies, but in situations as described here, the resolution of the surveillance network remains very limited. Molecular epidemiological analyses are helpful in advancing our understanding of virus cycles and the transboundary movement of viruses in the larger region. The phylogenetic component of this study represents the first application of molecular epidemiology to specifically investigate the occurrence of endemic rabies within Lesotho. The results of our study were helpful to demonstrate that host species in Lesotho maintain three independent rabies cycles, which could impact negatively on any rabies intervention initiatives that are implemented in either of the two countries as animals can move freely between the two countries due to the porous nature of the borders on the African continent $[12,34]$.

Although the presence of cross-border spread of rabies between Lesotho and the FS province is not a new observation [9], the sequence similarity observed for samples originating from Lesotho and the FS province (sub-clade AI) indicates that cross-border spread has been ongoing since the last investigation was performed in 2009 (Figure 2). As such, it could be speculated that human movement (along with their livestock and companion animals) is responsible for the ongoing exchange of rabies between two geographically-separated dog populations. This supposition is further supported by the observation that the Maseru district, which is approximately $11 \mathrm{~km}$ from the nearest border post between South Africa and Lesotho, is a potential rabies hotspot where all the various known genetic cycles of rabies occur (sub-clade AI-AIII) (Figure 3).

The sequence similarity observed for samples forming part of sub-clade AII indicates that cross-border spread occurs between Lesotho and two neighbouring provinces of South Africa (EC and FS provinces) (Figure 2). To our knowledge, the involvement of Lesotho in this active cycle is a novel observation and contradicts previous speculations that the sequence similarity between samples collected in the FS and EC province was due to a single spill-over event [9]. 
Sub-clade AIII demonstrates the value of undertaking continuous molecular investigations while relying on contemporary samples. Prior to this study, no molecular epidemiological information was available for this rural area in the southern highland districts of Lesotho. By including samples recently collected within Lesotho, it has become evident that rabies is not only present in this region, but that the Lesotho samples in this sub-clade have a higher level of sequence diversity to those in the other sub-clades (Figure 2). Our conjecture is that the endemic cycle observed in sub-clade AIII might be maintained by sylvatic species such as the black-backed jackal rather than dog populations. This observation is based on the sequence diversity, high number of rabies-positive livestock cases, comparatively low number of rabies-positive dog cases from the area, and the presence of jackal species in the surrounding highlands areas of Lesotho [35-37]. However, the lack of samples originating from sylvatic species in Lesotho prevents any firm conclusion in this regard.

\section{Conclusions}

The presence of multiple endemic cycles involved in the cross-border spread of rabies between Lesotho and South Africa highlight the importance of regional collaboration towards rabies control [38,39]. Without the regional collaboration of all the stakeholders, the success of disease intervention campaigns will not be sustainable or long-lasting as the re-introduction of immunologically naïve dog populations could result in a reduced vaccination coverage or negative impact on the sustainability of existing vaccination campaigns. By creating vaccination buffer zones on both sides of pre-determined national or regional borders [40], the re-introduction of rabies can be prevented and the vaccination coverage can be systematically increased and maintained within and beyond the buffer zones. As such, the collaboration between all interested stakeholders will not only prevent low vaccination coverage, but will also ensure that neighbouring countries work towards the same objective of being declared free of canine-mediated human rabies by 2030, an objective in line with the sustainable development goals [41]

Supplementary Materials: The following are available online at http://www.mdpi.com/2414-6366/2/3/30/s1, Table S1. Panel of rabies viruses from Lesotho and neighbouring South African provinces included in the phylogenetic analysis performed in this study.

Acknowledgments: This work is based on the research supported in part by grants from the World Animal Protection (WAP) (grant number: WAP/AF/IHC/GR/2016-01), the National Research Foundation (NRF) of South Africa (grant number 78566, NRF Research Infrastructure Support Programmes (RISP) grant for the ABI3500), and the Cooperative Agreement Number, [93.318 5 NU2GGH001874-02-00], funded by the Centers for Disease Control and Prevention. Its contents are solely the responsibility of the authors and do not necessarily represent the official views of the Centres for Disease Control and Prevention.

Author Contributions: L.H.N., W.M., and M.M. were the project leaders. A.C., M.J.M. performed the DRIT reactions and subsequent diagnostic confirmation. A.C., J.C., and M.J.M. performed molecular assays and sequencing. A.C. and J.C. performed phylogenetic analysis. A.C. performed the statistical analyses. All authors contributed equally to writing the manuscript.

Conflicts of Interest: The authors declare no conflict of interest.

\section{References}

1. Hampson, K.; Coudeville, L.; Lembo, T.; Sambo, M.; Kieffer, A.; Attlan, M.; Barrat, J.; Blanton, J.D.; Briggs, D.J.; Cleaveland, S.; et al. Estimating the global burden of endemic canine rabies. PLoS Negl. Trop. Dis. 2015, 9. [CrossRef]

2. Coleman, P.G.; Fevre, E.M.; Cleaveland, S. Estimating the public health impact of rabies. Emerg. Infect. Dis. 2004, 10, 140-142. [CrossRef] [PubMed]

3. World Health Organization (WHO). WHO Expert Consultation on Rabies: Second Report; World Health Organization: Geneva, Switzerland, 2013; pp. 1-141.

4. Taylor, L.H.; Hampson, K.; Fahrion, A.; Abela-Ridder, B.; Nel, L.H. Difficulties in estimating the human burden of canine rabies. Acta Trop. 2015, 165, 133-140. [CrossRef] [PubMed]

5. Swanepoel, R.; Barnard, B.J.H.; Meredith, C.D.; Bishop, G.C.; Bruckner, G.K.; Foggin, C.M.; Hübschle, O.J. Rabies in southern Africa. Onderstepoort J. Vet. Res. 1993, 60, 325-346. [PubMed] 
6. Khomari, L. Rabies in Lesotho. In Proceedings of the international conference on epidemiology, control and prevention of rabies in eastern and southern Africa, Lusaka, Zambia, 2-5 June 1992; pp. 45-46.

7. Scott, C. Rabies in Lesotho. Vet. Rec. 1988, 122. [CrossRef]

8. Makalo, M.J.R.; Khanyane, M.; Maseko, L. Paracon Country Report: Lesotho (Available on request from the PARACON Steering Committee). Johannesburg, South Africa, 2015. Available online: https://rabiesalliance. org/contact-us?src=paracon (accessed on July 2015).

9. Ngoepe, C.E.; Sabeta, C.; Nel, L. The spread of canine rabies into Free State Province of South Africa: A molecular epidemiological characterization. Virus Res. 2009, 142, 175-180. [CrossRef] [PubMed]

10. Bishop, G.C.; Durrheim, D.N.; Kloeck, P.E.; Godlonton, J.D.; Bingham, J.; Speare, R.; Rabies Advisory Group 2000. Rabies: Guide for the Medical, Veterinary and allied Professions, 2nd ed.; Department of Agriculture and Department of Health: Pretoria, South Africa, 2010.

11. Davis, P.L.; Rambaut, A.; Bourhy, H.; Holmes, E.C. The evolutionary dynamics of canid and mongoose rabies virus in southern Africa. Arch. Virol. 2007, 152, 1251-1258. [CrossRef] [PubMed]

12. Coetzer, A.; Anahory, I.; Dias, P.T.; Sabeta, C.T.; Scott, T.P.; Markotter, W.; Nel, L.H. Enhanced diagnosis of rabies and molecular evidence for the transboundary spread of the disease in Mozambique. J. S. Afr. Vet. Assoc. 2017, 88. [CrossRef] [PubMed]

13. Dean, D.J.; Abelseth, M.K.; Atanasiu, P. The Fluorescent Antibody Test. In Laboratory Techniques in Rabies, 4th ed.; Meslin, F.-X., Kaplan, M.M., Koprowski, H., Eds.; World Health Organization: Geneva, Switzerland, 1996; pp. 88-89.

14. Barrat, J. Simple technique for the collection and shipment of brain specimens for rabies diagnosis. In Laboratory Techniques in Rabies, 4th ed.; Meslin, F.-X., Kaplan, M.M., Koprowski, H., Eds.; World Health Organization: Geneva, Switzerland, 1996; pp. 425-432.

15. Coetzer, A. Comparison of Biotinylated Monoclonal and Polyclonal Antibodies in An Evaluation of A Direct Rapid Immunohistochemical Test for the Routine Diagnosis of Rabies in Southern Africa. Master's Thesis, University of Pretoria, Pretoria, South Africa, June 2013.

16. Coetzer, A.; Nel, L.H.; Rupprecht, C.E. Demonstration of Lyssavirus antigens by a direct rapid immunohistochemical test. In Current Laboratory Techniques in Rabies Diagnosis, Research and Prevention, 1st ed.; Rupprecht, C.E., Nagarajan, J., Eds.; Elsevier: Amsterdam, The Netherlands, 2014; pp. 27-36.

17. Centers for Disease Control and Prevention (CDC). Protocol for Postmortem Diagnosis of Rabies in Animals by Direct Fluorescent Antibody Testing. 2003. Available online: https://www.cdc.gov/rabies/pdf/ rabiesdfaspv2.pdf (accessed on 27 September 2016).

18. Coertse, J.; Weyer, J.; Nel, L.H.; Markotter, W. Improved PCR methods for detection of African rabies and rabies-related lyssaviruses. J. Clin. Microbiol. 2010, 48, 3949-3955. [CrossRef] [PubMed]

19. Sacramento, D.; Bourhy, H.; Tordo, N. PCR technique as an alternative method for diagnosis and molecular epidemiology of rabies virus. Mol. Cell. Probes 1991, 5, 229-240. [CrossRef]

20. Von Teichman, B.F.; Thomson, G.R.; Meredith, C.D.; Nel, L.H. Molecular epidemiology of rabies virus in South Africa: Evidence for two distinct virus groups. J. Gen. Virol. 1995, 76, 73-82. [CrossRef] [PubMed]

21. Hall, T.A. BioEdit: A user-friendly biological sequence alignment editor and analysis program for Windows 95/98/NT. Nucleic Acid Symp. 1999, 41, 95-98.

22. Drummond, A.J.; Suchard, M.A.; Xie, D.; Rambaut, A. Bayesian phylogenetics with BEAUti and the BEAST 1.7. Mol. Biol. Evol. 2012, 29, 1969-1973. [CrossRef] [PubMed]

23. KwaZulu-Natal Department of the Agriculture Rural Development (KZNDARD). Jackal Rabies in the KwaZulu-Natal Midlands; 2015. Available online: http://www.kzndard.gov.za/images/Documents/ AnimalHealth/AnimalDiseases/Jackal-Rabies-in-the-KwaZulu-Natal-Midlands.pdf (accessed on 18 July 2017).

24. Durr, S.; Naissengar, S.; Mindekem, R.; Diguimbye, C.; Niezgoda, M.; Kuzmin, I.; Rupprecht, C.E.; Zinsstag, J. Rabies diagnosis for developing countries. PLoS Negl. Trop. Dis. 2008, 2. [CrossRef] [PubMed]

25. Weyer, J.; Blumberg, L. Rabies: Challenge of diagnosis in resource poor countries. Infect Dis. J. Pak. 2007, 16, 86-88.

26. McElhinney, L.M.; Marston, D.A.; Brookes, S.M.; Fooks, A.R. Effects of carcase decomposition on rabies virus infectivity and detection. J. Virol. Methods 2014, 207, 110-113. [CrossRef] [PubMed]

27. Mani, R.S.; Madhusudana, S.N. Laboratory diagnosis of human rabies: Recent advances. Sci. World J. 2013, 2013. [CrossRef] [PubMed] 
28. Rojas Anaya, E.; Loza-Rubio, E.; Banda Ruiz, V.M.; Hernández Baumgarten, E. Use of reverse transcription-polymerase chain reaction to determine the stability of rabies virus genome in brains kept at room temperature. J. Vet. Diagn. Investig. 2006, 18, 98-101. [CrossRef] [PubMed]

29. Lopes, M.C.; Venditti, L.L.R.; Queiroz, L.H. Comparison between RT-PCR and the mouse inoculation test for detection of rabies virus in samples kept for long periods under different conditions. J. Virol. Methods 2010, 164, 19-23. [CrossRef] [PubMed]

30. Aguiar, T.D.; Teixeira, M.F.; Costa, E.C.; Vitaliano, A.B.; Teles, C.H.; Barroso, I.C.; Dias, R.P.; Moraes, N.B. Medium-term cryopreservation of rabies virus samples. Rev. Soc. Bras. Med. Trop. 2013, 46, 678-683. [CrossRef] [PubMed]

31. Lembo, T.; Niezgoda, M.; Velasco-Villa, A.; Cleaveland, S.; Ernest, E.; Rupprecht, C.E. Evaluation of a direct, rapid immunohistochemical test for rabies diagnosis. Emerg. Infect. Dis. 2006, 12, 310-313. [CrossRef] [PubMed]

32. Rupprecht, C.E.; Cliquet, F.; Fehlner-Gardiner, C.; Fooks, A.R.; Mueller, T.; Sabeta, C.; Slate, D. Progress in the development of a direct rapid immunohistochemical test for diagnosing rabies. News Colleagues 2014, 3, $87-95$

33. Coetzer, A.; Sebeta, C.T.; Markotter, W.; Rupprecht, C.E.; Nel, L.H. Comparison of biotinylated monoclonal and polyclonal antibodies in an evaluation of a direct rapid immunohistochemical test for the routine diagnosis of rabies in southern Africa. PLoS Negl. Trop. Dis. 2014, 9. [CrossRef]

34. Mkhize, G.C.; Ngoepe, E.C.; Du Plessis, B.J.; Reininghaus, B.; Sabeta, C.T. Re-emergence of dog rabies in Mpumalanga Province, South Africa. Vector-Borne Zoonotic Dis. 2010, 10, 921-926. [CrossRef] [PubMed]

35. Lynch, C. The mammals of Lesotho. Res. Natl. Museum. Bloemfontein. 1994, 10, 171-241.

36. Rowe-Rowe, D.T. Black-backed jackal diet in relation to food availability in the Natal Drakensberg. S. Afr. J. Wildl. Res. 1983, 13, 17-23.

37. Lesotho; Ministry of Local Government and Chieftainship. Quthing District Council: Local Government District Information Handbook: A Compilation of Crucial Information for the District, 1st ed.; June 2008. Available online: https://www.giz.de/en/downloads/en-lesotho-quthing-information-handbook.pdf (accessed on 23 July 2017).

38. Day, M.J. One health: The importance of companion animal vector-borne diseases. Parasites Vectors 2011, 4, 49. [CrossRef] [PubMed]

39. Fooks, A.R.; Banyard, A.C.; Horton, D.L.; Johnson, N.; McElhinney, L.M.; Jackson, A.C. Current status of rabies and prospects for elimination. Lancet 2014, 384, 1389-1399. [CrossRef]

40. Russel, C.A.; Real, L.A.; Smith, D.L. Spatial control of rabies on heterogeneous landscapes. PLoS ONE 2006, 1, e27. [CrossRef] [PubMed]

41. United Nations Department of Economic and Social Affairs; United Nations Department of Economic and Social Affairs: New York, NY, USA, 2014.

(C) 2017 by the authors. Licensee MDPI, Basel, Switzerland. This article is an open access article distributed under the terms and conditions of the Creative Commons Attribution (CC BY) license (http:/ / creativecommons.org/licenses/by/4.0/). 


\title{
The Importance of a Participatory and Integrated One Health Approach for Rabies Control: The Case of N’Djaména, Chad
}

\author{
Monique Lechenne ${ }^{1,2, *}$, Rolande Mindekem ${ }^{3}$, Séraphin Madjadinan ${ }^{3}$, Assandi Oussiguéré ${ }^{4}$, \\ Daugla Doumagoum Moto ${ }^{3}$, Kemdongarti Naissengar ${ }^{4}$ and Jakob Zinsstag ${ }^{1,2}$ \\ 1 Swiss Tropical and Public Health Institute, P.O.Box, Socinstrasse 57, CH-4002 Basel, Switzerland; \\ jakob.zinsstag@unibas.ch \\ 2 University of Basel, Petersplatz 1, CH-4051 Basel, Switzerland \\ 3 Centre de Support en Santé International, BP: 972, Moursal, N’Djaména, Chad; mrola2002@yahoo.fr (R.M.); \\ mseraphin41@gmail.com (S.M.); daugla.doumagoum@gmail.com (D.D.M.) \\ 4 Institut de Recherché en Elevage pour le Développement, BP: 433, Farcha, N’Djaména, Chad; \\ assandi_oussiguere@yahoo.fr (A.O.); naissengar@gmail.com (K.N.) \\ * Correspondence: monique.lechenne@swisstph.ch; Tel.: +4-161-284-8748; Fax: +4-161-284-8105
}

Received: 31 May 2017; Accepted: 3 August 2017; Published: 23 August 2017

\begin{abstract}
This study compares data on animal rabies cases from the Chadian national rabies laboratory, hosted at the Insitut de Recherche en Elevage pour le Developpement (IRED), with bite case reporting from health facilities. The data collection accompanied a mass dog vaccination intervention over two years in N'Djaména, Chad. This allowed for a comparison of the dynamics of the incidence of animal rabies cases, human bite exposure incidence and post-exposure prophylaxis (PEP) demand during a dog rabies elimination attempt. Following the mass vaccination, the monthly animal rabies incidence dropped from 1.1/10,000 dogs, as observed prior to the campaign in 2012 , to $0.061 / 10,000$ dogs in 2014 . However, the PEP demand was found to be largely unaffected. The suspicion of the rabies exposure as reported by health personnel in most cases did not reflect the status of the biting animal but rather the severity of the bite wound, resulting in inappropriate PEP recommendations. In addition, the levels of reporting dead or killed animals to the rabies laboratory was found to be very low. These results reveal a profound lack of communication between health facilities and veterinary structures and the absence of an integrated bite case management (IBCM) approach. Improved communication between human health and veterinary workers is imperative to prevent human rabies deaths through the appropriate use of PEP and to further translate success in animal rabies control into cost savings for the public health sector through a lower PEP demand. Improved training of health and veterinary personnel and the sensitisation of the public are needed to achieve good IBCM practice, to increase the rate of diagnostic testing, to provide adequate and timely PEP, and to reduce the wastage of scarce vaccine resources.
\end{abstract}

Keywords: rabies incidence; post-exposure prophylaxis; integrated bite case management (IBCM); One Health

\section{Introduction}

Within a One Health framework, rabies is likely the best documented example for the added value of closer collaboration of human and veterinary medicine for the control of zoonotic diseases [1]. With a few singular exceptions, humans only contract the disease through contact with an infected animal [2]. The highest disease burden is found in resource-poor settings where rabies is endemic in domestic dogs, which are the predominant species causing exposure in humans [3]. Poverty negatively impacts the access to post-exposure prophylaxis (PEP), which is urgently needed after a bite from 
a suspected rabid animal. In most rabies-endemic countries in Africa, the cost for PEP exceeds the monthly income of people living below the poverty level [1,3,4]. In many remote areas, PEP is not available because of long distances to a health facility or the inefficiency of the health system [5]. In order to achieve the challenging goal of zero human deaths from dog-mediated rabies by 2030, as postulated by the World Health Organization (WHO) and partners [6], access to and the adequate use of PEP must be implemented. Because only a fraction of all bite cases are inflicted by a rabid animal $[7,8]$ and because many countries face a shortage of the human vaccine for PEP, an integrated bite case management (IBCM) approach is required to guide treatment recommendations in order to save the highest percentage of human lives in the short term. The long-term sustainable control of rabies and the reduction of human fatalities can only be achieved through interventions that interrupt transmission in the reservoir species. Vaccination of dogs is the only control measure that will lead to the elimination of rabies in domestic animals and result in a reduction of the exposure risk in humans by more than $90 \%$ [3]. Dog vaccination reduces the need for PEP and considerably reduces the burden of premature deaths from rabies, averting a high number of years of life lost (YLL) $[9,10]$. Therefore, investment in dog vaccination, especially mass vaccination, although potentially more expensive than prevention in humans in the short term, is advantageous in the long term, with higher cost-efficiency compared to the cumulative costs of PEP alone [11-13]. However, reduction of the dog rabies incidence does not necessarily translate directly into reduced demand for PEP. Rabies control can lead to even higher PEP demand in the face of decreasing the exposure risk, which can be explained by heightened rabies awareness in the community [14-16]. To maximise the beneficial financial effects, dog vaccination should be carried out in conjunction with IBCM to prevent the overuse of PEP. The identification of bite victims who are not exposed to a suspected animal can be achieved through closer communication of medical staff with veterinary workers who are informed of the status of the respective animal. Ultimately, IBCM would also improve surveillance for the validation (proof of the absence of dog-mediated human rabies deaths) and verification (proof of the absence of dog rabies) of the 2030 goal.

The present study describes a lack of communication between the human and animal health sectors in the absence of IBCM, as shown by the comparison of laboratory and health center data. The data collection was performed during an epidemiological follow up study on the dynamics of the dog rabies incidence, the human dog-bite incidence and the PEP demand during a rabies elimination program in N'Djaména, Chad.

\section{Methods}

\subsection{Background}

In 2000, research on rabies control was initiated in N'Djaména, the capital city of Chad. Prior to the intervention, rabies was endemic in the local dog population, circulating at a low and stable level with an effective reproductive ratio $\left(R_{\mathrm{e}}\right)$ of just over 1 [12]. Pilot vaccination campaigns in 2003 and 2006 validated the feasibility of dog vaccination in the city, showing good participation by dog owners, provided the vaccine was offered without charge $[17,18]$.

Given the promising initial results, the Swiss Tropical and Public Health Institute (Swiss TPH) implemented a large-scale mass dog vaccination intervention, together with two local partners, the Institut de Recherche en Elevage pour le Développement (IRED) and the Centre de Support en Santé International (CSSI). In May 2012, community awareness was emphasised to obtain accurate incidence data before the planned vaccination campaigns. Posters in French and Arabic illustrating the best practices after a bite incident were distributed to health centers, hospitals, pharmacies and veterinary facilities throughout N'Djamena. Drawings were used to accompany the text, because of the high illiteracy rate in Chad. The information included the importance of washing wounds after a bite, the need to seek medical treatment, and the importance of contacting a veterinarian (in the case of a live animal) or bringing the body to the IRED (in the case of animal death). Fixed-post 
parenteral vaccination campaigns took place across the entire city from October to December in 2012 and 2013. The organisational details and results of the vaccination campaigns are explained in detail elsewhere $[13,19,20]$. Both campaigns reached consecutive vaccination coverage of above $70 \%$ leading to the short-term elimination of the rabies virus from N'Djaména [20]. However, the PEP demand remained high even when there were no animal rabies cases (January-October 2014) [13]. To investigate why successful rabies control in the animal sector did not translate to beneficial effects in the human health sector through a lower demand for PEP, we investigated the available epidemiological follow-up data at the laboratory and health facility level.

\subsection{Laboratory Data on Suspected and Confirmed Animal Rabies Cases}

The IRED is the only rabies laboratory in Chad equipped to perform the standard fluorescent antibody test (FAT). In addition to the FAT, samples at the IRED were analysed with the Rapid Immunodiagnostic Test (RIDT) [21]. All positive samples were sent to the Pasteur Institute in Paris for virus isolation by polymerase chain reaction (PCR), to confirm the test results. Rabies surveillance in Chad is based on passive reporting; thus, animals are brought to the IRED on a voluntary basis with no active contact tracing. In most cases, the animal dies or is killed before its submission to the IRED. When an animal is still alive, the rabies laboratory refers the owner to the nearby public veterinary clinic for observation. The IRED charges the owner of the animal 5000 FCFA (8 USD) for rabies diagnostic testing, and there is no charge for feral dogs. The rabies surveillance in N'Djamena continued before, during and after the vaccination campaigns. Some samples from areas outside of N'Djaména were also sent to the IRED for a rabies diagnosis. The present analysis includes cases reported within the time period from June 2012 to end of December 2014, to mirror the data collection period at the health facility level. Information on the animal (vaccination status, location, symptoms observed, and outcome), on the bite victims (number, age, sex, and bite location and severity) and on the history of the bite (time, place, and circumstances) were routinely collected on the diagnostic request sheet. If the test result was positive, the victims were advised to initiate PEP at the Mother and Child Hospital (Hôpital Mère et Enfant), where the vaccine was available free of charge to women and children. Adult male victims were referred to the Central National Reference Hospital (Hôpital Centrale de Reference National).

\subsection{Health Facility Data on Animal Bite Victims}

Data collection on bite cases was performed as in a previous study estimating human deaths from animal bite injuries in N'Djaména [22]. The health facilities for inclusion were identified using the same list as the previous study performed in 2008 [22]. However, not all facilities were still operating, and some new structures were identified during exploratory visits to the districts. In total, 91 facilities were contacted and included in the awareness campaign, representing all the public health centers in N'Djaména, the most frequented private health structures (medical practice) and hospitals (for profit and non-profit), and major pharmacies that had the capability to store the rabies vaccine. The largest private veterinary facility (veterinary practice) was also included. A questionnaire, developed for the study in 2008 [22], was distributed to the facilities, and personnel were asked to complete a form for every bite case presented. The information collected included demographic information about the victim (residence, age, and sex), the nature of the bite wound (severity, number and location), the circumstances of the bite incident (place, provoked/unprovoked, and other victims), the background of the animal (owner status, vaccination status, location, and outcome) and contact with other human health or veterinary structures (referrals from or to other facilities, including the IRED). The source of information related to the biting animal was sometimes the dog owner but could also be the victim or their representative (especially in the case of feral dogs). The decisions on the actions to be taken regarding the animal were primarily made by the owner, but they could also be made by the victim, in the cases of unowned dogs. The questionnaires were collected biweekly by study personnel, with an incentive of 300 FCFA (0.5 EUR) per completed questionnaire provided to the participating health structure. Health facilities were informed about the study in May 2012, and the questionnaires 
were collected from June 2012 until the end of December 2014. Sixty-one facilities responded with at least one questionnaire (mean of 19.7, median of 4, and range of 1-143; Table 1). This number represented about $30 \%$ of the health facilities identified during the study in 2008 [22].

Table 1. Number of responding health facilities and questionnaires collected.

\begin{tabular}{cccccc}
\hline \multirow{2}{*}{ Facility Type } & \multicolumn{2}{c}{ Health Facilities } & \multicolumn{2}{c}{ Questionnaires } & \multirow{2}{*}{ Quest/Facility } \\
\cline { 2 - 4 } & Count & Percent & Count & Percent & \\
\hline Pharmacy & 33 & $54 \%$ & 729 & $61 \%$ & 22 \\
Veterinary practice & 1 & $2 \%$ & 69 & $6 \%$ & 69 \\
Hospital (public) & 6 & $10 \%$ & 210 & $18 \%$ & 35 \\
Medical practice & 6 & $10 \%$ & 33 & $3 \%$ & 6 \\
Health center (public) & 15 & $25 \%$ & 154 & $13 \%$ & 10 \\
Missing information & $\mathrm{N} / \mathrm{A}$ & $\mathrm{N} / \mathrm{A}$ & 4 & $0 \%$ & N/A \\
Total & $\mathbf{6 1}$ & $\mathbf{1 0 0} \%$ & $\mathbf{1 1 9 9}$ & $\mathbf{1 0 0} \%$ & N/A \\
\hline
\end{tabular}

\subsection{PEP Use and Cost}

The WHO recommends including rabies immunoglobulin (RIG) in the PEP protocol for cases with a category III exposure (transdermal injuries or contact of saliva with mucosa) [23]. However, RIG is not available in Chad, and therefore PEP only includes active vaccination with cell culture vaccine $(\mathrm{CCV})$ given according to the intramuscular five-dose Essen regimen [24]. The price of one dose of the human rabies vaccine ranges between 9000 and 12,000 FCFA in N'Djamena, such that a full course of PEP costs 45,000-60,000 CFA (80-100 USD). Adding the costs for wound treatment (antiseptic, antibiotics, or tetanus vaccine), the private costs of lost work time and the transportation to a health facility, the full PEP and bite treatment costs are estimated to be over 90,000 FCFA (160 USD) per case [13]. Our study did not include any follow up of the bite victims; thus, data on the completion rate and the outcome for rabies-exposed people is not available.

\subsection{Data Analysis}

The questionnaire data was double entered and compared using Epi Info, and was then transferred to an Access (Microsoft, Redmond, DS, USA) database. Data collected at the rabies laboratory were entered continuously into an Excel spreadsheet. For both data sets, the analysis was performed with Stata/IC 14. The dog rabies incidence was calculated on the basis of the number of positive dog rabies cases observed in N'Djaména over the study period and the dog population estimates for the city obtained during the two vaccination campaigns, ranging from 24,547 in 2012 to 30,074 in 2013 [19]. The national human population census of 2009 provided by the Chadian national statistical institute for economic and demographic studies (Institut National de la Statistique des Etudes Economiques et Démographiques; INSEED) served as the basis for the calculation of the bite exposure and PEP incidence. Only bite cases reported from N'Djaména (1143) were included for this calculation. To statistically evaluate differences in the incidences (dog rabies cases, dog bites, and PEP use) before and after the mass vaccination intervention, paired $t$-tests were performed. The respective monthly incidences observed from June to December 2012 were compared to the monthly incidences of the period of June to December 2013.

For the analysis of the health facility data, the vaccination status of the biting animals was categorised as "vaccinated" (date of vaccination reported and less than one year before reported bite incident), "vaccination unconfirmed" (missing vaccination date or more than one year before bite incident) or "unvaccinated" (vaccination status reported as unvaccinated or unknown). In addition, each bite case was attributed a rabies-exposure risk variable on the basis of the status and outcome of the animal as drawn from the information in the questionnaire: "high exposure risk" was attributed to animals reported to have disappeared or have been killed after the bite attack; "moderate exposure risk" was attributed to animals with a negative, unclear or out-dated vaccination status, regardless of 
being under observation or not. Vaccinated animals that bit more than two people were also defined as having a moderate exposure risk because data from the laboratory level showed that the number of victims by case was related to a positive test result. In the cases of no known owner for an animal that was reported to be under observation, the exposure was also considered to be moderate. "No exposure risk" was attributed when the animal had a confirmed vaccination status, had bitten no more than two people, and was placed under observation. The rabies-exposure risk categories, derived from the animal's status as described above, were compared to the rabies suspicion as noted by the health personnel in the questionnaire ("yes", "no", or "do not know"). To evaluate the parameters influencing the PEP recommendation, the respective explanatory variables were coded into categories: the severity of the bite was coded as WHO category II exposure/WHO category III exposure (WHO category I was not observed in this data) [23]; age was coded as adults ( $>15$ years)/children ( $\leq 15$ years); the number of bites was coded as single bite/multiples bites; the number of victims was coded as single victim/multiple victims. The categories per parameter were then compared by risk ratio $(R R)$ analysis with calculation of respective confidence interval $(C I)$. A statistical comparison of the $\mathrm{PEP}$ recommendations per respective categories was performed by an odds ratio $(O R)$ calculation. Regarding the risk of a dog being killed after having inflicted a bite, the 10 districts of N'Djaména were assigned an observed predominant cultural background (Christian/Muslim) and the differences between the two categories were evaluated by a calculation of the $R R$.

\subsection{Ethical Consideration}

The dog rabies mass vaccination intervention was approved and co-funded by the government of Chad. The data on rabid animals and human bite exposure was collected on a routine basis by the rabies laboratory at the IRED. This study was approved by the ministry for higher education in Chad (Letter N012/PR/PM/MES/SG/DGESRSFP/DRST/012; Date: 31 May 2012). Meetings were held with the mayor of N'Djaména and the district and quarter chiefs in each administrative area who granted permission prior to beginning the study.

\section{Results}

\subsection{Rabies Diagnostic Results and Respective Case Histories}

The awareness campaign before the mass vaccination led to a rapid and considerable increase in the number of rabies-suspicious animals reported to the IRED, from a monthly mean of 1.2 diagnostic requests observed from January to May 2012 (prior to the study period) to 3.6 observed from June to December 2012 (during the study period). Throughout the study period (June 2012-December 2014), a total of 60 rabies-suspect animals were sent to the IRED, of which 46 originated from N'Djamena, 9 originated from other areas in Chad (mostly located very close to N’Djaména), and 2 originated from Cameroon (which borders N'Djaména). In three cases, the sample origin was unknown. Overall, 32 samples tested positive, 25 were negative and 3 were not testable because of a poor sample quality. Table 2 shows the distribution of the test results by species.

Table 2. Summary of results of samples received for rabies diagnosis at the Institut de Recherche en Elevage pour le Développement (IRED), by species.

\begin{tabular}{ccccc}
\hline Species & Negative & Positive & No Result & Total \\
\hline Dog & 13 & 30 & 2 & 45 \\
Cat & 3 & 2 & 1 & 6 \\
Monkey & 6 & 0 & 0 & 6 \\
Sheep & 2 & 0 & 0 & 2 \\
Shrew & 1 & 0 & 0 & 1 \\
Total & $\mathbf{2 5}$ & $\mathbf{3 2}$ & $\mathbf{3}$ & $\mathbf{6 0}$ \\
\hline
\end{tabular}


In total, $30(67 \%)$ of the submitted dog samples and $2(33 \%)$ of the cat samples were positive. No positive cases were observed in other species. Amongst all animals sent to the IRED, only $10 \%$ (five dogs and one cat) were initially put under observation prior to death and subsequent submission to the IRED. In two of those six cases, the animals tested positive for rabies. In most cases, the animal was killed immediately after a bite rather than put under observation ( 43 cases; $72 \%$ ). The percentage of positive cases among killed animals was $67 \%$ ( 29 out of 43 ). The percentage of confirmed rabid animals that were found dead or that died during the observation period was $22 \%$ (two out of nine). This observed difference was found to be significant, but with a large confidence interval due to limited sample size ( $R R$ 3.7; 95\% CI: 1-13.2; $p=0.043)$. In eight cases, the circumstances of death were not specified.

The majority of animals brought to the IRED were owned (72\%), but only 2 out of $32(6 \%)$ owned dogs had a valid vaccination (vaccination $<1$ year), which was confirmed by a certificate. In one of these two cases, the dog nonetheless tested positive. In six cases, the vaccination status was unconfirmed or out of date and five of these dogs tested positive. Animals other than dogs were all unvaccinated. The most commonly observed symptoms were aggression ( $88 \%$ of cases) and a sudden change of behaviour ( $40 \%$ of cases).

On average, two (min: one; max: six) human bite victims were observed per rabid animal. The proportion of children among the bite victims of confirmed rabies cases was $42 \%$ ( 25 of 59 ). For rabies-negative cases, the proportion of children among all victims was only $27 \%$ ( 3 out of 11 ). However, risk ratio analysis showed that this difference was not statistically significant ( $R R$ 1.4; $95 \%$ CI: $0.5-3.8 ; p=0.5)$

\subsection{Reported Bite Cases and Related Animal History at the Health Facility Level}

In total, 1203 questionnaires were collected from health facilities during the survey. Three questionnaires were excluded from the data set because the biting animal was a snake and one questionnaire was not completed. The vast majority of the remaining 1199 bite cases were those inflicted by dogs (936 cases; $78 \%$ ), followed by cats (58 cases; $5 \%$ ) and monkeys (15 cases; $1.5 \%$ ). For the remaining $16 \%$ (190 cases), information on the animal was missing. A high number of reported victims were children $\leq 13$ years of age $(42 \%)$.

More than $58 \%$ of bite exposures took place at the victim's home, while an additional $36 \%$ occurred very close to the place of residence. Table 3 shows the distribution of reported bite cases and health facilities by district and inhabitants on the basis of the population census of 2009 (INSEED). District 10 was very sparsely represented; only one health facility participated and only 11 bite cases were reported from the entire district (Table 3). There was a low representation of health facilities in this district because of its remote location on the periphery of the town. Additionally, a very low dog population density was reported from this district during the vaccination campaigns [19]. In contrast, districts 6 and 7 had the highest rate of questionnaires per inhabitants (Table 3). This was in accordance with the high density of health facilities and the very high dog-to-human ratio found in these two districts (Figure 1). 
Table 3. Number of questionnaires and participating health facilities per district and inhabitants on the basis of the population census of 2009 (INSEED).

\begin{tabular}{ccccccccc}
\hline \multirow{2}{*}{ District Number } & \multicolumn{2}{c}{ Questionnaires (Q) } & \multicolumn{2}{c}{ Health Facilities (HS) } & \multicolumn{2}{c}{ Population (P) 2009 } & \multirow{2}{*}{ HS/1000P } & \multirow{2}{*}{ Q/1000P } \\
\cline { 2 - 7 } & Count & Percent & Count & Percent & Count & Percent & & \\
\hline 1 & 54 & $5 \%$ & 8 & $13 \%$ & 72,742 & $8 \%$ & 0.11 & 0.73 \\
2 & 9 & $1 \%$ & 3 & $5 \%$ & 36,450 & $4 \%$ & 0.08 & 0.25 \\
3 & 22 & $2 \%$ & 6 & $10 \%$ & 38,101 & $4 \%$ & 0.16 & 0.58 \\
4 & 14 & $1 \%$ & 3 & $5 \%$ & 72,954 & $8 \%$ & 0.04 & 0.19 \\
5 & 39 & $3 \%$ & 3 & $5 \%$ & 102,169 & $11 \%$ & 0.03 & 0.38 \\
6 & 122 & $11 \%$ & 6 & $10 \%$ & 43,948 & $5 \%$ & 0.14 & 2.64 \\
7 & 700 & $61 \%$ & 17 & $28 \%$ & 221,811 & $23 \%$ & 0.08 & 3.08 \\
8 & 106 & $9 \%$ & 12 & $20 \%$ & 185,065 & $20 \%$ & 0.06 & 0.53 \\
9 & 66 & $6 \%$ & 2 & $3 \%$ & 75,893 & $8 \%$ & 0.03 & 0.86 \\
10 & 11 & $1 \%$ & 1 & $2 \%$ & 98,982 & $10 \%$ & 0.01 & 0.10 \\
Total (N'Djaména) & $\mathbf{1 1 4 3}$ & $\mathbf{1 0 0} \%$ & $\mathbf{6 1}$ & $\mathbf{1 0 0} \%$ & $\mathbf{9 4 8 , 1 1 5}$ & $\mathbf{1 0 0} \%$ & $\mathbf{0 . 0 6}$ & $\mathbf{1 . 1 7}$ \\
\hline
\end{tabular}

District 9 had a similar dog density to district 7, however, like district 10, it was an area at the periphery of the town, where health facilities were not numerous. Figure 1 also shows the monthly incidences of dog rabies and bite exposures by district reported before and during the first vaccination round in 2012 (June-December).

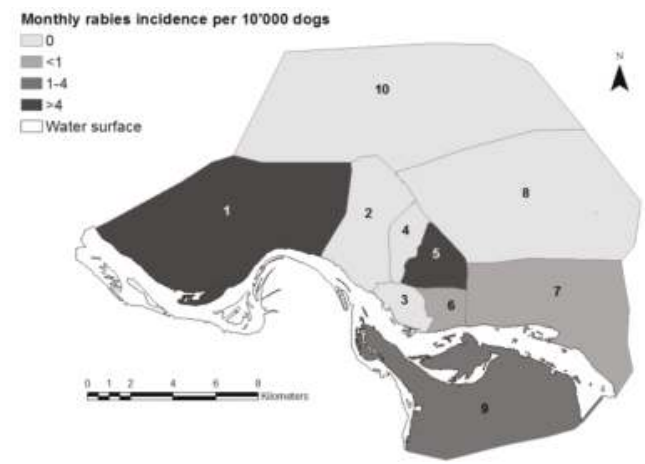

(a)

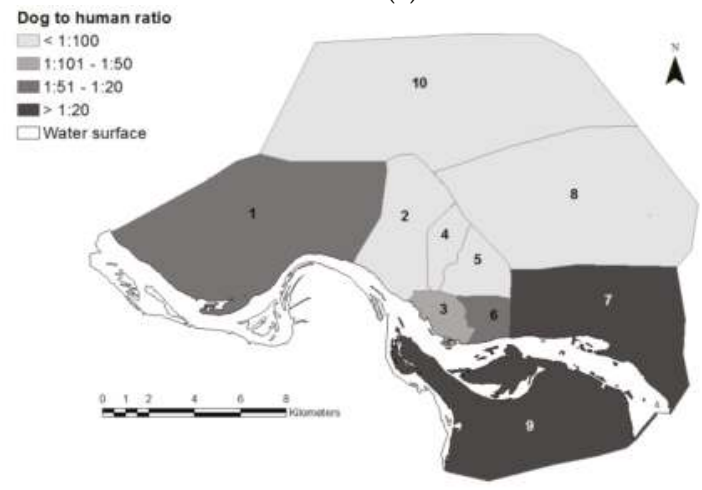

(b)

Figure 1. Cont. 


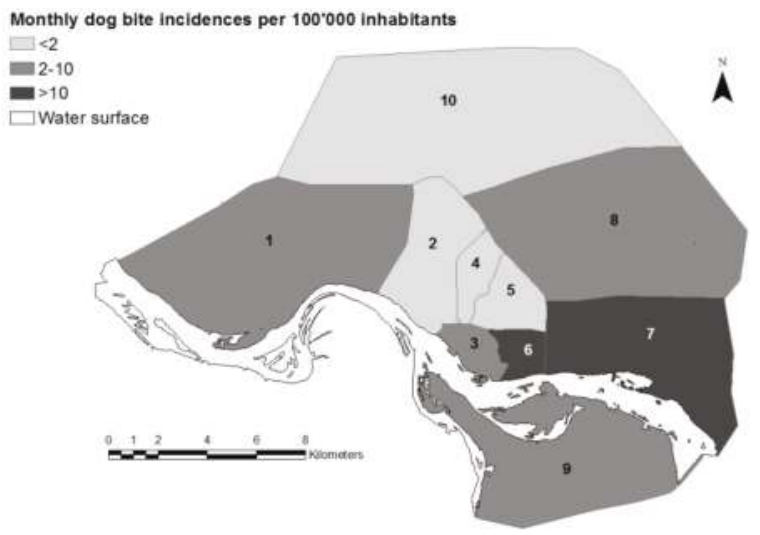

(c)

Figure 1. Maps of N’Djaména depicting monthly dog rabies incidences (a); dog-to-human ratios (b) and monthly dog bite incidences (c) observed from June to December 2012. Dog population estimates are based on the results of the vaccination coverage analysis in 2012 published previousely [19]. The human population by district is derived from the population census of 2009 (INSEED). Numbers on the maps indicate the district number.

In over $70 \%$ of the bite cases, the animal was reported to be put under observation, but in less than one in four of these cases $(23.5 \%)$ was it noted that the animal was taken to a veterinary facility. A total of 144 cases $(15 \%)$ stated that the animal was brought to the rabies laboratory at the IRED. However, this number does not correspond to the actual number of animals submitted to the rabies laboratory within the same time period; see above. Moreover, in only 2 out of 72 cases for which the animal was killed and in 1 out of 4 cases for which the animal died was it reported that the carcass was sent to the rabies laboratory. Six dogs were killed, despite a reported confirmed vaccination status. For bite cases reported from districts with a predominantly Muslim background, the animal was 10 times more likely to be killed, compared to those of bite cases occurring in districts with a predominantly Christian background ( $R R$ : 10.5; 95\% CI: 6.37-17.36; $p<0.0001$ ). The mean number of victims per biting animal observed during the health facility survey was 1.5 (max: 13$)$. In the majority of cases (82\%), only one victim was reported.

The highest number of bite victims was reported by pharmacies. Compared to the other types of health facilities involved, hospitals had the highest mean number of reported bite cases, followed by pharmacies and health centers (Table 1).

In total, 161 victims were referred to another facility (Figure 2), and pharmacies were the facilities referring the highest numbers of people to another facility. In $64 \%$ of the referrals, the patients were sent to another human health facility, the majority to hospitals (54\%), likely because of a shortage of the vaccine or for further wound treatment. In only $36 \%$ of referrals were the victims sent to a veterinary facility (28.5\% to veterinarians and $7.5 \%$ to the IRED). Hospitals and health centers were the facilities that referred the highest numbers of cases to veterinary facilities or to the rabies laboratory at IRED (83\% of overall referred cases). The single veterinary facility that participated referred $74 \%$ of their bite victims to a hospital or a health center, assumedly because a veterinary facility would not provide the human vaccine. 


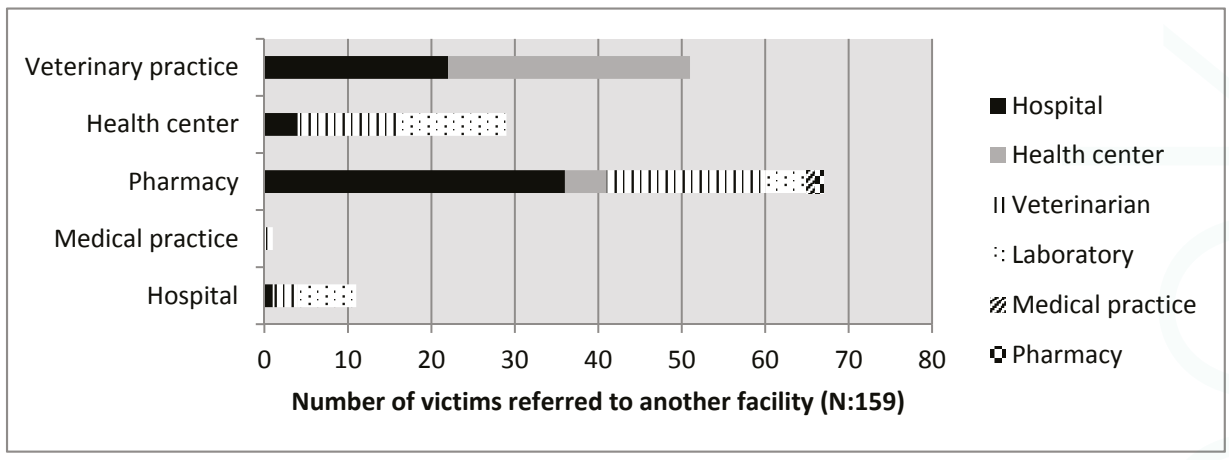

Figure 2. Cases of referral of victims to another health facility.

\subsection{PEP Treatment Decisions on the Health Facility Level}

The PEP treatment recommendation was not always consistent with the rabies suspicion status reported by the health personnel (Figure 3). In $27 \%$ of the bite cases, it was noted that the animal was not suspected for rabies but PEP was recommended. In contrast, 56 patients $(0.05 \%)$ were not recommended to undergo PEP although the animal was reported as a rabies suspect (Figure 3).

When comparing the rabies exposure risk status defined during analysis (as based on the information available regarding the biting animal), with the suspicion status reported by the health personnel, we found 40 cases in which no suspicion was reported but a high exposure risk was assigned on the basis of the case history. Similarly, when the exposure risk was absent, as assessed by the case history, 54 cases were nonetheless identified by the health personnel as suspected for exposure to a rabid animal.
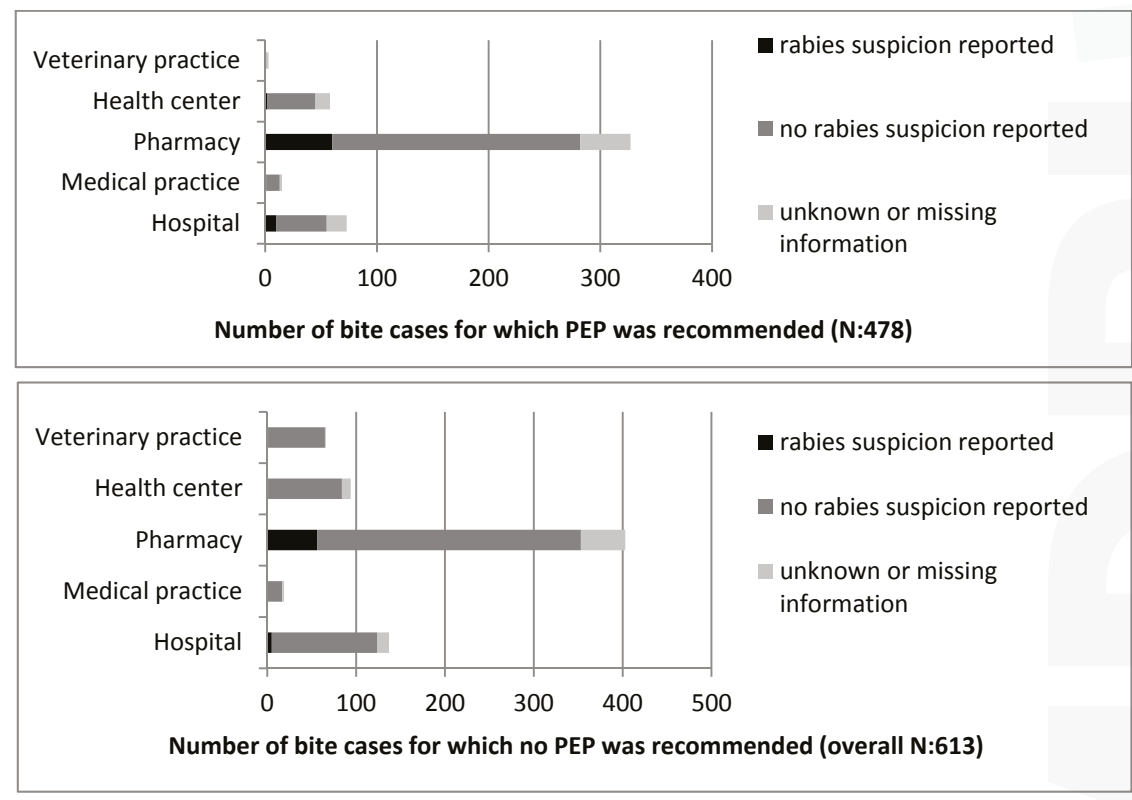

Figure 3. Comparison of post-exposure prophylaxis (PEP) recommendation and reported rabies suspicion by facility type. 
The comparison of the rabies exposure risk status with the PEP recommendation illustrated even higher discrepancies. Of all the bite cases, including those reported from outside N'Djamé na, with no indication of suspected rabies exposure, 36\% (208 out of 577) were recommended to undergo PEP treatment. In 38\% (189 out of 487) of the cases for which PEP was recommended, the exposure risk was moderate. Finally, in only 17\% (81 out of 487) of the cases for which PEP was recommended did the history of the animal indicate a high exposure risk. Most alarmingly, in $62 \%$ (312 out of 501) of all the cases judged to be of moderate exposure risk and in 33\% (40 out of 121) of those judged as high exposure risk, the bite victims were not advised to undergo PEP treatment. Detailed results on the PEP recommendations by facility type and the comparison to the rabies exposure risk are presented in Figure 4 .
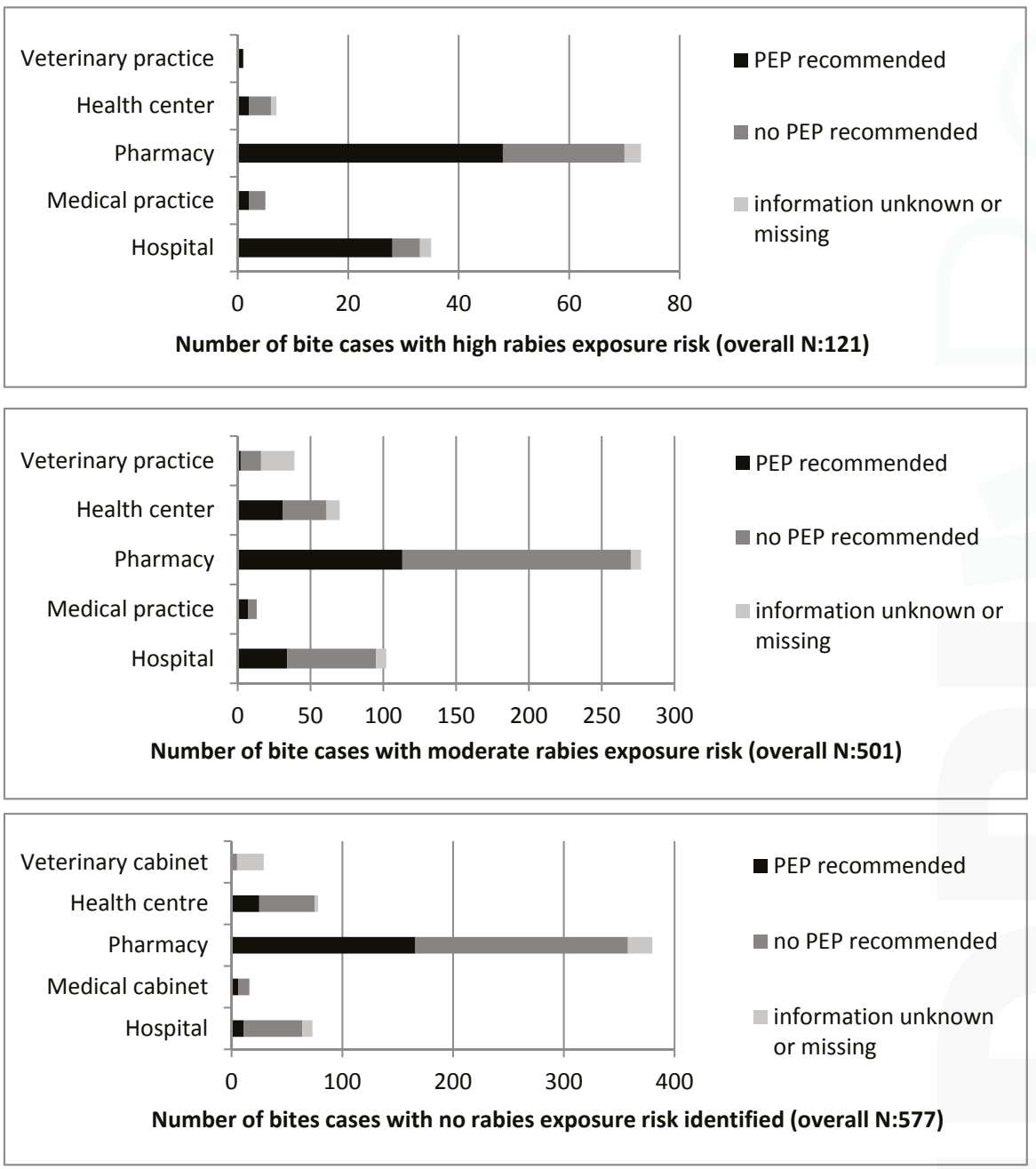

Figure 4. Comparison of post-exposure prophylaxis (PEP) recommendations made by facility type and rabies exposure risk category (as attributed to bite cases on the basis of the animal status). 
The inconsistencies in the PEP recommendations can be explained by the fact that health personnel were more likely to judge the rabies suspicion according to the severity of the bite inflicted rather than on the vaccination status of the animal. When the wound was deep or the skin was clearly broken, one in five cases was declared as suspicious, and in 50\% of these cases, PEP was recommended. In contrast, when the wound was reported as superficial or only a minor scratch, less than 1 in 20 were reported suspicious and $28 \%$ of these patients were recommended to undergo PEP. PEP was found to be more likely recommended for WHO category III than category II exposures (OR: $0.36 ; 95 \%$ CI: 0.28-0.46; $p<0.0001)$. No difference was observed for the PEP recommendation between children and adults (OR $1.0065 ; 95 \%$ CI: $0.79-1.28 ; p=0.96$ ) or the number of bites inflicted (single or multiple; OR: $1.17,95 \%$ CI: $0.9-1.52 ; p=0.22$ ). There was also no relation observed between the number of victims reported per animal (single or multiple) and the rabies suspicion status defined by the health personnel (OR: 0.81; 95\% CI: 0.51-1.3; $p=0.4$ ).

\subsection{Impact of Mass Dog Vaccination on Dog Rabies Incidence, Animal Bite Incidence and PEP Demand}

After the beginning of the vaccination intervention in October 2012, rabies reports from N'Djaména as observed at the IRED dropped steadily (Figure 5). Following the mass vaccination, the monthly animal rabies incidence dropped from $1.1 / 10,000$ dogs, observed prior to the campaign in 2012 , to $0.12 / 10,000$ dogs in 2013 , and only $0.061 / 10,000$ dogs in 2014 . This translates as a reduction from one rabid dog per week in 2012 to only two rabid dogs throughout the whole year in 2014. During the same period of time, the reporting of rabies cases from areas outside of N'Djaména was steady but remained low (only 11 cases over the study period), mainly due to lower public awareness and logistical challenges. Before the vaccination intervention, most rabies cases were reported from the seventh district (Figure 1). After the mass vaccination, rabies cases were absent from districts north of the Chari River for well over a year (February 2013 to October 2014); the only cases observed during this period came from district 9, which lay south of the Chari River.

Figure 5 shows that the incidence of PEP treatment did not decline with the decline of the animal rabies incidence but was instead closely linked to the overall bite incidence rates observed from the health facility data over the study period. For the dog rabies incidence, the paired $t$-test showed a significant difference between the two periods from June to December in 2012 and 2013 ( $p=0.0063$; $t=3.8)$. The difference in the monthly mean PEP incidences over the same period of time was not significant $(p=0.1 ; t=1.4)$, nor was the difference observed between the monthly mean dog bite incidences $(p=0.1 ; t=1.5)$.

The proportion of confirmed vaccinated animals among all the bite-inflicting animals observed on the health facility level only increased by $15 \%$, from $47 \%$, observed prior to the start of the vaccination campaign, to $62 \%$ by the end of 2014 . The percentage of unvaccinated animals decreased from $23 \%$ to $11 \%$ and cases with an unconfirmed, out-of-date or unknown vaccination status remained stable at around $30 \%$. 


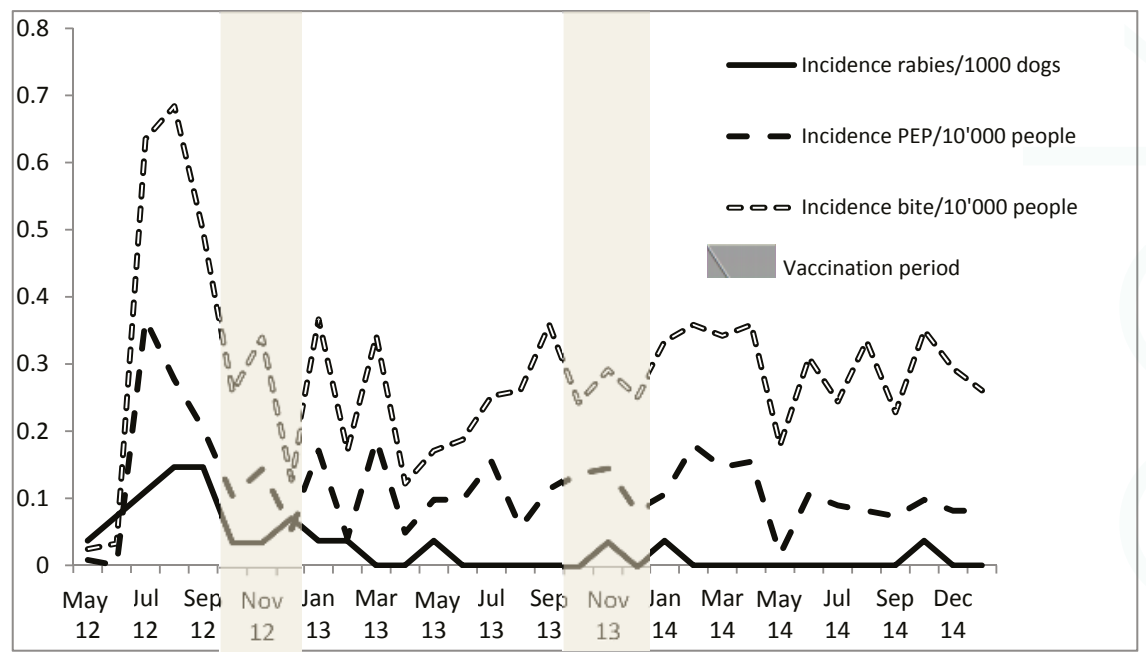

Figure 5. Dynamics of monthly animal rabies, human bite exposure and post-exposure prophylaxis (PEP) demand incidence rates following the dog mass vaccination intervention in N’Djaména.

\section{Discussion}

The multiple studies undertaken in N'Djaména since 2000 serve as a good example for investigation on the feasibility and description of barriers and shortcomings for rabies control in Sub-Saharan Africa. The most recent work that included a citywide dog mass vaccination and a follow-up of the epidemiological impact has demonstrated the interruption of rabies transmission [20], but it highlights the need for better communication between the veterinary and human health sectors to translate success in dog vaccination to beneficial economic effects in public health [13]. In the absence of dog vaccination, the current PEP use in N'Djaména is inadequate to prevent all dog-mediated human deaths [13]. In this paper, we describe underlying problems that contribute and that should hypothetically be similar in other countries. These factors constitute barriers to the goal of achieving zero human deaths due to dog mediated rabies and they should be addressed early towards the 2030 agenda. The challenges crystallise around the implementation of an integrated, community-based One Health approach for efficient rabies surveillance and control. This can only be achieved through high public participation in control measures (vaccination and surveillance), compulsory dog registration and IBCM training for health and veterinary personnel to ensure the best practice use of PEP.

Our data illustrate the evident fact that the elimination of dog-mediated rabies will not lead to considerably lower bite case incidences, as only a very small proportion of bites are caused by rabid animals. For example, in the present study, the number of bite victims of truly rabid animals recorded at the laboratory constituted only $5 \%$ of the overall observed bites in the health facility survey during the same period of time. Therefore, it would be an unnecessary burden on the public health sector to recommend PEP for every bite case. Such extensive use of PEP would even be counterproductive given the current shortage of the vaccine, as it would lead to insufficient PEP for actual rabies-exposed victims.

Our reported numbers for the bite incidence are conservative. Not all victims present to a health facility, as many use traditional forms of treatment [25]. In addition, this study only covered about one-third of the facilities in N'Djaména. Therefore, the actual numbers of bite exposures are believed to have been considerably higher. In general, there were fewer health facilities per inhabitant observed in districts at the periphery of the town compared to the central districts, which could have led to 
an underrepresentation of cases from the peripheral districts. The socio-economic background also differed between the central (wealthier areas) and peripheral (underprivileged areas) districts; poorer communities might have been less represented in this study. However, N'Djaména is a relatively small town $\left(292 \mathrm{~km}^{2}\right)$ with adequate road access and public transportation; therefore, the geographical distance to a respective health facility should have a minor influence on health seeking and PEP accessibility. Most dogs in N'Djaména are owned but are free roaming, which results in high contact between humans and dogs. Nonetheless, notable differences in the bite exposure incidences were observed between different districts. N'Djaména reflects the diverse socio-cultural and socio-economic context of Chad. This background has a significant influence on dog ownership [19]. Districts with a predominantly Muslim background (2nd, 4th and 10th district) have a much lower dog-to-human ratio than areas with a Christian context (1st, 7th and 9th district). Similarly, the dog density is extremely low in the wealthy neighborhoods found in the 2 nd district as compared to the very high densities found in the slum areas at the periphery of the town (9th district). Because of this diverse context, dog rabies cases and dog bite exposures are likewise heterogeneously distributed. As the dog population estimates were derived from extensive surveys during the mass vaccination campaigns, and because the number of health facilities per district did not depend on the district cultural background, we are confident that these differences were not a result of underreporting in predominantly Muslim areas.

The study did not include a follow-up of bite patients, and therefore we do not know if victims completed all the PEP doses required. Additionally, we do not know how many cases of human rabies occurred during the study period in N'Djaména, as the disease is not notifiable in Chad. In 2008/2009, the annual number of human rabies cases in N'Djaména was estimated to be seven, and an extrapolation of the mean number of victims per rabid dog registered revealed a huge proportion of possibly exposed people who did not seek PEP [22].

Another study limitation was the lack of follow-up on the observation of biting animals, as the collection of such data on the veterinary level was not included. Regional governmental veterinary institutions in Chad do maintain registries on animal observations, but the results are not regularly reported to higher national levels. In our study, we observed that although, after most exposures, the biting animal was reported to be put under observation, a veterinarian was rarely contacted. This indicates that the owner judged his animal to be alive and well, but that no action was taken to check the animal for signs of rabies by a veterinarian. No legislation on rabies control exists in Chad, other than a short paragraph from 1961 that recommends culling stray dogs. Therefore, the 10 day observation period for an animal that has bitten a person cannot be enforced by law. In our study, animals that died were less likely to be tested positive for rabies at the laboratory level. This has important implications for animal welfare; for instance, dogs accustomed to free-roaming were reported by owners to have died of strangulation while kept on a leash.

The high number of rabies-positive cases among animals with an unconfirmed or out-of-date vaccination status highlights the importance of confirming the owner-reported vaccination status by a certificate. This issue is also highlighted when comparing the proportion of biting animals reported as vaccinated by the health facility survey prior to the mass vaccination campaign, which was $47 \%$, with data from a household survey conducted in 2001, for which the proportion of vaccinated dogs was only $19 \%$ [26]. As the negative financial implications (cost of PEP for all bite victims) and social consequences (responsibility for a human death) for owners of a rabid dog are unbearable, some may not accurately represent the vaccination status of their animal. On the other hand, the small increase in the proportion of confirmed vaccinated animals observed over all the reported bite cases during the dog vaccination intervention was concerning, and could have been related to the high likelihood of losing paper-based vaccination certificates [19]. Therefore, to establish an effective IBCM, a unique identification and registration system for all dogs is necessary.

The positive result found in a dog that was certified as vaccinated highlights the need for an observation period even for vaccinated animals. Vaccine failure due to inappropriate storage conditions 
or the inadequate immune response of the animal can never be excluded. Rabies antibody detection and titration is not yet possible in Chad.

Our findings at the laboratory level indicate that the symptoms of rabies and the abnormal behavior of animals are generally well interpreted. When there was a suspicion of rabies, especially for aggressive dogs, the animal was killed quickly. However, the focus on aggression could mean that the paralytic form of rabies remains undetected in most cases. The IRED is regularly contacted by bite victims seeking PEP treatment who have already killed and disposed of the biting animal. The extremely low number of animals brought to the IRED after being killed or found dead shows that the importance of testing is not adequately perceived. One explanation could be the cost of the diagnostic fee, which is borne by the dog owner. Interaction with victims at the IRED indicated that they usually had little doubt about the symptoms observed in the biting animal and whether they had been truly exposed. This could explain a perception that additional laboratory testing is not necessary.

In addition to cases in which animals that died or were killed were not submitted for testing, there were several cases in which the animal disappeared. This could indicate that the actual number of rabies cases was significantly higher than reported in this study. The observed difference in killing rates between different cultural backgrounds could further point towards an underrepresentation of rabies cases from specific areas of town. However, even when simulating different case detection rates using a rabies transmission meta-population model established for N'Djaména, the outcome of the model, which suggested an interruption of rabies transmission, remained robust [27].

Despite the observed drop in the rabies incidence and the absence of animal rabies cases for nine months following the mass vaccination intervention in N'Djaména, the PEP demand remained largely unaffected by this epidemiological change. The PEP demand was clearly correlated to the overall number of bite exposures observed. The assessment of the rabies risk by health personnel was found to be based on the severity of the bite inflicted. However, scratches are listed as WHO category II exposures and they would therefore also warrant PEP treatment [23]. The influence of the animal status on the rabies risk rating was secondary. Moreover, very few patients were referred by health facilities to a veterinarian for animal observation/advice. All these findings clearly indicate that exchange between health personnel and veterinary workers remains inadequate for IBCM, and should be improved using inter-disciplinary training and communication platforms.

We only included one veterinary facility and this data was insufficient to compare the performance of veterinary facilities with human health facilities. However, the 69 cases of animal bite victims who sought help at the private veterinary practice likely indicate an understanding amongst the public for the link between human and animal health, which provides a basis for the scaling-up of knowledge.

Similarly to other studies, we report a significant number of children among the bite victims [28-30]. Also, we found that a high number of bite incidents occurred at home. School-based education and the sensitisation of dog owners regarding rabies and the prevention of dog bites should lead to a decline in bite cases. Raising awareness and knowledge about the rabies risk in communities is an important element to prevent the excessive demand of PEP [31,32] and the unnecessary killing of suspected dogs $[33,34]$ resulting from a fear of rabies. Therefore, a third pillar to establish effective IBCM, along with dog registration and interdisciplinary training, includes community engagement and culturally sensitive education.

Acknowledgments: We thank all the health facilities for their contribution to this study. We also thank Dieudonné Adoumngar and Maina Abbani for collection of the questionnaires. Further we greatly acknowledge the help of the data entry team, under the lead of Nathan Naibei, at CSSI. We also warmly thank Hamit Kessely, head of the research team at CSSI. The study was funded by UBS Optimus and the Federal Office of Food Safety and Veterinary Affairs of Switzerland. The vaccination campaign was partly financed by the Chadian ministry of livestock.

Author Contributions: J.Z. and M.L. conceived and designed the study; R.M., S.M., A.O. and K.N. collected the data, M.L. S.M., and R.M. analyzed the data; D.D. provided medical supervision, J.Z. provided scientific supervision; M.L. and R.M. wrote the paper. 
Conflicts of Interest: The authors declare no conflict of interest. The funding sponsors had no role in the design of the study; in the collection, analyses, or interpretation of data; in the writing of the manuscript, and in the decision to publish the results.

\section{References}

1. Léchenne, M.; Miranda, M.E.; Zinsstag, J. Integrated Rabies Control. In One Health: The Theory and Practice of Integrated Health Approaches; CABI: Wallingford, UK, 2015; p. 176.

2. Jackson, A.C. Current and future approaches to the therapy of human rabies. Antivir. Res. 2013, 99, 61-67. [CrossRef] [PubMed]

3. Hampson, K.; Coudeville, L.; Lembo, T.; Sambo, M.; Kieffer, A.; Attlan, M.; Barrat, J.; Blanton, J.D.; Briggs, D.J.; Cleaveland, S.; et al. Estimating the global burden of endemic canine rabies. PLoS Negl. Trop. Dis. 2015, 9, e0003709.

4. Diop, S.A.; Manga, N.M.; Dia, N.M.; Ndour, C.T.; Seydi, M.; Soumare, M.; Diop, B.M.; Sow, P.S. The point on human rabies in Senegal from 1986 to 2005. Med. Mal. Infect. 2007, 37, 787-791. [CrossRef] [PubMed]

5. Tiembré, I.; Aka-Kone, D.M.B.; Konan, Y.E.; Vroh, J.B.B.; Ekra Kouadio, D.; Dagnan, S.; Aka, J.; Tagliante-Saracino, J.; Odehouri-Koudou, P. Observance du traitement vaccinal antirabique chez les sujets exposés à la rage à Abidjan (Côte d'Ivoire). Santé Publique 2010, 21, 595-603.

6. WHO. Global Elimination of Dog-Mediated Human Rabies—The Time Is Now! WHO: Geneva, Switzerland, 2015.

7. Cleaveland, S.; Fevre, E.M.; Kaare, M.; Coleman, P.G. Estimating human rabies mortality in the United Republic of Tanzania from dog bite injuries. Bull. World Health Organ. 2002, 80, 304-310. [PubMed]

8. Undurraga, E.A.; Meltzer, M.I.; Tran, C.H.; Atkins, C.Y.; Etheart, M.D.; Millien, M.F.; Adrien, P.; Wallace, R.M. Cost-effectiveness evaluation of a novel integrated bite case management program for the control of human rabies, Haiti 2014-2015. Am. J. Trop. Med. Hyg. 2017, 96, 1307-1317. [CrossRef] [PubMed]

9. Cleaveland, S.; Kaare, M.; Tiringa, P.; Mlengeya, T.; Barrat, J. A dog rabies vaccination campaign in rural Africa: Impact on the incidence of dog rabies and human dog-bite injuries. Vaccine 2003, 21, 1965-1973. [CrossRef]

10. Tenzin, W.K.; Ward, M.P. Human and animal rabies prevention and control cost in Bhutan, 2001-2008: The cost-benefit of dog rabies elimination. Vaccine 2012, 31, 260-270. [CrossRef] [PubMed]

11. Bogel, K.; Meslin, F.X. Economics of human and canine rabies elimination: Guidelines for programme orientation. Bull World Health Organ. 1990, 68, 281-291. [PubMed]

12. Zinsstag, J.; Durr, S.; Penny, M.A.; Mindekem, R.; Roth, F.; Menendez Gonzalez, S.; Naissengar, S.; Hattendorf, J. Transmission dynamics and economics of rabies control in dogs and humans in an African city. Proc. Natl. Acad. Sci. USA 2009, 106, 14996-15001. [CrossRef] [PubMed]

13. Mindekem, R.; Léchenne, M.; Oussiguere, A.; Naissengar, K.; Kebkiba, B.; Salifou, S.; Ouedraogo, L.; Alfaroukh, I.; Daugla, D.; Zinsstag, J. Cost description and comparative cost-efficiency of Post-Exposure-Prophylaxis and canine mass vaccination against rabies in N'Djamena, Chad. Front. Vet. Sci. 2017, 4. [CrossRef] [PubMed]

14. Mitmoonpitak, C.; Tepsumethanon, V.; Wilde, H. Rabies in Thailand. Epidemiol. Infect. 1998, 120, $165-169$. [CrossRef] [PubMed]

15. Kumarapeli, V.; Awerbuch-Friedlander, T. Human rabies focusing on dog ecology-A challenge to public health in Sri Lanka. Acta Trop. 2009, 112, 33-37. [CrossRef] [PubMed]

16. Touihri, L.; Zaouia, I.; Elhili, K.; Dellagi, K.; Bahloul, C. Evaluation of mass vaccination campaign coverage against rabies in dogs in Tunisia. Zoonoses Public Health 2011, 58, 110-118. [CrossRef] [PubMed]

17. Kayali, U.; Mindekem, R.; Yemadji, N.; Vounatsou, P.; Kaninga, Y.; Ndoutamia, A.G.; Zinsstag, J. Coverage of pilot parenteral vaccination campaign against canine rabies in N'Djaména, Chad. Bull. World Health Organ. 2003, 81, 739-744. [PubMed]

18. Mindekem, R.; Kaninga, Y.; Doumagoum Moto, D.; Melther, M.I.; Vounatsou, P.; Zinsstag, J. Effectiveness of dog rabies vaccination programmes: Comparison of owner-charged and free vaccination campaigns. Epidemiol. Infect. 2009, 137, 1558-1567.

19. Lechenne, M.; Oussiguere, A.; Naissengar, K.; Mindekem, R.; Mosimann, L.; Rives, G.; Hattendorf, J.; Moto, D.D.; Alfaroukh, I.O.; Zinsstag, J.; et al. Operational performance and analysis of two rabies vaccination campaigns in N’Djaména, Chad. Vaccine 2016, 34, 571-577. [CrossRef] [PubMed] 
20. Zinsstag, J.L.M.; Laager, M.; Mindekem, R.; Naïssengar, S.; Oussigéré, A.; Bidjeh, K.; Rives, G.; Teissier, J.; Madjaninan, S.; Ouagal, M.; et al. Mass dog vaccination rapidly interrupts rabies transmission and human exposure in an African city. Sci. Transl. Med. 2017, in press.

21. Lechenne, M.; Naissengar, K.; Lepelletier, A.; Alfaroukh, I.O.; Bourhy, H.; Zinsstag, J.; Dacheux, L. Validation of a rapid rabies diagnostic tool for field surveillance in developing countries. PLoS Negl. Trop. Dis. 2016, 10, e0005010. [CrossRef] [PubMed]

22. Frey, J.; Mindekem, R.; Kessely, H.; Doumagoum Moto, D.; Naïssengar, S.; Zinsstag, J.; Schelling, E. Survey of animal bite injuries and their management for an estimate of human rabies deaths in N'Djaména, Chad. Trop. Med. Int. Health 2013, 18, 1555-1562. [CrossRef] [PubMed]

23. WHO. WHO Expert Consultation on Rabies. Second report. World Health Organ. Tech. Rep. 2013, 982, 1-139.

24. Warrell, M.J.; Warrell, D.A. Rabies: The clinical features, management and prevention of the classic zoonosis. Clin. Med. 2015, 15, 78-81. [CrossRef] [PubMed]

25. Mbilo, C.; Léchenne, M.; Hattendorf, J.; Madjadinan, S.; Anyiam, F.; Zinsstag, J. Rabies awareness and dog ownership among rural northern and southern Chadian communities-Analysis of a community-based, cross-sectional household survey. Acta Trop. 2016. [CrossRef] [PubMed]

26. Mindekem, R.; Kayali, U.; Yemadji, N.; Ndoutamia, A.G.; Zinsstag, J. Impact of canine demography on rabies transmission in N'Djaména, Chad. Med. Trop. 2005, 65, 53-58.

27. Laager, M.; Lechenne, M.; Naissengar, K.; Mindekem, R.; Oussiguere, A.; Zinsstag, J.; Chitnis, N. A metapopulation model of dog rabies transmission in N’Djaména, Chad. J. Theor. Biol. 2017, submitted.

28. Hampson, K.; Dobson, A.; Kaare, M.; Dushoff, J.; Magoto, M.; Sindoya, E.; Cleaveland, S. Rabies exposures, post-exposure prophylaxis and deaths in a region of endemic canine rabies. PLoS Negl. Trop. Dis. 2008, 2, e339. [CrossRef] [PubMed]

29. Tenzin, D.N.K.; Gyeltshen, T.; Firestone, S.; Zangmo, C.; Dema, C.; Gyeltshen, R.; Ward, M.P. Dog bites in humans and estimating human rabies mortality in rabies endemic areas of Bhutan. PLoS Negl. Trop. Dis. 2011, 5, e1391. [CrossRef] [PubMed]

30. Ramos, J.M.; Melendez, N.; Reyes, F.; Gudiso, G.; Biru, D.; Fano, G.; Aberra, G.; Tessema, D.; Tesfamariam, A.; Balcha, S.; et al. Epidemiology of animal bites and other potential rabies exposures and anti-rabies vaccine utilization in a rural area in Southern Ethiopia. Ann. Agric. Environ. Med. AAEM 2015, 22, 76-79. [CrossRef] [PubMed]

31. Cleveland, S.; Kaare, M.; Knobel, D.; Laurenson, M.K. Canine vaccination-providing broader benefits for disease control. Vet. Microbiol. 2006, 117, 43-50. [CrossRef] [PubMed]

32. Gautret, P.; Labreuil, C.; Seyni, M.; Delmont, J.; Parola, P.; Brouqui, P. Effect of media warnings on rabies postexposure prophylaxis, France. Emerg. Infect. Dis. 2011, 17, 1131-1132. [CrossRef] [PubMed]

33. Sambo, M.; Lembo, T.; Cleaveland, S.; Ferguson, H.M.; Sikana, L.; Simon, C.; Urassa, H.; Hampson, K. Knowledge, attitudes and practices (KAP) about rabies prevention and control: A community survey in Tanzania. PLoS Negl. Trop. Dis. 2014, 8, e3310. [CrossRef] [PubMed]

34. Kabeta, T.; Deresa, B.; Tigre, W.; Ward, M.P.; Mor, S.M. Knowledge, Attitudes and practices of animal bite victims attending an anti-rabies health center in Jimma Town, Ethiopia. PLoS Negl. Trop. Dis. 2015, 9, e0003867. [CrossRef] [PubMed]

(C) 2017 by the authors. Licensee MDPI, Basel, Switzerland. This article is an open access article distributed under the terms and conditions of the Creative Commons Attribution (CC BY) license (http:/ / creativecommons.org/licenses/by/4.0/). 


\title{
Retrospective Cohort Study to Assess the Risk of Rabies in Biting Dogs, 2013-2015, Republic of Haiti
}

\author{
Alexandra M. Medley ${ }^{1, *}$, Max Francois Millien ${ }^{2}$, Jesse D. Blanton ${ }^{1}$, Xiaoyue Ma ${ }^{1}$, \\ Pierre Augustin ${ }^{2}$, Kelly Crowdis ${ }^{3}$ and Ryan M. Wallace ${ }^{1}$ \\ 1 Centers for Disease Control and Prevention, Atlanta, GA 30329, USA; asi5@cdc.gov (J.D.B.); \\ hjv4@cdc.gov (X.M.); euk5@cdc.gov (R.M.W.) \\ 2 Ministry of Agriculture and Natural Resources and Rural Development, Port-au-Prince, Haiti; \\ maxfrancoismillien@gmail.com (M.F.M.); pdilius@yahoo.fr (P.A.) \\ 3 Christian Veterinary Mission, Port-au-Prince, Haiti; crowdisk@yahoo.com \\ * Correspondence: alexandramedley@gmail.com; Tel.: +1-540-246-8523
}

Academic Editors: Charles Rupprecht and Bernhard Dietzschold

Received: 29 April 2017; Accepted: 6 June 2017; Published: 12 June 2017

\begin{abstract}
Background: In canine rabies endemic countries the World Health Organization recommends post-exposure prophylaxis (PEP) be initiated immediately after exposure to an animal suspected to have rabies. Limited capacity in low and middle income countries to assess biting animals for rabies may result in the over prescription of rabies biologics. Few guidelines exist to determine the risk of whether a dog that has bitten someone is rabid. Given PEP cost and access limitations in many countries, accurate and timely assessment of dogs that have bitten people may reduce unwarranted PEP use and improve healthcare seeking behaviors. Methods: Haiti's animal rabies surveillance program utilizes veterinary professionals to conduct rabies assessments on reported biting dogs and records characteristics of the dog, health outcomes, and laboratory results in a national database. Characteristics of rabid dogs were assessed through a retrospective cohort study of biting dogs investigated during the period from January 2013-December 2015. 1409 biting dogs were analyzed; 1361 dogs that were determined to not have rabies were compared to 48 laboratory-confirmed rabid dogs. Rate ratios, sensitivity, specificity, positive predictive values, negative predictive values, likelihood ratios, quarantine survival of biting dogs, and a risk matrix were developed. Findings: The assessor's determination that the animal likely had rabies was the most significant predictive factor for a rabid $\operatorname{dog}(R R=413.4,95 \%$ CI 57.33-2985, $\mathrm{Sn}=79.17, \mathrm{Sp}=91.92)$. Clinical factors significantly associated with rabid dogs included hypersalivation, paralysis, and lethargy ( $R R=31.2,19.7,15.4$, respectively). Rabid dogs were 23.2 times more likely to be found dead at the time of the investigation compared to case negative dogs (95\% CI 14.0-38.6). Rabid dogs were also significantly more likely to lack a history of rabies vaccination or be unowned $(R R=10.395 \%$ CI $2.5-42.3$ and $R R=4.595 \%$ CI 2.0-10.1, respectively). Rabid dogs were four times more likely to have bitten multiple people ( $R R=4.095 \%$ CI 1.9-8.3). Most rabid dogs died or were killed before quarantine $(75 \%)$ and all died by day 3 of quarantine, compared to $<1 \%$ of quarantined case-negatives. The greatest risk of death was predicted to be for persons bitten on the head or neck from symptomatic dogs. Bites from dogs deemed healthy by veterinary assessors and which were available for quarantine presented less than a $0.05 \%$ risk of rabies death to the victim. Conclusions: Vaccination of all persons exposed to a suspected rabid dog is a highly effective approach to minimize human rabies deaths. However, this may place undue financial burden on bite victims that have had a low-risk exposure and over-prescription may contribute to regional supply shortages. The results here indicate that in a low-resource country such as Haiti, a well-trained veterinary assessor can provide an accurate risk assessment of biting dogs based on a standard case investigation protocol. In canine rabies endemic countries with limited access to PEP, or where PEP costs may cause undue burden on bite victims, structured risk assessments by trained professionals may be a reliable method of triaging PEP for bite victims. Evaluating rabies risk through a matrix of bite location and risk
\end{abstract}


factor in the dog presents a clear delineation of high and low risk encounters and should be used to develop data-derived PEP recommendations.

Keywords: rabies; post-exposure-prophylaxis (PEP); surveillance; risk assessment; dog bite; Haiti; retrospective cohort

\section{Introduction}

Rabies is a zoonotic disease responsible for at least 2.5 million human rabies deaths over the past century [1]. The overwhelming majority of human cases are the result of a bite from a rabid dog [1,2]. Rabies is vaccine-preventable; however, in the absence of appropriate post-exposure prophylaxis (PEP) the rabies virus induces an acute neurologic illness followed by inevitable death. Canine rabies is endemic in the Republic of Haiti, where an estimated 130 human rabies deaths occur annually $[1,3]$. Persistent human rabies deaths are due to a culmination of factors often seen in low and middle income countries: low dog vaccination coverage, low awareness, and lack of access to PEP in rural areas, all of which are barriers encountered in Haiti [3].

Until the rabies virus is eliminated in the reservoir population, humans will remain at risk of exposure. In rabies endemic countries, appropriate and timely wound management and PEP are critical for preventing human rabies deaths [4]. The World Health Organization (WHO) provides recommendations for rabies post-exposure prophylaxis after a dog bite in a canine rabies-endemic country but the recommendations leave ambiguity in interpretation [5]. These recommendations state that a risk assessment should be performed when considering initiating PEP [6]. However, they also recommend that "prophylaxis should be instituted immediately" and "continued while awaiting laboratory results or during the observation period" [6]. Information regarding how to assess rabies risk in a biting animal, and when assessment results should impact initiation of PEP, are not explicit in this WHO document.

While Haiti is considered endemic for rabies, results from a multi-year surveillance program revealed that only $1 \%-5 \%$ of biting dogs had rabies [3]. Considering current WHO recommendations, this combination of a low rabies prevalence in biting dogs and a risk-averse, conservative recommendation for PEP initiation may result in over-prescription of rabies biologics [7]. In low and middle income countries, the cost of PEP in relation to income can be quite burdensome to households [8]. As many as five rabies vaccine doses over 4 weeks are required, placing a burden on those who cannot afford the travel or time off of work, let alone the cost of biologics [6]. Furthermore, there is an unmet need in many countries for safe and accessible PEP [5]. This warrants investigation into how limited and expensive rabies biologics can be used as efficiently as possible while ensuring that truly exposed bite victims seek medical care for prevention of this $100 \%$ fatal disease.

The need to characterize low-risk rabies exposures has become an increasingly important issue in Haiti, where a government-operated post-bite dog investigation program resulted in an $85 \%$ increase in the detection of persons with dog bites [3]. As Haiti has adopted the WHO rabies exposure recommendations, this increase in bite detection significantly increased PEP utilization and costs for bite victims [9,10]. Undurraga et al. reported in 2017 that delaying PEP when the risk of rabies was low, and when the dog was available for quarantine, could reduce PEP costs without imposing undue risk to bite victims in Haiti [9].

This community based animal rabies surveillance program, Haiti Animal Rabies Surveillance Program (HARSP), employs veterinary professionals to investigate biting dogs, conduct a rabies assessment, quarantine or euthanize, and provide rabies counseling to bite victims [3]. Under this type of structured program, the possibility for standardized risk assessment has become possible, but there is an unmet need to specify what WHO considers to be a low-risk exposure. This study provides a descriptive analysis of the characteristics of rabid versus non-rabid dogs that have 
bitten humans. The purpose of this study was to evaluate whether a risk assessment conducted by veterinary professionals in a program such as HARSP could reliably approximate the risk of rabies in a biting dog, and to generate evidence for the classification of low-risk exposures in the canine rabies endemic setting.

\section{Methods}

\subsection{Data Set and Cohort Selection}

Data analyzed for this study were made available from the Haiti Ministry of Agriculture from the national HARSP database (2013-2015). HARSP assessors are trained veterinary agents from the Ministry of Agriculture, Natural Resources, and Rural Development (MARNDR) and undergo a one-week field training program conducted by the CDC and the Christian Veterinary Mission, and must pass the Global Alliance for Rabies Control's Rabies Educator Certification program [11,12]. HARSP has standard investigation protocols and investigation forms (see Supplementary Materials) for which veterinary agents must display proficiency. New assessors conduct job shadowing for 2-4 weeks. Each department has one lead technician who typically has two years of agriculture-focused education at the University level and is responsible for compiling reports for central collection.

Assessors receive reports of animals that are suspected to have rabies from the Ministry of Health, hospitals, veterinarians, and directly from community members. Assessors respond within $24 \mathrm{~h}$ to assess the animal, make a determination as to whether to pursue a 14-day quarantine or euthanasia, and to counsel the bite victim on appropriate post-bite wound care. Animals considered symptomatic for rabies are immediately euthanized and submitted to the national laboratory for testing. All samples are confirmed by the direct fluorescent antibody test. Results are validated bi-annually at the United States Centers for Disease Control and Prevention (CDC) to ensure diagnostic proficiency. Standardized data are collected and entered into a national database (Microsoft Access). At the conclusion of an investigation, each dog is classified as 1-confirmed case, 2-probable case (clinical case definition), 3-suspect case (unavailable for assessment), 4-case negative (14-day quarantine or negative direct fluorescent antibody result) [3]. All investigation forms and case determinations are reviewed by a program manager weekly.

Data for the time period from 1 January 2013 to 31 December 2015 were used for analysis. The analysis was limited to dogs involved in a human bite event for which diagnostic test results or quarantine results were recorded (classifications 1 and 4). Dogs classified as probable or suspect rabies cases were excluded. The final cohort analyzed comprised 48 rabies positive dogs and 1361 dogs for which rabies was ruled out (total $n=1409$ ).

\subsection{Evaluation of Single Variables}

HARSP surveillance data contained twelve stratified and binary variables that were considered in this study to represent various demographics and clinical signs present in rabid dogs: entity reporting the bite, ownership status of the dog, the number of individuals bitten, dog's sex, dog's age, presence of aggression, hypersalivation, paralysis, lethargy, vaccination status of the dog, condition of the dog upon location, and the decision of the trained veterinary agent (also referred to as the assessor). Further details on each variable are described in Table 1. Risk ratio (RR) and corresponding 95\% confidence interval (CI), sensitivity (Sn), specificity (Sp), positive predictive value (PPV), negative predictive value (NPV), positive likelihood ratio (PLR), and negative likelihood ratio (NLR ${ }^{-1}$ ) of each variable were calculated, using both Microsoft Excel and CDC Epi Info software. Risk ratios were calculated for variables with greater than 2 strata against an assigned reference group within that variable. 


\subsection{Evaluation of Mortality during Quarantine}

All case negatives $(n=1361)$ were compared to confirmed rabies cases $(n=48)$ to determine how many died before and during quarantine. The time period between the date of report and the date of death-regardless of quarantine status-was used to calculate the variable corresponding to the number of days until a dog died. The date of death is the date that the dog was reported to have died, was found dead by a veterinary agent, was killed (by the public or in quarantine for humane purposes), or died by natural causes (rabies or other disease). The percent of biting dogs which were alive was calculated on a daily basis for a total of 14 days, the quarantine duration used for biting dogs in the Republic of Haiti.

Table 1. Summary of variables.

\begin{tabular}{|c|c|c|}
\hline Variable & Strata & Specifics \\
\hline Entity Reporting the Dog Bite Incident & $\begin{array}{l}\text { All Health Sectors } \\
\text { Veterinary Sectors } \\
\text { Public }\end{array}$ & $\begin{array}{l}\text { Ministry of Health, Local Health Department, Hospitals } \\
\text { Veterinarians and Veterinary Agents } \\
\text { Notifications originating directly from a community member }\end{array}$ \\
\hline Ownership Status & $\begin{array}{l}\text { Owned } \\
\text { Stray/owner not identified }\end{array}$ & \\
\hline Number of People Bitten & $\begin{array}{l}1 \text { person bitten } \\
2 \text { people bitten } \\
3 \text { or more people bitten }\end{array}$ & \\
\hline Age & $\begin{array}{l}\text { Puppy } \\
\text { Junior } \\
\text { Adult } \\
\text { Unknown }\end{array}$ & $\begin{array}{l}<6 \text { months } \\
6 \text { months }-1 \text { year } \\
>1 \text { year } \\
\text { No age reported }\end{array}$ \\
\hline Sex & $\begin{array}{l}\text { Female } \\
\text { Male } \\
\text { Unknown }\end{array}$ & \\
\hline Aggression & Present or Absent & Aggression is determined by the rabies assessor \\
\hline Hypersalivation & Present or Absent & Hypersalivation is determined by the rabies assessor \\
\hline Paralysis & Present or Absent & Paralysis is determined by the rabies assessor \\
\hline Lethargy & Present or Absent & Lethargy is determined by the rabies assessor \\
\hline Vaccination Status & $\begin{array}{l}\text { Vaccinated } \\
\text { Not Vaccinated }\end{array}$ & $\begin{array}{l}\text { Owner-reported that dog was vaccinated at least once } \\
\text { Includes unvaccinated and unknown vaccination status }\end{array}$ \\
\hline $\begin{array}{l}\text { Status of Dog at the Time of } \\
\text { Investigation }\end{array}$ & $\begin{array}{l}\text { Alive } \\
\text { Dead }\end{array}$ & Hit by car, killed, died of natural causes \\
\hline Rabies Assessor's Decision & $\begin{array}{l}\text { Probably not Rabies } \\
\text { Probably Rabies } \\
\text { Dead/Not Assessed }\end{array}$ & \\
\hline
\end{tabular}

\subsection{Risk Matrix}

A risk matrix was created to assess the probability of dying from rabies based on the physical location of the dog bite and the characteristics of the biting dog. The probability of rabies in dogs was calculated for selected high and low-risk variables assessed in this study. The probability of rabies death was obtained by the product of the two variables: probability of rabies in the biting dog and probability of death based on location of exposure. Probability of death by exposure was obtained from Babes et al. [13].

\section{Results}

1409 animals were eligible for this retrospective cohort analysis. Rabies was confirmed in 48 animals and ruled out in 1361. Suspect and probable cases were excluded from the study, as no definitive case determination could be assigned (probable cases, $n=42$ and suspect cases, $n=265$ ). Of the rabies-positive dogs included in the study, $29(60.4 \%)$ were dead at the time of investigation, $7(14.6 \%)$ were euthanized on the day of the investigation, and 12 (25\%) were placed into quarantine. Table 2 and Figure 1 show risk ratios and 95\% confidence intervals. Table 3 and Figure 2 show the Sn, Sp, PPV, NPV, PLR and NLR ${ }^{-1}$ of all variables. 


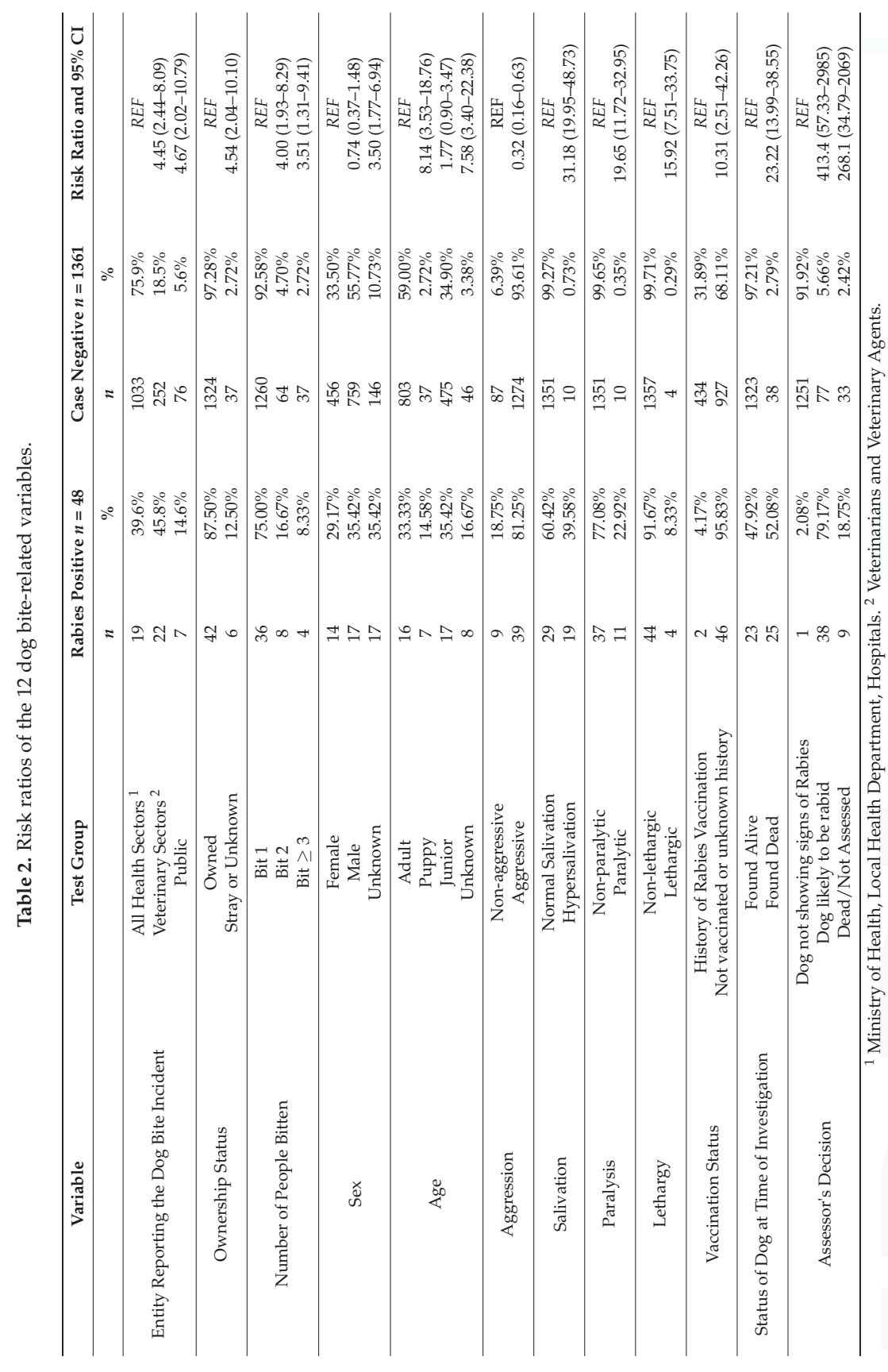


Table 3. Sensitivity, specificity, positive predictive value, negative predictive value, negative likelihood ratio, and positive likelihood ratio of the $12 \mathrm{dog}$ bite-related variables.

\begin{tabular}{|c|c|c|c|c|c|c|c|}
\hline Variable & Test Group & SENS & SPEC & PPV & NPV & $\mathrm{NLR}^{-1}$ & PLR \\
\hline \multirow{3}{*}{$\begin{array}{l}\text { Entity Reporting the } \\
\text { Dog Bite Incident }\end{array}$} & All Health Sectors & $39.58 \%$ & $24.10 \%$ & $1.81 \%$ & $91.88 \%$ & 0.399 & 0.522 \\
\hline & Veterinary Sectors & $45.83 \%$ & $81.48 \%$ & $8.03 \%$ & $97.71 \%$ & 1.504 & 2.475 \\
\hline & Public & $14.58 \%$ & $94.42 \%$ & $8.43 \%$ & $96.91 \%$ & 1.105 & 2.612 \\
\hline \multirow{2}{*}{ Ownership Status } & Owned & $87.50 \%$ & $2.72 \%$ & $3.07 \%$ & $86.05 \%$ & 0.217 & 0.899 \\
\hline & Stray or Unknown & $12.50 \%$ & $97.28 \%$ & $13.95 \%$ & $96.93 \%$ & 1.112 & 4.598 \\
\hline \multirow{3}{*}{$\begin{array}{l}\text { Number of People } \\
\text { Bitten }\end{array}$} & Bit 1 & $75.00 \%$ & $7.42 \%$ & $2.86 \%$ & $89.38 \%$ & 0.297 & 0.810 \\
\hline & Bit 2 & $16.67 \%$ & $95.30 \%$ & $12.50 \%$ & $97.01 \%$ & 1.144 & 3.544 \\
\hline & Bit $\geq 3$ & $8.33 \%$ & $97.28 \%$ & $10.81 \%$ & $96.78 \%$ & 1.061 & 3.065 \\
\hline \multirow{3}{*}{ Sex } & Female & $29.17 \%$ & $66.50 \%$ & $2.98 \%$ & $96.38 \%$ & 0.939 & 0.871 \\
\hline & Male & $35.42 \%$ & $44.23 \%$ & $2.19 \%$ & $95.10 \%$ & 0.685 & 0.635 \\
\hline & Unknown & $35.42 \%$ & $89.27 \%$ & $10.43 \%$ & $97.51 \%$ & 1.382 & 3.302 \\
\hline \multirow{4}{*}{ Age } & Adult & $33.33 \%$ & $41.00 \%$ & $1.95 \%$ & $94.58 \%$ & 0.615 & 0.565 \\
\hline & Puppy & $14.58 \%$ & $97.28 \%$ & $15.91 \%$ & $97.00 \%$ & 1.139 & 5.364 \\
\hline & Junior & $35.42 \%$ & $65.10 \%$ & $3.46 \%$ & $96.62 \%$ & 1.008 & 1.015 \\
\hline & Unknown & $16.67 \%$ & $96.62 \%$ & $14.81 \%$ & $97.05 \%$ & 1.159 & 4.931 \\
\hline \multirow{2}{*}{ Aggression } & Non-aggressive & $18.75 \%$ & $93.61 \%$ & $9.38 \%$ & $97.03 \%$ & 1.152 & 2.933 \\
\hline & Aggressive & $81.25 \%$ & $6.39 \%$ & $97.03 \%$ & $90.63 \%$ & 0.341 & 0.868 \\
\hline \multirow[b]{2}{*}{ Salivation } & Normal Salivation & $60.42 \%$ & $0.73 \%$ & $2.10 \%$ & $34.48 \%$ & 0.019 & 0.609 \\
\hline & Hypersalivation & $39.58 \%$ & $99.27 \%$ & $65.52 \%$ & $97.90 \%$ & 1.643 & 53.873 \\
\hline \multirow{2}{*}{ Paralysis } & Non-paralytic & $77.08 \%$ & $0.73 \%$ & $2.67 \%$ & $47.62 \%$ & 0.008 & 0.027 \\
\hline & Paralytic & $22.92 \%$ & $99.27 \%$ & $52.38 \%$ & $97.33 \%$ & 1.288 & 31.190 \\
\hline \multirow{2}{*}{ Lethargy } & Non-lethargic & $91.67 \%$ & $0.29 \%$ & $3.14 \%$ & $50.00 \%$ & 0.035 & 0.919 \\
\hline & Lethargic & $8.33 \%$ & $99.71 \%$ & $50.00 \%$ & $96.86 \%$ & 1.088 & 28.354 \\
\hline \multirow{2}{*}{ Vaccination Status } & History of Vaccination & $4.17 \%$ & $79.96 \%$ & $0.46 \%$ & $95.74 \%$ & 0.834 & 0.208 \\
\hline & $\begin{array}{l}\text { Not vaccinated or unknown } \\
\text { history }\end{array}$ & $95.83 \%$ & $57.20 \%$ & $4.73 \%$ & $97.41 \%$ & 13.718 & 2.239 \\
\hline \multirow{2}{*}{$\begin{array}{l}\text { Status of Dog at Time } \\
\text { of Investigation }\end{array}$} & Found Alive & $47.92 \%$ & $2.36 \%$ & $1.71 \%$ & $58.18 \%$ & 0.045 & 0.491 \\
\hline & Found Dead & $52.08 \%$ & $97.21 \%$ & $39.68 \%$ & $98.29 \%$ & 2.029 & 18.654 \\
\hline \multirow{3}{*}{ Assessor's Decision } & Dog not showing signs of Rabies & $2.08 \%$ & $8.08 \%$ & $0.08 \%$ & $99.86 \%$ & 1.020 & 14.496 \\
\hline & Dog likely to be rabid & $79.17 \%$ & $91.92 \%$ & $33.04 \%$ & $99.23 \%$ & 4.764 & 102.446 \\
\hline & Dead/Not Assessed & $18.75 \%$ & $97.58 \%$ & $21.43 \%$ & $97.15 \%$ & 1.196 & 6.572 \\
\hline
\end{tabular}

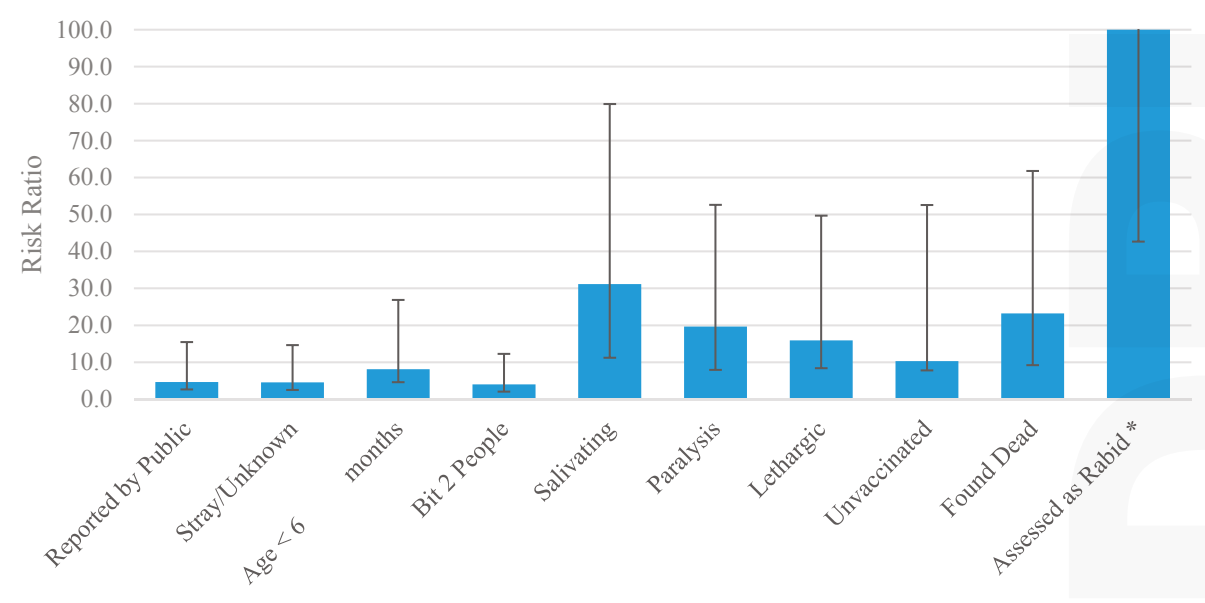

Figure 1. Risk ratio of significant variables and their $95 \%$ CI. * "Assessed as rabid" has a RR $=413$ and $95 \%$ CI upper limit $=2985$. For ease of comparison to other variables in this figure, it is limited to $\mathrm{RR}=100$ and no upper limit is shown. 


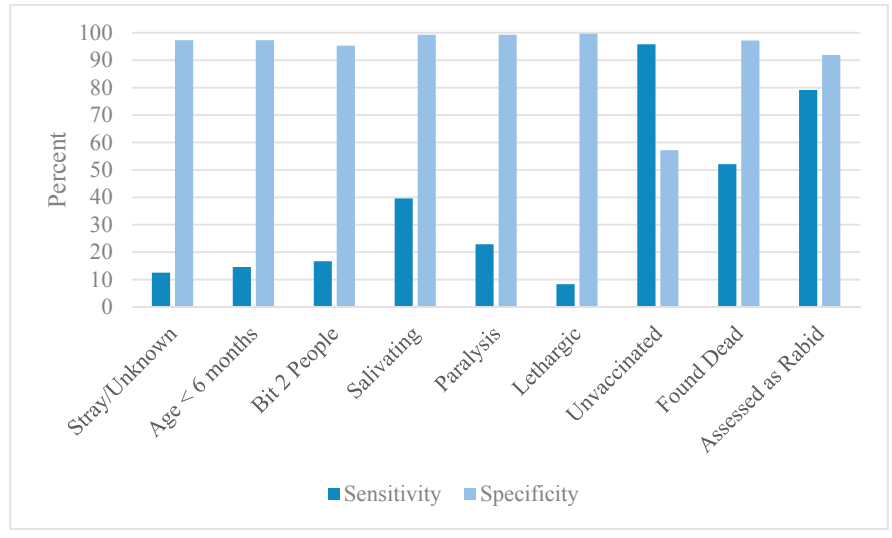

Figure 2. Sensitivity and specificity of the relevant variables.

\subsection{Single Variable Results}

The assessor's determination that the animal likely had rabies was the most significant predictive factor for a rabid $\operatorname{dog}(\mathrm{RR}=413.4,95 \%$ CI 57.33-2985). Clinical factors significantly associated with rabid dogs included hypersalivation, paralysis, and lethargy ( $R R=31.2$ 95\% CI 20.0-48.7, 19.7 95\% CI 11.7-33.0, and 15.9 95\% CI 7.5-33.8, respectively). Dogs that were dead at the time the assessor arrived for investigation were 23.2 times more likely to have rabies compared to those that were alive (95\% CI 14.0-38.6). Rabid dogs were 8.1 times more likely to be puppies than adult dogs (95\% CI 3.5-18.8). Dogs lacking a history of rabies vaccination and unowned dogs were significantly more likely to be rabies positive ( $R R=10.395 \%$ CI 2.5-42.3 and $R R=4.595 \%$ CI 2.0-10.1, respectively). Rabid dogs were four times more likely to have bitten multiple people ( $R R=4.095 \%$ CI 1.9-8.3). Sex was the only variable assessed in this study that did not display an association with rabid dogs. Aggressive behavior was protective $(\mathrm{RR}<1)$. However, this dataset is limited to biting dogs, therefore this should be interpreted cautiously.

When analyzed independently, the sensitivity of most variables was low. Of those that were above $50 \%$, a lack of rabies vaccination was the highest $(\mathrm{Sn}=97.8 \%)$. Other notable variables with good sensitivity were the rabies determination of the assessor and when the dog was found dead at the time of investigation ( $\mathrm{Sn}=79.2 \%$ and $52.1 \%$, respectively). In contrast, most variables had a specificity $>90 \%$. The notably low specificities were the vaccination status (57.2\%) and the presence of aggression (6.4\%).

Likelihood ratios indicate the probability that a biting dog with the presence of a particular variable is rabies positive, compared to a biting dog that does not have the presence of that variable [14]. Likelihood ratios were interpreted as follows: $>4$ indicated a $25 \%$ increase in probability of an outcome (moderate), and those $>10$ indicated a $45 \%$ increase in probability of an outcome (large) $[15,16]$. The NLR ${ }^{-1}$ results show a moderate increase in the probability that a rabid dog will be classified as rabid by a veterinary agent compared to case negatives (4.8), and a large increase in the likelihood that a biting dog is rabid if it has an unknown or no vaccination history (13.7). The PLR results indicate a moderate increase in the probability of rabies for stray/unknown dogs (4.6) and puppies (5.4), and a large increase for hypersalivation (53.8), paralysis (31.2), lethargy (28.4), and being found dead (18.7). A large increase in probability was found in the PLR for both assessor decisions of a dog that has rabies (102.4) and does not have rabies (14.5).

\subsection{Mortality and Quarantine Results}

Twenty-four of the total cohort died during the quarantine period, of which 12 tested positive and 12 tested negative for the rabies virus. The majority of rabid dogs were dead at the time of 
investigation ( $n=36,75 \%$ ), and of the 12 dogs quarantined, $100 \%$ were dead by the third day of quarantine. The average duration until death for a rabid dog that was placed in quarantine was 1.75 days (Figure 3). Forty-two of the case-negatives died before a quarantine was issued (3.1\%). Assessors placed 1319 of the case-negatives into quarantine, of which 1307 (99.1\%) were healthy after 14 days, and 12 died $(0.9 \%)$. The average duration until death for a case-negative dog that was placed into quarantine was 3.67 days, 2.1 times longer than for rabid dogs (See Supplementary Materials for the table of values that correspond to Figure 3).

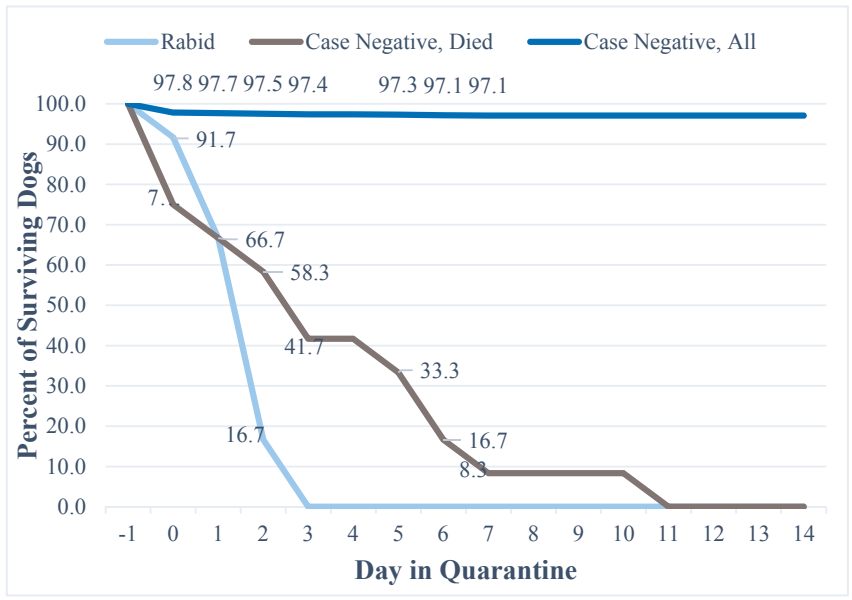

Figure 3. Proportion of surviving dogs during a 14-day rabies quarantine.

\section{Discussion}

\subsection{Objective of the Study}

Although untreated rabies infections are $100 \%$ fatal, vaccination of all persons bitten by a dog in a canine rabies endemic country is a highly conservative approach to minimize rabies cases, and it may place an undue burden on low-risk exposure bite victims while also contributing to regional vaccine supply shortages $[7,9,10]$. Few studies describe the risk of rabies in biting dogs in low and middle income countries, and global recommendations provide little guidance on how biting animals should be assessed. A 2005 study by Tepsumethanon et al. in Thailand looked at six criteria in living dogs to determine rabies status, with all but one of the variables focusing on clinical signs and disease course [17]. This algorithm was reported to have high $\mathrm{Sn}$ and $\mathrm{Sp}(\mathrm{Sn}=90.6 \%, \mathrm{Sp}=96.0 \%)$, establishing the precedent that risk assessments may be a reliable method for determining PEP recommendations. However, the Tepsumethanon evaluation must be completed over a 10-day period, making the results incompatible for determining risk for the purpose of PEP initiation [5,17]. This study included rabies positive and case negative dogs, but excluded dogs that were defined as suspect or probable. This selection bias was essential, because determining defining characteristics of rabid versus non-rabid dogs requires a definitive diagnosis. In addition, there is likely a contingent of dogs who are not reported, and therefore the data set is limited to only those biting dogs that have been assessed by veterinary agents. It is possible that this data set does not fully represent the biting dog population, although it is not feasible to say for certain how excluding these dogs would affect the results. The data presented here account the characteristics of over 1400 biting dogs and show that some factors collected as part of a post-bite rabies risk assessment are highly predictive for rabies and could be used to inform decisions to initiate a rabies PEP series. 


\subsection{Characteristics of Rabid Dogs}

While it is commonly assumed that biting dogs in canine-rabies endemic countries present a high risk for rabies, this study of a post-bite surveillance system found that only $3.4 \%$ of biting dogs are actually affected with rabies. Haiti is largely considered to have one of the highest rates of canine rabies, globally. Therefore, this should not be interpreted as evidence of a low rate of enzootic rabies transmission, rather this is likely a reflection of the frequent and continuous bite exposures that occur in countries that value dog ownership, which obscures the lower rate of continuous bite exposures from rabid dogs. This low frequency of rabies among biting dogs in Haiti supports the need to develop risk assessment criteria that can reliably identify low-risk situations in which it would present little to no risk to delay PEP during a quarantine period.

This is the largest evaluation of characteristics of biting dogs in a canine-rabies endemic country, and establishes common characteristics that increase the likelihood that a biting dog is affected with the rabies virus. To little surprise, dogs with symptoms consistent with rabies were at higher risk of being confirmed rabid (hypersalivation, paralysis and lethargy, $R R=31.2,19.7,15.9$ respectively). Even more significant predictors that a biting dog would have rabies were a lack of previous rabies vaccination and when the dog was dead at the time of the post-bite investigation. However, the greatest risk factor for predicting whether a biting dog was or was not rabid, was not a clinical sign, but rather the subjective opinion of the assessor. An assessor declaring an animal as 'rabid' increased the likelihood of rabies 400-fold. This variable has no concrete, reproducible definition, rather it is the assessor's overall judgment after considering a combination of clinical factors, vaccination history, and the circumstances surrounding the bite event. Other variables such as age, number of people bitten, and ownership status were significantly associated with rabies among biting animals, but to a lesser degree. The findings presented here confirm that it is possible to identify rabid animals, with high confidence, based on a basic health evaluation by trained veterinary professionals.

\subsection{Decision Making Based on the Variables}

Sensitivity refers to a test's ability to identify positive cases, and a high sensitivity would result in few rabid dogs being misclassified as case-negative [18]. Rabies is an invariably fatal disease if $\mathrm{PEP}$ is not initiated in a timely manner, therefore it is more prudent to consider the sensitivity of variables in a risk assessment for PEP determination. Relying on variables with low sensitivity for PEP recommendations could result in a proportion of bite victims being incorrectly told that rabies was not a risk, PEP would incorrectly be delayed or not given, and these bite victims would risk death. Relying on variables with low specificity for PEP recommendations could result in a proportion of bite victims being incorrectly told that they had a rabies exposure, PEP would be given unnecessarily, and these bite victims would have undergone an unnecessary expense. Clearly, when considering the lethality of rabies, variables with high sensitivity should be prioritized during a risk assessment.

Considering that rapid and reliable rabies diagnostic capacity is lacking in most rabies endemic countries, risk assessments and quarantine periods may be the only tools available to guide PEP recommendations [19]. For this analysis we considered the variables collected in HARSP'S risk assessment as 'diagnostic evaluations' and compared them to a rabies outcome (i.e., rabid vs. case-negative). In this respect, the diagnostic sensitivity of most risk assessment variables was fairly low (on average, between 30\% and 50\%). Many variables, when considered alone, would not be reliable for determining rabies risk and influencing PEP decisions. Only vaccination status and assessor decision had relatively high sensitivities (95.8\% and 79.2\%, respectively) when compared to the Tepsumethanon criteria (91\%) [17]. The ideal variable for determining rabies PEP need would be $100 \%$ sensitive, which no single variable achieved. However, the objective of this study was to determine situations that present low-risk, not no-risk, and to identify scenarios in which PEP could be safely delayed. Given that all rabid animals died within 3 days of quarantine, reduced sensitivity of risk assessment variables may be tolerable when the dogs are available for quarantine. Certain variables stand out as having multiple significant diagnostic properties. Unowned dogs and puppies were 
moderately diagnostic, with a fairly high RR, Sp, and PPV. Stronger still were the three clinical signs of lethargy, paralysis, and hypersalivation, which had high RR, Sp, PPV, and PLR. Dogs that were dead at the time of the bite investigation, and those without a documented rabies vaccination history, also displayed good diagnostic performance. However, the most important diagnostic test considered in this analysis was the rabies determination made by the assessor, which displayed consistent prognostic value across the single variables. $(\mathrm{Sn}=79.2 \%, \mathrm{Sp}=91.9)$.

Consideration of the interactions of multiple variables may help further clarify a classification scheme to gauge low-risk exposures, as has been done for other diseases that require treatment before laboratory diagnosis is possible $[15,20,21]$. In the case of rabies, this would mean identifying a combination of easily assessable variables at the time of the bite incident for the purpose of immediate PEP decisions. There are also benefits to quick assessment of high risk exposures, as this leads to prompt healthcare seeking behaviors as well as increases adherence to treatment recommendations.

In addition to aiding risk assessment decisions, some variables may provide critical data for monitoring rabies programs. For example, in Haiti a large proportion of rabid dogs were unowned, which may influence policy makers to promote responsible dog ownership. While some variables have a clear impact on risk assessments, others may act as programmatic and policy indicators.

\subsection{Evaluation of Mortality and Quarantine Data}

During this study period, HARSP veterinary agents only misclassified one rabid dog as probably not having rabies at the time of the risk assessment $(2.1 \%)$. In this instance the dog was quarantined and died 3 days later, suggesting that the quarantine could serve as a secondary measure to gauge rabies risk [4,22]. It is not surprising that all the confirmed rabid animals died in quarantine, but it is interesting and of relevance that $75 \%$ died before the quarantine was instituted, and that the remaining dogs died within three days of placement in quarantine. Death took over a week for the majority of case-negative dogs that died in quarantine. Of all the case negative dogs that entered quarantine, over $99 \%$ were still alive by day 14 . This study evaluated factors that could lead to an immediate risk assessment determination to influence PEP decisions. This data would indicate that even if a risk assessment were misclassified after a bite, rabid dogs are likely to die early during the quarantine period and this early death event should trigger a re-assessment of rabies risk.

It has been well established that a dog that is shedding the virus will show signs of illness within a 10-day time period [2,22-25]. This finding was supported by the results of this study; all rabid dogs died within 3 days of quarantine. Given both the historical findings, and findings from this study, a 10-day post-bite quarantine is supported in dogs. Programs, such as in Haiti, utilizing longer quarantine periods may be inefficiently utilizing resources that could be diverted to post-bite follow up of dogs or dog vaccination.

\subsection{Risk Matrix}

The risk of developing rabies from a dog bite is dependent on multiple factors including the epidemiology of rabies in the country, the type of exposure, and the probability the biting animal was infectious. By systematically collecting surveillance data through Haiti's Integrated Bite Case Management program, the risk of developing rabies can be calculated and presented as a matrix to visualize situations of high and low probability of rabies death (see Table 4). Regardless of the assessment of the biting dog, nearly all head/neck bites were associated with a high probability of death $(28-0.04 \%)$. Likewise, regardless of the location of exposure, nearly all bites from dogs with symptoms of rabies were associated with the high probability of death $(28-0.6 \%)$. Contrasting these high-risk settings, the probability of death was very low for most situations of non-penetrating bite exposures and all situations in which the animal was assessed as 'healthy and available for quarantine'. Tolerance for 'risk' is subjective, therefore interpretation of the risk matrix may vary. However, this presents an objective method for beginning to develop algorithms for PEP determination. The risk matrix presented here utilizes data specific to biting dogs in Haiti and may not be representative of all cultural and epidemiologic situations. 
Trop. Med. Infect. Dis. 2017, 2, 14

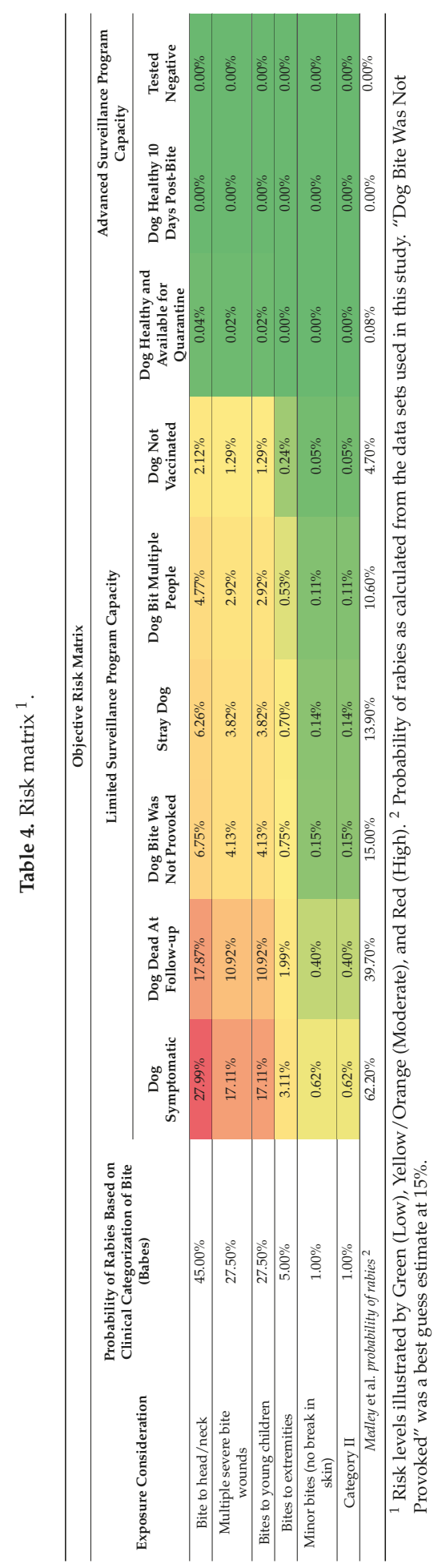




\section{Conclusions}

HARSP is a unique integrated bite case management program for low-resource settings that employs para-veterinary professionals dedicated to assessing biting animals. The risk factors identified in this study will act to inform veterinary agents in Haiti as they conduct in the field assessments of biting dogs. These assessors operate under a defined protocol and training regimen. It is unclear whether similar results could be reproduced in other programs where assessors might receive different training or follow different protocols. Therefore, the generalizability of these findings to other country's programs should be undertaken with attention to these differences. In many developed nations, existing infrastructure allows public health systems to delay PEP in low-risk scenarios while diagnostic testing is pursued [4]. However, in low-resource settings, reliable and timely diagnostic capacity is often not available $[3,8,26]$. As a consequence, the WHO's conservative vaccination policy, although prudent given rabies infection has nearly $100 \%$ mortality, may result in the over-prescription of PEP. The results here indicate that in a low-resource country, such as Haiti, a well-trained assessor can provide a highly accurate estimate of the rabies risk from a biting dog for the purposes of recommending no treatment or advising high risk victims of the need for timely treatment. Policy makers who wish to divert resources from reactive, PEP-based, prevention to pro-active, dog-vaccination oriented prevention may wish to consider conducting similar risk analyses.

Supplementary Materials: The following are available online at www.mdpi.com/2414-6366/2/2/14/s1, Supplementary S1: HARSP Surveillance Form and Investigation Checklist. Supplementary S2: Proportion of Surviving Dogs during 14-Day Rabies Quarantine.

Acknowledgments: The authors would like to acknowledge those who both trained the HARSP employees, and those who have worked diligently for the past five years to implement the program throughout the Republic of Haiti. Those persons include, but are not limited to: Max Millien (MARNDR), Pierre Dilius Augustin (MARNDR), Ludder Fleurinord (MARNDR), Andrew Coetzer (GARC), Emanuel Maciel (HSI), and Kelly Crowdis (Christian Veterinary Mission).

Author Contributions: A.M., R.W. X.M., and J.B. conceived and designed the study; K.C., P.A., and M.F.M. assisted with and performed the original data collection; A.M. and R.W. analyzed the data; A.M. wrote the paper.

Conflicts of Interest: The authors declare no conflict of interest.

Disclaimer: The views expressed here are those of the authors and do not necessarily represent policy of the federal government.

\section{References}

1. Hampson, K.; Coudeville, L.; Lembo, T.; Sambo, M.; Kieffer, A.; Attlan, M.; Barrat, J.; Blanton, J.D.; Briggs, D.J.; Cleaveland, S.; et al. Estimating the global burden of endemic canine rabies. PLoS Negl. Trop. Dis. 2015, 9, e0003786. [CrossRef] [PubMed]

2. Tierkel, E.S. Chapter 8: Canine rabies. In The Natural History of Rabies; Academic Press: New York, NY, USA, 1975.

3. Wallace, R.M.; Reses, H.; Franka, R.; Dilius, P.; Fenelon, N.; Orciari, L.; Etheart, M.; Destine, A.; Crowdis, K.; Blanton, J.D.; et al. Establishment of a canine rabies burden in Haiti through the implementation of a novel surveillance program. PLoS Negl. Trop. Dis. 2015, 10, e0004245. [CrossRef] [PubMed]

4. $\quad$ Rupprecht, C.E.; Briggs, D.; Brown, C.M.; Franka, R.; Katz, S.L.; Kerr, H.D.; Lett, S.M.; Levis, R.; Meltzer, M.I; William Schaffner, W.; et al. Use of a reduced (4-dose) vaccine schedule for postexposure prophylaxis to prevent human rabies: Recommendations of the Advisory Committee on Immunization Practices. MMWR Recomm. Rep. 2010, 59, 1-9. [PubMed]

5. World Health Organization. WHO Guide for Rabies Pre and Post Exposure Prophylaxis in Humans. Updates 2014. Available online: http://www.who.int/rabies/PEP_Prophylaxis_guideline_15_12_2014.pdf (accessed on 11 November 2016).

6. World Health Organization. WHO Expert Consultation on Rabies; Second Report; WHO Technical Report Series; WHO: Geneva, Switzerland, 2014; Volume 982, pp. 33-44.

7. Shantavasinkul, P.; Wilde, H. Post-exposure prophylaxis for rabies in resource-limited/poor countries. Adv. Virus Res. 2011, 17, 291-307. 
8. Hampson, K.; Cleaveland, S.; Briggs, D. Evaluation of cost-effective strategies for rabies post-exposure vaccination in low-income countries. PLoS Negl. Trop. Dis. 2011, 5. [CrossRef] [PubMed]

9. Undurraga, E.A.; Wallace, R.M.; Blanton, J.D.; Cleaton, J.; Franka, R. Elimination of dog-mediated human rabies deaths by 2030: Needs assessment and alternatives for progress based on dog vaccination. Front. Vet. Sci. 2017, 4. [CrossRef]

10. Etheart, M. 2017-currently in review with Lancet Global Health. (Unpublished).

11. Coetzer, A.; Kidane, A.H.; Bekele, M.; Hundera, D.D.; Pieracci, E.G.; Shiferaw, M.L.; Wallace, R.M.; Nel, L.H. The SARE tool for rabies control: Current experience in Ethiopia. Antivir. Res. 2016, 135, 74-80. [CrossRef] [PubMed]

12. The Global Alliance for Rabies Control Website. Available online: rabiesalliance.org (accessed on 10 February 2017).

13. Babes, V. Traité de la Rage (Treatise on Rabies); Baillière et Fils: Paris, France, 1912.

14. Deeks, J.J.; Altman, D.G. Statistics Notes: Diagnostic tests 4: Likelihood ratios. BMJ 2004, 329, 168-169. [CrossRef] [PubMed]

15. Knust, B.; MacNeil, A.; Rollin, P.E. Hantavirus pulmonary syndrome clinical findings: Evaluating a surveillance case definition. Vector Borne Zoonotic Dis. 2011, 12, 393-399. [CrossRef] [PubMed]

16. McGee, S. Simplifying Likelihood Ratios. J. Gen. Intern. Med. 2002, 17, 647-650. [CrossRef]

17. Tepsumethanon, V.; Wilde, H.; Meslin, F.X. Six criteria for rabies diagnosis in living dogs. J. Med. Assoc. Thail. 2005, 88, 419-422.

18. Indrayan, A. Basic Methods of Medical Research, 3rd ed.; Sensitivity-Specificity, Bayes' Rule, and Predictives; AITBS Publishers: Krishan Nagar, Delhi, India, 2013.

19. Abela-Ridder, B.; Knopf, L.; Martin, S.; Taylor, L.; Torres, G.; De Balough, K. 2016: The beginning of the end of rabies? Lancet Glob. Health 2016, 4, 780-781. [CrossRef]

20. Benotti, P.; Wood, G.C.; Winegar, D.A.; Petrick, A.T.; Still, C.D.; Argyropoulos, G.; Gerhard, G.S. Risk factors associated with mortality after Roux-en-Y gastric bypass surgery. Ann. Surg. 2014, 259, 123-130. [CrossRef] [PubMed]

21. Sriaroon, C.; Sriaroon, S.; Svastijaya, D.; Pakamatz, K.; Wilde, H. Retrospective: Animal attacks and rabies exposures in Thai children. Travel Med. Infect. Dis. 2005, 4, 270-274. [CrossRef] [PubMed]

22. Brown, C.M.; Slavinski, S.; Ettestad, P.; Sidwa, T.J.; Sorhage, F.E. Compendium of animal rabies prevention and control: National Association of State Public Health Veterinarians, Inc. J. Am. Vet. Med. Assoc. 2011, 248, $1-13$.

23. Tepsumethanon, V.; Wilde, H.; Sitprija, V. Ten-day observation of live rabies suspected dogs. Dev. Biol. (Basel) 2008, 131, 543-546. [PubMed]

24. Consales, C.A.; Bolzan, V.L. Rabies review: Immunopathology, clinical aspects and treatment. J. Venom. Anim. Toxins Incl. Trop. Dis. 2007, 13, 5-38. [CrossRef]

25. Tipold, A. Diagnosis of inflammatory and infectious diseases of the central nervous system in dogs: A retrospective study. J. Vet. Intern. Med. 1995, 9, 304-314. [CrossRef] [PubMed]

26. Taylor, L.H.; Knopf, L. Partners for rabies prevention. surveillance of human rabies by national authorities-A global survey. Zoonoses Public Health 2015, 62, 543-552. [CrossRef] [PubMed]

(C) 2017 by the authors. Licensee MDPI, Basel, Switzerland. This article is an open access article distributed under the terms and conditions of the Creative Commons Attribution (CC BY) license (http:/ / creativecommons.org/licenses/by/4.0/). 


\title{
The History of Rabies in Trinidad: Epidemiology and Control Measures
}

\author{
Janine F. R. Seetahal ${ }^{1, *}$, Alexandra Vokaty ${ }^{2}$, Christine V.F. Carrington ${ }^{1}$, Abiodun A. Adesiyun ${ }^{3}$, \\ Ron Mahabir ${ }^{4}$, Avery Q. J. Hinds ${ }^{5}$ and Charles E. Rupprecht ${ }^{6}$ \\ 1 Department of Preclinical Sciences, Faculty of Medical Sciences, The University of the West Indies, \\ St. Augustine Campus, St. Augustine, Trinidad and Tobago; christine.carrington@sta.uwi.edu \\ 2 Pan American Health Organization, Trinidad and Tobago Country Office, St. Clair, Trinidad and Tobago; \\ vokatyal@paho.org \\ 3 School of Veterinary Medicine, Faculty of Medical Sciences, The University of the West Indies, \\ St. Augustine Campus, St. Augustine, Trinidad and Tobago; abiodun.adesiyun@sta.uwi.edu \\ 4 Department of Geography and Geoinformation Science, George Mason University, Fairfax, VA 22030, USA; \\ rsmahabir@gmail.com \\ 5 Caribbean Public Health Agency, 16-18 Jamaica Boulevard, Port of Spain, Trinidad and Tobago; \\ hindsave@carpha.org \\ 6 The Wistar Institute, Philadelphia, PA 19104, USA; charleserupprechtii@gmail.com \\ * Correspondence: jseetahal@gmail.com; Tel.: +1-868-645-2640
}

Received: 19 May 2017; Accepted: 3 July 2017; Published: 11 July 2017

\begin{abstract}
Vampire bat-transmitted rabies was first recognized in Trinidad during a major outbreak reported in 1925. Trinidad is the only Caribbean island with vampire bat-transmitted rabies. We conducted a literature review to describe the changing epidemiology of rabies in Trinidad and give a historical perspective to rabies prevention and control measures on the island. The last human case of rabies occurred in 1937 and although no case of canine-transmitted rabies was reported since 1914, sporadic outbreaks of bat-transmitted rabies still occur in livestock to date. Over the last century, seven notable epidemics were recorded in Trinidad with the loss of over 3000 animals. During the 1950s, several measures were effectively adopted for the prevention and control of the disease which led to a significant reduction in the number of cases. These measures include: vampire bat population control, livestock vaccination, and animal surveillance. However, due to lapses in these measures over the years (e.g., periods of limited vampire control and incomplete herd vaccination), epidemics have occurred. In light of the significant negative impact of rabies on animal production and human health, rabies surveillance in Trinidad should be enhanced and cases evaluated towards the design and implementation of more evidence-based prevention and control programs.
\end{abstract}

Keywords: rabies; Trinidad; Caribbean; public health; vampire bat; Desmodus rotundus; bat-transmitted rabies; epidemic; zoonosis; One Health

\section{Introduction}

Rabies is a neglected viral zoonosis of major public health and veterinary importance, present in more than 100 countries and territories worldwide [1-4]. Although vaccine-preventable, this disease is estimated to cause in excess of 60,000 annual human deaths worldwide, with the vast majority in Africa and Asia [5]. Rabies viruses are maintained and transmitted by several mammalian hosts, primarily carnivores and bats [6]. In the Americas, bats are significant reservoirs of rabies viruses, and although rabies virus can affect any species of bat, vampire bats are considered an especially effective vector due to their haematophagous nature $[1,7,8]$. Vampire bat-transmitted rabies is on the increase in the tropical Americas [9], where it is considered a limiting factor to livestock production [10,11], causing the death of more than 100,000 cattle annually at costs likely exceeding US \$30 million dollars [5]. 
Bovine rabies outbreaks (only later attributed to vampire bats) were first reported in the Americas during the late 16th century in Guatemala [12]. Similar incidents were subsequently observed in Ecuador, Brazil, and Trinidad [13,14]. In 1931, the scientific correlation between bats and human rabies was demonstrated in Trinidad, during a historical multi-species rabies outbreak [15-17]. Subsequent to this, the disease was diagnosed on the South American mainland with increasing prevalence, and was noted to have affected at least 18 countries by 1968 [1,11,16,18-21].

The twin island republic of Trinidad and Tobago is located off the northeastern coast of South America, lying approximately $12 \mathrm{~km}$ from Venezuela [22]. Trinidad is the only Caribbean island with vampire bat-transmitted rabies. To date, Tobago (which lies $42 \mathrm{~km}$ to the northeast of Trinidad [23]), remains free of vampire bats [22], hence, bat-transmitted rabies has not been reported on this island [24]. Given its importance to the natural history of bat-transmitted rabies, the objective of this study was to present a descriptive summary of the epidemiology and control of rabies in Trinidad and to provide a historical perspective to the current measures for prevention and control of the disease on the island. Specifically, we aimed to describe how the overall burden of the disease has changed over the last century in relation to the control and prevention measures implemented and use this to inform future prevention activities for this zoonosis.

\section{Methodology}

A literature review was conducted on rabies in Trinidad from the first reported case of the disease onwards. We leveraged the use of various well-established electronic databases, which included PubMed, WHOLIS (World Health Organization Library Database), SciELO, ScienceDirect, and the AFPMB (Armed Forces Pest Management Board). Key words included "rabies", "epidemiology", "rabies epidemic", "rabies epizootic", "Trinidad", "bat rabies", "bat-transmitted rabies", "Desmodus rotundus", and "paralytic rabies". Multiple references also were sourced from the West Indiana Special Collection of the Alma Jordon Library, University of the West Indies, St. Augustine Campus, and the Library Collection at the Caribbean Public Health Agency (formerly the Caribbean Epidemiology Centre), Port of Spain, Trinidad. Supplemental case information, livestock vaccination and human post-exposure prophylaxis data were also collected from personal accounts of field investigations of contemporary animal cases, where possible.

\section{Epizootiology and Epidemiology in Susceptible Hosts}

\subsection{Terrestrial Rabies in Trinidad}

Historically, rigid quarantine laws were employed in Trinidad whereby all dogs and cats entering the British colony (apart from those from the United Kingdom) were subjected to at least six months quarantine and inspection with subsequent certification by a Government Veterinarian [25]. The last confirmed case of canine-transmitted human rabies (classical hydrophobia) in Trinidad was in 1912. No case of this type of rabies in dogs or other carnivores has been reported since 1914 [15,26-28]. In contrast, up to 1993, canine rabies was still a significant problem in the western region of Venezuela, where a minimum of 468 cases of canine-transmitted rabies occurred between 1989 and 1993 [29].

Despite the prevalence of rabies in the mongoose population in Grenada and other Caribbean islands (Puerto Rico, Cuba, and Hispaniola), to date, more than a century after the introduction of the small Indian mongoose (Herpestes auropunctatus) into Trinidad (1870s), this invasive species still remains on record as rabies-free [30]. In 1955, Dr. Malaga-Alba, a World Health Organization (WHO) rabies expert, detected Negri bodies in a mongoose carcass during his visit to Trinidad [31]. However, island-wide surveys conducted during the same year, and later in 1957 to assess the likelihood of the mongoose as vector for rabies in Trinidad, did not yield any evidence of rabies virus in this species [31,32]. Therefore, it is possible that either the earlier (1955) case may have represented a false positive or the sample size of the second study was not sufficient to detect the virus in the population. 


\subsection{Bat-Transmitted Rabies in Trinidad}

The first documented human outbreak of bat-transmitted rabies occurred in Trinidad, during the first half of the 20th century. At the time the first human case was diagnosed, in 1929, the disease was already occurring in the cattle population, but was misdiagnosed [17,27]. A historical multispecies vampire bat-transmitted outbreak followed (1925-1937) that recorded the deaths of approximately 73 humans and thousands of livestock [24,26,33]. Although animals deaths attributed to poisoning were recorded from 1923 in the northwest and southwest of the island, animal deaths ascribed to an infectious agent began during July 1925 with cattle dying on the northwestern Government pastures around the capital of Port of Spain, recording a cumulative herd mortality of approximately $20 \%[16,17,26]$. The disease spread further within the colony for the next four years until 1929, when there was a sudden spike in livestock mortality in the two southern villages of Siparia and Fyzabad [16]. In July of that year, the first documented case of bat-transmitted human rabies occurred in Siparia. The disease advanced within the human population and by the end of 1929 there was a total of 13 human cases [17].

During the period of 1929-1931, when the disease was first recognized, over 1000 animals per year (mainly cattle) were estimated to have died from rabies [15]. However, the actual mortality figures (based on clinical signs) that were recorded were substantially lower [16]. Laboratory confirmation was employed for animal cases from 1931 onwards. Animal cases occurred throughout the island, but were most prevalent in the southern districts until 1933 when a shift occurred in the geographical distribution of cases, from south to north [34]. Human case distribution followed a similar trend until 1935, when disease prevalence peaked with cases occurring principally in the northern community of Santa Cruz [16,17,34], as illustrated in Figure 1. During the human epidemic the highest numbers of cases were reported in Siparia (9), Santa Cruz (10), and Biche (12), and the disease progressed from southwest to northeast within the island [35]. The last human rabies case was in 1937 [24,28,36]. At this time, there was a notable decline in rabies prevalence in the animal population, with approximately $74 \%$ fewer cases than the previous year [34]. The clinical disease in humans was typically acute myelitis with spreading (flaccid) paralysis of the lower or upper limbs depending on the bite site $[17,33]$. Incubation was usually 3-6 weeks with paresthesia (numbness and tingling) and paresis preceding paralysis $[17,33]$. Other common symptoms included pyrexia $\left(99-104^{\circ} \mathrm{C}\right)$, urine retention, constipation, and profuse salivation and perspiration [17]. Disease duration was generally 6-10 days resulting in death and laboratory confirmation was made by the visualization of Negri bodies in brain tissue [17].

After 1937, a reduced prevalence of rabies was observed in the resident animal population, with sporadic outbreaks every few years [16,24,34]. As illustrated in Figure 2, large outbreaks were noted during 1944, 1951, 1954-1955, 1997-1998, and 2010, with smaller events occurring in 1953, 1958, 1960, 1974, 2000, and 2012-2013 [16,24,34,37]. During 1944, 73 bovine cases were documented in the central and northeastern regions of the island followed by a shift to a southern geographic distribution with a similar sized outbreak in 1951, a smaller outbreak in 1953 (41 cases) and a total of 328 rabies cases (89\% bovine) between 1954 and 1955 during a major epizootic event [31,34]. During the smaller 1958 event (18 cases), in addition to cattle, cases also occurred in goats, donkeys, and even pigs [38]. In contrast, a comparable sized outbreak two years later (1960) only affected the bovine population [38]. Figure 3a illustrates the distribution of animal cases from the first observation of the disease until 1962 around which time there was an apparent decrease in the geographic range of cases. Figure 3b illustrates the distribution of animal cases from 1971-2015 which, when compared to Figure 3a, demonstrates the decrease in the geographic range of cases. 

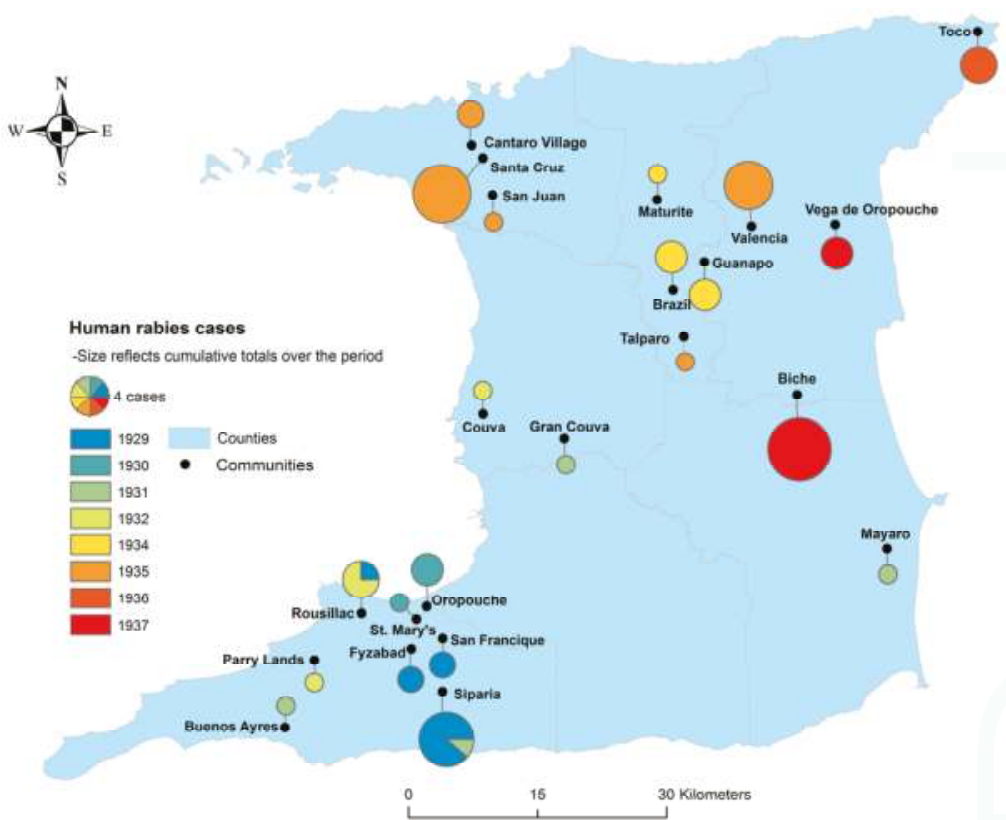

Figure 1. Geographic locations and number of cases by year for bat-transmitted human rabies cases in Trinidad during the period of 1929-1937.

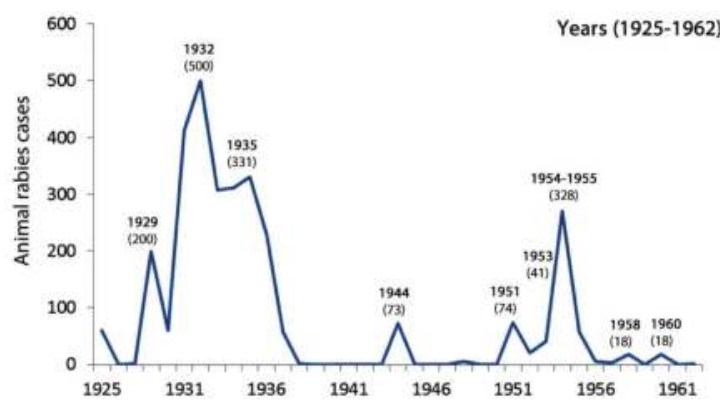

(a)

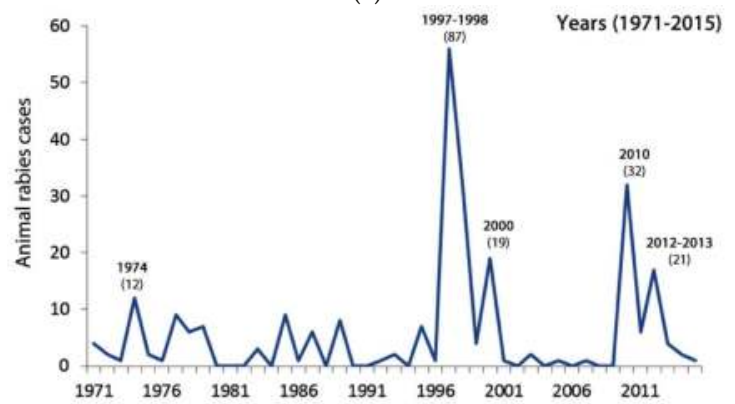

(b)

Figure 2. Animal rabies cases reported in Trinidad during the periods (a) 1925-1962 and (b) 1971-2015. 


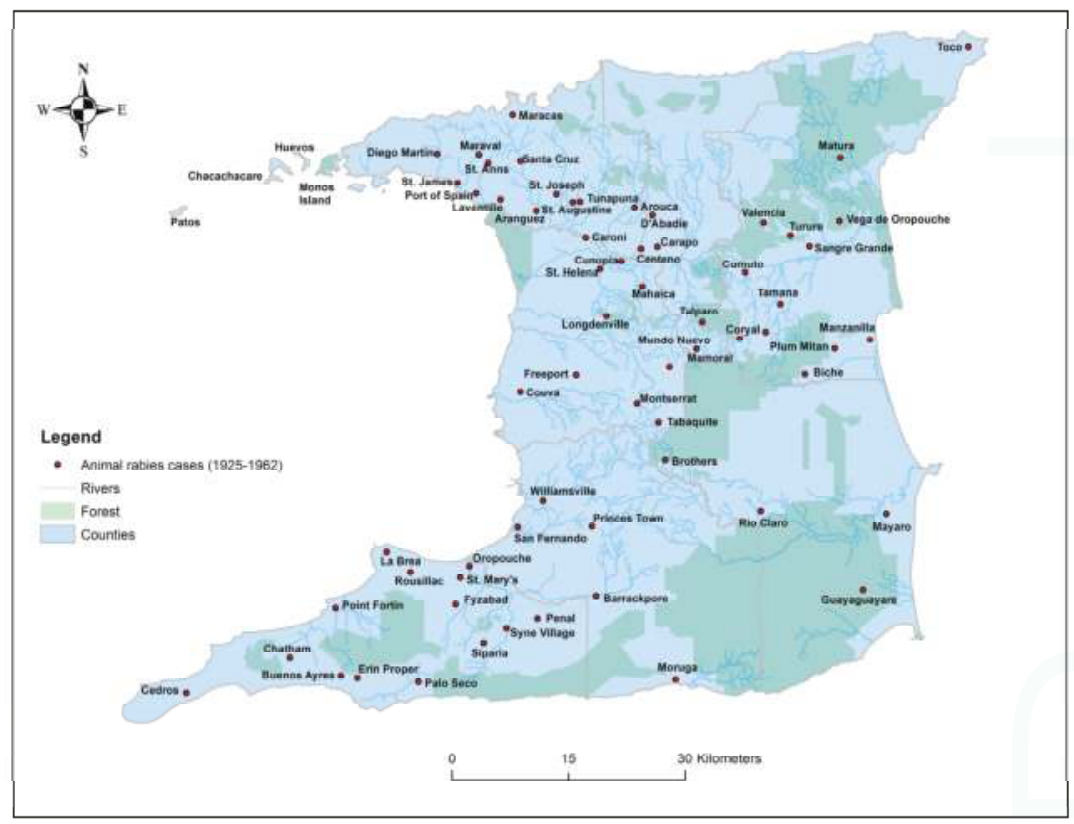

(a)

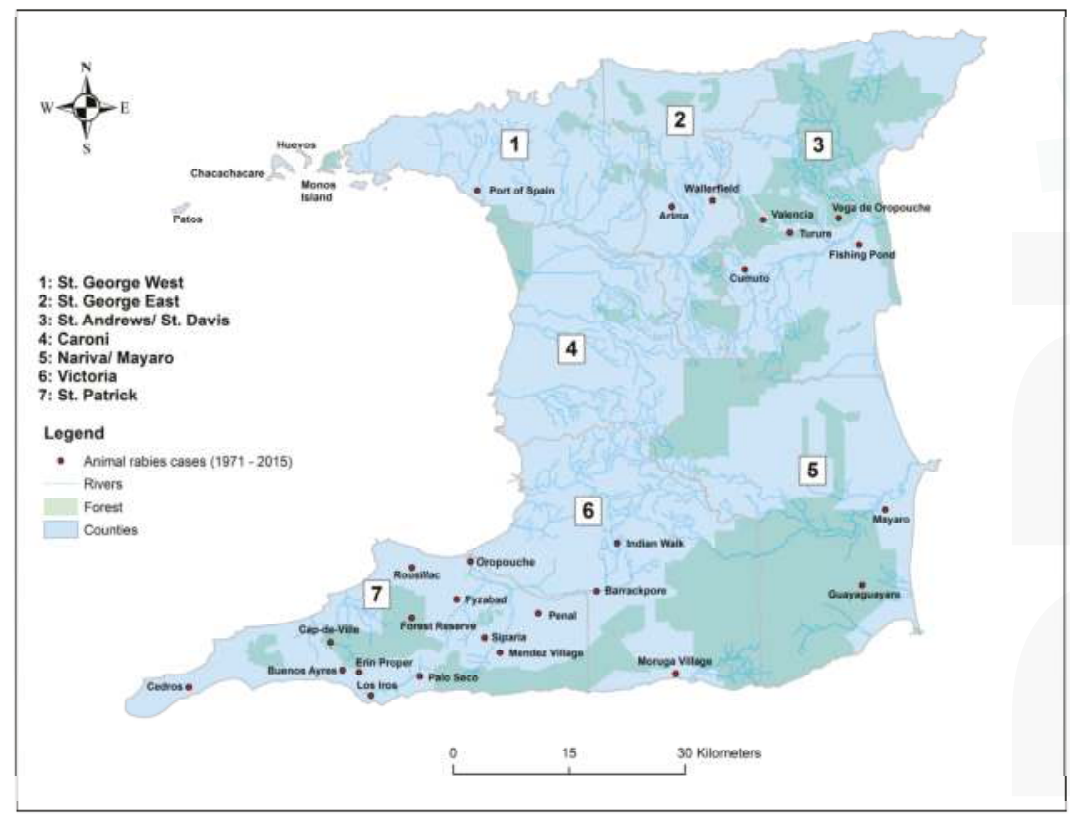

(b)

Figure 3. Geographic locations from which animal rabies cases were reported in Trinidad during the periods (a) 1925-1962 and (b) 1971-2015. 
After a single case of bovine rabies in 1962 [39], limited information was available on cases until 1971. One study reported two cases of rabies from Trinidad in 1965 [40], and another noted that there was a low sporadic incidence of the disease on the island from 1968 to 1985 [21]. In 1971, four bovine cases were diagnosed [37] by the Veterinary Diagnostic Laboratory (VDL) of the Ministry of Agriculture, which assumed responsibility for rabies diagnostics in 1956 [39]. Initially, diagnostic testing in Trinidad was conducted by histopathological examination of brain tissue for Negri bodies, and intracerebral inoculation of mice with the brain tissue homogenate [15,26,41,42]. However, these methods were phased out and replaced by the direct fluorescent antibody (DFA) test, which was implemented at the VDL in the 1970s [43].

The number of rabies cases decreased proportionally until 1974 when there was an abrupt spike of 12 ruminant cases [37]. Thereafter, cases occurred sporadically, primarily in the southwestern area of the island, until 1997 [37]. An epizootic spike occurred during 1997-1998 consisting of 87 cases ( $90 \%$ bovine), mainly from the northeast region of the country, particularly Wallerfield (76\%) [37]. In 1999, the disease again appeared inthe south with fourcases (including one bat) confirmed from Guayaguayare in the southeast [37]. In 2000, 19 bovine cases were diagnosed [37], mostly from the southern villages of Fyzabad and Mayaro. Isolated cases of bovine rabies occurred from 2001 to 2007 in the northeast (Valencia and Fishing Pond) and southwest (Barrackpore and Siparia) regions, until the most recent epizootics in 2010 (32 cases) and 2012-2013 (21 cases), which consisted of ruminant cases and one bat case in 2012, with a notable increase in the prevalence of small ruminant (caprine and ovine) cases, occurring primarily in the southwest particularly from the town of Penal [37].

During the 2010 epizootic, 91\% (21 cases) of confirmed animal rabies cases for which age was recorded ( $n=23$ cases) were $\geq 4$ months and eligible for rabies vaccination under the national rabies vaccination program [44]. Forty-nine percent (14 cases) of confirmed cases $(n=29)$ for which vaccination status was recorded were eligible for vaccination due to their age but not vaccinated [44]. For the 2012-2013 event, 85\% (17 cases) of confirmed cases were eligible for vaccination, but only $15 \%$ (three of 20) were documented as being vaccinated [44]. Animal vaccination data was not available for the previous epizootics. The only epizootic event for which human rabies post-exposure prophylaxis (PEP) data was available was in 2010. During this event, 54 humans ( $82 \%$ male) received rabies PEP within the main outbreak area of county St. Patrick, the majority (41 persons) were between the ages of 22-63 years old [45]. Only $72 \%$ completed the full course of vaccination, while $28 \%$ did not complete PEP [44,45]. Rabies immune globulin was not administered, as it was neither warranted due to the categories of exposure nor available locally at that point in time [44]. No human rabies cases occurred.

\section{Rabies Control and Prevention Strategies}

Over the last century, bat-transmitted rabies in Trinidad has evolved from a mysterious syndrome causing significant loss of both human and animal life to a vaccine-controllable disease of ruminants. As a prototypic zoonosis, the prevention and control of rabies is mainly targeted at the animal host. In this light, historically, several strategies have been adopted to prevent rabies in Trinidad. These focus on surveillance, vampire batcontrol, and livestock vaccination strategies, and will be discussed herein within the context of the epidemiology, socio-cultural factors, and natural history of the disease in Trinidad.

\subsection{Vampire Bat Population Control}

Trinidad was the first country to administer a government program for the control of vampire bats. The Bat Control Unit was established during 1934 under the Medical Department, but due to the predominance of livestock cases after 1937 it has since been relocated to the Ministry of Agriculture, where it currently resides as the Anti-Rabies Unit [34,46]. Vampire bats are the primary focus of control efforts as their haematophagous feeding upon mammals favors viral transmission [15]. In Trinidad, two species of vampire bats are indigenous, Diaemus youngi, and the more common Desmodus rotundus [22]. As previously noted, no vampires have been reported in Tobago [22,24,47]. 
Methods of vampire bat control have been studied extensively and implemented in Trinidad, based on correlations between the ecology and behavior of these bats and rabies outbreaks [24,26,48-51]. The control method presently promoted is the topical application of an anticoagulant (most commonly warfarin) paste to the vampire bats, which then return to the roost where they contaminate others in the colony, leading to decimation of the roost population [52].

In Trinidad, culling resulted in an approximately $88 \%$ reduction in the annual numbers of Desmodus bats caught from 1936 to 1942 [34] The average annual cull rate of 2000 Desmodus bats during this period was estimated to have saved 3720 gallons of livestock blood per year and presumably reduced rabies virus transmission [10]. In recent times the annual vampire bat cull rates have been more conservative (e.g., 812 bats caught in 2002 compared to 2136 in 1971) [44]. This could be the cumulative effect of years of successful vampire population control programs with decreased overall population size leading to fewer bats being caught and a reduction in trapping efforts as disease priority and resource allocation dropped. For example, since about 2004, night trapping and anticoagulant pasting of vampire bats have been limited and was further challenged in 2006 by a shortage of anticoagulant paste in Trinidad [44]. This, in turn, appears to have precipitated increased reports of vampire bat-biting in livestock (e.g., from 2007 to 2009 there was an increase of 1369 reported bat biting cases in livestock) [44] cumulating in the 2010 epizootic.

Reduced cull rates have been manifested by observations of increased numbers of vampires in known roosts and increasing bite rates in both animals and humans. While vampire vector control by culling may pose a challenge to the conservation of biodiversity and some studies have indicated a possible increase in circulating virus due to the elimination of virus immune adults [53], there are currently no known feasible alternatives. Therefore, vector control by culling is the practice currently applied by all countries with vampire bat-transmitted rabies. Although genetic evidence for male-biased dispersal of rabies virus [54] may allow for selective culling, more ecologically sustainable approaches should be actively sought for the long term. It is also recommended that personnel charged with conducting control measures be properly trained in bat identification to avoid decimation of other bat species essential to pollination, seed dispersal, and insect control [55]. Some potential avenues to explore include a topical oral vaccine delivered in a similar fashion to the anticoagulant paste, a vaccine introduced to livestock which inoculates the vampire bats during feeding and prey management strategies to selectively exclude populations from depredation [56].

\subsection{Animal Vaccination}

In 1932, mass animal inoculations against rabies were initiated in Trinidad utilizing a locally-produced carbolised brain tissue vaccine, which was eventually phased out and replaced by a commercial purified chicken embryo cell vaccine [34]. In 1956, the Paralytic Rabies Regulations was enacted, which made animal rabies vaccination mandatory and stipulated a penalty charge for contravention [57]. Rabies livestock vaccination is currently provided by the government free of charge and only one commercially-available (inactivated cell culture based) rabies vaccine formulation has been used for this purpose in Trinidad for over 20 years. Due to the feeding habits of the D. rotundus vampire bat, bovine rabies cases typically predominate on the island [7,37]. As such, the bovine population has been the traditional target for rabies immunization in Trinidad, although recent increases in case attack rates for the caprine population [37] would suggest value in routinely vaccinating other livestock species. Vaccination was also recently extended to exotic mammals from private zoo collections (e.g., camels, llamas, zebras) as vampire biting was observed on these animals. In light of increased bat biting, further consideration should also be given to include hunting dogs in the national rabies vaccination scheme.

Most of the animal rabies cases that have occurred in Trinidad were not vaccinated for the disease. However, in some instances, as noted in 2010 and 2012, cases were reported in apparently vaccinated animals. These may represent situations of vaccine failure due to improper storage and handling of the biological agents, improper vaccine administration, variability in host immune-competence, or late 
administration of the vaccine during the course of natural infection. An example of the latter scenario was the single vaccinated case in 2012, in which the vaccine was administered less than one month prior to the development of clinical signs. In this case, the immune response would not have had sufficient time to produce adequate antibodies to combat natural infection considering the peak rabies viral neutralizing antibody response is typically 28 days post vaccination [58]. Vaccine efficacy may also be affected if vaccination regimes differ from the manufacturers' recommendations due to factors such as the interference of the immune response by maternal antibodies. All these factors must be individually examined to determine the causes of variations in vaccine efficacy and decide upon appropriate action (e.g., education on proper vaccine handling, storage and administration) to rectify gaps in coverage. In 2015 the rabies vaccine coverage for the bovine population was estimated to be $70 \%$ [59] but this level is recognized to vary on a year-to-year basis, depending on resources available to deploy the annual rabies vaccination program. Additionally, records document that the vaccine population coverage does not necessarily reflect the level of herd immunity, especially given the possibility of vaccine failure. For example, in 2009, only 2780 rabies vaccines were dispensed for livestock vaccination island-wide [44,60], despite a bovine population estimate of 19,088 animals [61]. This would have represented less than $50 \%$ coverage of the bovine population, and may have contributed to the 2010 epizootic event. Current estimates of bovine rabies vaccine coverage from the field are around 40-50\% [62], which maybe sub-optimal to afford herd immunity.

In 2013, a decision was taken to abolish the quarantine of imported dogs and cats. Since then an import protocol for dogs and cats entering Trinidad from canine rabies-endemic countries, including mandatory rabies vaccination and serological testing (to prove a protective rabies titer response), is the main method of canine-rabies prevention by precluding entry of the virus. Import control in Trinidad and Tobago is aided by exclusive sea borders and legislatively supported under the Animal (Importation) Control Regulations under the Animal (Diseases and Importation) Act (1954) [63]. However, these measures do not protect against the introduction of rabies virus by bats.

\subsection{Surveillance}

\subsubsection{General Rabies Surveillance Activities and Surveillance in Livestock}

Rabies surveillance in Trinidad includes active and passive activities, both of which depend heavily on the effectiveness of reporting systems. Active surveillance is conducted in the D. rotundus bat population, while passive surveillance is conducted for all mammals with particular emphasis on livestock. Epidemiological surveillance in livestock entails the reporting of animals being attacked by vampire bats or that are clinically suspected as being rabid. The dependence of rabies surveillance on passive reporting systems may likely result in under-reporting and under-estimation of the actual number of animal cases in general. Other factors which may contribute to the under-reporting of animal rabies cases include: (i) farm inaccessibility to the veterinary services; (ii) limited farmer knowledge of disease etiology and reporting protocols; (iii) cases in small ruminants which are more easily lost or buried; (iv) misdiagnosis of cases (e.g., canine distemper in dogs and tick fever in ruminants); and (v) missed cases due to lack of surveillance in wildlife populations.

\subsubsection{Surveillance in the Bat Population}

Bat biting case reports allow for the identification of areas with high vampire bat activity and facilitates active bat sampling and the implementation of vampire bat control measures. Areas on the island where high vampire activity is usually noted include Penal and Barrackpore in the southwest, Valencia and Wallerfield in the northeast, and valleys along the foothills of the Northern Range, such as Maracas, Santa Cruz, and Maraval [34]. As a result, these areas have historically demonstrated high densities of rabies cases [34,37]. Earlier uncorroborated studies conducted in Trinidad, suggested that, although rabies causes aberrant behavior and death in bats, apparently healthy vampire bats could also harbor and transmit the virus for extended periods [26,41,42]. On this basis, active surveillance of 
D. rotundus populations was established and is still conducted in parallel with vector control activities. However, virus isolation is rare. For example, during the period 1971-2015, only two of 4399 bats tested were diagnosed rabid by DFA testing [37]. This represents a slightly higher rabies positive rate $(0.05 \%)$ than previous findings $(0.03 \%)$, but less than earlier reports of up to $3.3 \%[41,64,65]$. Local testing mainly targets apparently healthy vampire bats in areas of high bat activity (as guided by reports of bat biting cases). On the other hand, early passive surveillance studies conducted on non-vampire bats in the United States found viral isolation rates of $76 \%$ in sick bats [66], and approximately $5-6 \%$ positivity in all bats tested $[66,67]$. This may perhaps indicate lower viral circulation in vampire bats due to immunity, although, higher rates would be expected with passive surveillance as mainly sick or moribund bats would be tested. Other than the two vampire species, rabies virus has been isolated from seven other bat species in Trinidad (Carollia perspicillata, Artibeuslituratus, Artibeus jamaicensis, Molossus molossus, Diclidurus albus, Pteronotus davyi, and Pteronotus parnellii) $[15,24,41,48,68,69]$ under earlier active surveillance programs. In a more recent study, Desmodus variant viruses were found to be the cause of Trinidadian rabies epizootics [64]. Other bat variants have not been documented and, therefore, transmission to other mammalian species from non-vampire bat species has also not been conclusively documented in Trinidad.

Routine monitoring of vampire bat populations for the presence of rabies viruscould potentially provide an early warning of the risk of virus transmission to a susceptible host. Alternatively, since virus isolation in the bat population is often difficult, rabies antibody titers can be monitored for increases which may indicate increased virus exposure and risk of spill-over to livestock [37]. Epizootics of rabies in vampire populations have been suggested to occur at most every four years with variable viral levels at different stages of the epizootic event [70,71]. However, further studies need to be conducted in the Trinidadian vampire bat population to confirm the frequency of epizootics and the relationship between virus and antibody levels and risk of viral transmission.

\subsubsection{Surveillance in the Canine Population}

Trinidad remained a British colony until 1962 [72], so the early date of canine rabies elimination (1914), when compared to neighboring Latin America, may have been attributed to the elimination of canine rabies in Britain during 1903 [73], given the implementation of similar disease control measures. Additionally, although rabies has been enzootic on Trinidad since the early 20th century, despite reports of bat biting in dogs (particularly hunting dogs), no cases of rabies have been documented in this population since the 1930s [16]. However, no routine surveillance is focused presently on detecting rabies virus in the dog population of Trinidad. Recent reports of bat biting in dogs [74] underscores the importance of having protocols in place for dealing with a potential canine rabies case. Typically, when not available for testing, wild mammalian reservoirs, such as bats, are regarded as rabid [75] and the animals they bite are considered to be exposed to the virus. As the resident dog population is not routinely vaccinated against rabies, an exposed dog would likely be unvaccinated. Given that there are currently no biologics licensed for post-exposure prophylaxis of unvaccinated domestic animals, and since evidence suggests that vaccine alone is not reliable for prevention of disease in these animals, it has been recommended that unvaccinated exposed dogs should be euthanized [76]. Alternatively, the dog can be held under strict quarantine and observation for four months (with immediate post-exposure rabies vaccination) or six months (if vaccine administration is delayed past $96 \mathrm{~h}$ post-exposure) [75]. However, if signs suggestive of rabies develop while under quarantine, the animal should be immediately euthanized and the brain submitted for rabies testing [75]. Stray dog management protocols should also be enforced, particularly in rural forested areas where the risk of bat biting in dogs is higher. A serological approach may also be taken to monitor rabies exposure in this population, which would determine the risk of rabies virus transmission from bats to dogs and can inform preventative measures. 


\subsubsection{Surveillance in the Mongoose Population and Other Terrestrial Wildlife Populations}

Unlike several other Caribbean islands [30], mongoose rabies has not been documented in Trinidad. Relative to these islands, Trinidad has a lower mongoose population density, which may have allowed the population to remain apparently disease-free [77]. Alternatively, cases could go unrecognized due to the small carcass size and rapid decomposition under the tropical conditions. In Latin America, an increased risk of rabies virus transmission from wildlife has been noted [78,79]. Additionally, in North America, the first case of natural infection of an armadillo with a skunk rabies virus variant and multiple spillover events from bat rabies viruses into foxes and skunks, demonstrates the possibility of rabies virus infection in non-conspecific mammalian taxa [80]. In light of these findings, local studies should be undertaken to determine if there are unrecognized terrestrial (wildlife) reservoirs for sylvatic rabies. The possibility of the initiation of a new virus-host relationship with sustained propagation in a species previously considered a dead-end mammalian host should not be precluded, and monitoring of various potential host species, (e.g., mongoose, ocelot, etc.) is recommended to identify the emergence of new viral reservoir hosts. In this regard, passive surveillance could be used to gather preliminary information which could then inform the development of more structured surveillance activities. As suggested above, serology may also be used in tandem with viral surveillance in the mongoose and other terrestrial wildlife populations to determine the extent of viral exposure and detect possible host shifts from bats.

\subsection{Movement Control of Bats and Rabies Viruses}

The geographic spread of rabies virus during epidemic events may be a result of the movement of the animal hosts or vectors. In the case of the former, animal movement control may curtail the spread of the disease. In Trinidad, there are regulations prohibiting the movement of potentially-rabid animals [57], but there is not enough manpower to enforce these regulations on a day-to-day basis so the appearance of livestock cases outside of the main outbreak areas usually represent human-mediated animal movement. On the other hand, viral spread facilitated by bat movement is much more difficult to control than with domestic species, as vampires from different districts visit communal feeding grounds and common livestock feeding may expedite district to district spread of the virus [26]. Nevertheless, spread of the virus during an outbreak event may be limited by the implementation of ring-vaccination of livestock around the index case(s). At present the maximum radius for ring-vaccination activities during outbreaks in Trinidad is eight miles around the index case [62]. Given a reported flight range of about 12 miles for the common vampire bat, the optimum range for ring-vaccination during an outbreak is recommended to be up to 12 miles around the last animal case $[7,81]$. A southwest-northeast pattern of intra-island virus progression has been observed for rabies epidemics in Trinidad [35,37]. As can be illustrated by Figure 3, over the years the geographic distribution of cases has narrowed to the southwestern regions of St. Patrick and Victoria and northwestern regions of St. Andrew/St. David and St. George East. These are areas with high-density livestock farming at forest fringes where numerous roosting sites may be found in hollow trees [37]. It is also possible that passive surveillance is more effective in these areas because their larger animal populations trigger more efficient case reporting.

Rabies virus importation to Trinidad from the South American mainland, was proposed by early researchers who also suggested that the virus was first introduced to Trinidad via this route around 1925 [42]. It is plausible that this initial introduction, considering the location of the first animal cases, occurred through the northwest peninsular by bats flying along the island chain (Patos, Chacahacare, Huevos and Monos Islands) between Venezuela and Trinidad (see Figure 3), with the first island only 2.5 miles from the mainland [24]. Subsequently, the northwest-southwest progression of animal rabies cases from 1925-1929 may have represented the initial flight path of infected bats possibly driven by the availability of food sources. Thereafter, human cases followed a southwest to northeast unidirectional pattern, previously hypothesized to be due to bats moving along the Earth's magnetic field [35]. More recently, a study on the phylogeography of Trinidad rabies viruses provided evidence 
for at least three independent introductions of virus into Trinidad from the mainland during 1972, 1989, and 2004, and suggested the D. rotundus bat as the vector of introduction at the southwestern peninsular of the island with similar northeasterly progression of the virus during epizootics [64]. The flight range for the more common vampire (D. rotundus) is $20 \mathrm{~km} \mathrm{[82],} \mathrm{so} \mathrm{the} \mathrm{distance} \mathrm{between}$ Trinidad and Tobago (42 km) [23] (in contrast to only $12 \mathrm{~km}$ between Trinidad and the mainland [22]) may preclude the movement of vampire bats between these islands, which would explain the absence of vampire bat rabies in Tobago. Further studies are currently underway to investigate the relationship between rabies virus spatiotemporal dynamics and vampire bat population ecology in Trinidad.

The lack of human rabies cases since 1937, may be attributed to the modernization of housing and associated infrastructure (including indoor and outdoor lighting), which may preclude the free entry of bats into human dwellings. Evidence of this effect may be illustrated by the fact that no rabies cases were reported in urban areas during the human outbreak in the 1930s where housing conditions were generally better than in rural areas, where cases occurred exclusively [35]. Recently, in some rural areas in Trinidad, human bat biting has noted to be increasing, possibly due to an increase in the vampire population. Furthermore, human population expansion into rural areas and the accompanying reduction in total forest cover over the last few decades [83] may result in increased human-bat contact and facilitate viral transmission to vulnerable groups.

\subsection{Human Vaccinationand Risk Communication Programs}

In Trinidad, pre-exposure rabies vaccination is conducted for high-risk personnel (e.g., laboratory staff, veterinarians, and animal health staff), with biennial booster vaccinations. However, ideally, rabies virus neutralizing antibody levels should be monitored every six months or two years in these personnel depending on their risk of exposure, with booster doses if serum titer levels fall below $0.5 \mathrm{IU} / \mathrm{mL}$ [5]. The WHO-recommended Essen (five-dose) regimen is used for rabies post-exposure prophylaxis (PEP) of previously-unvaccinated individuals, with the rationale for PEP administration ideally based on the WHO guidelines [2,4]. Using these guidelines, the risk of rabies virus transmission by the handling of suspect ruminant cases is thought to be low, which is further supported by infrequent virus isolation from bovine saliva with bat-transmitted disease [84]. However, during 2006, an unvaccinated Brazilian veterinarian was infected via non-bite exposure while treating a rabid herbivore and died, highlighting the fact that the benefits of vaccination far outweigh the risks [85].

In Trinidad during 2010, the demographic of the cohort of humans administered PEP was consistent with that of small scale livestock farmers and butchers. The level of contact reported for farmers was primarily the handling and attempted treatment of suspect animals, which mainly involved manual (bare-handed) manipulation of the oral cavity of cattle during attempts to remove an assumed foreign body during suspected choking events. Even though the physical handling of a rabid animal on its own is not generally considered an exposure, the potential opportunity for scratches and abrasions from bovine teeth and oral cavity papillae complicated the risk assessment. The risk for butchers was based on possible splash exposure during the slaughtering of potentially-rabid animals. In most instances PEP was administered as a precaution due to the opportunity for exposure. In total, during the 2010 epizootic, 342 doses of human diploid cell vaccine (HDCV) were administered [44,45], which was projected to cost more than US\$75,500 using previously published HDCV cost estimates [86]. This figure would also have been higher if rabies immune globulin was needed and if all individuals adhered to recommendations for completion of the full-course of PEP. This emphasizes the relevance of risk communication to occupationally high-risk groups in an effort to reduce such exposures. Apart from the public health risks during animal production and slaughter, other risks are associated with consumption of raw or improperly-cooked meat. In fact, in New Mexico, $4 \%$ of cattle slaughtered for human consumption were reported to be infected with rabies, and although no human cases were documented to arise from the meat consumption, dogs which consumed the uncooked meat were noted to develop a paralytic disease [87]. In Trinidad, the carcasses of suspect rabid animals are buried on site 
at the farm after samples have been taken for laboratory testing and in some instances (especially in cases of sudden death) the whole carcass is buried by the farmer without sampling. Dogs have been known to try digging up these carcasses, especially in cases of shallow burial. This poses a risk to dogs, as well as humans in contact with these animals.

Rabies educational programs, which are predominately reactive outbreak communications, can incite and scare the recipient population, with detrimental outcomes on the livestock market. Therefore, in Trinidad, where the disease is endemic, a recommended approach to risk communications would be routine rabies awareness programs with precaution advocacy in high-risk areas targeting high-risk groups. This may additionally increase compliance to vaccination programs and reduce the rabies prevalence in the animal population. Public education and awareness activities must also take into account the local cultural practices and provide information in a strategically-targeted, timely manner. For example, large-scale domestic slaughtering of livestock often conducted prior to specific cultural events in Trinidad provides an ideal opportunity for educating butchers on the potential risk of slaughtering rabid animals. Furthermore, the annual observation of World Rabies Day on 28 September presents a unique opportunity to conduct large-scale rabies awareness activities on a predictable basis.

\section{Conclusions}

Rabies poses major public health and veterinary health challenges in Trinidad. Given the epidemiology of rabies in Trinidad and existing prevention and control measures, rabies epizootics are likely due to gaps in preventative programs, such as prolonged periods of limited vampire bat population control, pockets of unvaccinated susceptible animals, and inadequate public awareness of the disease and the existing preventative measures. Therefore, actions taken to address these shortcomings should include sustained vampire control and vaccination activities (to afford herd immunity) particularly within high risk areas, as well as the implementation of routine public awareness programs. The age of primary vaccination, duration of immunity of vaccines, and the effective range of ring-vaccination efforts during outbreaks need to be evaluated in light of the available scientific data. These actions would not only result in the minimization of livestock losses, but also a substantive reduction in human healthcare costs. Furthermore, surveillance in Trinidad should be enhanced and the results examined actively to elucidate disease trends and risk factors.

Given the inter-related variable of the environmental, pathogen, public health, and veterinary concerns, future considerations should focus upon enhanced laboratory-based surveillance, epidemiologically sound livestock vaccination and risk-based prophylaxis of exposed humans, as well as novel methods for vampire bat management. In a One Health context, such information would aid in the reduction of rabies risks in both human and animal populations by facilitating the development of efficient evidence-based ecologically-sustainable approaches to disease prevention and control.

Acknowledgments: We recognise past and present staff of the Anti-Rabies Unit, the Veterinary Diagnostic Laboratory and the Field Veterinary Services of the Ministry of Agriculture and the Veterinary Public Health Unit of the Ministry of Health for their many years of collaborative efforts towards the control and prevention of rabies in Trinidad.

Author Contributions: J.F.R.S. conceived the idea for the study and conducted the data collection. J.F.R.S., A.V., C.V.F.C., A.A.A., R.M., A.Q.J.H. and C.E.R. jointly prepared the manuscript for publication.

Conflicts of Interest: The authors declare no conflict of interest.

\section{References}

1. Rupprecht, C.E.; Hanlon, C.A.; Hemachudha, T. Rabies re-examined. Lancet Infect. Dis. 2002, 2, 327-343. [CrossRef]

2. Blanton, J.D.; Rupprecht, C.E. Travel vaccination for rabies. Expert Rev. Vaccines 2008, 7, 613-620. [CrossRef] [PubMed] 
3. Schneider, M.C.; Romijn, P.C.; Uieda, W.; Tamayo, H.; da Silva, D.F.; Belotto, A.; da Silva, J.B.; Leanes, L.F. Rabies transmitted by vampire bats to humans: An emerging zoonotic disease in Latin America? Rev. Panam. Salud Publ. 2009, 25, 260-269. [CrossRef]

4. World Health Organization. Rabies vaccines: WHO position paper. Wkly. Epidemiol. Rec. 2010, 309, 309-320.

5. World Health Organization (WHO) Expert Committee on Rabies. WHO Expert Consulation on Rabies; World Health Organization: Geneva, Switzerland, 2013; p. 982.

6. Velasco-Villa, A.; Reeder, S.A.; Orciari, L.A.; Yager, P.A.; Franka, R.; Blanton, J.D.; Zuckero, L.; Hunt, P.; Oertli, E.H.; Robinson, L.E.; et al. Enzootic rabies elimination from dogs and re-emergence in wild terrestrial carnivores, United States. Emerg. Infect. Dis. 2008, 14, 1849-1854. [CrossRef] [PubMed]

7. Greenhall, A.M. Effects of vampire bats and paralytic rabies on livestock production. In Parasites, Pests and Predators; Gaafar, S.M., Howards, W.E., Marsh, R.E., Eds.; Elsevier: Amsterdam, The Netherlands, 1985; pp. 537-553.

8. Nadin-Davis, S.A.; Huang, W.; Armstrong, J.; Casey, G.A.; Bahloul, C.; Tordo, N.; Wandeler, A. Antigenic and genetic divergence of rabies viruses from bat species indigenous to Canada. Virus Res. 2001, 74, 139-156. [CrossRef]

9. Johnson, N.; Arechiga-Ceballos, N.; Augilar-Setien, A. Vampire bat rabies: Ecology, epidemiology and control. Viruses 2014, 6, 1911-1928. [CrossRef] [PubMed]

10. Greenhall, A.M. Bats, rabies and control problems. Oryx 1968, 9, 263-266. [CrossRef]

11. World Health Organization (WHO) Expert Committee on Rabies. WHO Expert Committe on Rabies Fifth Report; World Health Organization: Geneva, Switzerland, 1966.

12. Baer, G.M. The history of rabies. In Rabies, 2nd ed.; Jackson, A.C., Wunner, W.H., Eds.; Elsevier: London, UK, 2007; pp. 1-22.

13. Childs, J.E.; Leslie, A.; Real, L.A. Epidemiology. In Rabies, 2nd ed.; Jackson, A.C., William, W.H., Eds.; Elsevier: London, UK, 2007; pp. 123-200.

14. Carini, A. Defendiendo un diagnostico. Argent. Biol. 1913, 161.

15. Pawan, J.L. The transmission of paralytic rabies in Trinidad by the vampire bat (Desmodus rotundus murinus wagner 1840). Ann. Trop. Med. Parasitol. 1936, 30, 101-129. [CrossRef]

16. Metivier, H.V.M. Paralytic rabies in livestock. J. Comp. Pathol. Ther. 1935, 48, 245-260. [CrossRef]

17. Waterman, J.A. Acute ascending rabic myelitis. Rabies-Transmitted by bats to human beings and animals. Caribb. Med. J. 1959, 21, 46-74. [PubMed]

18. Novicky, R. Contribution to the study of bovine paralytic rabies in Venezuela. Can. J. Comp. Med. 1947, 11, 46-74.

19. Nehaul, B.B.G. Rabies transmitted by bats in British Guiana. Am. J. Trop. Med. Hyg. 1955, 4, 550-553. [CrossRef] [PubMed]

20. Greenhall, A.M. Profile of a vampire. Pageant 1952, 8, 52-57.

21. Arellano-Sota, C. Vampire bat-transmitted rabies in cattle. Rev. Infect. Dis. 1988, 10, 707-709. [CrossRef]

22. Gomes, G.A.; Reid, F.A. Bats of Trinidad and Tobago: A Field Guide and Natural History; Trinibats: Trinidad, Cuba, 2015.

23. ffrench, R. A Guide to the Birds of Trinidad and Tobago, 2nd ed.; Cornell University Press: New York, NY, USA, 1991.

24. Goodwin, G.G.; Greenhall, A.M. A Review of the Bats of Trinidad and Tobago: Descriptions, Rabies Infection and Ecology; Bulletin of the American Museum of Natural History: New York, NY, USA, 1961; p. 122.

25. Hurst, E.W.; Pawan, J.L. An outbreak of rabies in Trinidad without history of bites, and with the symptoms of acute ascending myelitis. Lancet 1931, 218, 622-628. [CrossRef]

26. De Verteuil, E.; Urich, F.W. The study and control of paralytic rabies transmitted by bats in Trinidad, british west indies. Trans. R. Soc. Trop. Med. Hyg. 1936, 29, 317-328. [CrossRef]

27. Hurst, E.W.; Pawan, J.L. A further account of the Trinidad outbreak of acute rabic myelitis: Histology of the experimental disease. J. Pathol. Bacteriol. 1932, 35, 301-321. [CrossRef]

28. Butcher, L.V. The present status of paralytic rabies (bat transmitted) in Trinidad. West Indian Med. J. 1958, 7, 17-20. [PubMed]

29. De Mattos, C.A.; De Mattos, C.C.; Smith, J.S.; Miller, E.T.; Papo, A.; Utrea, A.; Osburn, B.I. Genetic characterization of rabies field isolates from Venezuela. J. Clin. Microbiol. 1996, 34, 1553-1558. [PubMed] 
30. Everard, C.O.R.; Everard, J.D. Mongoose rabies in the Caribbean. Ann. N. Y. Acad. Sci. 1992, 653, 356-366. [CrossRef] [PubMed]

31. Director of Medical Services. Administration Report of the Surgeon General for the Year 1955; Department of Health: Port of Spain, Trinidad and Tobago, 1955.

32. Director of Medical Services. Administration Report of the Surgeon General for the Year 1957; Department of Health: Port of Spain, Trinidad and Tobago, 1957.

33. Pawan, J.L. Paralysis as a clinical manifestation in human rabies. Ann. Trop. Med. Parasitol. 1939, 33, 21-29. [CrossRef]

34. Director of Agriculture of Trinidad and Tobago. Extracts from the adminstration reports of the director of agriculture for the years 1923-1948. Caribb. Med. J. 1959, 21, 172-184.

35. Mungrue, K.; Mahabir, R. The rabies epidemic in Trinidad of 1923 to 1937: An evaluation with a geographic information system. Wilderness Environ. Med. 2011, 22, 28-36. [CrossRef] [PubMed]

36. Director of Medical Services. Administration Report of the Surgeon General for the Year 1956; Department of Health: Port of Spain, Trinidad and Tobago, 1956.

37. Seetahal, J.F.R.; Sanchez-Vazquez, M.J.; Vokaty, A.; Carrington, C.V.F.; Mahabir, R.; Adesiyun, A.A.; Rupprecht, C.E. Of bats and livestock: The epidemiology of rabies in Trinidad, West Indies. Unpublished manuscript, 14 Feburary 2017.

38. Director of Medical Services. Administrative Report of the Surgeon General for the Year 1960; Department of Health: Port of Spain, Trinidad and Tobago, 1960.

39. Pemberton, R. Animal disease and veterinary aministration in Trinidad and Tobago, 1879-1962. In Healing the Herds: Disease, Livestock Economies and the Globalization of Veterinary Medicine; Brown, K., Gilfoyle, D., Eds.; Ohio University Press: Athens, OH, USA, 2010; pp. 163-179.

40. Acha, P.N. Epidemiology of paralytic bovine rabies and bat rabies. Bull. Off. Int. Epizooties 1967, 67, 343-382.

41. Pawan, J.L. Fruit-eating bats and paralytic rabies in Trinidad. Ann. Trop. Med. Parasitol. 1948, 42, $173-177$. [CrossRef] [PubMed]

42. Pawan, J.L. Rabies in the vampire bat of Trinidad with special reference to the clinical course and the latency of infection. Ann. Trop. Med. Parasitol. 1936, 30, 137-156. [CrossRef]

43. Bissessar, J.; Veterinary Diagnostic Laboratory, Ministry of Agriculture, Land and Fisheries, Trinidad and Tobago; Seetahal, J.F.R.; Champs Fleurs, Trinidad. Personal communication, May 2011.

44. Seetahal, J.F.R. Molecular Epidemiology of Rabies in Trinidad and Characteristics of the 2010 Epizootic. Master's Thesis, The University of the West Indies, Alma Jordan Library. St. Augustine Campus, St. Augustine, Trinidad and Tobago, 2011

45. National Surveillance Unit (NSU). NSU Administrative Report 2010; Ministry of Health: Port of Spain, Trinidad and Tobago, 2010.

46. Greenhall, A.M. Problems and Ecological Implications in the Control of Vampire Bats. In Proceedings of the Latin American Conference on the Conservation of Renewable Natural Resources, San Carlos de Bariloche, Argentina, 27 March-2 April 1968.

47. Belotto, A.; Leanes, L.F.; Schneider, M.C.; Tamayo, H.; Correa, E. Overview of rabies in the Americas. Virus Res. 2005, 111, 5-12. [CrossRef] [PubMed]

48. Delpietro, H.; de Diaz, A.M.C.; Fuenzalida, E.; Bell, J.F. Determinacion de las tasa de ataque de rabia en murciclagos. Bol. Oficina Sanit. Panam. 1972, 73, 222-230. [PubMed]

49. Smith, J.S.; Baer, G.M. Epizootiology of rabies: The Americas. In Rabies (Developments in Veterinary Virology); Campbell, J.B., Charlton, K.M., Eds.; Kluwe (Springer) Academic Publishers: Norwell, MA, USA, 1988; p. 452 .

50. Greenhall, A.M. Use of mist nets and strychnine for vampire control in Trinidad. J. Mammal. 1963, 44, 396-398. [CrossRef]

51. Greenhall, A.M. Vampire bat control in the americas: A review and proposed program for action. Bull. Pan Am. Health Organ. 1974, 8, 30-36.

52. World Health Organization. WHO Expert Committe on Rabies Sixth Report; World Health Organization: Geneva, Switzerland, 1973. 
53. Streicker, D.G.R.S.; Valderrama, W.; Gomez, J.; Benavides, I.V.; Pacheco, V.; Condori, R.E.; Montgomery, J.; Rupprecht, C.; Rohani, P.; Altizer, S. Ecological and anthropogenic drivers of rabies exposure in vampire bats: Implications for transmission and control. Proc. R. Soc. Lond. B Biol. Sci. 2012, 279, 3384-3392. [CrossRef] [PubMed]

54. Streicker, D.G.; Winternitz, J.C.; Satterfield, D.A.; Condori-Condori, R.E.; Broos, A.; Tello, C.; Recuenco, S.; Velasco-Villa, A.; Altizer, S.; Valderrama, W. Host-pathogen evolutionary signature reveal dynamics and future invasions of vampire bat rabies. Proc. Natl. Acad. Sci. USA 2016, 113, 10926-10931. [CrossRef] [PubMed]

55. International Union for the Conservation of Nature and Natural Resources (IUCN). Resolution No. 1. Vampire Bats. In Proceedings of the IUCN Latin American Conference on the Conservation of Renewable Natural Resources, San Carlos Bariloche, Argentina, 27 March-2 April 1968.

56. Stoner-Duncan, B.; Streicker, D.G.; Tedeschi, C.M. Vampire bats and rabies: Towards an ecological solution to a public health problem. PLoS Negl. Trop. Dis. 2014, 8. [CrossRef] [PubMed]

57. Government of Trinidad and Tobago. Paralytic rabies regulations. Animals (diseases and importation) act. In Laws of Trinidad and Tobago; Ministry of Legal Affairs: Port of Spain, Trinidad and Tobago, 1956; Chapter 67:02, pp. 62-65.

58. Gilbert, A.; Greenberg, L.; Moran, D.; Alvarez, D.; Alvarado, M.; Garcia, D.L.; Peruski, L. Antibody response of cattle to vaccination with commercial modified live rabies vaccines in Guatemala. Prev. Vet. Med. 2015, 118, 36-44. [CrossRef] [PubMed]

59. Seetahal, J.F.R.; Vokaty, A.; Pradel, J.; Carrington, C.V.F.; Louison, B.; Roopnarine, R.; Van Sauers, A.; James, C.; Millien, M.F.; Rupprecht, C.E. Rabies in the Caribbean: A Situation Analysis. In Proceedings of the Xth International Congress for Veterinary Virology, Montpellier, France, 31 August-3 September 2015.

60. Veterinary Services. Annual Report 2009; Veterinary Services, Animal Production and Health Division; Ministry of Agriculture Land and Fisheries: Port of Spain, Trinidad and Tobago, 2009.

61. Trinidad and Tobago Central Statistical Office. Agricultural Census. Agricultural Statistics 2004. Available online: http:/ /www.cso.gov.tt/statistics/ (accessed on 1 July 2011).

62. Phillip-Hosein, A.; Penal Demonstration Station, Ministry of Agriculture, Land and Fisheries, Trinidad and Tobago; Seetahal, J.F.R.; Champs Fleurs, Trinidad. Personal communication, April 2017.

63. Government of Trinidad and Tobago. Animals (importation) control regulations. Animals (diseases and importation) act. In Laws of Trinidad and Tobago; Ministry of Legal Affairs: Port of Spain, Trinidad and Tobago, 1956; Chapter 67:02, pp. 88-106.

64. Seetahal, J.F.R.; Velasco-Villa, A.; Allicock, O.M.; Adesiyun, A.A.; Bissessar, J.; Amor, K.; Phillip-Hosein, A.; Marston, D.A.; McElhinney, L.M.; Shi, M.; et al. Evolutionary history and phylogeography of rabies viruses associated with outbreaks in Trinidad. PLoS Negl. Trop. Dis. 2013, 7. [CrossRef] [PubMed]

65. Surgeon General of Trinidad and Tobago. Extracts from the administration report of the surgeon general 1925-1941. In Caribbean Medical Journal: Paralytic Rabies Transmitted by Bats in Trinidad; Waterman, J.A., Ed.; Trinidad and Tobago Medical Association: Cascade, Trinidad and Tobago, 1959; pp. 204-238.

66. World Health Organization. Transmission of rabies by bats in the Americas. WHO Chron. 1962, 16, 447-450.

67. Blanton, J.D.; Dyer, J.; Mc Brayer, J.; Rupprecht, C.E. Rabies surveillance in the United States during 2011. J. Am. Vet. Med. Assoc. 2012, 24, 712-722. [CrossRef] [PubMed]

68. Greenhall, A.M. Bats: Their Public Health Importance and Control with Special Reference to Trinidad. In Proceedings of the 2nd Vertebrate Pest Control Conference, Anaheim, CA, USA, 4-5 March 1964.

69. Escobar, L.E.; Peterson, A.T.; Favi, M.; Yung, V.; Medina-Vog, G. Bat-borne rabies in Latin America. Rev. Inst. Med. Trop. Sao Paulo 2015, 57, 63-72. [CrossRef] [PubMed]

70. Linhart, S.B.; Crespo, R.F.; Mitchel, G.C. Control of vampire bats by topical application of an anticoagulant, chlorophacinone. Bol. Oficina Sanit. Panam. 1972, 1, 31-38.

71. Lord, R.D. An ecological strategy for controlling rabies through the elimination of vampire bats. Proc. Verteb. Pest Conf. 1980, 9, 4-6.

72. Williams, E. History of the People of Trinidad and Tobago; Frederick A. Praeger Inc. Publisher: New York, NY, USA, 1962; p. 287.

73. Kaplan, C. Rabies: A worldwide disease. In Population Dynamics of Rabies in Wildlife; Bacon, P.J., Ed.; Academic Press Inc. (London) Ltd.: London, UK, 1985. 
74. Herrera, H.D. Vampires in 'guaya'. Available online: http://www.trinidadexpress.com/20160608/features/ vampires-in-8216guaya8217 (accessed on 5 May 2017).

75. Brown, C.M.; Slavinski, S.; Ettestad, P.; Sidwa, T.J.; Sorhage, F.E. Compendium of animal rabies prevention and control, 2016. J. Am. Vet. Med. Assoc. 2016, 248, 505-517. [PubMed]

76. Hanlon, C.A.; Niezgoda, M.; Rupprecht, C.E. Postexposure prophylaxis for prevention of rabies in dogs. Am. J. Vet. Res. 2002, 63, 1096-1100. [CrossRef] [PubMed]

77. Everard, C.O.R.; Everard, J.D. Mongoose rabies in Grenada. In Population Dynamics of Rabies in Wildlife; Bacon, P.J., Ed.; Academic Press Inc. (London) Ltd.: London, UK, 1985; p. 358.

78. Schneider, M.C.; Belotto, A.; Ade, M.P.; Leanes, L.F.; Correa, E.; Tamayo, H.; Medina, G.; Rodrigues, M.J.; Consultores, O.P.S. Epidemiologic situation of human rabies in Latin America in 2004. Epidemiol. Bull. Pan Am. Health Organ. 2005, 26, 2-4.

79. Favoretto, S.R.; De Mattos, C.C.; de Morais, N.B.; Carrieri, M.L.; Rolim, B.N.; Silva, L.M.; Rupprecht, C.E.; Durigon, E.L.; de Mattos, C.A. Rabies virus maintained by dogs in humans and terrestrial wildlife, Ceara State, Brazil. Emerg. Infect. Dis. 2006, 12, 1978-1981. [CrossRef] [PubMed]

80. Leffingwell, L.M.; Neill, S.U. Naturally acquired rabies in an armadillo (Dasypus novemcinctus) in Texas. J. Clin. Microbiol. 1989, 27, 174-175. [PubMed]

81. Greenhall, A.M.; Joermann, G.; Schmidt, U.; Seidel, M.R. Desmodus rotundus. Mamm. Species 1983, 202, 1-6. [CrossRef]

82. Malaga-Alba, A. Vampire bat as a carrier of rabies. Am. J. Public Health 1954, 44, 909-918. [CrossRef]

83. Food and Agricultural Organization (FAO). Global Forest Resources Assessment 2010: Main Report; FAO: Rome, Italy, 2010; p. 163.

84. Delpietro, H.A.; Larghi, O.P.; Russo, R.G. Virus isolation from saliva and salivary glands of cattle naturally infected with paralytic rabies. Prev. Vet. Med. 2001, 48, 223-228. [CrossRef]

85. De Brito, M.G.; Chamone, T.L.; da Silva, F.; Wada, M.Y.; de Miranda, A.B.; Castilho, J.G. Antemortem diagnosis of human rabies in a veterinarian infected when handling a herbivore in Minas Gerais, Brazil. Rev. Inst. Med. Trop. São Paulo 2011, 53, 39-44. [CrossRef]

86. Kreindel, S.M.; McGuill, M.; Meltzer, M.; Rupprecht, C.; DeMaria, A. The cost of rabies postexposure prophylaxis: One state's experience. Public Health Rep. 1998, 113, 247-251. [PubMed]

87. Constantine, D.G. Transmission of pathogenic organisms by vampire bats. In Natural History of Vampire Bats; Greenhall, A.M., Schmidt, U., Eds.; CDC Press: Boca Raton, FL, USA, 1988; pp. 167-189.

(C) 2017 by the authors. Licensee MDPI, Basel, Switzerland. This article is an open access article distributed under the terms and conditions of the Creative Commons Attribution (CC BY) license (http:/ / creativecommons.org/licenses/by/4.0/). 
Article

\title{
Spatial Association of Canine Rabies Outbreak and Ecological Urban Corridors, Arequipa, Peru
}

\author{
Ricardo Castillo-Neyra ${ }^{1,2, *}$, Edith Zegarra ${ }^{3}$, Ynes Monroy ${ }^{3}$, Reyno F. Bernedo ${ }^{3}$, \\ Ismael Cornejo-Rosello ${ }^{3}$, Valerie A. Paz-Soldan ${ }^{2,4}$ and Michael Z. Levy ${ }^{1,2}$ \\ 1 Department of Biostatistics and Epidemiology, Perelman School of Medicine, University of Pennsylvania, \\ Philadelphia, PA 19104, USA; mzlevy@mail.med.upenn.edu \\ 2 Zoonotic Disease Research Lab, One Health Unit, School of Public Health, \\ Universidad Peruana Cayetano Heredia, Lima 15102, Peru \\ 3 Gerencia Regional de Salud de Arequipa, Ministerio de Salud, Arequipa 04002, Peru; \\ zegarraedith@gmail.com (E.Z.); yni1923@hotmail.com (Y.M.); florentino39@hotmail.com (R.F.B.); \\ quilco2005@yahoo.es (I.C.-R.) \\ 4 Department of Global Community Health and Behavioral Sciences, \\ Tulane University School of Public Health and Tropical Medicine, New Orleans, LA 70112, USA; \\ vpazsold@tulane.edu \\ * Correspondence: cricardo@upenn.edu; Tel.: +1-215-746-7333
}

Received: 1 July 2017; Accepted: 9 August 2017; Published: 13 August 2017

\begin{abstract}
In the city of Arequipa, Peru, a rabid dog was detected in March 2015, marking the reintroduction of the rabies virus in the area; more rabid dogs have been detected since then. The presence of free-roaming dogs in Arequipa seems to be higher in dry water channels, which are widespread in the city. We created a geographic information system (GIS) with surveillance data on the location of rabid dogs detected during the first year of the outbreak, as well as the water channels. We conducted a spatial analysis using Monte Carlo simulations to determine if detected rabid dogs were closer to the water channels than expected. Thirty rabid dogs were detected during the first year of the outbreak, and they were statistically associated with the water channels (average distance to closest water channel $=334 \mathrm{~m} ; p$-value $=0.027$ ). Water channels might play a role in the ecology of free-roaming dog populations, functioning as ecological corridors. Landscape ecology could assist in understanding the impact of these urban structures on control activities and the persistence of transmission.
\end{abstract}

Keywords: dogs; geographical information system; GIS; Monte Carlo method; rabies; spatial analysis; zoonosis

\section{Introduction}

The reintroduction of canine rabies to areas declared free of the virus is a rare event globally [1-4]. The outbreak of canine rabies in Arequipa, Peru in March 2015 is the first instance of canine rabies reintroduction in Latin America, where enormous advances have been achieved through dog vaccination [5]. Fortunately, no human cases have been detected in Arequipa to date. Genetic sequencing suggests that the rabies virus was introduced to Arequipa by dogs imported from Puno, a neighboring region in southern Peru that has reported sustained transmission of canine rabies for the last 15 years [6]. Interestingly, the urban landscape in Arequipa is characterized by the presence of large open water channels that are dry most of the time, where free-roaming dogs can be found.

In Arequipa, where $22 \%$ of owned dogs have free access to the street all the time, and $48 \%$ of owned dogs are unrestricted at some point during the day [7], it is unknown which proportion of dogs seen on the streets are actually stray dogs and which are owned. Upon detection of the first rabid dog, 
Ministry of Health $(\mathrm{MOH})$ authorities attempted containment by ring vaccination of an approximately five-block radius, in accordance with the Peruvian technical guidelines to control and prevent human rabies [8]. In addition, they conducted contact tracing: dogs that lived within that approximate five-block radius and that could be considered potentially exposed to the virus (unvaccinated and with relatively free access to the street or known history of contact with free-roaming dogs) were euthanized [8]. Humans potentially exposed to the virus were offered post-exposure prophylaxis [8]. Days later, a second case was detected in another district, over 1.25 kilometers from the original case (Figure 1); the same containment strategy was implemented. The next case appeared in still another district, and each subsequent case continued to be detected far beyond the containment area of the last (Figure 1). Four months after the first case was detected, mass dog vaccination campaigns were implemented by the $\mathrm{MOH}$. Despite the initiation of this city-level approach in 2015, ring containment immediately following the detection of a case has also been practiced until 2017. The median vaccination coverage reported among the 29 districts of the province of Arequipa was $101 \%$ in the first year of the outbreak, with three districts reporting coverage above $200 \%$. Similarly, the reported coverage in the ring vaccination activities was higher than $100 \%$ in all cases, suggesting a substantial underestimation of the dog population at that time. Additionally, culling of free-roaming dogs (without evidence in favor of this strategy [9-11]) has been conducted by some groups.

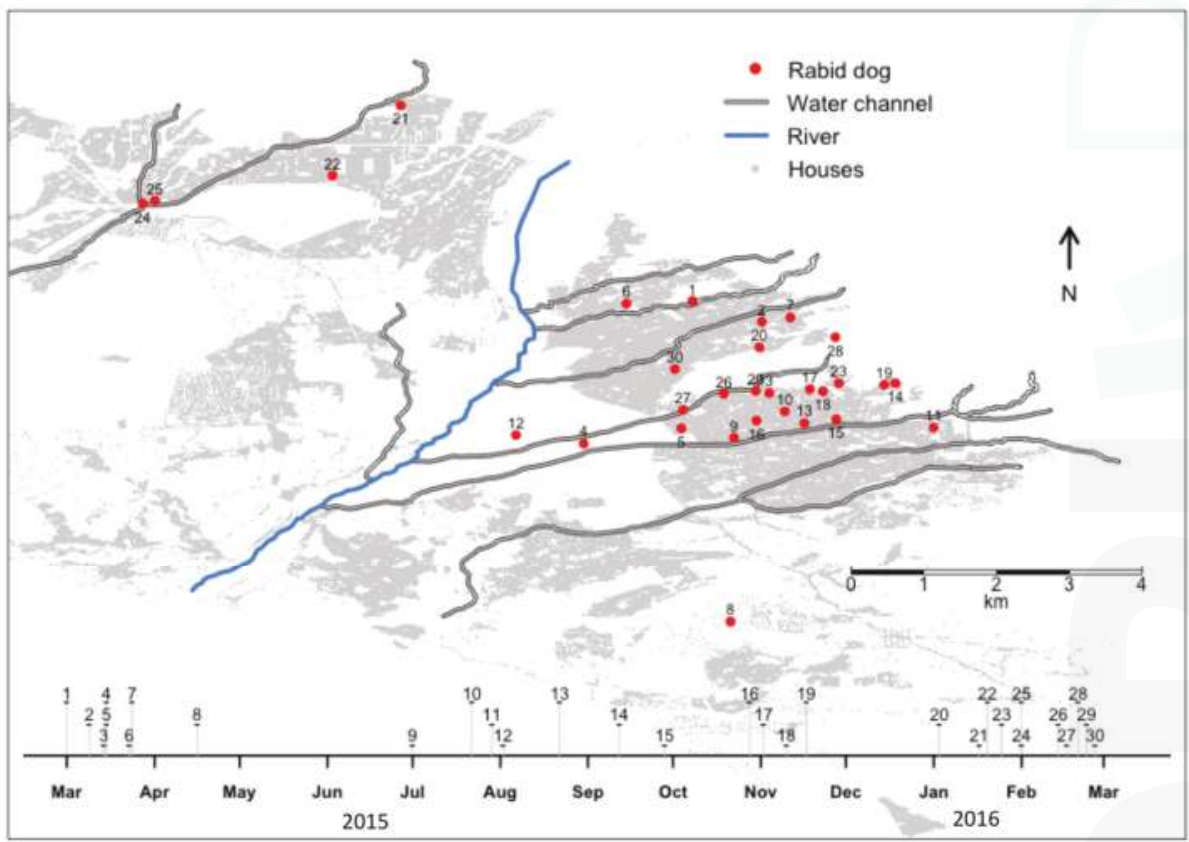

Figure 1. Spatio-temporal distribution of laboratory-confirmed rabid dogs and water channels system in the city of Arequipa, March 2015-March 2016 (different heights in timeline are used only to avoid overlap).

The reemergence of the virus transmission in Arequipa has been associated with the high density of free-roaming dogs in the city (i.e., stray and owned dogs that spend unsupervised time in the streets and water channels), and with low dog vaccination coverage [12]. The authorities report that water channels are central to the problem, because the density of dogs is higher in them, dogs feed on trash disposed in the channels, and large packs of dogs have been seen moving along these urban structures. In other parts of the world, urban structures similar to the dry water channels in 
Arequipa are used by wild animals to move within city matrices. Foxes use ravines to move across urban areas of Toronto [13], and bobcats and coyotes use culverts and linear fragments of vegetation to circulate in southern California [14]. Here we considered the dry water channels of Arequipa as ecological corridors, following the definition given by Freemark for corridors [15]: "a physical linkage between habitat patches within a landscape that may serve as a pathway by which organisms move or interchange, or as a habitat in which organisms can feed or breed en route from one patch to another." These urban ecological corridors and other physical aspects of urbanization in fast-growing cities such as Arequipa facilitate the emergence and persistence of zoonotic and emergent disease [16-18] and may complicate canine rabies control.

Despite the efforts to control the outbreak, transmission of the rabies virus continues in the city of Arequipa, placing the approximately 1 million inhabitants of the city at risk of infection. The main objective of our study was to assess the spatial association between detected rabid dogs and the most salient urban structures in the city of Arequipa-the dry water channels.

\section{Materials and Methods}

\subsection{Study Setting}

The city of Arequipa is located in the Andes at $2300 \mathrm{~m}$ above sea level; its temperature ranges from $10^{\circ} \mathrm{C}$ to $29^{\circ} \mathrm{C}$. The Chili River runs through the city, and rainwater drains to it via uncovered semi-natural water channels. The rainy season lasts 8 weeks; the channels are dry the remainder of the year (Figure 2). The city of Arequipa has grown significantly during recent decades, reaching a population of approximately 998,000 people in 2015 and covering an urban area of over 101 square kilometers. On the outskirts of the city, urbanization creates peri-urban areas that, after decades, are absorbed by the continuous expansion of the city [18]. Arequipa is surrounded by desert, which has little wildlife that could sustain the rabies virus, nor resources (shelter, food) to support feral dog populations.

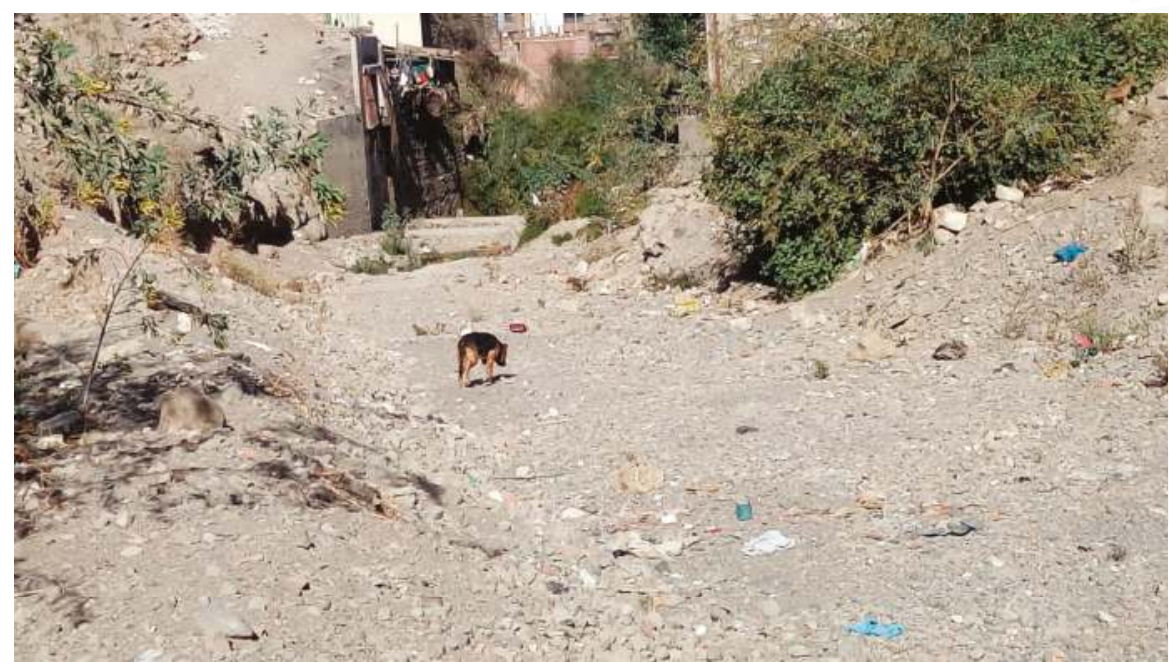

Figure 2. Dog in a dry water channel in the city of Arequipa.

\subsection{Data}

As part of routine surveillance activities, the $\mathrm{MOH}$ Reference Laboratory in Arequipa tested brain samples of suspected rabies cases using direct fluorescent antibody [19]. Additionally, mouse inoculation 
testing [19] was conducted at the National Institute of Health Laboratory in Lima. Samples positive to either test were considered rabies positive. We created a geographic information system (GIS) with the coordinates of all the houses in the city of Arequipa, as well as those of the system of water channels. Over these geographic layers, we added the location of the canine rabies cases detected during the first year of the outbreak (March 2015 to March 2016). The rabies surveillance system in Peru only acquires location data of the health facility catchment where the sample was collected (areal data). Our team investigated the exact point location of positive samples. Some of these point locations were the house of the reporting owner, or the spot where a dead dog was found or an aggressive or disoriented dog was captured. We report the number of samples analyzed and why they were submitted for diagnosis.

\subsection{Statistical Analysis}

We conducted a spatial analysis to test the hypothesis that rabid dogs were detected closer to a water channel than would be expected by chance. We calculated the average shortest Euclidian distance between the location of rabid dogs and the closest water channel. The exact coordinates of negative dogs were not available. We used a Monte Carlo random-labeling simulation with 1000 trials to compare the average distance between observed rabid dogs and water channels to the distance from water channels of a randomly-generated spatial sample of households [20], matched on locality. We have found that the number of owned dogs per house can vary by locality [7], and we also wanted to take into account any unobserved difference in surveillance intensity at the locality level. Localities are informal district subdivisions which are widely used by the health inspectors to differentiate their catchment areas and organize their work. Under the null hypothesis, we assumed that all households are equally likely to have a rabid dog regardless of their distance to the water channels—on a door-to-door survey conducted in more than 4000 houses by our team, we did not find an association between the number of owned dogs per house and the water channels [7]. To determine whether the observed distance of rabid dogs to water channels was statistically different from the distance of the water channel to the random spatial sample, we compared the average observed distance to the distance distribution derived from the Monte Carlo trials. The proportion of distances in the Monte Carlo-generated random sample which were lower than the average observed distance was the estimate Monte Carlo $p$-value.

Separately, we assessed the spatial clustering of rabid dogs using the L statistic [20]. Briefly, spatial clustering is defined as a general tendency for point pattern events (here, detected rabid dogs) to occur more closely together than would be expected under complete spatial randomness (CSR) [21]. We also estimated the distance between each case and the subsequent case. Finally, we present if detected cases were owned dogs, and if it was reported that they bit any humans. The analyses were conducted in $\mathrm{R}[22]$.

\section{Results}

Out of 559 samples analyzed between 17 March 2015 and 16 March 2016, only 397 of the analyzed samples had some data about the case in the reporting form: 77 samples came from dogs hit by a car, 55 samples were collected during ring-containment activities, 43 forms reported that the dog was found dead or dying outdoors, 41 samples reportedly came from aggressive dogs, 37 samples came from dogs with neurological signs, 25 dogs were reported as "sick" or "sick and died", 21 samples came from dogs that were killed or euthanized by their owners, 18 came from dogs found in the water channels, and 11 were samples or dogs sent by private veterinarians. Sixty-nine (69) forms state that the dog was found outside or was stray, but do not mention if the dog was dead when found. Thirty (30) dogs were diagnosed positive for rabies (5.37\%) (Figure 1); 13 of the positive dogs were first suspected cases because they were aggressive, one was the contact of a positive dog, one was sent by a private veterinarian, one had clinical signs compatible with rabies, one was captured because it was a stray dog, and one was sent to the lab because it was "sick". 
The average distance between detected rabid dogs and water channels was $334 \mathrm{~m}$. In only 27 of the 1000 Monte-Carlo simulated location sets was the average distance to the water channels $334 \mathrm{~m}$ or lower (Monte Carlo $p$-value $=0.027$ ). When analyzing all the detected cases together, we found significant spatial clustering of confirmed rabid dogs: overall, cases were detected more closely together than we would expect at random (Figure 3). However, some of these cases that were close to each other were detected several months apart. The median distance between each detected case and the next case was $2.253 \mathrm{~km}$, and $86.7 \%$ of the cases were detected one $\mathrm{km}$ or farther from the previous case. Importantly, at least $43 \%$ of the rabid dogs in this study had bitten at least one human and $76 \%$ of the rabid dogs were turned in to authorities by their owners. These percentages likely underestimate the actual percentages of dog bites by rabid dogs and dog ownership among detected rabid dogs.

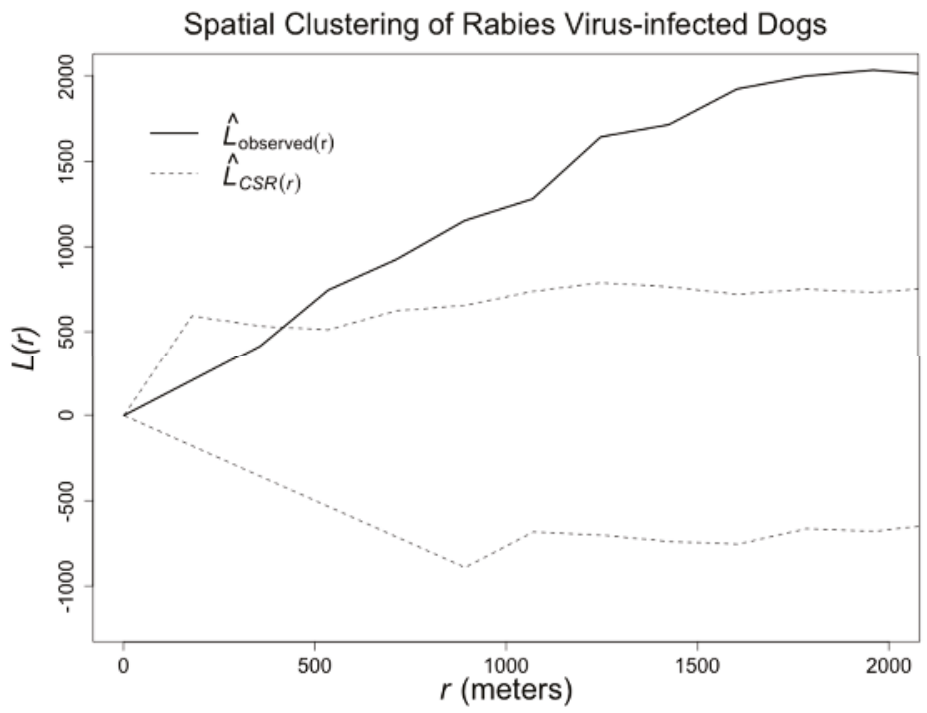

Figure 3. Strong clustering of rabid dogs evaluated with the L function. Envelopes (dashed lines) produced assuming complete spatial randomness (CSR).

\section{Discussion}

Rabies-virus positive dogs are spatially associated with water channels in the city of Arequipa. This association is unlikely to be related to sampling bias, as the rabies surveillance program is mostly passive: the majority of rabid dogs detected during this outbreak were reported by their owners. Free-roaming dog ecology and rabies virus transmission (e.g., habitat, movement, interactions) could be strongly influenced by water channels, as these urban structures-where trash is commonly dumped by dwellers-can produce an "ecological assembly" [23] within the city, increasing the density of dogs. Water channels may also form ecological corridors [24], increasing the connectivity of spatially-distant dog populations. It is possible that by increasing the connectivity of dog packs, the water channels facilitate the persistence of the virus by allowing it to reach new susceptible packs, similar to what has been observed at larger scales in raccoon rabies [25].

In the city of Arequipa, the high spatial heterogeneity created by the water channels poses challenges to modeling contact and networks that capture the spatial dog population structure, and analyzing models that include long-distance interactions between individuals or packs [26]. In addition, what facilitates dog movement could impede human movement: the water channels are barriers for pedestrians and could decrease access to vaccination points, thereby creating pockets of low canine vaccination coverage, which could enable the persistence of rabies virus [27]. 
Clearly, containment activities have not controlled the outbreak; cases have been reported regularly through June 2017 in spatially disparate areas. A first look at the spatial distribution of cases could lead to the determination that cases are generally close to each other, which is also captured by the clustering analysis. The clustering analysis simply suggests that cases are not dispersed randomly all over the city. However, the distance between each case and the next detected case suggests that subsequent cases are not occurring close—or at least not close enough—to support focalized containment activities; thus, a citywide response is needed. The initial focalized containment strategy may have diverted resources [27] and delayed population-level responses such as mass dog vaccination [27] that have proven to be successful in other settings, but are not reaching the appropriate coverage levels [5,28-30] in Arequipa [31]. It is worth highlighting that Davlin and VonVille, in a systematic review on canine rabies vaccination, concluded that understanding of the local dog population ecology is important to achieve effective vaccination coverage [32]. The unrealistic vaccination coverage estimates reported during the first year of the outbreak reflect inaccurate estimates of the dog population in the city of Arequipa. The human-to-dog ratio used to estimate the dog population was 10:1 in 2015; that ratio has been reduced to 6:1 for 2016 and 2017, approaching the true ratio, but a better knowledge of the canine population is still necessary.

In Arequipa, there are a number of plans to control the canine population that is found in the water channels. To some extent, these plans recognize the spatial heterogeneity produced by urban structures. However, if plans include the culling of free-roaming dogs, there may be negative unintended consequences [10,11,33-36]. In addition, these measures may not take into account the potential functionality of these ecological urban corridors [24] on free-roaming dog ecology. Additionally, these water channels serve a political function: they delineate boundaries between districts, which determine jurisdictions for rabies health inspectors. These areas within the water channels become a no-man's-land in the surveillance system; dead dogs are left uncollected and undiagnosed. A centralized surveillance system at the city level could better address these areas that seemingly do not belong to any district jurisdiction. The design of urban landscapes has received much attention around the world to improve health outcomes. However, most of this attention is focused on chronic disease, mental health, violence and injuries, and pollution [37]. Landscape ecology has the potential to be used in urban areas to understand zoonotic diseases and guide land management, as it has been applied for rabies in wild and rural areas [25,38-42].

One limitation of our study was the lack of locations for negative dogs-more detailed data accompanying the samples sent to the laboratory would allow for analyses with fewer assumptions. Related to the surveillance system, it is important to note that surveillance systems that are based on meeting a pre-defined quota of samples frequently receive and analyze samples of non-suspicious animals and miss the vast majority of cases [43]; therefore, the 30 rabies-positive dogs detected during the first year of this outbreak most likely represent only a fraction of the total number of cases. New surveillance systems based on active rabid-dog finding guided by triage data from dog-bite patients has the potential to increase the probability of case detection by several orders of magnitude [43]. Given that a great extent of cases were most likely missed, there is the possibility that our results of spatial clustering may be different if it were possible to account for those cases not detected by the surveillance system. It is also possible that other less ecological and more social phenomena are explaining the association between cases and water channels: dog vaccination status could be lower around the water channels due to spatial differences in educational attainment, economics, logistical constraints, among other factors. Dog ownership practices also affect dog ecology: households closest to the water channels may restrain their animals less, which would result in an increase of the free-roaming dog population in the water channel areas. Further investigations on vaccination patterns, the urban landscape, and the ecology of dogs in Arequipa could inform surveillance and control activities.

Supplementary Materials: The following are available online at www.mdpi.com/2414-6366/2/3/38/s1, S1 Abstract. Resumen en español (alternative language abstract). 
Acknowledgments: We acknowledge the contribution of members of the Zoonotic Disease Research Lab to this work, especially Jorge Apaza and Gian Franco Condori. We gratefully acknowledge the contributions of the Ministerio de Salud del Peru (MINSA) and the Laboratorio de Referencia Regional Arequipa.

Author Contributions: R.C.N., E.Z., Y.M., and M.Z.L. conceived and designed the study; E.Z., Y.M., R.F.B., and I.C.R. acquired the data, V.A.P.S. and M.Z.L. administered and supervised the study; and R.C.N., V.A.P.S. and M.Z.L wrote the paper.

Conflicts of Interest: The authors declare no conflict of interest.

\section{References}

1. Clark, K.A.; Neill, S.U.; Smith, J.S.; Wilson, P.J.; Whadford, V.W.; McKirahan, G.W. Epizootic canine rabies transmitted by coyotes in south Texas. J. Am. Vet. Med. Assoc. 1994, 204, 536-540. [PubMed]

2. $\quad$ Chang, S.-S.; Tsai, H.-J.; Chang, F.-Y.; Lee, T.-S.; Huang, K.-C.; Fang, K.-Y.; Wallace, R.M.; Inoue, S.; Fei, C.-Y. Government response to the discovery of a rabies virus reservoir species on a previously designated rabies-free Island, Taiwan, 1999-2014. Zoonoses Public Health 2016, 63, 396-402. [CrossRef] [PubMed]

3. Wu, X.; Hu, R.; Zhang, Y.; Dong, G.; Rupprecht, C.E. Reemerging rabies and lack of systemic surveillance in People's Republic of China. Emerg. Infect. Dis. 2009, 15, 1159-1164. [CrossRef] [PubMed]

4. Knobel, D.L.; Lembo, T.; Morters, M.; Townsend, S.E.; Cleaveland, S.; Hampson, K. Dog rabies and its control. In Rabies: Scientific Basis of the Disease and Its Management, 3rd ed.; Elsevier: Philadelphia, PA, USA, 2013; pp. 591-615.

5. Vigilato, M.A.N.; Clavijo, A.; Knobl, T.; Silva, H.M.T.; Cosivi, O.; Schneider, M.C.; Leanes, L.F.; Belotto, A.J.; Espinal, M.A. Progress towards eliminating canine rabies: Policies and perspectives from Latin America and the Caribbean. Philos. Trans. R. Soc. Lond. B 2013, 368, 20120143. [CrossRef] [PubMed]

6. Dirección General. Alert for the presentation of cases of human rabies and expansion of canine rabies. In Epidemiología Epidemiologic Alert-Risk; Ministerio de Salud: Lima, Peru, 2015; pp. 1-2.

7. Castillo-Neyra, R.; MacDonald, H.; Toledo Vizcarra, A.M.; Johnson, A.; Paja, W.; Buttenheim, A.M.; et al. University of Pennsylvania: Philadelphia, PA, USA. Unpublished work, 2017.

8. Dirección General de Salud; Dirección de Atención Integral de Salud. Norma Técnica de Salud para la Prevención y Control de la Rabia Humana en el Perú [Technical Health Norm for the Prevention and Control of Human Rabies in Peru], 1st ed.; Ministerio de Salud: Lima, Peru, 2006; pp. 1-101.

9. Aréchiga Ceballos, N.; Karunaratna, D.; Aguilar Setién, A. Control of canine rabies in developing countries: Key features and animal welfare implications. Rev. Sci. Tech. Off. Int. Epizoot. 2014, 33, 311-321. [CrossRef]

10. Morters, M.K.; Restif, O.; Hampson, K.; Cleaveland, S.; Wood, J.L.N.; Conlan, A.J.K. Evidence-based control of canine rabies: A critical review of population density reduction. J. Anim. Ecol. 2013, 82, 6-14. [CrossRef] [PubMed]

11. Castillo-Neyra, R.; Levy, M.Z.; Náquira, C. Effect of free-roaming dogs culling on the control of canine rabies. Rev. Peru. Med. Exp. Salud Publica 2016, 33, 772-779. [CrossRef] [PubMed]

12. Tasso, O.H.; Valdivia, A.V. Decreto supremo que declara en emergencia sanitaria por el plazo de noventa (90) días calendario, a la provincia de Arequipa. Available online: http://busquedas.elperuano.com.pe/ normaslegales/decreto-supremo-que-declara-en-emergencia-sanitaria-por-el-p-decreto-supremo-n-0152016-sa-1363166-5/ (accessed on 8 August 2017).

13. Rosatte, R.C.; Power, M.J.; Donovan, D.; Davies, J.C.; Allan, M.; Bachmann, P.; Stevenson, B.; Wandeler, A.; Muldoon, F. Elimination of arctic variant rabies in red foxes, metropolitan Toronto. Emerg. Infect. Dis. 2007, 13, 25-27. [CrossRef] [PubMed]

14. Tigas, L.A.; Van Vuren, D.H.; Sauvajot, R.M. Behavioral responses of bobcats and coyotes to habitat fragmentation and corridors in an urban environment. Biol. Conserv. 2002, 108, 299-306. [CrossRef]

15. Freemark, K.; Bert, D.; Villard, M.-A. Patch-, landscape-, and regional-scale effects on Biota. In Applying Landscape Ecology in Biological Conservation, 1st ed.; Springer: New York, NY, USA, 2002; pp. 58-83.

16. Campbell, T.; Campbell, A. Emerging disease burdens and the poor in cities of the developing world. J. Urban Health 2007, 84, 54-64. [CrossRef] [PubMed]

17. Neiderud, C.-J. How urbanization affects the epidemiology of emerging infectious diseases. Infect. Ecol. Epidemiol. 2015, 5, 27060. [CrossRef] [PubMed] 
18. Levy, M.Z.; Barbu, C.M.; Castillo-Neyra, R.; Quispe Machaca, V.R.; Ancca Juárez, J.; Escalante-Mejia, P.; Borrini-Mayori, K.; Niemierko, M.; Mabud, T.S.; Behrman, J.R.; et al. Urbanization, land tenure security and vector-borne Chagas disease. Proc. Biol. Sci. 2014, 281, 20141003. [CrossRef] [PubMed]

19. Duong, V.; Tarantola, A.; Ong, S.; Mey, C.; Choeung, R.; Ly, S.; Bourhyc, H.; Dussarta, P.; Buchyd, P. Laboratory diagnostics in dog-mediated rabies: An overview of performance and a proposed strategy for various settings. Int. J. Infect. Dis. 2016, 46, 107-114. [CrossRef] [PubMed]

20. Waller, L.A.; Gotway, C.A. Applied Spatial Statistics for Public Health Data; John Wiley \& Sons: Hoboken, NJ, USA, 2004; pp. 1-482.

21. Diggle, P.J. Statistical Analysis of Spatial Point Patterns, 2nd ed.; Hodder Education Publishers: London, UK, 2003; p. 159.

22. Team, R. A Language and Environment for Statistical Computing; R Foundation for Statistical Computing: Vienna, Austria, 2013; p. 3604.

23. Gulachenski, A.; Ghersi, B.; Lesen, A.; Blum, M. Abandonment, ecological assembly and public health risks in counter-urbanizing cities. Sustainability 2016, 8, 491. [CrossRef]

24. Vogt, P.; Riitters, K.H.; Iwanowski, M.; Estreguil, C.; Kozak, J.; Soille, P. Mapping landscape corridors. Ecol. Indic. 2007, 7, 481-488. [CrossRef]

25. Rees, E.E.; Pond, B.A.; Tinline, R.R.; Bélanger, D. Understanding effects of barriers on the spread and control of rabies. Adv. Virus Res. 2011, 79, 421-447. [CrossRef] [PubMed]

26. Riley, S.; Eames, K.; Isham, V.; Mollison, D.; Trapman, P. Five challenges for spatial epidemic models. Epidemics 2015, 10, 68-71. [CrossRef] [PubMed]

27. Townsend, S.E.; Lembo, T.; Cleaveland, S.; Meslin, F.X.; Miranda, M.E.; Putra, A.A.G.; Haydona, D.T.; Hampsona, K. Surveillance guidelines for disease elimination: A case study of canine rabies. Comp. Immunol. Microbiol. Infect. Dis. 2013, 36, 249-261. [CrossRef] [PubMed]

28. Hampson, K.; Dushoff, J.; Cleaveland, S.; Haydon, D.T.; Kaare, M.; Packer, C.; Dobson, A. Transmission dynamics and prospects for the elimination of canine rabies. PLoS Biol. 2009, 7, e53. [CrossRef] [PubMed]

29. Coleman, P.G.; Dye, C. Immunization coverage required to prevent outbreaks of dog rabies. Vaccine 1996, 14, 185-186. [CrossRef]

30. Townsend, S.E.; Sumantra, I.P.; Pudjiatmoko; Bagus, G.N.; Brum, E.; Cleaveland, S.; Crafter, S.; Dewi, A.P.M.; Dharma, D.M.N.; Dushoff, J.; et al. Designing programs for eliminating canine rabies from islands: Bali, Indonesia as a case study. PLoS Negl. Trop. Dis. 2013, 7, e2372. [CrossRef] [PubMed]

31. Castillo-Neyra, R.; Brown, J.; Borrini, K.; Arevalo, C.; Levy, M.Z.; Buttenheim, A.; Hunter, G.C.; Becerra, V.; Behrman, J.; Paz-Soldan, V.A. Barriers to dog rabies vaccination during an urban rabies outbreak: Qualitative findings from Arequipa, Peru. PLoS Negl. Trop. Dis. 2017, 11, e0005460. [CrossRef] [PubMed]

32. Davlin, S.L.; Vonville, H.M. Canine rabies vaccination and domestic dog population characteristics in the developing world: A systematic review. Vaccine 2012, 30, 3492-3502. [CrossRef] [PubMed]

33. Morters, M.K.; McKinley, T.J.; Restif, O.; Conlan, A.J.K.; Cleaveland, S.; Hampson, K.; Whay, H.R.; Damriyasa, I.M.; Wood, J.L.N. The demography of free-roaming dog populations and applications to disease and population control. J. Appl. Ecol. 2014, 51, 1096-1106. [CrossRef] [PubMed]

34. Wera, E.; Velthuis, A.G.J.; Geong, M.; Hogeveen, H. Costs of rabies control: An economic calculation method applied to Flores Island. PLoS ONE 2013, 8, e83654. [CrossRef] [PubMed]

35. Zinsstag, J.; Durr, S.; Penny, M.A.; Mindekem, R.; Roth, F.; Menendez Gonzalez, S.; Naissengard, S.; Hattendorfa, J. Transmission dynamics and economics of rabies control in dogs and humans in an African city. Proc. Natl. Acad. Sci. USA 2009, 106, 14996-15001. [CrossRef] [PubMed]

36. Putra, A.A.G.; Hampson, K.; Girardi, J.; Hiby, E.; Knobel, D.; Mardiana, I.W.; Townsend, S.; Scott-Orr, H. Response to a rabies epidemic, Bali, Indonesia, 2008-2011. Emerg. Infect. Dis. 2013, 19, 648-651. [CrossRef] [PubMed]

37. Dannenberg, A.L.; Jackson, R.J.; Frumkin, H.; Schieber, R.A.; Pratt, M.; Kochtitzky, C.; Tilson, H.H. The impact of community design and land-use choices on public health: A scientific research agenda. Am. Public Health 2003, 93, 1500-1508. [CrossRef]

38. Nagarajan, T.; Mohanasubramanian, B.; Seshagiri, E.V.; Nagendrakumar, S.B.; Saseendranath, M.R.; Satyanarayana, M.L.; Thiagarajan, D.; Rangarajan, P.N.; Srinivasan, V.A. Molecular epidemiology of rabies virus isolates in India. J. Clin. Microbiol. 2006, 44, 3218-3224. [CrossRef] [PubMed] 
39. Duke, J.E.; Blanton, J.D.; Ivey, M.; Rupprecht, C. Modeling enzootic raccoon rabies from land use patterns-Georgia (USA) 2006-2010. F1000Research 2013, 2, 285. [CrossRef] [PubMed]

40. Recuenco, S.; Eidson, M.; Cherry, B.; Kulldorff, M.; Johnson, G. Factors associated with endemic raccoon (Procyon lotor) rabies in terrestrial mammals in New York State, USA. Prev. Vet. Med. 2008, 86, $30-42$. [CrossRef] [PubMed]

41. Arjo, W.M.; Fisher, C.E.; Armstrong, J.; Boyd, F.; Slate, D. Effects of natural barriers and habitat on the western spread of raccoon rabies in Alabama. J. Wildl. Manag. 2008, 72, 1725-1735. [CrossRef]

42. Bourhy, H.; Kissi, B.; Audry, L.; Smreczak, M.; Sadkowska-Todys, M.; Kulonen, K.; Tordo, N.; Zmudzinski, J.F.; Holmes, E.C. Ecology and evolution of rabies virus in Europe. J. Gen. Virol. 1999, 80, 2545-2557. [CrossRef] [PubMed]

43. Hampson, K.; Abela-Ridder, B.; Brunker, K.; Bucheli, S.T.M.; Carvalho, M.; Caldas, E.; Changalucha, J.; Cleaveland, S.; Dushoff, J.; Gutierrez, V.; et al. Surveillance to establish elimination of transmission and freedom from dog-mediated rabies. bioRxiv 2016, 096883. [CrossRef]

(C) 2017 by the authors. Licensee MDPI, Basel, Switzerland. This article is an open access article distributed under the terms and conditions of the Creative Commons Attribution (CC BY) license (http:/ / creativecommons.org/licenses/by/4.0/). 


\title{
Heterogeneity of Rabies Vaccination Recommendations across Asia
}

\author{
Philippe Buchy ${ }^{1}$, Scott Preiss ${ }^{2}$, Ved Singh ${ }^{2}$ and Piyali Mukherjee ${ }^{1, *}$ \\ 1 GSK, 23 Rochester Park, Singapore 139234, Singapore; philippe.x.buchy@gsk.com \\ 2 GSK, 20 Avenue Fleming, 1300 Wavre, Belgium; scott.s.preiss@gsk.com (S.P.); ved.s.singh@gsk.com (V.S.) \\ * Correspondence: piyali.x.mukherjee@gsk.com; Tel.: +65-623-283-98
}

Received: 30 May 2017; Accepted: 29 June 2017; Published: 6 July 2017

\begin{abstract}
Asian countries bear the greatest burden of the disease, with a majority (59\%) of rabies-related deaths occurring in Asia. In order to promote best practices, we summarized national human vaccination guidelines across this region, to highlight differences and similarities and to discuss the aspects that would benefit from updates. National management guidelines for rabies were retrieved from various sources to extract information on rabies pre- and post-exposure prophylaxis (PrEP, and PEP), booster vaccination, and route of administration. Rabies guidelines recommendations for wound management and PrEP across Asia are broadly aligned to the World Health Organization (WHO) guidelines. For PEP, the 5-dose Essen, and the 4-dose Zagreb are the regimens of choice for intramuscular (IM), and the Thai Red Cross regimen for intradermal (ID), administration. Several national guidelines have yet to endorse ID vaccine administration. Most guidelines recommend rabies immunoglobulin in category III exposures. Booster recommendations are not included in all guidelines, with limited clarity on booster requirement across the spectrum of risk of rabies exposure. In conclusion, national recommendations across Asian countries differ and while some guidelines are closely aligned to the WHO recommendations, resource-saving ID administration and use of rational abbreviated schedules have yet to be endorsed.
\end{abstract}

Keywords: Asia; guidelines; prevention and control; rabies; vaccination

\section{Highlights}

- The recommended practices for rabies pre- and post-exposure prophylaxis vary widely from country to country in Asia.

- Overall, the WHO recommendations for wound management are consistent in national guidelines. The post-exposure prophylaxis (PEP) 5-dose Essen and 4-dose Zagreb intramuscular (IM) regimens are uniformly recommended.

- The value of intradermal (ID) administration in reducing costs is not considered in several country guidelines.

- In the majority of the national recommendations, concurrent administration of rabies immunoglobulin (RIG) in category III exposures is recommended; however, there are concerns regarding availability and cost.

- Booster recommendations are not included in all guidelines, with limited clarity on booster requirement across the spectrum of risk of rabies exposure.

- Limited recommendations are available for special populations including pregnant women, aged population, and immunocompromised patients. 


\section{Introduction}

Despite being entirely preventable, human rabies is estimated to cause 59,000 global deaths annually, of which 59\% occur in the Asia region [1,2]. Bites from infected dogs cause $95 \%$ of human rabies deaths, $40 \%$ of which occur in children [3,4]. If prompt vaccination is not given, rabies infection causes death in virtually all cases [3]. However, the death toll can be considerably reduced through access to post-exposure prophylaxis (PEP), consisting of wound cleaning, rabies immunoglobulin (RIG) and vaccination. Additionally, the broader use of pre-exposure (PrEP) vaccination and mass dog vaccination would further reduce deaths and help control and eventually eliminate dog-mediated human rabies $[1,4,5]$. Human and canine rabies control are therefore interdependent, and experience has shown that a collaboration between human and animal health sectors is required to enhance cost-effectiveness of rabies control measures, and effectively reduce rabies incidence and associated societal burden [6-8]. This approach, under the "One Health" framework, with the goal to eliminate dog-mediated rabies by 2030, is endorsed and jointly advocated by the World Health Organization (WHO), the World Organisation for Animal Health (OIE), the Food and Agriculture Organization of the United Nations (FAO), and the Global Alliance for Rabies Control (GARC) [5].

Activities aiming to control rabies disease have been initiated, and some governments of disease-endemic countries have committed to its elimination by 2030. In this process, it is important to have reliable country-level epidemiology data, active surveillance systems seeking to register any new cases, appropriate vaccine requirement forecasting, and other such tools that can track progress made towards achieving this goal [3].

However, national reporting systems and public awareness are often lacking [2,3]. People living in countries with endemic rabies disease are sometimes insufficiently aware of the risk and the need for vaccination. Furthermore, the total cost of vaccination-including, for instance, travel expenses to-and-from the vaccination center, and lost work income-is a major consideration for these individuals [2,4,9-13]. Moreover, healthcare personnel are sometimes unaware of appropriate wound management, of PEP regimens, and of the existence of PrEP [4,14].

In this context, safe and effective, yet cost-saving and/or shorter regimens are appealing. Both intramuscular (IM) and intradermal (ID) vaccine schedules are endorsed by the WHO (Table 1). ID administration requires fewer vaccine vials than IM, reducing the direct vaccination cost by 60-80\% [13]. For optimal cost benefit of the ID administration, the health seeking rate should be sufficiently high to utilize the entire vial within 6-8 h [1,13]. Importantly, patients receiving IM or ID cell culture rabies vaccination should reach $0.5 \mathrm{IU} / \mathrm{mL}$ or higher titers of rabies virus neutralizing antibodies (RVNA) within 14 days from vaccination (the level considered indicative of adequate immune response to vaccination). Both vaccines administration methods demonstrate acceptable safety profiles. In this respect, in an otherwise healthy population, ID vaccination is clinically equivalent to that of IM [13]. The shorter, dose-sparing vaccination regimens are equally effective alternatives, improving compliance and allowing for more animal bite victims to successfully complete a full vaccination course [1,13,15-20]. However, these have not yet been endorsed by all countries with endemic disease in Asia region. To achieve the 2030 goal for rabies elimination, national PrEP and PEP strategies and clear public health guidelines following WHO recommendations must be implemented to increase access to vaccination with optimal efficacy of the vaccine and control the disease [1,4]. A Working Group on rabies vaccines and rabies immunoglobulins established by the WHO Strategic Advisory Group of Experts on Immunization (SAGE) is currently reviewing new evidence on country practices in the use of RIG, PrEP, and the cost-effectiveness of the interventions. The findings will be discussed and SAGE will consider recommendations on the WHO position on rabies during its October 2017 meeting [21,22]. 
Trop. Med. Infect. Dis. 2017, 2, 23

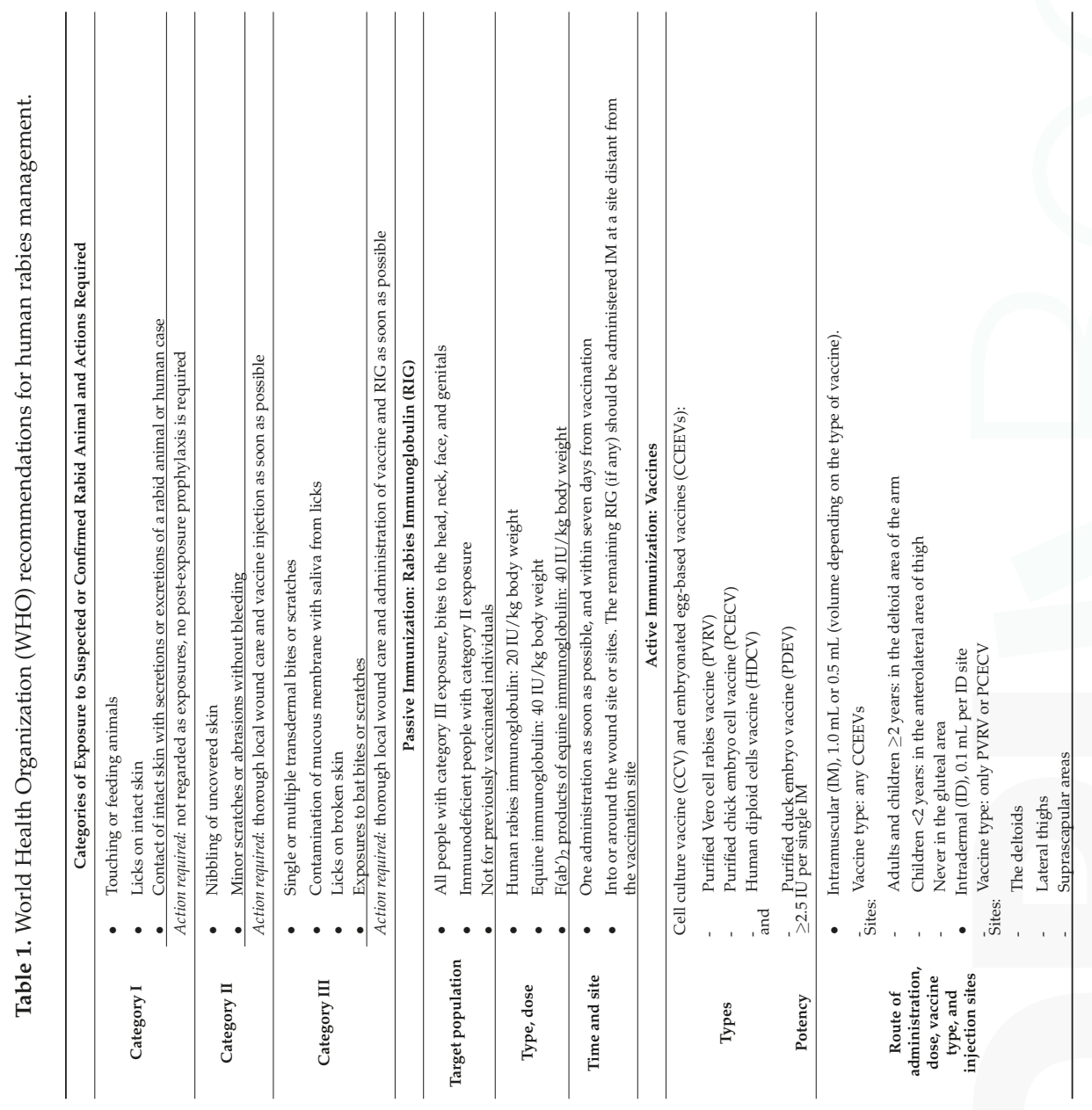




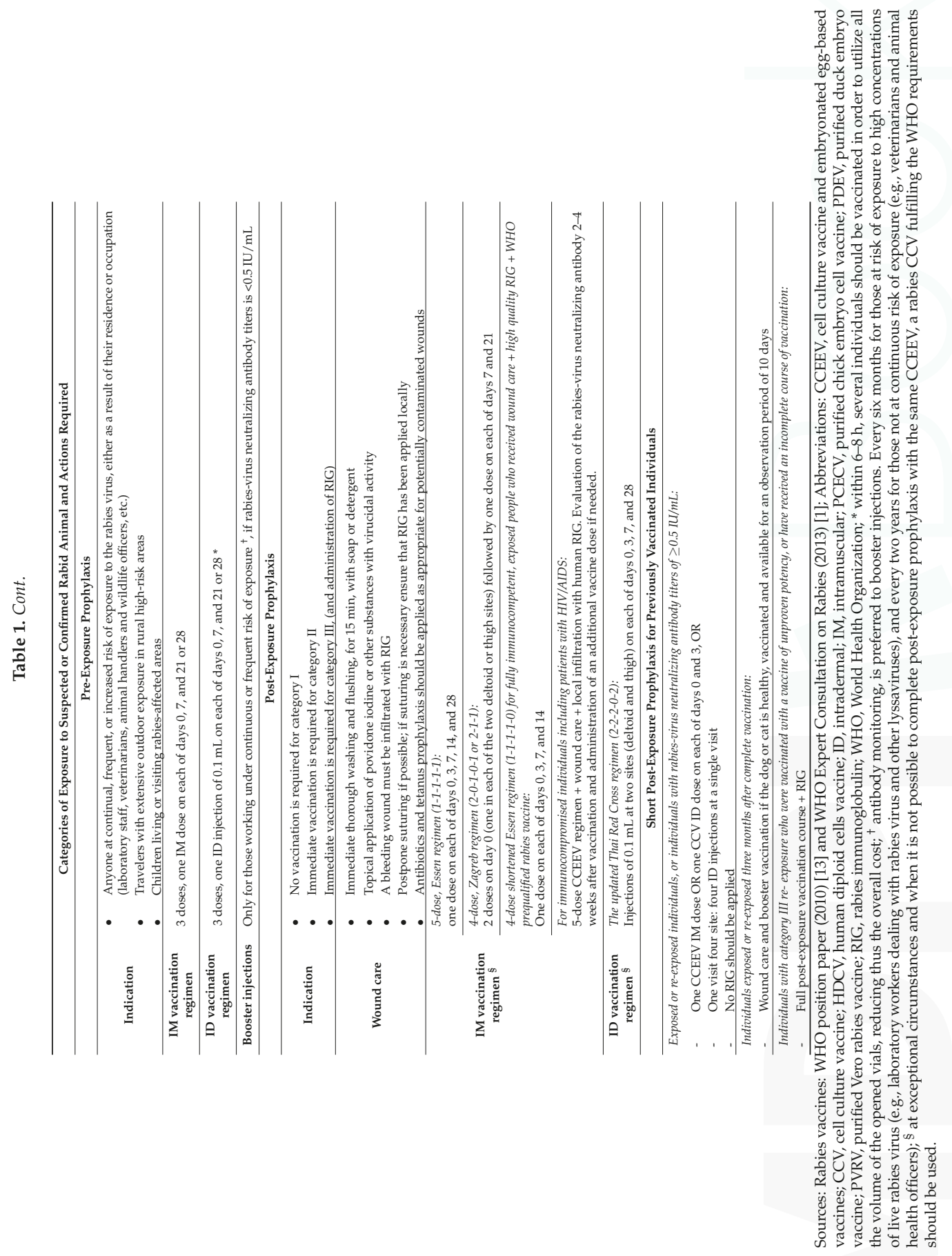


We collected current national human vaccination recommendations across Asia to summarize and highlight differences and similarities, and to identify best practices. The ultimate aim was to increase knowledge of current needs and identify gaps, in turn encouraging adoption of uniform rabies vaccination methods across all countries to ensure optimization of resource utilization.

\section{Methods}

We aimed to retrieve national guidelines on management of human rabies exposures from 21 Asian countries: Bangladesh, Bhutan, Brunei, Cambodia, China, Hong Kong, India, Indonesia, Japan, Lao People's Democratic Republic (PDR), Malaysia, Myanmar, Nepal, Pakistan, Philippines, Republic of Korea, Singapore, Sri Lanka, Taiwan, Thailand, and Vietnam. The research for the guidelines was performed between January and March 2017. Our investigation included scientific literature review searches, Ministry of Health web pages, other web pages (e.g., travel information pages), surveillance platforms and databases, medical association guidelines, publications for healthcare professionals and the public, and personal communications with people working on the specific field in each country. English and country-specific websites were reviewed in the local language. Due to the nature of this research, systematic review methods could not be applied. Indeed, national guidelines are not expected to be necessarily published in scientific journals, hence this work did rely mostly on information provided by Ministry of Health websites (often in local language), by national experts, etc. Findings were classified by document type, publisher, and year of publication. We aimed (a) to summarize PEP and PrEP recommendations and compare them to the WHO recommendations; (b) to explore variations between countries in human rabies prophylaxis and discuss opportunities for a harmonized approach; (c) to identify pitfalls and drawbacks in the adaptation of successful human rabies treatment and prophylaxis programs sufficiently harmonized with the WHO recommendations; (d) to highlight best practices.

\section{Findings}

\subsection{Overall Findings}

We retrieved national vaccination guidelines from 13 of the 21 countries considered: Bangladesh [23], Bhutan [24], Cambodia [25], China [26], India [27,28], Indonesia [29], Malaysia [30], Pakistan [31], Philippines [32], Sri Lanka [33], Taiwan [34], Thailand [35], and Vietnam [36]. Official documents, outlining current rabies prevention and treatment practices, were retrieved for Hong Kong [37-39], Japan [40], Lao PDR [41], and the Republic of Korea [42]. The national guidelines retrieved were usually issued by the Ministry of Health. We did not succeed to retrieve national documentation for four countries: Brunei, Myanmar, Nepal, and Singapore (Figure 1 and Table 2).

As expected, all national guidelines were considerably detailed and incorporated the WHO recommendations for PrEP and PEP vaccination. All recommended vaccines were cell culture vaccines and embryonated egg-based vaccines (CCEEVs). The schedules are summarized in Table 2. Overall characteristics are given below.

\subsection{Post-Exposure Prophylaxis (PEP)}

\subsubsection{Wound Care}

Overall, the WHO recommendations for wound management are consistent in national guidelines. The guidelines from China [26], India [27], and Pakistan [31] were more detailed than others, containing explicit recommendations for wound care with photographs. The Indian [27], Pakistani [31], Philippine [32], and Sri Lankan [33] guidelines recommend avoidance of wound suturing to allow for antibody (RIG) diffusion throughout the tissues, unless there is life-threatening bleeding. The Pakistani guidelines recommend daily dressing instead of suturing, except for very loose suturing for severe facial bites, with proper suturing 2-3 days after initial wound management [31]. Cauterization is no 
longer recommended in India as it does not offer additional benefit over washing while tetanus and antibiotics should be given if required, and if sepsis prevention is needed [27]. The Philippines recommend adhesive strips as an alternative to suturing, and also include detailed recommendations on antibiotic treatment [32]. In Sri Lanka, wound dressing is recommended, but not suturing [33].

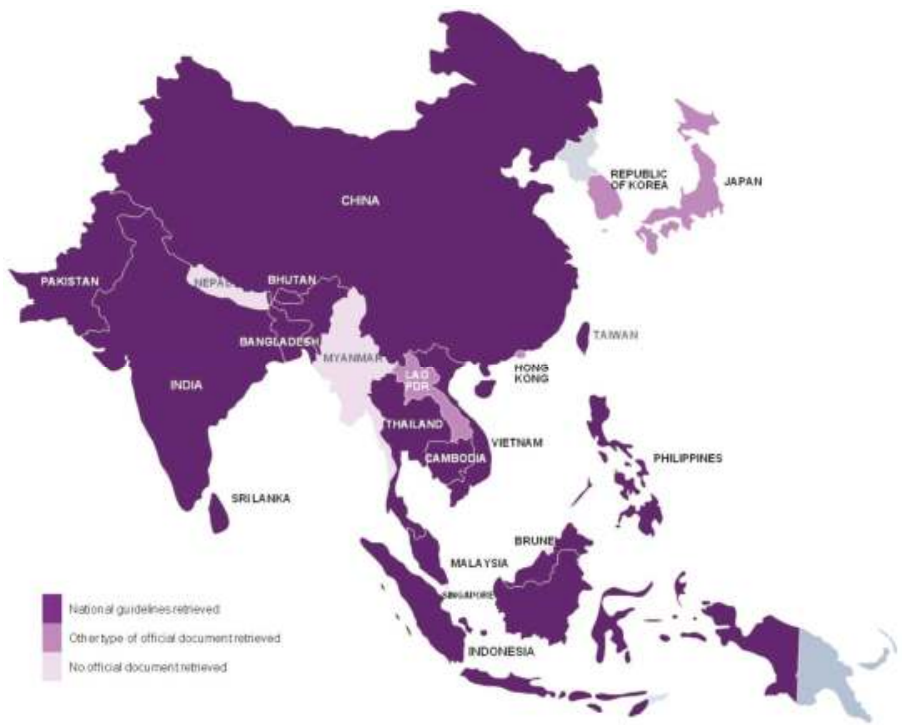

Figure 1. Countries for which national guidelines or other type of rabies-related official document on rabies human vaccination schedules were retrieved and included in the analysis.

\subsubsection{RIG}

Most guidelines follow WHO recommendations regarding RIG administration; however, there are some concerns related to the associated cost. Thus, for Lao PDR, the 2000 WHO report shows that RIG is rarely used due to its high cost [41], and in a number of countries [25,32,35], equine immunoglobulin (ERIG) is more commonly used than human immunoglobulin (HRIG) because it is cheaper and therefore more commonly available for free. The Philippine guidelines also contain details on the size of needles, skin tests to check whether human RIG should be preferred, special considerations for bites to the finger and toes, and they recommend HRIG for multiple bites and in symptomatic patients infected with human immunodeficiency virus (HIV) [32].

\subsubsection{PEP Vaccination Schedules}

- $\quad$ The 5-dose Essen, 4-dose Zagreb, or both schedules were the regimens of choice for IM administration. The Essen is used in Bhutan, Cambodia, China, India, Philippines, Sri Lanka, Taiwan, Thailand, Vietnam; and Zagreb in Bangladesh, Cambodia, China, Indonesia, Pakistan, Philippines, Sri Lanka (Table 2). The 4-dose shortened Essen was the regimen of choice in the Malaysian recommendations, and was also recommended in the guidelines of Philippines (Tables 2 and 3).

- We found recommendation for ID administration in 9 of the 13 retrieved national guidelines; the guidelines of China, Indonesia, Malaysia, and Taiwan do not include such recommendation (Tables 2 and 3). Also in the official documents retrieved for Japan and Lao PDR we did not find ID recommendations (Tables 2 and 3). All guidelines with ID recommendation suggested the updated Thai Red Cross regimen (Tables 2 and 3).

- $\quad$ The Japanese guidelines recommend only subcutaneous (SC) administration as shown in Table 2. 


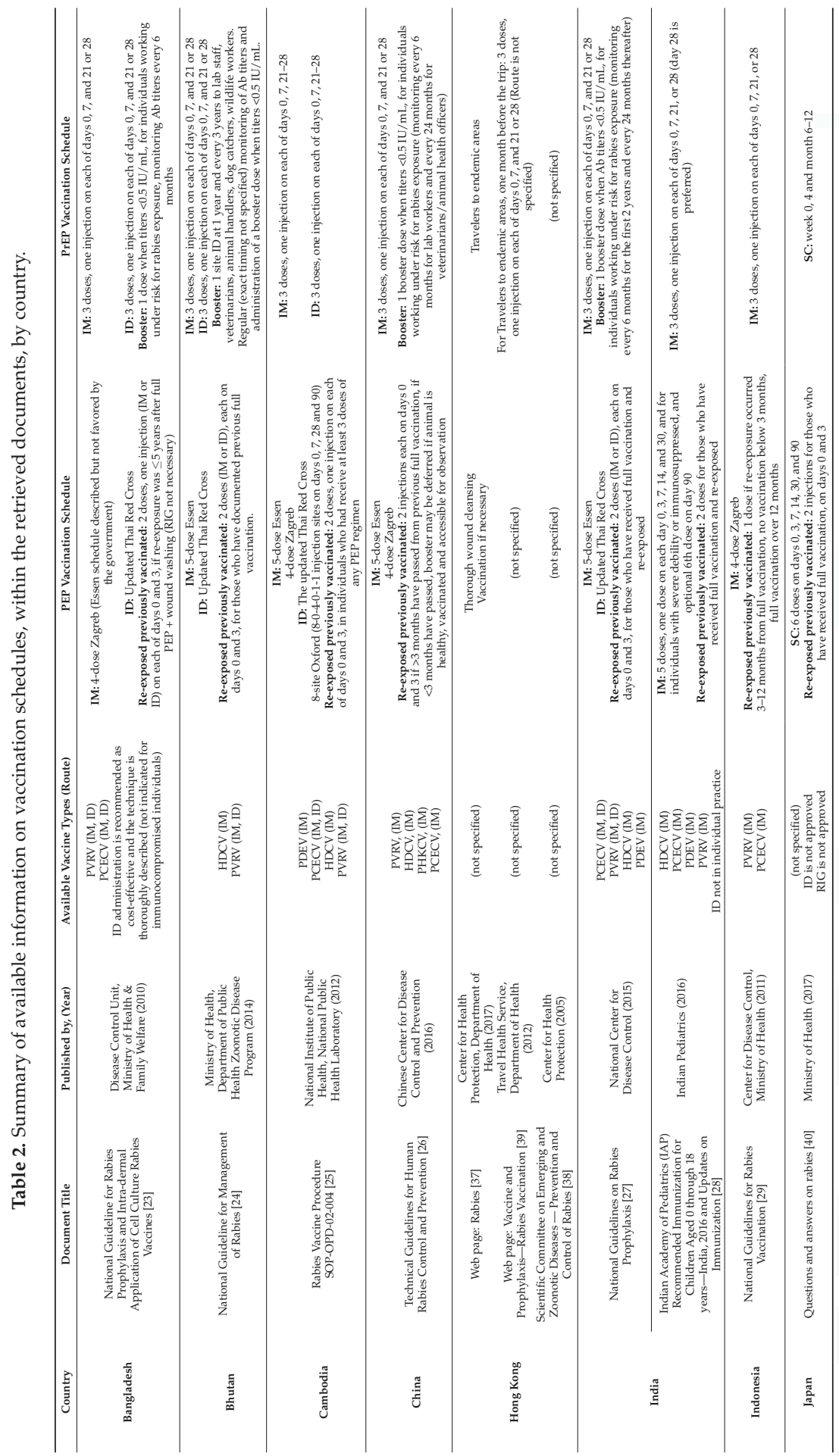




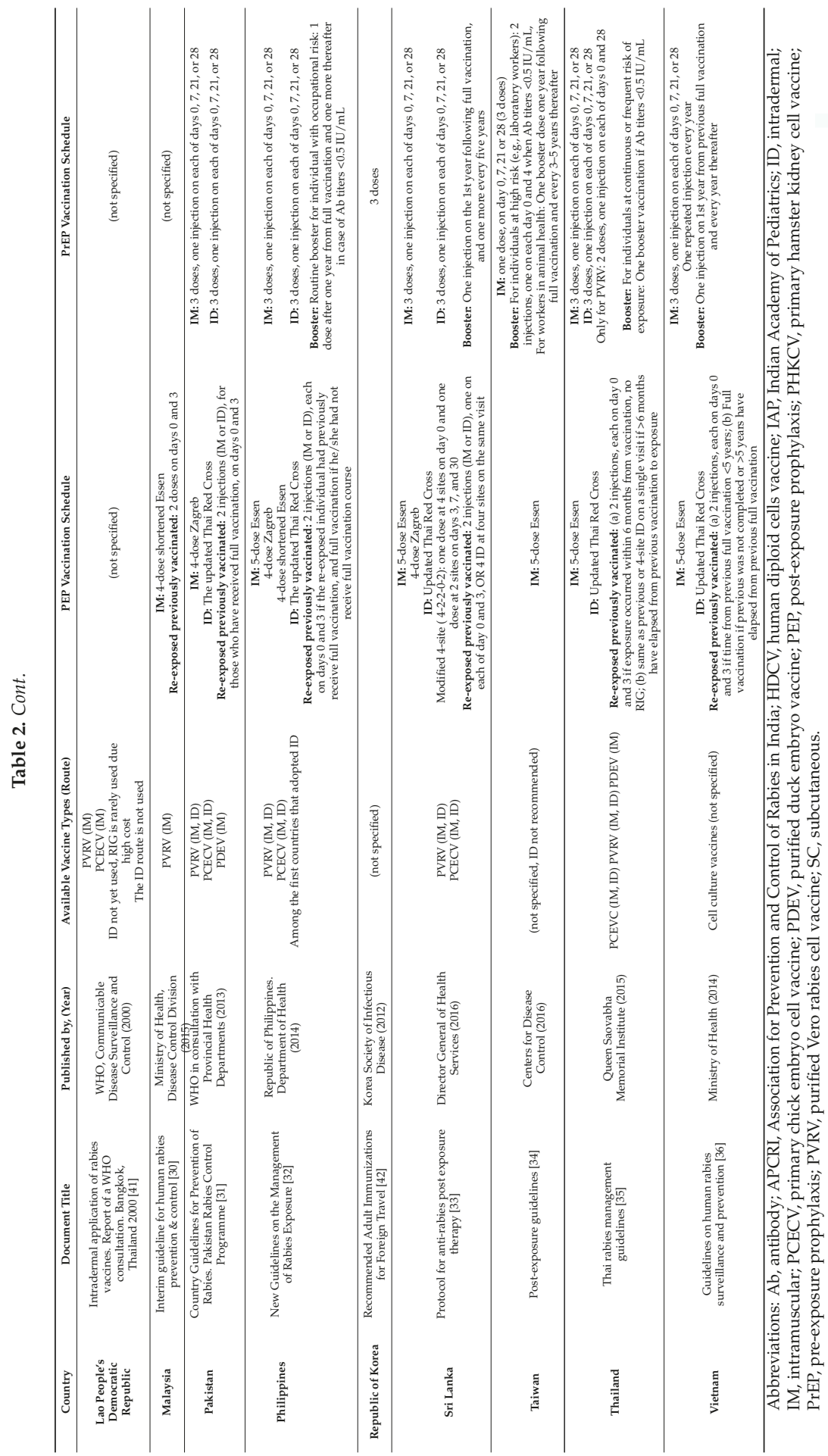


Table 3. National guidelines endorsing the WHO recommended PEP vaccination regimens: Essen, Zagreb, and the updated Thai Red Cross.

\begin{tabular}{|c|c|c|c|c|}
\hline Country & $\begin{array}{c}\text { 5-Dose Essen } \\
(1-1-1-1-1)\end{array}$ & $\begin{array}{c}\text { 4-Dose Zagreb } \\
(2-0-1-0-1 \text { or } 2-1-1)\end{array}$ & $\begin{array}{l}\text { 4-Dose Essen } \\
(1-1-1-1-0)\end{array}$ & $\begin{array}{l}\text { Updated Thai Red } \\
\text { Cross }(2-2-2-0-2)\end{array}$ \\
\hline Bangladesh & $x$ & $x$ & & $x$ \\
\hline Bhutan & $x$ & & & $x$ \\
\hline Cambodia & $X$ & $x$ & & $x$ \\
\hline China & $x$ & $x$ & & \\
\hline India & $x$ & & & $x$ \\
\hline Indonesia & & $x$ & & \\
\hline Malaysia & & & $x$ & \\
\hline Pakistan & & $x$ & & $X$ \\
\hline Philippines & $x$ & $x$ & $x$ & $x$ \\
\hline Sri Lanka & $x$ & $x$ & & $x$ \\
\hline Taiwan & $x$ & & & \\
\hline Thailand & $x$ & & & $x$ \\
\hline Vietnam & $X$ & & & $x$ \\
\hline
\end{tabular}

\subsubsection{PEP Vaccination for Re-Exposed Individuals}

Not all guidelines advise on the post-exposure management that should be followed when an individual who has previously received rabies vaccination is re-exposed (Table 2). The guidelines of Bangladesh [23], Bhutan [24], China [26], India [27], and Philippines [32] recommend new full vaccination when previous full exposure cannot be documented or is uncertain.

\subsection{Pre-Exposure Prophylaxis (PrEP)}

\subsubsection{PrEP Vaccination Schedules}

With the exception of Japanese guidelines, all other guidelines recommend IM or ID vaccination schedules (Table 2). IM administration is included in all of the 13 retrieved national guidelines. ID is included in only seven national guidelines, these of Bangladesh, Bhutan, Cambodia, Pakistan, Philippines, Sri Lanka, and Thailand (Table 2). The Malaysian interim guidelines do not include any reference to PrEP [30].

\subsubsection{Booster after PrEP Vaccination}

Eight national guidelines include booster recommendations and there are differences between countries; all relevant recommendations are described in detail in Table 2. For individuals working under a high risk (laboratory workers dealing with rabies virus and other lyssaviruses) or continuous risk (veterinarians and animal health officers) of exposure to rabies, all recommendations agree that a booster vaccination should be given when antibody titers fall below $0.5 \mathrm{IU} / \mathrm{mL}$.

\subsection{Vaccination Recommendations for Special Populations}

We found PEP recommendations for special populations in the guidelines of Bangladesh [23], Bhutan [24], Cambodia [25], China [26], India [27], Malaysia [30], Pakistan [31], Philippines [32], and Sri Lanka [33]. Chinese guidelines have an additional entry for PrEP recommendations in those populations [26].

\section{PEP recommendations}

- Pregnant and lactating women: The guidelines of Bangladesh, Bhutan, Cambodia, India, Pakistan, Philippines, and Sri Lanka state that there is no contraindication for vaccination in this population. The Chinese guidelines do not directly state whether PEP should be given or not, however they 
make reference to studies demonstrating that rabies vaccines are safe for pregnant women and for the fetus.

- Aged population and individuals with comorbidities: the same as above in the guidelines of Bangladesh, India, Pakistan, Philippines, and Sri Lanka.

- Immunocompromised population: full PEP and IM route is recommended in the guidelines of Bangladesh, Bhutan, India, Malaysia, Philippines, and Sri Lanka. There is no special reference to this population in the guidelines of Cambodia and Pakistan. Chinese guidelines indicate that passive immunization can be administered in patients with immunodeficiency disorder and that the antibody response should be closely monitored.

- Individuals on treatment for malaria taking chloroquine: ID is contraindicated and IM is recommended in the guidelines of Bangladesh, Cambodia, India, Malaysia, Pakistan, Philippines, and Sri Lanka.

- Other populations: Philippine's guidelines also note that IM is contraindicated for individuals with hematologic conditions, for whom the ID route should be chosen and that ID is contraindicated for individuals with chronic liver disease.

Chinese PrEP recommendations: Only in the Chinese guidelines, we found recommendations specific to PrEP. According to these, PrEP can be delayed in case of (a) pregnancy; (b) acute febrile disease or other acute disease; (c) active chronic disease; (d) use of steroids and immunosuppressive products. PrEP is not recommended for patients with immunodeficiency disease.

\section{Discussion}

\subsection{Characteristics of Human Rabies Burden}

In endemic areas rabies disease is largely underreported, and reliable occurrence data are often scarce or non-existent [2,3,43]. Patients often seek no treatment [44], and some leave hospital against medical advice believing there is no cure [45] or because treatment cannot be offered [3]. Laboratory confirmation is sought in only a limited number of cases $[44,46]$ because of limited resources and training [46,47]. Information systems for the collection of rabies cases may not be available [46] and often local authorities do not report rabies cases to central authorities $[44,46]$. In many countries, the officially reported numbers of rabies cases and deaths are substantially lower than the actual numbers [1]. In Cambodia for example, the incidence of human rabies deaths was estimated to be 5.8 per 100,000 , which was 15 times higher than the officially reported incidence [48].

Younger children who are unable to protect themselves are at higher risk because they may interact with dogs in a manner perceived as threatening by the animal, e.g., stepping on the tail or trying to play when the dogs are eating $[3,4,49,50]$. Because of their smaller stature, children are more prone to get bitten multiple times on the face, head, and neck, being thus exposed to the more severe type of bites with the shortest incubation period [51,52]. Furthermore, children do no not always report minor bites or exposures by licks to their parents [52,53].

\subsection{Rabies: An Unjustified Disease Burden}

The development of vaccines against rabies started 100 years ago, and highly effective life-saving vaccines are currently available [19]. There is also a heightened awareness of rabies symptoms and inevitable fatal outcome without appropriate treatment $[5,54,55]$. Despite these advances, important knowledge gaps still exist. For example there are still those unaware that the wound must be immediately washed with soap and water $[55,56]$, or that a laboratory test can confirm or reject suspected rabies in biting animal [55]. Furthermore, the rural population has limited access to vaccination centers as they are usually located in big cities, many animal bite victims do not seek medical care, and most infected individuals die at home [2,13]. In addition, RIG is often not made available because a large fraction of the population cannot afford it [56,57]. Poor people, living far from 
vaccination centers cannot afford to travel back-and-forth for injections, even if the vaccine is provided free of charge, and they often fail to complete complicated vaccination schedules [48,56]. The problem is further accentuated by a lack of access to vaccines and RIG globally.

\subsection{Rabies Vaccination Schedules Across Asia: Current Situation}

\section{PEP Recommendations}

Adequate wound cleaning can reduce the number of infectious viral particles inoculated via saliva during the bite from the rabid animal [58]. Improper or incomplete wound care is one of the reasons for PEP failure [59]. Thorough washing of the wound can eliminate or substantially reduce the viral load [60]. Unfortunately, this critical intervention is often undervalued or ignored [60]. The level of detail on wound washing techniques were highly heterogeneous in the national guidelines, suggesting a local need for specific operational guidelines on wound treatment.

Although international guidelines on the provision of RIG are clear, local recommendations are often different and almost universally the use of RIG in practice is not aligned to international recommendations due to significant access barriers [61].

The 5-dose Essen and 4-dose Zagreb IM regimens are considered equivalent in countries where both are recommended, except for the Bangladeshi guidelines that clearly favor the Zagreb regimen. The Zagreb regimen, however, is not endorsed by all national guidelines.

ID PEP vaccination was endorsed in nine national guidelines; however, the value of ID administration in reducing costs was not considered regarding PEP in six national guidelines or other official documents. Clearly, there is still a need to emphasize the cost savings achieved using ID administration as opposed to the cost of the five IM regimen of similar vaccine efficacy. However, these cost savings can only occur in facilities with well-trained staff and with sufficient patients presenting with bite wounds to ensure that the maximum number of doses are extracted per vial of vaccine. With no preservative in the available vaccines, the vial should not be left open for longer than $6-8 \mathrm{~h}[1,13]$ and for smaller clinics this will not result in any cost saving vs. IM.

There are limited recommendations on the vaccination of patients who have a history of vaccination against rabies (PEP or PrEP). This could lead to overtreatment of patients presenting for treatment on multiple occasions. Given the risk factors for being bitten are associated with socio-economic factors, e.g., rural environments, working outdoors, it is likely that those who receive a bite are at a higher risk of subsequent bites than the general population. As such, multiple exposures are likely to occur. Clearer guidance could result in reduced use of vaccine and, where available, RIG for these patients.

Pregnancy, lactation, infancy, older age and comorbidities are not considered contraindications in the few guidelines that make reference to vaccination for special populations. Immunosuppressed individuals might have an inadequate antibody response in rabies PEP; however, specific recommendations can be found in very few guidelines.

\subsection{PrEP Recommendations}

Most country recommendations on patients for whom PrEP should be considered are aligned to WHO. Although recommendations are in place, uptake remains low because of complicated schedules, cost, and competing priorities especially within the context of limited PEP vaccine supply or resources for rabies control [62]. Less complicated vaccination schedules with shorter regimens and fewer doses would make PrEP simpler and reduce associated costs [62]. In addition, educational campaigns and rabies prevention and elimination programs should be conducted in areas where the infection rate is high; one such program was introduced in 2007 in the Bohol district of the Philippines, an area with the highest rabies incidence in the country [63]. The program included free routine PrEP for children aged 5-14 years and lasted four years (2007-2010) [52,62]. Up to April 2010, this program achieved high PrEP vaccination coverage (47\%) of the target population [62]. 
Booster recommendations are not included in all guidelines and this may become an additional impediment to the optimal use of PrEP as there is little agreement on duration of protection or clinical benefit. Guidelines are more established for individuals at continual risk (lab workers, veterinarians, animal health workers) than for individuals at increased risk (children living in endemic areas, or travelers), and the intervals for serological follow-up (a test that is not consistently available everywhere) vary. It should also be noted that serological follow-up, even when recommended, is rarely practical or affordable. PrEP may be associated with cost savings because a previously vaccinated person needs shorter PEP and no RIG [62]. Children may benefit from receiving PrEP from 1 year of age and clear boosting recommendations are needed [62].

\subsection{Country-Specific Information for Countries Whose National Guidelines Were Not Retrieved}

In Hong Kong public hospitals, 10,255 individuals received PEP between 2000 and 2004, all of whom received rabies vaccine and 1\% also received RIG [38]. The country's rabies control program contains disease surveillance systems, laboratory diagnostic testing, PEP, and wound management [38].

For Lao PDR, the SEARS initiative (South-East Asia Rabies Strategy, 2013) indicates the rabies control program was not clearly defined, human resources were short, the surveillance system was inadequate, and laboratory confirmation was unavailable [64].

Brunei and Singapore are considered as free-of-rabies areas [43]. Singapore has been free from rabies since the 1950s and this was achieved through specific legislation, with which several rabies prevention strategies were implemented [43].

For Myanmar, the Association of Southeast Asian Nations 2016 report drew attention to the lack of a national rabies control strategy, low level of awareness and surveillance, and limited funding for rabies control [43].

In Nepal, public hospitals provide free post-exposure vaccination since 2007 [65]. RIG is available only in Kathmandu, and even there is mainly used by tourists and expats who can afford it [65].

\subsection{Future Perspective}

The Sustainable Development Goals (SDG), established by the September 2015 UN General Assembly, included the target to end epidemics of Neglected Tropical Diseases (NTDs) by 2030 [66]. Coinciding with these SDGs, WHO and OIE in collaboration with the FAO and supported by the GARC, have jointly set the goal for rabies elimination by 2030 [3,5]. Lessons learned from areas of the world where rabies has been successfully eliminated show that the "One Health" agenda will be the only way to achieve the 2030 goal of elimination of disease in Asia [5]. This framework resulted in substantial decrease in dog rabies incidence in 21 countries of Latin America and the Caribbean region, and several countries have been declared free of human rabies cases [67]. This was achieved thanks to a strong political commitment to control rabies in coordination with the Pan American Health Organization (PAHO). The program promoted mass canine vaccination, epidemiological surveillance, and provision of PEP and PrEP to people at risk. PEP became broadly available and, as part of the program, rabies vaccination centers were decentralized. PAHO's Veterinary Public Health Program provided technical support for a disease notification system and coordinated actions between Ministries of Agriculture and Health and the executive councils of the WHO and OIE. Community education and involvement was part of the program to engage people in mass dog vaccination. The educational resources of the GARC were used to achieve this. Mass media campaigns on the radio, and in schools, health facilities, and similar organizations were staged to convince people to have their dogs vaccinated [67]. Similarly, in 2015, the Pan-African Rabies Control Network was launched, to integrate the One Health approach in the 33 member states, aiming to meet the 2030 target [68]. In a similar way, the Association of Southeast Asian Nations (ASEAN) developed the ASEAN Rabies Elimination Strategy in a One Health approach, integrating political, organizational, sociocultural, and technical collaboration to achieve rabies elimination by 2020 in the ASEAN member states, plus China, Japan, and Korea [43]. 
It is hoped that findings presented here might be useful to the authorities, health care providers, and patient organizations in the development and implementation of their initiatives for rabies elimination. This is more likely attainable through increased awareness of disease and encouraging the adoption of uniform rabies vaccination across Asia to ensure optimization of resource utilization, most often in resource-constrained environments. In that respect, the findings of the SAGE Working Group on rabies vaccines and rabies immunoglobulins will be highly significant.

To the best of our knowledge, this was the first work summarizing national rabies guidelines of the endemic Asian countries. However, we were unable to recover all national guidelines. Lack of information on vaccines' origin and shortages are further limitations. Our work could not retrieve real-life data on proportions of use of ID and IM; a future prospective study would be necessary in that respect.

\section{Conclusions}

National recommendations across these countries differ and while some guidelines are closely aligned to the WHO recommendations, other countries specify PEP schedules that are very demanding on resources. A lot of progress has been made with respect to rabies control programs in many countries; however, efforts should be continued through closer collaboration between human and animal health sectors to meet the 2030 goal for rabies elimination. These efforts will have the opportunity to incorporate the most current findings of the SAGE Working Group on rabies vaccines and rabies immunoglobulins.

Acknowledgments: GlaxoSmithKline Biologicals S.A. funded all costs related to the development of this publication. The authors would like to thank Business \& Decision Life Sciences platform for editorial assistance and publication coordination, on behalf of GSK. Nathalie Arts coordinated publication development and provided editorial support and Athanasia Benekou provided medical writing support. The authors would also like to thank all the GSK Vaccines Medical Directors from Asia region for their kind collaboration and assistance to translate the national policies.

Author Contributions: All authors meet the ICMJE criteria for authorship of this publication, take responsibility for the integrity of the work as a whole and have reviewed and given final approval of the version to be published. All authors participated in the development of this manuscript. All authors had full access to the data and gave final approval before submission.

Conflicts of Interest: All authors are employees of the GSK group of companies. P.B. and V.S. hold shares in the GSK group of companies.

$\begin{array}{ll}\text { Abbreviations } \\ \text { Ab } & \text { antibody } \\ \text { APCRI } & \text { Association for Prevention and Control of Rabies in India } \\ \text { CCEEV } & \text { cell culture vaccine and embryonated egg-based vaccines } \\ \text { CCV } & \text { cell culture vaccine } \\ \text { ERIG } & \text { equine immunoglobulin } \\ \text { FAO } & \text { Food and Agriculture Organization } \\ \text { GARC } & \text { Global Alliance for Rabies Control } \\ \text { HDCV } & \text { human diploid cells vaccine } \\ \text { HIV } & \text { human immunodeficiency virus } \\ \text { HRIG } & \text { human immunoglobulin } \\ \text { IAP } & \text { Indian Academy of Pediatrics } \\ \text { ID } & \text { intradermal } \\ \text { IM } & \text { intramuscular } \\ \text { NTD } & \text { Neglected Tropical Diseases } \\ \text { OIE } & \text { World Organization for Animal Health } \\ \text { PAHO } & \text { Pan American Health Organization } \\ \text { PCECV } & \text { purified chick embryo cell vaccine }\end{array}$




$\begin{array}{ll}\text { PDEV } & \text { purified duck embryo vaccine } \\ \text { PEP } & \text { post-exposure prophylaxis } \\ \text { PHKCV } & \text { primary hamster kidney cell vaccine } \\ \text { PrEP } & \text { pre-exposure prophylaxis } \\ \text { PVRV } & \text { purified Vero rabies vaccine } \\ \text { RIG } & \text { rabies immunoglobulin } \\ \text { RVNA } & \text { rabies virus neutralizing antibodies } \\ \text { SAGE } & \text { Strategic Advisory Group of Experts } \\ \text { SC } & \text { subcutaneous } \\ \text { SDG } & \text { Sustainable Development Goals } \\ \text { SEARS } & \text { South-East Asia Rabies Strategy } \\ \text { UN } & \text { United Nations } \\ \text { WHO } & \text { World Health Organization }\end{array}$

\section{References}

1. World Health Organization. WHO Expert Consultation on Rabies (Second Report); World Health Organization: Geneva, Switzerland, 2013.

2. Hampson, K.; Coudeville, L.; Lembo, T.; Sambo, M.; Kieffer, A.; Attlan, M.; Barrat, J.; Blanton, J.D.; Briggs, D.J.; Cleaveland, S.; et al. Estimating the global burden of endemic canine rabies. PLoS Negl. Trop. Dis. 2015, 9, e0003709. [CrossRef]

3. Fahrion, A.; Mikhailov, A.; Abela-Ridder, B.; Giacinti, J.; Harries, J. Human Rabies Transmitted by Dogs: Current Status of Global Data, 2015; World Health Organisation: Geneva, Switzerland, 2016.

4. Food and Agriculture Organization of the United Nations (FAO). Developing a Stepwise Approach for Rabies Prevention and Control; FAO: Rome, Italy, 2013.

5. World Health Organization; World Organisation for Animal Health (OIE); Food and Agriculture Organization of the United Nations (FAO); Global Alliance for Rabies Control (GARC). Global Elimination of Dog-Mediated Human Rabies: The Time is Now; Report of the Rabies Global Conference, 10-11 December 2015, Geneva, Switzerland; World Health Organization: Geneva, Switzerland, 2015.

6. Lavan, R.P.; King, A.I.; Sutton, D.J.; Tunceli, K. Rationale and support for a One Health program for canine vaccination as the most cost-effective means of controlling zoonotic rabies in endemic settings. Vaccine 2017, 35, 1668-1674. [CrossRef] [PubMed]

7. Cleaveland, S.; Lankester, F.; Townsend, S.; Lembo, T.; Hampson, K. Rabies control and elimination: A test case for One Health. Vet. Rec. 2014, 175, 188-193. [CrossRef] [PubMed]

8. Wangdi, K.; Ward, M.P. Human and animal rabies prevention and control cost in Bhutan, 2001-2008: The cost-benefit of dog rabies elimination. Vaccine 2012, 31, 260-270. [CrossRef]

9. Maurya, I.; Vagholkar, K.; Patel, B.; Siddiqui, M.; Tiwari, S.; Maurya, P. State of globe: Rabies: The lethality since antiquity! J. Glob. Infect. Dis. 2015, 7, 1-2. [CrossRef] [PubMed]

10. Canine Rabies Blueprint. The Stepwise Approach towards Rabies Elimination: A Tool for Planning and Evaluation. Available online: http://caninerabiesblueprint.org/IMG/pdf/sare_outline_2017_f.pdf (accessed on 2 April 2017).

11. Sugiyama, M.; Ito, N. Control of rabies: Epidemiology of rabies in Asia and development of new-generation vaccines for rabies. Comp. Immunol. Microbiol. Infect. Dis. 2007, 30, 273-286. [CrossRef] [PubMed]

12. Dodet, B.; Goswami, A.; Gunasekera, A.; de Guzman, F.; Jamali, S.; Montalban, C.; Purba, W.; Quiambao, B.; Salahuddin, N.; Sampath, G.; Tang, Q.; Tantawichien, T.; Wimalaratne, O.; Ziauddin, A. Rabies awareness in eight Asian countries. Vaccine 2008, 26, 6344-6348. [CrossRef] [PubMed]

13. World Health Organization. Rabies Vaccines: WHO Position Paper; Weekly Epidemiological Record, No. 32 (85); World Health Organization: Geneva, Switzerland, 2010; Available online: http:/ /www.who.int/wer/2010/ wer8532.pdf?ua=1 (accessed on 6 April 2017).

14. Wilde, H. Failures of post-exposure rabies prophylaxis. Vaccine 2007, 25, 7605-7609. [CrossRef] [PubMed]

15. Madhusudana, S.N.; Mani, R.S. Intradermal vaccination for rabies prophylaxis: Conceptualization, evolution, present status and future. Expert Rev. Vaccines 2014, 13, 641-655. [CrossRef] [PubMed] 
16. Narayana, A.; Manoharan, A.; Narayan, M.S.; Kalappa, S.M.; Biligumba, G.; Haradanahalli, R.; Anand, A.M. Comparison of safety and immunogenicity of 2 WHO prequalified rabies vaccines administered by one week, 4 site intradermal regimen (4-4-4-0-0) in animal bite cases. Hum. Vaccines Immunother. 2015, 11, 1748-1753. [CrossRef] [PubMed]

17. Tarantola, A.; Blanchi, S.; Cappelle, J.; Ly, S.; Chan, M.; In, S.; Peng, Y.; Hing, C.; Taing, C.N.; Ly, S.; et al. Rabies postexposure prophylaxis (PEP) noncompletion after dog bites: Estimating the unseen to meet the needs of the underserved. Am. J. Epidemiol. 2017, (accepted for publication).

18. Dhaduk, K.M.; Unadkat, S.V.; Katharotiya, P.R.; Mer, A.R.; Chaudhary, M.C.; Prajapati, M.M. Case profile, volume analysis, and dropout rate of antirabies vaccination regimens among animal bite victims in Gujarat. Indian J. Public Health 2016, 60, 268-272. [CrossRef] [PubMed]

19. Tarantola, A. Four thousand years of concepts relating to rabies in animals and humans, its prevention and its cure. Trop. Med. Infect. Dis. 2017, 2. [CrossRef]

20. Mahendra, B.J.; Narayana, D.A.; Agarkhedkar, S.; Ravish, H.S.; Harish, B.R.; Agarkhedkar, S.; Madhusudana, S.N.; Belludi, A.; Ahmed, K.; Jonnalagedda, R.; et al. Comparative study on the immunogenicity and safety of a purified chick embryo cell rabies vaccine (PCECV) administered according to two different simulated post exposure intramuscular regimens (Zagreb versus Essen). Hum. Vaccines Immunother. 2015, 11, 428-434. [CrossRef] [PubMed]

21. World Health Organization. Strategic Advisory Group of Experts (SAGE) Working Group on Rabies Vaccines and Rabies Immunoglobulins (Established July 2016). Available online: http:/ /www.who.int/ immunization/policy/sage/sage_wg_rabies_jul2016/en/ (accessed on 22 June 2017).

22. World Health Organization. Human Rabies: 2016 Updates and Call for Data; World Health Organization: Geneva, Switzerland, 2017.

23. Bangladesh Disease Control Unit Directorate General of Health Services. National Guideline for Rabies Prophylaxis and Intra-Dermal Application of Cell Culture Rabies Vaccines; Ahmad, Z., Amin, R., Ussaman, S., Jamil, M., Ahmed, M., Eds.; Ministry of Health \& Family Welfare: Dhaka, Bangladesh, 2010.

24. Royal Government of Bhutan Ministry of Health Department of Pubic Health Zoonotic Disease Program. National Guideline for Management of Rabies, 2nd ed.; Royal Government of Bhutan Ministry of Health: Thimphu, Bhutan, 2014.

25. Vanneth, D. Rabies Vaccine Procedure SOP-OPD-02-004, Rev. 2; National Institute of Public Health: Phnom Penh, Cambodia, 2012.

26. Zhou, H.; Li, Y.; Chen, R.F.; Tao, X.Y.; Yu, P.C.; Cao, S.C.; Li, L.; Chen, Z.H.; Zhu, W.Y.; Yin, W.W.; et al. Technical guideline for human rabies prevention and control (2016). Zhonghua Liu Xing Bing Xue Za Zhi 2016, 37, 139-163. [PubMed]

27. Indian National Centre for Disease Control. National Rabies Control Programme. National Guidelines on Rabies Prophylaxis; Directorate General of Health Services: Sham Nath Marg, Delhi, India, 2015.

28. Vashishtha, V.M.; Choudhary, J.; Jog, P.; Yadav, S.; Unni, J.C.; Kamath, S.; Sachdeva, A.; Srirampur, S.; Prajapati, B.; Parekh, B.; et al. Indian Academy of Pediatrics (IAP) recommended immunization schedule for children aged 0 through 18 years-India, 2016 and updates on immunization. Indian Pediatr. 2016, (accepted for publication).

29. Indonesia Kementerian Kesehatan RI Directorat Jenderal PP dan PL. Pedoman Pelaksanaan Program Penanggulangan Rabies Di Indonesia; Indonesia Ministry of Health: Jakarta, Indonesia, 2011.

30. Malaysia Disease Control Division, Ministry of Health. Interim Guideline for Human Rabies Prevention \& Control in Malaysia; Ministry of Health: Putrajaya, Malaysia, 2015.

31. Pakistan Rabies Control Programme. Country Guidelines for the Prevention of Rabies; World Health Organization in consultation with Provincial Health Deaprtments: Geneva, Switzerland, 2013.

32. Republic of the Philippines. New Guidelines on the Management of Rabies Exposures; Department of Health Office of the Secretary: Manila, Philippines, 2014.

33. Mahipala, P.G.; Director General of Health Services. Protocol for Anti-Rabies Post Exposure Therapy (PET); Medical Research Institute: Colombo, Sri Lanka, 2016.

34. Taiwan Center for Disease Control. (2016) Rabies Post Exposure Guidelines. Dissertation. Available online: http:/ / www.cdc.gov.tw / professional/page.aspx?treeid=beac9c103df952c4\&nowtreeid=b2db963d0bad6639 (accessed on 17 May 2017). 
35. Thai Department of Disease Control MOPH. Rabies Guideline and Frequent Questions; Thai Department of Disease Control MOPH: Nonthaburi, Thailand, 2015.

36. Socialist Republic of Vietnam, Ministry of Health. Guidelines on Human Rabies Surveillance and Prevention; Ministry of Health: Hanoi, Vietnam, 2014.

37. Hong Kong Center for Health Protection, Department of Health The Goverment of Hong Kong Special Administrative Region. Rabies. Available online: http:/ /www.chp.gov.hk/en/content/9/24/3149.html (accessed on 29 March 2017).

38. Hong Kong Center for Health Protection. Scientific Committee on Emerging and Zoonotic Diseases—Prevention and Control of Rabies; Hong Kong Center for Health Protection: Kowloon, Hong Kong, China, 2005.

39. Hong Kong Travel Health Service Department of Health The Government of Hong Kong Special Administrative Region. Vaccine and Prophylaxis-Rabies Vaccination. Available online: http://www. travelhealth.gov.hk/english/vaccine_prophylaxis/rabies.html (accessed on 29 March 2017).

40. Japan Ministry of Health Labour and Welfare. Q \& A on Rabies Vaccination Guidelines. Available online: http:/ / www.mhlw.go.jp/bunya/kenkou/kekkaku-kansenshou10/07.html (accessed on 17 May 2017).

41. World Health Organization. Intradermal Application of Rabies Vaccines-Report of a WHO Consultation, Bangkok, Thailand; WHO Communicable Disease Surveillance and Control: Geneva, Switzerland, 2000.

42. Korea Society of Infectious Disease. Recommended Adult Immunization for Foreign Travel. Available online: http:/ / www.ksid.or.kr/file/vaccine_eng.pdf (accessed on 19 May 2017).

43. Association of Southeast Asian Nations (ASEAN). ASEAN Rabies Elimination Strategy; OIE World Organisation for Animal Health: Bankok, Thailand, 2016.

44. Knobel, D.L.; Cleaveland, S.; Coleman, P.G.; Fevre, E.M.; Meltzer, M.I.; Miranda, M.E.; Shaw, A.; Zinsstag, J.; Meslin, F.X. Re-evaluating the burden of rabies in Africa and Asia. Bull. World Health Organ. 2005, 83, 360-368. [CrossRef] [PubMed]

45. Sudarshan, M.K.; Madhusudana, S.N.; Mahendra, B.J.; Rao, N.S.; Narayana, D.A.; Rahman, S.A.; Meslin, F.X.; Lobo, D.; Ravikumar, K.; Gangaboraiah. Assessing the burden of human rabies in India: Results of a national multi-center epidemiological survey. Int. J. Infect. Dis. 2007, 11, 29-35. [CrossRef] [PubMed]

46. Taylor, L.H.; Hampson, K.; Fahrion, A.; Abela-Ridder, B.; Nel, L.H. Difficulties in estimating the human burden of canine rabies. Acta Trop. 2017, 165, 133-140. [CrossRef] [PubMed]

47. Banyard, A.C.; Horton, D.L.; Freuling, C.; Muller, T.; Fooks, A.R. Control and prevention of canine rabies: The need for building laboratory-based surveillance capacity. Antivir. Res. 2013, 98, 357-364. [CrossRef] [PubMed]

48. Ly, S.; Buchy, P.; Heng, N.Y.; Ong, S.; Chhor, N.; Bourhy, H.; Vong, S. Rabies situation in Cambodia. PLoS Negl. Trop. Dis. 2009, 3, e511. [CrossRef] [PubMed]

49. Daniels, D.M.; Ritzi, R.B.; O'Neil, J.; Scherer, L.R. Analysis of nonfatal dog bites in children. J. Trauma Acute Care Surg. 2009, 66, S17-S22. [CrossRef] [PubMed]

50. Dhand, N.K.; Gyeltshen, T.; Firestone, S.; Zangmo, C.; Dema, C.; Gyeltshen, R.; Ward, M.P. Dog bites in humans and estimating human rabies mortality in rabies endemic areas of Bhutan. PLoS Negl. Trop. Dis. 2011, 5, e1391. [CrossRef]

51. Schalamon, J.; Ainoedhofer, H.; Singer, G.; Petnehazy, T.; Mayr, J.; Kiss, K.; Hollwarth, M.E. Analysis of dog bites in children who are younger than 17 years. Pediatrics 2006, 117, e374-e379. [CrossRef] [PubMed]

52. Dodet, B. Report of the sixth AREB meeting, Manila, The Philippines, 10-12 November 2009. Vaccine 2010, 28, 3265-3268. [CrossRef] [PubMed]

53. Sudarshan, M.K. Guidelines for Rabies Prophylaxis in Children. In Textbook of Pediatric Infectious Diseases, 1st ed.; Parthasarathy, A., Kundu, R., Agrawal, R., Eds.; Jaypee Brothers Medical Publishers: New Delhi, India, 2013; pp. 424-431.

54. Matibag, G.C.; Kamigaki, T.; Kumarasiri, P.V.; Wijewardana, T.G.; Kalupahana, A.W.; Dissanayake, D.R.; De Silva, D.D.; Gunawardena, G.S.; Obayashi, Y.; Kanda, K.; et al. Knowledge, attitudes, and practices survey of rabies in a community in Sri Lanka. Environ. Health Prev. Med. 2007, 12, 84-89. [CrossRef] [PubMed]

55. Dhand, N.K.; Rai, B.D.; Tenzin, S.; Tsheten, K.; Ugyen, P.; Singye, K.; Ward, M.P. Community-based study on knowledge, attitudes and perception of rabies in Gelephu, south-central Bhutan. Int. Health 2012, 4, 210-219. [CrossRef]

56. Salahuddin, N.; Gohar, M.A.; Baig-Ansari, N. Reducing cost of rabies post-exposure prophylaxis: experience of a tertiary care hospital in Pakistan. PLoS Negl. Trop. Dis. 2016, 10, e0004448. [CrossRef] [PubMed] 
57. Hampson, K.; Cleaveland, S.; Briggs, D. Evaluation of cost-effective strategies for rabies post-exposure vaccination in low-income countries. PLoS Negl. Trop. Dis. 2011, 5, e982. [CrossRef] [PubMed]

58. Hemachudha, T.; Ugolini, G.; Wacharapluesadee, S.; Sungkarat, W.; Shuangshoti, S.; Laothamatas, J. Human rabies: Neuropathogenesis, diagnosis, and management. Lancet Neurol. 2013, 12, 498-513. [CrossRef]

59. Rupprecht, C.E.; Briggs, D.; Brown, C.M.; Franka, R.; Katz, S.L.; Kerr, H.D.; Lett, S.; Levis, R.; Meltzer, M.I.; Schaffner, W.; et al. Evidence for a 4-dose vaccine schedule for human rabies post-exposure prophylaxis in previously non-vaccinated individuals. Vaccine 2009, 27, 7141-7148. [CrossRef] [PubMed]

60. Dodet, B. An important date in rabies history. Vaccine 2007, 25, 8647-8650. [CrossRef] [PubMed]

61. Tarantola, A.; Ly, S.; In, S.; Ong, S.; Peng, Y.; Heng, N.; Buchy, P. Rabies vaccine and rabies immunoglobulin in Cambodia: use and obstacles to use. J. Travel Med. 2015, 22, 348-352. [CrossRef] [PubMed]

62. Kessels, J.A.; Recuenco, S.; Navarro-Vela, A.M.; Deray, R.; Vigilato, M.; Ertl, H.; Durrheim, D.; Rees, H.; Nel, L.H.; Abela-Ridder, B.; et al. Pre-exposure rabies prophylaxis: A systematic review. Bull. World Health Organ. 2017, 95, 210-219C. [CrossRef] [PubMed]

63. Davlin, S.L.; Lapiz, S.M.; Miranda, M.E.; Murray, K.O. Knowledge, attitudes, and practices regarding rabies in Filipinos following implementation of the Bohol Rabies Prevention and Elimination Programme. Epidemiol. Infect. 2014, 142, 1476-1485. [CrossRef] [PubMed]

64. The South-East Asia Dog Rabies Elimination Strategy (SEARS). Rabies; OIE Regional Commission: Bangkok, Thailand, 2013.

65. Devleesschauwer, B.; Aryal, A.; Sharma, B.K.; Ale, A.; Declercq, A.; Depraz, S.; Gaire, T.N.; Gongal, G.; Karki, S.; Pandey, B.D.; et al. Epidemiology, impact and control of rabies in Nepal: A systematic review. PLoS Negl. Trop. Dis. 2016, 10, e0004461. [CrossRef] [PubMed]

66. GBD 2015 SDG Collaborators. Measuring the health-related Sustainable Development Goals in 188 countries: A baseline analysis from the Global Burden of Disease Study 2015. Lancet 2016, 388, 1813-1850. [CrossRef]

67. Vigilato, M.A.; Clavijo, A.; Knobl, T.; Silva, H.M.; Cosivi, O.; Schneider, M.C.; Leanes, L.F.; Belotto, A.J.; Espinal, M.A. Progress towards eliminating canine rabies: Policies and perspectives from Latin America and the Caribbean. Philos. Trans. R. Soc. Lond. B Biol. Sci. 2013, 368, 20120143. [CrossRef] [PubMed]

68. Scott, T.P.; Coetzer, A.; de, B.K.; Wright, N.; Nel, L.H. The Pan-African Rabies Control Network (PARACON): A unified approach to eliminating canine rabies in Africa. Antivir. Res. 2015, 124, 93-100. [CrossRef] [PubMed]

(C) 2017 by the authors. Licensee MDPI, Basel, Switzerland. This article is an open access article distributed under the terms and conditions of the Creative Commons Attribution (CC BY) license (http:/ / creativecommons.org/licenses/by/4.0/). 
Article

\title{
Public Preference for Pet-Rabies Prophylaxis: Opportunities and Information Dissemination
}

\author{
Maria B. Palamar ${ }^{1, *}$, Maria T. Correa ${ }^{2}$, Nils M. Peterson ${ }^{3}$ and Christopher S. DePerno ${ }^{3}$ \\ 1 NC Wildlife Resources Commission, 1751 Varsity Dr., Raleigh, NC 27606, USA \\ 2 NC State University College of Veterinary Medicine, 1060 William Moore Dr., Raleigh, NC 27606, USA; \\ correa@ncsu.edu \\ 3 NC State University College of Natural Resources, Fisheries and Wildlife Conservation Biology, Raleigh, \\ NC 27606, USA; nils_peterson@ncsu.edu (N.M.P.); chris_deperno@ncsu.edu (C.S.D.) \\ * Correspondence: maria.palamar@ncwildlife.org; Tel.: +1-919-707-0056
}

Received: 20 June 2017; Accepted: 7 September 2017; Published: 13 September 2017

\begin{abstract}
Risky human behavior and high density of rabies vectors in urban environments combine to increase the risk of rabies. Pet vaccination, wildlife vector management, and public health education may be the most efficient ways to prevent urban rabies epidemics. Racial, ethnic, and socio-economic factors influence the use of low-cost rabies vaccination clinics, understanding rabies reporting requirements, and learning preferences. In collaboration with the City of Greensboro and Animal Control in Guilford County, NC, we conducted a survey of rabies prevention and transmission across socio-economic strata representing Latinos, African Americans, and Whites, and different income and education levels. Compliance with vaccination was low among Latinos; African Americans and Latinos were not aware of low-cost rabies vaccination clinics; and most respondents were willing to report rabid animals but did not know whom to call. White respondents preferred online information delivery, whereas Latinos and African Americans preferred postal mail. Communication targeting the public requires the consideration of different message decoding and interpretation based on the ethnicity, income, and educational level, and other barriers such as language. Differing message delivery methods may be required to achieve full dissemination.
\end{abstract}

Keywords: rabies; rabies prevention; public health outreach; race; ethnicity

\section{Introduction}

Several factors are combined to make urban environments ideal for the spread of zoonotic diseases [1]. First, human population densities are highest in urban areas. Second, population densities of wildlife species which serve as rabies vectors (e.g., raccoons, foxes, and coyotes) are often highest in urban areas because these species are highly adaptable and take advantage of anthropogenic factors (e.g., garbage, denning sites in buildings, green areas protected of larger predators) that facilitate high reproduction rates and increased survival [2]. Third, pet densities are highest in urban areas. Finally, human behaviors in urban areas, such as attempting to help approachable animals, feeding wildlife purposively or not (e.g., feeding corn to raccoons, leaving pets' food outside), increases the risk of disease transmission in urban environments. This may happen by directly relating to wildlife or by attracting a larger number of animals to a particular area.

Rabies is an important zoonosis that affects wild and domestic animals, as well as humans. The current rabies epidemic in the eastern United States is associated with a raccoon (Procyon lotor) variant of the virus [3]. Raccoons are widespread throughout North America and are present in high densities in urban environments $[4,5]$. They are well adapted to urban and suburban areas, using human housing to den, and garbage, pet food, plants in residential gardens, and urban proximate crops as a food sources [6]. These animals are hosts to a large number of pathogens (e.g., Leptospira interrogans, 
and canine distemper, rabies, and feline panleukopenia viruses) that can infect other animal species and humans [7]. Therefore, interactions between raccoons, humans, and their companion animals have led to increasing public health concerns [6].

Pet vaccination, wildlife vector management, and public health education may be the most efficient ways to prevent a rabies epidemic in urban environments [8]. Public health officials in Greensboro, NC, indicated that compliance with rabies vaccination laws is low. For example, of the 11 cases of pets that had been in contact with a suspected rabid animal in 2012, 10 had to be euthanized or quarantined because they did not have the proper rabies vaccination [9]. Although rabies vaccination by professionals is required by law for dogs, cats, and ferrets, and is reportable in NC, rabies immunization and reporting is difficult to enforce and the number of unvaccinated animals is difficult to estimate. There has not been any other comparable reporting method in place.

Cultural norms may contribute to challenges with pet immunization efforts. Ethnic minorities-particularly Hispanic/Latinos-are increasing in the United States, and are becoming a critically important focus of wildlife management and outreach programs [10]. Engaging minorities in wildlife management and public health programs requires the creation of language-appropriate, culturally-sensitive, and relevant information to be delivered in an accepted format and through media outlets favored by the target population. Compared to Whites, Hispanic/Latinos and African Americans know less about the signs of rabies infection in animals, transmission routes, wildlife vectors, and about first response after rabies exposure [11]. Health and illness perception, risk-taking or -aversion behaviors, and lack of access to information, may increase exposure to rabies or the reporting of suspected rabid animals [11]. The challenge of reaching minorities has been documented in other public health areas, including sexually transmitted diseases (STDs) and oral health [12].

Guilford County, NC, USA was a good place to find solutions for some of these challenges. In 2006, Guilford County had 37 confirmed cases of wild animal rabies, and 20 of these cases were raccoons (others included one cat, one coyote, two bats, four foxes, and five skunks). In addition, Guilford County animal control officials were anecdotally reporting a low turnout of ethnic minorities to their pet rabies vaccination clinics. After the 2006 rabies report, Guilford County Environmental Health officers were concerned with raccoon population dynamics in urban areas and in particular in Greensboro (a major city in the county), and decided to reach out to North Carolina State University to express the need for public health research. Their concern also extended to public awareness, understanding of rabies transmission, symptoms, and early treatment, as well as low-cost options for pet vaccination. The city has a total population of 237,423, of whom Hispanic/Latinos $(15,412)$ and African Americans $(88,587)$ account for roughly half of the population [13]. This diverse population made the city a good case study to answer some of the concerns presented by Environmental Health officials and to gain insight about the public's knowledge, get an estimate of pet vaccination status, and understand how people would respond to an encounter with a rabid animal. Therefore, we conducted a bilingual (English/Spanish) survey in Greensboro, NC, to determine pet vaccination compliance and awareness and use of low-cost rabies vaccination clinics. Information about the understanding of the requirements for reporting suspected rabid animals (e.g., who they would report to) and differing public preferences for communication content, format, and delivery of rabies information were elicited from survey participants.

\section{Materials and Methods}

Four neighborhoods located within the northwest quadrant of the city of Greensboro were selected for the survey, given the high number of rabies-positive raccoon cases reported in 2006 and 2007 [14]. We conducted the survey during October and November 2009. We interviewed the adult (18 years or older) who answered the door in every third dwelling in each of the selected neighborhoods. If nobody answered or the person who answered refused to participate in the survey in the selected house, the next dwelling was considered the replacement. This systematic sampling strategy ensured we 
engaged diverse audiences often left out of sample frames based on phone numbers or formal mailing addresses $[15,16]$. Surveys were conducted on weekdays and weekends, alternating mornings and afternoons to decrease possible bias associated with sampling weekday and time. A total of nine interviewers participated, four males and five females, who worked in pairs with at least one bilingual interviewer in each pair. All interviewers were trained by the primary author, and carried English and Spanish copies of the questionnaire. Each respondent was asked which language (English or Spanish) they preferred; when Spanish was chosen, the respondent was asked if they wanted to talk to one of the bilingual interviewers.

Survey design and administration-An English version of the survey was designed and translated into Spanish by two of the authors who are bilingual. The survey was then back-translated to English in order to check for semantic and conceptual equivalence. Information was elicited on: learning about rabies, attitudes towards and reporting on rabies, pet-vaccination status, demographic and socio-economic status i.e., previous year's income classified into categories of $0(\leq \$ 14,999)$ to $8(\geq \$ 60,000)$; age; education, categorised as 0 (grammar school) to 4 (graduate degree); years of residence in the area; number of household residents; and gender and ethnicity. Ethnicity included Hispanic/Latino and race options were White, Asian, Black or African American, Native American, and Hawaiian or other Pacific Islander as defined in US Census Bureau [17]. Twelve questions (12 closed-ended and 1 open-ended) pertained to pet vaccination status and knowledge and use of rabies vaccination clinics in the county, reaction to a rabid animal, and choice of outlets to receive rabies-associated public health information. This is a subset of the questionnaire; results from other portions of the survey have already been published in a previous manuscript [11].

Data analysis-Data are presented in tables with frequencies and percentages. Chi-square testing using SAS [18] was used to compare frequencies for specific questions with an alpha value of $\leq 0.05$.

\section{Results}

Socio-economic and demographic characteristics of respondents-The overall ethnic/racial distribution of the 301 respondents was: 220 White non-Hispanic/Latino (Whites 75\%); 33 Hispanic/Latino (11\%); 40 African American (13\%). Only 23 participants required a Spanish version of the survey. Hispanic/Latinos and African American respondents had lower income levels than Whites. Income varied by ethnic/racial groups, with $65 \%$ of the Hispanic/Latino respondents reporting earnings of less than $\$ 20,000$ /year while $77 \%$ of the White respondents reported earning more than $\$ 35,000 /$ year. Hispanic/Latino and African American respondents were younger and had lived in the area for less time compared to Whites [11]. Hispanic/Latinos had lower education levels than African American and Whites, with 39\% of the Hispanic/Latino respondents having only completed grammar school. College completion was eight times higher among White respondents (65\%) than African Americans (8\%).

Pet ownership and care-Overall, half of the respondents indicated owning one pet; however, only $30 \%$ of the Hispanic/Latino respondents owned a pet (Chi-square $p$-value $<0.00001$ for comparison between Whites and Hispanic/Latino and African Americans combined). Of the respondents that owned pets, $85 \%$ indicated that they vaccinated for rabies in the last 12 months. Reasons for no rabies vaccination were: vaccination is only done for outdoor pets, cost of the vaccine too high, pet was too young to vaccinate, or they could not catch the animal to have it vaccinated. African Americans (60\%) and Hispanic/Latinos (89\%) reported no knowledge of low-cost rabies vaccination clinics offered by Guilford County, whereas a larger percent of White respondents $(65 \%)$ were aware of the clinics. More Whites $(n=93)$ than Hispanic/Latinos and African Americans combined $(n=9)$ were aware of the low-cost clinics run by Guildford County Animal Control (Chi-square $p$-value $=0.000472$ ). Considering the people who were aware of the rabies clinics, $69 \%$ had heard about them from the local media (e.g., radio, television, or newspaper), but only $38 \%$ of them had vaccinated their pets at the low-cost clinics (Table 1). 
Table 1. Frequency of answers regarding pet vaccination status and awareness and use or rabies vaccination clinics in Greensboro, NC, 2009.

\begin{tabular}{|c|c|c|c|c|}
\hline \multirow[t]{2}{*}{ Survey Questions and Possible Answers } & \multicolumn{4}{|c|}{ Responses \% $(n)$} \\
\hline & $\begin{array}{c}\text { Total } \\
\text { Responses }\end{array}$ & $\begin{array}{l}\text { Hispanicl } \\
\text { Latinos }\end{array}$ & $\begin{array}{l}\text { African } \\
\text { Americans }\end{array}$ & Whites \\
\hline \multicolumn{5}{|l|}{$\begin{array}{l}\text { Do you own or live with someone who owns a cat, } \\
\qquad \text { dog, or ferret? }\end{array}$} \\
\hline Yes & $58.19(174)$ & $28.13(9)$ & $50(20)$ & $64.38(141)$ \\
\hline No & $41.81(125)$ & $71.88(23)$ & $50(20)$ & $35.62(78)$ \\
\hline \multicolumn{5}{|l|}{$\begin{array}{l}\text { Have these pets been vaccinated against rabies in the } \\
\text { last } 12 \text { months? }\end{array}$} \\
\hline Yes, all of them & $84.57(148)$ & $66.67(6)$ & $95(19)$ & $84.51(120)$ \\
\hline Yes, some of them & $8.57(15)$ & $11.11(1)$ & $5(1)$ & $8.45(12)$ \\
\hline No & $6.86(12)$ & $22.22(2)$ & 0 & $7.04(10)$ \\
\hline \multicolumn{5}{|l|}{ Why did you not vaccinate some of the pets? } \\
\hline I only vaccinate pets that live outside & $6.67(1)$ & 0 & 0 & $9.09(1)$ \\
\hline I only vaccinate pets who live inside & $13.33(2)$ & $33.33(1)$ & 0 & $9.09(1)$ \\
\hline Is too expensive & $13.33(2)$ & $33.33(1)$ & 0 & $9.09(1)$ \\
\hline The pet is too young & $13.33(2)$ & 0 & 0 & $18.18(2)$ \\
\hline The pet is too old & $6.67(1)$ & 0 & 0 & $9.09(1)$ \\
\hline Given three-year vaccination & $20(3)$ & 0 & $100(1)$ & $18.18(2)$ \\
\hline I have no time to take the pets to the veterinarian & $6.67(1)$ & 0 & 0 & $9.09(1)$ \\
\hline Cannot catch the animal & $13.33(2)$ & 0 & 0 & $18.18(2)$ \\
\hline Lack of attention to pet's vaccinations & $6.67(1)$ & $33.33(1)$ & 0 & 0 \\
\hline \multicolumn{5}{|l|}{$\begin{array}{c}\text { Are you aware of the low-cost/free rabies clinics } \\
\text { offered by Guilford County? }\end{array}$} \\
\hline Yes & $60.34(105)$ & $11.11(1)$ & $40(8)$ & $65.96(93)$ \\
\hline No & $39.66(69)$ & $88.89(8)$ & $60(12)$ & $34.04(48)$ \\
\hline \multicolumn{5}{|l|}{$\begin{array}{l}\text { Have you ever vaccinated your pets in the low-cost/ } \\
\text { free rabies clinics offered by Guilford County? }\end{array}$} \\
\hline Yes & $38.1(40)$ & $50(1)$ & $71.43(5)$ & $34.41(32)$ \\
\hline No & $61.9(65)$ & $50(1)$ & $28.57(2)$ & $65.59(61)$ \\
\hline \multicolumn{5}{|l|}{$\begin{array}{l}\text { How did you find out about the low-cost/free rabies } \\
\text { vaccination clinics offered by Guilford County? }\end{array}$} \\
\hline Media (newspaper, radio, TV, internet, email) & $68.75(66)$ & $100(1)$ & $42.86(3)$ & $70.59(60)$ \\
\hline Family or friends & $23.16(22)$ & 0 & $28.57(2)$ & $22.62(19)$ \\
\hline Veterinarian & $18.75(18)$ & 0 & $28.57(2)$ & $16.47(14)$ \\
\hline Shelter & $5.21(5)$ & 0 & 0 & $5.88(5)$ \\
\hline
\end{tabular}

When asked what they would do if they encountered a dog which they suspected had rabies, most respondents, regardless of ethnicity, indicated that they would call someone to handle the animal. Latinos indicated they would call Animal Control but did not have the number. Conversely, African Americans and Whites indicated they would call Animal Control, and did have the number (Table 2). A total of $30 \%$ of respondents indicated that they would call 911 . The majority of respondents of all ethnic groups indicated that they would go to the emergency room if they were bitten by a dog. Similarly, the majority of the respondents indicated that they would report the offending dog to Animal Control (Table 2).

A total of $53 \%$ of the White respondents indicated they would like to receive future information about rabies over the internet, whereas Latinos (43\%) and African Americans (51\%) preferred to receive the information by postal mail. When asked what would be the best way to deliver information about future rabies clinics, most respondents (35\%) chose local media outlets such as local radio and TV (Table 3). 
Table 2. Frequency of answers regarding rabid animal reporting and first response after rabies exposure in Greensboro, North Carolina, 2009.

\begin{tabular}{|c|c|c|c|c|}
\hline \multirow[t]{2}{*}{ Survey Questions and Possible Answers } & \multicolumn{4}{|c|}{ Responses \% ( $n)$} \\
\hline & $\begin{array}{c}\text { Total } \\
\text { Responses }\end{array}$ & $\begin{array}{c}\text { Hispanic/ } \\
\text { Latinos }\end{array}$ & $\begin{array}{l}\text { African } \\
\text { Americans }\end{array}$ & Whites \\
\hline \multicolumn{5}{|l|}{$\begin{array}{c}\text { If you were to encounter a large dog you suspect has rabies } \\
\text { in your neighborhood, what would you do? }\end{array}$} \\
\hline Try to capture the animal to try to help it & $0.67(2)$ & $3.03(1)$ & 0 & $0.46(1)$ \\
\hline Try to scare the animal away & $2.01(6)$ & 0 & $5.13(2)$ & $1.83(4)$ \\
\hline Try to kill the animal & $2.34(7)$ & 0 & $2.56(1)$ & $2.74(1)$ \\
\hline I would do nothing & $1(3)$ & 0 & $2.56(1)$ & $0.91(1)$ \\
\hline Call someone that can take care of it & $93.65(280)$ & $96.97(4)$ & $89.74(35)$ & $93.61(205)$ \\
\hline \multicolumn{5}{|l|}{$\begin{array}{c}\text { If you have to call someone about a rabid animal, who } \\
\text { would be the easiest for you to call? }\end{array}$} \\
\hline Family member, friend, or neighbor & $0.68(2)$ & 0 & 0 & $0.92(2)$ \\
\hline Animal control (I have the number) & $35.37(104)$ & $12.9(4)$ & $47.37(18)$ & $36.41(79)$ \\
\hline Animal control (I do not have the number) & $31.97(94)$ & $61.29(19)$ & $31.58(12)$ & $27.65(60)$ \\
\hline Local Public Health Department (I have the number) & $0.68(2)$ & 0 & 0 & $0.92(2)$ \\
\hline Local Public Health Department (I do not have the number) & $0.68(2)$ & 0 & $2.63(1)$ & $0.46(1)$ \\
\hline Police/911 & $30.61(90)$ & $25.81(8)$ & $18.42(7)$ & $33.64(73)$ \\
\hline \multicolumn{5}{|l|}{ How would you respond to a dog biting your hand? } \\
\hline Call a doctor & $16.67(50)$ & $15.15(5)$ & $10(4)$ & $18.72(41)$ \\
\hline Care for the wound yourself & $4(12)$ & $3.03(1)$ & 0 & $5.02(11)$ \\
\hline Go to the emergency room & $60.33(181)$ & $69.67(23)$ & $77.5(31)$ & $55.25(121)$ \\
\hline Find the dog's owner and ask for vaccination records & $19(57)$ & $12.12(4)$ & $12.5(5)$ & $21(46)$ \\
\hline \multicolumn{5}{|l|}{ Would you report the dog to anyone? } \\
\hline Yes & $96.66(289)$ & $93.94(31)$ & $100(40)$ & $96.33(210)$ \\
\hline No & $3.34(10)$ & $6.06(2)$ & 0 & $3.67(8)$ \\
\hline \multicolumn{5}{|l|}{ If you have to report the dog, who would you report to? } \\
\hline Family member, friend, neighbor & $1.71(5)$ & $6.45(2)$ & 0 & $1.4(3)$ \\
\hline Animal Control & $71.92(210)$ & $51.61(16)$ & $84.21(32)$ & $72.56(156)$ \\
\hline Local Public Health Department & $5.82(17)$ & $9.68(3)$ & $5.26(2)$ & $5.58(12)$ \\
\hline Police $/ 911$ & $20.55(60)$ & $32.26(10)$ & $10.53(4)$ & $20.47(44)$ \\
\hline
\end{tabular}

Table 3. Frequency of answers regarding rabies information outlet preference in Greensboro, North Carolina, 2009 .

\begin{tabular}{ccccc}
\hline Survey Questions and Possible Answers & \multicolumn{2}{c}{ Responses \% $(n)$} \\
\hline & $\begin{array}{c}\text { Total } \\
\text { Responses }\end{array}$ & $\begin{array}{c}\text { Hispanicl } \\
\text { Latinos }\end{array}$ & $\begin{array}{c}\text { African } \\
\text { Americans }\end{array}$ & Whites \\
\hline $\begin{array}{c}\text { If you want to learn more about rabies, what would } \\
\text { be the BEST way to deliver that information to you? }\end{array}$ & & & & \\
\hline Internet & $47.98(119)$ & $32.14(9)$ & $32.43(12)$ & $53.11(94)$ \\
Mail & $34.27(85)$ & $42.86(12)$ & $51.35(19)$ & $29.94(53)$ \\
Television & $15.32(38)$ & $14.29(4)$ & $16.22(6)$ & $15.25(27)$ \\
Radio & $2.42(6)$ & $10.71(3)$ & 0 & $1.69(3)$ \\
\hline How would you like to be informed about future low & & & & \\
cost/free rabies clinics offered by Guilford County? & & & & \\
\hline Media (newspaper, radio, TV, Internet, email) & $35.34(41)$ & $75(6)$ & $20(4)$ & $35.63(31)$ \\
Family of friends & $17.24(20)$ & 0 & $20(4)$ & $17.24(15)$ \\
Veterinarian & $12.93(15)$ & $25(1)$ & $5(1)$ & $14.94(13)$ \\
\hline
\end{tabular}

\section{Discussion}

Pet vaccination rates reported by respondents was surprisingly high ( $85 \%)$. In surveys when the public are asked about regulatory compliance without penalty, there is a tendency to respond what it 
is expected and not what actually is done. Therefore, the results may reflect a response bias-more specifically, an expectation bias. Pet owners know that they should be vaccinating their pets for rabies and report they have done it, even when they have not. The average one-year tags for vaccination in the state of North Carolina is 520 and for three-year tags is 445; these are tags issued by veterinary or animal control agencies [19]. The pet population in Greensboro is expected to be of the order of 53,000 dogs and 58,000 cats using the American Veterinary Medicine Association Pet Ownership Calculator (https:/ / www.avma.org/KB/Resources/Statistics/Pages/US-pet-ownership-calculator. aspx). These numbers exceed the reported averages of rabies tags issues by veterinarians or animal control agencies.

Most Hispanic/Latino respondents indicated they were not aware of the rabies vaccination clinics offered by the county. Lack of information in Spanish is a possible explanation, in combination with a delivery system not favored by Hispanic/Latinos. The responses highlighted specific information outlets, giving public health officials a very clear direction on how to disseminate information. In NC there are a few Spanish-speaking radio stations, one television channel, and a couple of newspapers either sold at low cost or provided for free at stores selling food or products from Latin America and the Caribbean. Hispanic/Latinos frequent stores owned by other Hispanic/Latinos, and information regarding low cost/free rabies vaccination clinics and preventive information can be posted on information boards usually available at these places.

Information regarding whom to contact if an animal suspected of having rabies is encountered should be made available to the public. Although most survey respondents indicated that they would report a rabid animal to Animal Control, they were unaware of the correct number to call. Many respondents (30\%) indicated they would report their concerns to 911, especially after being asked if they knew the number for Animal Control. Animal Control could provide the public with educational resources such as multilingual information leaflets, refrigerator magnets, and calendar reminders to disseminate rabies information about reporting rabies suspicious animals, telephones to contact authorities, vaccination protocols and laws, and reporting an animal bite. Furthermore, 911 emergency respondents could be provided with a protocol for responding to calls about rabies while dispatching Animal Control.

Our results suggest that outreach efforts would benefit from considering how ethnicity, income, and education impact the information outlets used by the public. Hispanic/Latinos and African Americans responded that they would like to receive information through postal mail, whereas Whites indicated that they would prefer the information be made available via the internet. These differences may reflect differential access to the internet, as only $51 \%$ of Hispanic/Latinos and $49 \%$ of African Americans have a home internet connection, compared to $66 \%$ of non-Hispanic/Latino Whites in 2011 in United States [20]. Similarly, $41 \%$ of those surveyed by Pew Research Center reported earning less than $\$ 30,000$ and having internet access at home, and only $22 \%$ of people without high school diploma had home internet access [20]. The mean income for Hispanic/Latinos in our study was $\$ 19,000$ a year, and had lower education levels than any other demographic group (39\% did not have a high school diploma). Most African Americans in this study fared similarly to Hispanic/Latinos in income (less than $\$ 30,000$ /year); however, they reported a higher level of education (45\% reported having a high school diploma and some college education). Half of the Hispanic/Latinos and African Americans reported access to a mobile internet connection. Many state and county websites are not designed to be accessed by phone, and present limited content when accessed by mobile devices. Websites enhanced for mobile access are a possible system to use adding to the other preferred methods to receive information [20]. Cellular phones could also be used to send information to the public about rabies, rabies vaccinations, and exposure notifications [21], particularly as these messages can be delivered to target segments of the population by creating geographical boundaries for message recipients.

Risk perception and aversion is associated with culture and complicated by socio-economic and demographic status. Language is one of the many factors affecting message decoding and interpretation, but is a very important one. Knowing the population at risk is fundamental to 
establishing a public health program for rabies and other zoonoses. Studies like the one presented offer a glimpse of where to start, not only in one county in NC, but other places where a public health campaign is needed. Our studies have prompted county public health officials throughout the country to request our survey instrument. Several officials have shared the need to better inform different segments of the population, and the lack of research efforts in the area of outreach and publicity of vaccination and other community-service oriented efforts.

The Centers for Disease Control and Prevention 'Simply Put' guide for creating educational materials was used as the base for the elaboration of educational materials on rabies and other zoonotic diseases [22]. The educational materials are available for public, Animal Control, and non-governmental and animal rescue organizations, as well as public institutions. A bilingual trifold was developed; this contains a cutout portion where the public can write the numbers of the local Animal Control and Public Health. The effectiveness evaluation of the educational materials is pending. Additionally, a bilingual rabies coloring book, various brochures, and leaflets were made available to the Guildford Animal Control after the study completion; radio and television appearances and short messages were published in Spanish-language local newspapers.

Acknowledgments: The author received a small grant from North Carolina State University to cover the costs of printing the survey. Guilford County Animal Control and Guilford County Department of Public Health provided staff to help during the experiment stages of the project.

Author Contributions: Maria T. Correa and Maria B. Palamar conceived the project; Nils M. Peterson, Christopher S. DePerno, Maria T. Correa and Maria B. Palamar designed the experiments and analyzed the data. Maria B. Palamar performed the experiments with support from Guilford County Animal Control and Guilford County Department of Public Health. Maria B. Palamar and Maria T. Correa wrote the paper and Nils M. Peterson edited the paper.

Conflicts of Interest: The authors declare no conflict of interest.

\section{References}

1. Vandruff, L.W.; Bolen, E.G.; San Julian, G.J. Management of urban wildlife. In Research and Management Techniques for Wildlife and Habitats; The Wildlife Society: Bethesda, MD, USA, 1994; pp. 507-530.

2. Prange, S.; Gehrt, S.D.; Wiggers, E.P. Demographic factors contributing to high raccoon densities in urban landscapes. J. Wildl. Manag. 2003, 67, 324-333. [CrossRef]

3. Rupprecht, C.E.; Hamir, A.N.; Johnston, D.H.; Koprowski, H. Efficacy of a vaccinia-rabies glycoprotein recombinant virus vaccine in raccoons (Procyon lotor). Rev. Infect. Dis. 1988, 10, 803. [CrossRef]

4. Riley, S.; Hadidian, J.; Manski, D.A. Population density, survival, and rabies in raccoons in an urban national park. Can. J. Zool. 1998, 76, 1153-1164. [CrossRef]

5. Smith, H.T.; Engeman, R.M. An extraordinary raccoon, Procyon lotor, density at an urban park. Can. Field Nat. 2002, 116, 636-639.

6. Rosatte, R.C.; Power, M.J.; MacInnes, C.D. Ecology of urban skunks, raccoons and foxes in metropolitan Toronto. In Wildlife Conservation in Metropolitan Environments; Symposium Series 2; National Institute for Urban Wildlife: Columbia, MD, USA, 1991; pp. 31-38.

7. Junge, R.E.; Bauman, K.; King, M.; Gompper, M.E. A serologic assessment of exposure to viral pathogens and Leptospira in an urban raccoon (Procyon lotor) population inhabiting a large zoological park. J. Zoo Wildl. Med. 2007, 38, 18-26. [CrossRef] [PubMed]

8. Rupprecht, C.E.; Hanlon, C.A.; Hemachudha, T. Rabies re-examined. Lancet Infect. Dis. 2002, 2, 327-343. [CrossRef]

9. Green, S. Personal Communication; Guilford County Animal Control Director: Greensboro, NC, USA, 2012.

10. Lopez, R.R.A.; Lopez, A.; Wilkins, R.N.; Torres, C.C.; Valdez, R.; Teer, J.G.; Bowser, G. Changing Hispanic demographics: Challenges in natural resources management. Wildl. Soc. Bull. 2005, 33, 553-564. [CrossRef]

11. Palamar, M.B.; Peterson, M.N.; DePerno, C.S.; Correa, M.T. Assessing rabies knowledge and perceptions among ethnic minorities in Greensboro, North Carolina. J. Wildl. Manag. 2013, 77, 1321-1326. [CrossRef]

12. Altschuler, J.; Katz, A.D.; Tynan, M.A. Implications for HIV/AIDS research and education among ethnic minority older adults. J. HIV/AIDS Soc. Serv. 2008, 7, 209-228. [CrossRef] 
13. Anonymous. U.S. Census Bureau, 2005-2007. Available online: https://www.census.gov/programssurveys/acs/guidance/comparing-acs-data/2007.html (accessed on 20 May 2017).

14. Anonymous. Guilford County Environmental Health Department White Paper; Guilford County Environmental Health Department: Greensboro, NC, USA, 2007.

15. Nyhus, P.; Sumianto, J.; Tilson, R. Wildlife knowledge among migrants in southern Sumatra, Indonesia: Implications for conservation. Environ. Conserv. 2003, 30, 192-199. [CrossRef]

16. Peterson, M.N.; Sternberg, M.; Lopez, A.; Liu, J. Ocelot awareness among Latinos on the Texas and Tamaulipas border. Hum. Dimens. Wildl. 2008, 13, 339-347. [CrossRef]

17. Anonymous. U.S. Census Bureau, 2010. Available online: https://www.census.gov/topics/population/ race.html (accessed on 20 May 2017).

18. SAS Institute Inc. SAS 9.1.3. Help and Documentation; SAS Institute Inc.: Cary, NC, USA, 2002-2004.

19. Anonymous. NC Division of Human Health 2016. Available online: http://epi.publichealth.nc.gov/cd/ rabies / figures.html (accessed on 20 May 2017).

20. Anonymous. Pew Research Center Survey, 2011. Available online: http://www.pewinternet.org/2011/08/ 15/Americans-and-their-cell-phones/ (accessed on 20 May 2017).

21. Nathan, E. Mobilizing a Revolution: How Cellphones Are Transforming Public Health, 2017. Available online: https://www.hsph.harvard.edu/news/magazine/mobilizing-a-revolution/ (accessed on 20 May 2017).

22. U.S. Department of Health and Human Services, Centers for Disease Control and Prevention, Simply Put, 2009. Available online: https://communication4health.wordpress.com/2013/01/31/simply-put-a-cdcguide-for-creating-easy-to-understand-materials/ (accessed on 20 May 2017).

(C) 2017 by the authors. Licensee MDPI, Basel, Switzerland. This article is an open access article distributed under the terms and conditions of the Creative Commons Attribution (CC BY) license (http:/ / creativecommons.org/licenses/by/4.0/). 
Article

\title{
Field Studies Evaluating Bait Acceptance and Handling by Dogs in Navajo Nation, USA
}

\author{
Scott Bender ${ }^{1}$, David Bergman ${ }^{2}$, Adrian Vos ${ }^{3}$, Ashlee Martin ${ }^{4}$ and Richard Chipman ${ }^{4, *}$ \\ 1 Navajo Nation Veterinary Program, PO Box 2204, Chinle, AZ 86503, USA; scottbender@navajo-nsn.gov \\ 2 United States Department of Agriculture, Animal and Plant Health Inspection Service, Wildlife Services, \\ 8836 N 23rd Avenue, Suite 2, Phoenix, AZ 85021, USA; david.l.bergman@aphis.usda.gov \\ 3 IDT Biologika GmbH, Am Pharmapark, Dessau-Rosslau 06861, Germany; ad.vos@idt-biologika.de \\ 4 United States Department of Agriculture, Animal and Plant Health Inspection Service, Wildlife Services, \\ National Rabies Management Program, 59 Chenell Drive, Suite 2, Concord, NH 03301, USA; \\ ashlee.d.martin@aphis.usda.gov \\ * Correspondence: richard.b.chipman@aphis.usda.gov; Tel.: +1-603-223-9623; Fax: +1-603-229-0502
}

Academic Editors: Charles Rupprecht and Bernhard Dietzschold

Received: 26 April 2017; Accepted: 12 June 2017; Published: 15 June 2017

\begin{abstract}
Mass parenteral vaccination remains the cornerstone of dog rabies control. Oral rabies vaccination (ORV) could increase vaccination coverage where free-roaming dogs represent a sizeable segment of the population at risk. ORV's success is dependent on the acceptance of baits that release an efficacious vaccine into the oral cavity. A new egg-flavored bait was tested alongside boiled bovine intestine and a commercially available fishmeal bait using a hand-out model on the Navajo Nation, United States, during June 2016. A PVC capsule and biodegradable sachet were tested, and had no effect on bait acceptance. The intestine baits had the highest acceptance (91.9\%; $95 \%$ confidence interval (CI), 83.9-96.7\%), but the fishmeal (81.1\%; 95\% CI, 71.5-88.6\%) and the egg-flavored baits (77.4\%; $95 \%$ CI, $72.4-81.8 \%$ ) were also well accepted, suggesting that local bait preference studies may be warranted to enhance ORV's success in other areas where canine rabies is being managed. Based on a dyed water marker, the delivery of a placebo vaccine was best in the intestine baits (75.4\%; 95\% CI, 63.5-84.9\%), followed by the egg-flavored (68.0\%; 95\% CI, 62.4-73.2\%) and fishmeal (54.3\%; 95\% CI, 42.9-65.4\%) baits. Acceptance was not influenced by the supervision or ownership, or sex, age, and body condition of the dogs. This study illustrates that a portion of a dog population may be orally vaccinated as a complement to parenteral vaccination to achieve the immune thresholds required to eliminate dog rabies.
\end{abstract}

Keywords: rabies; bait; dog; oral vaccination

\section{Introduction}

Dogs (Canis lupus familiaris) account for approximately 95\% of all rabies cases reported worldwide, and they are also responsible for most human cases. Globally, the burden is not equal among countries [1]. Dog-mediated rabies has been eliminated from Europe, North America, and parts of Latin America. However, canine rabies remains a serious health problem in many countries in Africa and Asia. The most cost-effective method to control dog rabies is mass dog vaccination [2]. However, these campaigns have not always succeeded in achieving sufficient levels of herd immunity to interrupt the transmission cycle among dogs [3-5]. Poorly-supervised, free-roaming dogs play a pivotal role in transmission of rabies [6]. In some countries, a large proportion of the overall dog population is free-roaming, regardless of ownership. For example, over $50 \%$ and $66 \%$ of the owned dog population in Haiti and Bali, Indonesia, respectively, is allowed to roam freely $[3,5]$. During mass vaccination campaigns, these dogs are often not accessible for 
parenteral vaccination, or can only be vaccinated after considerable efforts to capture the free-roaming individuals $[7,8]$. Hence, alternative strategies—such as offering dogs vaccine baits-to reach these inaccessible dogs have been explored [9,10]. Initially, this novel approach targeted fox rabies in Europe and Canada. Later, this effective wildlife disease management tool was adapted for other reservoir species such as raccoon dogs (Nyctereutes procyonoides), raccoons (Procyon lotor), coyotes (Canis latrans), golden jackals (Canis aureus), and domestic dogs [11,12]. One of the essential components of this concept is a bait that is well accepted by the target population. Fishmeal baits used for the oral rabies vaccination (ORV) of red foxes (Vulpes vulpes) have been poorly accepted by dogs in many areas [13-15]. Nevertheless, a commercial fishmeal bait was accepted in previous studies on the Navajo Nation [16]. Several baits have been developed and tested in dogs around the world, including among others Mexico [17], Tunisia [18,19], Egypt [20], Turkey [13], the Philippines [21], and Guatemala [22]. Machine-made baits are generally not as well accepted as baits made from local available food sources [13,23]. However, the preparation of large quantities of baits from local food sources is problematic. Therefore, a well-accepted bait that can be produced on a large scale in a short period of time with quality assurance is required.

Most dogs on Navajo Nation lands are not subject to movement restrictions by their owners, and have little or no access to routine veterinary care, including vaccinations [16]. To react swiftly in the case of the re-emergence of rabies in the Navajo Nation, veterinary authorities have investigated the possibility of ORV in dogs, and bait studies have been previously conducted there $[16,24,25]$. The present study represents a continuation of these studies. The objective of this study was to evaluate the bait handling and acceptance of a recently developed bait by free-roaming dogs in the Navajo Nation. The new egg-flavored baits tested were previously found to be readily accepted by captive beagles and wolves (Canis lupus) [26].

\section{Materials and Methods}

\subsection{Study Area}

The Navajo Nation is a sovereign Native American Diné first nation located in the arid to semi-arid areas of high elevation (1600-3000 m) within northeastern Arizona, southeastern Utah, and northwestern New Mexico in the U.S. The reservation is $71,000 \mathrm{~km}^{2}$.

The Chinle (Chinle, Tsaile, Many Farms, Del Muerto, Lukachukai, Round Rock, and Rough Rock) and Shiprock (Shiprock, Hogback, and Cudii) Navajo Nation communities were selected for the bait trial, with the greater Chinle community located in Arizona, and the greater Shiprock community located in New Mexico (Figure 1). The study area comprised a combination of rural and semi-urban areas.

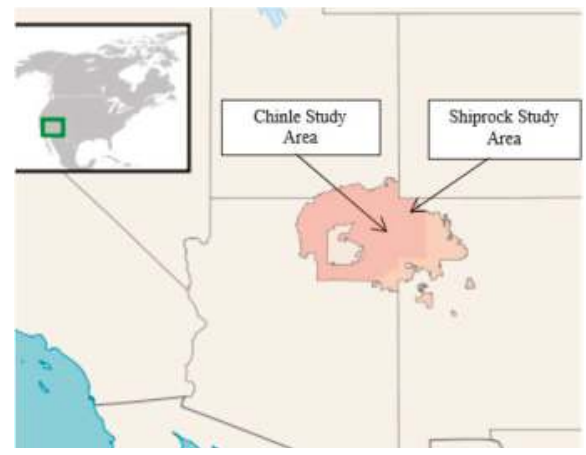

Figure 1. Location of the Navajo Nation (marked area) within the U.S., and the Chinle and Shiprock communities where the bait studies took place. 


\subsection{Field Trial}

Three different baits and two different blister systems were tested (Table 1). All blisters contained dyed water and no active ingredients. As part of the overall field evaluation, the dye was used to visually aid field personnel to see if any of the liquid from the bait was in the mouths of the dogs as they ingested the bait. The dye was Patentblau V (Sigma Aldrich), a blue dye used in the food industry that is safe for human consumption and therefore was assumed to be safe for dogs. All three baits have recently been tested with captive beagles and European wolves [26] (Figure 2). In addition to a new bait comprised of gelatin and egg powder, a bait matrix of boiled section of cow intestine and a bait matrix identical to a commercially available bait made from vegetable fats and fishmeal used in ORV in red foxes was tested. One blister was a PVC capsule sealed by aluminum foil previously tested in Turkey and the Philippines [21,27] and the other was a sachet made from biodegradable foil and is still under final development.

Table 1. Bait and blister components making up the combinations field tested on Navajo Nation, June 2016.

\begin{tabular}{llll}
\hline & Material & Size $(\mathbf{c m})$ & Weight $(g r)$ \\
\hline Bait & & & \\
\hline Intestine & boiled local cow intestine sections & $8-12 \mathrm{~cm}$ long & $20-30$ \\
Fishmeal & vegetable fats + fishmeal & $8.5 \times 4.0 \times 1.2$ & 43 \\
Egg & gelatin + egg powder & $8.5 \times 4.0 \times 1.2$ & 43 \\
\hline Blister & & & \\
\hline Capsule & PVC + aluminum foil & $6.5 \times 3.0 \times 0.7$ & $3.5 \mathrm{~mL}$ \\
Sachet & Biodegradable foil & $5.0 \times 3.0 \times 0.4$ & $3.5 \mathrm{~mL}$ \\
\hline
\end{tabular}

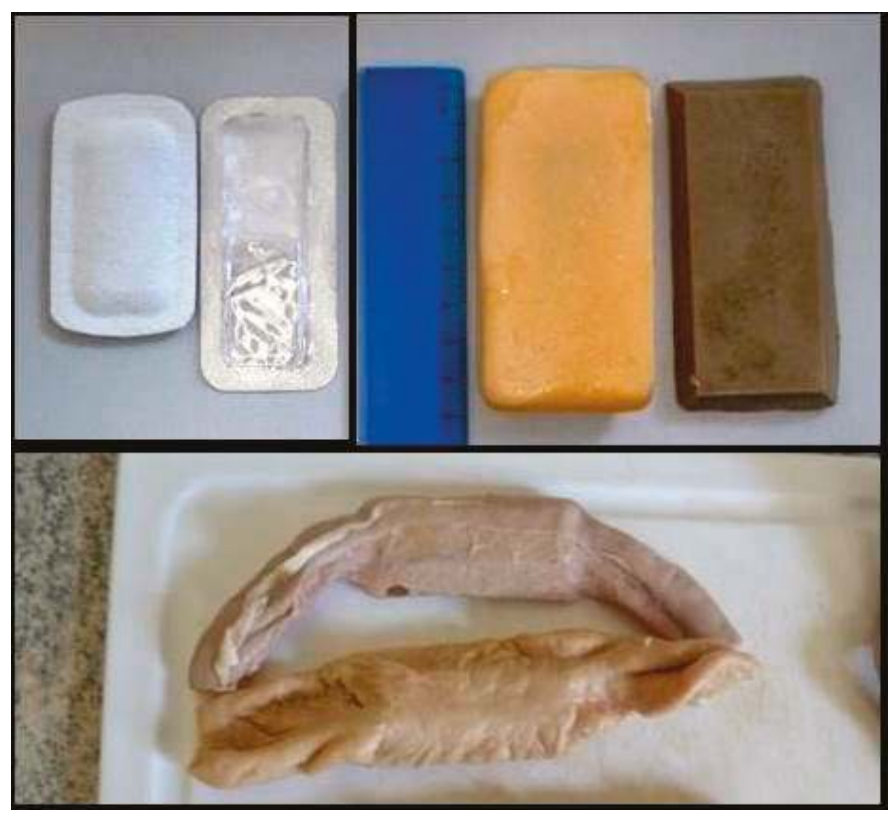

Figure 2. The two blister types used (left top; left-biodegradable, right-PVC) and the experimental egg-flavored bait (right top-yellow), fishmeal bait (right-top-brown), and intestine bait with capsule (bottom). 
Three person teams visited their allocated sections of the study area and systematically searched for dogs between 09:00 and 19:00 during 13-15 June 2016. If a dog was located, it was first determined if the dog had an owner and, if so, the dog was only offered a single bait with consent of the owner. Owners were given a leaflet that contained additional information and a phone number to report any potential adverse reactions. If the dog did not appear to have an owner, it was determined based on behavior if the dog was a stray/unowned (free-ranging dogs that survived and reproduced independently of human interaction or assistance) or community owned (free-ranging dogs that were fed and cared for by the community, but were not claimed by or residing with one single resident) by the ease of approachability of the dog. Community dogs were friendly and easily approached, while stray dogs were more cautious and would scare easily. All located dogs were offered a bait; stray/unowned and community dogs were approached and offered baits similar to owned dogs, with the exception that unowned dogs were approached more carefully to not scare them away. Bait type offered was randomly pre-determined. Half of all three bait types contained a hard PVC-capsule and the other half of all three bait types contained a soft biodegradable sachet. For every four experimental egg-flavored baits offered, one intestine and one fishmeal bait was included. The 4:1:1 ratio of bait flavor and the ratio of blister type were included in the randomization procedure. Since no data was available for bait uptake of the new egg-flavored population, this ratio were used to obtain as much data as possible on this bait. The intestine bait and fishmeal bait was used as a positive and negative control for comparison, respectively; it was assumed that the intestine bait would be well accepted and the fishmeal bait would be accepted poorly based on previous studies in the Philippines and Turkey [21,27]. A form was filled out during every baiting attempt to collect data on bait acceptance and handling. Bait handling describes what the dog does with the bait after acceptance, including handling time (time spent by the dog manipulating the bait; time was grouped into time intervals: $<10 \mathrm{~s}, 10-30 \mathrm{~s}, 30-60 \mathrm{~s}$, or $>60 \mathrm{~s}$ ) and if the vaccine container was perforated, discarded or swallowed. Based on these observations, an assessment was made by the observer if the dog would most likely have been successfully vaccinated based on the release of the contents of the blister into the oral cavity ("effectiveness"). Additional information recorded for each dog included: ownership, level of supervision, sex, age, size, and body condition. If the dog discarded the vaccine blister or if the dog did not accept the bait, the bait was recollected by the observer.

Data were initially analyzed using the statistical software package Modde 10.0, Umetrics by fitting the data in a model by multilinear regression or partial least squares (PLS). However, all but one factor examined were qualitative (blister type, day, ownership, level of supervision, sex, age, size, and body condition). The responses measured (bait acceptance and vaccinated) were also qualitative (yes, no). Since qualitative factors tend to negatively influence the statistical power, the model had an extremely poor fit and most of the model coefficients were not significant; only bait type, intestine (positive), and fish meal (negative) had a significant effect. Therefore, data were analyzed with chi-squared using the statistical software package GraphPad Prism 6.

\section{Results}

A total of 532 baiting attempts were recorded. Twenty-two data sheets with conflicting data were omitted from the analysis. Eighteen of the 22 omitted data sheets originated from a single team on the first day; most entries on those data sheets were not filled out or were filled out incorrectly. Also, two dogs ran off immediately when approached, and one dog was chased away by a passing car before it reached the bait offered. Hence, a total of 507 data sets was used for analysis, although it was not always possible to fill out the complete form. If no data was available for a specific parameter investigated, the data set was not included in the analysis for that parameter. Additional analysis on data collected for the various parameters of this study are included as Supplementary Tables S1-S9.

The ownership, confinement status, gender, age classification, body condition, and body size for the target dog population was documented and summarized (Figure 3). There were no significant effects on bait acceptance associated with dog age, sex, body condition, and size by contingency 
analysis. The overall bait acceptance (consumption) was 80.6\% (95\% CI, 76.8-83.9\%; Table 2); the intestine baits were refused significantly less often than the other two baits $\left(\chi^{2}=9.091, \mathrm{df}=2, p=0.01\right)$. The type of blister had no significant effect on bait acceptance $\left(\chi^{2}=1.276, \mathrm{df}=1, p=0.26\right)$. The dogs' level of confinement (restricted vs. unrestricted) or ownership status (owned vs. community, including ownerless) had no significant effect on bait acceptance (Figure 4a,b). Also, no significant effect in bait acceptance was observed for the time of day that baits were offered to the dogs $\left(\chi^{2}=3.765, \mathrm{df}=4, p=0.44\right)$.
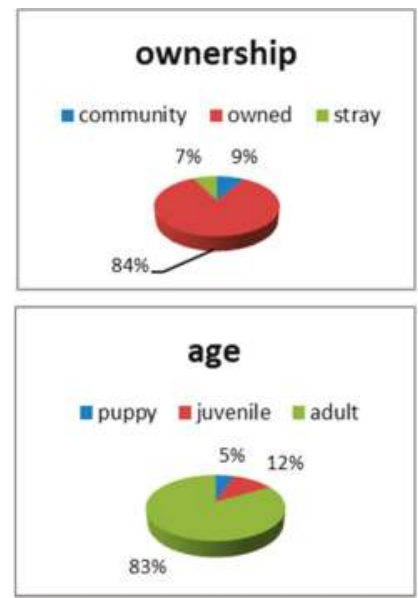
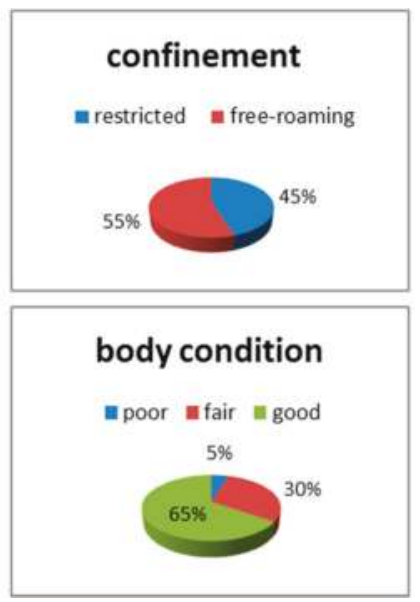
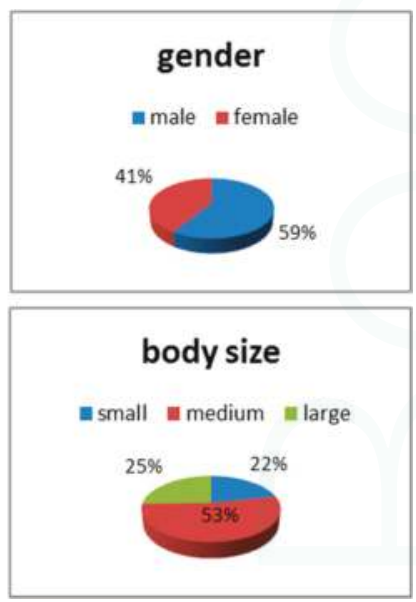

Figure 3. Characteristics of the dogs included in this study.

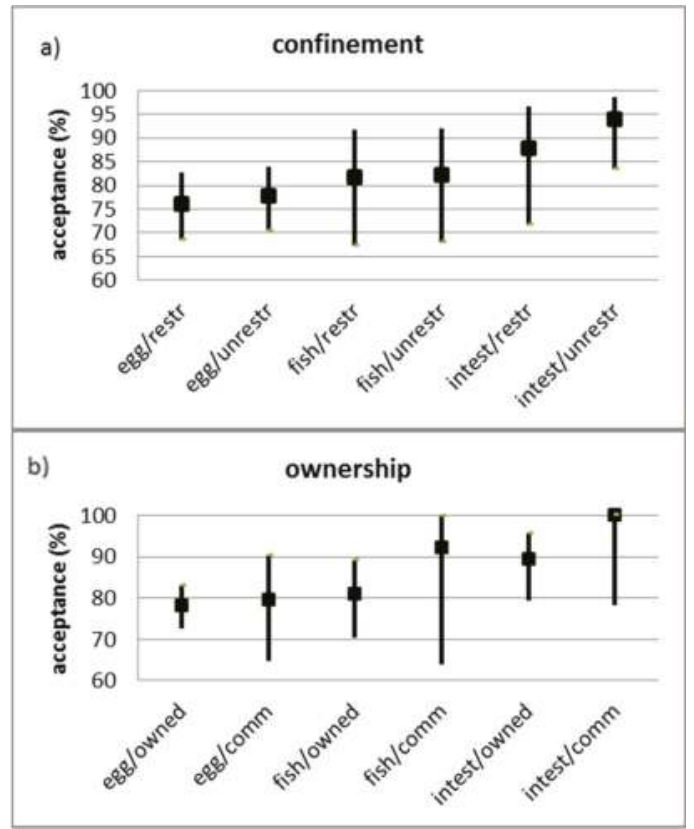

Figure 4. Bait acceptance (\%) (mean percentage and 95\% confidence interval) associated with (a) level of confinement (restr-restricted; unrest—unrestricted) and (b) ownership status (comm—community). 


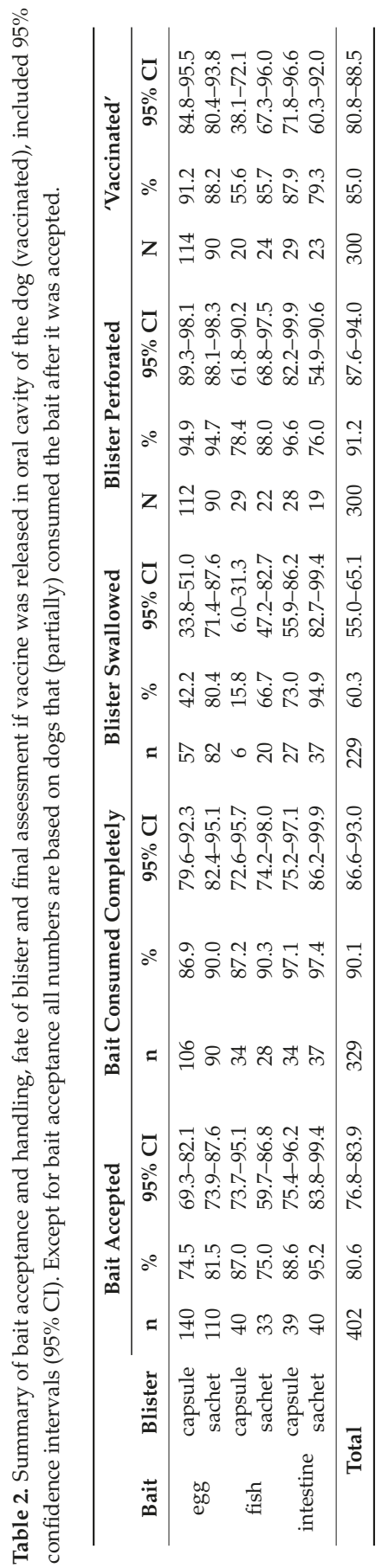


When baits were accepted by the dogs, 90.1\% (95\% CI, 86.6-93.0\%) of the animals consumed the whole bait. There was no significant difference between blisters $\left(\chi^{2}=0.8826, \mathrm{df}=1, p=0.35\right)$ and bait type $\left(\chi^{2}=5.213, \mathrm{df}=2, p=0.07\right)$ if the bait offered was consumed completely or partially. The intestine baits were consumed significantly faster than the other two baits $\left(\chi^{2}=40.90, \mathrm{df}=6\right.$, $p<0.0001$ ) (Figure 5). The baits containing a sachet were also consumed significantly more rapidly than baits with the hard PVC capsule $\left(\chi^{2}=10.65, \mathrm{df}=3, p=0.01\right)$. The intestine and sachet combination was consumed significantly much faster in comparison to intestine baits with the capsule; $59 \%$ (95\% CI, $42.1-74.4 \%)$ of the intestine baits accepted were consumed within $10 \mathrm{~s}\left(\chi^{2}=10.95, \mathrm{df}=3, p=0.01\right)$. No significant difference in consumption time between the blister types was observed for the egg baits $\left(\chi^{2}=1.413, \mathrm{df}=3, p=0.70\right)$ and fishmeal baits $\left(\chi^{2}=4.689, \mathrm{df}=3, p=0.20\right)$.

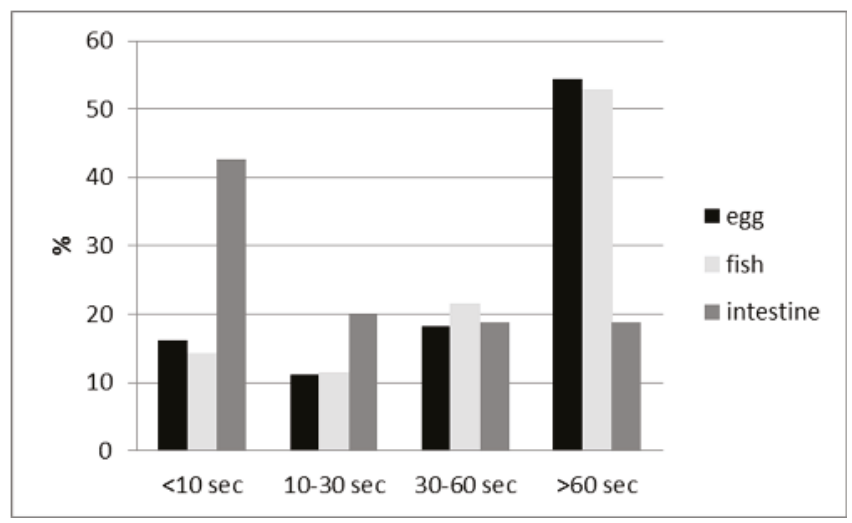

Figure 5. Bait handling time (seconds) for the 3 different baits.

There was a significant effect on the fate of the blister (swallowed or discarded) for both the bait and blister type. Almost all dogs (84.2\%; 95\% CI, 74.0-91.6\%) that consumed an intestine bait swallowed the blister, while only 58.6\% (95\% CI, 52.1-61.0\%) and 38.2\% (95\% CI, 26.7-50.8\%) of the dogs that accepted the egg and fishmeal baits, respectively, swallowed the blister $\left(\chi^{2}=32.19, \mathrm{df}=2\right.$, $p<0.0001)$. Irrespective of bait type, the sachets were swallowed more often than the PVC capsules; $81.3 \%$ (95\% CI, 74.6-86.8\%) of dogs swallowed the sachet, but only $42.9 \%$ (95\% CI, 30.1-49.8\%) of the capsules were swallowed $\left(\chi^{2}=58.05, \mathrm{df}=1, p<0.0001\right)$. However, overall, the type of blister did not have an influence on bait handling time.

The blisters in the egg baits (94.8\%; 95\% CI, 90.9-97.4\%) were more often perforated than those in the fishmeal baits $\left(82.3 \%\right.$; 95\% CI, 70.5-90.8\%) and intestine baits $\left(87.0 \%\right.$; 95\% CI, 75.1-94.6\%; $\chi^{2}=10.83$, $\mathrm{df}=2, p=0.004)$. Blister type did not seem to have any influence on perforation, except for the intestine baits, in which the PVC capsules $(96.6 \% ; 95 \%$ CI, 82.2-99.9\%) were significantly perforated more often than the sachets $\left(76.0 \% ; 95 \% \mathrm{CI}, 54.9-90.6 \% ; \chi^{2}=5.026, \mathrm{df}=1, p=0.03\right)$.

Overall, there was no significant effect of blister type on vaccination success based on dyed water marker $\left(\chi^{2}=0.3145, \mathrm{df}=1, p=0.5749\right)$, but there was a highly significant effect of bait type on vaccination success (effectiveness) $\left(\chi^{2}=17.52, \mathrm{df}=2, p=0.0002\right)$. The fishmeal baits had a significantly lower vaccine delivery success rate than the other two baits. The content of the blister was considered successfully released in the oral cavity of $68.8 \%$ (95\% CI, 55.9-79.8\%) of the dogs that accepted the fishmeal baits. For the egg and intestine baits, 89.9\% (95\% CI, 85.2-93.5\%) and 83.9\% (95\% CI, $72.3-92.0 \%$ ) of the dogs were considered successfully 'vaccinated', respectively. The better accepted intestine baits had a lower vaccination success rate due to the very short handling time; dogs that consumed baits in less than $10 \mathrm{~s}$ were significantly more often considered 'not vaccinated' $\left(\chi^{2}=33.45\right.$, $\mathrm{df}=3, p<0.0001)$. The low success rate of the fishmeal baits was predominantly caused by the blister 
type; using the hard PVC capsule, only 55.6\% (95\% CI, 38.1-72.1\%) of the dogs that accepted the bait were considered vaccinated, while for the sachet this percentage was $85.7 \%$ (95\% CI, 67.3-96.0\%; $\chi^{2}=6.668, \mathrm{df}=1, p=0.01$ ). For the other two baits, no significant effect of the blister was detected. A total of $91.2 \%$ (95\% CI, 84.8-95.5\%) and 88.2\% (95\% CI, 80.4-93.8\%) of the dogs accepting the egg baits containing the capsule or the sachet, respectively, were considered vaccinated $\left(\chi^{2}=0.54, \mathrm{df}=1\right.$, $p=0.46)$.

A total of $87.9 \%$ (95\% CI, 71.8-96.6\%) and 79.3\% (95\% CI, 60.3-92.0\%) of the dogs accepting the intestine baits with the capsule and sachet, respectively, were considered vaccinated $\left(\chi^{2}=0.84, \mathrm{df}=1\right.$, $p=0.36$ ). If we analyze bait acceptance and vaccination success in tandem, the discrepancy between acceptance and vaccination is much lower for the egg baits than for the other two baits (Figure 6). The effectiveness of the fishmeal baits was much lower than the other two bait types.

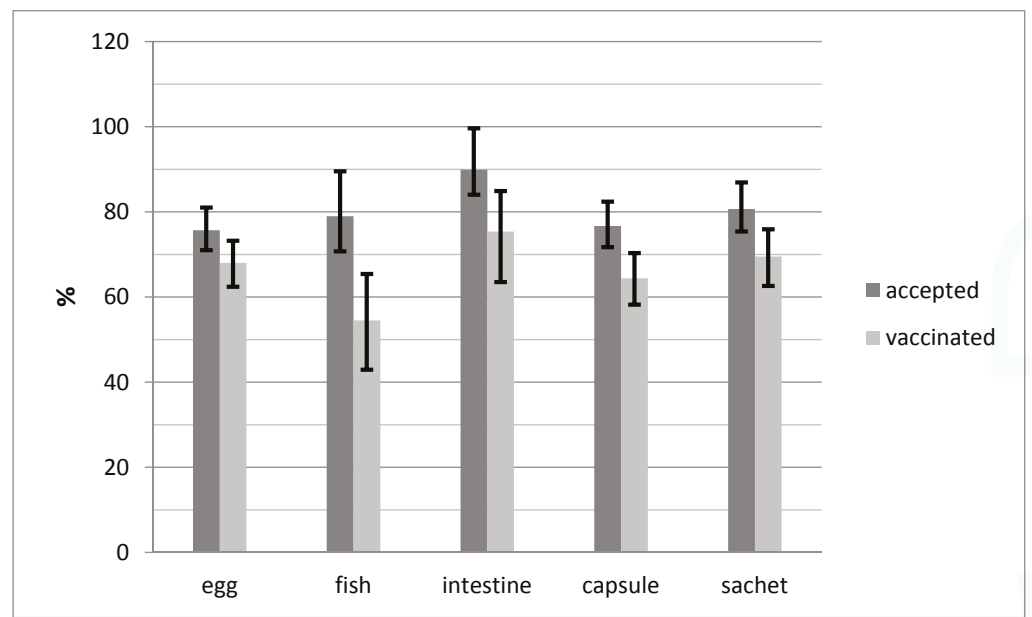

Figure 6. The difference in the proportion of dogs accepting and consuming baits and blisters and the subsequent assessment of a successful vaccination attempt (release of contents of vaccine blister in oral cavity) with associated $95 \%$ confidence intervals.

\section{Discussion}

An important precondition for oral vaccination is the availability of a bait that is well accepted by the target species under field conditions. Initially, efforts to develop baits for dogs were based on those previously developed for wildlife such as foxes and raccoons; a review of some of these early studies can be found in Linhart [28]. A bait that is poorly accepted by dogs has no use for oral vaccination of these animals against rabies, even if all of the other requirements have been fulfilled. Bait acceptance studies using a variety of baits have been conducted in different countries, and showed regional differences in bait preference [13,17-22]. For example, the significantly better accepted boiled intestine baits used in this study were only taken by $58.8 \%$ of the dogs in Guatemala. Poultry flavored baits were accepted more often than other bait types in Guatemala [22]. No significant difference in bait acceptance was observed between the fishmeal and egg-flavored baits in the Navajo Nation. During a previous study conducted on the Navajo Nation with confined shelter dogs, five flavors were tested using a commercial bait matrix: bacon, cheese, sweet, egg, and fish. The sweet-flavored baits were the least preferred, and among the other flavors no significant difference could be observed [25]. Interestingly, the acceptance of the egg-flavored baits $(79.9 \%)$ was quite similar to that observed in the current study $(77.4 \%)$, although a different ground bait substance was used. In another study at the dog shelter in the Navajo Nation, seven different flavors added to a commercial bait matrix were tested 
using the two-food-preference test approach [24]. Here, a dog-food flavor had the highest preference. However, the preference for dog-food flavor may have been a result of the familiarity of the dogs with this food source in the shelter. Bergman et al. [16] tested four different commercially available bait matrices, and found that the bait acceptance of free-roaming dogs in the Navajo Nation fluctuated between $56.5 \%$ and $84.5 \%$. The fish-flavored coated sachet had the highest bait consumption among the four baits tested. The relatively high acceptance rate of the fishmeal baits in these previous studies and our study in Navajo Nation was rather unexpected, considering that fish is an unusual food source for these animals and the poor results obtained with fish-flavored baits in free-roaming and confined dogs in other areas $[13,14,26]$. However, in Sri Lanka, a commercially available fish-flavored bait was well accepted (84\%) by owned dogs [29]. In several studies, a low acceptance of manufactured baits by free-roaming dogs was explained by the lack of familiarity with the taste, smell, shape, and texture of the baits [13]. Free-roaming dogs are often fed on household leftovers or offal. Hence, it can be expected that baits based on these resources are more attractive [30]. Thus, baits with a high acceptance rate in one area can be refused by dogs in another area, due to different local food preferences and experiences. Although several studies indicate high acceptance rates for manufactured baits $[15,23,29]$, generally, baits made from locally available material have a much higher acceptance rate $[13,21,22]$. During a field study in Turkey, $96 \%$ of all dogs accepted the locally-made bait based on minced-meat mixed with bread crumbs [13]. In the Philippines, more than $90 \%$ of the dogs accepted baits made from different local materials [21]. Locally produced baits are often not favored by field personnel due to difficulties in preparing, handling, and storing the baits [22]. However, due to the observed regional differences in bait acceptance, it may be difficult to develop a universally well-accepted bait for dogs. Furthermore, dog rabies is predominantly a problem in developing countries with limited financial resources available for rabies control. The cost of purchasing imported manufactured vaccine-loaded baits (including costs for their transportation and cold-storage) will most likely exceed the cost of the importation of vaccine-loaded blisters that could be incorporated locally in a suitable bait [21].

As shown in this study, when a dog accepts a bait, it does not automatically mean that the animal will be successfully vaccinated. The investigational phase and bait handling period upon acceptance should not last too long, because it increases the risk that external factors will lead to an interruption, and, consequently, a failed vaccination attempt. Hence, the selected bait should be immediately attractive to the dogs [13]. The handling time of the intestine bait was significantly shorter than for the other two bait types. However, the animal should not swallow the bait immediately, including the vaccine blister; the vaccine needs to be released in the oral cavity, and, therefore, the blister has to be punctured before it is swallowed or discarded. Actually, it was shown that the dogs consuming the bait within ten seconds were significantly more often considered 'not vaccinated'. The biodegradable sachet was significantly more often swallowed than the PVC capsule, but the type of blister did not influence the handling time of the bait. Dogs may separate the blister from the bait matrix, or it may drop out of the dogs' mouth before being punctured due to poor adherence with the bait matrix. In this study, it was observed that the fishmeal baits often broke into pieces when tossed to the dogs, consequently separating the vaccine blister from the bait matrix. Even when the blister is punctured, it does not guarantee a successful vaccination; sometimes large amounts of the vaccine are retained within the blister, and the released amount would not be sufficient to induce a protective immune response. Finally, during bait handling, the vaccine virus released from the punctured blister can be spilled on the ground [21]. Hence, not only does bait palatability need to be investigated and optimized, but also the influence of the shape, size, and texture of the bait matrix, as well as the blister, needs careful consideration in terms of the efficient release of the vaccine in the oral cavity. Experimental studies where the uptake of a single vaccine bait protected the dogs against a subsequent challenge infection have shown that this is feasible [27,31].

The swallowing of the PVC capsule can cause an adverse reaction (gastric intolerance) in dogs when swallowed [32], although no such adverse events were reported after the present study. The biodegradable sachet will cause less intolerance when swallowed. The swallowing of the blister 
after prolonged chewing actually has an advantage, by reducing the amount of discarded blisters in the environment. At the moment, it is suggested to re-collect all of the discarded vaccine containers to reduce unintentional human contact with the vaccine virus. However, sometimes the dog does not consume the bait immediately, but walks away with it, and subsequently the vaccine blister cannot be re-collected. If a vaccine container was used that is frequently swallowed, the number of discarded blisters not re-collected would be further reduced.

This study found no significant effect of the dogs' age, sex, body condition, and size on bait acceptance. Therefore, the age distribution, gender ratio, or health of a local dog population is not expected to impact the bait acceptance or the vaccination success of a population when using the bait types assessed in this study. There was also no significant effect on bait acceptance associated with ownership status or the dogs' level of confinement. Thus, similar conclusions could be drawn on the population regardless of the ownership status and level of confinement of the dogs.

It can be concluded that both bait types, manufactured or made from local material, were well accepted by the local dog population, but the bait, the blister, and the interaction between these two clearly influenced bait handling, and consequently the outcome of the vaccination attempt. There is a discrepancy between the bait acceptance rate and the subsequent estimated vaccination rate. It seems that the difference between these two was the lowest for the newly developed egg-flavored baits. However, this bait can be further optimized, and potentially this discrepancy could be further reduced. It was shown that several dogs had problems with the shape and texture of this bait. The animals had problems picking up the bait from the ground (a condition of shape) and sometimes seemed to consider the bait more as a toy than as a food item (a condition of texture). Both aspects increased the handling time, and subsequently the risk of disturbance and discontinuation of bait consumption. With minor improvements to the bait and further research, the egg-flavored baits have potential to be effectively used as an ORV bait for dogs in the Navajo Nation.

Supplementary Materials: The following are available online at http://www.mdpi.com/2414-6366/2/2/17/s1, Table S1. Bait acceptance for the 3 bait types and 2 blister types; unknowns not further included in statistical data analysis, Table S2. Amount (\%) of bait consumed by dog upon acceptance for the 3 bait types and 2 blister types; unknowns not further included in statistical data analysis, Table S3. Bait handling time (seconds) upon acceptance for the 3 bait types and 2 blister types; unknowns not further included in statistical data analysis, Table S4. The number of animals that swallowed or discarded the blister after bait acceptance for the 3 bait types and 2 blister types; unknowns not further included in statistical data analysis, Table S5. Number of blisters perforated/ruptured (yes) or not (no) after bait acceptance for the 3 bait types and 2 blister types; unknowns not further included in statistical data analysis, Table S6. Number of dogs that accepted a bait and were considered vaccinated (likely) or not (not likely) in case that the blister would have contained a vaccine for the 3 bait types and 2 blister types; unknowns not further included in statistical data analysis, Table S7. Bait acceptance and the effectiveness (dog likely to be vaccinated) for the 3 bait types and 2 blister types. Only animals were included for which data on both parameters, acceptance and effectiveness (likely vaccinated), were available, Table S8. Bait handling time (seconds) and the subsequent effectiveness of the vaccination attempt (likely or not likely vaccinated) for the 3 bait types; unknowns (effectiveness) not included in data analysis, and Table S9. Bait acceptance by owned and community (including ownerless) dogs for the 3 bait types and 2 blister types; unknowns (ownership status) not included in data analysis.

Acknowledgments: We would like to thank all of the staff of the Animal Control Program-Navajo Nation Fish \& Wildlife, the Navajo Nation Veterinary Program, the Office of Environmental Health-Indian Health Service, Navajo Area Office, and USDA, APHIS, and their Wildlife Service Arizona Program that actively supported us during the field work. Also, our special thanks to Steffen Ortmann for preparing the blisters and the manufactured baits.

Author Contributions: The author contribution to this study is as follows: S.B., D.B., A.V. and R.C. conceived, designed and performed the field experiment; S.B. and A.V. analyzed the data; A.V. provided the placebo baits and blisters for this study (S.B., D.B., R.C. and A.V. prepared the intestine baits that were locally sourced) and S.B., D.B., R.C., A.V. and A.M. collaboratively wrote and reviewed multiple drafts of this manuscript prior to submission.

Conflicts of Interest: A.V. is a full-time employee of IDT Biologika, Germany, a company that manufactured oral rabies vaccine placebo baits for this study. He was involved in the design of the study; in the collection, analyses and interpretation of data as well as the writing of the manuscript. However, I can affirm no direct funding was received from the vaccine company for this study. R.C. is the National Rabies Management Coordinator for the USDA, APHIS, Wildlife Services program and indirectly provided discretionary Federal funding to support field work and the writing of the manuscript. The Navajo Nation provided salaries of Navajo Nation employees (including S.B.) who participated in the field work. 


\section{References}

1. Hampson, K.; Coudeville, L.; Lembo, T.; Sambo, M.; Kieffer, A.; Attlan, M.; Barrat, J.; Blanton, J.D.; Briggs, D.J.; Cleaveland, S.; et al. Estimating the Global Burden of Endemic Canine Rabies. PLoS Negl. Trop. Dis. 2015, 9, $1-20$.

2. WHO (World Health Organization); OIE (World Organisation for Animal Health). Global Elimination of Dog-Mediated Human Rabies. In Proceedings of the Report of the Rabies Global Conference, Geneva, Switzerland, 10-11 December 2015.

3. Arief, R.A.; Hampson, K.; Jatikusumah, A.; Widyastuti, M.D.W.; Sunandar; Basri, C.; Putra, A.A.G.; Willyanto, I.; Estoepangestie, A.T.S.; Mardiana, I.W.; et al. Determinants of Vaccination Consequences for Rabies Control in Bali, Indonesia. Front. Vet. Sci. 2017, 3, 1-8. [CrossRef] [PubMed]

4. Castillo-Neyra, R.; Brown, J.; Borrini, K.; Arevalo, C.; Levy, M.Z.; Buttenheim, A.; Hunter, G.C.; Becerra, V.; Behrman, J.; Paz-Soldan, V.A. Barriers to Dog Rabies Vaccination during an Urban Rabies Outbreak: Qualitative Findings from Arequipa, Peru. PLoS Neglected Trop. Dis. 2017, 11, e0005460. [CrossRef] [PubMed]

5. Schildecker, S.; Millien, M.; Blanton, J.D.; Boone, J.; Emery, A.; Ludder, F.; Fenelon, N.; Crowdis, K.; Destine, A.; Etheart, M.; et al. Dog Ecology and Barriers to Canine Rabies Control in the Republic of Haiti, 2014-2015. Transbound. Emerg. Dis. 2016. [CrossRef] [PubMed]

6. Matter, H.C. Oral Immunization of Dogs: Analysis of Dog Populations and Bait Delivery Systems. In Rabies Control in Asia; Dodet, B., Meslin, F., Eds.; Elsevier: Paris, France, 1997; pp. 47-59.

7. Kaare, M.; Lembo, T.; Hampson, K.; Ernest, E.; Estes, A.; Mentzel, C.; Cleaveland, S. Rabies Control in Rural Africa: Evaluating Strategies for Effective Domestic Dog Vaccination. Vaccine 2009, 27, 152-160. [CrossRef] [PubMed]

8. Widyastuti, M.D.W.; Bardosh, K.L.; Sunandar; Basri, C.; Basuno, E.; Jatikusumah, A.; Arief, R.A.; Putra, A.A.G.; Rukmantara, A.; Estoepangestie, A.T.S.; et al. On Dogs, People, and a Rabies Epidemic: Results from a Sociocultural Study in Bali, Indonesia. Infect. Dis. Poverty 2015, 4, 30. [CrossRef] [PubMed]

9. WHO. Oral Vaccination of Dogs: Guidance for Research on Oral Rabies Vaccine and Field Application of Oral Vaccination of Dogs against Rabies; World Health Organization: Geneva, Switzerland, 2007.

10. WHO. WHO Expert Consultation on Rabies; World Health Organization: Geneva, Switzerland, 2013.

11. WHO. Report of WHO Consultation on Oral Immunization of Dogs against Rabies; World Health Organization: Geneva, Switzerland, 1988.

12. Rupprecht, C.E.; Barrett, J.; Briggs, D.; Cliquet, F.; Fooks, A.R.; Lumlertdacha, B.; Meslin, F.X.; Müler, T.; Nel, L.H.; Schneider, C.; et al. Can Rabies Be Eradicated? Dev. Biol. 2008, 131, 95-121.

13. Schuster, P.; Gülsen, N.; Neubert, A.; Vos, A. Field Trials Evaluating Bait Uptake by an Urban Dog Population in Turkey. J. Etlik Vet. Microbiol. 1998, 9, 73-81.

14. Yakobson, B.A.; King, R.; Sheichat, N.; Eventov, B.; David, D. Assessment of the Efficacy of Oral Vaccination of Livestock Guardian Dogs in the Framework of Oral Rabies Vaccination of Wild Canids in Israel. Dev. Biol. 2008, 131, 151-156.

15. Darkaoui, S.; Boué, F.; Demerson, J.M.; Fassi Fihri, O.; Yahia, K.I.S.; Cliquet, F. First Trials of Oral Vaccination with Rabies SAG2 Dog Baits in Morocco. Clin. Exp. Vaccine Res. 2014, 3, 220-226. [CrossRef] [PubMed]

16. Bergman, D.; Bender, S.; Wenning, K.; Slate, D.; Rupprecht, C.; Heuser, C.; Delibertoi, T. Bait Acceptability for Delivery of Oral Rabies Vaccine to Free-Ranging Dogs on the Navajo and Hopi Nations. Dev. Biol. 2008, 131, 145-150

17. Frontini, M.G.; Fishbein, D.B.; Garza Ramos, J.; Flores Collins, E.; Balderas Torres, J.M.; Quiroz Huerta, G.; Gamez Rodriguez, J.J.; Belotto, A.J.; Dobbins, J.G.; Linhart, S.B.; et al. A Field Evaluation in Mexico of Four Baits for Oral Rabies Vaccination of Dogs. Am. J. Trop. Med. Hyg. 1992, 47, 310-316. [CrossRef] [PubMed]

18. Kharmachi, H.; Haddad, N.; Matter, H. Tests of Four Baits for Oral Vaccination of Dogs against Rabies in Tunisia. Vet. Rec. 1992, 130, 494. [CrossRef] [PubMed]

19. Matter, H.C.; Kharmachi, H.; Haddad, N.; Youssef, S.B.; Sghaier, C.; Khelifa, R.B.; Jemli, J.; Mrabet, L.; Meslin, F.X.; Wandeler, A.I. Test of Three Bait Types for Oral Immunization of Dogs against Rabies in Tunisia. Am. J. Trop. Med. Hyg. 1995, 52, 489-495. [CrossRef] [PubMed]

20. Linhart, S.B.; Kappeler, A.; Windberg, L.A. A Review of Baits and Bait Delivery Systems for Free-Ranging Carnivores and Ungulates. In Contraception in Wildlife: Animal and Plant Health Inspection Service; United States Department of Agriculture: Oakland, CA, USA, 1993; pp. 69-132. 
21. Estrada, R.; Vos, A.; De Leon, R. Acceptability of Local-Made Baits for Oral Vaccination of Dogs against Rabies in the Philippines. BMC Infect. Dis. 2001, 1, 5. [CrossRef]

22. Corn, J.L.; Méndez, J.R.; Catalán, E.E. Evaluation of Baits for Delivery of Oral Rabies Vaccine to Dogs in Guatemala. Am. J. Trop. Med. Hyg. 2003, 69, 155-158. [PubMed]

23. Bishop, G.C. Increasing Dog Vaccination Coverage in South Africa: Is Oral Vaccination the Answer? In Rabies Control in Asia; Dodet, B., Meslin, F., Eds.; John Libbey Eurotext: Paris, France, 2001; pp. 105-109.

24. Berentsen, A.R.; Bender, S.; Bender, P.; Bergman, D.; Hausig, K.; VerCauteren, K.C. Preference among 7 Bait Flavors Delivered to Domestic Dogs in Arizona: Implications for Oral Rabies Vaccination on the Navajo Nation. J. Vet. Behav. Clin. Appl. Res. 2014, 9, 169-171. [CrossRef]

25. Berentsen, A.R.; Bender, S.; Bender, P.; Bergman, D.; Gilbert, A.T.; Rowland, H.M.; VerCauteren, K.C. Bait Flavor Preference and Immunogenicity of ONRAB Baits in Domestic Dogs on the Navajo Nation, Arizona. J. Vet. Behav. 2016, 15, 20-24. [CrossRef]

26. Gräßer, N. Beitrag Zur Entwicklung Eines Köders Für Wölfe (Canis Lupus) Zur Oralen Vakzination Gegen Tollwut; University of Veterinary Medicine: Hannover, Germany, 2016.

27. Aylan, O.; Vos, A. Efficacy of Oral Rabies Vaccine Baits in Indigenous Turkish Dogs. Rev. Infect. Dis. 2000, 2, 74-77.

28. Linhart, S.B. Bait Formulation and Distribution for Oral Rabies Vaccination of Domestic Dogs: An Overview. Onderstepoort J. Vet. Res. 1993, 60, 479-490. [PubMed]

29. Harischindra, P.A.L. Dog Vaccination Coverage and Oral Rabies Vaccination in Sri Lanka, an Update. In Rabies Control in Asia; Dodet, B., Meslin, F.X., Eds.; John Libbey Eurotext: Paris, France, 2001; pp. 97-100.

30. Perry, B.D.; Johnston, D.H.; Jenkins, S.R.; Foggin, C.M.; Garner, N.; Brooks, R.; Bleakley, J. Studies on the Delivery of Oral Rabies Vaccines to Wildlife and Dog Populations. Acta Vet. Scand. 1988, 84, 303-305.

31. Cliquet, F.; Gurbuxani, J.P.; Pradhan, H.K.; Pattnaik, B.; Patil, S.S.; Regnault, A.; Begouen, H.; Guiot, A.L.; Sood, R.; Mahl, P.; et al. The Safety and Efficacy of the Oral Rabies Vaccine SAG2 in Indian Stray Dogs. Vaccine 2007, 25, 3409-3418. [CrossRef] [PubMed]

32. Nokireki, T.; Nevalainen, M.; Sihvonen, L.; Gadd, T. Adverse Reactions from Consumption of Oral Rabies Vaccine Baits in Dogs in Finland. Acta Vet. Scand. 2016, 58, 1-4. [CrossRef]

(C) 2017 by the authors. Licensee MDPI, Basel, Switzerland. This article is an open access article distributed under the terms and conditions of the Creative Commons Attribution (CC BY) license (http:/ / creativecommons.org/licenses/by/4.0/). 


\title{
Modeling Raccoon (Procyon lotor) Habitat Connectivity to Identify Potential Corridors for Rabies Spread
}

\author{
Timothy P. Algeo ${ }^{1, *, \dagger}$, Dennis Slate ${ }^{1}$, Rosemary M. Caron ${ }^{2}$, Todd Atwood ${ }^{3, \ddagger}$, \\ Sergio Recuenco ${ }^{4,}$, Mark J. Ducey ${ }^{5}$, Richard B. Chipman ${ }^{1}$ and Michael Palace ${ }^{6}$ \\ 1 USDA, APHIS, Wildlife Services, National Rabies Management Program, Concord, NH 03301, USA; \\ dennis.slate@aphis.usda.gov (D.S.); richard.b.chipman@aphis.usda.gov (R.B.C.) \\ 2 Department of Health Management and Policy, University of New Hampshire, Durham, NH 03824, USA; \\ rosemary.caron@unh.edu \\ 3 USDA, APHIS, Wildlife Services, National Wildlife Research Center, Fort Collins, CO 80521, USA; \\ tatwood@usgs.gov \\ 4 National Center for Public Health (Insitituto Nacional de Salud), Capac Yupanqui 1400, Jesus Maria, \\ Lima 15073, Peru; srecuencoc@unmsm.edu.pe \\ 5 Department of Natural Resources and the Environment, University of New Hampshire, \\ Durham, NH 03824, USA; mjducey@unh.edu \\ 6 Department of Earth Sciences, University of New Hampshire, Durham, NH 03824, USA; \\ palace@guero.sr.unh.edu \\ * Correspondence: timothy.p.algeo@aphis.usda.gov; Tel.: +1-603-520-8946 \\ † Current address: USDA, APHIS, Wildlife Services, Concord, NH 03301, USA \\ $\ddagger$ Current address: USGS, Alaska Science Center, Polar Bear Project, Anchorage, AK 99508, USA. \\ $\S$ Current address: Department of Preventive Medicine and Public Health, Faculty of Medicine, \\ Universidad Nacional Mayor de San Marcos, Av Grau s/n, Lima 15081, Peru.
}

Received: 31 May 2017; Accepted: 10 August 2017; Published: 28 August 2017

\begin{abstract}
The United States Department of Agriculture (USDA), Animal and Plant Health Inspection Service (APHIS), Wildlife Services National Rabies Management Program has conducted cooperative oral rabies vaccination (ORV) programs since 1997. Understanding the eco-epidemiology of raccoon (Procyon lotor) variant rabies (raccoon rabies) is critical to successful management. Pine (Pinus spp.)-dominated landscapes generally support low relative raccoon densities that may inhibit rabies spread. However, confounding landscape features, such as wetlands and human development, represent potentially elevated risk corridors for rabies spread, possibly imperiling enhanced rabies surveillance and ORV planning. Raccoon habitat suitability in pine-dominated landscapes in Massachusetts, Florida, and Alabama was modeled by the maximum entropy (Maxent) procedure using raccoon presence, and landscape and environmental data. Replicated ( $n=100 /$ state) bootstrapped Maxent models based on raccoon sampling locations from 2012-2014 indicated that soil type was the most influential variable in Alabama (permutation importance PI = 38.3), which, based on its relation to landcover type and resource distribution and abundance, was unsurprising. Precipitation $(\mathrm{PI}=46.9)$ and temperature $(\mathrm{PI}=52.1)$ were the most important variables in Massachusetts and Florida, but these possibly spurious results require further investigation. The Alabama Maxent probability surface map was ingested into Circuitscape for conductance visualizations of potential areas of habitat connectivity. Incorporating these and future results into raccoon rabies containment and elimination strategies could result in significant cost-savings for rabies management here and elsewhere.
\end{abstract}

Keywords: circuit theory; habitat suitability; Maxent; pine; Pinus; Procyon lotor; rabies; raccoon; risk model 


\section{Introduction}

Rabies kills approximately 59,000 humans world-wide annually [1,2], but due to considerable control efforts, human cases are relatively rare in the developed world [1]. However, rabies control is expensive. Annual costs of living with rabies in the U.S. have been estimated at \$300 million [3] (\$646 million in 2017 USD [4]). Oral rabies vaccination (ORV) has proven effective for achieving wildlife rabies control [5] with noteworthy successes from a number of locations [6-12]. Raccoon (Procyon lotor) variant rabies (raccoon rabies) is currently present along the entire eastern seaboard, from Florida west to Alabama, north to the Canadian frontier, and west to Ohio. Consequently, it is one of the most important terrestrial variants currently circulating in North America in terms of incidence rates and proximity of raccoons to humans. Elimination of raccoon rabies is currently a high priority in the U.S. The United States Department of Agriculture (USDA), Animal and Plant Health Inspection Service (APHIS), Wildlife Services (WS) and cooperators have conducted ORV aimed at preventing the spread of raccoon rabies to the west (Phase I) since 1997. Phase II planning is underway and will focus on eliminating raccoon rabies from enzootic areas in the eastern U.S.

Considerable effort has been made to understand and model the spread, perpetuation, control, and economics of rabies. Deterministic and stochastic models for the spread of rabies in wildlife and for control scenarios with varying vaccination levels and barrier widths were evaluated, and the latter outperformed the former at rabies persistence and elimination simulations [13]. In Ontario, a time-series analysis was employed to try to understand regional differences in the dynamics of Arctic fox (Alopex lagopus) rabies in red foxes (Vulpes vulpes) [14], which ultimately led to the delineation of different rabies units with independent management strategies. Modeling has also demostrated geographic clustering of raccoon rabies cases in New York, and allowed for consideration of possible causes for these and related temporal patterns [15]. Additionally, modeled likely consequences of global climate change include a potential primary reservoir shift for Arctic fox variant rabies from Arctic to red foxes in Alaska [16], and range expansion for common vampire bats (Desmodus rotundus) [17]. Economic models of rabies and its control have been created for diverse scenarios, with the monetary burden from raccoon rabies estimated at $\$ 1.1$ billion without ORV intervention over a 22-year horizon from 2012 to 2033 [18].

The concept of connectivity, or the ease of movement between landscape features, is important to understand in the contexts of both conservation and eco-epidemiology [19]. Connectivity modeling procedures are designed to identify critical movement areas for species of concern to achieve any of a number of management goals [20,21]. A relatively new approach to connectivity modeling is the adoption of circuit theory, in which the principles of electrical circuits are applied in ecology for creating more robust representations of and effects from known sources of resistance and multiple available pathways [22]. Through the incorporation of random walk theory [23], and Ohm's Law-like resistances (wherein current $=$ voltage/resistance, or $\mathrm{I}=\mathrm{V} / \mathrm{R}$ ) in the form of resistance (or conductance) maps generated through habitat suitability index (HSI) modeling, circuit theory modeling can suggest pathways for the greatest likelihood of movement of members of a species between nodes or regions [22].

In the absence of complete information on habitat or site occupancy, assessments of distribution and habitat or site preference become problematic. The Maxent approach $[20,24]$ allows for the use of occurrence data without absence information, along with environmental data, to estimate distribution likelihood for a given landscape. The Maxent procedure output includes a receiver operating characteristic (ROC), with the area under curve (AUC) provided as a measure of performance of the model in terms of assessing habitat suitability. Used in tandem with Circuitscape [25], a visualization of likely areas of concern for managers is created and in the case of rabies, can delineate priority areas for surveillance and control.

Comparisons between Maxent and other available procedures suggest at least equal performance and often superiority for Maxent in many cases. For example, Poor et al. [26] compared Maxent to the expert-based analytic hierarchy process (AHP) for developing habitat suitability models (HSM). 
They deemed the overall performance of the two HSM procedures to be similarly satisfactory, except that they considered Maxent's cell-based habitat analyses inflexible compared with the expert-based approach in which temporal and spatial analysis units can be manipulated. However, they felt that Maxent performed somewhat better at ultimately producing more corridors that contained pronghorn antelope (Antilocapra americana) locations when the surfaces produced were utilized in connectivity models. A consideration worth noting is that in cases of relatively small sample sizes, information criteria procedures such as Akaike's information criteria for small sample sizes (AICc) [27] or Bayesian information criteria (BIC) [28] provide somewhat better results than does the Maxent default AUC measure of model performance [29]. In another example, traditional movement models for golden-headed lion tamarins (Leontopithecus chrysomelas) in Brazil used Circuitscape [25] with an HSI resistance map to increase the authenticity of the modeled conservation situation in terms of tamarin movements between patches [30]. Circuitscape was also compared to least cost method (LCM) procedures for modeling connectivity using surfaces created through both the Maxent and AHP processes. While the corridors created using Maxent input generally contained more pronghorn antelope locations, the LCM proved superior in terms of generating pronghorn-containing corridors [26]. However, the ease with which Circuitscape's seamless integration of Maxent outputs provides useful visualizations of landscape connectivity help it retain its appeal.

The WS ORV program along the Appalachian Ridge and the New England/New York-Canada frontier is designed to take advantage of research findings indicating relatively low raccoon densities at higher elevations ( $>610 \mathrm{~m}$ ), as established by raccoon density indexing (RDI) [31], and which are presumed to result in reduced raccoon contact rates. Also of importance, the spread of raccoon rabies appears to be negatively affected by rivers [32-34] and certain types of forested habitats [33,34].

Much of the area targeted for Phase II is comprised of pine-dominated (Pinus spp.) forests. For example, pitch pine (P. rigida) occurs in coastal areas from New England south through New Jersey; Virginia pine (P. virginiana) occurs from the mid-Atlantic coast inland to the Appalachian Ridge-south; longleaf pine (P. palustris) is found in coastal areas from southern Virginia to Texas, and loblolly pine ( $P$. taeda) is found in large commercial plantings in the southeast [35]. Relatively low RDIs have been developed for pitch pine and pitch pine-scrub oak (Quercus spp.) forest types of southeastern Massachusetts and New Jersey [36]. Similarly, RDIs developed within loblolly and longleaf pine-dominated landscapes were lower relative to adjacent types [34,37].

We modeled raccoon habitat suitability in pine-dominated landscapes in Massachusetts, Florida, and Alabama by the maximum entropy (Maxent) procedure [20] using raccoon presence and landscape and environmental data to optimize ORV operations in pine-dominated landscapes of the eastern United States. As is the case for many generalist mesocarnivores, absence data for raccoons are difficult to acquire. Consequently, the presence-only Maxent procedure was employed given the relatively large number of locations available to us as byproducts of rabies management activities. Environmental surfaces generated by Maxent were ingested into Circuitscape for conductivity analysis [21,22,25,26,38], which then illustrated potential risk pathways for the spread of raccoon rabies. These results provide us an opportunity to assess the potential utility of circuit theory modeling for providing insight into critical areas for consideration when developing rabies control strategies.

\section{Methods}

Raccoon sampling location data are collected as part of routine rabies virus and post-ORV rabies serological monitoring which occurs in diverse habitats, including pine-dominated sites. Post-ORV live-trapping was conducted for the purpose of program assessment randomly throughout treated areas using Tomahawk Model 608 live-traps (Tomahawk Live Trap LLC, Hazelhurst, WI, USA). Raccoon handling was as described in Slate et al. [39]. Data from unique raccoons $(n=2986)$ sampled in Massachusetts, Florida, and Alabama during 5 January 2012-26 June 2014 were analyzed in Maxent. This sampling timeframe was selected to overlap with contemporary land use status as recorded within the National Land Cover Database 2011 (NLCD 2011) [40]. Trap location selection 
was based on opportunity (safe locations-for trappers, raccoons, and the public), where observed microhabitats suggested that potential undiscovered (by the public) raccoon capture was likely. While this does not reflect true random sampling, we made every effort to remove the influence of assumptions about density to achieve the greatest degree of randomness we could expect given the study limitations. Consequently, 1869 raccoons met study selection criteria (captured/collected by WS since 1 January 2012; not captured within 30 days prior; not captured as part of density indexing; and with a geo-location available), and their locations were imported into the GIS (Table 1).

Additional selection within the study areas in three states and GIS layer coverages resulted in 1770 raccoon sample locations available for Maxent model training and Circuitscape risk analysis.

Table 1. Raccoon risk model sample data for pine-dominated landscapes of Massachusetts, Florida, and Alabama: 2012-2014. ${ }^{1}$

\begin{tabular}{ccccc}
\hline State & Dates Sampled & Sample Size & Age Ratio $^{\text {2,3 }}$ (n) & Sex Ratio (M:F; n) \\
\hline Massachusetts & 25 January 2012-26 June 2014 & 171 & $4.3: 1(32)$ & $1.7: 1(168)$ \\
Florida & 19 January 2012-30 May 2014 & 431 & $15.4: 1(278)$ & $1.7: 1(427)$ \\
Alabama & 5 January 2012-20 December 2013 & 1267 & NA & $1.2: 1(1251)$ \\
Total & & 1869 & $12.5: 1(310)$ & $1.3: 1(1846)$ \\
\hline
\end{tabular}

${ }^{1}$ Selection criteria for study inclusion: captured/collected by USDA, APHIS, Wildlife Services personnel since 1 January 2012; no capture within 30 days prior; not captured as part of a density study; geo-location available. Not all samples selected were ultimately included in each analysis. ${ }^{2}$ Age ratios are adult: juvenile; juvenile status $\leq 1$ year as aged by the cementum annuli procedure, Matson's Laboratory, Milltown, MT [41]. ${ }^{3}$ Age data not available for Alabama.

\subsection{Landscape Data}

Land class and use types were represented by $30 \mathrm{~m}$ NLCD 2011 data [40] for the areas of interest. Although not the only available coverage for assessing forest cover, land use, and other surface feature types, NLCD 2011 is the standard used by WS for flight planning. Consequently, modeling results based on this product can be more easily translated into management actions. Study area characteristic analysis indicate that evergreen forest (NLCD 2011 Class 42) ranks 3/15 classes available for the Massachusetts study area, 9/13 for the Florida study area, and 4/15 in Alabama. NLCD 2011 Class representation among raccoon sample locations used in initial analyses indicated that $8.8 \%$ of raccoon sample locations in Massachusetts fell into the evergreen class, while only $5.3 \%$ and $6.2 \%$ were in that class in Florida and Alabama, respectively (Table 2).

The Digital General Soil Map of the U.S. (STATSGO2) represents an inventory of soils mapped at 1:250,000 scale [42] and at the level of soil taxonomic order that provides appropriate resolution data for consideration at raccoon home range scales. Study area characteristic analysis in terms taxonomic soil orders (soils) indicates that entisols (dunes, floodplains) rank highest among soil orders for the Massachusetts study area ( $>98 \%)$, while in the Florida and Alabama study areas, soils from the alfisols (common in semiarid-moist regions) dominated at $>67 \%$ and almost $42 \%$, respectively. In terms of soils representation among the sample points used in initial analyses, $>99 \%(n=171)$ of raccoon sample locations in southeastern Massachusetts fell into the entisols, while in Florida the majority (almost 88\%) fell into the alfisols. A greater diversity of soils was represented among the Alabama raccoon sample locations (alfisols at 34\%, entisols at 37\%, inceptisols (characterized by varied productivity; layer formation developing) at $19 \%$, and ultisols at $9 \%$ ). 
Table 2. NLCD $2011^{1}$ class representation in raccoon risk model study area and sample point data (5 January 2012-26 June 2014) from within pine-dominated landscapes of Massachusetts, Florida, and Alabama.

\begin{tabular}{|c|c|c|c|c|c|c|}
\hline \multirow[b]{2}{*}{ NLCD 2011 Class ${ }^{1}$} & \multicolumn{2}{|c|}{ Massachusetts ( $n=171)$} & \multicolumn{2}{|c|}{ Florida $(n=431)$} & \multicolumn{2}{|c|}{ Alabama $(n=1168)$} \\
\hline & $\begin{array}{c}\text { Percent } \\
\text { Study } \\
\text { Area }\end{array}$ & $\begin{array}{l}\text { Percent } \\
\text { Sample } \\
\text { Points }\end{array}$ & $\begin{array}{c}\text { Percent } \\
\text { Study } \\
\text { Area }\end{array}$ & $\begin{array}{c}\text { Percent } \\
\text { Sample } \\
\text { Points }\end{array}$ & $\begin{array}{c}\text { Percent } \\
\text { Study } \\
\text { Area }\end{array}$ & $\begin{array}{c}\text { Percent } \\
\text { Sample } \\
\text { Points }\end{array}$ \\
\hline 11-open water & 2.1 & NA & 1.5 & NA & 0.9 & 2.1 \\
\hline 21-developed, open space & 19.6 & 19.3 & 19.0 & 15.8 & 10.3 & 23.7 \\
\hline 22-developed, low intensity & 17.7 & 40.9 & 13.3 & 7.7 & 2.3 & 4.5 \\
\hline 23-developed, medium intensity & 8.7 & 6.4 & 6.1 & 1.6 & 0.8 & 0.9 \\
\hline 24-developed, high intensity & 1.2 & 0.6 & 1.4 & 0.9 & 0.2 & 0.3 \\
\hline 31-barren land (rock/sand/clay) & 2.0 & NA & 1.0 & NA & 0.4 & 0.7 \\
\hline 41-deciduous forest & 11.0 & 4.1 & NA & NA & 17.0 & 24.7 \\
\hline 42-evergreen forest & 11.7 & 8.8 & 3.7 & 5.3 & 12.8 & 6.2 \\
\hline 43 mixed forest & 8.5 & 1.2 & NA & NA & 20.4 & 5.2 \\
\hline 52-shrub/scrub & 2.7 & NA & 7.3 & 6.5 & 15.0 & 6.2 \\
\hline 71-grassland/herbaceous & 2.9 & 1.2 & 7.7 & 1.9 & 5.3 & 4.8 \\
\hline 81-pasture/hay & 1.1 & NA & 5.6 & 1.6 & 6.2 & 13.2 \\
\hline 82-cultivated crops & 0.7 & NA & 0.9 & NA & 2.4 & 3.2 \\
\hline 90-woody wetlands & 5.6 & 8.2 & 19.9 & 54.1 & 5.1 & 4.3 \\
\hline 95-emergent herbaceous wetlands & 4.6 & 9.4 & 12.6 & 4.6 & 0.6 & 0 \\
\hline
\end{tabular}

${ }^{1}$ Source: U.S. Geological Survey, 2014 [40].

\subsection{Environmental Data}

Euclidean distance layers for distance to National Hydrography Dataset $(1: 24,000)$ lake, pond, swamp, marshland, reservoir, and estuary (nhd24kwb; water bodies); and stream, river, canal, ditch and coastline (nhd24kst; streams) data [43] were also incorporated. Environmental inputs were $1 \mathrm{~km}$ Worldclim Bio1 (Annual Mean Temperature; temperature) and Bio12 (Annual Mean Precipitation; precipitation) data [44]. Worldclim elevation (elevation) data [44] derived from the Shuttle Radar Topography Mission (SRTM) [45] were also used for assessing potential effects from elevation to RDI (Table 3).

\subsection{Human Environment Data}

To refine our assessment of potential effects from human development that may subsidize raccoon populations through the provision of garbage, garden and farm crops beyond what is demonstrated in the development classes within the NLCD 2011 [40], 2010 census data in the form of population and housing layers were incorporated [46]. Euclidean distance to primary and secondary road layers [46] for our study areas were also included, given the potential role of roads as travel corridors or barriers to movement (Table 3).

\subsection{Data Preparation and Processing}

Circuitscape requires ASCII raster-formatted data for analysis. The Circuitscape Exporter add-in tool for ArcMap [47] was used to export ArcGIS vector and raster data into ASCII rasters of identical cell sizes, extents, and spatial references for use in Maxent, and for eventual ingestion into Circuitscape. Separate global Maxent model (settings: 100 replicate bootstrap analysis, 25\% random-seeded test percentage, logistic output format, duplicate locations allowed, response curves created, jackknife measure of variable importance, and 5000 maximum iterations) runs were made for each state using raccoon sample locations from 2012-present and 10 'environmental layers' (Table 3). 
Table 3. Raccoon risk modeling: environmental variables, sources, and choice justification for pine-dominated landscapes of Massachusetts, Florida, and Alabama.

\begin{tabular}{|c|c|c|c|}
\hline Variable & Data Type & Source & Selection Justification \\
\hline $\begin{array}{l}\text { National LandcoverDataset } \\
\text { (NLCD 2011) }\end{array}$ & Landscape/categorical & $\begin{array}{l}30 \text { m GeoTIFF images-http: } \\
\text { //landcover.usgs.gov/ }\end{array}$ & Used by NRMP for ORV planning \\
\hline Euclidean Distance to (streams) & Landscape/continuous & $\begin{array}{l}\text { National Hydrography Dataset } \\
2014 \text { http://nhd.usgs.gov/ }\end{array}$ & $\begin{array}{l}\text { Raccoon foraging frequently focused in } \\
\text { riparian areas [48] }\end{array}$ \\
\hline $\begin{array}{l}\text { Euclidean Distance to water } \\
\text { (water bodies) }\end{array}$ & Landscape/continuous & $\begin{array}{l}\text { National Hydrography Dataset } \\
2014 \text { http://nhd.usgs.gov/ }\end{array}$ & $\begin{array}{l}\text { Raccoon foraging frequently focused in } \\
\text { riparian areas [48] }\end{array}$ \\
\hline $\begin{array}{l}\text { USDA soil taxonomic order } \\
\text { (soils) }\end{array}$ & Landscape/categorical & $\begin{array}{l}\text { STATSGO22 } \\
\text { http://www.nrcs.usda.gov/ }\end{array}$ & $\begin{array}{l}\text { Standing water, and invertebrate } \\
\text { availability [48] }\end{array}$ \\
\hline Elevation (elevation) & Landscape/continuous & $\begin{array}{l}\text { Shuttle Radar Topography } \\
\text { Mission http: } \\
\text { //www2.jpl.nasa.gov/srtm/ }\end{array}$ & Likely correlated with water/NLCD \\
\hline $\begin{array}{l}\text { Annual Mean Precipitation } \\
\text { (precipitation) }\end{array}$ & Environmental/continuous & $\begin{array}{l}\text { WorldClim, Global Climate Data } \\
\text { http://www.worldclim.org/ }\end{array}$ & Standing water, land cover/use types \\
\hline $\begin{array}{l}\text { Annual Mean Temperature } \\
\text { (temperature) }\end{array}$ & Environmental/continuous & $\begin{array}{l}\text { WorldClim, Global Climate Data } \\
\text { http://www.worldclim.org/ }\end{array}$ & $\begin{array}{l}\text { Foraging behavior and reproduction } \\
\text { timing }\end{array}$ \\
\hline $\begin{array}{l}\text { Human Housing Density } \\
\text { (housing) }\end{array}$ & Human environment/continuous & $\begin{array}{l}2010 \text { Census Population/Housing } \\
\text { Unit Counts-Blocks: Tiger/line } \\
\text { files www.census.gov }\end{array}$ & $\begin{array}{l}\text { Human subsidies to raccoons - garbage, } \\
\text { garden crops [48] }\end{array}$ \\
\hline $\begin{array}{l}\text { Human Population Density } \\
\text { (human population) }\end{array}$ & Human environment/continuous & $\begin{array}{l}2010 \text { Census Population/Housing } \\
\text { Unit Counts-Blocks: Tiger/line } \\
\text { files www.census.gov }\end{array}$ & $\begin{array}{l}\text { Human subsidies to raccoons - garbage, } \\
\text { garden crops [48] }\end{array}$ \\
\hline $\begin{array}{l}\text { Euclidean Distance to Roads } \\
\text { (roads) }\end{array}$ & Human environment/continuous & $\begin{array}{l}\text { U.S. Census Bureau } \\
\text { http://www.census.gov/geo/ } \\
\text { maps-data/data/tiger.html }\end{array}$ & Travel corridors \\
\hline
\end{tabular}

Maxent created ROC plots of true versus false positive locations in the model, and an assessment of the AUC created by plotting sensitivity (1-omission rate) against 1-specificity (the fractional predicted area), which is a threshold-independent measure of accuracy and ranges from between 0.5 (the random prediction) to the maximum achievable value of 1.0 [49]. Percent contribution and permutation importance values provided measures of variable performance, with the former being useful for assessing the roles of uncorrelated variables, and the latter for an assessment based on the AUC metric of the dependence of the model on a given variable. The jackknife results provide a visual interpretation of variable importance [50]. Resulting environmental surfaces were ingested into Circuitscape for conductivity analysis [25,38].

In Circuitscape, the input resistance data (environmental data) were set to represent conductances rather than resistances, and the focal nodes (samples) consisted of 500 random points created in ArcMap for the global models. To expedite analyses, the all-to-one modeling mode was selected. Resulting Circuitscape conductance maps provide no metrics, but despite this are extremely useful for visualizing areas of concern for the prevention of the spread, or the perpetuation, of rabies in our areas of interest.

In addition, for each environmental layer class (environmental = temperature and precipitation; landscape = NLCD 2011, elevation, stream, water body, and soils; and human-based = human population, housing, and roads) separate models were constructed to further develop an understanding of the importance of these variables as classes of landscape factors. A 5-replicate bootstrap Maxent analysis (all other settings as above) was conducted for each of these models. Circuitscape images were not created for these analyses.

\section{Results}

Raccoon sample location distribution $(n=171)$ was relatively even across areas of interest in Barnstable and Plymouth Counties, Massachusetts. The averaged 100-replicate bootstrapped Maxent model ROC AUC (model sensitivity relative to 1-specificity) for southeastern Massachusetts was relatively high at 0.958 . Higher levels of raccoon sample location probability are seen along the more heavily populated (by humans) and mixed-forest type dominated coasts. Precipitation was the most influential variable in the Massachusetts Maxent model (44\% contribution; 46.9 permutation 
importance), with a higher proportion of raccoon sample locations occurring where precipitation levels were higher, primarily along the outer portion of Cape Cod. The next most influential variable was NLCD $2011(15.3 \%$; 7) which had more raccoon sample locations $(40.9 \%)$ occurring on the developed low intensity (NLCD 2011 Class 22) than any other land class available, while soils was the third most influential (11.7\%; 3.8). All other variables fell below 10\% model contributions, although permutation importance was higher for several of these than for the second and third highest in terms of percent contributions (Table 4).

Table 4. Raccoon $(n=171)$ risk modeling sample data for pine-dominated landscapes of Massachusetts during 5 January 2012-26 June 2014. All values are means.

\begin{tabular}{ccc}
\hline Variable & Percent Contribution & Permutation Importance \\
\hline Annual Mean Precipitation & 44 & 46.9 \\
National Landcover Dataset 2011 & 15.3 & 7 \\
USDA Soil Taxonomic Order & 11.7 & 3.8 \\
Euclidean Distance to Roads & 9.5 & 9.1 \\
Human Population Density & 5.8 & 11.4 \\
Human Housing Density & 4.5 & 7 \\
Annual Mean Temperature & 3.6 & 4.8 \\
Euclidean Distance to Streams & 2.4 & 2.6 \\
SRTM Elevation & 2.3 & 5.9 \\
Euclidean Distance to Water bodies & 1 & 1.4 \\
\hline
\end{tabular}

The Maxent model for raccoon sample $(n=431)$ distribution in Florida performed slightly better than the model for Massachusetts, with an AUC $>0.975$. The distribution of raccoon sample locations and the resulting Maxent model representation for Florida demonstrate a potential difference between several urbanized areas in terms of predicted raccoon habitat suitability. Temperature played the most important role in raccoon sample collection location in Florida (30.1\%, 52.1), with the majority of raccoons at locations with slightly higher annual mean temperatures. Precipitation played the next most important role $(21.5 \%, 10.5)$. Soils was the third most important $(20.5 \%, 19.4)$ variable. All other variables made $<10$ percent contributions and scored below the topmost variables in terms of permutation importance as well (Table 5).

Of the three states sampled, the Maxent model for raccoon sample $(n=1168)$ location distribution in Alabama performed the least well, with an AUC of 0.932. Here, soil was the most influential variable $(39.4 \%, 38.3)$, followed by temperature $(18.3 \%, 22.7)$ and elevation $(12.1 \%, 15.9)$ (Table 6).

Raccoon sample locations and predicted raccoon habitat suitability for Alabama were fairly consistent. However, areas with relatively high probability predictions without raccoon samples having come from them were evident as well (Figure 1a). The Circuitscape output based on Maxent results for Alabama reveals areas of considerable risk for the movement of raccoon rabies (Figure 1b). 
Table 5. Raccoon $(n=431)$ risk modeling sample data for pine-dominated landscapes of Florida during 5 January 2012-26 June 2014. All values are means.

\begin{tabular}{ccc}
\hline Variable & Percent Contribution & Permutation Importance \\
\hline Annual Mean Temperature & 30.1 & 52.1 \\
Annual Mean Precipitation & 21.5 & 10.5 \\
USDA Soil Taxonomic Order & 20.5 & 19.4 \\
Euclidean Distance to Roads & 7.4 & 2.6 \\
SRTM Elevation Data & 7.1 & 6.6 \\
Euclidean Distance to Water bodies & 5.1 & 3 \\
National Landcover Dataset 2011 & 4.6 & 3.1 \\
Human Housing Density & 2.9 & 1.8 \\
Human Population Density & 0.6 & 0.4 \\
Euclidean Distance to Streams & 0.1 & 0.5 \\
\hline
\end{tabular}

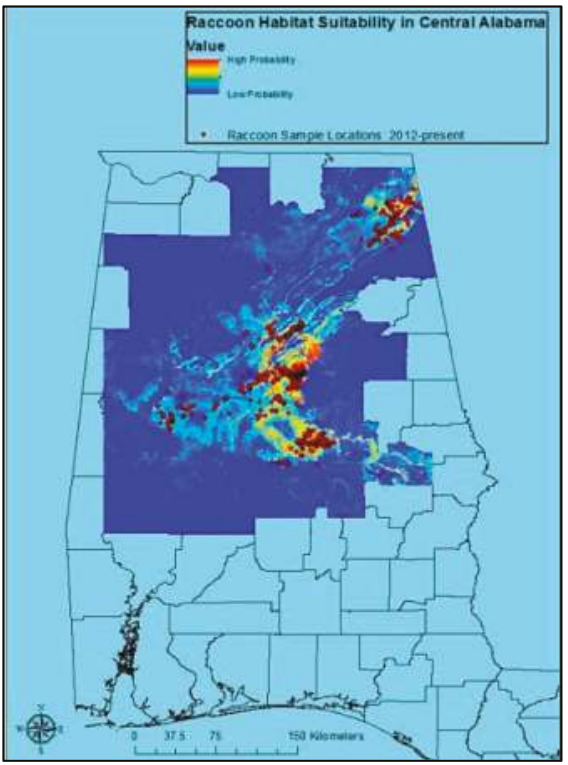

(a)

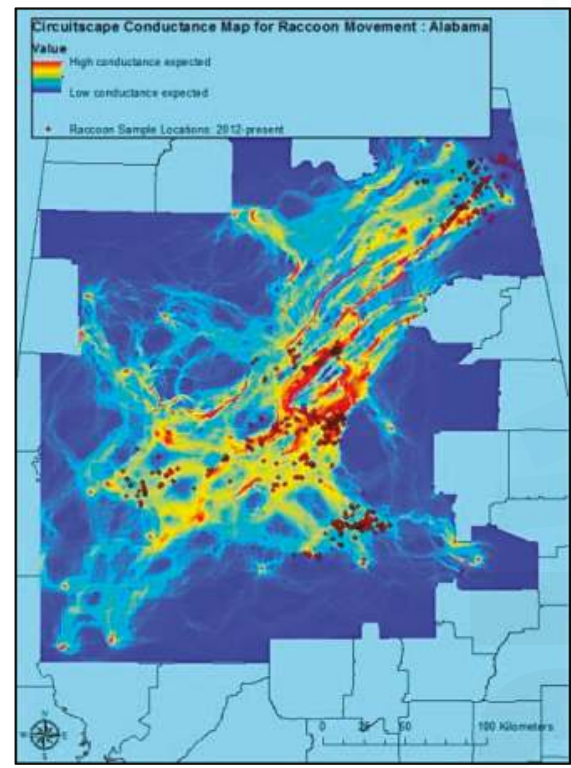

(b)

Figure 1. Maxent raccoon location probability map based on raccoon sample ((a); $n=1168 ; 5$ January 2012-26 June 2014) locations, annual mean precipitation, annual mean temperature, elevation, land cover/land use, human population density, housing density, Euclidean distance to roads, USDA Soil Taxonomic Order, Euclidean distance to streams/rivers, and Euclidean distance to water bodies for central Alabama; and Circuitscape conductance map for raccoon rabies risk in Alabama (b). 
Table 6. Raccoon $(n=1168)$ risk modeling sample data for pine-dominated landscapes of Alabama during 5 January 2012-26 June 2014. All values are means.

\begin{tabular}{ccc}
\hline Variable & Percent Contribution & Permutation Importance \\
\hline USDA Soil Taxonomic Order & 39.4 & 38.3 \\
Annual Mean Temperature & 18.3 & 22.7 \\
SRTM Elevation Data & 12.1 & 15.9 \\
Euclidean Distance to Roads & 11 & 7.1 \\
National Landcover Dataset 2011 & 8.3 & 2.4 \\
Annual Mean Precipitation & 6.1 & 11 \\
Euclidean Distance to Water bodies & 3.1 & 0.8 \\
Human Population Density & 1 & 1.2 \\
Human Housing Density & 0.6 & 0.4 \\
Euclidean Distance to Streams & 0.1 & 0.2 \\
\hline
\end{tabular}

Raccoon sample locations and predicted raccoon habitat suitability were also relatively consistent in Massachusetts and Florida (Figure 2a,b). As in Alabama, Circuitscape predicts raccoon movement risk (Figure 2c,d). However, given concerns over model results relative to program understanding of raccoon ecology, these are potentially less useful for management decision-making than the model for Alabama (Figure 1b).

Evaluated as groupings of like variables, the landscape suite performed slightly better than the environmental and human-based ones in terms of average AUC, with relatively high mean AUC values in both Florida and Alabama. Only Florida had a mean AUC that exceeded 0.90 for the environmental suite of variables, while none in the human-based category did (Table 7).

Table 7. Evaluation of environmental layer classes for their influence on raccoon risk model results for pine-dominated landscapes of Massachusetts, Florida, and Alabama during 5 January 2012-26 June 2014: 5 bootstrap replicated runs. All AUC values are means.

\begin{tabular}{|c|c|c|c|c|}
\hline State & Model Performance & Environmental Model $^{1}$ & Landscape Model $^{2}$ & Human-based Model $^{3}$ \\
\hline \multirow{3}{*}{ MA } & Mean AUC & 0.886 & 0.872 & 0.861 \\
\hline & $95 \% \mathrm{CI} \pm$ & 0.0023 & 0.0024 & 0.0031 \\
\hline & $\mathrm{n}$ & 166 & 153 & 171 \\
\hline \multirow{3}{*}{ FL } & Mean AUC & 0.956 & 0.963 & 0.824 \\
\hline & $95 \% \mathrm{CI} \pm$ & 0.0002 & 0.0004 & 0.0008 \\
\hline & $\mathrm{n}$ & 411 & 396 & 431 \\
\hline \multirow{3}{*}{$\mathrm{AL}$} & Mean AUC & 0.858 & 0.916 & 0.749 \\
\hline & $95 \% \mathrm{CI} \pm$ & 0.0003 & 0.0001 & 0.0002 \\
\hline & $\mathrm{n}$ & 1168 & 1168 & 1168 \\
\hline
\end{tabular}

${ }^{1}$ annual mean temperature and precipitation at the $1 \mathrm{~km}$ resolution; ${ }^{2}$ NLCD 2011, elevation, Euclidean distance to streams, Euclidean distance to water bodies, and soils; ${ }^{3}$ human population, human housing, and Euclidean distance to roads. 


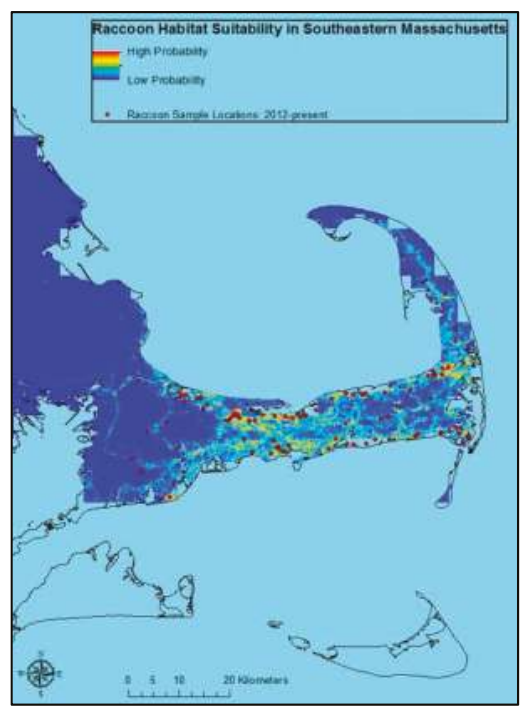

(a)

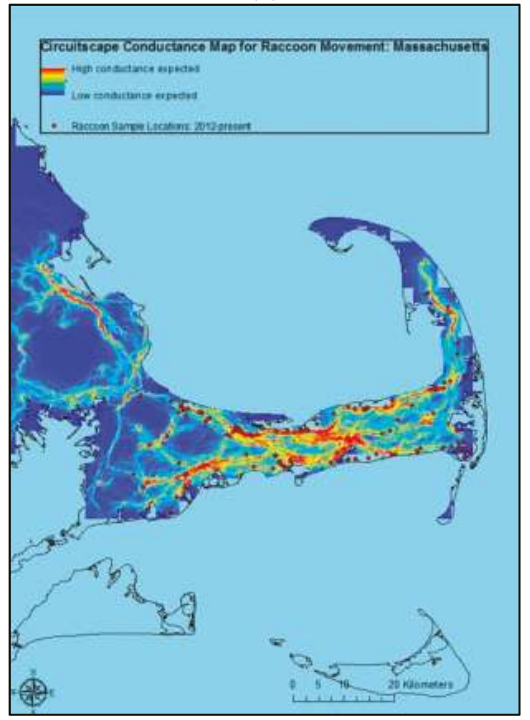

(c)

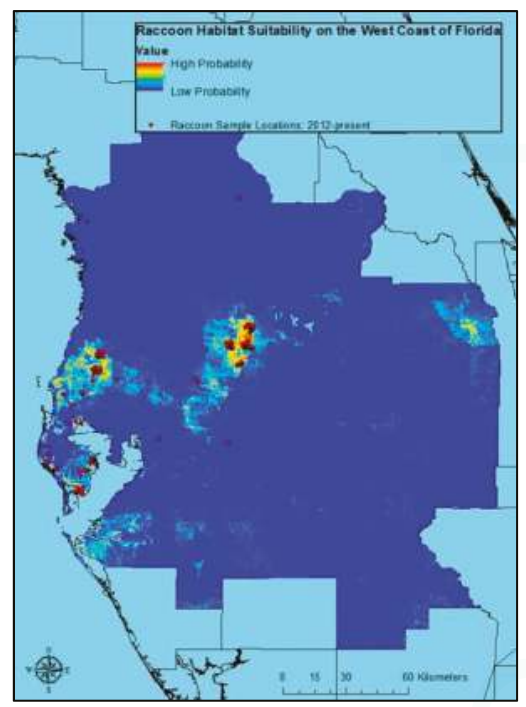

(b)

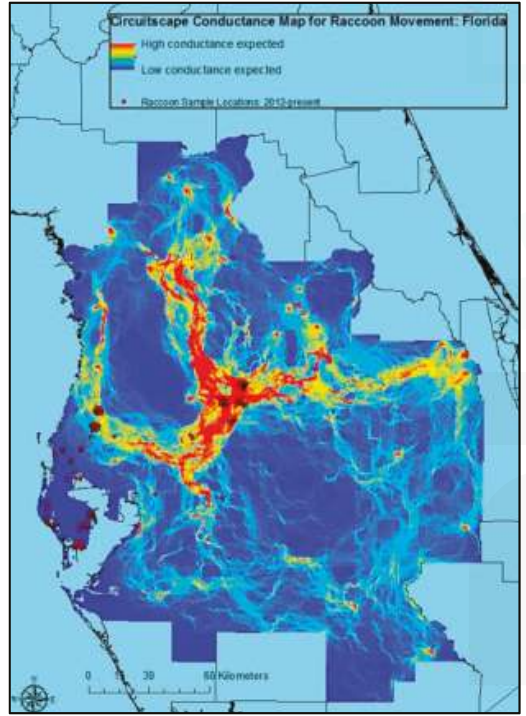

(d)

Figure 2. Maxent raccoon location probability map based on samples from Massachusetts(a; $n=171)$ and Florida ( $\mathbf{b} ; n=431)$ collected during 5 January 2012-26 June 2014) plus annual mean precipitation, annual mean temperature, elevation, land cover/land use, human population density, housing density, Euclidean distance to roads, USDA Soil Taxonomic Order, Euclidean distance to streams/rivers, and Euclidean distance to water bodies; and related Circuitscape conductance maps for raccoon rabies risk in Massachusetts (c) and Florida (d).

\section{Discussion}

The Maxent procedure provided unexpected results suggesting relatively strong environmental influence on raccoon distribution probability for both Massachusetts (precipitation) and Florida 
(temperature), while the contribution of soil in each was less important than would have been expected, given its relationship to landcover. In Alabama, the high percent contribution of soils data was less surprising given the influence of soils on not only the distribution of forest types, but also on water retention and very likely the distribution of invertebrate prey items. The strong influence of environmental variables suggests further investigation is warranted for Massachusetts and Florida. The three additional Maxent models run to explore the relative influence of groupings of variables in the absence of other variable types revealed a somewhat higher level of influence for the landscape class in terms of their average AUC, which is more in line with our expectations given what is known about raccoon ecology.

No variable or variable class ultimately emerged as the best all-around predictor in the settings modeled. However, the most influential variables in each state had strong effects in comparison to second tier variables. For example, in Massachusetts, precipitation with a percent contribution of 44 was also extremely influential when evaluated by itself, with the highest level of permutation importance (46.9) (Table 4). For Florida and Alabama, differences between percent contributions of the best performing variables were less dramatic.

Also in Massachusetts, the NLCD 2011 variable (15.3\%; 7) was expected to be highly influential. However, it performed only slightly better than soils $(11.7 \% ; 3.8)$, whereas soils greatly outperformed NLCD 2011 in Florida and Alabama. Results from the soils indicated that almost all (>99\%) raccoon samples came from within the entisols in Massachusetts, which characterize disturbed areas and which may be explained by relatively high levels of development and attendant soil disruption. In Florida, the alfisols dominated with almost $88 \%$ of samples originating there. Not surprisingly, these soils are somewhat characteristic of humid locations. In contrast, raccoon sample locations in Alabama were distributed among a number of soil types, with alfisols and entisols being almost equally represented among raccoon samples there at $34.4 \%$ and $36.6 \%$, respectively. One exception was the inceptisols, which while they represented $>25 \%$ of the Alabama study area, accounted for only $19.1 \%$ of raccoon sample locations.

Although neither human population nor housing ever represented $>5.8 \%$ contribution toward influencing of raccoon sample locations, planning for ORV bait distribution within residential and recreational areas has always been a priority given our knowledge of raccoon use of household wastes, garden crops, and invertebrates found in lawns, etc. However, based on our results, it appears that bypassing relatively small residential areas when conducting large scale ORV operations may have little impact on overall program success. Further confirmation of this from directed density and movement assessments could lead to greater understanding and considerable cost-savings given the complications of baiting in areas such as these. Roads was never among the top-performing variables, with a high of only 11 percent influence in Alabama. This suggests raccoons may not be dependent on them as travel corridors, nor deterred by them as potential obstacles. A potential bias from road kill- and roadside trapping-based sampling among surveillance and trapped raccoons, may have confounded this finding, however.

The consistently poor performance of streams, water bodies, human population and housing variables was somewhat surprising given the frequently documented attractiveness of these features to raccoons $[48,51]$. While it seems unlikely, the apparent scarcity of resources available to raccoons in pine-dominated landscapes may also extend to riparian areas contained within them, possibly explaining the phenomenon. It is also possible that raccoon population densities are low enough in some of the pine-dominated landscapes sampled that even these localized resources are not abundant enough to attract and sustain them.

The relatively high level of influence from temperature in all three states is somewhat surprising as well (Tables 4-6). Although these findings suggest further consideration of the potential role of temperature in predicting raccoon sample locations, it might also be important to consider revising this analysis to incorporate higher-resolution temperature and precipitation data to better determine if there is a real measurable influence. 
This modeling effort presented a number of challenges. For example, the raccoon samples utilized were byproducts of other research and management efforts. Much of the work done in these areas, and in particular in Massachusetts, was undertaken as emergency response to raccoon rabies epizootic front movements, barrier breaches, and perceived threats based on surveillance. In addition, samples were frequently road kills, and from residential areas where concerned citizens reported them. Finally, our primary knowledge of raccoon densities in these areas comes from 10-day, 500 trap night (with some allowance for initial results-based modifications), $3-\mathrm{km}^{2}$ density estimation procedures designed to provide enough information for responsive ORV and conducted on the fly and with limited resources [31]. More refined findings may also be required for full understanding of the role of commercial pine plantations in the south. For instance, seral stage was an important predictor for determining raccoon usage of commercial loblolly pine plantation habitat, and raccoon home ranges overlapped more frequently in commercial pine forests than in mixed forest types in one study in Alabama [34]. Consequently, further analysis incorporating remotely-sensed imagery capable of elucidating seral stage in near real time may be necessary for full understanding on commercial pine plantation-dominated landscapes. In addition, since edge habitats have emerged as important predictors of relative raccoon density in pine-dominated forest types [36], incorporating this landscape feature into future Maxent assessments may prove useful.

Applying the Maxent and Circuitscape procedures to problems such as we addressed here was useful. However, the application of these findings to future management efforts will occur only after a process that includes other inputs. Our examination of variable permutation importance aids in discerning variable input on model performance. However, for similar future analyses, we feel additional evaluation in the form of correlation analysis will provide an even clearer understanding of the potential problem of collinearity. Nonetheless, these Circuitscape outputs make clear to us areas for strong consideration for sampling in rabies surveillance efforts, and for concentrating treatment by ORV, or in limited cases, by trap-vaccinate-release (TVR). Although many of the higher risk corridors suggested jibe with what we know about raccoon rabies eco-epidemiology in these regions, we are aware of the limitations of modeling for management, regardless of the procedures utilized. The NRMP has traditionally modified management strategies based on modeling only after careful consideration of outputs in light of what is known from actual work on the ground, and then only where over-arching programmatic risks can be minimized.

\section{Summary}

Relatively new modeling tools such as the maximum entropy procedure (Maxent) $[20,25]$ hold promise for use in the field of eco-epidemiology by helping managers increase their understanding of the systems in which they work to control important diseases such as rabies. Although Circuitscape conductance maps provide no metrics, they are extremely useful for visualizing areas of concern for the prevention of the spread or the perpetuation of rabies in areas of interest. As such, they actually represent the input of greatest interest to discussions of management options and strategy formulation. If ORV or trap-vaccinate-release operations are to be implemented, these will help direct those efforts geographically in much the same way that forest fire managers strategize to achieve control. In addition, potentially wasteful efforts in low conductance areas may be avoided, adding cost-savings.

No variable or variable class emerged as the best all-around predictor for the three locations under consideration. However, the Maxent procedure for Alabama provided us with useful results suggesting optimal raccoon habitat (Table 6, Figure 1a), as well as conductance surfaces for use in visualizing risk corridors potentially useful for planning ORV and contingency actions in response to ORV zone breaches in Circuitscape (Figure 1b). These results are consistent with anecdotal information from a number of years and sources on areas of optimal raccoon habitat, and highest raccoon rabies spread in that state. The resulting NLCD 2011 data were somewhat less informative in modeling raccoon habitat suitability than soils, except in Massachusetts where NLCD 2011 performed slightly better. However, the ease with which NLCD 2011-based research and planning are translated to 
field decisions make it unlikely that a switch to soil data in decision-making, research, etc. would occur. Further exploration of the potential ties between these types of information, and the possible development of algorithms for incorporating soils information into field decisions may be worth exploring, however.

Functionally equivalent forest types dominated by other members of Pinus occur along coastal portions of the Atlantic and Gulf of Mexico coasts as well, so the apparent pine effect noted here may be widespread within Phase II ORV treatment areas. Pine-dominated forests comprise significant proportions of the forest types of the eastern U.S. For example, 69 million acres of the southeastern U.S. is coniferous forest, with the majority of the area occupied by loblolly and longleaf pine [52], and pitch pine forests occur from as far north as southern Maine to northern Georgia, with concentrations found on the Atlantic coastal plain [35]. Considerable savings may accrue to ORV efforts dedicated to controlling raccoon rabies in pine-dominated regions by application of these and future findings. This effort may also suggest procedures of potential utility for controlling rabies elsewhere with different reservoirs species, and may provide important inputs for future economic modeling of rabies control.

Acknowledgments: Thanks are owed to USDA, APHIS, Wildlife Services employees Bradley Hicks, Robert Hale, Jordona Kirby, and Ashlee Martin (NRMP); Frank Boyd, Dana Johnson, David Beaty, Jackie Malone, Tonya Mallin, and Timothy (Scott) Wease (AL), Betsy Haley (FL); Odin Stephens (GA); Monte Chandler, Brian Bjorklund, Ryan Bevilacqua, and Randall Mickley (MA/CT/RI); Jacob Borgeson (NH/VT); Eric Wilhelm and Brandon Hofer (VA); Wendy Anderson, Matthew Swallow, and Adam Randall (NJ); and Luke Harvard (GA). We also thank the staffs of Myles Standish State Forest (MA Department of Forest and Parks) and the Massachusetts Military Reservation; Wharton State Forest (NJ Division of Parks and Forestry), and the New Jersey Division of Fish and Wildlife; and The Alabama Department of Conservation and Natural Resources, and Alabama Resource Management Services; and the Apalachicola National Forest (USDA Forest Service).

Author Contributions: D.S., M.P., T.P.A., R.B.C., M.J.D., T.A., R.M.C., and S.R. conceived and designed the experiments; T.P.A. and M.P. performed the experiments; T.P.A., M.P., and M.J.D. analyzed the data; T.P.A., M.P., M.J.D., D.S., T.A., R.B.C., R.M.C., and S.R. wrote the paper.

Conflicts of Interest: The authors declare no conflict of interest. Please note that Richard B. Chipman is the current National Rabies Management Coordinator for the USDA, APHIS, Wildlife Services, National Rabies Management Program, and Dennis Slate is the former National Rabies Management Coordinator; both indirectly provided discretionary Federal funding to support field work.

\section{References}

1. Hampson, K.; Coudeville, L.; Lembo, T.; Sambo, M.; Kieffer, A.; Attlan, M.; Barrat, J.; Blanton, J.D.; Briggs, D.J.; Cleaveland, S.; et al. Estimating the global burden of endemic canine rabies. PLoS Negl. Trop. Dis. 2015, 9, $1-20$.

2. WHO/Department of Control of Neglected Tropical Diseases. Human rabies: 2016 updates and a call for data. Available online: http://www.who.int/rabies/resources/who_wer9207/en/ (accessed on 15 August 2017).

3. Fishbein, D.B.; Arcangeli, S. Rabies prevention in primary care: A four-step approach. Postgrad. Med. 1987, 82, 83-95. [CrossRef] [PubMed]

4. CoinNews Media Group. Inflation Calculator: Money's Real Worth Over Time. Available online: http:/ /www. coinnews.net/tools/cpi-inflation-calculator/ (accessed on 5 April 2013).

5. Slate, D.; Algeo, T.P.; Nelson, K.M.; Chipman, R.B.; Donovan, D.; Blanton, J.D.; Niezgoda, M.; Rupprecht, C.E. Oral rabies vaccination in North America: Opportunities, complexities, and challenges. PLoS Negl. Trop. Dis. 2009, 3, e549. [CrossRef] [PubMed]

6. Blancou, J. The control of rabies in Eurasia: Overview, history and background. Dev. Biol. (Basel) 2008, 131, 3-15. [PubMed]

7. Wandeler, A.I. The rabies situation in western Europe. Dev. Biol. (Basel) 2008, 131, 19-25.

8. MacInnes, C.D.; Smith, S.M.; Tinline, R.R.; Ayers, N.R.; Bachmann, P.; Ball, D.G.; Calder, L.A.; Crosgrey, S.J.; Fielding, C.; Hauschildt, P.; et al. Elimination of rabies from red foxes in eastern Ontario. J. Wildl. Dis. 2001, 37, 119-132. [CrossRef]

9. Rosatte, R.C.; Power, M.J.; Donovan, D.; Davies, J.C.; Allan, M.; Bachmann, P.; Stevenson, B.; Wandeler, A.; Muldoon, F. Elimination of arctic variant rabies in red foxes, metropolitan Toronto. Emerg. Infect. Dis. 2007, 13, 25-27. [CrossRef] [PubMed] 
10. Fearneyhough, M.G.; Wilson, P.J.; Clark, K.A.; Smith, D.R.; Johnston, D.H.; Hicks, B.N.; Moore, G.M. Results of an oral rabies vaccination program for coyotes. J. Am. Vet. Med. Assoc. 1998, 212, 498-502. [PubMed]

11. Velasco-Villa, A.; Reeder, S.A.; Orciari, L.A.; Yager, P.A.; Franka, R.; Blanton, J.D.; Zuckero, L.; Hunt, P.; Oertli, E.H.; Robinson, L.E.; et al. Enzootic rabies elimination from dogs and reemergence in wild terrestrial carnivores, United States. Emerg. Infect. Dis. 2008, 14, 1849-1854. [CrossRef]

12. Sidwa, T.J.; Wilson, P.J.; Moore, G.M.; Oertli, E.H.; Hicks, B.N.; Rohde, R.E.; Johnston, D.H. Evaluation of oral rabies vaccination programs for control of rabies epizootics in coyotes and gray foxes: 1995-2003. J. Am. Vet. Med. Assoc. 2005, 227, 785-792. [CrossRef] [PubMed]

13. Allen, L.J.S.; Flores, D.A.; Ratnayake, R.K.; Herbold, J.R. Discrete-time deterministic and stochastic models for the spread of rabies. Appl. Math. Comput. 2002, 132, 271-292. [CrossRef]

14. Tinline, R.R.; MacInnes, C.D. Ecogeographic patterns of rabies in southern Ontario based on time series analysis. J. Wildl. Dis. 2004, 40, 212-221. [CrossRef] [PubMed]

15. Recuenco, S.; Johnson, G.; Cherry, B.; Eidson, M.; Kulldorff, M. Spatial and temporal patterns of enzootic raccoon rabies adjusted for multiple covariates. Int. J. Health Geogr. 2007, 6, 14. [CrossRef] [PubMed]

16. Kim, B.I.; Blanton, J.D.; Gilbert, A.; Castrodale, L.; Hueffer, K.; Slate, D.; Rupprecht, C.E. A conceptual model for the impact of climate change on fox rabies in Alaska, 1980-2010. Zoonoses Public Health 2014, 61, 72-80. [CrossRef] [PubMed]

17. Lee, D.N.; Papeş, M.; Van den Bussche, R.A. Present and potential future distribution of common vampire bats in the Americas and the associated risk to cattle. PLoS ONE 2012, 7, e42466. [CrossRef] [PubMed]

18. Anderson, A.; Shwiff, S.A.; Chipman, R.B.; Atwood, T.; Cozzens, T.; Fillo, F.; Hale, R.; Hatch, B.; Maki, J.; Rhodes, O.E.; et al. Forecasting the spread of raccoon rabies using a purpose-specific group decision-making process. Human-Wildlife Interact. 2014, 8, 130-138.

19. Pinto, N.; Keitt, T.H. Beyond the least-cost path: Evaluating corridor redundancy using a graph-theoretic approach. Landsc. Ecol. 2009, 24, 253-266. [CrossRef]

20. Phillips, S.J.; Anderson, R.P.; Schapire, R.E. Maximum entropy modeling of species geographic distributions. Ecol. Modell. 2006, 190, 231-259. [CrossRef]

21. Amaral, K.E.; Palace, M.; O’Brien, K.M.; Fenderson, L.E.; Kovach, A.I. Anthropogenic habitats facilitate dispersal of an early successional obligate: Implications for restoration of an endangered ecosystem. PLOS ONE 2016, 11, 1-21. [CrossRef] [PubMed]

22. McRae, B.H.; Dickson, B.G.; Keitt, T.H.; Shah, V.B. Using circuit theory to model connectivity in ecology, evolution, and conservation. Ecology 2008, 89, 2712-2724. [CrossRef] [PubMed]

23. Bovet, P.; Benhamou, S. Spatial analysis of animals' movements using a correlated random walk model. J. Theor. Biol. 1988, 131, 419-433. [CrossRef]

24. Howey, M.C.L.; Palace, M.W.; McMichael, C.H. Geospatial modeling approach to monument construction using Michigan from A.D. 1000-1600 as a case study. Proc. Natl. Acad. Sci. 2016, 113, 7443-7448. [CrossRef] [PubMed]

25. McRae, B.; Shah, V. Circuitscape user guide. Available online: http://docs.circuitscape.org/circuitscape_4_ 0_user_guide.html?andid=gsite (accessed on 17 May 2014).

26. Poor, E.E.; Loucks, C.; Jakes, A.; Urban, D.L. Comparing habitat suitability and connectivity modeling methods for conserving pronghorn migrations. PLoS ONE 2012, 7, e49390. [CrossRef] [PubMed]

27. Burnham, K.P.; Anderson, D.R. Model Selection and Multimodel Inference: A Practical Information-Theoretic Approach, 2nd ed.; Springer: New York, NY, USA, 1998.

28. Burnham, K.P.; Anderson, D.R. Multimodel inference: Understanding AIC and BIC in model selection. Sociol. Methods Res. 2004, 33, 261-304. [CrossRef]

29. Warren, D.L.; Seifert, S.N. Ecological niche modeling in Maxent: The importance of model complexity and the performance of model selection criteria. Ecol. Appl. 2011, 21, 335-342. [CrossRef] [PubMed]

30. Zeigler, S.L.; Neel, M.C.; Oliveira, L.; Raboy, B.E.; Fagan, W.F. Conspecific and heterospecific attraction in assessments of functional connectivity. Biodivers. Conserv. 2011, 20, 2779-2796. [CrossRef]

31. Slate, D.; USDA, APHIS, Wildlife Services National Rabies Program, Concord, NH, USA. Unpublished Work. 2017.

32. Lucey, B.T.; Russell, C.A.; Smith, D.; Wilson, M.L.; Long, A.; Waller, L.A.; Childs, J.E.; Real, L.A. Spatiotemporal analysis of epizootic racoon rabies propagation in Connecticut, 1991-1995. Vector Borne Zoonotic Dis. 2002, 2, 77-87. [CrossRef] [PubMed] 
33. Smith, D.L.; Waller, L.A.; Russell, C.A.; Childs, J.E.; Real, L.A. Assessing the role of long-distance translocation and spatial heterogeneity in the raccoon rabies epidemic in Connecticut. Prev. Vet. Med. 2005, 71, 225-240. [CrossRef] [PubMed]

34. Arjo, W.M.; Fisher, C.E.; Armstrong, J.; Boyd, F.; Slate, D. Effects of natural barriers and habitat on the western spread of raccoon rabies in Alabama. J. Wildl. Manage. 2008, 72, 1725-1735. [CrossRef]

35. Burns, R.M.; Honkala, B.H. Silvics of North America: 1. Conifers; 2. Hardwoods. Agriculture Handbook 654; U.S. Department of Agriculture, Forest Service: Washington, DC, USA, 1990.

36. Algeo, T.; USDA, APHIS, Wildlife Services National Rabies Management Program. Unpublished Work. 2017.

37. Chamberlain, M.J.; Conner, L.; Leopold, B. Seasonal habitat selection by raccoons (Procyon Lotor) in intensively managed pine forests of central Mississippi. Am. Midl. Nat. 2002, 147, 102-108. [CrossRef]

38. McRae, B.H.; Shah, V.B.; Mohapatra, T.K. Circuitscape User Guide. Available online: http:/ / docs.circuitscape. org/circuitscape_4_0_user_guide.html?id=Desktop_v4.0.5 (accessed on 25 May 2014).

39. Slate, D.; Chipman, R.B.; Algeo, T.P.; Mills, S.A.; Nelson, K.M.; Croson, C.K.; Dubovi, E.J.; Vercauteren, K.; Renshaw, R.W.; Atwood, T.; et al. Safety and immunogenicity of Ontario rabies vaccine bait (ONRAB) in the first US field trial in raccoons (Procyon lotor). J. Wildl. Dis. 2014, 50, 582-595. [CrossRef] [PubMed]

40. USGS. Multi-Resolution Land Characteristics Consortium (MRLC). Available online: https://www.mrlc. gov/index.php (accessed on 26 May 2014).

41. Algeo, T.P.; Norhenberg, G.; Hale, R.; Montoney, A.; Chipman, R.B.; Slate, D. Oral rabies vaccination variation in tetracycline biomarking among Ohio raccoons. J. Wildl. Dis. 2013, 49, 332-337. [CrossRef] [PubMed]

42. USDA NRCS. Description of STATSGO2 database. Available online: http://www.nrcs.usda.gov/wps/ portal/nrcs/detail/soils/survey/?cid=nrcs142p2_053629 (accessed on 1 May 2017).

43. USGS. U.S. Geological Survey-National Hydrography Dataset. Available online: http://nhd.usgs.gov/ index.html (accessed on 23 March 2014).

44. Hijmans, R.J.; Cameron, S.E.; Parra, J.L.; Jones, P.G.; Jarvis, A. Very high resolution interpolated climate surfaces for global land areas. Int. J. Climatol. 2005, 25, 1965-1978. [CrossRef]

45. NASA Jet Propulsion Laboratory. Shuttle Radar Topography Mission (SRTM). Available online: http://www2.jpl. nasa.gov/srtm/ (accessed on 1 May 2017).

46. U.S. Census Bureau. U.S. Census-2010. Available online: http://www.census.gov/geo/ (accessed on 11 April 2014).

47. ESRI. ArcGIS-Mapping and spatial analysis for understanding our world. Available online: http://www. esri.com/software/arcgis (accessed on 3 June 2014).

48. Sanderson, G.C. Raccoon. In Wild Furbearer Management and Conservation in North America; Novak, M., Baker, J.A., Obbard, M.E., Malloch, B., Eds.; Ontario Trappers Association: Ontario, ON, Canada, 1987; pp. 486-499.

49. Fielding, A.H.; Bell, J.F. A review of methods for the assessment of prediction errors in conservation presence/absence models. Environ. Conserv. 1997, 24, 38-49. [CrossRef]

50. Phillips, S. Maxent tutorial. Available online: http://www.cs.princeton.edu/ schapire/maxent/ (accessed on 1 March 2014).

51. Prange, S.; Gehrt, S.D.; Wiggers, E.P. Influences of anthropogenic resources on raccoon (Procyon lotor) movements and spatial distribution. J. Mammal. 2004, 85, 483-490. [CrossRef]

52. USDA Forest Service. Indicator 1.01: Area and percent of forest by type. Available online: http://www.fs. fed.us/research/sustain/criteria-indicators/indicators/indicator-101.php (accessed on 3 June 2014).

(C) 2017 by the authors. Licensee MDPI, Basel, Switzerland. This article is an open access article distributed under the terms and conditions of the Creative Commons Attribution (CC BY) license (http:/ / creativecommons.org/licenses/by/4.0/). 
Article

\title{
Incorporating Direct Rapid Immunohistochemical Testing into Large-Scale Wildlife Rabies Surveillance
}

\author{
Kevin Middel ${ }^{1}$, Christine Fehlner-Gardiner ${ }^{2}$, Natalie Pulham ${ }^{1}$ and Tore Buchanan ${ }^{1, *}$ \\ 1 Ontario Ministry of Natural Resources and Forestry, Wildlife Research and Monitoring Section, \\ Peterborough, ON K9L 0G2, Canada; kevin.middel@ontario.ca (K.M.); natalie.pulham@ontario.ca (N.P.) \\ 2 Canadian Food Inspection Agency, Centre of Expertise for Rabies, Ottawa, ON K2H 8P9, Canada; \\ Christine.Fehlner-Gardiner@inspection.gc.ca \\ * Correspondence: tore.buchanan@ontario.ca; Tel.: +1-705-755-2275
}

Received: 31 May 2017; Accepted: 25 June 2017; Published: 30 June 2017

\begin{abstract}
Following an incursion of the mid-Atlantic raccoon variant of the rabies virus into southern Ontario, Canada, in late 2015, the direct rapid immunohistochemical test for rabies (dRIT) was employed on a large scale to establish the outbreak perimeter and to diagnose specific cases to inform rabies control management actions. In a 17-month period, 5800 wildlife carcasses were tested using the dRIT, of which 307 were identified as rabid. When compared with the gold standard fluorescent antibody test (FAT), the dRIT was found to have a sensitivity of $100 \%$ and a specificity of $98.2 \%$. Positive and negative test agreement was shown to be $98.3 \%$ and $99.1 \%$, respectively, with an overall test agreement of $98.8 \%$. The average cost to test a sample was $\$ 3.13 \mathrm{CAD}$ for materials, and hands-on technical time to complete the test is estimated at $0.55 \mathrm{~h}$. The dRIT procedure was found to be accurate, fast, inexpensive, easy to learn and perform, and an excellent tool for monitoring the progression of a wildlife rabies incursion.
\end{abstract}

Keywords: dRIT; Ontario; rabies; surveillance

\section{Introduction}

In December 2015 a raccoon (Procyon lotor) from Hamilton, Ontario, Canada, was diagnosed with rabies caused by the mid-Atlantic raccoon virus variant, the first case of rabies caused by this virus variant to occur in the province in 10 years. To assess the extent of this rabies outbreak and to direct rabies management actions, large-scale testing of raccoons and striped skunks (Mephitis mephitis) collected within a 50-km radius of diagnosed cases was undertaken. Animals were primarily collected by partnering agencies, such as municipal animal control agencies, humane societies and roads departments. Collection was focussed on sick-acting animals, animals found dead, or roadkill, and carcasses were kept frozen until they could be collected by Ministry of Natural Resources and Forestry (MNRF) staff. Frozen carcasses were collected weekly from partners and brought back to the MNRF laboratory for weekly testing using the direct rapid immunohistochemical test (dRIT). Samples diagnosed as rabies positive by dRIT were sent to the Canadian Food Inspection Agency (CFIA) for confirmation by fluorescent antibody test (FAT). Animals that had any previous contact with humans were not tested as part of this procedure. The dRIT test was developed by the Rabies and Poxvirus Section of the US Centers for Disease Control and Prevention (CDC), and was first evaluated in the field in Tanzania with very promising results [1]. The test was developed to provide a diagnostic methodology for quickly and inexpensively testing for rabies virus without the need for specialized equipment or facilities, making rabies testing more widely available worldwide, and has since been shown in many studies to be an effective tool for rabies surveillance [2]. The dRIT procedure was initiated in the rabies surveillance programs of the provinces of Québec [3] and Ontario in 2010. Until the most recent outbreak, the MNRF typically tested 10-40 animals annually, with four staff 
having been trained in dRIT procedures by CDC dRIT experts. Since raccoon rabies detection in December 2015, the dRIT surveillance program in Ontario has increased exponentially, and is currently the largest such surveillance program in Canada, testing anywhere from 23-258 (mean = 82.2) animals per week.

\section{Materials and Methods}

Test procedures: Brain tissue was collected by inserting a modified $3 \mathrm{~mL}$ or $1 \mathrm{~mL}$ syringe through the foramen magnum of animals and removing 1-2 $\mathrm{mL}$ of brain matter for touch impressions to slides for subsequent dRIT. dRIT was performed according to the CDC standard operating procedure as described previously [4], using a cocktail of two anti-nucleoprotein, biotinylated monoclonal antibodies (502 and 802) sourced from The Wistar Institute (Philadelphia, PA, USA). FAT was performed as described previously [5], using the same brain tissue samples collected for the dRIT. A fluorescein isothiocyanate-conjugated polyclonal antibody (goat serum, raised against purified ERA (Evelyn-Rokitnicki-Abelseth) rabies virus ribonucleoprotein), prepared in-house at the CFIA Centre of Expertise for Rabies (Ottawa, Canada), was used in the FAT.

Test comparison: Determination of dRIT sensitivity, specificity, and test agreement with FAT were estimated using an online calculator (EpiTools; http://epitools.ausvet.com.au).

\section{Results}

\subsection{Surveillance Samples}

In the 17-month period from December 2015 to April 2017, approximately 5800 mammalian wildlife carcasses were collected from southern Ontario and tested for rabies using the dRIT methodology (Figure 1). Species tested comprised primarily raccoons $(80 \%)$ and striped skunks $(17 \%)$. Other species tested included bat, feral cat (Felis spp.), coyote (Canis latrans), fisher (Martes pennant), red fox (Vulpes vulpes), groundhog (Marmota monax), muskrat (Ondatra zibithecus), opossum (Didelphis virginiana), cottontail rabbit (Sylvilagus floridanus), squirrel (Sciurius spp.), and weasel (Mustela spp.).

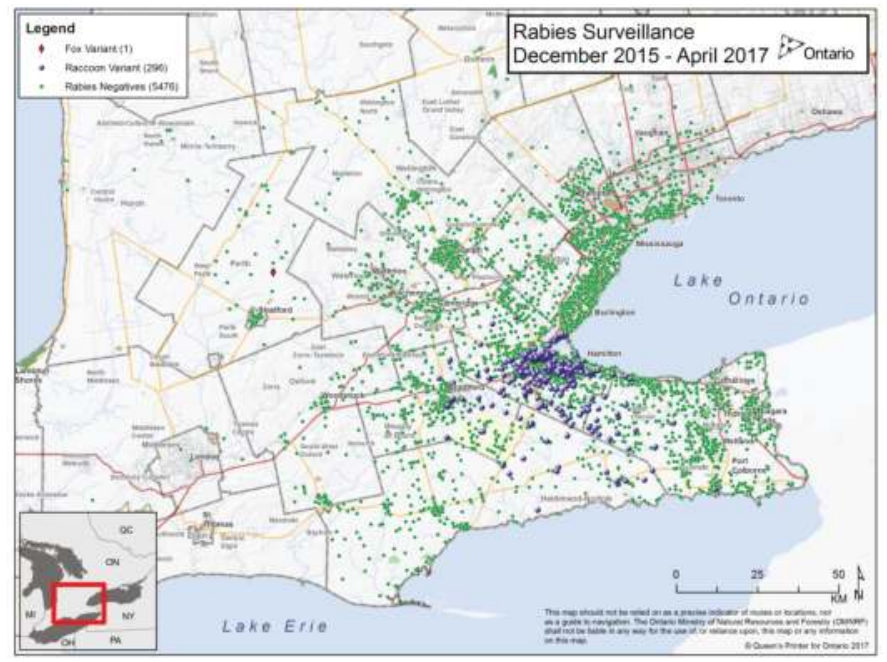

Figure 1. Ontario rabies surveillance map showing the negative (green) and positive (red and blue symbols) samples tested by dRIT. 


\section{2. dRIT Performance in Comparison with FAT}

All dRIT-positive samples were submitted to CFIA for confirmation using FAT. Of the 5800 wildlife samples tested by MNRF, 215 raccoons, 91 skunks and 1 red fox were diagnosed as being positive for rabies in the dRIT. When the same samples were tested by FAT, 205 of the raccoons, all the skunks and the fox were positive. Five hundred and fifty dRIT-negative samples were also tested in FAT. The samples were selected from random geographic locations from a time period between February and June 2016, and comprised 490 raccoons and 60 skunks. All of the dRIT-negative samples were also negative in the FAT. The dRIT had a sensitivity of $100 \%$ and specificity of $98.2 \%$ when compared with FAT (Table 1 ). Overall agreement between dRIT and FAT was high $(98.8 \%, \mathrm{k}=0.9744)$, with negative test agreement being slightly higher than positive test agreement (99.1\% vs. $98.3 \%)$. On occasion, samples processed by dRIT were found to be inconclusive, typically due to poor sample conditions. Inconclusive samples were tested a second time to make a final dRIT diagnosis. In order to verify results of inconclusive samples where a second dRIT was conducted and was determined to be negative, 40 such samples were also evaluated by FAT. Of the 40 samples, 3 were untestable by FAT due to advanced sample decomposition; the remaining 37 samples had 100\% diagnostic agreement between dRIT and FAT as being negative.

Table 1. Test comparison between fluorescent antibody test (FAT) and direct rapid immunohistochemical test (dRIT) for rabies.

\begin{tabular}{cccc}
\hline & FAT Positive & FAT Negative & Total \\
\hline dRIT positive & 297 & 10 & 307 \\
dRIT negative & 0 & 550 & 550 \\
Total & 297 & 560 & \\
\hline & Value & $\mathbf{9 5 \%}$ CI & \\
\hline dRIT Sensitivity & $100.0 \%$ & $98.77 \%-100.00 \%$ & \\
dRIT Specificity & $98.21 \%$ & $97.74 \%-99.14 \%$ & \\
Kappa & 0.9744 & $0.9587-0.9902$ & \\
Negative agreement & 0.9910 & - & \\
Positive agreement & 0.9834 & - & \\
Overall agreement & 0.9883 & - &
\end{tabular}

\subsection{Cost}

Through the collection and processing of approximately 5800 samples using dRIT procedures in the MNRF laboratory, an average cost of \$3.13 CAD per sample for chemicals, reagents and laboratory consumables was estimated. In contrast, the materials cost for the FAT as performed at the CFIA is approximately \$7.75 CAD per sample. Laboratory technical labour was comparable for the two tests, estimated at $0.55 \mathrm{~h}$ of hands-on time (i.e., not counting incubation periods), and thus labour costs are estimated to be similar, contingent upon local rates of remuneration. These estimates of cost do not include collection and transportation of samples, laboratory setup and maintenance, specimen disposal or administrative overhead, and were based on processing between 70 and 150 samples per week on average.

\section{Discussion}

The MNRF has responded to the most recent incursion of raccoon rabies by initiating an intensive surveillance program and testing over 5800 samples using the dRIT procedure. Since December 2015, $297(96.4 \%)$ of the 308 cases of raccoon variant rabies diagnosed in Ontario have been diagnosed using MNRF dRIT surveillance, enabling the MNRF and partners to accurately and rapidly direct rabies control actions. Although dRIT and FAT diagnostic agreement was very high at $98.8 \%$, it likely would have been closer to $100 \%$ were it not for a few early learning experiences with diagnostic procedures 
and processes. All 10 of the cases where samples were diagnosed positive by dRIT but negative by FAT were tested within the first three months of the outbreak. Additionally, during the same time period, samples that were inconclusive after the first dRIT test were sent directly to CFIA lab for additional testing by FAT. After receiving notification of these false positives, as well as dRIT-inconclusives that tested FAT-negative, two changes were implemented with regard to staff training and diagnostic processes. First, an expert in dRIT procedures was brought in to provide first-hand training to all staff performing the dRIT, to ensure that all test procedures were consistently done in accordance with the standardized protocol. Second, a new process, in which any sample with an inconclusive dRIT result was tested a second time before making a final dRIT diagnosis, was implemented. After implementing these two changes three months into the outbreak in February 2016, and in addition to staff gaining considerable experience with the dRIT test, agreement with FAT was $100 \%$ in the following 14 months and 4500 subsequent samples tested (of which 244 were positive). These data speak to the importance of thorough training and proficiency evaluation when implementing the dRIT, or any other diagnostic test for rabies. Based on these results, the dRIT has been found to be an excellent tool for monitoring the progression of a rabies incursion and will continue to be used for enhanced wildlife rabies surveillance within the province of Ontario. These data, along with those from many previous studies, also support the use of dRIT for improved rabies surveillance in regions where FAT cannot be practicably implemented.

Acknowledgments: The authors would like to thank the organizations in Ontario that have submitted animal carcasses for rabies testing, the MNRF technicians who performed carcass collections, rabies case mapping and dRIT evaluations and the CFIA diagnostic staff who performed FAT evaluations on these samples.

Author Contributions: Christine Fehlner-Gardiner, Kevin Middel and Tore Buchanan conceived and designed the study and analyzed the data; Natalie Pulham coordinated the dRIT testing and sample exchange between laboratories; all four authors wrote the paper.

Conflicts of Interest: The authors declare no conflict of interest.

\section{References}

1. Lembo, T.; Niezgoda, M.; Velasco-Villa, A.; Cleaveland, S.; Ernest, E.; Rupprecht, C.E. Evaluation of a direct, rapid immunohistochemical test for rabies diagnosis. Emerg. Infect. Dis. 2006, 12, 310-313. [CrossRef] [PubMed]

2. Rupprecht, C.E.; Cliquet, F.; Fehlner-Gardiner, C.; Fooks, A.R.; Mueller, T.; Sabeta, C.; Slate, D. Progress in the development of a direct rapid immunohistochemical test for diagnosing rabies. Bull. OIE 2014, 2014, 87-95.

3. Healthy Wildlife: The Blog of the Canadian Wildlife Health Cooperative. Available online: http://blog. healthywildlife.ca/drit-and-rabies-surveillance-in-quebec/ (accessed on 29 May 2017).

4. Niezgoda, M.; Rupprecht, C.E. Standard Operating Procedure for the Direct Rapid Immunohistochemistry Test for the Detection of Rabies Virus Antigen. National Laboratory Training Network Course; US Department of Health and Human Services, Centers for Disease Control and Prevention: Atlanta, GA, USA, 2006; pp. 1-16.

5. Fehlner-Gardiner, C.; Nadin-Davis, S.; Armstrong, J.; Muldoon, F.; Bachmann, P.; Wandeler, A. ERA vaccine-derived cases of rabies in wildlife and domestic animals in Ontario, Canada, 1989-2004. J. Wildl. Dis. 2008, 44, 71-85. [CrossRef] [PubMed]

(C) 2017 by the authors. Licensee MDPI, Basel, Switzerland. This article is an open access article distributed under the terms and conditions of the Creative Commons Attribution (CC BY) license (http:/ / creativecommons.org/licenses/by/4.0/). 
Article

\title{
Progress towards Bait Station Integration into Oral Rabies Vaccination Programs in the United States: Field Trials in Massachusetts and Florida
}

\author{
Brian M. Bjorklund ${ }^{1, *}$, Betsy S. Haley ${ }^{2}$ Ryan J. Bevilacqua ${ }^{1}$, Monte D. Chandler ${ }^{3}$, \\ Anthony G. Duffiney ${ }^{4}$, Karl W. von Hone ${ }^{5}$, Dennis Slate ${ }^{2}$, Richard B. Chipman ${ }^{2}$, \\ Ashlee Martin ${ }^{2}$ and Timothy P. Algeo ${ }^{6}$
}

1 United States Department of Agriculture, Animal and Plant Health Inspection Service, Wildlife Services, 9 Main St., Suite 1M, Sutton, MA 01590, USA; ryan.bevilacqua@aphis.usda.gov

2 United States Department of Agriculture, Animal and Plant Health Inspection Service, Wildlife Services, National Rabies Management Program, 59 Chenell Dr., Suite 2, Concord, NH 03301, USA; betsy.s.haley@aphis.usda.gov (B.S.H.); dennis.slate@aphis.usda.gov (D.S.); richard.b.chipman@aphis.usda.gov (R.B.C.); ashlee.d.martin@aphis.usda.gov (A.M.)

3 United States Department of Agriculture, Animal and Plant Health Inspection Service, Wildlife Services, 463 West St., Amherst, MA 01002, USA; monte.d.chandler@aphis.usda.gov

4 United States Department of Agriculture, Animal and Plant Health Inspection Service, Wildlife Services, 2803 Jolly Rd., Suite 100, Okemos, MI 48864, USA; anthony.g.duffiney@aphis.usda.gov

5 Yarmouth Division of National Resources, 424 Route 28, West Yarmouth, MA 02673, USA; kvonhone@yarmouth.ma.us

6 United States Department of Agriculture, Animal and Plant Health Inspection Service, Wildlife Services, 59 Chenell Dr., Suite 7, Concord, NH 03301, USA; timothy.p.algeo@aphis.usda.gov

* Correspondence: brian.bjorklund@aphis.usda.gov; Tel.: +1-508-476-2715

Received: 14 July 2017; Accepted: 11 August 2017; Published: 21 August 2017

\begin{abstract}
Bait stations for distribution of oral rabies vaccine baits are designed for rabies management in highly-developed areas where traditional distribution of oral rabies vaccine baits may be difficult. As part of national efforts to contain and eliminate the raccoon (Procyon lotor) variant of the rabies virus (raccoon rabies) in the eastern United States, the United States Department of Agriculture, Animal and Plant Health Inspection Service, Wildlife Services program, distributed vaccine baits by bait stations experimentally and operationally in Massachusetts during 2006-present, and in Florida during 2009-2015. In Massachusetts, a rabies virus-neutralizing antibody (RVNA) response of $42.1 \%$ for raccoons captured in areas baited with high density bait stations during 2011-2015 was achieved, compared with $46.2 \%$ in areas baited by hand, suggesting the continuation of this as a strategy for the oral rabies vaccination (ORV) program there, and for similar locations. Non-target competition for vaccine baits is problematic, regardless of distribution method. In Massachusetts, bait station visitation rates for targeted raccoons and non-target opossums (Didelphis virginiana) were similar (1.18:1) during 2006-2009 $(p>0.05)$. Bait station modifications for reducing non-target uptake were tested, and in Massachusetts, reduced non-target bait access was achieved with two design alternatives $(p<0.001)$. However, no difference was noted between the control and these two alternative designs in Florida. Due to ongoing trials of new vaccines and baits, the bait station performance of an adenovirus rabies glycoprotein recombinant vaccine bait, ONRAB ${ }^{\circledR}$ bait (Artemis Technologies, Guelph, ON, Canada) and a vaccinia-rabies glycoprotein recombinant vaccine bait, RABORAL V-RG ${ }^{\circledR}$ bait (Merial Limited, Athens, GA, USA), was compared. While uptake of the ONRAB bait was greater in Massachusetts $(p<0.001)$ in this limited trial, both types performed equally well in Florida. Since bait station tampering or theft as well as potential human bait contacts has been problematic, performance of camouflaged versus unpainted white bait stations was analyzed in terms of internal temperatures and maintaining a stable bait storage environment. In Massachusetts, camouflaged bait station interiors did not reach higher average temperatures than plain white bait
\end{abstract}


stations in partially- or fully-shaded locations, while in Florida, camouflaged bait stations were significantly warmer in light exposure categories $(p<0.05)$. As ORV operations expand into more heavily-urbanized areas, bait stations will be increasingly important for vaccine bait distribution, and continued refinements in the strategy will be key to that success.

Keywords: bait stations; oral rabies vaccination; raccoon; rabies; vaccine; non-target

\section{Introduction}

Oral rabies vaccination (ORV) is an effective and socially acceptable strategy for wildlife rabies management [1]. Various ORV strategies have been employed successfully, including for the control of fox rabies in Western Europe [2,3] and Canada [4-6]. ORV has been used in Texas to eliminate canine rabies in coyotes (Canis latrans) [7,8], and to eliminate and prevent rabies in gray foxes (Urocyon cinereoargenteus) [9].

The United States Department of Agriculture, Animal and Plant Health Inspection Service, Wildlife Services (WS), National Rabies Management Program (NRMP), is conducting cooperative ORV operations to prevent the westward spread of the raccoon (Procyon lotor) variant of the rabies virus (raccoon rabies) into the mid-western states and eastern Canada (Phase I), and has begun work towards its eventual elimination from the eastern United States (Phase II) [1]. Much of the eastern United States is highly developed and features high human densities. Traditional aerial ORV strategies are complicated in these areas by high off-times of vaccine bait distribution equipment due to treatment area development, and concern for potential human and pet contact with vaccine baits. Bait stations for distribution of oral rabies vaccine baits provide an opportunity to conduct ORV plans at minimized risk levels in settings such as these.

In 2001, WS began full-time collaboration on the Cape Cod Oral Rabies Vaccination Program (CCORV) with Tufts University and other cooperators as part of national wildlife rabies control efforts (Figure 1).

The primary objective of the CCORV was to use ORV in tandem with the physical barrier of the Cape Cod Canal to prevent the spread of raccoon rabies onto peninsular Cape Cod. In 2003, after an increase in raccoon rabies cases within the CCORV zone, vaccine bait distribution efforts were modified to reduce the risk of raccoon rabies spreading onto peninsular Cape Cod. Despite this, raccoon rabies was detected for the first time there in March 2004. A WS trap-vaccinate-release campaign plus expanded ORV efforts did not prevent the further spread of raccoon rabies. Rabies surveillance on Cape Cod became a high priority $[10,11]$, with the aim of delineating the epizootic front to begin ORV and define priority areas for trap-vaccinate-release efforts to prevent further spread. However, in 2006, raccoon rabies was detected at the farthest tip of Cape Cod, in Provincetown. From 2006 through the spring of 2010, twice-yearly ORV treatments from Yarmouth to Provincetown were conducted using fishmeal polymer (FMP) block baits and coated sachet baits containing RABORAL V-RG ${ }^{\circledR}$ vaccine (a vaccinia rabies glycoprotein recombinant oral vaccine; Merial Limited, Athens, GA, USA) distributed by hand from vehicles and on foot to reduce the enzootic area.

Cornell University began investigating the use of bait stations for the distribution of vaccine baits in New York in 2003 [12], based on a design for the control of voles (Microtus spp.) in orchards [13]. Experimental bait stations based partially on the Cornell design were constructed from polyvinyl chloride (PVC), filled with RABORAL V-RG FMP baits, and deployed over a $3 \mathrm{~km}^{2}$ study area in South Yarmouth $(2006-2008)$ at a very high density $\left(8 / \mathrm{km}^{2} ; n=24\right)$ to assess their utility there. In addition to investigations into the use of bait stations by WS in Massachusetts in 2006, bait station trials also began in Florida in 2009 [14]. 


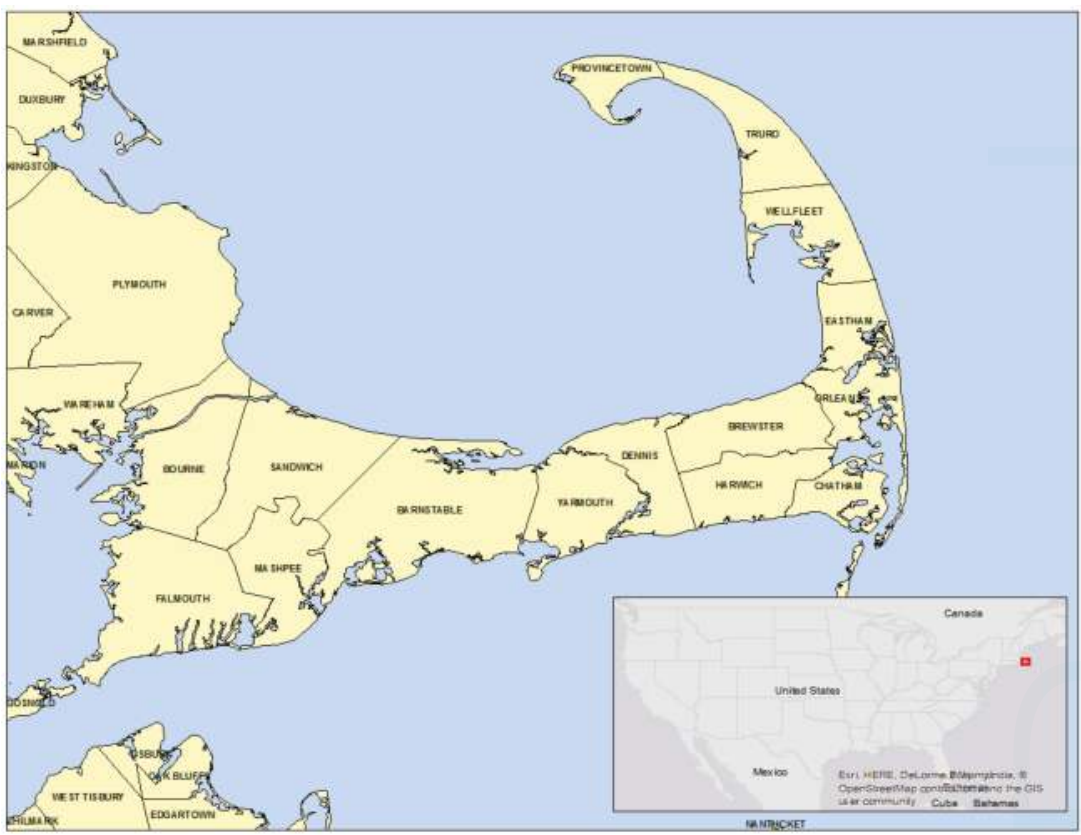

Figure 1. Cape Cod, Massachusetts, USA.

Due to partial funding loss reducing the CCORV program's ability to distribute vaccine baits during 2006-2009, operational bait station use began in key locations of high human and pet densities and likely travel corridors in areas in which low raccoon densities has been indexed [15] in an attempt to treat the same area with fewer baits (Figure 2).
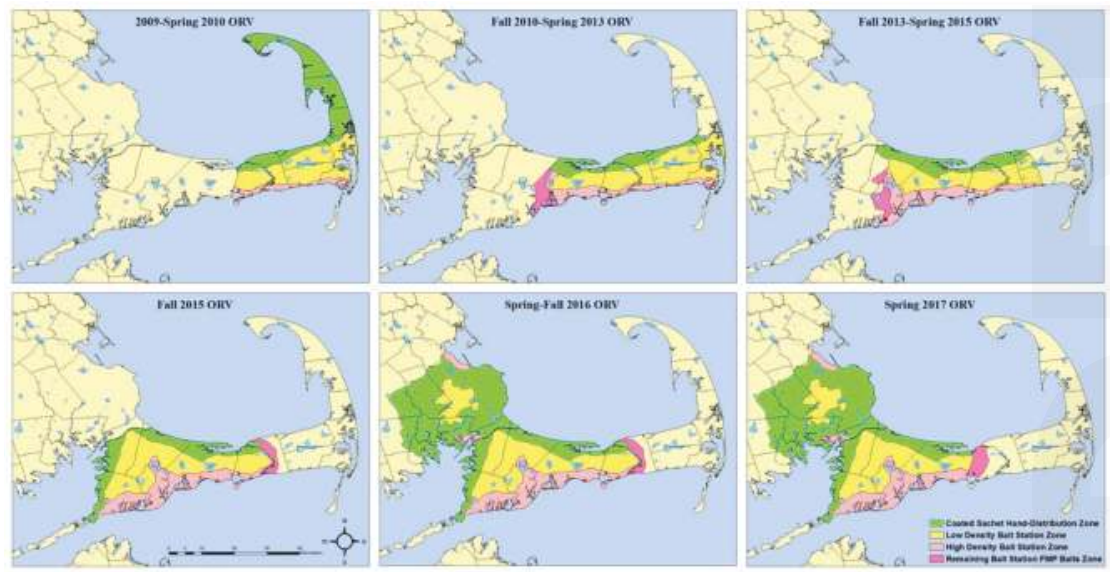

Figure 2. Cape Cod oral rabies vaccination baiting zones, spring 2009-spring 2017.

Five years of operational bait station use is reported as part of raccoon rabies elimination efforts on Cape Cod and compared to traditional hand-distribution of vaccine baits. In addition, since raccoon and non-target Virginia opossum (Didelphis virginiana) visitation to Cape Cod bait stations during 2006-2009 was statistically equivalent (1.18:1; $p>0.05)$, two bait station modifications designed to 
reduce opossum bait uptake were evaluated in Massachusetts and Florida. The relative performance of two vaccine bait types was also assessed to be sure these were equally useful in bait stations in Massachusetts and Florida. Lastly, the interior temperature conditions of camouflaged and unpainted white bait stations were evaluated in Massachusetts and Florida to be sure the former provided both the desired effect of preventing discovery and tampering by humans, but also to maintain adequate interior temperatures for maintaining bait and vaccine integrity.

Locations for the non-target bait uptake reduction, alternate bait trials, and interior temperature conditions in both states were selected based on habitat type. South Yarmouth, Massachusetts was selected as a representative developed coastal study location due to its mix of residential, commercial, resort, and conservation lands. The Polk County, Florida study site was selected due to its mix of wooded areas, wetlands, and urbanized or moderately-developed areas. Achieving rabies control in communities like these will play an essential role in the elimination of raccoon rabies in the U.S.

\section{Materials and Methods}

\subsection{Bait Stations on Cape Cod}

From 2011 through 2015, bait stations (Figure 3) were constructed and deployed operationally on Cape Cod, Massachusetts at two densities (high density -1.8 bait stations $/ \mathrm{km}^{2}$; low density- 0.1 bait stations $/ \mathrm{km}^{2}$ ) based on habitat type (mixed forest, woody wetlands, or medium intensity developed, featuring relatively high raccoon densities, and pine-dominated landscapes, featuring lower raccoon densities) (Figure 2). Habitat type was determined using the National Land Cover Database (NLCD 2001). Bait stations were affixed to trees or fence posts using heavy duty cable ties, with the openings $0.3-0.5 \mathrm{~m}$ above the ground. RABORAL V-RG baits $(n=60-63)$ were inserted in each bait station and monitored over a three-week period in the spring (April-May) and fall (October-November (2011-2014); September-October (2015)). Bait stations were visited weekly to ensure bait stations were functioning properly and to document bait uptake. Bait location relative to bait station, bait coating, and sachet condition were recorded at each bait station. In addition to bait station use, traditional hand-distribution of baits by vehicle and foot occurred where possible with treatment type overlap avoided.

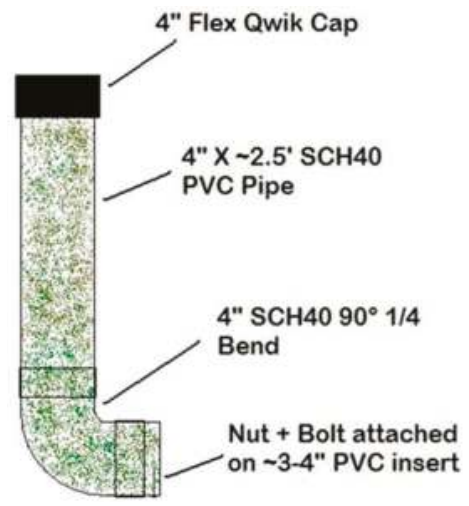

Figure 3. A USDA WS oral rabies vaccination standard bait station.

Serological surveillance occurred 4-8 weeks after each bait distribution was completed to assess rabies virus neutralizing antibody (RVNA) response in areas baited during the most recent ORV campaign. Raccoons were live captured using Tomahawk Live Trap ${ }^{\mathrm{TM}}$ (Hazelhurst, WI, USA) model 108 raccoon traps baited with Hard-Core ${ }^{\circledR}$ Raccoon Lure-coated marshmallows and a sardine in both bait zone types. Traps were checked every $24 \mathrm{~h}$, in accordance with state law. Blood samples were 
taken for rabies antibody prevalence and first premolar teeth were extracted for age and tetracycline biomarker analysis. Serum samples from spring 2011-spring 2015 were sent to the Centers for Disease Control and Prevention (CDC) for analysis using the rapid fluorescent focus inhibition test (RFFIT) with a positive sero-conversion cut-off of $\geq 0.05 \mathrm{IU} / \mathrm{mL}$ [16]. Fisher's exact tests were used to determine if there was a difference between seropositive raccoons within treatment zones (hand-distribution vs. bait station). Raccoons that had been previously captured and hand-vaccinated against raccoon rabies as well as juvenile raccoons that would not have been exposed to a vaccine bait were omitted from all analysis. Tetracycline biomarker is present in all RABORAL V-RG baits; however, results were not available for analysis at the time of publication. All target species were marked with ear tags that were labeled with a unique identifier to identify recaptured animals. In order to meet programmatic goals, post-ORV sampling within high-density bait station and hand-distribution zones took precedence over sampling from within low-density bait station areas.

Baits are marked with a phone number stamped on the bait matrix and on the plastic vaccine sachets to facilitate the reporting of human or pet bait contacts. Bait contact reports between bait distribution types (i.e., bait station vs. hand-distribition) were compared by Fisher's exact tests.

\subsection{Non-Target Bait Uptake Reduction}

During 2011, WS initiated efforts to reduce non-target bait uptake from standard WS bait stations (Figure 3). 'Qwik Cap Starburst' (QCS; 4" Fernco ${ }^{\mathrm{TM}}$ (Davison, MI, USA) Qwik Cap over the opening with a star-shape cutout), and 'Sanitary T Station' (STS; 4" to 2" reducer fitting to the end) bait stations were developed. Four-inch mechanical wing nut test plugs were installed in the bottom of each STS bait station to allow for easy removal of leftover baits at the end of the trials (Figure 4).

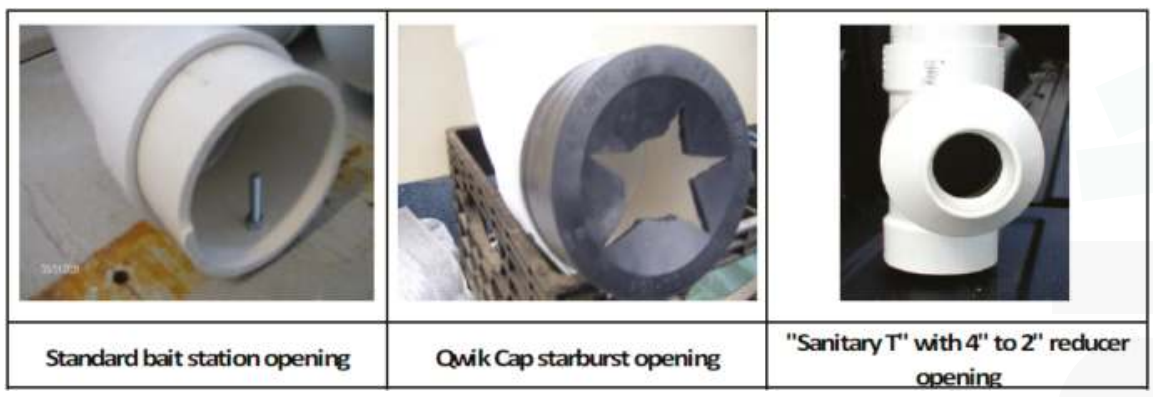

Figure 4. Candidate bait station modifications reducing non-target bait uptake in Barnstable County, Massachusetts and in Polk County, Florida, in 2011.

In April 2011, two candidate bait stations types and control bait stations were deployed over 3-km² study areas in Barnstable County, Massachusetts and in Polk County, Florida. Eight bait stations of each type (control, QCS, and STS) were deployed concurrently for ten nights in each state, located $>0.4 \mathrm{~km}$ apart. Other bait station location considerations included the relative suitability of raccoon and opossum habitat, and the ability to conceal bait stations from the public. Bait station locations and types deployed were quasi-randomized (i.e., random selection from among available sites) because, in a suburban landscape, extra care had to be taken to avoid theft of the bait station and of the baits contained within. Bait stations were initially deployed with ten RABORAL V-RG baits. Bait counts were maintained in each bait station throughout the study by daily replacements of missing baits, with the exception of weekends. Automatic digital trail cameras (Massachusetts: Reconyx ${ }^{\mathrm{TM}}$ RC60 (Holmen, WI, USA), Reconyx ${ }^{\mathrm{TM}}$ Silent Image, and $\mathrm{HCO}^{\mathrm{TM}}$ (Norcross, GA, USA); Florida: Moultrie ${ }^{\mathrm{TM}}$ (Alabaster, AL, USA) GameSpy D55IR and Moultrie ${ }^{\mathrm{TM}}$ I40) were used to monitor bait stations throughout the study for target and non-target visits and response to the bait stations. Bait status was recorded on a daily basis for each station. Individual animal visits were tallied, using activity breaks of 
$15 \mathrm{~min}$ as a proxy for individual identification, unless identification based on unique appearances was possible. Animal response was recorded as 'successful' when animals appeared to acquire a bait from a bait station, and 'unsuccessful' when they appeared to have been deterred. Fisher's exact tests were used to assess whether visits to each bait station type differed between raccoons and opossums.

\subsection{Alternate Baits for Bait Stations}

$\mathrm{ONRAB}^{\circledR}$ baits (adenovirus rabies glycoprotein recombinant oral vaccine in Ultralite bait matrix; Artemis Technologies, Guelph, ON, Canada) have been used in Canada and the U.S. [17-19]. ONRAB bait dispersal performance in bait stations was assessed relative to the more commonly used RABORAL V-RG bait. Locations for sixteen camouflaged bait stations were established in Massachusetts and Florida (8/bait type) in suitable raccoon habitats (e.g., mixed forest, wooded wetlands, or medium-intensity developed woody, wetlands) within a $3-\mathrm{km}^{2}$ area based on the National Land Cover Database (NLCD 2001). Bait stations were placed at least $0.4 \mathrm{~km}$ apart. Locations and bait types were selected quasi-randomly as above. To mimic an actual ORV operation, 60 vaccine baits were loaded in each bait station; eight bait stations received traditional RABORAL V-RG baits, while the other eight received placebo ONRAB baits. Automatic digital trail cameras (Massachusetts: Reconyx ${ }^{\mathrm{TM}}$ RC60; Florida: Moultrie ${ }^{\mathrm{TM}} \mathrm{I} 40$ ) were used to document wildlife activities at each bait station. Bait stations were checked daily, with the exception of weekends, from 6-16 March 2012 in Florida and 10-20 April 2012 in Massachusetts, and the number of baits remaining in each bait station was recorded. Bait condition (for those found on the ground) was recorded as: bait matrix gone, bait matrix partially gone, or fully intact; and sachet punctured, or sachet unpunctured. Trail camera images were analyzed daily and the number of interactions between any animal and bait or bait station was tallied. Number of target (e.g., raccoons) and non-target species (e.g., opossums, cats (Felis catus), dogs (Canis lupus familiaris)) were tallied, as well as individual actions when possible. Activity breaks of $15 \mathrm{~min}$ were used to separate visits from individual animals, unless unique identification of animals allowed otherwise. Fisher's exact tests were used to assess bait consumption by each bait type.

\subsection{Decreasing Human Interference with Bait Stations}

Bait stations are generally painted with camouflage paint as a way to reduce human disturbance and theft. To determine if painting bait stations significantly increases internal temperature (which may imperil vaccine viability and bait integrity), WS constructed sixteen standard bait stations (Figure 2). Eight bait stations were used in both Massachusetts and Florida. Four bait stations from each state were painted with camouflage paint and the other four bait stations remained unpainted (white).

Paired bait stations were located in full sun, partial shade, and full shade. Locations of full sun were exposed to direct sunlight throughout the entire day. Areas of partial shade had direct sun exposure for approximately one-half of a day, or had intermittent exposure. Locations in full shade were not exposed to direct sunlight at any point. Two white bait stations and two camouflaged bait stations were deployed in locations of full sun. One bait station of each color was also deployed in the partial sun and full shade locations.

Each bait station was equipped with a maximum/minimum thermometer (Taylor ${ }^{\mathrm{TM}}$ (Las Cruces, NM, USA) 5460 Indoor/Outdoor Maximum/Minimum Thermometer) and monitored on a daily basis over 10 days in Massachusetts (16-19, 23-26, and 30-31 August 2011) and 12 days in Florida (16-19, 21-26, and 28-29 August 2011). Thermometers were suspended by string at the lowest upright part of each bait station. Maximum temperatures for each bait station were recorded daily, as well as the weather conditions and any problems encountered with the thermometers. Thermometers were also deployed outside of the bait stations to document external temperatures. T-tests were used to determine differences between internal temperatures in painted and unpainted bait stations in each light exposure type. 


\section{Results}

\subsection{Bait Stations on Cape Cod}

From Spring 2011-Spring 2015, adult raccoons from within the high-density bait station zone ( 1.8 bait stations $/ \mathrm{km}^{2}, 113$ baits $/ \mathrm{km}^{2}$ ) that had not been captured and hand-vaccinated in prior years showed seroconversion $(\geq 0.05 \mathrm{IU} / \mathrm{mL})$ rates of $42.1 \%(n=126)$. Traditional hand-distribution of RABORAL V-RG coated sachet baits on Cape Cod $\left(138\right.$ baits $\left./ \mathrm{km}^{2}\right)$ during the same timeframe resulted in vaccination rates of $46.2 \%(n=182)$ (Table 1$)$.

Raccoon seroconversion within high density bait station zones in Massachusetts in 2012 and 2014 resulted in higher RVNA response, however, these results were not significant (both $p=1.00$ ). Seroconversion in 2011, 2013, and 2015 showed reduced seropositivity for bait stations (2011 and $2013 p=1.00 ; 2015 p=0.29)$ but were also not significant. Raccoons recaptured that had been previously hand-vaccinated were omitted from analysis, as well as juvenile animals that would not have encountered a bait during prior ORV operations.

Table 1. Post-ORV raccoon serology rates on Cape Cod, MA-2011-2015.

\begin{tabular}{|c|c|c|}
\hline Year & $\begin{array}{c}\text { Percent Seropositive by Hand } \\
\text { Distribution } \\
(n ; 95 \% \text { CI })\left(138 \text { Baits } / \mathrm{Km}^{2}\right)\end{array}$ & $\begin{array}{c}\text { Percent Seropositive by High Density } \\
\text { Bait Station }(n ; 95 \% \mathrm{CI}) \\
\left(1.8 \text { Bait Stations } / \mathrm{Km}^{2}, 113 \text { Baits } / \mathrm{Km}^{2}\right)\end{array}$ \\
\hline 2011 & $43.9(41 ; 0.30,0.59)$ & $38.5(13 ; 0.18,0.64)$ \\
\hline 2012 & $38.5(13 ; 0.18,0.64)$ & $41.1(17 ; 0.22,0.64)$ \\
\hline 2013 & $36.1(36 ; 0.22,0.52)$ & $31.6(19 ; 0.15,0.54)$ \\
\hline 2014 & $38.5(39 ; 0.25,0.54)$ & $40.5(37 ; 0.26,0.57)$ \\
\hline 2015 & $62.3(53 ; 0.49,0.74)$ & $50.0(40 ; 0.35,0.65)$ \\
\hline $\begin{array}{c}\text { Total } \\
(2011-2015)\end{array}$ & $46.2(182 ; 0.39,0.53)$ & $42.1(126 ; 0.34,0.51)$ \\
\hline
\end{tabular}

In Massachusetts, areas with bait stations had significantly less bait contact calls compared to hand-baited areas from 2010-2016 ( $p$ < 0.001). During 2010-2016, vaccine bait distribution campaigns in Massachusetts resulted in a total of 153 bait contact calls within hand-baited areas compared with 24 from bait station-baited areas. In hand-baited areas, at least 441 baits were found by people or their pets $(0.13 \%)$. However, within areas baited by bait stations, only 38 baits were involved with a pet or human bait contact $(0.02 \%)$.

\subsection{Non-Target Bait Uptake Reduction}

During April 2011 in Massachusetts and Florida, raccoons accounted for $74.8 \%$ of the apparent successful visits to control bait stations, while $25.2 \%$ were by opossums $(n=107)$. A similar relationship was observed for QCS bait stations, where $82.6 \%$ of apparent successful visits to bait stations were by raccoons and $17.4 \%$ were by opossums $(n=138)$. However, the ratio of raccoons photographed at STS bait stations was higher than the control and QCS bait stations (90.9\%) and lower for opossums $(9.1 \% ; n=44)$.

In Massachusetts, visitation and apparent bait retrieval by raccoons and opossums significantly differed by opening type $(p<0.001)$. Control bait stations visited in Massachusetts had a 1.8:1 raccoon to opossum ratio, while QCS and STS bait stations had raccoon to opossum visitation ratios of 55:1 and 14:1, respectively. However, apparent access by raccoons and opossums in Florida did not differ $(p=0.131)$.

\subsection{Alternate Baits for Bait Stations}

In Massachusetts, all bait stations containing ONRAB baits were emptied and all baits were consumed and/or punctured. Only one bait station containing RABORAL V-RG baits was completely 
emptied of baits by the end of the study. Of the 240 RABORAL V-RG baits originally deployed, 122 remained on day 10. In Florida, all baits were taken from the bait stations by the end of the study; however, one bait station containing ONRAB baits in Florida had baits through day 9, but was emptied prior to the day 10 check. In Massachusetts, all intact baits that had been pulled out of the bait station to the ground were redeployed in each bait station to maximize documenting bait-uptake and bait station access. Baits on the ground in Florida were left in front of the bait station to document if they would be consumed after the bait station was emptied. Of the baits left on the ground at the bait stations in Florida, all were consumed by day 6 . The relation between the removal of ONRAB and RABORAL V-RG baits was statistically significant $(p<0.001)$ in Massachusetts, but not in Florida $(p=1.00)$.

\subsection{Decreasing Human Interference with Bait Stations}

In Massachusetts, as might be expected, bait stations deployed in areas of full sun had a higher average temperature than those in shady locations. Camouflaged bait stations were also warmer than white bait stations, especially in full sun locations $(p=0.009)$, averaging $35.5^{\circ} \mathrm{C}$ compared to $29.6^{\circ} \mathrm{C}$. Both camouflaged and white bait stations in full shade locations had a similar average high temperature of $26.2^{\circ} \mathrm{C}$ and $25.7^{\circ} \mathrm{C}$, respectively $(p=0.32)$. Similarly, camouflaged and white bait stations also had similar average high temperatures in partial shade areas $\left(27.6^{\circ} \mathrm{C}\right.$ and $26.4^{\circ} \mathrm{C}$, respectively) ( $p=0.13)$. Several camouflaged bait stations in full sun showed high temperatures of over $40^{\circ} \mathrm{C}$ (Figure 5a).

In Florida, camouflaged bait stations in partial shade had higher average temperatures $\left(42.8^{\circ} \mathrm{C}\right)$ than any of the other bait stations. In full sun, camouflaged bait stations were warmer $\left(38.6^{\circ} \mathrm{C}\right)$, but they also had a slightly cooler average low temperature than white bait stations $\left(24.4^{\circ} \mathrm{C}\right.$ and $25.3^{\circ} \mathrm{C}$, respectively). In full shade, white bait stations were warmer than camouflaged bait stations $\left(30.6^{\circ} \mathrm{C}\right.$ and $27.9^{\circ} \mathrm{C}$, respectively) while both remaining about the same temperature at night $\left(24.0^{\circ} \mathrm{C}\right.$ and $24.2^{\circ} \mathrm{C}$, respectively). Average interior temperatures for camouflaged and white bait stations in Florida were statistically different in full shade, partial shade, and full sun ( $p=0.0003,0.017, \& 0.001$, respectively). In each location, average internal temperatures within white bait stations were significantly cooler than camouflage bait stations (Figure $5 b$ ).

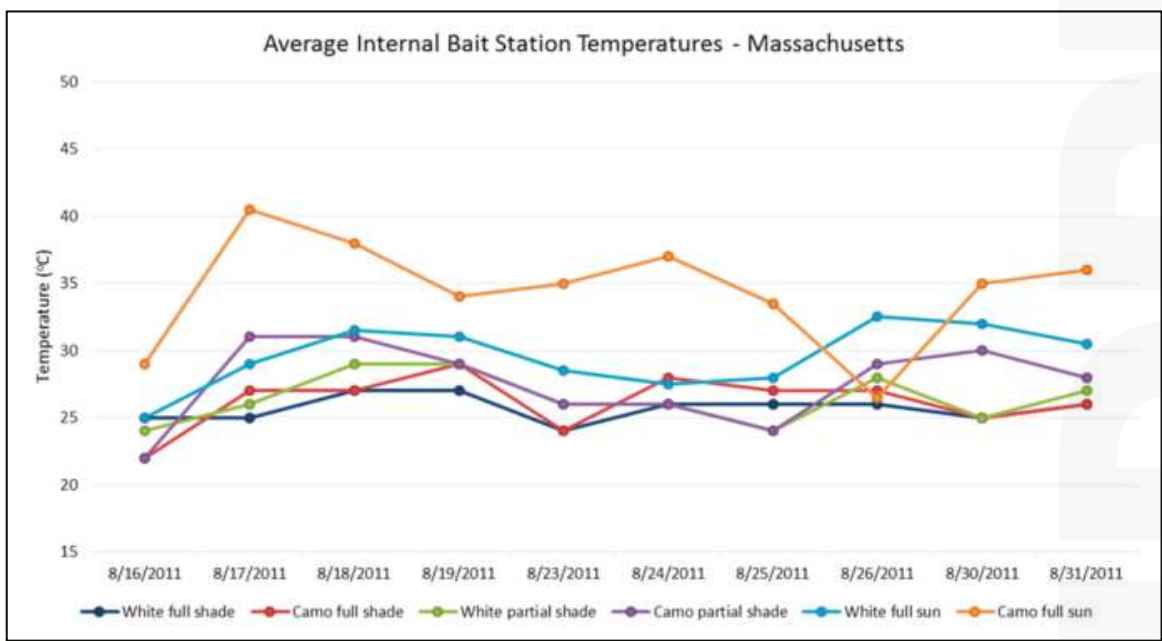

(a)

Figure 5. Cont. 


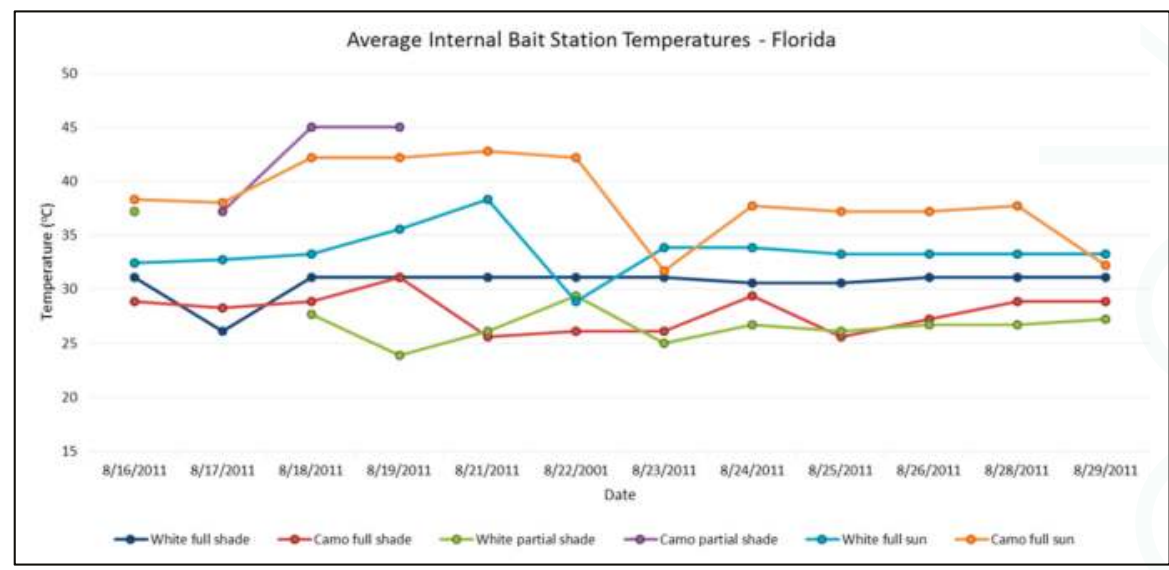

(b)

Figure 5. (a) Average internal bait station temperatures in Massachusetts. (b) Average internal bait station temperatures in Florida.

\section{Discussion}

\subsection{Bait Stations on Cape Cod}

When WS lost cooperative program funding for the CCORV in 2009, the use of bait stations was a logical next step, given that they could be efficiently deployed in more developed areas, and to intercept raccoons moving through apparently poorer raccoon habitats where broadcast baiting is likely wasteful [15]. As the ORV zone shifted west due to decreased raccoon rabies cases in treatment areas, baiting was increasingly conducted in more highly developed areas, increasing the need to switch to bait stations to reduce potential bait contacts. The use of bait stations on Cape Cod resulted in similar RVNA responses to those areas treated by hand-distribution of baits. This suggests that bait stations hold promise for ORV in the more highly-developed areas to be encountered as the NRMP approaches elimination of raccoon rabies along the eastern seaboard [20].

Bait contact by people or pets is a concern and therefore, reduction in bait contacts is desired. Additionally, every discovered bait potentially represents a lost dose for an unvaccinated raccoon. As evidenced by the reduced number of bait contact-related phone calls and reports, the use of bait stations in developed areas has resulted in fewer contact events. The use of bait stations will continue to play an important role in reducing these bait contacts, especially in heavily developed areas.

\subsection{Non-Target Bait Uptake Reduction}

During a previous assessment of bait station visitation by non-target species on Cape Cod, raccoon visits to bait stations occurred at a similar frequency to non-target opossums (1.18:1; $p>0.05)$. Based on the low total number of apparent successful raccoon and opossum visits to STS bait stations compared to visits to control and QCS bait stations, it appears that this bait station prohibits easy access to baits by both species. Consequently, STS bait stations are not suitable for distribution of vaccine baits. Results of the bait station opening study did not differ between tested modifications in Florida. However, in Massachusetts, raccoon to opossum successful visitation ratios improved at QCS and STS bait stations, although the number of raccoon visits to STS bait stations decreased. Consequently, the strategy of modifying bait station openings seems to hold promise for reducing the waste represented by non-target bait consumption, and further trials will likely be conducted with better photographic equipment to more clearly document bait uptake. The control bait station design remains the best operational design until further trails are conducted. 
A number of unquantifiable factors could account for differences between Massachusetts and Florida results, such as raccoon and opossum population density differences, weather, and food item competition in the surrounding landscape [21]. An obvious limitation in this assessment was the lack of complete certainty that a visit resulted in actual bait access or uptake. Future use of increasingly available video options to capture more definitive evidence that animals visiting bait stations are actually obtaining baits may help clarify this. In addition to camera capture data, serologic data would be important when comparing bait uptake from different bait station opening modifications, which would require increased geographic areas and effort.

Skunks found within the Massachusetts and Florida study locations (striped skunks, Mephitis mephitis (MA and FL) and spotted skunks, Spilogale putorius (FL)) were not documented visiting any bait stations during this study, but their roles as potential bait competitors need further attention based on their relative densities in many locations suitable for bait station use.

\subsection{Alternate Baits for Bait Stations}

In Massachusetts, ONRAB baits performed better in bait stations than traditional RABORAL V-RG baits based on successful removal. Both baits performed equally as well in Florida. Given the mixed results for bait removal by type between the two locations, further testing is necessary to determine whether real performance differences exist. In addition, since bait stations often dispense baits over a two- to three-week period, future bait station bait performance assessments should occur under conditions where vaccine titers can be assessed. Despite ONRAB baits preference by raccoons on Cape Cod, RABORAL V-RG baits continue to be used, and will be until further examination of ONRAB baits in bait stations is conducted.

Competition for baits, primarily in areas with high non-target populations, limits consumption by target raccoons. In Massachusetts, raccoons were photographed at bait stations containing ONRAB baits more frequently than at bait stations containing RABORAL V-RG baits, while bait stations containing RABORAL-VRG baits were more frequented by opossums. It did not appear that raccoons or opossums showed any preference towards either bait type in Florida. Further study may be necessary to examine bait-type preference on a location-by-location basis, as preference may vary by geographic region. Additional bait station modification may be necessary to prevent non-target uptake in both locations.

\subsection{Decreasing Human Interference with Bait Stations}

Human discovery of bait stations is problematic due to tampering, theft and increased potential for human vaccine contact. However, before bait stations could be uniformly camouflaged, it was important to assess whether these modifications could affect bait and vaccine quality. The most obvious candidate agent for reduced quality was assumed to be internal temperature. As a result of this study, it is recommended that bait stations be deployed in areas of full shade, as internal temperatures in those bait stations were cooler, regardless of color. Operationally, bait stations are rarely placed in areas of full sun due to visibility by the public and to prevent the excessive heating of vaccine baits. Where it became absolutely necessary in some instances to place bait stations in areas of full sun, white bait stations would be recommended rather than camouflage bait stations as a result of this study. Differing results between Massachusetts and Florida may be accounted for by higher ambient temperatures in Florida. However, given the need for vaccine and bait stability, these trials might bear repeating under more controlled circumstances. Additionally, bait and vaccine thermostability trials need to be conducted to examine efficacy of the vaccine at varying times throughout the typical three-week timeframe in which bait stations may contain baits.

\section{Conclusions}

Integrating bait stations into rabies control efforts on Cape Cod has led to similar sero-conversion rates and wildlife rabies management performance compared to traditional hand-baiting alone. 
Additionally, the use of bait stations has reduced bait contact reports, maximizing the number of baits available to raccoons and other target species. Alternate bait station openings may eventually play a role in limiting non-target bait uptake. Furthermore, it was discovered that ONRAB vaccine baits were removed at a faster rate by target and non-target species when compared to RABORAL V-RG. This study also showed that bait stations should be placed in areas with limited sun exposure when possible. Although serology results are an important component to the evaluation of ORV success, the ultimate factors are the absence of raccoon rabies cases in the currently-treated zone, and those areas from where ORV has been shifted away. On Cape Cod from 2014-2016, 542 animals were tested for rabies, of which six were confirmed positive for raccoon rabies. All six animals (two raccoons and four skunks) were from west of the Cape Cod Canal. This integrated approach, subject to continued trials to achieve better bait station performance, may play an important role in rabies control and prevention in other areas of the U.S., especially as rabies management turns its focus from preventing raccoon rabies spread to elimination from the eastern U.S. However, some important questions regarding optimal bait station design and effectiveness remain.

Acknowledgments: The authors would like to thank members of the Cape Cod Rabies Task Force for their continued support of the Cape Cod Rabies Program. We also thank Bartow Municipal Airport for use of their property as a study location, the CDC for running RFFIT on serum samples, and the National Rabies Management Program. We also thank Massachusetts and Florida Wildlife Services for their collaboration on this study.

Author Contributions: T.P.A., B.M.B., B.S.H., and D.S. conceived and designed the trials and analyzed the data; B.M.B., B.S.H., and R.J.B. performed the trials; R.B.C., M.D.C., and A.G.D. contributed materials; and B.M.B., T.P.A., B.S.H., R.J.B., R.B.C., A.M., D.S., and K.W.V. collaboratively wrote and/or reviewed the manuscript.

Conflicts of Interest: R.B.C. is the current National Rabies Management Coordinator for the USDA, APHIS, Wildlife Services, National Rabies Management Program, and D.S. is the former National Rabies Management Coordinator and both indirectly provided discretionary Federal funding to support field work.

\section{References}

1. Slate, D.; Algeo, T.P.; Nelson, K.M.; Chipman, R.B.; Donovan, D.; Blanton, J.D.; Niezgoda, M.; Rupprecht, C.E. Oral rabies vaccination in North America: Opportunities, complexities, and challenges. PLoS Negl. Trop. Dis. 2009, 3, e549. [CrossRef] [PubMed]

2. Blancou, J. The control of rabies in Eurasia: Overview, history and background. Dev. Biol. 2008, 131, 3-15.

3. Wandeler, A.I. The rabies situation in western Europe. Dev. Biol. 2008, 131, 19-25.

4. MacInnes, C.D.; Smith, S.M.; Tinline, R.R.; Ayers, N.R.; Bachmann, P.; Ball, D.G.; Calder, L.A.; Crosgrey, S.J.; Fielding, C.; Hauschildt, P.; et al. Elimination of rabies from red foxes in eastern Ontario. J. Wildl. Dis. 2001, 37, 119-132. [CrossRef] [PubMed]

5. Rosatte, R.C.; Power, M.J.; Donovan, D.; Davies, J.C.; Allan, M.; Bachmann, P.; Stevenson, B.; Wandeler, A.; Muldoon, F. Elimination of arctic variant rabies in red foxes, metropolitan Toronto. Emerg. Infect. Dis. 2007, 13, 25-27. [CrossRef] [PubMed]

6. Rosatte, R.C.; Donovan, D.; Allan, M.; Bruce, L.; Buchanan, T.; Sobey, K.; Stevenson, B.; Gibson, M.; MacDonald, T.; Whalen, M.; et al. The control of raccoon rabies in Ontario Canada: Proactive and reactive tactics, 1994-2007. J. Wildl. Dis. 2009, 45, 772-784. [CrossRef] [PubMed]

7. Fearneyhough, M.G.; Wilson, P.J.; Clark, K.A.; Smith, D.R.; Johnston, D.H.; Hicks, B.N.; Moore, G.M. Results of an oral rabies vaccination program for coyotes. J. Am. Vet. Med. Assoc. 1998, 212, 498-502. [PubMed]

8. Velasco-Villa, A.; Reeder, S.A.; Orciari, L.A.; Yager, P.A.; Franka, R.; Blanton, J.D.; Zuckero, L.; Hunt, P.; Oertli, E.H.; Robinson, L.E.; et al. Enzootic rabies elimination from dogs and reemergence in wild terrestrial carnivores, United States. Emerg. Infect. Dis. 2008, 14, 1849-1854. [CrossRef] [PubMed]

9. Sidwa, T.J.; Wilson, P.J.; Moore, G.M.; Oertli, E.H.; Hicks, B.N.; Rohde, R.E.; Johnston, D.H. Evaluation of oral rabies vaccination programs for control of rabies epizootics in coyotes and gray foxes: 1995-2003. J. Am. Vet. Med. Assoc. 2005, 227, 785-792. [CrossRef] [PubMed]

10. Bjorklund, B.M.; Algeo, T.P.; Chandler, M.D.; Wilda, D.J.; Slate, D. Terrestrial rabies surveillance on Cape Cod: A community-based multi-agency strategy to provide critical information for rabies control. In Proceedings of the 22nd Vertebrate Pest Conference, Berkeley, CA, USA, 6-9 March 2006; Timm, R., O'Brien, J., Eds.; University of California, Davis: Davis, CA, USA, 2006; pp. 346-350. 
11. Algeo, T.P.; Chipman, R.B.; Bjorklund, B.M.; Chandler, M.D.; Wang, X.; Slate, D.; Rupprecht, C.E. Anatomy of the Cape Cod oral rabies vaccination program. In Proceedings of the 23rd Vertebrate Pest Conference, San Diego, CA, USA, 17-20 March 2008; University of California: Davis, CA, USA, 2008; pp. 264-269.

12. Boulanger, J.R.; Bigler, L.L.; Curtis, P.D.; Lein, D.H.; Arthur, J. A polyvinyl chloride bait station for dispensing rabies vaccine to raccoons in suburban landscapes. Wildl. Soc. Bull. 2006, 34, 1206-1211. [CrossRef]

13. Tobin, M.E.; Richmond, M.E. Bait Stations for Controlling Voles in Apple Orchards. In Proceedings of the Third Eastern Wildlife Damage Control Conference, Gulf Shores, AL, USA, 18-21 October 1987; pp. 287-295.

14. Haley, B.S.; Algeo, T.P.; Bjorklund, B.; Duffiney, A.G.; Hartin, R.E.; Martin, A.; Nelson, K.M.; Chipman, R.B.; Slate, D. Evaluation of bait station density for oral rabies vaccination of raccoons in urban and rural habitats in Florida. Trop. Med. Infect. Dis. 2017, (in press).

15. Algeo, T.; Slate, D.; Caron, R.; Atwood, T.; Recuenco, S.; Ducey, M.; Chipman, R.; Palace, M. Modeling raccoon (Procyon lotor) habitat connectivity to identify potential corridors for rabies spread. Trop. Med. Infect. Dis. 2017, (in press).

16. Smith, J.S.; Yager, P.A.; Baer, G.M. A rapid fluorescent focus inhibition test (RFFIT) for determining rabies virus-neutralizing antibody. In Laboratory Techniques in Rabies; Meslin, F.X., Kaplan, M.M., Koprowski, H., Eds.; World Health Organization: Geneva, Switzerland, 1996; pp. 181-190.

17. Fehlner-Gardiner, C.; Rudd, R.; Donovan, D.; Slate, D.; Kempf, L.; Badcock, J. Comparing ONRAB ${ }^{\circledR}$ and RABORAL V-RG ${ }^{\circledR}$ oral rabies vaccine field performance in raccoons and striped skunks, New Brunswick, Canada, and Maine, USA. J. Wildl. Dis. 2012, 48, 157-167. [CrossRef] [PubMed]

18. Slate, D.; Chipman, R.B.; Algeo, T.P.; Mills, S.A.; Nelson, K.M.; Croson, C.K.; Dubovi, E.J.; Vercauteren, K.; Renshaw, R.W.; Atwood, T.; et al. Safety and immunogenicity of Ontario rabies vaccine bait (ONRAB) in the first US field trial in raccoons (Procyon lotor). J. Wildl. Dis. 2014, 50, 582-595. [CrossRef] [PubMed]

19. Rosatte, R.C.; Donovan, D.; Davies, J.C.; Allan, M.; Bachmann, P.; Stevenson, B.; Sobey, K.; Brown, L.; Silver, A.; Bennett, K.; et al. Aerial distribution of onrab baits as a tactic to control rabies in raccoons and striped skunks in Ontario, Canada. J. Wildl. Dis. 2009, 45, 363-374. [CrossRef] [PubMed]

20. Anderson, A.; Shwiff, S.A.; Chipman, R.B.; Atwood, T.; Cozzens, T.; Fillo, F.; Hale, R.; Hatch, B.; Maki, J.; Rhodes, O.E.; et al. Forecasting the spread of raccoon rabies using a purpose-specific group decision-making process. Hum. Wildl. Interact. 2014, 8, 130-138.

21. Bjorklund, B.M.; Thomas, H.H.; Palmiotto, P.A.; Algeo, T.P.; Slate, D.; Chipman, R.B.; Chandler, M.D.; Wilda, D.J. Potential food item distractions during raccoon ORV baiting campaigns on Cape Cod, Massachusetts: would you like fries with that? In Proceedings of the 23rd Vertebrate Pest Conference, San Diego, CA, USA, 17-20 March 2008; Timm, R.M., Madon, M.B., Eds.; pp. 270-274.

(C) 2017 by the authors. Licensee MDPI, Basel, Switzerland. This article is an open access article distributed under the terms and conditions of the Creative Commons Attribution (CC BY) license (http:/ / creativecommons.org/licenses/by/4.0/). 
Article

\title{
Evaluation of Bait Station Density for Oral Rabies Vaccination of Raccoons in Urban and Rural Habitats in Florida
}

\author{
Betsy S. Haley ${ }^{1}{ }^{(0)}$, Timothy P. Algeo ${ }^{2}$, Brian Bjorklund ${ }^{3}$, Anthony G. Duffiney ${ }^{4}$, \\ Robert Edwin Hartin ${ }^{5}$, Ashlee Martin ${ }^{1, *}$, Kathleen M. Nelson ${ }^{1}$, Richard B. Chipman ${ }^{1}$ \\ and Dennis Slate ${ }^{1}$
}

1 United States Department of Agriculture, Animal and Plant Health Inspection Service, Wildlife Services, National Rabies Management Program, 59 Chenell Dr., Suite 2, Concord, NH 03301, USA; betsy.s.haley@aphis.usda.gov (B.S.H.); kathleen.m.nelson@aphis.usda.gov (K.M.N.); richard.b.chipman@aphis.usda.gov (R.B.C.); dennis.slate@aphis.usda.gov (D.S.)

2 United States Department of Agriculture, Animal and Plant Health Inspection Service, Wildlife Services, 59 Chenell Dr., Suite 7, Concord, NH 03301, USA; timothy.p.algeo@aphis.usda.gov

3 United States Department of Agriculture, Animal and Plant Health Inspection Service, Wildlife Services, 9 Main St., Suite 1M, Sutton, MA 01590, USA; brian.bjorklund@aphis.usda.gov

4 United States Department of Agriculture, Animal and Plant Health Inspection Service, Wildlife Services, 2803 Jolly Rd., Suite 100, Okemos, MI 48864, USA; anthony.g.duffiney@aphis.usda.gov

5 United States Department of Agriculture, Animal and Plant Health Inspection Service, Wildlife Services, 2820 E University Ave., Gainesville, FL 32641, USA; edwin.hartin@aphis.usda.gov

* Correspondence: ashlee.d.martin@aphis.usda.gov; Tel.: +1-603-223-9623

Received: 7 July 2017; Accepted: 18 August 2017; Published: 22 August 2017

\begin{abstract}
Efforts to eliminate the raccoon variant of the rabies virus (raccoon rabies) in the eastern United States by USDA, APHIS, Wildlife Services and cooperators have included the distribution of oral rabies vaccine baits from polyvinyl chloride (PVC) bait stations in west-central Florida from 2009 to 2015. Achieving sufficient vaccine bait uptake among urban raccoons is problematic, given limitations on aerial and vehicle-based bait distribution for safety and other reasons. One or three bait stations $/ \mathrm{km}^{2}$ were deployed across four $9-\mathrm{km}^{2}$ sites within rural and urban sites in Pasco and Pinellas Counties, Florida. Based on tetracycline biomarker analysis, bait uptake was only significantly different among the urban (Pinellas County) high and low bait station densities in 2012 $(p=0.0133)$. Significant differences in RVNA were found between the two bait station densities for both urban 2011 and 2012 samples ( $p=0.0054$ and $p=0.0031)$. Landscape differences in terms of urban structure and human population density may modify raccoon travel routes and behavior enough for these differences to emerge in highly urbanized Pinellas County, but not in rural Pasco County. The results suggest that, in urban settings, bait stations deployed at densities of $>1 / \mathrm{km}^{2}$ are likely to achieve higher seroprevalence as an index of population immunity critical to successful raccoon rabies control.
\end{abstract}

Keywords: bait stations; raccoons; rabies; vaccine; oral rabies vaccination

\section{Introduction}

Globally, rabies kills approximately 59,000 humans annually, and impacts on human and animal health result in a significant economic burden [1]. In the United States, the cost of living with the virus ranges from $\$ 245-510$ million annually [2]. Oral rabies vaccination (ORV) is an effective and socially-acceptable approach to wildlife rabies control [3]. ORV has been used to control fox rabies in western Europe [4,5] and in Canada [6-8]. In the U.S., ORV is currently aimed at the elimination and 
prevention of new epizootics of canine rabies in coyotes (Canis latrans) [9,10], the elimination of rabies in gray fox (Urocyon cinereoargenteus) in Texas [11] and the containment and elimination of the raccoon (Procyon lotor) variant of the rabies virus (raccoon rabies) in the eastern U.S. [3].

While there are many variants of the rabies virus, and many vector species, raccoon rabies is primarily perpetuated within the raccoon. Raccoons often occur at extremely high population densities along the rural-urban interface, and are ecological generalists [12]. Raccoon rabies has spread rapidly in the abundant raccoon populations of eastern North America; however, the virus has not moved west of the Appalachian Mountain Range. Using this range as a natural barrier, USDA, APHIS, Wildlife Services (WS), National Rabies Management Program (NRMP) has implemented a large-scale ORV program to prevent the westward spread of raccoon rabies [3]. WS NRMP is conducting cooperative ORV operations to continue preventing the spread of raccoon rabies into the mid-western U.S. and eastern Canada (Phase I), and has begun work towards its elimination from the eastern U.S. (Phase II) [3], much of which is highly urbanized.

Bait stations for distribution of oral rabies vaccine baits have become an increasingly important bait delivery method in urban areas where aerial and vehicle-based (or hand) vaccine bait delivery is hampered by high human and pet densities, and in rural areas where raccoon densities are low, but target species may be concentrated in smaller localized populations, reducing the need to widely broadcast vaccine baits. Bait station use began in New York in 2003, and in key locations in Massachusetts in 2006 [13,14], with important questions regarding optimal design and effectiveness left unanswered. Although bait station design and deployment has been evaluated, including modification to reduce non-target uptake, especially by opossums (Didelphis virginiana), future design improvements and optimized strategies for their use require additional study $[13,15,16]$. Opossums are a non-target species due to their low incidence of rabies. They are attracted to vaccine baits and are able to remove baits from the bait stations with little difficulty. Direct competition with raccoons for the baits can confound rabies management efforts [17,18].

To better understand the best management strategies for using bait stations to control raccoon rabies in central Florida during 2011 and 2012, presence of tetracycline (TTCC) biomarker and rabies virus neutralizing antibodies (RVNA) as indices of bait station performance [3] were compared between two bait station densities in rural and urban settings using fishmeal polymer (FMP) baits containing RABORAL V-RG ${ }^{\circledR}$ (Merial, Athens, GA, USA) vaccine. It was predicted that placing 3 bait stations $/ \mathrm{km}^{2}$ would result in significantly higher RVNA and TTCC percentages than having 1 bait station $/ \mathrm{km}^{2}$ among the urban study sites, and that there would be no significant difference between 3 bait stations $/ \mathrm{km}^{2}$ and 1 bait station $/ \mathrm{km}^{2}$ among the rural study sites.

\section{Materials and Methods}

Rural study sites were selected within the Starkey Wilderness Preserve in Pasco County, Florida, which is owned and managed by the Southwest Florida Water Management District (SWFWMD), and urban sites were selected within St. Petersburg in Pinellas County, Florida (Figure 1). The rural study sites were dominated by oak (Quercus spp.) and pine (Pinus spp.) woodlands, with few to no houses in the area. In this study, there were 87 houses within the northeast corner of the study site and bait stations were set at least $0.04 \mathrm{~km}$ from the property lines. The rural study sites were interspersed with dirt trails maintained by SWFWMD. An understory of scrub and shrub species was throughout the rural study sites. The urban sites were located within St. Petersburg, Florida, which had a population of approximately 245,300 at the time of the studies, with a population density of approximately 3970 people $/ \mathrm{mi}^{2}$ (or 1533 people $/ \mathrm{km}^{2}$ ) [19]. The landscape was dominated by residential and commercial properties. The study sites will be referenced as rural (Pasco County) or urban (Pinellas County) high bait station density (HBSD)—-those sites with 3 bait stations $/ \mathrm{km}^{2}$, and rural or urban low bait station density (LBSD)—-those sites with 1 bait station $/ \mathrm{km}^{2}$. 


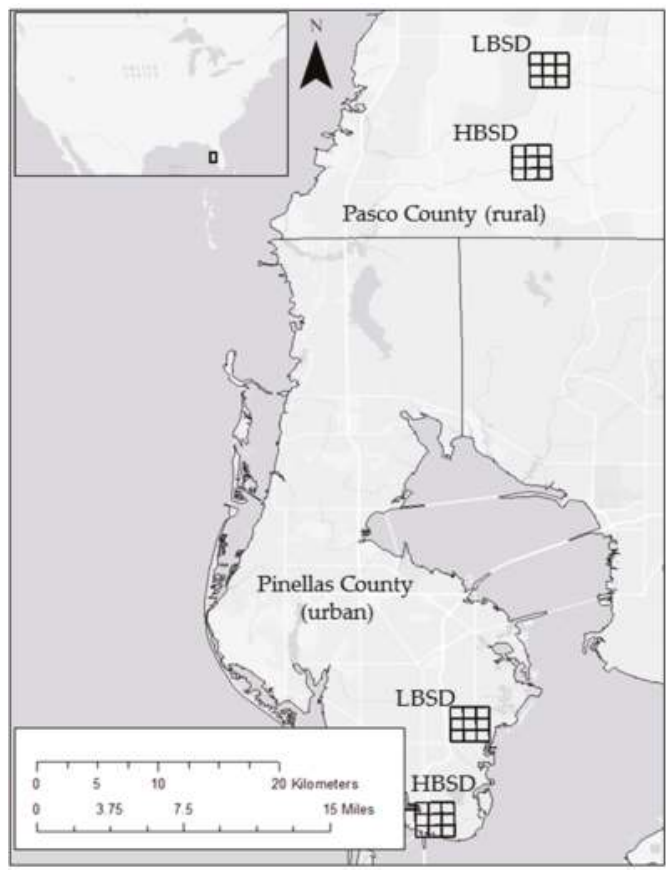

Figure 1. Location of 2011 and 2012 bait station sites within rural (Pasco County) and urban (Pinellas County) locations. The LBSD sites in each county had one bait station $/ \mathrm{km}^{2}$, while the HBSD sites in each county had three bait stations $/ \mathrm{km}^{2}$.

Bait stations were constructed of 2.5 -foot sections of 4-inch diameter polyvinyl chloride (PVC) schedule 40 pipe, painted in camouflaged colors to reduce the likelihood of human tampering. Open PVC-tops were covered with 4-inch flexible Qwik ${ }^{\circledR}$ (United States Plastic Corp, Lima, OH, USA) caps to prevent rain and bait access for animals from the top. PVC elbows (90 degree angle) were attached to the 2.5-foot PVC section bottoms, and a 3-4 inch PVC pipe extended from the elbow with a nut and bolt to prevent baits from falling out of the bait station (Figure 2). The bolt acts as a stop to prevent the baits from sliding out and the nut holds the bolt in place. This design was based on the bait station design by Boulanger et al. [13], and then modified to accommodate more baits at one time.

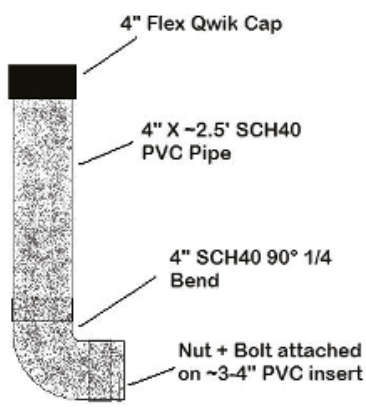

Figure 2. Bait station specifications used in Pasco and Pinellas Counties, Florida, during 2011-2012. 
Bait stations were deployed over 10 consecutive nights during 9-20 May 2011 and 21 February-5 March 2012. Due to the number of bait stations to be deployed, not all bait stations were set on the same day. Each bait station area was active for 10 days, though the total number of study days was $>10$ days. Study sites were selected within $5 \mathrm{~km}$ of previous WS raccoon density study or bait station study sites to provide working knowledge of the raccoon populations in the study areas. The raccoon density in Pasco County was estimated at approximately 10 raccoons $/ \mathrm{km}^{2}$ during a density study conducted in 2011; however, there were no density studies conducted in Pinellas County. Target bait densities on all sites were $75 / \mathrm{km}^{2}$, the standard base rate for distributing baits based on current raccoon densities [3]. The bait densities were kept constant across the study sites to ensure study sites could be compared to one another. Two $9-\mathrm{km}^{2}$ study sites were selected (within one habitat type (i.e., woodland-dominated or urban/residential-dominated) to the greatest degree possible) at least $5 \mathrm{~km}$ apart in each of the two counties (urban LBSD and HBSD, and rural LBSD and HBSD). Thirty-six bait stations were deployed in each county, and 1350 vaccine baits containing TTCC hydrochloride as a biomarker were deployed on Day 0 in each county. The FMP baits containing RABORAL V-RG ${ }^{\circledR}$ vaccine were 1.25 inch $\times 1.25$ inch $\times 0.5$ inch brown square blocks made of fishmeal. Inside the bait was a sachet sealed in the block with wax. The pink liquid inside the sachet was the vaccine. The amount of vaccine was intended to be a single dose.

The LBSD site in each county was equipped with one bait station $/ \mathrm{km}^{2}$, containing 75 baits each (9 bait stations/site). The HBSD site in each county was equipped with three bait stations $/ \mathrm{km}^{2}$ containing 25 baits each ( 27 bait stations/site). Even distribution of the bait stations within the rural sites was possible due to the rural nature (woodlands with scrub/shrub understory) of the site, and single ownership; only vegetation and a lack of trails influenced bait station distribution. These sites were dominated by saw palmettos (Serenoa repens), oaks, and pines. Thorny vines, like greenbrier (Smilax bona-nox), made human movement difficult. Access to trails in 2012 that were available for use in 2011 was reduced by storm damage. The distribution of bait stations within the urban HBSD site was clustered in several 1- $\mathrm{km}^{2}$ sections based on landowner permission, vegetative cover and the need to hide bait stations from the view of the public to reduce tampering.

Bait stations were visited three to five times during each study period to monitor activity, equipment and site conditions. In the urban sites, four infrared automated cameras were positioned in LBSD, and six in HBSD, while in the rural sites, five were set in LBSD, and six in HBSD. All cameras were Moultrie $^{\circledR}$ (EBSCO Industries, Inc., Birmingham, AL, USA), and both Gamespy D55IR and I40 Digital Game Camera models were used. The D55IR was a 5.0-megapixel camera and accepted SD cards of up to 16 GB. The I40 was a 4.0-megapixel camera and accepted SD cards of up to 4 GB. Photos were set at high image quality, with 1-minute activation intervals and with the multi-shot function turned on to capture 3 photos for each activation on both cameras. No flash was used; only the infrared flash was used at night. Sensor, aperture, and focal lengths were adjusted automatically as needed; these were not changed from the original setting as there was no means to adjust them. Cameras were set 12-24 inches from the ground, a minimum of 3 feet from the bait station, and aimed toward bait station openings to determine the species (raccoon vs. non-target) taking bait. Direction of the cameras was not accounted for, as most of the bait stations were set within clumps of vegetation so direct sunlight was not a factor. Each camera was given a unique ID number, which was printed on the photos to enable proper location of the photos. While setting the bait stations and cameras, the bait station number was recorded along with the corresponding camera ID. Any removal of vegetation in the rural sites that may have interfered with the cameras capturing photos was kept to a minimum so as not to make changes to the habitat that could deter animal visitations. In the urban sites, no vegetation changes were made, since the bait stations were set primarily on private property, and damage the landowners' plants was not desired. Camera event counters were reset during each site visit, and the time between photographs was minimized. During each bait station visit, the following information was recorded: date of visit, bait station ID, camera type, number of photos on camera (since last visit), number of images by species, and bait condition. The photos were viewed on a 
laptop computer. Each new event was determined by a 15-minute interval between photos showing individual animals. If the animal could be accurately identified by its markings as the same animal in the previous event photo (15 min prior), then this was considered a new event but not a new individual. If a bait station was emptied prior to the end of the of the 10-day study period, it was removed along with the camera, if one was associated with the bait station, to reduce tampering and damage to the bait station.

Trapping began 24 days after bait stations were removed to allow sufficient time for TTCC biomarker deposition and RVNA development, and to approximate the time between standard ORV bait distribution and post-ORV sampling. Trapping occurred within $0.5 \mathrm{~km}$ of each study site to optimize capture rates, and $\geq 30$ unique raccoons/study site were targeted to facilitate TTCC biomarker and serological analyses. Trapping was completed 84 days post-station removal. Raccoons were marked with a metal \#4 ear tag (National Band \& Tag Co., Newport, KY, USA) stamped with a unique identifying number so as to identify each individual raccoon captured. Given that all past and present captured raccoons are marked in the same fashion, any animals recaptured from previous studies could be easily identified and removed from testing if treated in a manner (i.e., given vaccination by injection) that would affect this study's results. Standard biological samples were collected, including blood sera to determine vaccine-induced immunity, and first premolar (PM1) teeth for biomarker evaluation. Although biomarking frequently occurs in fewer animals than actually demonstrate vaccine-induced serological responses due to extraction of a first premolar from live tapped and released raccoons, it remains useful when considered with other vaccination assessment tools [20,21]. The teeth were labeled and prepared for shipment to Matson's Laboratory, LLC (Manhattan, MT, USA) where the tetracycline biomarker analysis was performed. Methods used for this test were performed as stated in Algeo et al. [20] and Linhart and Kenelly [22]. Rabies virus neutralizing antibody tests were conducted at the Centers for Diseases Control and Prevention (CDC) in Atlanta, GA, using the rapid fluorescent focus inhibition test (RFFIT). Methods for this test were performed as stated in Smith et al. [23] and CDC [24]. A cut-off of both $\geq 0.05$ and $\geq 0.1 \mathrm{IU} / \mathrm{mL}$ were used to indicate a positive RVNA response. It was desired to determine if there was a detectable difference with using the lower $0.05 \mathrm{IU} / \mathrm{mL}$ versus the higher $0.1 \mathrm{IU} / \mathrm{mL}$.

Fisher's exact tests were used to compare RVNA rates within and between treatments and sites. GraphPad QuickCalcs (GraphPad Software, Inc., La Jolla, CA, USA) statistical software was used for analyses [25], with $\alpha=0.05$.

\section{Results}

The photographs captured by each camera were examined and the number of individual animals photographed was documented. One camera was removed from the rural HBSD counts in both 2011 and 2012 for lack of photographs showing any individual animals. In 2011, total camera days were 44 (rural LBSD, 5 cameras), 42 (rural HBSD, 5 cameras), 40 (urban LBSD, 4 cameras) and 22 (urban HBSD, 6 cameras). Total camera days in 2012 were 34 (rural LBSD, 5 cameras), 24 (rural HBSD, 5 cameras), 40 (urban LBSD, 4 cameras) and 31 (urban HBSD, 6 cameras). Photographs were analyzed for individual identifiable animals by markings. If an animal was not identified as the same with certainty, then it was counted as a new individual. Raccoons were photographed more frequently in five of the eight sampling periods than were opossums, the primary non-target species in the area. However, during 2012 in the rural LBSD site, and during 2011 and 2012 in the urban LBSD site, more opossums were photographed (Figure 3). Only in the rural LBSD site did raccoons predominate amongst the photographed individuals in 2011, and opossums predominated in 2012. 


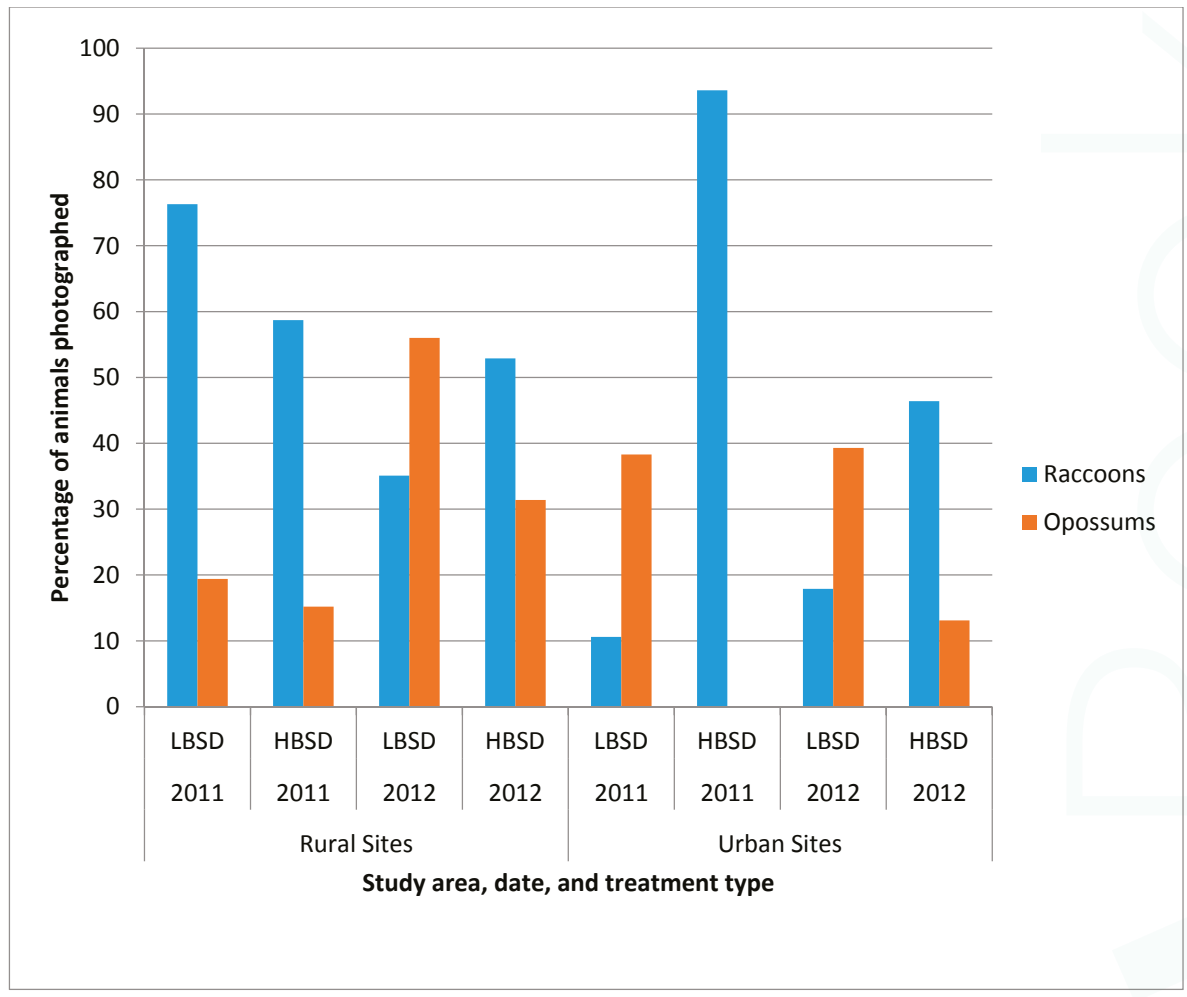

Figure 3. Comparison of raccoon and non-target opossum ratios in automatic camera images at LBSD and HBSD sites in rural and urban environments in Pasco and Pinellas Counties, Florida, during 2011-2012.

A total of 244 raccoons was trapped and sampled during 2011 and 2012; seven of these were removed from the results due to previous vaccination by injection during 2011. RVNA rates ranged from 6.3\% (urban LBSD 2012) to 53.8\% (rural HBSD 2012) (Table 1). The HBSD sites resulted in more elevated RVNA rates in 2012 (53.8\% and 51.6\%) than did the LBSD sites (44.4\% and 6.3\%). The 2012 rural and urban HBSD sites also had more elevated RVNA rates (53.8\% and 51.6\%) than both rural and urban HBSD in 2011 (35.1\% and 45.2\%). Tetracycline biomarker was present in more teeth collected from both rural and urban HBSD sites in 2012 (30.4\% and 33.3\%) than in both 2012 rural and urban LBSD sites (26.9\% and $0.0 \%$ ) (Table 1$)$. 
Trop. Med. Infect. Dis. 2017, 2, 41

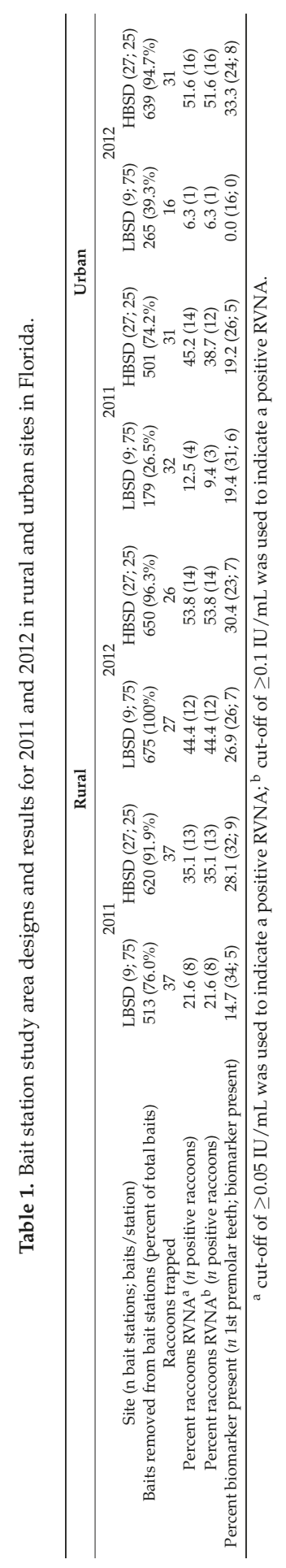


Bait removal from bait stations varied between sites and between years. The nine urban LBSD bait stations started each year with a total of 675 baits, and had only 179 baits removed (26.5\%) by the end of the 10-day study period in 2011 and 265 baits removed (39.3\%) in 2012 (Table 1). A greater percentage of baits were taken from bait stations in 2012 than 2011. Within the urban sites, a larger number of baits were taken from the bait stations in the HBSD site regardless of year. However, within the rural areas, one bait station in the HBSD site did not have any baits removed in 2012 while all the baits within the LBSD site were removed from the bait stations (Table 1).

RVNA rates were significantly higher ( $p=0.0054$ and 0.0031 , respectively) in urban HBSD sites in 2011 and 2012 using an RVNA cutoff of $\geq 0.05 \mathrm{IU} / \mathrm{mL}$, indicating a relationship with increased bait station density in urban areas. However, the rural sites did not differ (Table 2A). RVNA rates were significantly higher ( $p=0.0081$ and 0.0031 , respectively) in urban HBSD sites in 2011 and 2012 using an RVNA cutoff of $\geq 0.1 \mathrm{IU} / \mathrm{mL}$, indicating a relationship with increased bait station density in urban areas. However, the rural sites did not differ (Table 2B).

Table 2. Comparison of raccoon RVNA (at 75 baits $/ \mathrm{km}^{2}$ ) with deployment of LBSD versus HBSD in rural and urban environments in Florida, 2011-2012.

\begin{tabular}{ccc}
\hline County/Year & Percent RVNA $(n)$ & Fisher's Exact Test \\
\hline A. Showing results using RVNA cutoff of $\geq 0.05 \mathrm{IU} / \mathrm{mL}$ \\
Rural 2011 (LBSD vs. HBSD) & $21.6(37)$ vs. 35.1 (37) & $p=0.3024$ \\
Rural 2012 (LBSD vs. HBSD) & $44.4(27)$ vs. 53.8 (26) & $p=0.5867$ \\
Urban 2011 (LBSD vs. HBSD) & $12.5(32)$ vs. $45.2(31)$ & $p=0.0054$ \\
Urban 2012 (LBSD vs. HBSD) & $6.3(16)$ vs. 51.6 (31) & $p=0.0031$ \\
B. Showing results using RVNA cutoff of $\geq 0.1 \mathrm{IU} / \mathrm{mL}$ & \\
Rural 2011 (LBSD vs. HBSD) & $21.6(37)$ vs. 35.1 (37) & $p=0.3024$ \\
Rural 2012 (LBSD vs. HBSD) & $44.4(27)$ vs. 53.8 (26) & $p=0.5867$ \\
Urban 2011 (LBSD vs. HBSD) & $9.4(32)$ vs. 38.7 (31) & $p=0.0081$ \\
Urban 2012 (LBSD vs. HBSD) & $6.3(16)$ vs. 51.6 (31) & $p=0.0031$ \\
\hline
\end{tabular}

Tetracycline biomarker was higher in the urban HBSD site in $2012(p=0.0133$; Table 3). No significant differences were found between the rural sites or the 2011 urban sites.

Table 3. Comparison of raccoon tetracycline deposition (at 75 baits $/ \mathrm{km}^{2}$ ) with deployment of LBSD versus HBSD in rural and urban environments in Florida, 2011-2012.

\begin{tabular}{ccc}
\hline County/Year & Percent Tetracycline-Positive $(n)$ & Fisher's Exact Test Result \\
\hline Rural 2011 (LBSD vs. HBSD) & $14.7(34)$ vs. 28.1 (32) & $p=0.2344$ \\
Rural 2012 (LBSD vs. HBSD) & $26.9(26)$ vs. 30.4 (23) & $p=1.000$ \\
Urban 2011 (LBSD vs. HBSD) & $19.4(31)$ vs. 19.2 (26) & $p=1.000$ \\
Urban 2012 (LBSD vs. HBSD) & $0(16)$ vs. 33.3 (24) & $p=0.0133$ \\
\hline
\end{tabular}

\section{Discussion}

Achieving sufficient vaccine bait uptake among urban raccoons is critical. Limitations on aerial and vehicle-based (hand) bait distribution for safety and other reasons necessitate finding other bait distribution means and optimized strategies for achieving RVNA rabies management goals. Bait stations represent one potential tool for specific settings that may achieve management goals while reducing non-target bait loss and pet and human bait contact, mitigating many concerns from managers, cooperating agencies, and the public. Even though the bait stations were studied in May 2011 and February 2012, it was anticipated that these differences in times of year did not have any impact on the results. Though warmer temperatures may impact raccoon movements during the day, when looking at the total baits removed per year, it does not appear that time of year had any effect on the results of this study. It was believed that raccoon movement was sufficient to ensure that 
many raccoons came in contact with the baits in both years. The warmer temperatures during the 2011 trapping period may have been thought to negatively impact the capture rate, but capturing raccoons within the urban LBSD site in 2012 proved to be more difficult ( $n=16$; Table 1 ).

Bait removal from bait stations resulted in higher RVNA percentages in the urban HBSD sites, irrespective of RVNA cutoff level. The lack of uptake in the urban LBSD site $(<40 \%$ of baits removed in both 2011 and 2012 out of 675 baits) may be due to a perceived relatively low localized raccoon density at the time of this study, which can be evidenced from the relatively low percentage of raccoon photos in this area in 2011 and 2012 (Figure 3). A lack of travel corridors due to roads through the area, fenced and relatively barren yards, few park and recreational areas, and people and pet interference may also have had negative impacts on raccoon movements through this site. In contrast, the urban HBSD site (74.2\% and $94.7 \%$ of baits removed in 2011 and 2012, respectively, out of 675 baits) contained multiple parks, ideal tree cover, food resources, and habitats for raccoons, as well as a golf course and conservation areas with multiple fresh water ponds. Many of the house lots in this site contained several large trees as potential denning sites.

Domestic dogs (Canis familiaris) and cats (Felis catus) were both captured in photos only at the urban bait stations; however, none were documented taking a bait from the bait stations. Therefore they were not reported in the results. Since these animals did not take any baits and were not observed eating a bait that was on the ground, neither dogs nor cats were considered a non-target species for the bait.

Greater bait removal from the bait stations in 2012 than in 2011 may be due to identical bait station locations in both years, possibly resulting in bait stations being more easily found in the second year. Several authors [26-30] have documented learned behavior in raccoons-from traversing a maze after being shown the end, to pulling a lever for a reward after watching someone pull the same lever, to gaining access to garbage cans after lid modifications have been made. Female raccoons with young were documented in the 2011 photos. It is possible that those young returned the next year after learning the bait stations provided bait. A single bait station in the rural HBSD site had no baits taken, possibly due to the presence of acrobat ants (Crematogaster ashmeadi) that were observed covering the baits. These native fire ants potentially reduced the bait scent attractant to wildlife. Fire ants have been observed by multiple wildlife personnel throughout the southeastern U.S. covering bait in traps, as well as vaccine baits on the ground, thereby preventing raccoons and other animals access to the bait.

Two RVNA cutoff levels of $\geq 0.05 \mathrm{IU} / \mathrm{mL}$ (used by CDC [24]) and $\geq 0.1 \mathrm{IU} / \mathrm{mL}$ (suggested by Canadian and European counterparts) were examined. No comparable difference in the results was found when using the higher cutoff (Table 2). For this study, no justifiable reason was found to conclude that using $\geq 0.05 \mathrm{IU} / \mathrm{mL}$ as the cutoff was limiting or accounted for animals with false-elevated RVNA results. There remains much debate about the levels of rabies antibodies that confer resistance to rabies virus infection. No single cutoff level of RVNA is recognized as being invariably protective [31]. Repeated observations that small fractions of animals presenting detectable levels of antibody prior to challenge have shown the animals can still succumb to rabies infection, and conversely that some seronegative animals survive challenge [32,33]. While these discrepancies exist, Blanton et al. [33] did observe that no raccoon succumbed to rabies challenge after vaccination with $R A B O R A L{ }^{\circledR}$ V-RG, even with an RVNA level of $0.06 \mathrm{IU} / \mathrm{mL}$ at the time of challenge. This result indicates to us that a cutoff of $\geq 0.05 \mathrm{IU} / \mathrm{mL}$ for this study was sufficient.

Lower RVNA response in the urban LBSD site may be related to a lower population of raccoons (Figure 3) or a preponderance of private properties surrounded by fences and smaller lots than in the urban HBSD site. To set the bait stations on private property in the LBSD site, the bait stations were placed inside the fences, as requested by property owners. This placement may have reduced the opportunities for raccoons to find the baits. Bozek et al. [34] found raccoons in urban areas had smaller home ranges than those in rural areas. Raccoons in urban habitats have access to anthropogenic food sources and can thereby reduce their foraging distances and patterns. These human food sources may 
also explain why baits were left in the urban LBSD bait stations. By providing increased bait station density within yards without fences, raccoons likely had easier access to the bait stations in the urban HBSD site, resulting in more baits taken and a significantly higher RVNA response.

Tetracycline biomarker results and RVNA rates were not compared in this study for a few reasons. First, canine teeth and mandibular bone are superior tissues for tetracycline biomarking [20,22], but first premolar teeth were collected for this study as a less intrusive procedure, so that raccoons could be released after full recovery from sedation. Canine tooth sampling would have required euthanasia and eliminated the opportunity to obtain valuable biologic information in future field trials through recaptures. First premolar teeth continue to be the most acceptable, least intrusive sample to collect from live-trapped raccoons. Second, while not noted earlier in this study, unpunctured sachet packets were found at every bait station. The FMP coating was missing, presumably eaten by a raccoon or opossum. This would result in a positive biomarker in the tooth, but no positive RVNA response. Third, background sources could have contributed to tetracycline biomarking. The most likely background tetracycline sources may have included consumption of medicated feeds sometimes used for cattle production and nonspecific fluorescence that may be found naturally [35]. While all study sites had lower biomarker percentages than elevated RVNA percentages, the 2011 urban LBSD site had a higher percentage of biomarkers present than percentage of elevated RVNA. It is unsure why this could be, unless tetracycline is present in the environment or the raccoons were avoiding the vaccine sachet and strictly eating the FMP coating. The sites with higher percentages of elevated RVNA than percentage of tetracycline biomarker may suggest a natural response to rabies in the area, poor tetracycline uptake in the first premolar tooth samples, or, as could be the case in 2012, trapping 'missed' animals from 2011 that ingested the vaccine. Additionally, the easier locating of bait stations by the animals, as evidenced by the increased number of baits removed from the bait stations in 2012, could have resulted in the higher percentages of elevated RVNA (Table 1).

The findings from this study support a higher bait station distribution density, to provide greater access to raccoons in urban settings to achieve higher RVNA to meet raccoon rabies management goals. However, additional well-designed studies are required to better understand optimized bait station density and distribution to achieve raccoon rabies elimination in the urban environments that form the mosaic of landscapes on which raccoon rabies occurs.

Acknowledgments: The authors would like to thank the Southwest Florida Water Management District for access to Starkey Wilderness Preserve, the Pinellas and Pasco County Animal Services for assisting with carcass disposal when needed, CDC for running RFFIT on the serum samples, and Matson's Laboratory for testing teeth for tetracycline biomarker. We also thank Florida Wildlife Services for their collaboration on this study.

Author Contributions: Dennis Slate and Tim Algeo conceived and designed the experiment; Betsy Haley performed the experiment; Tim Algeo and Ashlee Martin analyzed the data; Richard Chipman, Robert Edwin Hartin and Anthony Duffiney contributed materials; Betsy Haley, Tim Algeo, Richard Chipman, Ashlee Martin, Dennis Slate, Kathleen Nelson, and Brian Bjorklund collaboratively wrote and/or reviewed multiple drafts and substantially contributed to this manuscript.

Conflicts of Interest: Richard Chipman is the current National Rabies Management Coordinator for the USDA, APHIS, Wildlife Services program and Dennis Slate is the former National Rabies Management Coordinator and both indirectly provided discretionary Federal funding to support field work and the writing of the manuscript.

\section{References}

1. Hampson, K.; Coudeville, L.; Lembo, T.; Sambo, M.; Kieffer, A.; Attlan, M.; Barrat, J.; Blanton, J.D.; Briggs, D.J.; Cleaveland, S.; et al. Estimating the global burden of endemic canine rabies. PLoS Negl. Trop. Dis. 2015, 9, $1-20$.

2. Centers for Disease Control and Prevention. Cost of rabies prevention. http://www.cdc.gov/rabies/ location/usa/cost.html (accessed on 16 June 2017).

3. Slate, D.; Algeo, T.P.; Nelson, K.M.; Chipman, R.B.; Donovan, D.; Blanton, J.D.; Niezgoda, M.; Rupprecht, C.E. Oral rabies vaccination in North America: Opportunities, complexities, and challenges. PLoS Neglect. Trop. Dis. 2009, 3, e549. [CrossRef] [PubMed] 
4. Blancou, J. The control of rabies in Eurasia: Overview, history and background. Dev. Biol. 2008, 131, 3-15.

5. Wandeler, A.I. The rabies situation in western Europe. Dev. Biol. 2008, 131, 19-25.

6. MacInnes, C.D.; Smith, S.M.; Tinline, R.R.; Ayers, N.R.; Bachmann, P.; Ball, D.G.; Calder, L.A.; Crosgrey, S.J.; Fielding, C.; Hauschildt, P.; et al. Elimination of rabies from red foxes in eastern Ontario. J. Wildl. Dis. 2001, 37, 119-132. [CrossRef] [PubMed]

7. Rosatte, R.C.; Power, M.J.; Donovan, D.; Davies, J.C.; Allan, M.; Bachmann, P.; Stevenson, B.; Wandeler, A.; Muldoon, F. Elimination of arctic variant rabies in red foxes, metropolitan Toronto. Emerg. Infect. Dis. 2007, 13, 25-27. [CrossRef] [PubMed]

8. Rosatte, R.C.; Donovan, D.; Allan, M.; Bruce, L.; Buchanan, T.; Sobey, K.; Stevenson, B.; Gibson, M.; MacDonald, T.; Whalen, M.; et al. The control of raccoon rabies in Ontario, Canada: Proactive and reactive tactics, 1994-2007. J. Wildl. Dis. 2009, 45, 772-784. [CrossRef] [PubMed]

9. Fearneyhough, M.G.; Wilson, P.J.; Clark, K.A.; Smith, D.R.; Johnston, D.H.; Hicks, B.N.; Moore, G.M. Results of an oral rabies vaccination program for coyotes. J. Am. Vet. Med. Assoc. 1998, 212, 498-502. [PubMed]

10. Velasco-Villa, A.; Reeder, S.A.; Orciari, L.A.; Yager, P.A.; Franka, R.; Blanton, J.D.; Zuckero, L.; Hunt, P.; Oertli, E.H.; Robinson, L.E.; et al. Enzootic rabies elimination from dogs and reemergence in wild terrestrial carnivores, United States. Emerg. Infect. Dis. 2008, 14, 1849-1854. [CrossRef] [PubMed]

11. Sidwa, T.J.; Wilson, P.J.; Moore, G.M.; Oertli, E.H.; Hicks, B.N.; Rohde, R.E.; Johnston, D.H. Evaluation of oral rabies vaccination programs for control of rabies epizootics in coyotes and gray foxes: 1995-2003. J. Am. Vet. Med. Assoc. 2005, 227, 785-792. [CrossRef] [PubMed]

12. Randa, L.A.; Yunger, J.A. Carnivore occurrence along an urban-rural gradient: A landscape-level analysis. J. Mammal. 2006, 87, 1154-1164. [CrossRef]

13. Boulanger, J.R.; Bigler, L.L.; Curtis, P.D.; Lein, D.H.; Arthur, J. A polyvinyl chloride bait station for dispensing rabies vaccine to raccoons in suburban landscapes. Wildl. Soc. Bull. 2006, 34, 1206-1211. [CrossRef]

14. Algeo, T.P.; Chipman, R.B.; Bjorklund, B.M.; Chandler, M.D.; Wang, X.; Slate, D.; Rupprecht, C.E. Anatomy of the Cape Cod oral rabies vaccination program. In Proceedings of the 23rd Vertebrate Pest Conference, San Diego, CA, USA, 17-20 March 2008; Timm, R.M., Madon, M.B., Eds.; University of California: Davis, CA, USA, 2008; pp. 264-269.

15. Manzo, A.; Theimer, T.; Delph, R.; Hall, J.; Hernandez, N.; Holt, B.; Maloney, M.; Moreno, M.; Bergman, D.; Heuser, C. A preliminary field trial of bait stations for the delivery of oral rabies vaccines: can varying diameter exclude non-target species? In Proceedings of the 22nd Vertebrate Pest Conference, Berkeley, CA, USA, 6-9 March 2006; Timm, R.M., O’Brien, J.M., Eds.; University of California: Davis, CA, USA, 2006; pp. 351-353.

16. Smyser, T.J.; Redding, J.V., Jr.; RBevis, C.M.; Page, L.K.; Swihart, R.K. Development of an automated dispenser for the delivery of medicinal or vaccine-laden baits to raccoons (Procyon lotor). J. Wildl. Dis. 2015, 51, 513-518. [CrossRef] [PubMed]

17. Smyser, T.J.; Beasley, J.C.; Olson, Z.H.; Rhodes, O.E., Jr. Use of rhodamine B to reveal patterns of interspecific competition and bait acceptance in raccoons. J. Wildl. Manag. 2010, 74, 1405-1416. [CrossRef]

18. Olson, C.A.; Mitchell, K.D.; Werner, P.A. Bait ingestion by free-ranging raccoons and nontarget species in an oral rabies vaccine field trial in Florida. J. Wildl. Dis. 2000, 36, 734-743. [CrossRef] [PubMed]

19. Data for St. Petersburg, FL. https://www.opendatanetwork.com/entity/1600000US1263000/St_Petersburg FL/demographics.population.count?year=2011 (accessed on 1 July 2017).

20. Algeo, T.P.; Norhenberg, G.; Hale, R.; Montoney, A.; Chipman, R.B.; Slate, D. Oral rabies vaccination variation in tetracycline biomarking among Ohio raccoons. J. Wildl. Dis. 2013, 49, 332-337. [CrossRef] [PubMed]

21. Slate, D.; Chipman, R.B.; Algeo, T.P.; Mills, S.A.; Nelson, K.M.; Croson, C.K.; Dubovi, E.J.; Vercauteren, K.; Renshaw, R.W.; Atwood, T.; et al. Safety and immunogenicity of Ontario rabies vaccine bait (ONRAB) in the first US field trial in raccoons (Procyon lotor). J. Wildl. Dis. 2014, 50, 1-16. [CrossRef] [PubMed]

22. Linhart, S.B.; Kennelly, J.J. Fluorescent bone labeling of coyotes with demethylchlortetracycline. J. Wildl. Manage. 1967, 31, 317-321. [CrossRef]

23. Smith, J.S.; Yager, P.A.; Baer, G.M. A rapid fluorescent focus inhibition test (RFFIT) for determining rabies virus-neutralizing antibody. In Laboratory Techniques in Rabies; Meslin, F.X., Kaplan, M.M., Koprowski, H., Eds.; World Health Organization: Geneva, Switzerland, 1996; pp. 181-190.

24. CDC. Rabies serology. http://www.cdc.gov/rabies/specific_groups/doctors/serology.html (accessed on 1 August 2017). 
25. GraphPad Software. GraphPad QuickCalcs: La Jolla, CA, USA, 2017.

26. Cole, L.W. Concerning the intelligence of raccoons. J. Comp. Neurol. Psychol. 1907, 17, 211-261. [CrossRef]

27. Cole, L.W. The Chicago experiments with raccoons. J. Anim. Behav. 1915, 5, 158-173. [CrossRef]

28. Davis, H.B. The raccoons: A study of animal intelligence. Am. J. Psychol. 1907, 18, 447-489. [CrossRef]

29. Hunter, W.S. The Delayed Reaction in Animals and Children; H. Holt \& Company: New York, NY, USA, 1913.

30. Pettt, M. The problem of raccoon intelligence in behaviourist America. Br. J. Hist. Sci. 2010, 43, 391-421. [CrossRef]

31. Moore, S.M.; Hanlon, C.A. Rabies-specific antibodies: Measuring surrogates of protection against a fatal disease. PLoS Negl. Trop. Dis. 2010, 4, e595. [CrossRef] [PubMed]

32. Sikes, R.K.; Peacock, G.V.; Acha, P.; Arko, R.J.; Dierks, R. Rabies vaccines: Duration-of-immunity study in dogs. J. Am. Vet. Med. Assoc. 1971, 159, 1491-1499. [CrossRef] [PubMed]

33. Blanton, J.D.; Self, J.; Niezgoda, M.; Faber, M.-L.; Dietzschold, B.; Rupprecht, C. Oral vaccination of raccoons (Procyon lotor) with genetically modified rabies virus vaccines. Vaccine 2007, 25, 7296-7300. [CrossRef] [PubMed]

34. Bozek, C.K.; Prange, S.; Gehrt, S.D. The influence of anthropogenic resources on multi-scale habitat selection by raccoons. Urban Ecosyst. 2007, 10, 413-425. [CrossRef]

35. Chopra, I.; Roberts, M. Tetracycline antibiotics: mode of action, applications, molecular biology, and epidemiology of bacterial resistance. Microbiol. Mol. Biol. Rev. 2001, 65, 232-260. [CrossRef] [PubMed]

(C) 2017 by the authors. Licensee MDPI, Basel, Switzerland. This article is an open access article distributed under the terms and conditions of the Creative Commons Attribution (CC BY) license (http:/ / creativecommons.org/licenses/by/4.0/). 
Article

\title{
Cost and Relative Value of Road Kill Surveys for Enhanced Rabies Surveillance in Raccoon Rabies Management
}

\author{
Dennis Slate ${ }^{1}$, Jordona D. Kirby ${ }^{1}$, Daniel P. Morgan ${ }^{2}$, Timothy P. Algeo ${ }^{1, *}$, \\ Charles V. Trimarchi ${ }^{3}$, Kathleen M. Nelson ${ }^{1}$, Robert J. Rudd ${ }^{4}$, Adam R. Randall ${ }^{5}$, \\ Mark S. Carrara ${ }^{6}$ and Richard B. Chipman ${ }^{1}$
}

1 National Rabies Management Program, Wildlife Services, Animal and Plant Health Inspection Service, United States Department of Agriculture, 59 Chenell Drive, Suite 2, Concord, NH 03301, USA; Dennis.Slate@aphis.usda.gov (D.S.); jordona.d.kirby@aphis.usda.gov (J.D.K.); kathleen.m.nelson@aphis.usda.gov (K.M.N.); richard.b.chipman@aphis.usda.gov (R.B.C.)

2 New York Program, Wildlife Services, Animal and Plant Health Inspection Service, United States Department of Agriculture, 230 Timerman Hall, SUNY Potsdam, Potsdam, NY 13676, USA; dan.p.morgan@aphis.usda.gov

3 Laboratory of Zoonotic Disease and Clinical Virology, Griffin Laboratory, Wadsworth Center, New York State Department of Health, 61 Mordella Road, Albany, NY 12205, USA; chucktrimarchi@yahoo.com

4 Rabies Laboratory, Griffin Laboratory, Wadsworth Center, New York State Department of Health, 5668 State Farm Rd., Slingerlands, NY 12159, USA; robert.rudd@health.ny.gov

5 New Jersey Program, Wildlife Services, Animal and Plant Health Inspection Service, United States Department of Agriculture, Pittstown, NJ 08867, USA; adam.r.randall@aphis.usda.gov

6 Forest Service, United States Department of Agriculture, Cedar City, UT 84721, USA; mcarrara@fs.fed.us

* Correspondence: Timothy.P.Algeo@aphis.usda.gov; Tel: +1-603-520-8946

Academic Editors: Charles Rupprecht and Bernhard Dietzschold Received: 7 March 2017; Accepted: 10 May 2017; Published: 23 May 2017

\begin{abstract}
Oral rabies vaccination (ORV) requires knowledge of the spatial-temporal distribution of rabies virus variants targeted for control. Rabies-exposure based public health surveillance alone may not provide a sound basis for ORV decisions. The value and cost of road kill surveys was evaluated for the late spring-early fall 2005-2007 as a part of enhanced rabies surveillance in northern New York, where raccoon rabies is enzootic and ORV has occurred since the late 1990s. Structured surveys were conducted to collect raccoons and other meso-carnivores for rabies testing at the New York State Rabies Laboratory. Of the 209 meso-carnivore heads collected and submitted for testing, 175 were testable by direct fluorescent antibody; none was rabid. Rabies was also not reported through public health surveillance in survey zones during 2005-2007. Overall, survey costs were $\$ 37,118$ (2016 USD). Salaries and benefits accounted for $61 \%$ of costs, followed by fuel (22\%), vehicle depreciation ( $14 \%$ ), and sample shipping ( $3 \%$ ). Mean daily distance driven was $303 \pm 37 \mathrm{~km}$ and $381 \pm 28 \mathrm{~km}$ for total road kills and raccoons, respectively. Costs $/$ road kill collected and submitted was $\$ 176 /$ all species and $\$ 224 /$ raccoon. This study provides costs for planning road kill surveys and underscores the need to continually improve enhanced rabies surveillance approaches to support ORV decision making.
\end{abstract}

Keywords: raccoon; skunk; rabies; enhanced rabies surveillance; road kill; oral rabies vaccination (ORV); meso-carnivores

\section{Introduction}

Rabies surveillance is characterized as being active or passive [1]. Much of the rabies surveillance in the U.S. is based on exposure events brought to the attention of public health officials [2]. 
While effective in protecting the public from rabies, passive surveillance is inadequate to delineate the spatial-temporal distribution of rabies in meso-carnivore reservoirs such as the raccoon (Procyon lotor) in near real time [3].

Enhanced rabies surveillance is characterized as a form of surveillance with special emphasis on specific areas, species, and rabies management goals [4]. Since 2005, enhanced rabies surveillance has been extensively used in proximity to oral rabies vaccination (ORV) zones in the USA to increase sampling scope and intensity to delineate rabies distribution among wildlife rabies reservoir species for improved management.

Enhanced rabies surveillance serves as a complement to exposure-based public health surveillance, and collectively this information provides a more comprehensive spatial-temporal view of rabies for strategic ORV decisions to achieve rabies management goals in the U.S. Enhanced rabies surveillance targets a range of sample sources within or near $(\leq 80 \mathrm{~km})$ ORV zones, without a known human or domestic animal exposure history.

Sampling scope includes:

1. Animals exhibiting unusual behaviors suggestive of rabies brought to the attention of U.S. Department of Agriculture (USDA), Animal and Plant Health Inspection Service (APHIS), Wildlife Services (WS), or collected by program cooperators; these typically have the highest rabies prevalence among animals not involved in human or domestic animal exposure events;

2. Animals found dead (other than road kills);

3. Road kills from formal or opportunistic surveys;

4. Animals WS trapped and euthanized or shot in specified raccoon rabies risk areas, often where recent cases warrant sampling;

5. Animals captured by Nuisance Wildlife Control Operators (NWCOs) or others near ORV zones $[4,5]$.

Road kill surveys have been conducted for a variety of wildlife management purposes, such as indexing population trends and abundance [6-9]; wildlife disease monitoring [10]; and characterization of population genomics [11]. We assessed the relative value of structured road kill surveys as a complement to public health surveillance to determine the presence or absence of raccoon rabies variant in raccoons and other meso-carnivore species into which spillover of this rabies virus variant occurs [12] (striped skunk (Mephitis mephitis), red fox (Vulpes vulpes), gray fox (Urocyon cinereoargenteus), coyote (Canis latrans), and fisher (Martes pennanti)) in northern New York. ORV had been conducted since 2001 (USDA, APHIS, Wildlife Services 2001) throughout much of the area where road kill surveys were conducted. These surveys were evaluated in the context of the cost of samples acquired and their contribution to rabies surveillance in the areas surveyed.

\section{Materials and Methods}

From 2005 to 2007, formal road kill surveys were initiated within or near ORV zones in northern New York (Figures 1-3). Differences in routes among years were necessary in response to staffing availability. The same two personnel conducted nearly all the road kill surveys from 2005 to 2007. All personnel who participated in the road kill surveys received the recommended rabies pre-exposure vaccine series prior to conducting surveys.

Personnel were trained so that activities were uniformly conducted in a coordinated fashion, although there was not a strict protocol for speed driven by highway type or road-scanning breadth, as these may vary for safety, road shoulder width, and roadside mowing activities. Surveys were conducted in full-sized pickup trucks, which provided an improved road/road shoulder view over lower-framed vehicles.

Survey routes were driven from 6:00 am until approximately noon. State, County, and Municipal highway officials were contacted to inform them of the road kill survey times. Species subject to collection included: raccoon, skunk, foxes (red and gray), coyote, and fisher. 


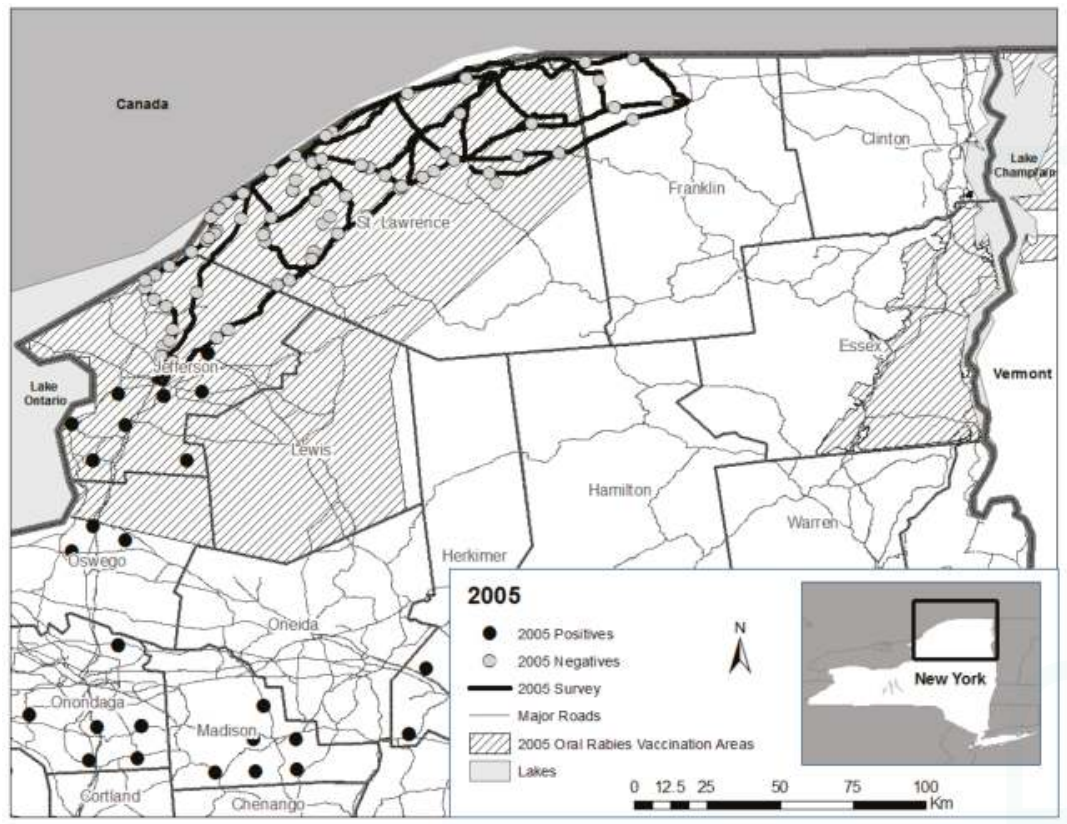

Figure 1. Rabies negative road kills collected during surveys (27 June-21 September) in Jefferson, St. Lawrence, and Franklin counties in 2005 relative to the oral rabies vaccination zone and public health positive cases.

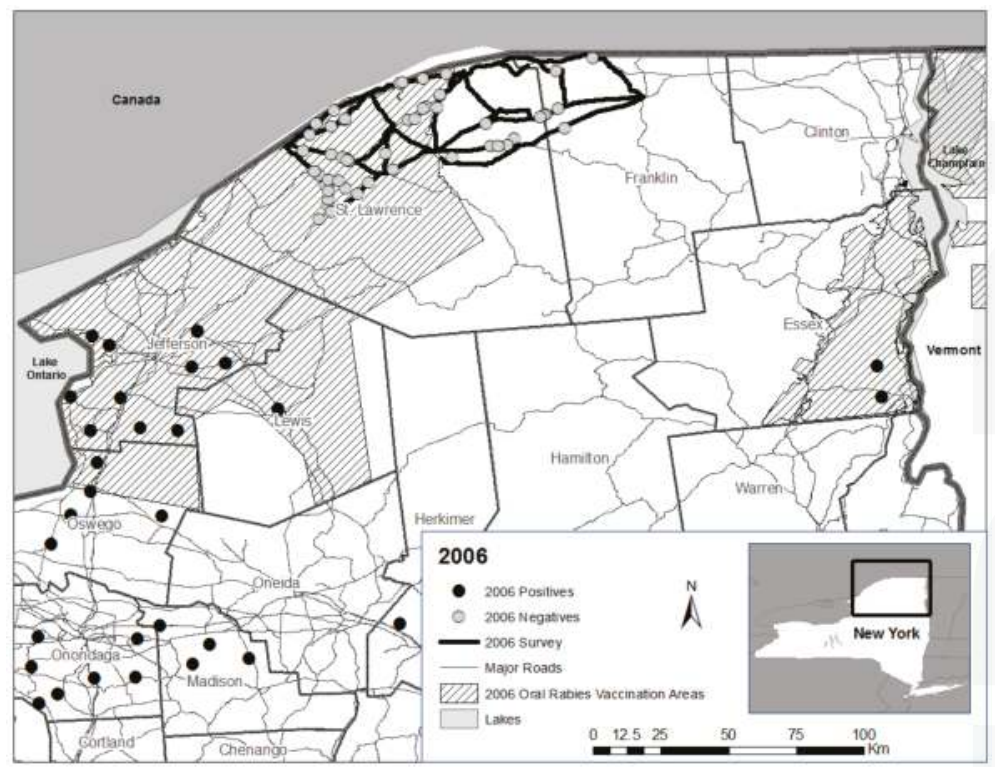

Figure 2. Rabies negative road kills collected during surveys (5 June-17 August) in St. Lawrence and Franklin counties in 2006 relative to the oral rabies vaccination zone and public health positive cases. 


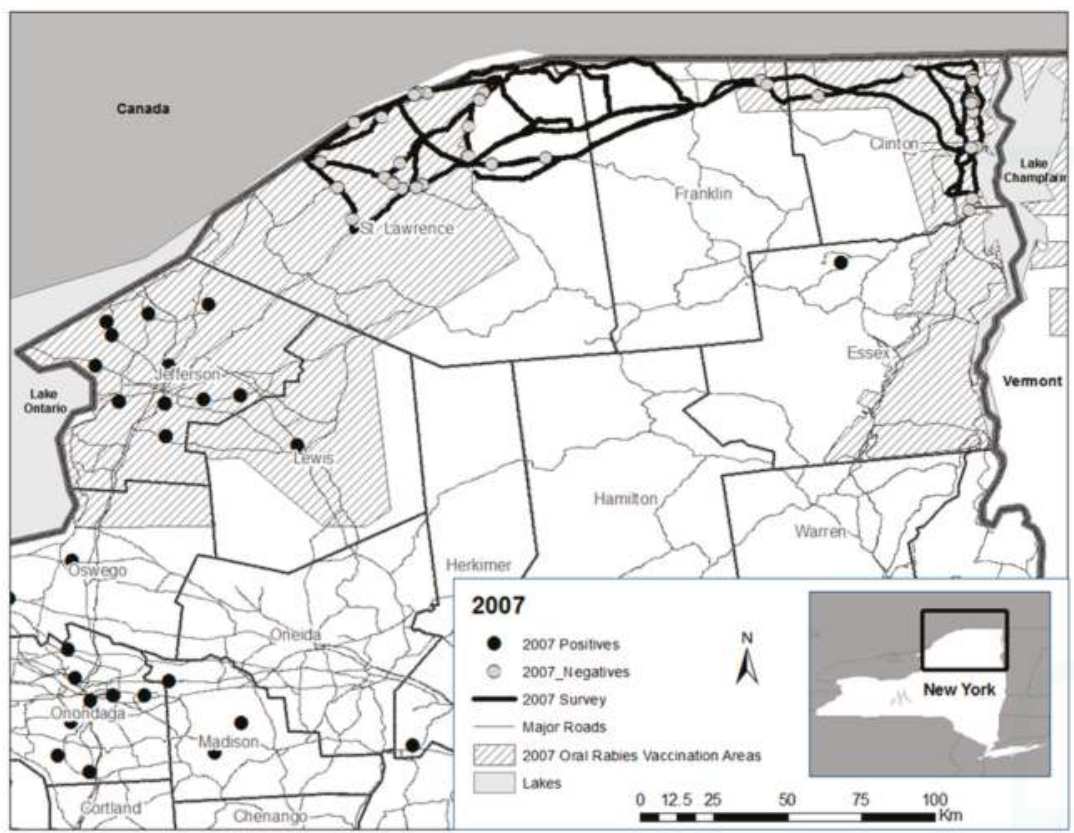

Figure 3. Rabies negative road kills collected during surveys (25 June-27 July) in St. Lawrence, Franklin, and Clinton counties in 2007 relative to the oral rabies vaccination zone and public health positive cases.

In 2005, specified routes were surveyed four days/week for 10 weeks from 27 June to 21 September (Figure 1). For staffing efficiency, the road kill survey area was divided into approximately equal east and west zones. The western zone was bordered on the west by U.S. Interstate 81 from Watertown (Jefferson County) to the St. Lawrence River, and State Route 812 between Ogdensburg and the intersection of State Route 11 near DeKalb on the east. The eastern zone included major roads (State Routes 37 and 11B) from this point East to Malone, which encompassed portions of St. Lawrence and Franklin Counties where ORV had not occurred (Figure 4). Both areas were further divided so that half of each area was sampled two days/week with minor exceptions, by two personnel (Tuesday and Thursday; and Wednesday and Friday).

In 2006, the portion of the road kill survey zone in Jefferson and southwestern St. Lawrence Counties was discontinued, reducing the zone that was sampled in 2005 by about half. The new 2006 zone was then divided approximately in half. However, unlike in 2005, each half was not further sub-divided and the entire zone was surveyed four days/week by two personnel with minor exceptions from 5 June to 17 August (Figure 2).

In 2007, the 2006 road kill survey zone was extended to include portions of eastern Clinton County, with State Routes 190 and 11 surveyed for road kills traveling to and from Franklin into Clinton County, and U.S. Interstate 87 and State Routes 9 and 22 making up much of the road matrix surveyed in the northern Lake Champlain Valley (Figure 3). Due to staffing demands, road kill surveys were conducted four days/week by two personnel during the period 25 June-27 July-a five, rather than a 10-week survey.

During sample collection, personnel wore appropriate personal protective equipment including nitrile gloves, hard hats, and safety vests for compliance with permits issued by the New York State Department of Transportation. When road kill carcasses were observed, personnel quickly and safely parked alongside the roadway to retrieve the carcass. Once personnel moved to a safe location, 
each carcass was inspected to determine if a viable sample could be collected and submitted for testing. For carcasses deemed viable, GPS coordinates were recorded for the road kill location, unique numbered ear tags were attached, and the whole head was removed at the base of the neck using heavy duty brush loppers. Samples were frozen until shipping.

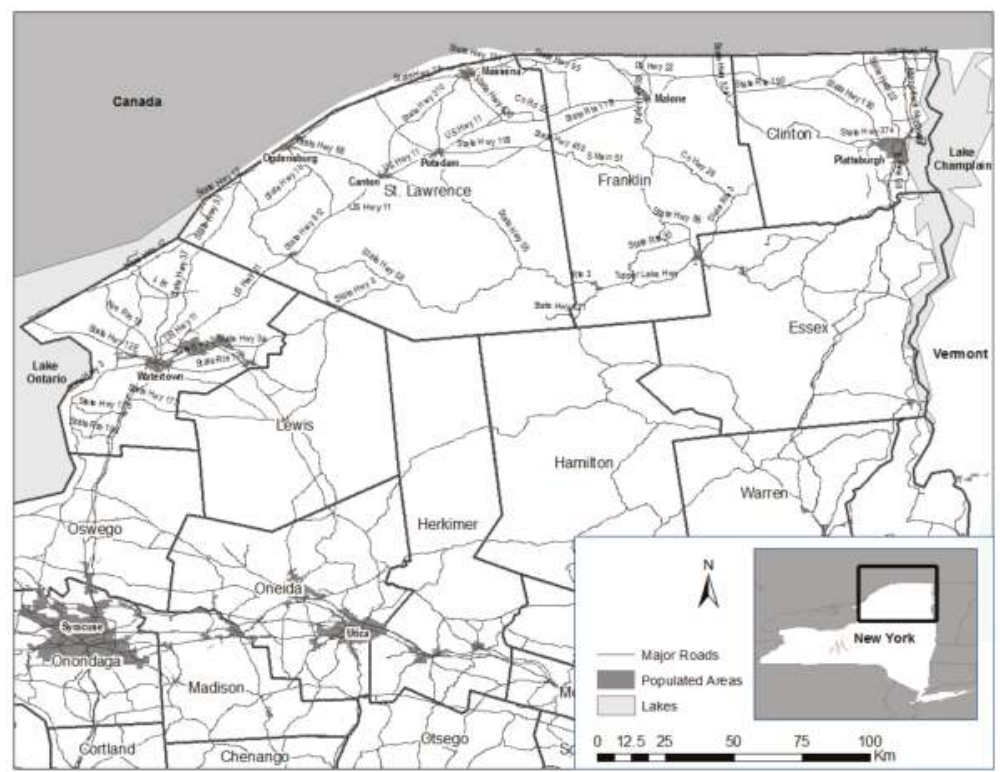

Figure 4. Reference map for counties, villages and cities, and routes that occurred within road kill survey areas, New York.

Samples were prepared and packaged for shipment to the New York State Department of Health (NYSDOH) Rabies Laboratory at Wadsworth Center, New York on Monday of each week. Intact head samples were wrapped in newspaper and double-bagged (resealable plastic bags) separately with specimen labels containing the sample ear tag numbers. Multiple intact head specimens were included in each shipment in double-walled, insulated containers, in accordance with the UN-3373 Biological Specimen Category regulations. The following data were entered into the WS National Rabies Management Program (NRMP) database: date and GPS coordinates of sample collection; species; sex; relative age (juvenile or adult); and reproductive status.

Samples were categorized for data analysis as detected, submitted, and tested. Samples detected represented species of interest found on survey routes that often included animals deemed not suitable to be submitted for testing. Submitted samples included those that field personnel collected and determined to be candidates for rabies testing. NYSDOH Rabies Laboratory personnel made the final determination if submitted samples were suitable to be tested for rabies. The direct fluorescent antibody (dFA) test was used to determine the rabies status of road kills [13]. In 2005, road kills detected but considered unsuitable for rabies testing by WS staff were not recorded. All three categories were recorded in 2006 and 2007.

Direct or estimated costs for four major components of road kill surveys included staff salary and benefits [14], fuel costs [15], vehicle depreciation, and sample shipment costs adjusted to 2016 U.S. dollars.

Statistical Analysis System (SAS) 9.3 (SAS Institute, Cary, NC, USA) statistical software was used for analyses [16]. 


\section{Results}

Six meso-carnivore species were observed during road kill surveys in the St. Lawrence River Valley (Jefferson and St. Lawrence Counties), in northern Franklin County, and the northern Lake Champlain Valley (Clinton County) along the U.S.-Canada border from 2005 to 2007. Raccoons were most frequently detected $(n=320)$, followed by striped skunks $(n=136)$, and red foxes $(n=13)$ (Table 1). These were the only species that were submitted for rabies testing in all three years. Two gray foxes were detected and submitted during 2006 that were deemed not suitable for testing by the NYSDOH. A single fisher was submitted and tested negative in 2007, but was excluded from statistical analysis because of low sample size. None of the 140 raccoons, 26 skunks, 8 red foxes, and 1 fisher $(n=175)$ tested over the survey period was rabid by dFA.

Table 1. Summary of road kill samples detected, submitted, and tested for rabies from road kill surveys conducted in northern New York during late spring-early fall 2005-2007.

\begin{tabular}{cccccccccc}
\hline Year $\mathbf{1 , 2}^{\mathbf{2}} \mathbf{2 0 0 \mathbf { 5 } ^ { \mathbf { 3 } }}$ & \multicolumn{3}{c}{$\mathbf{2 0 0 6}$} & \multicolumn{3}{c}{$\mathbf{2 0 0 7}$} \\
\hline Species & Detect & Submit & Test & Detect & Submit & Test & Detect & Submit & Test \\
Raccoon & 62 & 62 & 196 & 59 & 50 & 124 & 45 & 28 \\
Striped Skunk & 12 & 12 & 90 & 8 & 7 & 46 & 12 & 7 \\
Red Fox & 6 & 6 & 8 & 1 & 1 & 5 & 1 & 1 \\
Gray Fox & 0 & 0 & 2 & 2 & 0 & 0 & 0 & 0 \\
Coyote & 0 & 0 & 1 & 0 & 0 & 1 & 0 & 0 \\
Fisher & 0 & 0 & 0 & 0 & 0 & 1 & 1 & 1 \\
Total & 80 & 80 & 297 & 70 & 58 & 177 & 59 & 37 \\
\hline
\end{tabular}

1 Some of the road kill areas varied among years. ${ }^{2}$ Survey dates were: 27 June 2005-21 September 2005; 5 June 2006-17 August 2006; 25 June 2007-27 July 2007. ${ }^{3}$ Road kill samples detected that were unsuitable to be submitted to the rabies laboratory were not recorded in 2005 only; all samples submitted in 2005 were tested for rabies by direct fluorescent antibody (dFA).

In 2006 and 2007, 297 and 177 total road kills were detected, and 70 (24\%) and 59 (33\%) were deemed suitable to be submitted, with $58(83 \%)$ and $37(63 \%)$ tested, respectively. Raccoons accounted for most of the detected road kills in 2006 and 2007 at 196 (66\%) and 124 (70\%), respectively; 59 (30\%) and $45(36 \%)$ of detected raccoons were submitted for testing, with $50(85 \%)$ and $28(62 \%)$ of submitted raccoons tested, respectively. In 2005, road kills detected and deemed not suitable for testing were not recorded, but all 80 samples submitted were tested for rabies.

The raccoon was the only species that occurred in all weekly samples from 2005 to 2007 (Figure 5a-c); the striped skunk occurred in an average of 73\% of weekly samples during 2005-2007. Skunk representation among road kills was not different $(p=0.03)$ among the survey years relative to raccoons and averaged $19 \%$ of road kill raccoon submitted for testing annually.

On average, $19 \%$ of survey days resulted in collection of no road kills to be submitted for testing, ranging from $14 \%(n=3 / 22)$ in 2007 to $22 \%(n=9 / 41)$ in 2005 and 2006 . No road-killed raccoons were collected for submission an average of $27 \%$ of survey days, ranging from $23 \%(n=5 / 22)$ in 2007 to $32 \%$ $(n=13 / 41)$ in 2005. No road-killed skunks were collected for submission an average of $74 \%$ survey days, ranging from $68 \%(n=15 / 22)$ in 2007 to $81 \%(n=33 / 41)$ in 2006 (Figure 6a-c).

On average, $35 \%$ of survey days resulted in collection of one road kill that was submitted for testing, ranging from 32\% in 2005 and 2006 to 41\% in 2007. One road-killed raccoon was collected and submitted for testing an average of 36\% of survey days, ranging from 34\% $(n=14 / 41)$ in both 2005 and 2006 to $41 \%(n=9 / 22)$ in 2007. One road-killed skunk was collected and submitted an average $22 \%$ of survey days, ranging from $15 \%(n=6 / 41)$ in 2006 to $27 \%(n=6 / 22)$ in 2007 . Seven total road kills were collected for submission on single days in 2005 and 2007, which also included either red foxes or a fisher. The highest number of raccoons collected/day to be submitted for testing was six, which occurred on two days in 2005 (Figure 6a). 
The mean daily $\mathrm{km}$ driven/raccoon collected for submission from 2005 to 2007 was $381 \pm 28$ (SD) for raccoons, $2099 \pm 845$ (SD) for skunks, and $303 \pm 37$ (SD) for total road kills. On the average, there was greater than a 5-fold increase in driving distance to collect a skunk to be submitted for rabies testing in comparison to a raccoon. A mean of 1.5 (range 0-6) raccoons was collected/day in all years; road-killed skunks collected/day averaged 0.4, 0.2, and 0.6 (range 0-2) in 2005, 2006, and 2007, respectively.

\section{Raccoon, Skunk, and Red Fox Samples \\ Submitted/Week 2005}

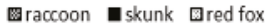

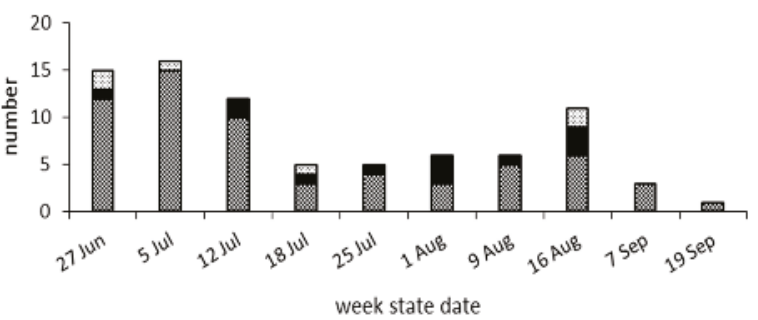

(a)

Raccoon, Skunk, and Red Fox Samples

Submitted/Week 2006

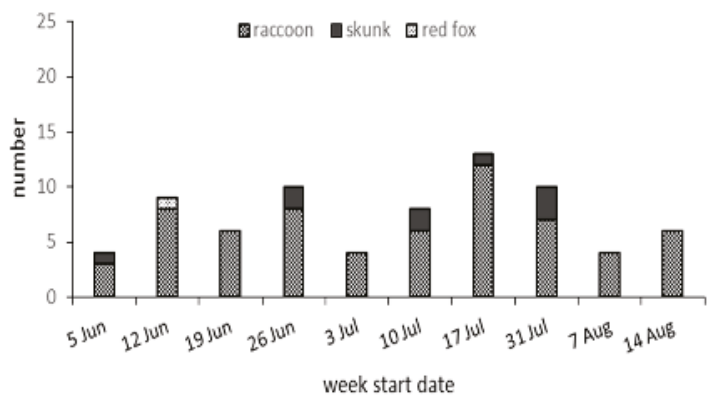

(b)

Raccoon, Skunk, and Red Fox Samples Submitted/Week 2007

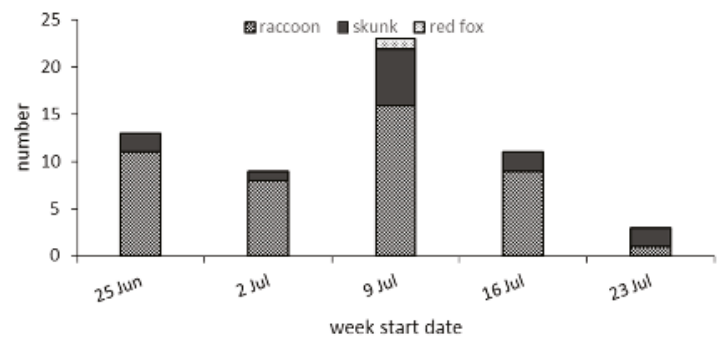

(c)

Figure 5. Number of raccoons, striped skunks, and red foxes submitted weekly for potential rabies diagnostics to the New York State Rabies Laboratory at Wadsworth Center, Albany, New York from road kill surveys in (a) 2005, (b) 2006 and (c) 2007. 
Days Road Kills Collected for Submission 2005

\raccoon skunk $\mathbf{m}$ total

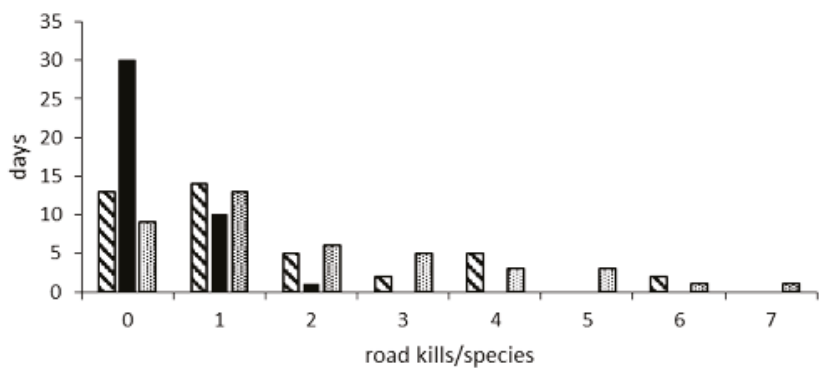

(a)

Days Road Kills Collected for Submission 2006

Draccoon - skunk iototal

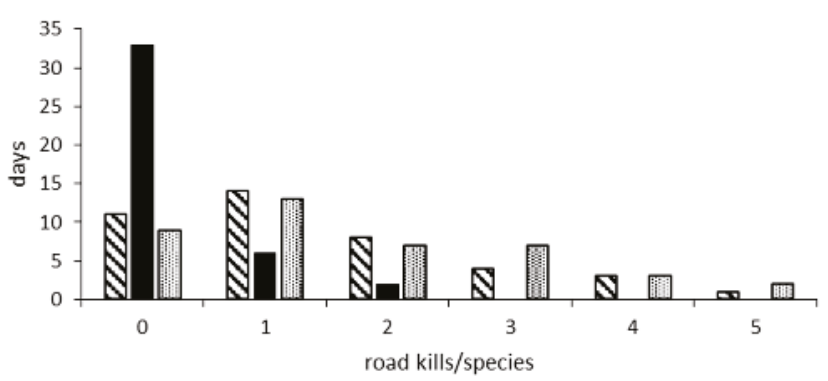

(b)

Days Road Kills Collected for Submission 2007

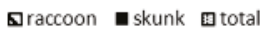

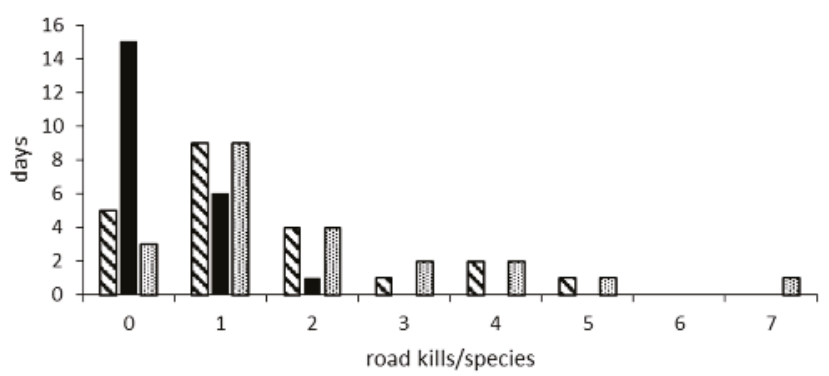

(c)

Figure 6. Frequency of days where raccoon, skunk, and total road kills collected for submission ranged from 0 to 7 (total may include red or gray fox, coyote, or fisher) in (a) 2005, (b) 2006 and (c) 2007.

Simple linear regression revealed a significant $(p<0.02)$ positive relationship between weekly $\mathrm{km}$ driven and road kills collected in 2005 only. Weekly km driven accounted for about half of the variation $\left(r^{2}=0.52\right)$ in the dependent response weekly road kills that were collected and submitted for testing. 
Weekly surveys resulted in increasing samples of juvenile raccoons during July, when young often begin traveling more extensively in family groups at north temperate latitudes [17] (Figure 7a-c). There was no difference $(p=0.82)$ in sex and relative age among road-killed raccoons within and across survey years. While there were more adult females and juveniles collected and tested in all survey years, there was not a significant association $(p=0.48)$ when juveniles were pooled with adult females in comparison to adult males.

2005 Road Kill New York

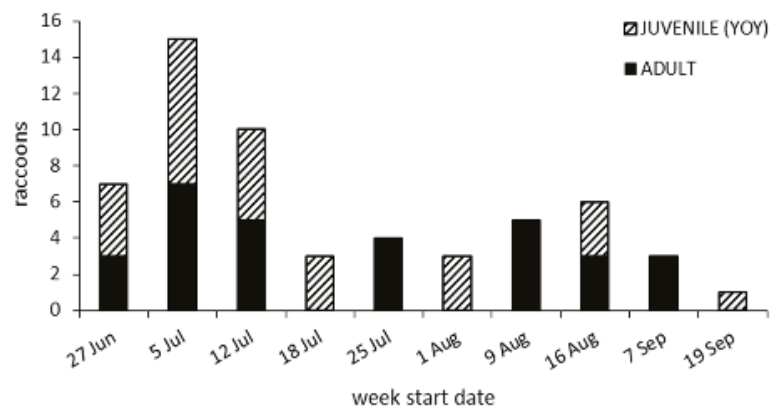

(a)

2006 Road Kill New York

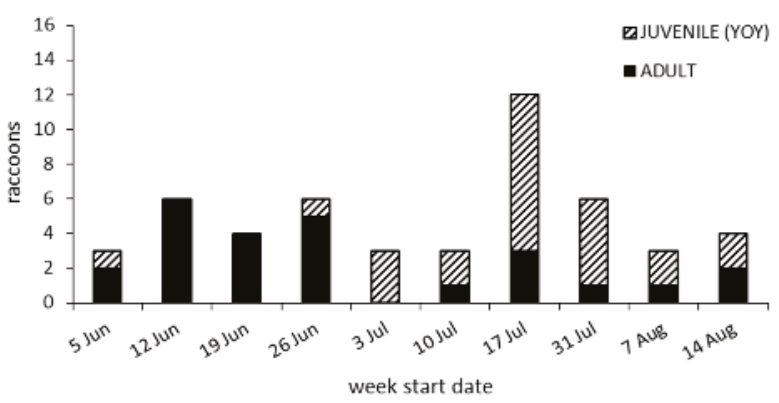

(b)

2007 Road Kill New York

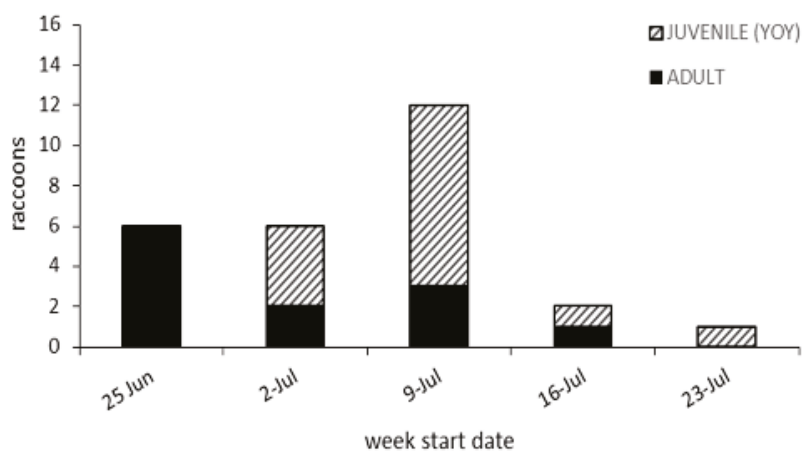

(c)

Figure 7. Adult and juvenile (young of the year) raccoons collected deemed suitable for submission for rabies testing (a) 2005, (b) 2006 and (c) 2007. 
Road kill surveys required a commitment of two trained wildlife staff for 25 weeks over the survey period. Cumulative mean weekly driving distances ranged from $2372 \mathrm{~km}$ in 2005 to $3169 \mathrm{~km}$ in 2007 , requiring a mean range of 35 to $50 \mathrm{~h}$ driving and sample preparation time. Annual variation in survey routes and adaptive changes resulted in more kilometers $(\mathrm{km})$ driven over five days in 2007 than 10 days in 2005. The survey area was larger in 2005 and 2007 than 2006, but the 2005 survey area was split in half and each half only driven two days/week.

Costs associated with road kill surveys from 2005 to 2007 in 2016 USD in decreasing order of importance were: salaries and benefits $(\$ 22,778 ; 61 \%)$, fuel $(\$ 8142 ; 22 \%)$, vehicle depreciation ( $\$ 5274$; $14 \%$ ), and sample shipping ( $\$ 924 ; 3 \%$ ) (Table 2). The cost/road kill collected to be submitted for testing was: $\$ 176 /$ all species, $\$ 224 /$ raccoon, and $\$ 1160 /$ skunk. While we did not estimate rabies diagnostic and associated laboratory costs for testing road kills, the NYSDOH Rabies Laboratory approximates the cost for rabies testing/specimen at \$150.00 in 2016. This cost does not include equipment depreciation, training, safety measures, administrative burden, database management, and other related costs that would be included in a comprehensive laboratory cost analysis.

Table 2. Estimated annual cost of formal road kill surveys in Northern New York State in 2005-2007 (all values are shown in 2016 USD).

\begin{tabular}{|c|c|c|c|c|c|}
\hline Year & Salary and Benefits ${ }^{1}$ & Fuel $^{2}$ & Vehicle Depreciation $^{3}$ & Sample Shipping ${ }^{4}$ & Totals \\
\hline 2005 & 8306 & 3104 & 1812 & 389 & 13,611 \\
\hline 2006 & 8322 & 3043 & 1755 & 351 & 13,471 \\
\hline 2007 & 6150 & 1995 & 1707 & 184 & 10,036 \\
\hline Totals & 22,778 & 8142 & 5274 & 924 & 37,118 \\
\hline
\end{tabular}

${ }^{1}$ Salary hourly rates for 2016 for the employee grades (GS $5_{1}, 6_{1}, 6_{3}, 7_{1}$, and $7_{2}$ ) for two personnel who conducted almost all of the road kill surveys and prepared samples for overnight pick-up and shipping, plus a mean benefit rate of 0.35 [14]. ${ }^{2}$ Includes five month late spring-early fall mean for the price of a US gallon of gasoline plus taxes based on 2006 (\$302.40) and 2007 (\$304.80) pump rates at an estimated $7.2 \mathrm{~km} / \mathrm{L}$ (17 mi/gal). [15]. The $2006 \mathrm{rate}$ was also applied for 2005, which was not readily available. ${ }^{3}$ A simple linear annual rate based on Blue Book value for the vehicle with 150,000 mi "life expectancy" in 2016. ${ }^{4}$ Based on $\$ 14.50 /$ shipment from Potsdam, NY to the NYSDOH Rabies Laboratory, Wadsworth Center, Slingerlands, NY, where total heads submitted $/ 2.5$ shipments $\geq 2$ then an estimated 2.5 shipments occurred/week; otherwise 1 or no shipments occurred/week.

\section{Discussion}

The stated goals of surveillance include: (1) detection of the potential emergence of a disease as early as possible; (2) characterization of the spatial-temporal distribution of a disease once it is detected; (3) determination of factors that contributed to its emergence and distribution; and (4) determining whether the disease has disappeared or been controlled or eliminated through intervention [1].

Rabies surveillance in the U.S. has been and continues to be predominantly based on human and domestic animal exposures as a priority to ensure that public health is protected against this invariably fatal disease once clinical signs manifest. With the integration of ORV into rabies control in wild meso-carnivores, there is a management need for a more comprehensive near real-time view of the spatial-temporal distribution of specific rabies virus variants. Road kills as well as other sources of samples (e.g., strange acting animals not involved in human or domestic animal exposures, animals found dead in addition to road kills) not traditionally tested for rabies provide greater spatial-temporal surveillance scope and intensity than public health exposure-based samples alone for improved ORV decision making [4]. None of the 175 wild meso-carnivores tested from road kill surveys during 2005-2007 was rabid by dFA. During the same period, no meso-carnivores were tested or reported rabid by the NYSDOH Rabies Laboratory within the road kill survey zone; a single rabid raccoon was reported by NYSDOH near the edge of the road kill zone in 2005, northeast of Watertown, NY, USA (Figure 1). That no rabid terrestrial mammals were reported during the road kill survey period may have reflected suppression or elimination of raccoon rabies at the multiple county level, which may not be unexpected given that ORV intervention with RABORAL V-RG ${ }^{\circledR}$ baits (Merial Ltd., Athens, GA, USA) had been annually in place in portions of northern Jefferson and southern Clinton counties since 
1995; portions of St. Lawrence and Franklin Counties were added in 1997 and 1998, respectively, along with a portion of northern Clinton County in 2007.

However, reemergence of raccoon rabies within northernmost Jefferson and portions of St. Lawrence counties in 2008 (Figure 8), where ORV continued annually but where road kill surveillance ceased as a complement to public health surveillance points to two potential issues, independently or in combination.

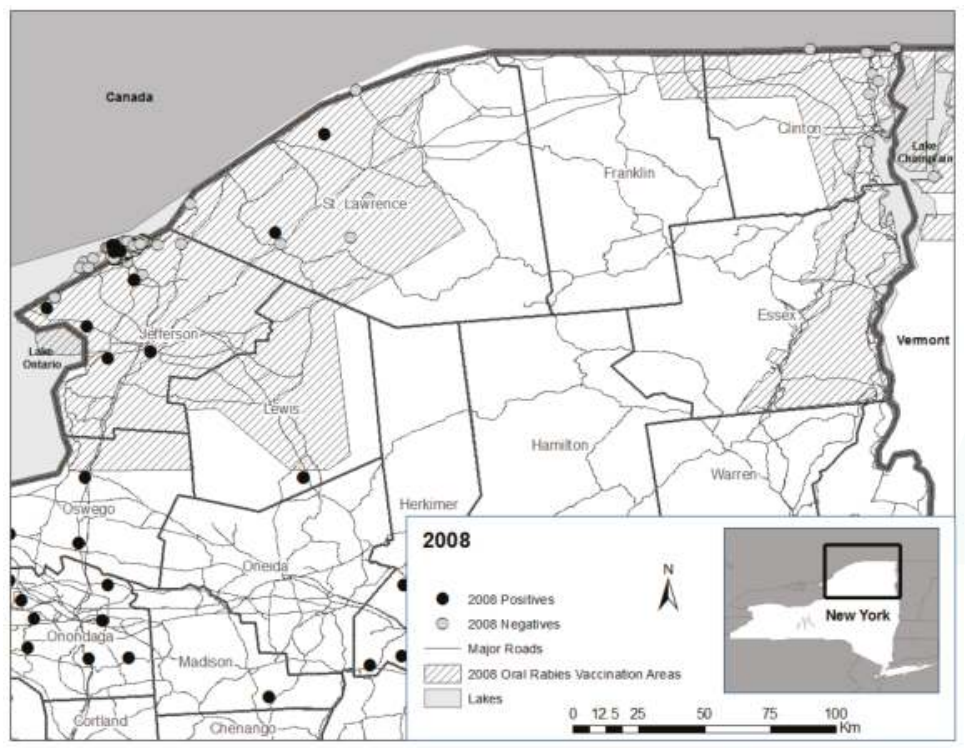

Figure 8. Distribution of raccoon rabies cases in 2008 in northern New York within and outside of long standing oral rabies vaccination (ORV) zones.

(1) It is not known if raccoon rabies had been transiently eliminated as suggested by enhanced surveillance through road kills in combination with public health surveillance, or if enhanced surveillance in combination with public health surveillance was insufficient to detect raccoon rabies presence that may have been suppressed by ORV or other factors; (2) Also, it is not known if vaccine-baits or implemented strategies (or their interaction), given generally low rabies virus neutralizing antibody seroprevalence observed in raccoon populations post-ORV [5], were adequate to contribute to lasting raccoon rabies suppression or perhaps elimination at this county scale given the perpetuation of rabies cases within the contiguous ORV zone that extended south beyond road kill survey areas in Jefferson County (Figures 1-3 and Figure 5).

The ultimate goal of the NRMP is elimination of specific terrestrial rabies variants, including raccoon rabies [18]. The detection of rabies within this specific survey area beginning in 2008 does not alter this goal or negate the value of road kills as a form of enhanced rabies surveillance or ORV as a means of controlling and eliminating specific rabies variants. Rather, this outcome underscores the need to continually seek improvements in enhanced rabies surveillance approaches by emphasizing detection of strange behaving raccoons and other meso-carnivores not involved in human or domestic animal exposures to facilitate improved ORV decisions to achieve national wildlife rabies management goals of control and elimination [19].

Road kill collection was not inexpensive at \$176/road kill and \$224/road-killed raccoon over the three-year survey period. However, we are not aware of systematic economic analysis for rabies 
surveillance in the U.S. to formally compare the relative cost of road kill samples to other rabies surveillance sample categories (e.g., suspect strange behaving raccoons).

Opportunistic road kill sampling, in lieu of more structured road kill surveys, represents an alternate if areas of interest can be adequately sampled through routine travel to and from the office and field work sites by experienced personnel over regular routes. Such sampling may better integrate into surveillance budgets without compromising area coverage and effort. Also, eliciting cooperation from personnel within transportation departments who may have the responsibility of removing road kills should be explored [20], so long as protective measures are taken to ensure against rabies exposure from carcass collection. In some instances, state wildlife conservation officers or game wardens may be an option for road kill sampling, given the extensive amount of travel required to accomplish their job duties.

This study served in part as a basis for future enhanced rabies surveillance planning. While it accomplished that goal, study limitations of note included the lack of consistency across years in road kill survey routes and effort due to changing staffing needs for rabies control in New York and the eastern U.S. Also, we did not attempt to predict road kill frequency based on estimated raccoon population density indices, traffic volume, or road type (i.e., primary, secondary, tertiary). The roads driven in these surveys were largely state routes and some county connecting roads, with small segments of Interstates 81 and 87 in 2005 and 2007, respectively (Figure 5a,c). For context, estimated daily traffic volume (number of vehicles) for select roads within the St. Lawrence County portion of road kill surveys in 2006 was: 4900 for the end of Route 812 at Route 11; 620 at the end of Route 58 at Route 37; 2530 from Route 37 west of the City of Ogdensburg; and, 11,770 at the start of Route 11 in Canton [21]. Raccoon population density indices were available only from 1998 to 2000 from three sites in St. Lawrence County that ranged from 2 to 8 animals $/ \mathrm{km}^{2}$ (USDA unpublished data). Given these examples of variation in estimated traffic volume and raccoon densities, their potential value in determining expected sample size/effort for future road kill surveys should be explored. We also did not record animals detected and discarded that were deemed unsuitable to be submitted for rabies testing in 2005. That additional year would have better characterized variation in the proportion of road-killed animals submitted for testing relative to the total detected. The differential between road kills detected and collected serves as a measure of efficiency and is particularly informative for road kills detected on day one that may be unsuitable because they were killed during the weekend and were cleared from the highway by WS on Monday because of extended exposure to road traffic, heat, scavenging, or other factors. At more southern latitudes where road kills quickly degrade in high temperatures, the ratio of animals submitted:detected may be useful to delineate times when road kill surveys may not be a wise commitment of resources. Finally, there is a strong suspicion that the abnormal behaviors commonly associated with clinically rabid raccoons and other animals increase their likelihood of being killed on highways above that observed for healthy subjects. However, to test this hypothesis would require additional well-designed field studies.

In 2005, 2006, and 2007, during a raccoon rabies epizootic in northeast Ohio, road kills ranked third among five enhanced rabies surveillance categories for detection of rabies $(2 / 399,0 / 159,1 / 481)$. Strange behaving raccoons not involved in human or domestic animal exposures had the highest probability of rabies detection $(17 / 578,5 / 263,15 / 191)$, followed by animals found dead not as road kills $(2 / 142,1 / 97,3 / 106)$. NWCO-captured, apparently healthy animals ranked last at $(0 / 1680$, $0 / 17,0 / 12$ ) for the three years (no rabies positives in 2005 and direct rapid immunohistochemistry test (dRIT) WS laboratory burden led to reduced testing of NWCO derived samples in 2006 and 2007), with WS trapped and tested animals from within or near the epizootic ranking number four $(1 / 738,0 / 296,0 / 90)$ [22]. While all of these enhanced rabies surveillance categories may be valuable during rabies emergence requiring ORV intervention, road-killed raccoons and other meso-carnivores represents a dependable source of samples that appears to add value to enhanced rabies surveillance in combination with strange acting animals and animals found dead. Collectively, enhanced, and 
public health rabies surveillance provides a more complete spatial-temporal view of rabies distribution on which to make the most informed ORV decisions for controlling rabies in wildlife.

Acknowledgments: The authors thank the respective staffs of the United States Department of Agriculture, Animal and Plant Health Inspection Service, Wildlife Services, and the Laboratory of Zoonotic Disease and Clinical Virology, Griffin Laboratory, Wadsworth Center, New York State Department of Health Rabies Laboratory for their contributions to this project.

Author Contributions: D.S. co-conceived the formal road kill survey, participated in data analysis and wrote the draft manuscript; J.D.K. prepared, cleaned and validated the data from the database for analysis, and reviewed the manuscript; D.P.M. conducted road kill surveys, prepared and shipped specimens for rabies diagnosis, and assisted with historic data; T.P.A. served as corresponding author, prepared references, and assisted with data analysis; C.V.T. provided rabies diagnostics for New York State, oversight for road kill samples tested, and reviewed the manuscript; K.M.N. reviewed and proofread the manuscript, and validated some historic data; R.J.R. provided rabies diagnostics for New York State, oversight for road kill samples tested, and reviewed the manuscript; A.R.R. conducted road kill surveys and assisted with some historic data; M.S.C. supervised road kill surveys and reviewed the manuscript; and R.B.C. co-conceived the formal road kill survey and reviewed the manuscript.

Conflicts of Interest: The authors declare no conflict of interest.

$\begin{array}{ll}\text { Abbreviations } \\ \text { APHIS } & \text { Animal and Plant Health Inspection Service } \\ \text { dFA } & \text { direct fluorescent antibody } \\ \text { NRMP } & \text { National Rabies Management Program } \\ \text { NYSDOH } & \text { New York State Department of Health } \\ \text { NWCO } & \text { Nuisance Wildlife Control Operator } \\ \text { ORV } & \text { oral rabies vaccination } \\ \text { USDA } & \text { U.S. Department of Agriculture } \\ \text { WS } & \text { Wildlife Services }\end{array}$

\section{References}

1. World Organisation for Animal Health. Terrestrial Animal Health Code; Chapter 14 Animal Health Surveillance; OIE: Paris, France, 2010; pp. 1-11.

2. Blanton, J.D.; Hanlon, C.A.; Rupprecht, C.E. Public Veterinary Medicine: Public Health Rabies surveillance in the United States during 2006. J. Am. Vet. Med. Assoc. 2007, 231, 540-556. [CrossRef] [PubMed]

3. Blanton, J.D.; Palmer, D.; Christian, K.A.; Rupprecht, C.E. Public Veterinary Medicine: Public Health Rabies surveillance in the United States during 2007. J. Am. Vet. Med. Assoc. 2008, 233, 884-897. [CrossRef] [PubMed]

4. Rupprecht, C.E.; Cliquet, F.; Fehlner-Gardiner, C.; Fooks, A.R.; Mueller, T.; Sabeta, C.; Slate, D. Progress in the Development of a Direct Rapid Immunohistochemical Test for Diagnosing Rabies. OIE Bull News from Our Colleagues. Available online: http:/ / scholarworks.bgsu.edu/cgi/viewcontent.cgi?article=9081\&context= bg-news (accessed on 6 June 2016).

5. Slate, D.; Algeo, T.P.; Nelson, K.M.; Chipman, R.B.; Donovan, D.; Blanton, J.D.; Niezgoda, M.; Rupprecht, C.E. Oral rabies vaccination in North America: Opportunities, complexities, and challenges. PLoS Negl. Trop. Dis. 2009, 3, e549. [CrossRef] [PubMed]

6. Wasserberg, G.; Osnas, E.E.; Rolley, R.E.; Samuel, M.D. Host culling as an adaptive management tool for chronic wasting disease in white-tailed deer: A modelling study. J. Appl. Ecol. 2009, 46, 457-466. [CrossRef] [PubMed]

7. Rolley, R.E.; Lehman, L.E. Relationships among raccoon road-kill surveys, harvests, and traffic. Wildl. Soc. Bull. 1992, 20, 313-318.

8. Gehrt, S.D. Evaluation of spotlight and road-kill surveys as indicators of local raccoon abundance. Wildl. Soc. Bull. 2002, 30, 449-456.

9. Gehrt, S.D.; Hubert, G.F.; Ellis, J.A.; Gehrt, S.D.; Hubert, G.F.; Ellis, J.A. Long-term population trends of raccoons in Illinois. Wildl. Soc. Bull. 2002, 30, 457-463. 
10. Chadwick, E.A.; Cable, J.; Chinchen, A.; Francis, J.; Guy, E.; Kean, E.F.; Paul, S.C.; Perkins, S.E.; Sherrard-Smith, E.; Wilkinson, C.; et al. Seroprevalence of Toxoplasma gondii in the Eurasian otter (Lutra lutra) in England and Wales. Parasites Vectors 2013, 6, 75. [CrossRef] [PubMed]

11. Kierepka, E.M.; Latch, E.K. Fine-scale landscape genetics of the American badger (Taxidea taxus): Disentangling landscape effects and sampling artifacts in a poorly understood species. Heredity (Edinb) 2016, 116, 33-43. [CrossRef] [PubMed]

12. Wallace, R.M.; Gilbert, A.; Slate, D.; Chipman, R.; Singh, A.; Wedd, C.; Blanton, J.D. Right place, wrong species: A 20-year review of rabies virus cross species transmission among terrestrial mammals in the United States. PLoS ONE 2014, 9, e107539. [CrossRef] [PubMed]

13. U.S. Centers for Disease Control and Prevention. Protocol for Postmortem Diagnosis of Rabies in Animals by Direct Fluorescent Antibody Testing, A Minimum Standard for Rabies Diagnosis in the United States. Available online: https://www.cdc.gov/rabies/pdf/rabiesdfaspv2.pdf (accessed on 1 July 2016).

14. U.S. Office of Personnel Management. 2016 General Schedule (GS) Locality Pay Tables. In Pay and Leave: Salaries and Wages. Available online: https://www.opm.gov/policy-data-oversight/pay-leave/salarieswages/2016/general-schedule/ (accessed on 7 January 2016).

15. New York State Energy Research and Development Authority. Monthly Average Motor Gasoline Prices. In: Energy Prices and Weather Data. Available online: http:/ / www.nyserda.ny.gov/Cleantech-and-Innovation/ Energy-Prices/Motor-Gasoline/Monthly-Average-Motor-Gasoline-Prices (accessed on 1 July 2016).

16. SAS Institute Inc. SAS 9.3 Software 2011. Available online: http://www.sas.com/software/sas9/ (accessed on 3 March 2017).

17. Whitaker, J.; Hamilton, W., Jr. Mammals of the Eastern United States; Cornell University Press: Ithaca, NY, USA, 1998.

18. USDA. North American Rabies Management Plan. 2008; p. 78. Available online: http://www.aphis. usda.gov/wildlife_damage/oral_rabies/downloads/FinalNARMP9--30--2008(ENGLISH).pdf (accessed on 1 January 2013).

19. Slate, D.; Rupprecht, C.; Donovan, D.; Badcock, J.; Messier, A.; Chipman, R.; Mendoza, M.; Nelson, K. Attaining raccoon rabies management goals: History and challenges. Dev. Biol. 2008, 131, 439-447.

20. Case, R. Interstate Highway Road-Killed Animals: A Data Source for Biologists. Wildl. Soc. Bull. 1978, 6, 8-13.

21. New York State Department of Transportation. Traffic Data Report. In Traffic Data Report for New York State; NYSDOT: Albany, NY, USA, 2016.

22. Slate, D.; Rupprecht, C. Rabies management in wild meso-carnivores. In Zoo and Wild Animal Medicine Current Therapy; Miller, E., Fowler, M., Eds.; Elsevier: St. Louis, MO, USA, 2012; Volume 7, pp. 366-375.

Sample Availability: Samples are not available from the authors.

(c) 2017 by the authors. Licensee MDPI, Basel, Switzerland. This article is an open access article distributed under the terms and conditions of the Creative Commons Attribution (CC BY) license (http:/ / creativecommons.org/licenses/by/4.0/). 
Article

\title{
Enhanced Rabies Surveillance to Support Effective Oral Rabies Vaccination of Raccoons in the Eastern United States
}

\author{
Jordona D. Kirby ${ }^{1, *}$, Richard B. Chipman ${ }^{1}$, Kathleen M. Nelson ${ }^{1}$, Charles E. Rupprecht ${ }^{2}$, \\ Jesse D. Blanton $^{3}$, Timothy P. Algeo ${ }^{1}$ and Dennis Slate ${ }^{1}$ \\ 1 United States Department of Agriculture, Animal and Plant Health Inspection Service, Wildlife Services, \\ National Rabies Management Program, Concord, NH 03301, USA; \\ richard.b.chipman@aphis.usda.gov (R.B.C.); kathleen.m.nelson@aphis.usda.gov (K.M.N.); \\ timothy.p.algeo@aphis.usda.gov (T.P.A.); dennis.slate@aphis.usda.gov (D.S.) \\ 2 LYSSA, LLC, Atlanta, GA 30333, USA; charleserupprechtii@gmail.com \\ 3 Poxvirus and Rabies Branch, Division of High-Consequence Pathogens and Pathology, National Center for \\ Emerging and Zoonotic Infectious Diseases, Centers for Disease Control and Prevention, Atlanta, GA 30333, \\ USA; asi6@cdc.gov \\ * Correspondence: jordona.d.kirby@aphis.usda.gov; Tel.: +1-865-363-9381
}

Received: 31 May 2017; Accepted: 24 July 2017; Published: 28 July 2017

\begin{abstract}
Enhanced rabies surveillance (ERS) is essential for sound oral rabies vaccination (ORV) decisions to prevent the spread of specific rabies virus variants in meso-carnivores and to achieve disease elimination. Use of a direct rapid immunohistochemistry test (dRIT) in North America for timely, accurate rabies diagnosis in the field has facilitated greater ERS emphasis since 2005. ERS used in tandem with exposure-based public health surveillance provides a comprehensive understanding of the geographic distribution of rabies as an aid to formulate effective management strategies for raccoons and other meso-carnivores. In 2015, best management practices were implemented for improving, reinvigorating, and standardizing ERS. A point system for weighing ERS sample categories was evaluated, to determine whether sampling emphasis should be focused upon ill or strange-acting animals, the highest quality category. During 2016, 70.7\% of rabid animals detected through ERS in raccoon rabies management states were obtained from strange-acting animals, followed by animals found dead (14.1\%), road kills (9.1\%), and nuisance-collected specimens $(6.1 \%)$. Sample category weights may be adjusted based on additional evaluation to ensure continued emphasis on the highest value samples. High quality ERS, in conjunction with serologic evidence of population-based immunity, form the backbone for ORV decisions in the elimination of raccoon rabies.
\end{abstract}

Keywords: enhanced rabies surveillance; oral rabies vaccination; rabies elimination; raccoon; wildlife; zoonosis

\section{Introduction}

Surveillance is the cornerstone in providing actionable data for effective wildlife disease management. Knowing specifically when and where disease occurs is vital to formulate prevention, control and elimination strategies. The World Organisation for Animal Health (OIE) has endorsed prevention of rabies in source populations [1], which includes terrestrial meso-carnivore species in North America such as raccoons (Procyon lotor) and striped skunks (Mephitis mephitis). Oral rabies vaccination (ORV) has enabled a shift in rabies management focus to the source of disease in wildlife reservoirs. The use of ORV has proven successful in eliminating rabies in European foxes [2], and multiple terrestrial reservoirs in Canada [3-5]. In the U.S., considerable emphasis has been focused on 
preventing the spread of the raccoon rabies virus variant in the eastern part of the country by creating vaccination barriers ahead of the disease front [6].

To achieve the goal of controlling and eliminating rabies in terrestrial wildlife, ORV is indispensable. Yet, without near-real time surveillance to delineate where ORV should be applied, its effectiveness at a landscape scale is doubtful. Diverse meso-carnivore hosts for many of the documented rabies virus variants in the U.S. further underscore the value of prompt rabies virus detection, variant typing and timely, accurate mapping of cases by virus variant and species.

In the U.S., rabies surveillance continues to be largely exposure-based in relation to public health [7]. Public health surveillance, often used interchangeably with passive surveillance, implies rabies detection without an active effort targeting a specific area or species to search for the disease [8]. While this system has been, and continues to be, effective in protecting human and animal health, exposure-based surveillance often may not adequately characterize the spatial-temporal distribution of rabies in wild meso-carnivores in real-time for effective intervention. Public health surveillance tends to be biased by human population density, and often discounts potentially rabid animals if no human or domestic animal exposure has occurred [6].

In recognition of this limitation in relation to ORV, a paradigm shift took place in the U.S. during 2004, where enhanced rabies surveillance (ERS) was initiated to complement public health surveillanceto provide a more comprehensive picture of rabies distribution by virus variant $[6,9]$. ERS is planned targeted surveillance that emphasizes a special effort to meet specific management needs. ERS is frequently used interchangeably with active rabies surveillance, is targeted, preferably based on risk factors, and is typically initiated with a designed sampling scheme to meet specific disease management needs [8]. This shift was facilitated largely through the application of a field-efficient, direct immunohistochemical test (dRIT) $[10,11]$ by trained wildlife biologists in collaboration with the Centers for Disease Control and Prevention (CDC, Atlanta, Georgia, GA, USA); the World Health Organization (WHO) Collaborating Centre, Wistar Institute (Philadelphia, Pennsylvania, PA, USA); and state health departments.

The United States Department of Agriculture (USDA), Animal and Plant Health Inspection Service (APHIS), Wildlife Services (WS), National Rabies Management Program (NRMP; hereafter WS) conducts ERS in support of national rabies management goals that are focused on preventing the spread of, and ultimately eliminating specific rabies virus variants in meso-carnivores. The range of ERS samples collected includesthe following categories: suspect, ill or strange-acting animals without a rabies virus exposure record (hereafter, strange-acting), animals found dead and not associated with highway mortality, road kills; animals captured from focal areas where rabies cases have occurred recently (hereafter, surveillance-trapped), and apparently healthy animals collected through nuisance wildlife control operators (NWCO) or submitted by homeowners [6].

The value of ERS to raccoon rabies management was illustrated in highly urban-suburban northeastern Ohio during 2007. Public health surveillance rabies cases had been declining from 2004-2006 in an area where emergency ORV and trap-vaccinate-release rabies management strategies were ongoing, as part of a contingency response to an epizootic that began in 2004 [6,9]. All rabid animals were detected through ERS during 2007, highlighting its importance as a complement to public health surveillance to make informed rabies control decisions [9].

With a programmatic transition towardsthe elimination of raccoon rabies in the eastern U.S., the absence of cases will serve as the key metric to measure success in tandem with rabies virus neutralizing antibody (rVNA) sero-prevalence as an index to vaccine-induced herd immunity.These metrics form the basis to make decisions to move ORV zones farther into raccoon rabies enzootic areas. During 2015, a new U.S. program initiative was developed to standardize best management practices (BMPs) and reinvigorate ERS. The program was implemented in four pilot states to expand the diversity of surveillance collaborators and to enhance detection of strange-acting animals, the highest valued ERS sample category [9]. The program was expanded during 2016 to 16 rabies management states that implemented some components of the new ERS initiative with full ERS implementation 
by these statesin 2017. This revitalized ERS system includes well-defined categories to track sources of samples combined with a stratified point value system to weigh the quality of samples collected and tested. The point system and a quarterly point threshold were established to provide incentive to collect the highest quality ERS samples for detection of rabid animals. This system also provides a platform for evaluating and adjusting ERS performance in participating states, and serves as a means for making adjustments in surveillance sampling emphasis over time.

The objective of this paper is to summarize the first year of categorized ERS data from 16 eastern states seasonally and annually. In addition, we categorized ERS retrospective data from the four pilot states during 2015, for comparison to 2016, within the context of the value of ERS data for planning and implementing raccoon rabies elimination.

\section{Materials and Methods}

During 2015, WS developed BMPs for ERS to integrate four primary components into an improved, adaptive approach to surveillance: (1) an established diverse, cooperative surveillance networking matrix; (2) an algorithm for strange-acting animals, sample prioritization, and freezer support for temporary sample storage; (3) rabies laboratory support; and (4) data entry, monitoring and analyses.

Alabama, Maine, Ohio and West Virginia were selected as pilot states to lead implementation of the ERS initiative in 2015, with a focus on establishing a diverse, cooperative surveillance networking matrix. Potential network links were represented by federal, state, county, and municipal agencies, special interest groups, the private sector, national organizations having regional and state affiliates, and international collaborators (Table 1). A recommended minimum number of contacts for each cooperator level was established to ensure diversity of cooperators within the network. Pilot states were selected, in part, on the range of their strategic rabies management history and current value to national ORV goals. In addition, these states were selected because their existing ERS strategies were not standardized prior to 2015. The purpose of establishing and maintaining a diverse, cooperator-based network was to increase the likelihood of collecting high quality samples from suspect animals that displayed behaviors suggestive of rabies.

Table 1. Examples of expanded enhanced rabies surveillance cooperative network contacts.

\begin{tabular}{|c|c|c|}
\hline Cooperator Level & Cooperator & $\begin{array}{l}\text { Recommended } \\
\text { Minimum Contacts }\end{array}$ \\
\hline Federal & $\begin{array}{c}\text { United States Department of Agriculture (USDA) Forest } \\
\text { Service, USDA Veterinary Services, U.S. Fish and Wildlife } \\
\text { Service, U.S. Department of Energy, U.S. Department of } \\
\text { Defense, Tribal Nations }\end{array}$ & 2 \\
\hline County & $\begin{array}{l}\text { Animal Control, Health, Police, Municipal Waste, } \\
\text { Transportation, Agriculture Extension, Parks/Recreation }\end{array}$ & 4 \\
\hline City/Town/Hamlet & $\begin{array}{c}\text { Local Police, Fire Department, Community Clubs, } \\
\text { Homeowners Associations, }\end{array}$ & 3 \\
\hline Other & $\begin{array}{l}\text { 4-H, U.S. Animal Health Association, Zoos, Wildlife and } \\
\text { Public Health Professional Societies }\end{array}$ & $\begin{array}{l}\text { No minimum but } \\
\text { highly encouraged }\end{array}$ \\
\hline
\end{tabular}

Historically, ERS emphasized areas within and on the leading edge of ORV zones, where the risk of rabies spread beyond existing barriers was assumed to be high [12]. During 2015, the ERS area was formally designated to include the western half $(20 \mathrm{~km})$ of ORV zones, and the area extending $80 \mathrm{~km}$ west from the edge of current ORV zones along the Appalachian Ridge mountains, a $100 \mathrm{~km}$-wide 
priority ERS focus area (Figure 1). In states bordering Canada (Maine, ME, New Hampshire, NH, New York, NY, and Vermont, VT, USA), the highest priority areas were identified as the existing ORV zones, which represented a $\geq 40 \mathrm{~km}$ wide vaccination zone along the USA-Canadian border, and $80 \mathrm{~km}$ south of the existing ORV zones. Other critical areas were also defined, including peninsular Cape Cod, Massachusetts, and potential risk corridors with a perceived increased likelihood of rabies spread in Alabama, Kentucky, Louisiana, Michigan, and Mississippi.

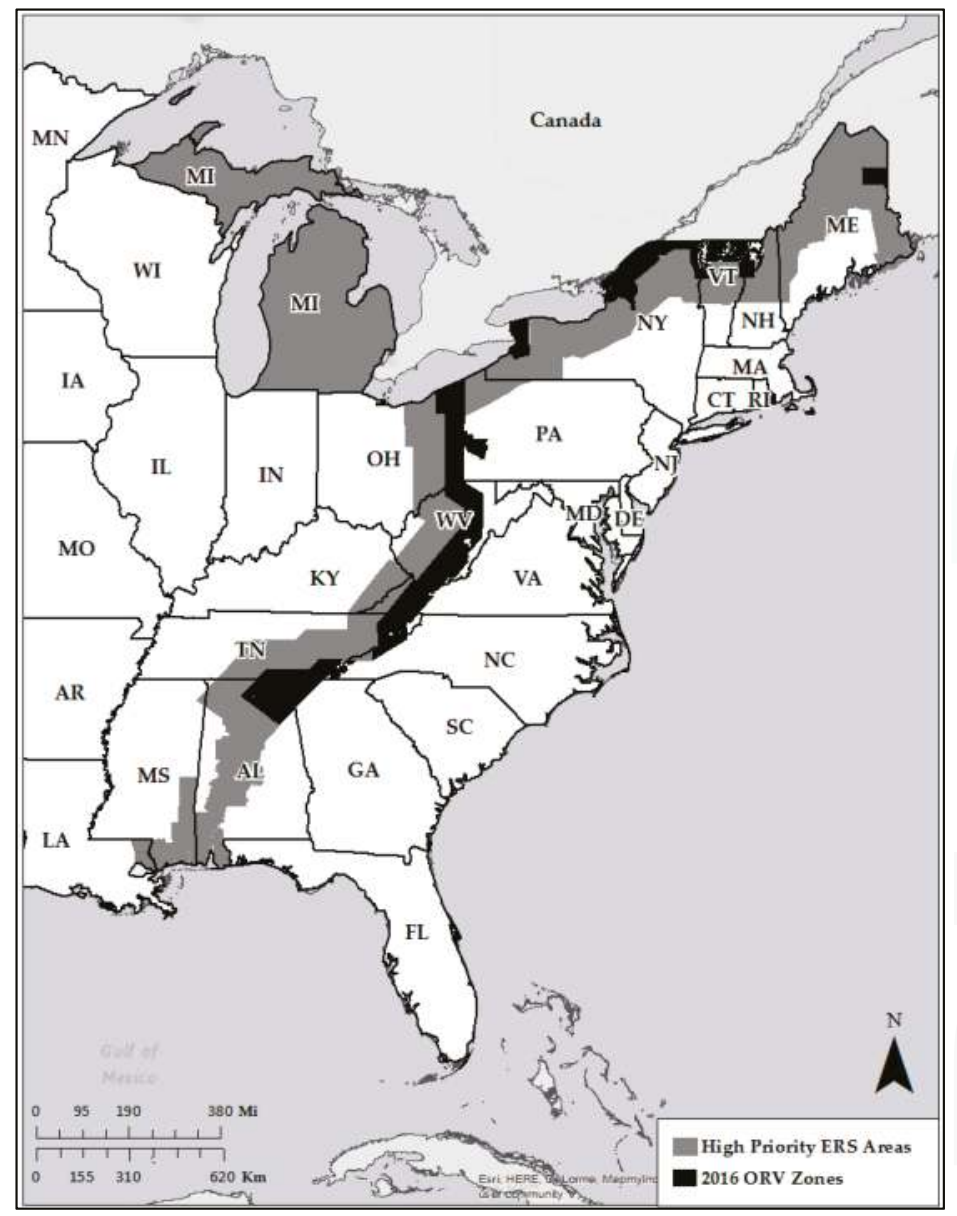

Figure 1. Highest priority enhanced rabies surveillance areas that extended $80 \mathrm{~km}$ west (Appalachian Ridge) or generally south (northeastern states) of current oral rabies vaccination (ORV) zones in the eastern U.S. and other critical risk areas.

We defined 6 standardized ERS sample categories within a stratified point system to value samples according to a preliminary expectation of meso-carnivore specimens that might test positive for rabies antigen (Table 2) [9]. Initial point values were devised, based on an interpretative review of ERS category data from Ohio during 2005-2007, which illustrated that strange-acting animals had a higher likelihood of being rabid compared to all other ERS categories by 6-35 times [9]. Thus the point value assigned to this category was three-fold greater than the next most valuable category, and 15 times greater than the least valuable categories. In lieu of mandating sample sizes for ERS, we initially 
established a minimum threshold value of 100 points / quarter beginning in January 2016. This initial baseline threshold was designed to provide incentives for the collection of high quality surveillance samples evenly through time, as well as a guide to ensure a minimum consistent effort. It was not designed to account for seasonal spikes in rabies incidence; rather, it was designed to refocus ERS efforts on more consistent sample collection throughout the entire year.

Table 2. Six standardized sample categories and associated stratified point values (i.e., weights) for enhanced rabies surveillance.

\begin{tabular}{ccl}
\hline Category & Point Value & Description \\
\hline Strange-acting & 15 & Suspect behavior suggestive of neurological disease \\
Found dead & 5 & Unexplained with no obvious signs of trauma; not road kill \\
Road kill & 3 & Formal survey or opportunistically; 1 additional point/mile driven \\
Surveillance-trapped & 2 & Active trapping in specified raccoon rabies risk areas/response to an outbreak \\
NWCO/other & 1 & Nuisance-trapped or homeowner-derived; apparently healthy \\
Unknown & 1 & Behavior not observed; fate not determined \\
\hline
\end{tabular}

We evaluated the stratified point system by assigning one of the six defined sample categories to all ERS samples collected by WS in 16 raccoon rabies management states, 1 January 2016-19 March 2017 (Figure 1). We evaluated data by calendar year (1 January-31 December 2016) and by calendar season (20 March 2016-19 March 2017). Calendar seasons were defined as follows: spring 2016 = 20 March-19 June 2016, summer 2016 = 20 June-21 September 2016, fall $2016=$ 22 September-20 December 2016, and winter 2017 = 21 December 2016-19 March 2017. For each sample acquired through ERS, the minimum data collected included: date of sample collection, species, location (county-level or finer spatial scale), and behavior (if observed).

We used a univariate regression analysis to evaluate the relationship between rabid animal detection and each of the six sample categories for 16 states in calendar year 2016. To compare the categorized data in the four pilot states (Alabama, AL; Maine, ME; Ohio, OH; West Virginia, WV; USA) that implemented this surveillance system during calendar year 2015, we retrospectively assigned sample categories to all ERS samples collected in the four pilot states from 1 January-31 December 2015.

An algorithm was established to define the procedure for response to telephone calls received by cooperators regarding strange-acting animals. The algorithm provides a call-tree system to triage incoming calls from the general public about potentially rabid wildlife. Call algorithms were adapted in each state, dependent on cooperative entities within county or municipal areas responsible for responding to calls from the public. For example, a county health department that fielded a call about a suspect animal with no exposure might refer the caller to their respective game warden, whom in turn would dispatch the animal and submit it to WS.

A network of freezers was established in states or expanded in several states (e.g., Ohio, $\mathrm{OH}$ and Tennessee, TN, USA) that had previously distributed freezers in strategic locations for sample submission and temporary sample storage prior to rabies testing. Freezer locations included county health departments, municipal animal control offices, and department of transportation facilities. The BMPs recommendation was for freezer samples to be collected a minimum of twice monthly and subsequently tested within a week when practical, with an expectation that high priority samples would be tested within 48 hours of collection.

Laboratory support outlined through the program initiative included state-level reaffirmation of cooperative relationships with state rabies diagnostic facilities. At the national programmatic level, WS engaged with the CDC, The Wistar Institute and the New York State Department of Health (NYSDOH) to ensure continued diagnostic support for confirmation of WS-tested dRIT samples using the gold standard direct fluorescent antibody (dFA) test, variant-typing for all rabid animal specimens, and availability of non-commercial monoclonal antibodies for the dRIT [6]. All dRIT positive and indeterminate specimens, in addition to $10 \%$ of negatives, were confirmed using the dFAtest. Once 
confirmed and variant-typed, all rabid specimen reports were provided to the appropriate cooperators in the surveillance network, though only raccoon rabies virus variant cases had implications for ORV.

The BMPs also outlined improved mechanisms for data entry, monitoring and analyses, including structured timelines for entering data into the WS Management Information System, quality assurance practices for data management, and guidelines for logging information to track cooperator network contact events to maintain a viable network over time. Improvements to data management also included assigning and recording ERS sample categories for every specimen collected and tested, which were not recorded formally prior to 2016 .

\section{Results}

From 2005-2016, approximately 99,991 ERS samples were collected and tested through WS surveillance in 26 states and Puerto Rico, including 19 eastern states and seven states west of the Mississippi River. Rabid animals detected through ERS comprised 2.1\% of all samples $(n=2107)$. Approximately $82.0 \%$ of all ERS samples were tested by WS using the dRIT and $72.1 \%$ of all ERS positives were detected using this field diagnostic method.

From 1 January-31 December 2016, ERS resulted in collection and testing of 6852 ERS samples from 16 raccoon rabies management states (Table 3), and 99 rabid animals were identified. These ERS samples generated a total of 27,851 ERS points (Table 3), with rabid animals representing 1153 ERS points. The sample assigned the highest point value, strange-acting wildlife, accounted for $18.1 \%$ of all samples collected and represented $66.7 \%$ of all weighted samples (Table 3 ). Strange-acting animals accounted for $70.7 \%$ of rabid animals detected through ERS, followed by $14.1 \%$ found dead, $9.1 \%$ road kills, and $6.1 \%$ nuisance-collected specimens. No rabid animals were detected in the surveillance-trapped or unknown categories. Rabies-positive samples from strange-acting animals represented $5.7 \%$ of all samples collected within this respective category, followed by $6.2 \%$ for animals found dead, $0.7 \%$ for road kill, none for surveillance-trapped, $0.2 \%$ for NWCO/other, and none for the unknown category.

Table 3. Total enhanced rabies surveillance samples collected and tested by Wildlife Services, and total category points assigned, 1 January-31 December 2016.

\begin{tabular}{lccc}
\hline Sample Category & Point Value & Total Samples (\%) & Total Points (\%) \\
\hline 1 = Strange-acting & 15 & $1239(18.1)$ & $18,585(66.7)$ \\
2 = Found dead & 5 & $225(3.3)$ & $1125(4.0)$ \\
3 = Road kill & 3 & $1370(20.0)$ & $4110(14.8)$ \\
4 Surveillance-trapped & 2 & $13(0.2)$ & $26(0.1)$ \\
5 = NWCO/other & 1 & $3924(57.3)$ & $3924(14.1)$ \\
$6=$ Unknown & 1 & $81(1.2)$ & $81(0.3)$ \\
Totals & & 6852 & 27,851 \\
\hline
\end{tabular}

Simple linear regression revealed a highly significant relationship $(p<0.0000002)$ between road kill samples collected and rabid meso-carnivores detected in $2016\left(\mathrm{r}^{2}=0.86\right)$. A significant relationship $(p<0.03)$ also occurred between animals found dead (not as road kills) and rabid meso-carnivores when data for Michigan (42 meso-carnivores found dead, with none testing rabies positive) were removed as a potential outlier, although the found dead sample category was not highly predictive $\left(\mathrm{r}^{2}=0.32\right)$. The strange-acting sample category was weakly related to rabid meso-carnivores with New York data removed (63 ill or strange acting, with 19 testing rabid) as a potential outlier $(0.07<p<0.05$; $\left.\mathrm{r}^{2}=0.23\right)$. We suspect that a high ratio of rabid meso-carnivores were detected in New York in this category because WS may more carefully screen suspect animals submitted to the NYSDOH based on their recommendations for dFA testing rather than conducting dRIT.

Twelve of 16 states achieved the $\geq 100$ point minimum quarterly threshold except during the first quarter of 2016, where 10 of 16 states met or exceeded the minimum sample size target. Strange-acting 
samples accounted for $56.8-73.7 \%$ of threshold points by quarter, followed by road kill (14.3-18.7\%), NWCO (8.2-18.9\%), and animals found dead other than road kill (1.9-4.8\%) (Figure 2).
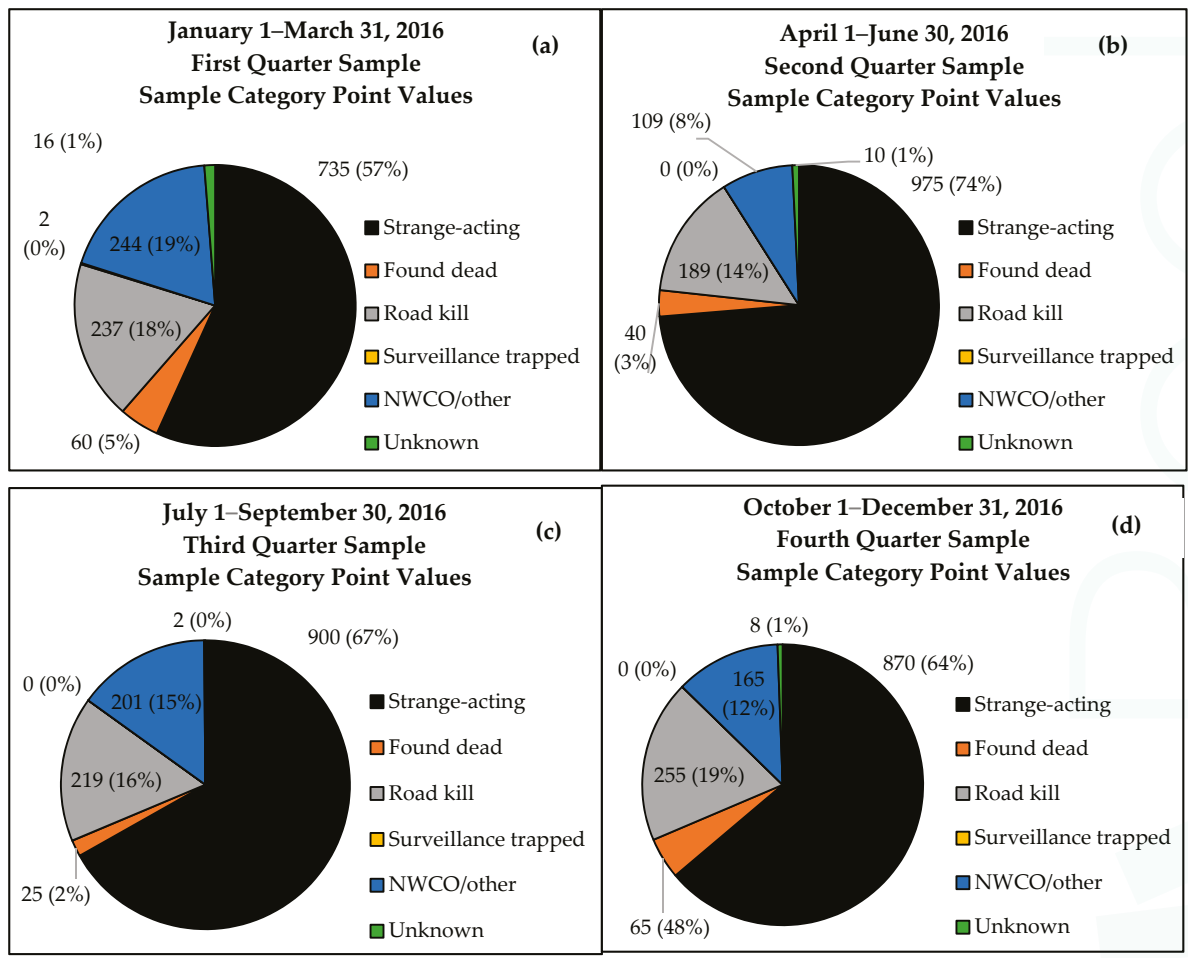

Figure 2. Minimum threshold weighted points and percentages by sample category for 16 states during (a) Quarter 1; (b) Quarter 2; (c) Quarter 3; and (d) Quarter 4 in 2016.

The highest volumeof samples were collected during summer $2016(n=2284)$, followed by spring $2016(n=2135)$, fall $2016(n=1486)$, and winter $2017(n=936)$. Samples from strange-acting animals were collected most frequently during spring 2016, followed by summer 2016, fall 2016, and winter 2017 (Figure 3a). The greatest proportion of rabid animal samples across all categories was detected during spring 2016 ( $n=37$ of 2135 samples), followed by summer 2016 ( $n=25$ of 2284), winter 2017 ( $n=19$ of 1486), and fall 2016 ( $n=18$ of 936; Figure 3b). The strange-acting category comprised the greatest proportion of rabid animals detected in all seasons except for winter 2017, during which road-killed animals represented the greatest proportion of rabies positives (Figure 3b). During fall 2016, animals found dead, road kills, and NWCO/other collected samples each represented $17 \%$ of rabid animal specimens. The NWCO/other positive samples represented a greater proportion of rabid animal samples during winter 2017 than those found dead, surveillance-trapped, and unknown categories. No rabid animals were detected from the surveillance-trapped or unknown categories during any season. 

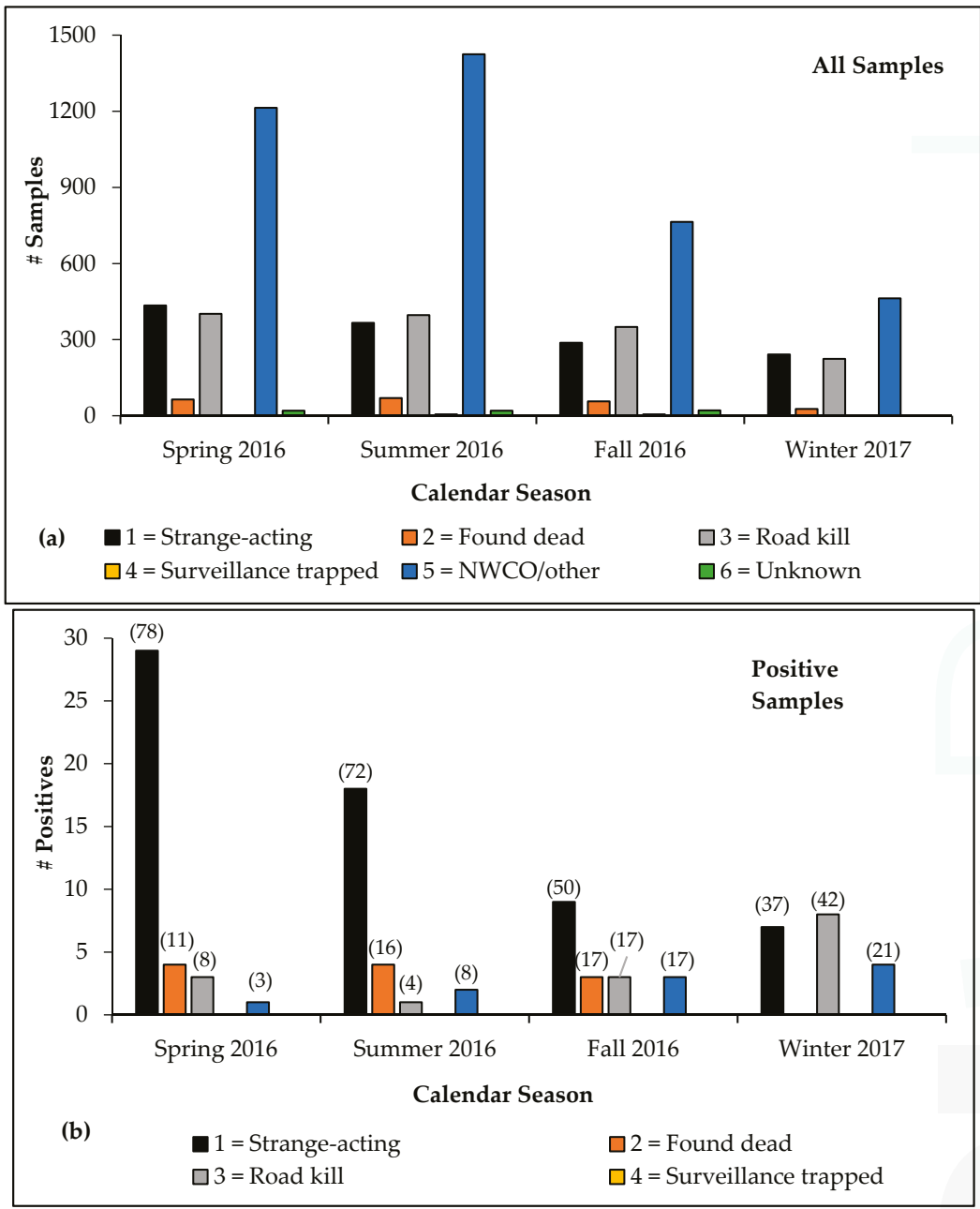

Figure 3. Comparison of enhanced rabies surveillance samples collected by season and sample category by Wildlife Services, spring 2016-winter 2017: (a) All samples and (b) Rabies-positive samples (value represents percent of all rabid animal samples detected according to sample category each season).

Alabama, Maine, Ohio and West Virginia, which implemented the new ERS initiative during 2015, increased ERS sample collection by $29.6 \%$ (and category points by $27.7 \%$ ) following full implementation in 2016. Specimens from strange-acting animals increased in two of four of these pilot states in 2016 compared to 2015, representing a 36.1\% increase in sample collection within this category (Figure 4a,b). Ohio collected 33 fewer samples from strange-acting animals during 2016 than 2015, and Maine collected two fewer samples from strange-acting animals during 2016 than 2015. During 2015, rabid animals $(n=13)$ were reported in all pilot states except Alabama; all four pilot states reported rabid animals $(n=19)$ during 2016. Strange-acting animals represented $38.5 \%$ and $47.4 \%$ of positive specimens during 2015 and 2016, respectively, in the pilot states. 

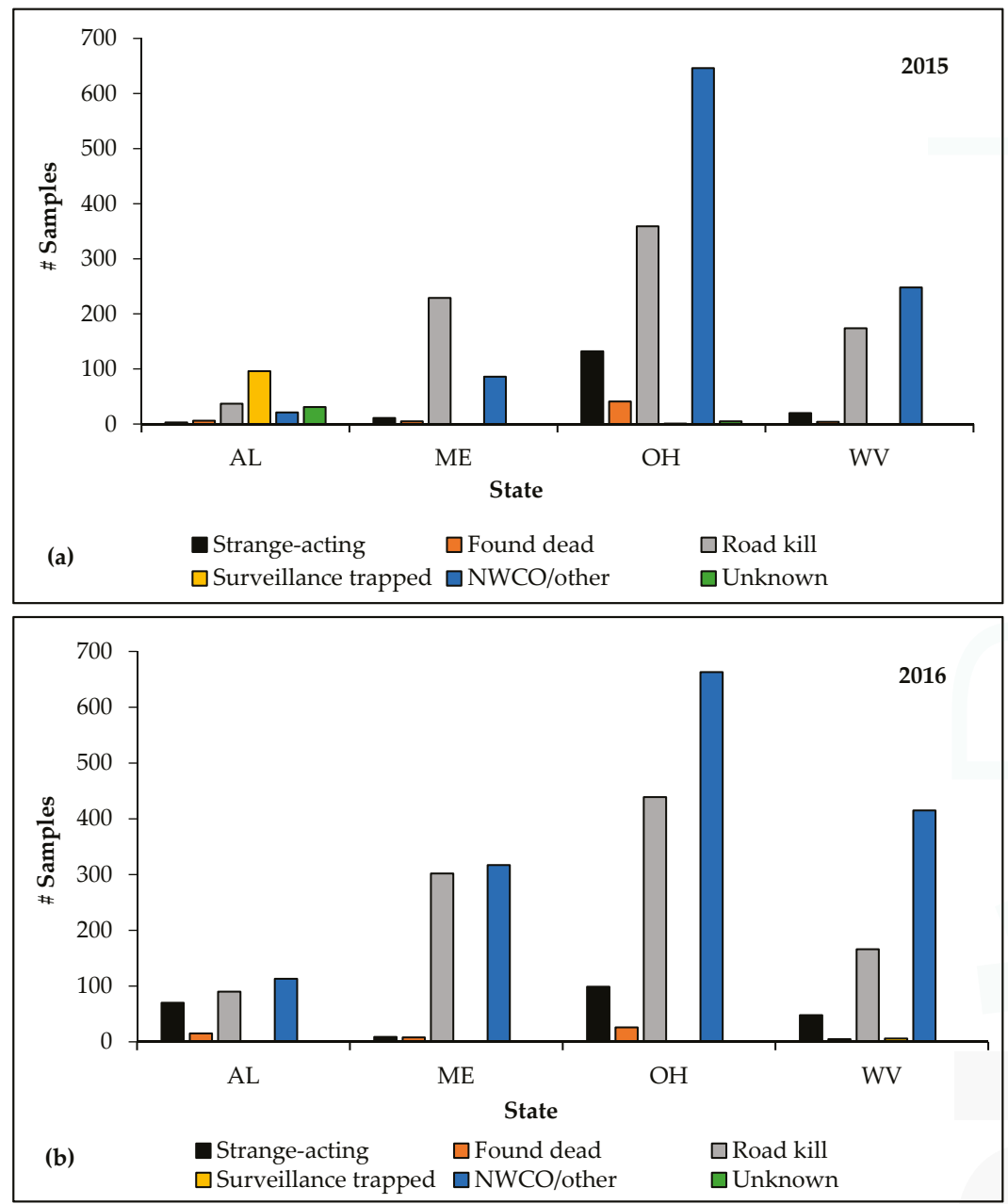

Figure 4. Comparison of enhanced rabies surveillance samples collected in 4 pilot states by Wildlife Services by sample category: (a) 1 January 2015-31 December 2015 and (b) 1 January 2016-31 December 2016. $\mathrm{AL}=$ Alabama; $\mathrm{ME}=$ Maine; $\mathrm{OH}=$ Ohio; $\mathrm{WV}=$ West Virginia.

Maine had the greatest increase in ERS samples among the fourpilot states in 2016 compared to 2015, at $92.1 \%$. Alabama, West Virginia, and Ohio increased total sample collection by $49.0 \%, 43.5 \%$, and 3.1\%, respectively. Alabama had the largest increase in ERS in total points and collection of the highest quality specimens among the four pilot states in 2016 compared to 2015. In Alabama, category points increased by 251\%, from 430 in 2015 to 1510 in 2016 and collection of strange-acting specimens increased by $2233 \%$, from three (2015) to 70 in 2016. Categorical points increased in Maine and West Virginia by $59.4 \%$ and $53.2 \%$, respectively, but decreased in Ohio by $8.3 \%$. Maine and West Virginia increased collection of the highest quality specimens by $72.7 \%$ and $140.0 \%$, respectively, while Ohio decreased collection of specimens from strange-acting animals by $25.0 \%$. 


\section{Discussion}

An ERS program has been in place in the U.S. since 2004, and has been recognized as an effective means to increase sampling intensity and geographic scope for rabies virus detection when applied in tandem with public health surveillance [9]. A routine annual finding of approximately $2 \%(n=176 /$ year $)$ of rabid animals detected directly through ERS from 2005 to 2016 near ORV zones is evidence of the value of ERS as a complement to public health surveillance. These rabid animals would not likely have been detected through exposure-based surveillance, and help to provide a more complete spatial and temporal picture of rabies virus distribution at a landscape level for improved management decision-making. A basic tenet of this surveillance paradigm shift beginning during 2004 was to promote more effective management of rabies at its source in reservoir species by focal detection, rather than mere increased testing of inappropriate or low-value specimens. Through the strategic application of ORV, there has been demonstrated success in preventing appreciable spread of the raccoon rabies virus variant in the eastern U.S. Clearly, ERS serves as a foundational component for managing rabies in wildlife reservoirs given that the absence of cases represents the ultimate measure of ORV success.

Experimental access to an additional oral rabies vaccine, capable of producing higher indices of population immunity based on rVNA sero-prevalence post-ORV, has prompted WS to shift from containment to elimination strategies, underscoring the need to develop a more effective, formalized categorical sampling regime for ERS. Limitations associated with historic ERS implementation strategies were identified in 2015, including non-standardized tactics among state programs. Not all states participating in raccoon rabies management were focused on the collection of high quality samples, and instead collected primarily nuisance or otherwise apparently healthy animals. Furthermore, sampling did not occur uniformly in all ERS emphasis areas within and on the leading edge of ORV zones, potentially resulting in critical spatial and temporal 'surveillance holes' through which rabies could spread without timely detection. One such temporal surveillance gap observed was associated with a limited number of samples collected during winter months, despite programmatic evidence to suggest that meso-carnivores that are strange-acting, found dead, or killed along highways during winter in northern latitudes may have a higher likelihood of being rabid. Implementation of standardized ERS with BMPs that emphasize establishment and maintenance of a diverse cooperator network and that employs a stratified point system for weighing the quality of sample sources, served as the foundation for revitalizing the ERS system.

Prior to 2015, WS coordinated primarily with the state departments of health, agriculture and wildlife on ERS. Through this ERS initiative, a diversity of other sources of suspect samples have been added to the historic suite of state agency collaborators, through strategic in-person meetings, telephone calls, mass mailings, and email blasts. A recommended minimum number of each contact type (e.g., federal, state, city/town, special interest, etc.) was provided as part of the BMPs (Table 1). Sample categories have been considered in ERS by WS since 2004, however, they were not formally defined for evaluation or put into a point system framework until the implementation of this ERS initiative during 2016. A weighted surveillance approach employing a stratified point system has been developed for other wildlife diseases, such as chronic wasting disease [13]. Point systems may improve ERS efficiency by stratifying sample collection according to biologically-relevant categories that may increase the probability of detecting a rabid animal [14]. A primary emphasis for the ERS point system was to create incentive by giving higher weight to higher quality ERS samples that have a greater chance for rabies virus detection. Initial point values were established based on an evaluation of ERS category data from Ohio [9] as well as historical WS ERS data collected over time.

An initial quarterly point minimum threshold of 100 was established, based on historic ERS data trends. The threshold was designed to provide additional motivation to reach the 100 point mark more easily by focusing on the collection of high quality samples, but states were advised that this was only a minimum threshold and once reached, sampling should continue at the same pace. The one-year categorized snapshot of data suggests that the 100 point minimum was exceeded in most participating 
state programs through emphasis on higher quality ERS samples. A comparison of the point values for the four pilot states from 2015 to 2016 further highlights that the minimum threshold provided incentive to focus sample collection efforts on high quality specimens. Points within this sample category increased in all pilot states except for Ohio, and collection of strange-acting animals improved overall. These initial values serve as a baseline from which further modifications can be made to refine the responsiveness of this system over time, including raising the minimum point thresholds and developing mechanisms to assist state programs that have difficulty meeting those thresholds.

For the 16 states, samples from animals categorized as strange-acting and found dead had a greater chance of being rabid, similar to the analysis of Ohio ERS data for 2005-2007 [9]. The strange-acting sample category resulted in detection of the greatest number of rabid animals; however, due to considerable variability in the ratio among rabid animals and samples tested by category across states, there was a lower predictive value by simple linear regression than expected. Rabid animal predictability for this category may be confounded because strange-acting behaviors may be the result of other neurological diseases. In the future, we will promote an improved and standardized interpretation among WS staff and cooperators as to what constitutes a strange-acting animal. While there was a significant relationship between the category found dead and rabid meso-carnivores detected, additional data over time will be required to determine the ability to predict rabid meso-carnivores beyond the $r^{2}=0.32$ generated for 2016 with Michigan data removed as a potential outlier.

In Ohio during 2005-2007, all other ERS categories resulted in detection of rabid animals, except for samples provided predominantly through NWCO sources (i.e., healthy animals). While our results were consistent with Ohio findings, NWCO-derived positive cases were detected at a slightly higher rate than expected during 2016. Thus, the value of NWCO-collected or otherwise apparently healthy animals should not be totally discounted as a means to find rabid animals. Use of NWCO-provided samples could be important in helping to define the extent of disease spread in a newly emerging rabies focus, in high-risk spread corridors, such as urban-suburban environments that support larger reservoir populations, or in areas where rabies is enzootic, even though only six of 3926 (0.2\%) animals within this category were rabid.

Although rabies-positive samples from road-killed animals represented only $<1 \%$ of all specimens collected in this category, this source of samples remains important because opportunistic and formal road kill surveys may help to fill spatial and temporal ERS gaps. Moreover, the strong relationship between road-killed samples collected and rabid meso-carnivores detected in 2016 suggests future predictive value from this sample category. Road kills typically occur in proportion to population density of the target species and often increase or decrease seasonally relative to activity patterns [15-17]. In our seasonal analysis, road-killed animals were the most important source of rabies positive samples during winter, a time of year when rabies case detection is generally lower [18]. Future refinements to the ERS initiative will include improved definitions for opportunistic versus formal road kill surveys, and will better delineate a tiered structure for evaluating road types (e.g. county road, state highway, interstate) that should be surveyed at higher rates based on traffic volume and in areas where samples from other ERS categories are difficult to obtain.

No rabid animals were detected from surveillance-trapped animals during 2016 ERS efforts. However, there were no rabies outbreaks identified where focal trapping efforts were warranted. Targeted surveillance trapping has served as a source of rabid animals in other outbreak situations, but it is highly variable, costly and labor intensive $[14,19,20]$. In the U.S., the rabies detection rate in targeted surveillance-trapped animals has ranged from $0 \%$ in New York and Ohio to an unusually high detection rate of $2.2 \%$ in Alabama. Only $0.1 \%$ of targeted surveillance-trapped animals in Ohio were detected during 2005, with no rabid animals captured during 2006-2007 [9]. Trapping in response to an index or early identified cases may serve as a useful ERS tool to better define an outbreak focus. However, this form of ERS may be most effective for a transient period of a few weeks in close proximity to such cases in new outbreak locations, as observed in Quebec, Canada [14]. 
Seasonally, rabies was detected most frequently detected during the spring, followed by summer, which is consistent with reported seasonal peaks in other regions $[14,18]$. Peaks of rabies activity during spring may result from increased denning and mating contacts in winter [21]. Secondary summer peaks may be related to increased contact during juvenile dispersal $[14,18,22]$. Although total sample collection was similar in spring and summer, samples declined through the fall and winter months. This observation may be related in part to lapses in ERS due to other rabies management priorities in some states during the late summer-fall months (e.g., ORV baiting and post-ORV monitoring efforts). In some northern latitudes, lower sample size during winter months may also be influenced by reduced animal activity during extreme cold and high snowfall.

To target ERS seasonal activities better, it may be more appropriate to consider biological seasons in future analysis, though pregnancy/parturition, young-rearing, dispersal, and breeding roughly coincide with spring, summer, autumn, and winter, respectively [23]. However, surveillance should not completely cease even at northern latitudes. Strange-acting animals during cold, snowy periods may have a high chance of being rabid, as observed in Franklin County, NY during the winter of 2015, as well as a recent rabies incursion near Hamilton, Ontario, Canada [24]. Latitudinal variation should be considered, as seasonal behavior patterns in raccoons found in more northern latitudes may result in differences in both sample collection and disease detection rates, compared to more moderate winter conditions that occur in the southeastern U.S. [25].

This initial study suggests that qualitative stratification of sampling categories provides a more meaningful way to evaluate ERS. However, we expect that data for the first three consecutive years should provide an improved analytical milestone to determine if this ERS system warrants modifications.The value of a revitalized ERS network has been realized in Ohio, where two strange-acting raccoons with no known exposure history submitted through a cooperator network freezer tested positive for the raccoon rabies virus variant during March-April 2017. This prompted a contingency action response because the cases were $>8 \mathrm{~km}$ ( 5 miles) beyond the established ORV zone. An emergency ORV spring baiting occurred to eliminate this focus and prevent raccoon rabies from gaining a stronger foothold in east-central Ohio and beyond. Without an established ERS network, both cases would have gone undetected through traditional public health surveillance until a local epizootic emerged that resulted in human or pet exposures.

Applying point values to public health surveillance data may represent a logical progression to help refine sample category weights, because as expected, exposure-based suspect animals have a greater chance of being rabid based on the Ohio data for 2005-2007. Also, a better evaluation of ERS efforts through space and time may require more refined sample targets using defined spatial resolution and habitat type [14]. Among the pressing surveillance challenges is the need to identify significant risk corridorsin relation to ORV and geophysical 'barriers' through which rabies has a higher probability of spreading to naïve areas. Existing models have illuminated potential raccoon rabies spread scenarios $[26,27]$ as well as the value of targeted surveillance to formulate control plans, but developing models that possess predictive sensitivity to improve appropriate rabies management for a common, often ubiquitous, ecological generalist such as the raccoon remains a daunting task. Therefore, continuing to develop effective stratified sampling regimes to guard against spatial-temporal surveillance gaps in relation to a suite of variables, including epidemiologic facets, ecological differences, local host abundance, species behavior, rabies virus variant distribution, viral spillover potential, spatial distribution of rabies collaborators on the landscape, and other factors, will remain critical for successful implementation of wildlife management strategies to eliminate rabies.

Supplementary Materials: The following is available online at www.mdpi.com/2414-6366/2/3/34/s1: Figure S1: Call algorithm template for enhanced rabies surveillance.

Acknowledgments: The authors thank the many respective state programs of the USDA, APHIS, WS, the CDC, the Wistar Institute and the New York State Department of Health Rabies Laboratory for their contributions to this project. The authors also thank R.L. Hale, B.N. Hicks, B.S. Haley, and A. Martin for programmatic and data support. 
Author Contributions: J.D.K. served as corresponding author, prepared, cleaned, and validated the data from the database for analysis, and wrote the manuscript. R.B.C. co-conceived the enhanced rabies surveillance program initiative and reviewed the manuscript. K.M.N. reviewed and proofread the manuscript, and validated data. C.E.R. collaborated on dRIT diagnostics and reviewed the manuscript. T.P.A. conducted statistical analysis and reviewed the manuscript. J.D.B. collaborated on dRIT diagnostics and reviewed the manuscript. D.S. co-conceived the enhanced rabies surveillance program initiative, conducted data analysis, and wrote and reviewed the manuscript.

Conflicts of Interest: The authors declare no conflict of interest.

\section{References}

1. Fooks, A.R.; Müller, T. (Eds.) Rabies Control-Towards Sustainable Prevention at the Source. In Proceedings of the Compendium of the OIE Global Conference on Rabies Control, Incheon-Seoul, Korea, 7-19 September 2011; World Organisation for Animal Health (OIE): Paris, France, 2012.

2. Müller, T.F.; Schroder, R.; Wysocki, P.; Mettenleiter, T.C.; Freuling, C.M. Spatio-temporal use of oral rabies vaccines in fox rabies elimination programmes in Europe. PLoS Negl. Trop. Dis. 2015, 9, e0003953. [CrossRef] [PubMed]

3. MacInnes, C.D.; Smith, S.M.; Tinline, R.R.; Ayers, N.R.; Bachmann, P.; Ball, D.G.; Calder, L.A.; Crosgrey, S.J.; Fielding, C.; Hauschildt, P.; et al. Elimination of rabies from red foxes in eastern Ontario. J. Wildl. Dis. 2001, 37, 119-132. [CrossRef] [PubMed]

4. Rosatte, R.C.; Power, M.J.; Donovan, D.; Davies, J.C.; Allan, M.; Bachmann, P.; Stevenson, B.; Wandeler, A.; Muldoon, F. Elimination of arctic variant rabies in red foxes, metropolitan Toronto. Emerg. Infect. Dis. 2007, 13, 25-27. [CrossRef] [PubMed]

5. Rosatte, R.C.; Donovan, D.; Allan, M.; Bruce, L.; Buchanan, T.; Sobey, K.; Stevenson, B.; Gibson, M.; MacDonald, T.; Whalen, M.; et al. The control of raccoon rabies in Ontario Canada: Proactive and reactive tactics, 1994-2007. J. Wildl. Dis. 2009, 45, 772-784. [CrossRef] [PubMed]

6. Slate, D.; Algeo, T.P.; Nelson, K.M.; Chipman, R.B.; Donovan, D.; Blanton, J.D.; Niezgoda, M.; Rupprecht, C.E. Oral rabies vaccination in North America: Opportunities, complexities, and challenges. PLoS Negl. Trop. Dis. 2009, 3, e549. [CrossRef] [PubMed]

7. Blanton, J.D.; Hanlon, C.A.; Rupprecht, C.E. Rabies surveillance in the United States during 2006. J. Am. Vet. Med. Assoc. 2007, 231, 540-556. [CrossRef] [PubMed]

8. Surveillance Blueprint. Available online: http://rabiessurveillanceblueprint.org/-SURVEILLANCEBLUEPRINT (accessed on 07 July 2017).

9. Slate, D.; Rupprecht, C. Rabies management in wild meso-carnivores. In Zoo and Wild Animal Medicine Current Therapy; Miller, E., Fowler, M., Eds.; Elsevier: St. Louis, MO, USA, 2012; pp. 366-375.

10. Lembo, T.; Niezgoda, M.; Velasco-Villa, A.; Cleaveland, S.; Ernest, E.; Rupprecht, C.E. Evaluation of a direct, rapid immuno-histochemical test for rabies diagnosis. Emerg. Infect. Dis. 2006, 12, 310-313. [CrossRef] [PubMed]

11. Rupprecht, C.E.; Cliquet, F.; Fehlner-Gardiner, C.; Fooks, A.R.; Müller, T.; Sabeta, C.; Slate, D. Progress in the Development of a Direct Rapid Immunohistochemical Test for Diagnosing Rabies. OIE Bull News from Our Colleagues. Available online: http://www.oie.int/doc/ged/D14185.PDF (accessed on 15 March 2017).

12. Rupprecht, C.E.; Slate, D. 2012. Rabies prevention and control: Advances and challenges. In Rhabdoviruses: Molecular Taxonomy, Evolution, Genomics, Ecology, Host-Vector Interactions, Cytopathology and Control; Dietzgen, R.G., Kuzmin, I.V., Eds.; Caister Academic Press: Pool, UK, 2012; pp. 215-252.

13. Walsh, D.P.; Miller, M.W. A weighted surveillance approach for detecting chronic wasting disease foci. J. Wildl. Dis. 2010, 46, 118-135. [CrossRef] [PubMed]

14. Rees, E.E.; Belanger, D.; Lelievre, F.; Cote, N.; Lambert, L. Targeted surveillance of raccoon rabies in Quebec, Canada. J. Wildl. Manag. 2011, 75, 1406-1416. [CrossRef]

15. Rolley, R.E.; Lehman, L.E. Relationships among raccoon road kill surveys, harvests, and traffic. Wildl. Soc. Bull. 1992, 20, 313-318.

16. Gehrt, S.D. Evaluation of spotlight and road kill surveys as indicators of local raccoon abundance. Wildl. Soc. Bull. 2002, 30, 449-456.

17. Gehrt, S.D.; Hubert, G.F.; Ellis, J.A. Long-term population trends of raccoons in Illinois. Wildl. Soc. Bull. 2002, $30,457-463$. 
18. Ma, X.; Blanton, J.D.; Rathbun, S.L.; Recuenco, S.; Rupprecht, C.E. Time series analysis of the impact of oral vaccination on raccoon rabies in West Virginia, 1990-2007. Vector-Borne Zoonotic Dis. 2010, 10, 801-809. [CrossRef] [PubMed]

19. Houle, M.; Fortin, D.; Mainguy, J.; Canac-Marquis, P. Landscape composition and structure influence the abundance of mesopredators: Implications for the control of the raccoon (Procyon. lotor) variant of rabies. Can. J. Zool. 2011, 89, 1107-1116. [CrossRef]

20. Rosatte, R.C.; Donovan, D.; Allan, M.; Howes, L.A.; Silver, A.; Bennett, K.; MacInnes, C.; Davies, C.; Wandeler, A.; Radford, B. Emergency response to raccoon rabies introduction in Ontario. J. Wildl. Dis. 2001, 37, 265-279. [CrossRef] [PubMed]

21. Sanderson, G.C. Raccoon. In Wild furbearer management and conservation in North America; Novak, M., Baker, J.A., Obbard, M.E., Malloch, B., Eds.; Ontario Trappers Association: North Bay, Ontario, ON, Canada, 1987; pp. 486-499.

22. Rosatte, R.; Sobey, K.; Donovan, D.; Allan, M.; Bruce, L.; Buchanan, T.; Davies, C. Raccoon density and movements after population reduction to control rabies. J. Wildl. Manag. 2006, 71, 2373-2378. [CrossRef]

23. Prange, S.; Gehrt, S.D.; Wiggers, E.P. Demographic factors contributing to high raccoon densities in urban landscapes. J. Wildl. Manag. 2003, 67, 324-333. [CrossRef]

24. Canadian Food Inspection Agency. Rabies in Canada. Available online: http://www.inspection.gc. ca/animals/terrestrial-animals/diseases/reportable/rabies/rabies-in-canada/eng/1487180259340/ 1487180260042 (accessed on 22 May 2017).

25. Hirsch, B.; Reynolds, J.H.; Gehrt, S.; Craft, M.E. Which mechanisms drive seasonal rabies outbreak in raccoons? A test using dynamic social network models. J. Appl. Ecol. 2016, 53. [CrossRef]

26. Russell, C.A.; Smith, D.L.; Childs, J.E.; Real, L.A. Predictive spatial dynamics and strategic planning for raccoon rabies emergence in Ohio. PLoS Biol. 2005, 3, 382-388. [CrossRef] [PubMed]

27. Recuenco, S.; Blanton, J.D.; Rupprecht, C.E. A spatial model to forecast raccoon rabies emergence. Vector-Borne Zoonotic Dis. 2012, 12, 126-137. [CrossRef] [PubMed]

(C) 2017 by the authors. Licensee MDPI, Basel, Switzerland. This article is an open access article distributed under the terms and conditions of the Creative Commons Attribution (CC BY) license (http:/ / creativecommons.org/licenses/by/4.0/). 


\title{
Rabies Virus Antibodies from Oral Vaccination as a Correlate of Protection against Lethal Infection in Wildlife
}

\author{
Susan M. Moore ${ }^{1, *}$, Amy Gilbert ${ }^{2}$, Ad Vos ${ }^{3}$, Conrad M. Freuling ${ }^{4}$, Christine Ellis ${ }^{2}$, \\ Jeannette Kliemt ${ }^{4}$ and Thomas Müller ${ }^{4}$ \\ 1 Kansas State University, Veterinary Diagnostic Laboratory, Rabies Laboratory, Manhattan, KS 66502, USA \\ 2 National Wildlife Research Center, US Department of Agriculture, Animal and Plant Health Inspection \\ Service, Wildlife Services, Fort Collins, CO 80521, USA; Amy.T.Gilbert@aphis.usda.gov (A.G.); \\ Christine.K.Ellis@aphis.usda.gov (C.E.) \\ 3 IDT Biologika GmbH, 06861 Dessau-Rosslau, Germany; Ad.Vos@idt-biologika.de \\ 4 Friedrich-Loeffler-Institut, Federal Research Institute for Animal Health, Institute of Molecular Virology and \\ Cell Biology, 17493 Greifswald-Insel Riems, Germany; Conrad.Freuling@fli.de (C.M.F.); \\ Jeannette.Kliemt@fli.de (J.K.); Thomas.Mueller@fli.de (T.M.) \\ * Correspondence: smoore@vet.k-state.edu; Tel.: +1-785-532-4472
}

Received: 2 June 2017; Accepted: 8 July 2017; Published: 21 July 2017

\begin{abstract}
Both cell-mediated and humoral immune effectors are important in combating rabies infection, although the humoral response receives greater attention regarding rabies prevention. The principle of preventive vaccination has been adopted for strategies of oral rabies vaccination (ORV) of wildlife reservoir populations for decades to control circulation of rabies virus in free-ranging hosts. There remains much debate about the levels of rabies antibodies (and the assays to measure them) that confer resistance to rabies virus. In this paper, data from published literature and our own unpublished animal studies on the induction of rabies binding and neutralizing antibodies following oral immunization of animals with live attenuated or recombinant rabies vaccines, are examined as correlates of protection against lethal rabies infection in captive challenge settings. Analysis of our studies suggests that, though serum neutralization test results are expected to reflect in vivo protection, the blocking enzyme linked immunosorbent assay (ELISA) result at Day 28 was a better predictor of survival. ELISA kits may have an advantage of greater precision and ability to compare results among different studies and laboratories based on the inherent standardization of the kit format. This paper examines current knowledge and study findings to guide meaningful interpretation of serology results in oral baiting monitoring.
\end{abstract}

Keywords: rabies; wildlife; vaccination; antibodies; serology

\section{Introduction}

Rabies is caused by infection with lyssaviruses, which are a group of single-stranded negativesense RNA viruses in the family Rhabdoviridae. Lyssaviruses principally infect the nervous system (NS) of mammals, and this infection is nearly $100 \%$ fatal in both reservoir and incidental hosts after a prolonged incubation period of 1-3 months [1]. It is well recognized that both cell-mediated and humoral immune effectors are important in combating rabies infection [2], although the humoral response receives greater attention with regard to prevention of rabies. Rabies virus neutralizing antibodies comprise an important part of the humoral response and are able to block virus entry into cells, thus preventing or limiting infection, and entry of the virus into the NS. While the administration of post-exposure prophylaxis (PEP) is restricted to humans, preventive prophylaxis is recommended or required for domestic animal hosts in many parts of the world, and the principle of preventive 
vaccination has been adopted for strategies of oral rabies vaccination (ORV) of wildlife reservoir populations for decades to control circulation of rabies virus in free-ranging hosts [3,4]. Efficacy of the biologic in protecting against a lethal rabies infection in a significant proportion of vaccinated animals (e.g., $>86 \%$ ) must be demonstrated in a captive setting prior to product licensure [5]. There remains much debate about the levels of rabies antibodies that confer resistance to rabies virus infection and, although antibody levels are one key index of resistance to challenge in animal models [6,7], no single cutoff level of rabies antibody is recognized as being invariably protective [8]. This is due to repeated observations that small fractions of animals presenting detectable levels of antibody prior to challenge can still succumb to rabies infection, and conversely some seronegative animals survive challenge [8,9].

The immunogenicity of the vaccine, measured by induction of rabies binding and/or neutralizing antibodies, generally correlates well with survival to lethal challenge, although there may also be significant yet unmeasured cell-mediated responses involved during infection and replication of the live vaccine virus in the oral mucosa and tonsils. An inverse relationship between the strength of the humoral versus cell-mediated immune responses to inactivated rabies vaccination in humans was documented in one study [10], and it is unclear whether animals demonstrate a similar inverse relationship following infection with live oral rabies vaccines. Along with other host factors, this in part also contributes to the inability of rabies antibodies alone to serve as a perfect correlate of protection against lethal infection. Studies have demonstrated the level of immune response to vaccination is related to an individual's polygenetic major histocompatibility complex (MHC) phenotype [11-13]. Such genetic variation in peptide binding regions may also play a role in the induction of rabies virus antibodies [14]. Depending on the length of the experiment, rabies antibodies can be measured at several time points pre- and post-challenge, and are important for a greater understanding of antibody kinetics post-vaccination and anamnestic response induced following challenge. Despite this, two time periods appear to yield the critical information needed for predicting the survival of most vaccinated animals in efficacy studies: the initial induction or Days 15-30 post-vaccination antibody level, and the level of antibody present immediately prior to rabies virus challenge. Studies need only establish that the animals were naïve prior to vaccination, as ultimately the survival data alone following challenge determine vaccine efficacy. The gold standard in measurement of rabies antibodies has typically involved serum neutralization tests (SNT) to detect rabies virus neutralizing antibodies (rVNA) (i.e., the rapid fluorescent focus inhibition test (RFFIT) or fluorescent antibody virus neutralization test (FAVN)), although enzyme-linked immunosorbent assays (ELISAs) are now also recognized as acceptable tests to detect binding rabies antibodies. Few studies measure both by SNT and ELISA methods but, where they have, a strong but not strict correlation in levels is observed between these two different antibody detection methods [15-18].

Part of ORV post-campaign monitoring is assessing the vaccination coverage by demonstrating an immune response in the target species (population level antibody prevalence); animals are sampled during a pre-determined interval after bait distribution. The application of rabies serology for monitoring the immune response through sampling demands an understanding of the relationship of antibody measured and survival upon challenge. To date, no study has examined whether this sample measured by the prescribed assays with a set cutoff value is actually suitable in terms of predicting protective immunity in wildlife populations (population level immunity). Similarly, reliability of the prescribed assays has not been comprehensively established. The objective of this paper is to quantitatively examine the induction of rabies binding and neutralizing antibodies following oral immunization of animals with live attenuated or recombinant rabies vaccines, as correlates of protection against lethal rabies infection in captive challenge settings by reviewing both published literature and our own unpublished animal studies. Using these data, we challenge the notion of a single antibody cutoff level being used to indicate complete protection against lethal rabies challenge across animal species. 


\section{Materials and Methods}

\subsection{Literature Review}

Published peer-reviewed journal articles concerning oral rabies vaccination in wildlife that included rabies antibody measurement after oral vaccination and challenge were reviewed in an attempt to identify a protective level per rabies antibody. These were obtained through a search on PubMed with the terms "rabies oral vaccination", "rabies challenge studies in wildlife". Of the 42 articles initially identified by description in the abstracts, 6 were removed for lack of serological data leaving 35 articles [19-53]. Six of the articles included studies on more than one species. The number of articles by species included fox (17), skunk (9), raccoon, (7), dog (6), and one each for mongoose and raccoon dog. The articles were reviewed for information about vaccination construct and challenge virus doses and strains, serological assay type, and sampling time periods, as well as correlation of antibody measurement with survival/death outcomes and are summarized in Table 1. In particular, identification of discrepancies and sources of potential errors as well as studies that could be comparable due to consistent study designs were targeted.

\subsection{Animal Studies}

Empirical data from 28 different animal studies were analyzed (Table 2). All vaccinated animals received vaccine constructs by oral route; either by direct oral instillation or by offering a bait containing a vaccine-loaded blister. Hence, the animal species included in Table 2 are all considered target species for oral vaccination.

\subsection{Animals}

Animals described in Table 2 were obtained from commercial sources, except for the small Indian mongoose (Herpestes auropunctatus). Mongooses were wild-caught on a rabies-free island off the coast of Croatia. All studies were carried out according to prevailing guidelines. All experimental protocols had been reviewed and approved by the German and American Ethics Committees. All studies at IDT were approved by "Landesverwaltungsamt Sachsen-Anhalt, Referat Verbraucherschutz, Veterinär-angelegenheiten". All studies at Friedrich-Loeffler-Institut (FLI) were approved by "Landesamt für Landwirtschaft, Lebensmittelsicherheit und Fischerei Mecklenburg-Vorpommern". Studies at NWRC were approved by NWRC institutional animal care and use committee (IACUC), see Table 2 for approval information (approval board, number, date).

\subsection{Vaccine}

Five different vaccine constructs were used in the empirical studies. The four rabies virus constructs were modified by site-directed mutagenesis using reverse genetics. The live recombinant virus construct expresses the rabies virus glycoprotein SPBN GAS [54], SPBN GASGAS [55,56], SAD dIND [57], ORA-DPC [58,59], and HAdVRG1.3 [60,61]. 
Trop. Med. Infect. Dis. 2017, 2, 31

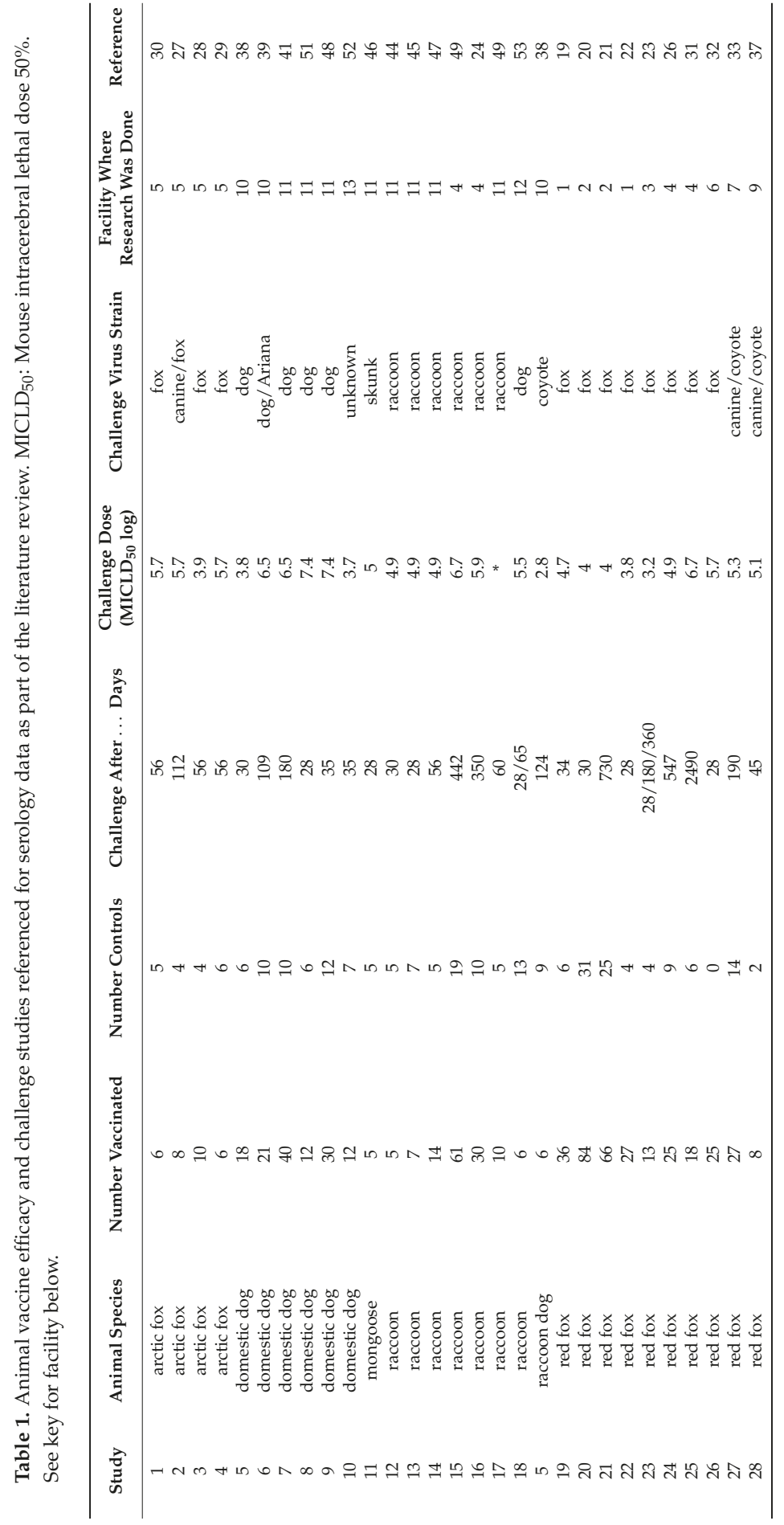


Trop. Med. Infect. Dis. 2017, 2, 31

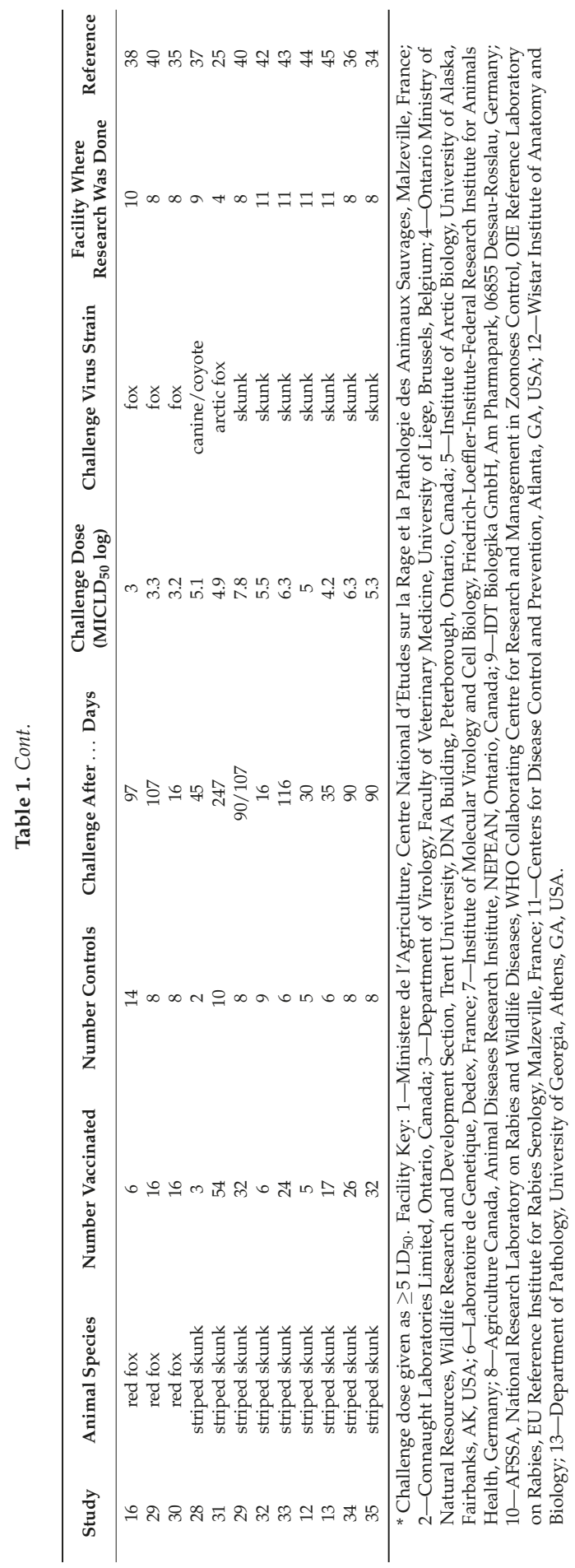




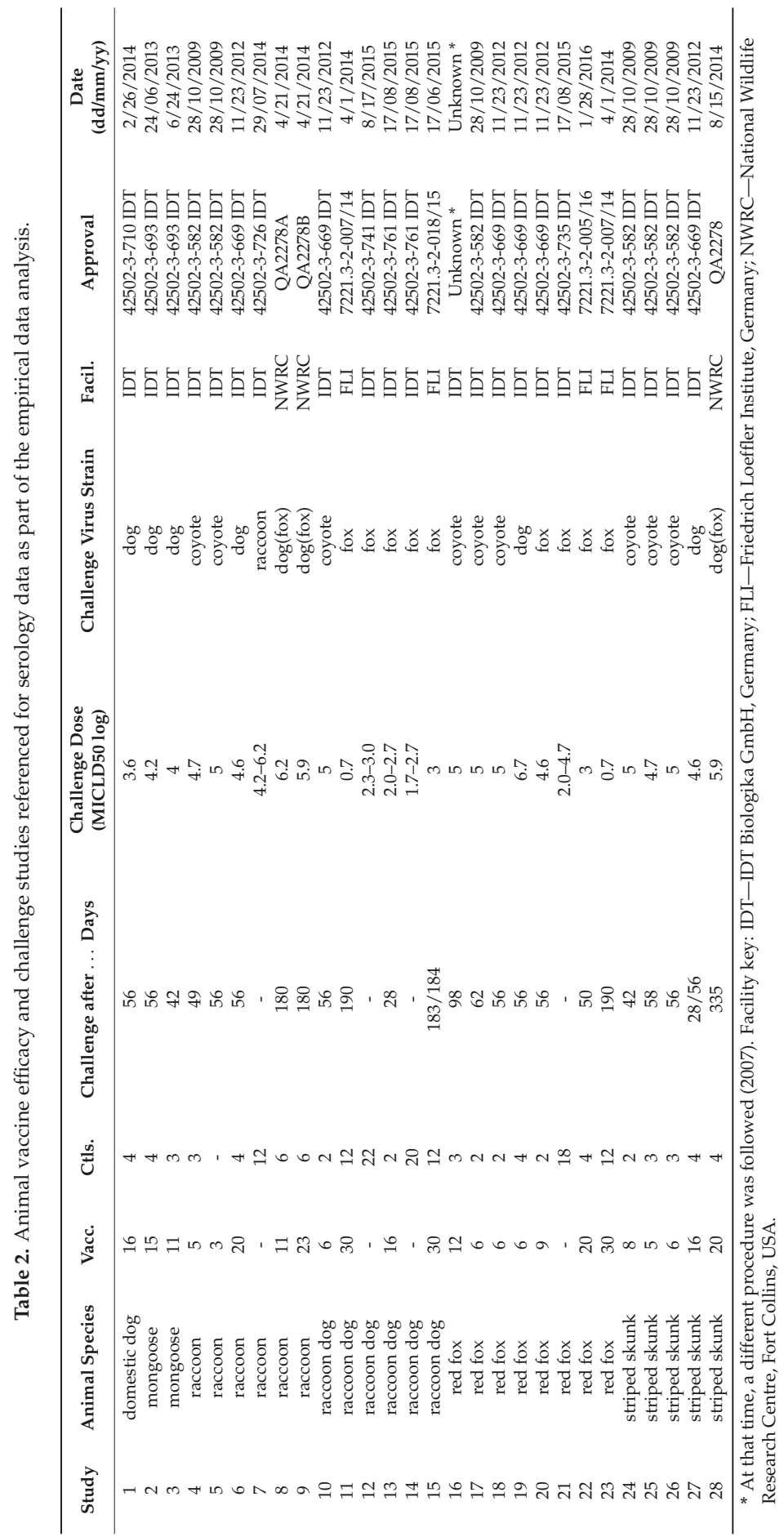




\subsection{Serum Samples}

Individual serum samples were used from experimental efficacy and challenge studies involving animals that were captive raised and never had prior vaccination against rabies, or that had been collected from a rabies-free area. In efficacy studies, depending on the experimental design, serum samples were taken at baseline and different time points post-vaccination prior to and post-challenge. For the purpose of this study, only serum samples collected at baseline (Day 0) and post-vaccination on Days 28-30 (referred to later as Day 28) and the day of or immediately prior to challenge virus administration were considered in the analysis. In challenge virus titration studies, blood samples were only taken at baseline prior to infection (Day 0). All sera were stored at $-20{ }^{\circ} \mathrm{C}$ and heat inactivated after thawing for $30 \mathrm{~min}$ at $56^{\circ} \mathrm{C}$ prior to testing. The samples were tested using a RFFIT (SNT) and ELISA assays. Sometimes no absolute value could be determined for the level of rVNA. In this case, and for the purpose of quantitative analyses, the upper limit was halved. For example, values less than 0.5 and 0.13 International Unit per milliliter (IU/mL) were converted to 0.25 and $0.07 \mathrm{IU} / \mathrm{mL}$, respectively.

\subsection{Serology}

At the FLI, rVNA for each sample was determined by using a modification of the RFFIT (Smith et al., 1973) essentially as described [62] using the standard rabies (RABV) challenge strain, challenge virus standard (CVS-11), as test virus. For titration, a two-fold lg2 dilution series of each serum sample (1:10 to 1:5120) in Dulbecco minimum essential medium (DMEM) was prepared. Subsequently, $50 \mu \mathrm{L}$ of the serum dilution was mixed with $50 \mu \mathrm{L}$ of a constant dilution of the test virus (adjusted to induce about 40 infected cells in a well of a Terasaki plate). After incubation for $90 \mathrm{~min}$ at $37^{\circ} \mathrm{C}, 0.1 \mathrm{~mL}$ of a $10^{6} / \mathrm{mL}$ concentration of baby hamster kidney (BHK)-21 C 13 cells in DMEM containing $10 \%(\mathrm{wt} / \mathrm{v}$ ) fetal calf serum was added. Subsequently, $10 \mu \mathrm{L}$ of the serum-virus-cell suspension was pipetted into wells of a Terasaki plate (Greiner, Germany) and incubated for $24 \mathrm{~h}$ in a controlled humidity, $\mathrm{CO}_{2}$ incubator at $37^{\circ} \mathrm{C}$. After fixation with acetone $(80 \%)$ for $30 \mathrm{~min}$ at $4{ }^{\circ} \mathrm{C}$, cells were stained with a fluorescein isothiocyanate (FITC) anti-rabies conjugate (Fujirebio Diagnostics, Malvern, PA, USA) for 30-60 min and examined with an inverse immunofluorescence microscope. In each test run, the World Health Organization (WHO) international standard immunoglobulin (2nd human rabies immunoglobulin preparation, National Institute for Biological Standards and Control, Potters Bar, UK) adjusted to $0.5 \mathrm{IU} / \mathrm{mL}$, and a naïve serum, served as a positive and negative control, respectively. The rVNA titer was defined as the dilution of the test serum showing a $50 \%$ reduction in the number of infected cells per microscopic field (50\% neutralizing dose, ND50) compared to the virus control. The exact titer was calculated using inverse interpolation as described [63] and subsequently converted into concentrations expressed in international units (IU/mL) using the calibrated positive control. As a national and OIE reference laboratory and WHO Collaborating Center for rabies the FLI is certified by the German accreditation body (DAkks) for human and animal rVNA testing and recognized by the German Ministry of Agriculture for performance of rVNA measurement of animal sera for pet travel purposes. The RFFIT assay described here has been internally validated per OIE guidelines for the purpose of rVNA measurement and per governmental approval, as it had been officially used for monitoring of oral vaccination campaigns of foxes in Germany for many years. Sensitivity and specificity was $95 \%$ and $98 \%$, respectively.

At Kansas State University, rVNAs were measured in serum samples following the RFFIT method [64] as published in the WHO and the World Organisation for Animal Health (OIE) manuals [5,65]. Briefly, $100 \mu \mathrm{L}$ of each serum sample, in duplicate, was diluted in serial five-fold dilutions in $10 \%$ fetal bovine serum supplemented Eagles minimum essential media (EMEM) and loaded into 8-well lab-tek chamber slides after which $100 \mu \mathrm{L}$ of the challenge virus, at a concentration of 50 tissue culture infective dose $50 \%\left(\mathrm{TCID}_{50}\right)$, was added. Slides were incubated at $37^{\circ} \mathrm{C}$ for $90 \mathrm{~min}$ after which $200 \mu \mathrm{L}$ of a suspension of $5 \times 10^{5}$ BHK-21 C 13 cells in 10\% FBS supplemented EMEM was added to each well. Slides were placed in a $2-5 \% \mathrm{CO}_{2}$ incubator at $37^{\circ} \mathrm{C}$ for $24 \mathrm{~h}$. After incubation, 
the slides were washed and fixed in $80 \%$ cold acetone, dried and stained with FITC conjugated anti-rabies antibody (Chemicon, Temecula, CA, USA). Twenty fields/well were examined under 100× magnification using a fluorescence microscope for the presence of rabies virus and rVNA titers were calculated using the Reed and Muench method [66]. In each test run, an international standard rabies immunoglobulin (SRIG) (WHO 1st human rabies immunoglobulin preparation Lot R-3, FDA/CBER, Rockville, MD, USA or WHO 2nd human rabies immunoglobulin preparation, National Institute for Biological Standards and Control, Potters Bar, UK) adjusted to $2.0 \mathrm{IU} / \mathrm{mL}$, internal rVNA standards, and naïve serum served as controls. The SRIG was also used as a calibrator to calculate the test sample IU/mL value by the flowing formula: SRIG titer/Sample titer $\times$ SRIG potency in IU $/ \mathrm{mL}$. The RFFIT assay has been internally validated for rVNA measurement at Kansas State University (KSU) to international standards for human samples [67] and per OIE guidelines and United States Department of Agriculture (USDA) recognized for the purpose of pet travel and wildlife serosurveys. Sensitivity and specificity was $98 \%$ and $98 \%$, respectively.

Sera were examined in a commercial blocking ELISA (BioPro Rabies ELISA, BioPro, Prague, Czech Republic) [68] for the presence of rabies-specific binding antibodies, following instruction of the manufacturer essentially as described [69]. Briefly, $100 \mu \mathrm{L}$ of a 1:2 dilution of each serum was pipetted into wells of full RABV antigen coated microplate. After overnight incubation at $2-8{ }^{\circ} \mathrm{C}$, in two consecutively-following steps $100 \mu \mathrm{L}$ of a biotinylated anti-rabies antibody and $100 \mu \mathrm{L}$ horseradish peroxidase (HRP)-conjugated streptavidin was added to each wells and incubated at $37^{\circ} \mathrm{C}$ for $30 \mathrm{~min}$ followed by four times rinsing to remove unbound conjugate. Color change was developed by adding $100 \mu \mathrm{L}$ of 3,3', 5,5-tetramethylbenzidine (TMB) chromogen solution to each well for 15-20 min at room temperature and the quantity of the analyte measured at $450 \mathrm{~nm}$. According to the manufacturer, a $40 \%$ inhibition of the test serum compared to the negative controls was considered a cutoff for positivity and a $70 \%$ inhibition considered equal to $0.5 \mathrm{IU} / \mathrm{mL}$. The performance characteristics were evaluated by the manufacturer and stated in the kit insert. The BioPro ELISA kit has been internally validated at FLI for humans, foxes, raccoon dogs, mongooses and raccoons using defined experimental (vaccinated/unvaccinated) as well as field sera.

A subset of sera was examined with a commercial indirect ELISA (Bio-Rad Platelia Rabies Kit II Ref: 355 1180, Marnes-la-Coquette, France) using the Bio-Rad Evolis instrument per the manufacturer's instructions. The kit contains strips of wells coated with rabies glycoprotein ( $\mathrm{G}$ protein). The secondary (detection) system is an enzyme conjugated Staphylococcus aureus protein A/substrate color reaction. The results were reported in equivalent units (EU)/mL (anti-rabies glycoprotein level) calculated by comparison of the sample optical density reading against a standard curve of positive standards supplied in the kit. The kit control is calibrated against the 2nd WHO (World Health Organization) international rabies immunoglobulin reference serum. The performance characteristics were evaluated by the manufacturer and stated in the kit insert [70]. The BioRad ELISA kit has been internally validated for use with raccoon sera at KSU.

\subsection{Statistical Analysis}

Data were analyzed using statistical software GraphPad Prism version 7.00 for Windows, GraphPad Software, La Jolla, California, USA. Test agreement was calculated using the GraphPad QuickCalcs Web site: http://graphpad.com/quickcalcs/kappa2/.

\section{Results}

\subsection{Literature Review}

\subsubsection{Serological Methods and Study Design Summary}

The vaccines studies covered a combination of live attenuated and/or genetically altered rabies viruses: SAD, SAG, and ERA; and live recombinant constructs incorporating only the rabies virus 
glycoprotein: VRG, HAdV5RG1.3, Ad5RG1, and CAV2-RVG, as well as mutants of these. Most are linked with the original SAD isolate in 1935. In general, the challenge virus strain used was derived from the species under study, with seven exceptions (Table 1). The challenge dose varied between $1 \times 10^{3}$ and $1 \times 10^{8}$ MICLD $_{50}$. The site of challenge was mostly the masseter and temporal muscles, but also targeted were the biceps, gluteal, abductor digiti quinti, and cervical musculature. The interval between vaccine and challenge ranged from 28 to 2490 days.

In these studies (Table 1), the RFFIT was the most frequently employed assay for measurement of rabies antibody levels in response to vaccination, and the majority (but not all) referenced the original method in Smith, 1973. The remaining studies, besides three using a competitive ELISA (cELISA), used other serum neutralization assays: four used FAVN method as described in the OIE manual; five used a fluorescence inhibition microtest (FIMT) that essentially represents a modified RFFIT [71], three used other modified RFFIT methods, and three used undefined serum neutralization assays. Only $54 \%$ (19 of 35) of the papers reported a cutoff level of seroconversion or seropositivity. In ten of the 19 studies, $0.5 \mathrm{IU} / \mathrm{mL}$ was the level defined as rVNA-positive; these included studies using RFFIT (4), FAVN (4), and modified RFFIT (2) assays. Three of the studies using FIMT applied $0.13 \mathrm{IU} / \mathrm{mL}$ as the level of seropositivity. Three referred to evidence of neutralization at a 1:5 dilution of the serum, but also reported the result in IU $/ \mathrm{mL}$. The three studies using the cELISA assay defined seroconversion as $\geq 25 \%, 26 \%$ and $28 \%$ inhibition, and one further defined it as three consecutive weeks of measurements above the cutoff, and measured antibody response by cELISA in weekly samples, but the pre-challenge samples by SNT.

\subsubsection{Serological Results Summary}

Due to the heterogeneity of experimental design and serological methods used, after review of the published studies listed in Table 1, the relationship of vaccinated status to serology and survival following challenge could only allow a general conclusion: the majority of the subjects in the studies that developed detectable rabies antibodies post-vaccination were also more likely to survive challenge. Those individual subjects with the highest titers in each separate study had the best likelihood of survival regardless of the range in titers produced in the vaccinated subjects, demonstrating that, though the assays used in these various studies had not been formally correlated, and indeed could vary in cutoff level and range, the results were generally consistent in identifying the likely survivors in a group by the level of antibody measured. Vaccinated status did not guarantee survival, and neither did demonstration of circulating rabies antibodies post-vaccination.

Thirty-five studies reported rabies antibody level in individual values, either IU / $\mathrm{mL}$, titer (for SNT assays), or percent inhibition (for cELISA assays). In regards to correlation of serology results to survival from challenge, in 18 of the 39 studies (46\%) the relationship was absolute: all subjects with detectable rabies antibodies survived challenge and all with no detectable antibody succumbed. For $66 \%(12 / 18)$ of those, the effective cutoff level was $0.5 \mathrm{IU} / \mathrm{mL}$. Animals with undetectable or below cutoff rVNA levels survived challenge in 14 of the 39 studies (36\%). However, in 6 of the 39 studies the opposite trend occurred where rVNA "positive" animals succumbed (e.g., levels of $0.65 \mathrm{IU} / \mathrm{mL}$, $0.57 \mathrm{IU} / \mathrm{mL},>0.5 \mathrm{IU} / \mathrm{mL}, 1.07 \mathrm{IU} / \mathrm{mL}, 1.3 \mathrm{IU} / \mathrm{mL}$, and $>1: 5$ titer); in many of these events, the animal that succumbed had the lowest rVNA level among the group of vaccinated subjects in the experiment. Only in one of the 39 studies was the relationship between serological response and survival weak; subjects that succumbed had rVNA levels at day of challenge between 0.06 and $2.2 \mathrm{IU} / \mathrm{mL}$ and, for the ones that survived, the range was 0.04 to $12.2 \mathrm{IU} / \mathrm{mL}$. In this study, the subjects were considered seroconverted if they had detectable rabies antibodies for more than three consecutive weeks; there was no correlation of seroconversion to survival, with the range of consecutive weeks for both the survivors and died encompassing 1-15 weeks.

The ability of the rabies serology results to predict percent survival is partially predicated on the day of sampling and the day of challenge. In the 26 studies where both Days 14-30 and day of challenge (within seven days) rabies antibody results were given, Days 14-30 antibody levels were 
higher or essentially the same as at day of challenge in $69 \%$ of the studies; the levels higher at day of challenge in $31 \%$ of the studies. For the remaining studies where the results were higher at the earlier time-point, the day of challenge occurred later than 90 days post-vaccination, thus in extended sampling it appears the determination of early seroconversion was a better predictor of survival than the level at day of challenge.

\subsection{Animal Studies}

\subsubsection{Correlation between Blocking ELISA and RFFIT Values and Test Agreement}

For pooled data independent of species (Figure 1) there was a poor correlation $\left(\mathrm{R}^{2}=0.0189\right)$ between ELISA and RFFIT values, although a significant positive trend is observed ( $p=0.0002$; $95 \%$ CI of slope 0.1792 to 0.5760 , Figure $1 \mathrm{~A}$ ). The correlation remains poor even if different subgroups, i.e., baseline versus day of challenge sera, are considered. For baseline samples, there was no detectable trend (Figure 1B-D). Only for the red fox $(n=212)$, was a significant positive trend detected $(p<0.0001$; 95\% CI of slope 5.569 to 9.850 , Figure 1D).

In studies 8 and 9 (Table 2), an indirect ELISA (Bio-Rad) was used. A better correlation between the RFFIT and the indirect ELISA values was demonstrated overall, although not linear (Figure 2A). However, when the correlation was determined for RFFIT values $\leq 1.0 \mathrm{IU} / \mathrm{mL}$, the correlation of this subset is relatively poor (Figure 2B). While it appears that the Bio-Rad ELISA is quite suitable in identifying true negatives, the test had difficulties in identifying vaccinated animals, particularly at Day 28 (Figure 2D). In total, 12 of 29 (41.4\%) vaccinated raccoons in this study tested "negative" $(\leq 0.125)$ in the Bio-Rad ELISA on day of challenge but subsequently survived the challenge infection (Figure 2C).
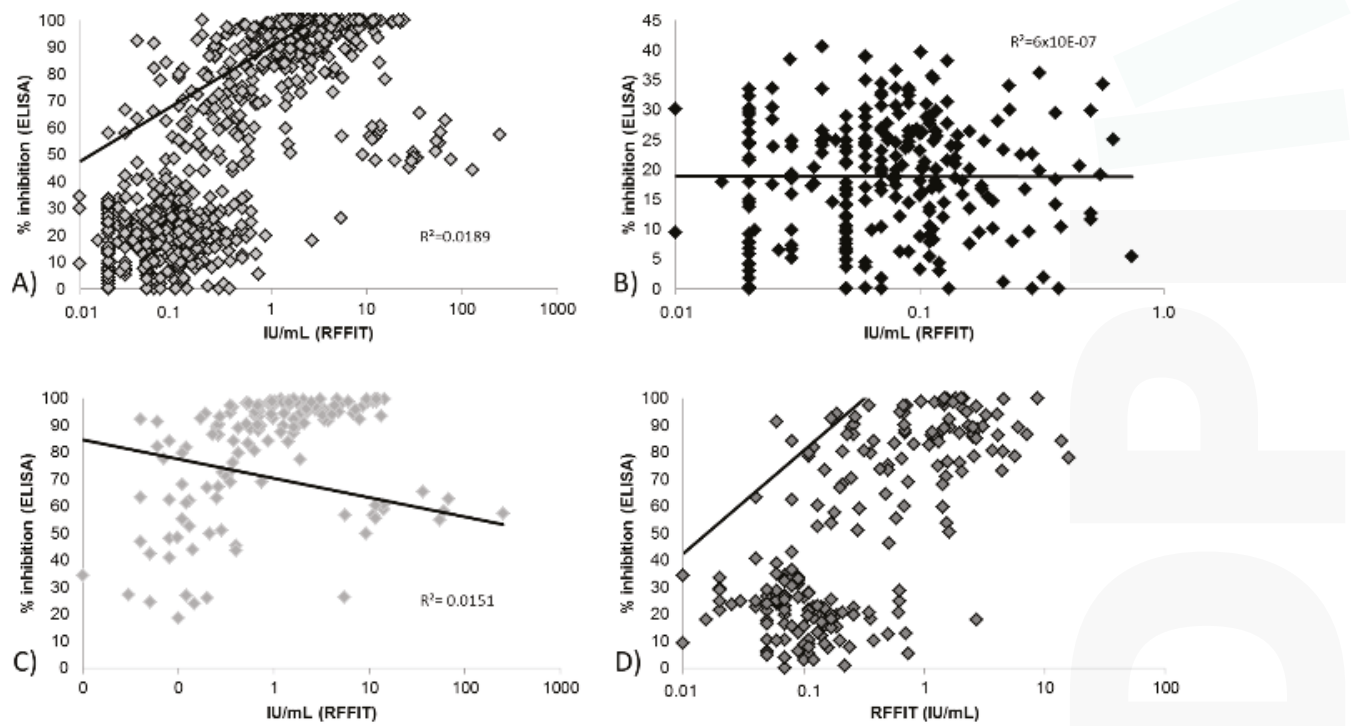

Figure 1. Correlation between the rapid fluorescent focus inhibition test (RFFIT) (IU/mL) and blocking enzyme linked immunosorbent assay (ELISA) (\% inhibition) results of: (A) pooled time points and species $(n=725)$; (B) pooled species baseline samples $(n=255)$; (C) pooled species day of challenge samples $(n=178)$; and (D) pooled time points fox samples $(n=212)$. Blocking ELISA values of $<0 \%$ and $>100 \%$ were set at $0 \%$ and $100 \%$, respectively. 

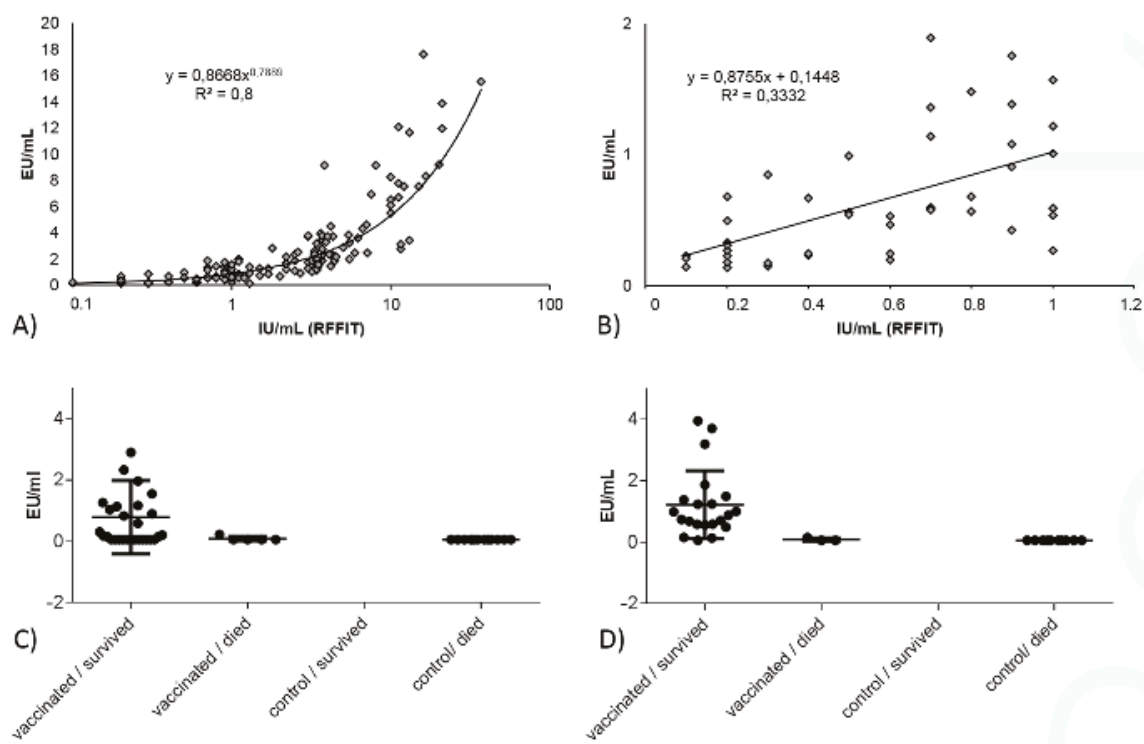

Figure 2. The correlation between RFFIT and indirect ELISA (Bio-Rad) for study 8 (Table 2): (A) the complete data set of absolute values, one outlier (indirect ELISA-48.78) was removed; (B) same data set but only for values with a RFFIT-result of $<1.0 \mathrm{IU} / \mathrm{mL}$; (C) indirect ELISA results at day of challenge for the vaccinated and control animals per outcome of challenge; and (D) indirect ELISA results on Day 28 post-vaccination for the vaccinated and control animals per outcome of the challenge infection. $\mathrm{EU} / \mathrm{mL}$ is Equivalent Unit per milliliter.

\subsubsection{Limit of Detection for Blocking ELISA and RFFIT}

For both assays, the lower limit of detection was assessed by analyzing the immune response measured in naïve (unvaccinated) animals. For the blocking ELISA the equation of best fit was $\mathrm{y}=8.44+\left(1-\mathrm{e}^{-0.0476 \mathrm{X}}\right)$, resulting in $95 \%$ of all samples from unvaccinated animals showing an inhibition of $<43 \%$ (Figure $3 \mathrm{~A}$ ). When the same analysis was done for RFFIT results using the same sample set, the equation of best fit was $y=100\left(1-\mathrm{e}^{-11.79 \mathrm{X}}\right)$. In this case, $95 \%$ and $70 \%$ of all samples from unvaccinated animals had rVNA-levels of $<0.25$ and $<0.10 \mathrm{IU} / \mathrm{mL}$, respectively. Hence, the lower limit of detection for RFFIT was $<0.25 \mathrm{IU} / \mathrm{mL}$ (Figure 3B).
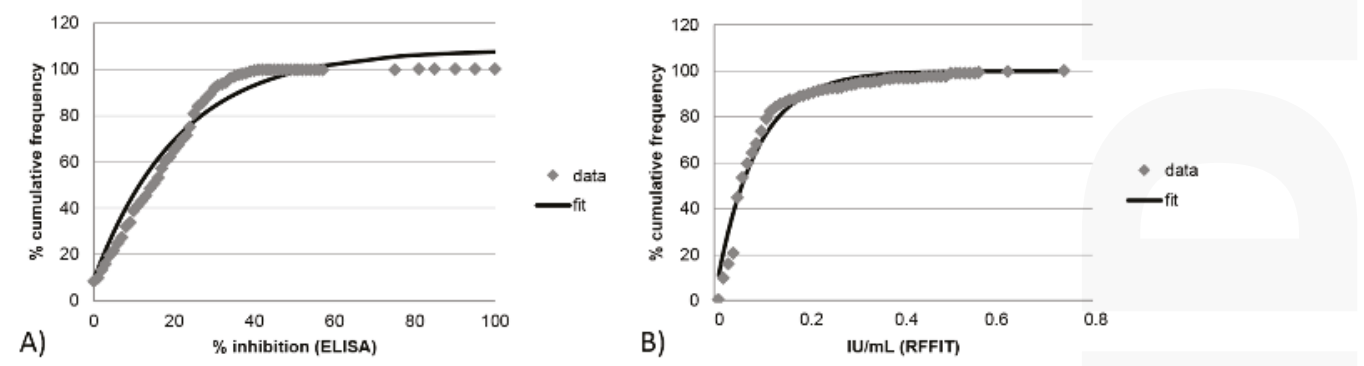

Figure 3. Cumulative frequency of rabies antibody test values in samples from unvaccinated animals (i.e., baseline samples of vaccinated animals and control unvaccinated animals) for the: blocking ELISA (A); and the RFFIT (B). For the latter, only absolute values were used and relative values of $<0.5$ or $<0.1 \mathrm{IU} / \mathrm{mL}$ were omitted. 
3.2.3. Correlation and Agreement of Test Results Obtained in Blocking ELISA and RFFIT with Survival/Death

Based on the currently used thresholds of seropositivity (blocking ELISA: cutoff $>40 \%$ inhibition; RFFIT $>0.5 \mathrm{IU} / \mathrm{mL})$, the agreement between the assays was high $(85.66 \%)$ resulting in a Kappa value of 0.71 (95\%CI: 0.66 to 0.76 ). When the RFFIT cutoff was set as $>0.25 \mathrm{IU} / \mathrm{mL}$, the agreement slightly increased to 0.75 (95\% CI: 0.70 to 0.80$)$. In both cases, the strength of agreement was considered to be "good" (Table 3).

When the immune response measured at Day 28 post vaccination, day of challenge, and the outcome of the challenge were analyzed using RFFIT values, a Michaelis Menten model demonstrated the best fit (Figure 4A,B). This model predicts a survivorship of $95 \%$ and $99 \%$ of the animals with rVNA levels of $\geq 0.43$ and $0.65 \mathrm{IU} / \mathrm{mL}$ at Day 28 post vaccination, irrespective of day of infection, respectively. In contrast, for the same time points and outcomes but using blocking ELISA values, a Boltzmann sigmoidal model demonstrated the best fit (Figure 3C,D). Here, survivorship of $93 \%$ and $57 \%$ are predicted when animals have inhibition values of $\geq 40 \%$ at Day 28 and at the day before challenge, respectively.

When comparing different thresholds of seropositivity for both assays, the relative chance of a seropositive animal to survive a challenge compared to a negative animal was highest for the blocking ELISA with the currently defined cutoff of $40 \%$ inhibition. In addition, the sensitivity was highest for this cutoff setting, while still demonstrating sufficient specificity (Table 3). While for all cutoff settings the positive predictive value was higher than $95 \%$, the negative predictive value was again highest for the blocking ELISA with the cutoff of $40 \%$ inhibition. Although the agreement between test result and outcome of infection varied across species, the best agreement (i.e., "good") was achieved for the $40 \%$ inhibition test setting.
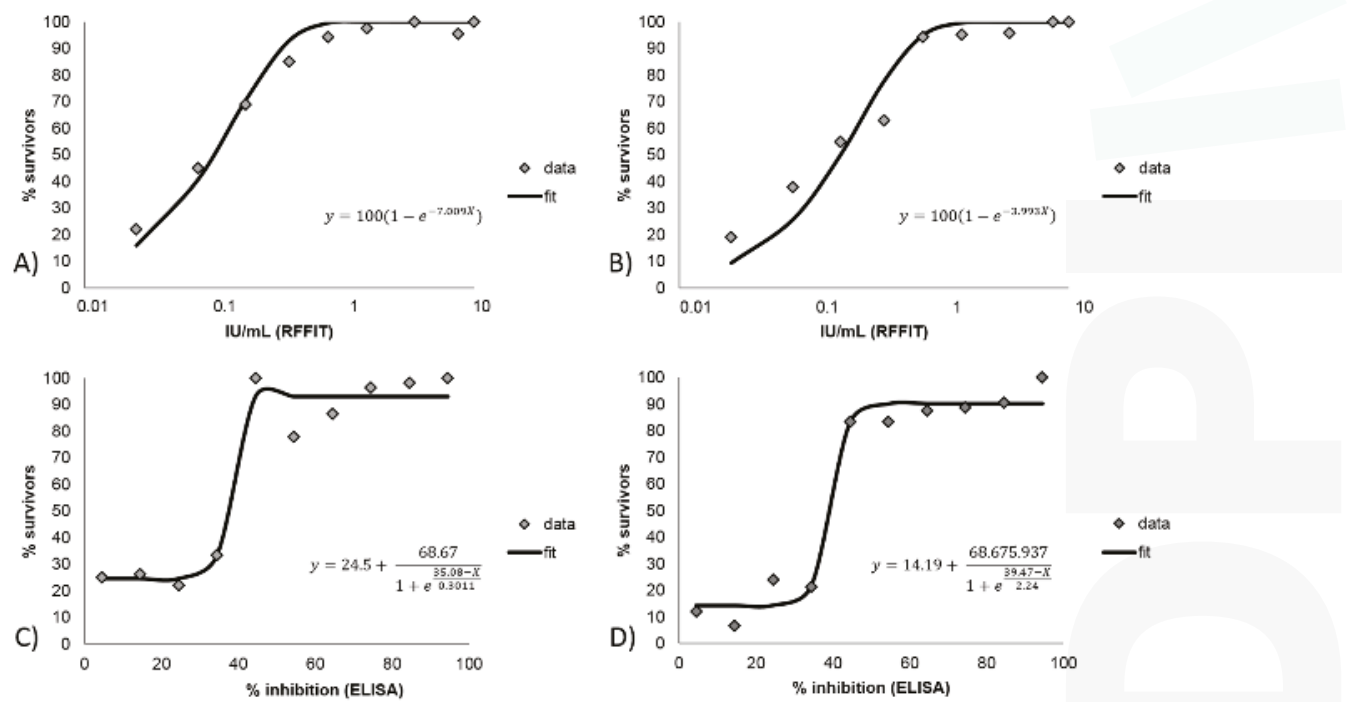

Figure 4. Relation between survivorship and immune response at: Day 28 post-vaccination (A,C); and the day of challenge (B,D). For RFFIT $(\mathbf{A}, \mathbf{B})$ the Michaelis Menten model is shown, while for blocking ELISA (C,D) the Boltzmann sigmoidal model is shown. 


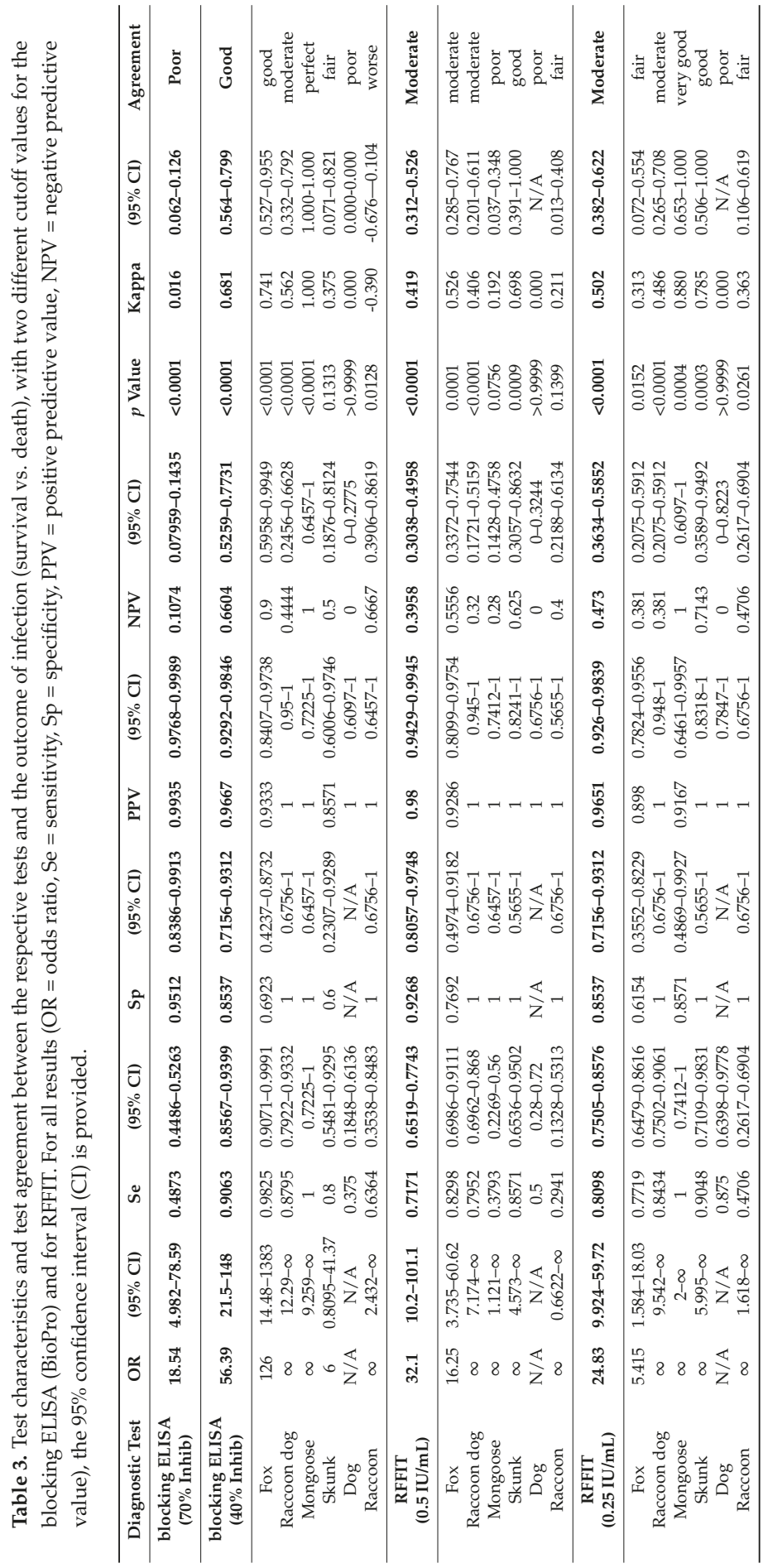


The good agreement with a cutoff of $40 \%$ inhibition for the blocking ELISA was also evident when species were analyzed separately, where except for raccoon dogs, very few animals with values $<40 \%$ survived a challenge infection (Figures 5 and 6 ). In contrast, low rVNAs (0.05 to $0.25 \mathrm{IU} / \mathrm{mL}$ ) were obtained in both survivors and animals that succumbed to rabies challenge. Some species-level differences were evident, with most survivors among mongooses having RFFIT titers $\geq 0.5 \mathrm{IU} / \mathrm{mL}$, while this proportion is lowest for dogs and raccoons. Except for raccoon dogs, where the proportion of RFFIT positives among survivors remains the same, a lower cutoff value of $0.25 \mathrm{IU} / \mathrm{mL}$ increases the proportion. The same applies to the day of testing, where samples taken 28 days post-vaccination have a greater proportion of RFFIT positive results than samples taken at the day of challenge (Figure 6A). This effect is not evident for the blocking ELISA, which generally provides a better match between survivorship and a positive result. Again, similar to the RFFIT, raccoons had the highest proportion of blocking ELISA negatives among survivors (Figure 6B).

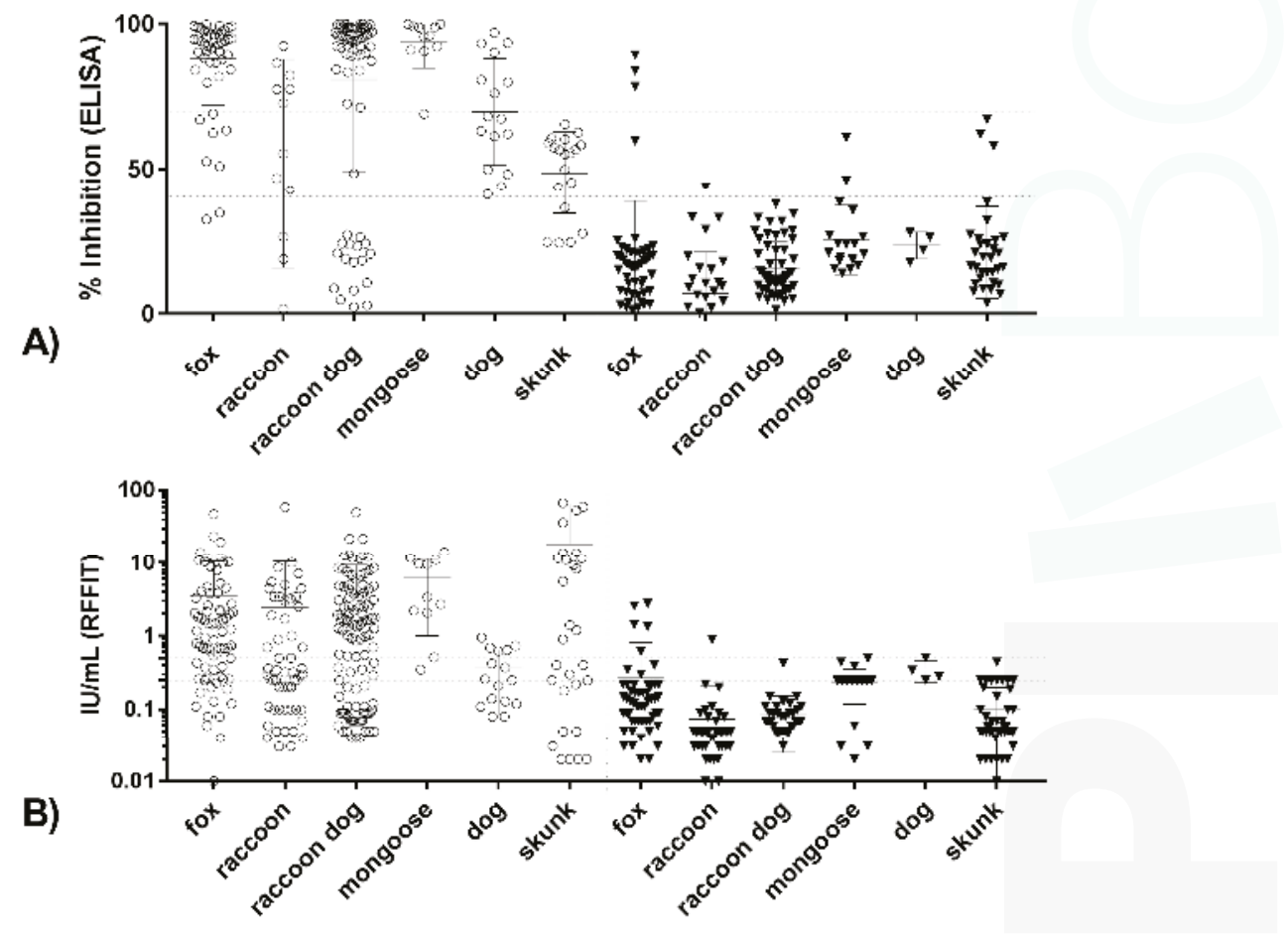

Figure 5. Scatter dot plot for: blocking ELISA (A); and RFFIT (B), for the individual species. Values are presented for survived (open circles) as well as for animals that succumbed to the infection (black triangle). Mean and standard deviation are indicated. Horizontal dotted lines indicate the thresholds used for blocking ELISA ( $40 \%$ and $70 \%$ inhibition) and for RFFIT (0.5 and $0.25 \mathrm{IU} / \mathrm{mL}$ ). 


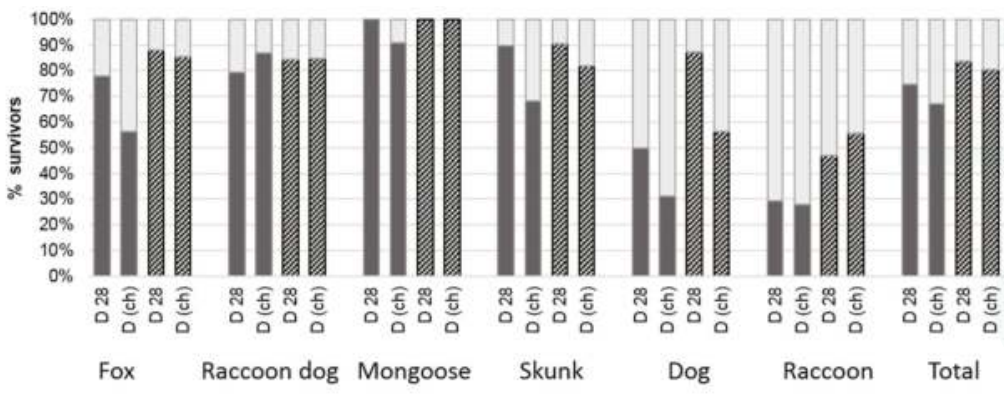

A)

$$
\square \geq 0.5 \mathrm{IU} / \mathrm{mL} \quad \mathbb{2} \geq 0.25 \mathrm{IU} / \mathrm{mL} \quad \square<0.5 \mathrm{IU} / \mathrm{mL},<0.25 \mathrm{IU} / \mathrm{mL}
$$

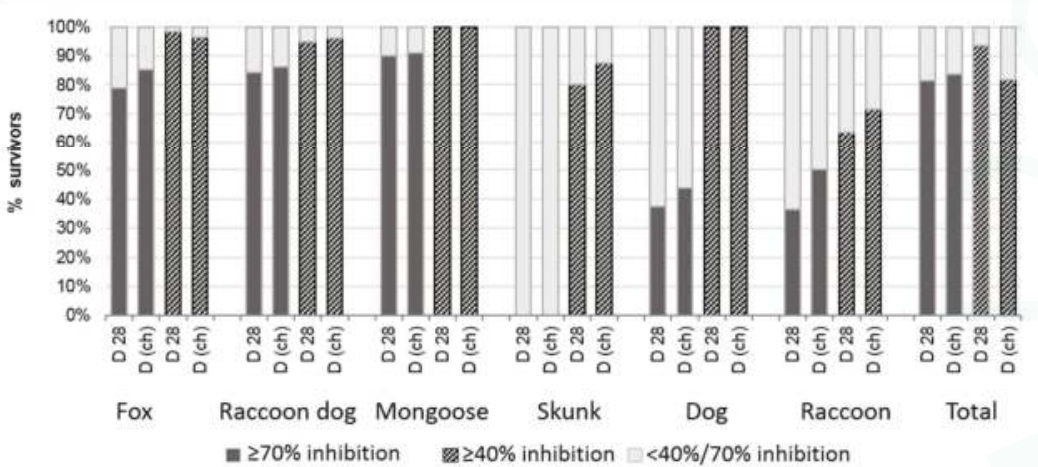

Figure 6. (A) Percentage of RFFIT positives and negatives per species among survivors, at different time points and using different cutoff values; and (B) percentage of blocking ELISA positives ( $\geq 40 \%$ inhibition) and negatives per species at Day 28 post-vaccination (D 28) and before challenge(D (ch)).

\section{Discussion}

Challenge studies demonstrating oral rabies vaccine efficacy in animals follow the same study design standards as parenterally-administered live or inactivated rabies vaccines. However, for oral vaccines, two efficacy studies are recommended by OIE guidelines [5], one involving direct instillation of the vaccine into the oral cavity, and the other involving bait delivery of the vaccine. However, U.S. and European specific guidelines appear to only require demonstration of bait efficacy for licensing $[72,73]$. The duration of vaccine immunity may vary according to product label intent and applicable guidelines. The minimum recommended duration standard for wildlife oral rabies vaccines is 180 days in the European Union [5] and 365 days in the U.S. [72]. Other differences include blood sampling at different time points and serological definition of population-level rabies immunity. For example, the US standards require several serum antibody measurements post-vaccination and prior to challenge [72], whereas the European Union does not [73]. Additionally, the proportion of vaccinated animals surviving challenge must be $87 \%$ or greater in the U.S. and with $80 \%$ or greater mortality of unvaccinated controls, but the European Union requires $92 \%$ or greater survival among vaccinates and $90 \%$ or greater mortality of unvaccinated controls $[72,73]$. These differences in acceptance standards pose difficulty for industry and end-users in defining adequate efficacy monitoring levels.

Tools to assess the effectiveness of ORV baiting programs to control rabies in an area are currently limited to measurement of rabies antibodies produced in response to vaccination, or case reductions or elimination of rabies cases following successive campaigns as the most definitive proof of baiting 
program effectiveness. However, particularly in rabies-free vaccination zones implemented to stop further spread, there is no other tool to verify effectiveness than to test population-based immunity. To this end, population-level antibody prevalence still is an imperfect means for assessing ORV baiting efforts, as antibodies are not the only informative measure of immunity against rabies infection. Clearly, the cellular as well as humoral immunity has been shown to play an important role in preventing disease, as well as innate immunity. However, the key to control rabies in susceptible wildlife is pre-exposure vaccination. This is due to unique viral mechanisms of the rabies virus. Pathogenic wild type rabies virus likely limits replication in nerves to lower the expression of glycoprotein, and downregulates receptors and signaling for infected nerve apoptosis by the immune system [74-76]. The virus also appears to downregulate the inflammatory response and enhance destruction of infiltrating lymphocytes to actively suppress the immune system [74]. Prior to accessing the NS, humoral and cell-mediated immune effector cells may have an opportunity to detect and clear the virus, which may permit host survival. In this regard, the type 1 helper $T$ cell pathway of response, signaled by increased production of interferon gamma (IFN- $\gamma$ ) and inflammation, is critical to activation of cytotoxic $T$ cells for clearance of the peripheral virus infection. However, nerve cells do not express class I MHC for presentation to activated T cells, and once rabies virus enters the immune-privileged central nervous system (CNS), the immunosubversive and evasive strategies of wild type RABV make it nearly impossible for the host to effectively combat the NS infection [2,74]. Vaccination prior to virus challenge induces immune effectors ( $B$ and $T$ cells) for establishment of rabies-specific antibody producing plasma cells. Circulating rabies antibodies will then be present to neutralize virus at the time of exposure as well as memory cells, which are primed and ready to respond and expand the response on repeated activation [77]. This effectively eliminates immunosubversive and evasive mechanisms of the rabies virus.

Oral vaccination of wildlife has led to the elimination of rabies in the target species in large parts of Europe and North America [78]. Application of serological monitoring as means of evaluating vaccination efficacy demands good understanding of the relationship of measured antibody level and survival from challenge. Certainly there are host factors that affect individual response to vaccination (e.g., genetic variation in MHC molecules) in addition to variable bait uptake interactions, but in strictly considering the means of predicting successful immunization (protection), establishing the reliability of serological monitoring as a tool is critical. The review of previous studies in which serological testing was performed in rabies challenge studies presented several difficulties in deducing what rabies antibody level was associated with a strong probability of survival. Analysis of the serological results in the literature review indicated a general positive correlation between level of rabies antibody and survival, but also revealed several variations in measurements, and in some studies, no solid relationship between antibody level and survival was demonstrated [24]. In regard to the assays used, understanding the abilities and limitations of the assay as well as use of quality control measures aids in interpretation of results [79]. While it is true that each study evaluated in the literature review did not use the same vaccine, same strain and dose of challenge virus, or same day of challenge, it is also true that use of a consistent method to measure rabies antibody would have allowed more robust comparison of antibody protection elicited by vaccination across studies. There are critical components of serum neutralization assays that will directly affect the accuracy of the antibody measurements. Key among them are the virus dose, virus strain, and reference serum [80]. Use of a high dose of virus may not allow detection of low antibody levels and too low a dose may overestimate the level. Use of a challenge strain that is not closely related antigenically to the vaccine strain may underestimate the antibody level [81]. Additionally, if the reference serum used to calibrate the titer results is not an international standard or qualified against one, the resulting values may be skewed $[8,82]$. Therefore, at minimum, the specificity, sensitivity, and measureable range of the assay employed should be defined and identified when reporting results to allow discernment as to the comparability of the findings with other studies. 
In the publications reviewed, the majority of serological measurements were performed with serum neutralization assays, which functionally should translate most clearly to protection. However, serum neutralization assays are less likely to be standardized when compared to ELISA assay kits, due to the many manual steps and component parts that can be independently sourced, thus less strictly controlled between laboratories. Therefore, while ELISA kits measure binding antibodies, not necessarily neutralizing antibodies, they have the advantage of ease of standardization and greater assurance of consistent results [8]. Several studies have demonstrated a good correlation between SNT and ELISA methods with human and animal sera at specific cutoffs $[15,17,18,69,83,84]$. In particular, a comparison of SNT and blocking ELISA in wild-caught raccoons and skunks from ORV areas demonstrated the utility and comparability of both assays at a cutoff of $0.5 \mathrm{IU} / \mathrm{mL}$ and $40 \%$ (or $25 \%$ as defined in some studies) respectively $[83,85]$. Overall, correlation between blocking ELISA and RFFIT values in this study for the all samples was poor, indicating that the two assays are measuring partially different antibody functions. This remains true even when the samples are analyzed in subgroups (survivors, died, Day 0, day of challenge, etc.) (Figure 1). Using the threshold for seropositivity (per BioPro, $>40 \%$ inhibition; per RFFIT, the commonly used level of $0.5 \mathrm{IU} / \mathrm{mL}$ ) good agreement between tests was obtained (Table 3). If a lower level was used for RFFIT seropositivity $(0.25 \mathrm{IU} / \mathrm{mL}$ ) the agreement was marginally improved. Correlation of BioRad ELISA and RFFIT results varied by day of draw with better correlation at day of challenge compared to Day 28, due to the fact that the ELISA only detects IgG antibodies, thus under-measures the total antibody response in the earlier time-point (Figure 2). Due to the simplicity, better precision, and repeatability of an ELISA kit compared to a complex, manual serum neutralization test, the functional test may not be the best test for the purpose of monitoring ORV campaigns. However, it is important to note ELISA techniques can vary in terms of ability to estimate protective (neutralizing) antibodies.

The key motivation for this study was to estimate a cutoff level associated with survival in animals vaccinated orally with live constructs. As can be surmised from the lack of correlation between seroconversion as assigned by cELISA results and challenge survival in one of the studies in the review [85], this is not an easy task. One of the complicating factors is species-associated matrix differences that can cause false positive results if the lower limit of detection has not been identified with a specific species serum, if there are interfering factors that prevent binding of competitive rabies antibodies in the cELISA or that non-specifically bind in the indirect ELISA $[8,86]$. The timing of blood draw for evaluation of antibody level appears to be critical in assessing protection conveyed by vaccination. Antibody development after vaccination has been well studied: a general pattern of detectable antibody level followed by a rise in neutralizing antibody, peaking between 14 and 30 days, followed by a slow decrease to a stable level; and if a booster dose is received a faster rise in level is expected followed by stabilization of a higher level $[26,87]$. While there are studies in dogs and cats that show a clear association between detectable rVNA before challenge and survival $[6,7]$, review of available published studies in wildlife and our own empirical studies included here indicate that detection of rVNA at Days 28-30 is also predictive of survival, and usually more so the later the day of challenge was in relation to the day of vaccination. In a study where the challenge day was 83 months from vaccination, $60 \%$ of the survivors had detectable rVNA at challenge and $40 \%$ did not; of those $40 \%$, all had detectable rVNA 66 months but only half of those had a level above $0.5 \mathrm{IU} / \mathrm{mL}$ at every sampling time point beyond the initial measurement at one month, indicating that measurable initial response was the better predictor of survival at challenge [31].

Determination of applicable cutoff level is important, as stated previously, for a specific assay given a specific purpose. Evaluation of background signal of negative samples provides information regarding a lower limit of detection. Ideally, negative samples will have levels significantly below the determined effective level to allow discernment between "positive" and "negative" samples. The same is true for determination of vaccination success and failure. Evaluation of Day 0 (unvaccinated subjects) samples (all species) revealed that $95 \%$ had a blocking ELISA result of $\leq 43 \%$ inhibition and a RFFIT result of $\leq 0.25 \mathrm{IU} / \mathrm{mL}$. Species differences were noted, with raccoons having less of a variation in 
result range than other species (Figure 5), indicating that further evaluation of negative samples by species is necessary for assignment of cutoffs for lower limit of detection of an assay. Figure 4 illustrates that the blocking ELISA "negative" and "positive" results are more clearly delineated in scale compared to the RFFIT data, which shows a more gradual relationship between rVNA level and survival. For example, the statistical probability for survival increases dramatically between blocking ELISA values of $35 \%(30-40 \%)$ and $45 \%(40-50 \%)$ inhibitions, whereas the same increase in probability occurs between an order of magnitude difference (i.e., 0.06 and $0.5 \mathrm{IU} / \mathrm{mL}$ ) for RFFIT values. For some species this may make assignment of a cutoff more difficult for RFFIT results than for the ELISA results (Table 1). This may indicate that the RFFIT is more sensitive at lower levels of antibody, causing poor delineation between "negative" and "positive" samples. Use of a specific challenge virus strain or increasing the challenge dose in the RFFIT procedure, possibly could correct this weakness. For RFFIT at $>0.50 \mathrm{IU} / \mathrm{mL}$, the probability of survival reaches $95 \%$ and at levels $>2.0 \mathrm{IU} / \mathrm{mL}$ it becomes $100 \%$ using a best fit curve of the data. For the blocking ELISA, $>80 \%$ probability of survival is obtained at $>40 \%$ inhibition and at $>70 \%$ inhibition over $90 \%$ probability of survival is attained. This analysis is remarkably similar whether the result used is from Day 28 or day of challenge, and our empirical results also demonstrated that Day 28 post-vaccination titer levels were a better predictor of survival than titers measured immediately prior to challenge. As expected, the higher the antibody level measured, whether by indirect ELISA, cELISA, blocking ELISA or RFFIT, the higher the probability of survival, to a robust point where the level is associated with $100 \%$ survival; beyond that point, higher titer levels do not translate into "better protection".

Oral vaccination has proven to be an effective tool in rabies prevention and control. The target species varies per endemic region and vaccines are developed that are of highest efficacy in their targeted species. The specific $\mathrm{G}$ protein, copies presented, and other details of the vaccine construct in combination with the specific assay used for antibody measurement theoretically can affect the relationship of rabies antibody level and probability of survival. An analysis of the results by vaccine construct indicates constructs are not the reason for the effect seen in raccoons and skunks, and that the limited data for dogs do not allow for a robust conclusion (data not shown). It is not unusual therefore to see various correlations of serological results and survival among different species. Indeed, the results of this study demonstrate that a single cutoff level of seropositivity is not universally applicable. As mentioned previously, the unvaccinated raccoon samples had a lower mean percent inhibition by blocking ELISA and lower mean IU/mL by RFFIT compared to the other species (Figure 5A,B), while unvaccinated fox samples had a small number of samples with results above the cutoffs for both methods. For all the species, except fox, the $70 \%$ inhibition cutoff for blocking ELISA was robust; the lower threshold ( $40 \%$ inhibition) allowed misidentification of unvaccinated fox, raccoon, mongoose, and skunk samples. For RFFIT, the $0.25 \mathrm{IU} / \mathrm{mL}$ cutoff was robust for raccoons, raccoon dogs, and skunks, and the higher cutoff of $0.5 \mathrm{IU}$ was better at identifying unvaccinated mongoose and dog samples (Figure 5A,B). The Bio-Rad ELISA results appeared to be better correlated to RFFIT results overall; however, for results below $1.0 \mathrm{IU} / \mathrm{mL}$, the correlation is poor, indicating that it may not be as useful in situations where low antibody levels are expected. The Bio-Rad ELISA was quite suitable in identifying true negatives, while the test had difficulties in identifying vaccinated animals (Figure 2C,D). It is possible that increasing the sensitivity of this assay by adjustment of conjugate or antigen could improve performance for wildlife species.

These findings illustrate the importance of evaluation of the appropriate cutoff by species and by assay. Similarly, relationship of rabies antibody level and challenge outcome varied by species, assay used, and cutoff level. For RFFIT the best predictor of survival having a result of $\geq 0.25 \mathrm{IU} / \mathrm{mL}$ at Day 28 across species, although for raccoon dogs and raccoons the best predictors were $\geq 0.25 \mathrm{IU} / \mathrm{mL}$ at day of challenge (Figure 6A). For the blocking ELISA results, the $40 \%$ inhibition cutoff was an excellent predictor of survival for fox, raccoon dog, mongoose, and dog, with $90 \%$ or more subjects at that inhibition level surviving challenge. Across species, the $70 \%$ inhibition level was a less accurate 
predictor of survival (Figure 6B). Overall, the $>40 \%$ inhibition blocking ELISA result at day of challenge determined survival most often, with the majority of results from fox and raccoon dog studies.

\section{Conclusions}

Acceptance standards for challenge studies determining an associated protective antibody level with challenge survival in the review of previous challenge studies in wildlife were not feasible (Table 1).

Assays must be evaluated for purpose (for example, to identify vaccinated animals, to identify vaccinated animals with protective immunity, and to identify free-ranging wild animals previously exposed to rabies infection) and generalizations should not be made to other purposes for which an assay was never evaluated.

Specificity (based on the vaccine antigen and assay antigen relationship), sensitivity, accuracy (including linear range) and precision of different assays may vary among species. Standardization and quality control of reagents and procedures, whether kits or manual procedures are established, is absolutely essential. These criteria should be evaluated before assigning the assay as fit for purpose.

Timing of sampling for antibody response to oral vaccine bait uptake should be optimized to target the initial seroconversion peak period, because this point predicts (given the appropriate cutoff and assay for the target species) survival as well as or even better than the level measured just before challenge.

In our study, positive blocking ELISA results are a better predictor for survival than the various SNTs applied overall. If the ELISA kits used have sufficiently good lot to lot quality control, the results from one study can be directly compared to another separated by time and space, with high confidence. Monitoring of ORVs based on seroconversion rates of the target population should make use of blocking ELISA tests instead of SNTs, for both strength as a survival predictor and ease of standardization.

Whatever assay is selected, it should have a defined (by validation) relationship to protection and robustly meet the minimum requirements for the purpose.

Supplementary Materials: The following are available online at http://www.mdpi.com/2414-6366/2/3/31/s1.

Acknowledgments: We thank Sami Pralle (KSU, Manhattan, KS, USA) and Dale Claassen (KSU, Manhattan, KS, USA) for excellent technical assistance. Gratefully acknowledged is the permission by Alex Beath (Artemis Technologies Inc., Guelph, ON, Canada), Klaus Conzelmann (Ludwig Maximilians University, Munich, Germany) and Normal Spibey (MSD Animal Health, Milton Keynes, UK) for use of the vaccine constructs data.

Author Contributions: S.M.M., A.G., C.M.F., A.V. and T.M. developed the idea, collected and analyzed the data, and prepared the manuscript. C.E. and J.K. collected and analyzed the data.

Conflicts of Interest: A.V. is a full-time employee of IDT Biologika, Germany, a company that also manufactures oral rabies vaccine baits. T.M. and C.M.F. received funding from IDT for research into mechanisms of oral rabies vaccination and serological response. The funding sponsors had no role in the design of the study; in the collection, analyses, or interpretation of data; in the writing of the manuscript, and in the decision to publish the results.

\section{References}

1. Dietzschold, B.; Ruppecht, C.E.; Fu, Z.F.; Koprowski, H. Rhabdoviruses. In Field's Virology, 3rd ed.; Fields, B.N, Knipe, D.M., Howley, P.M., Eds.; Raven Press: Philadelphia, PA, USA, 1996; pp. 1137-1159.

2. Dietzschold, B.; Li, J.; Faber, M.; Schnell, M. Concepts in the pathogenesis of rabies. Future Med. 2008, 3, 481-490. [CrossRef] [PubMed]

3. Steck, F.; Wandeler, A.; Bichsel, P.; Capt, S.; Hafliger, U.; Schneider, L. Oral immunization of foxes against rabies. Laboratory and field studies. Comp. Immunol. Microbiol. Infect. Dis. 1982, 5, 165-171. [CrossRef]

4. Wandeler, A.I.; Capt, S.; Kappeler, A.; Hauser, R. Oral immunization of wildlife against rabies: Concept and first field experiments. Rev. Infect. Dis. 1988, 10 (Suppl. 4), S649-S653. [CrossRef] [PubMed]

5. Fooks, A.; Horton, D.; Muller, T.; Freuling, C.; Rupprecht, C. Rabies. In Manual of Diagnostic Tests and Vaccines for Terrestrial Animals (Mammals, Birds, Bees), 7th ed.; Office International Des Epizooties: Paris, France, 2012; pp. 263-282. 
6. Bunn, T.O.; Ridpath, H.D. The Relationship Between Rabies Antibody Titers in Dogs and Cats and Protection from Challenge; U.S. Department of Health, Education and Welfare, Public Health: Washington, DC, USA, 1984; pp. $43-45$.

7. Aubert, M.F. Practical significance of rabies antibodies in cats and dogs. Rev. Sci. Tech. 1992, 11, 735-760. [CrossRef] [PubMed]

8. Moore, S.M.; Hanlon, C.A. Rabies-specific antibodies: Measuring surrogates of protection against a fatal disease. PLoS Negl. Trop. Dis. 2010, 4, e595. [CrossRef] [PubMed]

9. Sikes, R.K.; Peacock, G.V.; Acha, P.; Arko, R.J.; Dierks, R. Rabies vaccines: Duration-of-immunity study in dogs. J. Am. Vet. Med. Assoc. 1971, 159, 1491-1499. [CrossRef] [PubMed]

10. Moore, S.M.; Wilkerson, M.J.; Davis, R.D.; Wyatt, C.R.; Briggs, D.J. Detection of cellular immunity to rabies antigens in human vaccinees. J. Clin. Immunol. 2006, 26, 533-545. [CrossRef] [PubMed]

11. Haralambieva, I.H.; Ovsyannikova, I.G.; Pankratz, V.S.; Kennedy, R.B.; Jacobson, R.M.; Poland, G.A. The genetic basis for interindividual immune response variation to measles vaccine: New understanding and new vaccine approaches. Expert. Rev. Vaccines 2013, 12, 57-70. [CrossRef] [PubMed]

12. Ovsyannikova, I.G.; Schaid, D.J.; Larrabee, B.R.; Haralambieva, I.H.; Kennedy, R.B.; Poland, G.A. A large population-based association study between HLA and KIR genotypes and measles vaccine antibody responses. PLoS ONE 2017, 12, e0171261. [CrossRef] [PubMed]

13. Schaid, D.J.; Haralambieva, I.H.; Larrabee, B.R.; Ovsyannikova, I.G.; Kennedy, R.B.; Poland, G.A. Heritability of vaccine-induced measles neutralizing antibody titers. Vaccine 2017, 35, 1390-1394. [CrossRef] [PubMed]

14. Kuwert, E.; Barsenbach, J.; Werner, J.; Mardus, I.; Scheiermann, N.; Grosse-Wilde, H. Early/high and late/low responders among HDCS vaccinees. In Cell Culture Rabies Vaccines and their Protective Effect in Man; Wiktor, T.J., Koprowski, H., Eds.; International Green Cross: Geneva, Switzerland, 1981; pp. 160-168.

15. Feyssaguet, M.; Dacheux, L.; Audry, L.; Compoint, A.; Morize, J.L.; Blanchard, I.; Bourhy, H. Multicenter comparative study of a new ELISA, Platelia Rabies II, for the detection and titration of anti-rabies glycoprotein antibodies and comparison with the rapid fluorescent focus inhibition test (RFFIT) on human samples from vaccinated and non-vaccinated people. Vaccine 2007, 25, 2244-2251. [PubMed]

16. Welch, R.J.; Anderson, B.L.; Litwin, C.M. An evaluation of two commercially available ELISAs and one in-house reference laboratory ELISA for the determination of human anti-rabies virus antibodies. J. Med. Microbiol. 2009, 58, 806-810. [CrossRef] [PubMed]

17. Cliquet, F.; McElhinney, L.M.; Servat, A.; Boucher, J.M.; Lowings, J.P.; Goddard, T.; Mansfield, K.L.; Fooks, A.R. Development of a qualitative indirect ELISA for the measurement of rabies virus-specific antibodies from vaccinated dogs and cats. J. Virol. Methods 2004, 117, 1-8. [CrossRef] [PubMed]

18. Moore, S.M.; Pralle, S.; Engelman, L.; Hartschuh, H.; Smith, M. Rabies vaccine response measurement is assay dependent. Biologicals 2016, 44, 481-486. [CrossRef] [PubMed]

19. Artois, M.; Masson, E.; Barrat, J.; Aubert, M.F. Efficacy of three oral rabies vaccine-baits in the red fox: A comparison. Vet. Microbiol. 1993, 38, 167-172. [CrossRef]

20. Black, J.G.; Lawson, K.F. Further studies of sylvatic rabies in the fox (Vulpes vulpes). Vaccination by the oral route. Can. Vet. J. 1973, 14, 206-211. [PubMed]

21. Black, J.G.; Lawson, K.F. The safety and efficacy of immunizing foxes (Vulpes vulpes) using bait containing attenuated rabies virus vaccine. Can. J. Comp. Med. 1980, 44, 169-176. [PubMed]

22. Blancou, J.; Kieny, M.P.; Lathe, R.; Lecocq, J.P.; Pastoret, P.P.; Soulebot, J.P.; Desmettre, P. Oral vaccination of the fox against rabies using a live recombinant vaccinia virus. Nature 1986, 322, 373-375. [CrossRef] [PubMed]

23. Brochier, B.M.; Languet, B.; Blancou, J.; Kieny, M.P.; Lecocq, J.P.; Costy, F.; Desmettre, P.; Pastoret, P.P. Use of recombinant vaccinia-rabies virus for oral vaccination of fox cubs (Vulpes vulpes, 1) against rabies. Vet. Microbiol. 1988, 18, 103-108. [CrossRef]

24. Brown, L.J.; Rosatte, R.C.; Fehlner-Gardiner, C.; Taylor, J.S.; Davies, J.C.; Donovan, D. Immune response and protection in raccoons (Procyon lotor) following consumption of baits containing ONRAB ${ }^{\circledR}$, a human adenovirus rabies glycoprotein recombinant vaccine. J. Wildl. Dis. 2012, 48, 1010-1020. [CrossRef] [PubMed]

25. Brown, L.J.; Rosatte, R.C.; Fehlner-Gardiner, C.; Ellison, J.A.; Jackson, F.R.; Bachmann, P.; Taylor, J.S.; Franka, R.; Donovan, D. Oral vaccination and protection of striped skunks (Mephitis mephitis) against rabies using ONRAB ${ }^{\circledR}$. Vaccine 2014, 32, 3675-3679. [CrossRef] [PubMed] 
26. Brown, L.J.; Rosatte, R.C.; Fehlner-Gardiner, C.; Bachmann, P.; Ellison, J.A.; Jackson, F.R.; Taylor, J.S.; Davies, C.; Donovan, D. Oral vaccination and protection of red foxes (Vulpes vulpes) against rabies using ONRAB, an adenovirus-rabies recombinant vaccine. Vaccine 2014, 32, 984-989. [CrossRef] [PubMed]

27. Follmann, E.; Ritter, D.; Swor, R.; Dunbar, M.; Hueffer, K. Preliminary evaluation of Raboral V-RG ${ }^{\circledR}$ oral rabies vaccine in arctic foxes (Vulpes lagopus). J. Wildl. Dis. 2011, 47, 1032-1035. [CrossRef] [PubMed]

28. Follmann, E.H.; Ritter, D.G.; Donald, W.H. Oral vaccination of captive arctic foxes with lyophilized SAG2 rabies vaccine. J. Wildl. Dis. 2004, 40, 328-334. [CrossRef] [PubMed]

29. Follmann, E.H.; Ritter, D.G.; Baer, G.M. Oral rabies vaccination of arctic foxes (Alopex lagopus) with an attenuated vaccine. Vaccine 1992, 10, 305-308. [CrossRef]

30. Follmann, E.H.; Ritter, D.G.; Baer, G.M. Immunization of arctic foxes (Alopex lagopus) with oral rabies vaccine. J. Wildl. Dis. 1988, 24, 477-483. [CrossRef] [PubMed]

31. Lawson, K.F.; Chiu, H.; Crosgrey, S.J.; Matson, M.; Casey, G.A.; Campbell, J.B. Duration of immunity in foxes vaccinated orally with era vaccine in a bait. Can. J. Vet. Res. 1997, 61, 39-42. [PubMed]

32. Le Blois, H.; Tuffereau, C.; Blancou, J.; Artois, M.; Aubert, A.; Flamand, A. Oral immunization of foxes with avirulent rabies virus mutants. Vet. Microbiol. 1990, 23, 259-266.

33. Neubert, A.; Schuster, P.; Müller, T.; Vos, A.; Pommerening, E. Immunogenicity and efficacy of the oral rabies vaccine SAD B19 in foxes. J. Vet. Med. B Infect. Dis. Vet. Public Health 2001, 48, 179-183. [CrossRef] [PubMed]

34. Tolson, N.D.; Charlton, K.M.; Lawson, K.F.; Campbell, J.B.; Stewart, R.B. Studies of ERA/BHK-21 rabies vaccine in skunks and mice. Can. J. Vet. Res. 1988, 52, 58-62. [PubMed]

35. Tolson, N.D.; Charlton, K.M.; Casey, G.A.; Knowles, M.K.; Rupprecht, C.E.; Lawson, K.F.; Campbell, J.B. Immunization of foxes against rabies with a vaccinia recombinant virus expressing the rabies glycoprotein. Arch. Virol. 1988, 102, 297-301. [CrossRef] [PubMed]

36. Tolson, N.D.; Charlton, K.M.; Stewart, R.B.; Campbell, J.B.; Wiktor, T.J. Immune response in skunks to a vaccinia virus recombinant expressing the rabies virus glycoprotein. Can. J. Vet. Res. 1987, 51, 363-366. [PubMed]

37. Vos, A.; Conzelmann, K.K.; Finke, S.; Müller, T.; Teifke, J.; Fooks, A.R.; Neubert, A. Immunogenicity studies in carnivores using a rabies virus construct with a site-directed deletion in the phosphoprotein. Adv. Prev. Med. 2011, 2011, 898171. [CrossRef] [PubMed]

38. Cliquet, F.; Barrat, J.; Guiot, A.L.; Cael, N.; Boutrand, S.; Maki, J.; Schumacher, C.L. Efficacy and bait acceptance of vaccinia vectored rabies glycoprotein vaccine in captive foxes (Vulpes vulpes), raccoon dogs (Nyctereutes procyonoides) and dogs (Canis familiaris). Vaccine 2008, 26, 4627-4638. [CrossRef] [PubMed]

39. Cliquet, F.; Gurbuxani, J.P.; Pradhan, H.K.; Pattnaik, B.; Patil, S.S.; Regnault, A.; Begouen, H.; Guiot, A.L.; Sood, R.; Mahl, P.; et al. The safety and efficacy of the oral rabies vaccine SAG2 in indian stray dogs. Vaccine 2007, 25, 3409-3418. [CrossRef] [PubMed]

40. Charlton, K.M.; Artois, M.; Prevec, L.; Campbell, J.B.; Casey, G.A.; Wandeler, A.I.; Armstrong, J. Oral rabies vaccination of skunks and foxes with a recombinant human adenovirus vaccine. Arch. Virol. 1992, 123, 169-179. [CrossRef] [PubMed]

41. Fekadu, M.; Nesby, S.L.; Shaddock, J.H.; Schumacher, C.L.; Linhart, S.B.; Sanderlin, D.W. Immunogenicity, efficacy and safety of an oral rabies vaccine (SAG-2) in dogs. Vaccine 1996, 14, 465-468. [CrossRef]

42. Fekadu, M.; Shaddock, J.H.; Sumner, J.W.; Sanderlin, D.W.; Knight, J.C.; Esposito, J.J.; Baer, G.M. Oral vaccination of skunks with raccoon poxvirus recombinants expressing the rabies glycoprotein or the nucleoprotein. J. Wildl. Dis. 1991, 27, 681-684. [CrossRef] [PubMed]

43. Grosenbaugh, D.A.; Maki, J.L.; Rupprecht, C.E.; Wall, D.K. Rabies challenge of captive striped skunks (Mephitis mephitis) following oral administration of a live vaccinia-vectored rabies vaccine. J. Wildl. Dis. 2007, 43, 124-128. [CrossRef] [PubMed]

44. Hanlon, C.A.; Niezgoda, M.; Morrill, P.; Rupprecht, C.E. Oral efficacy of an attenuated rabies virus vaccine in skunks and raccoons. J. Wildl. Dis. 2002, 38, 420-427. [CrossRef] [PubMed]

45. Henderson, H.; Jackson, F.; Bean, K.; Panasuk, B.; Niezgoda, M.; Slate, D.; Li, J.; Dietzschold, B.; Mattis, J.; Rupprecht, C.E. Oral immunization of raccoons and skunks with a canine adenovirus recombinant rabies vaccine. Vaccine 2009, 27, 7194-7197. [CrossRef] [PubMed]

46. Blanton, J.D.; Meadows, A.; Murphy, S.M.; Manangan, J.; Hanlon, C.A.; Faber, M.L.; Dietzschold, B.; Rupprecht, C.E. Vaccination of small asian mongoose (Herpestes javanicus) against rabies. J. Wildl. Dis. 2006, 42, 663-666. [CrossRef] [PubMed] 
47. Blanton, J.D.; Self, J.; Niezgoda, M.; Faber, M.L.; Dietzschold, B.; Rupprecht, C. Oral vaccination of raccoons (Procyon lotor) with genetically modified rabies virus vaccines. Vaccine 2007, 25, 7296-7300. [CrossRef] [PubMed]

48. Rupprecht, C.E.; Hanlon, C.A.; Blanton, J.; Manangan, J.; Morrill, P.; Murphy, S.; Niezgoda, M.; Orciari, L.A.; Schumacher, C.L.; Dietzschold, B. Oral vaccination of dogs with recombinant rabies virus vaccines. Virus Res. 2005, 111, 101-105. [CrossRef] [PubMed]

49. Brown, L.J.; Rosatte, R.C.; Fehlner-Gardiner, C.; Knowles, M.K.; Bachmann, P.; Davies, J.C.; Wandeler, A.; Sobey, K.; Donovan, D. Immunogenicity and efficacy of two rabies vaccines in wild-caught, captive raccoons. J. Wildl. Dis. 2011, 47, 182-194. [CrossRef] [PubMed]

50. Esposito, J.J.; Knight, J.C.; Shaddock, J.H.; Novembre, F.J.; Baer, G.M. Successful oral rabies vaccination of raccoons with raccoon poxvirus recombinants expressing rabies virus glycoprotein. Virology 1988, 165, 313-316. [CrossRef]

51. Orciari, L.A.; Niezgoda, M.; Hanlon, C.A.; Shaddock, J.H.; Sanderlin, D.W.; Yager, P.A.; Rupprecht, C.E. Rapid clearance of SAG-2 rabies virus from dogs after oral vaccination. Vaccine 2001, 19, 4511-4518. [CrossRef]

52. Zhou, M.; Wang, L.; Zhou, S.; Wang, Z.; Ruan, J.; Tang, L.; Jia, Z.; Cui, M.; Zhao, L.; Fu, Z.F. Recombinant rabies virus expressing dog GM-CSF is an efficacious oral rabies vaccine for dogs. Oncotarget 2015, 6, 38504-38516. [PubMed]

53. Rupprecht, C.E.; Wiktor, T.J.; Johnston, D.H.; Hamir, A.N.; Dietzschold, B.; Wunner, W.H.; Glickman, L.T.; Koprowski, H. Oral immunization and protection of raccoons (Procyon lotor) with a vaccinia-rabies glycoprotein recombinant virus vaccine. Proc. Natl. Acad. Sci. USA 1986, 83, 7947-7950. [CrossRef] [PubMed]

54. Faber, M.; Faber, M.L.; Papaneri, A.; Bette, M.; Weihe, E.; Dietzschold, B.; Schnell, M.J. A single amino acid change in rabies virus glycoprotein increases virus spread and enhances virus pathogenicity. J. Virol. 2005, 79, 14141-14148. [CrossRef] [PubMed]

55. Faber, M.; Pulmanausahakul, R.; Hodawadekar, S.S.; Spitsin, S.; McGettigan, J.P.; Schnell, M.J.; Dietzschold, B. Overexpression of the rabies virus glycoprotein results in enhancement of apoptosis and antiviral immune response. J. Virol. 2002, 76, 3374-3381. [CrossRef] [PubMed]

56. Faber, M.; Faber, M.L.; Li, J.; Preuss, M.A.; Schnell, M.J.; Dietzschold, B. Dominance of a nonpathogenic glycoprotein gene over a pathogenic glycoprotein gene in rabies virus. J. Virol. 2007, 81, 7041-7047. [CrossRef] [PubMed]

57. Rieder, M.; Brzozka, K.; Pfaller, C.K.; Cox, J.H.; Stitz, L.; Conzelmann, K.K. Genetic dissection of interferon-antagonistic functions of rabies virus phosphoprotein: Inhibition of interferon regulatory factor 3 activation is important for pathogenicity. J. Virol. 2011, 85, 842-852. [CrossRef] [PubMed]

58. Mebatsion, T. Extensive attenuation of rabies virus by simultaneously modifying the dynein light chain binding site in the P protein and replacing Arg333 in the G protein. J. Virol. 2001, 75, 11496-11502. [CrossRef] [PubMed]

59. Visser, N.; Mebatsion, T.; Kilari, S. Oral rabies vaccine: Developing a safer and efficacious oral vaccine for dogs. In Proceedings of the SEARG Meeting, Windhoek, Namibia, January 2006; pp. 22-26.

60. Prevec, L.; Campbell, J.B.; Christie, B.S.; Belbeck, L.; Graham, F.L. A recombinant human adenovirus vaccine against rabies. J. Infect. Dis. 1990, 161, 27-30. [CrossRef] [PubMed]

61. Yarosh, O.K.; Wandeler, A.I.; Graham, F.L.; Campbell, J.B.; Prevec, L. Human adenovirus type 5 vectors expressing rabies glycoprotein. Vaccine 1996, 14, 1257-1264. [CrossRef]

62. Cox, J.H.; Schneider, L.G. Prophylactic immunization of humans against rabies by intradermal inoculation of human diploid cell culture vaccine. J. Clin. Microbiol. 1976, 3, 96-101. [PubMed]

63. Müller, T.; Selhorst, T.; Burow, J.; Schameitat, A.; Vos, A. Cross-reactive antigenicity in orally vaccinated foxes and raccoon dogs against European bat lyssavirus type 1 and 2. Dev. Biol. 2006, 125, 195-204.

64. Smith, J.S.; Yager, P.A.; Baer, G.M. A rapid reproducible test for determining rabies neutralizing antibody. Bull. World Health Organ. 1973, 48, 535-541. [PubMed]

65. Smith, J.S.; Yager, P.A.; Baer, G.M. A rapid fluorescent focus inhibition test (RFFIT) for determining rabies virus-neutralizing antibody. In Laboratory Techniques in Rabies, 4th ed.; Meslin, F.X., Kaplan, M.M., Koprowski, H., Eds.; World Health Organization: Geneva, Switzerland, 1996; pp. 181-192. 
66. Habel, K. Habel, K. Habel test for potency. In Laboratory Techniques in Rabies, 4th ed.; Meslin, F.X., Kaplan, M.M., Koprowski, H., Eds.; World Health Organization: Geneva, Switzerland, 1996; pp. 369-373.

67. Kostense, S.; Moore, S.; Companjen, A.; Bakker, A.B.; Marissen, W.E.; von, E.R.; Weverling, G.J.; Hanlon, C.; Goudsmit, J. Validation of the rapid fluorescent focus inhibition test (RFFIT) for rabies virus neutralizing antibodies in clinical samples. Antimicrob. Agents Chemother. 2012, 56, 3524-3530. [CrossRef] [PubMed]

68. Mojzis, M.; Korytar, P.; Jerg, S. Development and Validation of ELISA Test for Detection of Rabies Anti-Glycoprotein Antibodies. In Internationals Conference on Rabies in the Americas (RITA XIX); Centers for Disease Control and Prevention: Atlanta, GA, USA, 2008; pp. 48-49.

69. Wasniewski, M.; Guiot, A.L.; Schereffer, J.L.; Tribout, L.; Mahar, K.; Cliquet, F. Evaluation of an ELISA to detect rabies antibodies in orally vaccinated foxes and raccoon dogs sampled in the field. J. Virol. Methods 2013, 187, 264-270. [CrossRef] [PubMed]

70. Cliquet, F.; Sagne, L.; Schereffer, J.L.; Aubert, M.F. ELISA test for rabies antibody titration in orally vaccinated foxes sampled in the fields. Vaccine 2000, 18, 3272-3279. [CrossRef]

71. Zalan, E.; Wilson, C.; Pukitis, D. A microtest for the quantitation of rabies virus neutralizing antibodies. J. Biol. Stand. 1979, 7, 213-220. [CrossRef]

72. Rabies vaccine, live virus. In 9, Regulations; Code of Federal Regulations (annual edition); U.S. National Archives and Records Administration: City of College Park, Maryland, MD, USA, 2007; p. 4.

73. Council of Europe. Rabies vaccine (live, oral) for foxes and raccoon dogs-0746. In European Pharmacopoeia 8.0; EDQM: Strasbourg, France, 2014; pp. 1011-1012.

74. Lafon, M. Evasive strategies in rabies virus infection. Adv. Virus Res. 2011, 79, 33-53. [PubMed]

75. Dietzschold, B.; Morimoto, K.; Hooper, D.C. Mechanisms of virus-induced neuronal damage and the clearance of viruses from the cns. Curr. Top. Microbiol. Immunol. 2001, 253, 145-155. [PubMed]

76. Morimoto, K.; Hooper, D.C.; Spitsin, S.; Koprowski, H.; Dietzschold, B. Pathogenicity of different rabies virus variants inversely correlates with apoptosis and rabies virus glycoprotein expression in infected primary neuron cultures. J. Virol. 1999, 73, 510-518. [PubMed]

77. Knowlton, F.F.; Roetto, M.; Briggs, D. Serological responses of coyotes to two commercial rabies vaccines. J. Wildl. Dis. 2001, 37, 798-802. [CrossRef] [PubMed]

78. Rupprecht, C.E.; Barrett, J.; Briggs, D.; Cliquet, F.; Fooks, A.R.; Lumlertdacha, B.; Meslin, F.X.; Muler, T.; Nel, L.H.; Schneider, C.; et al. Can rabies be eradicated? Dev. Biol. 2008, 131, 95-121.

79. Moore, S.M.; Gordon, C.R.; Hanlon, C.A. Measures of rabies immunity. In Rabies, 3rd ed.; Jackson, A.C., Ed.; Elsevier: San Diego, CA, USA, 2013; pp. 461-496.

80. Smith, J. Rabies serology. In The Natural History of Rabies, 2nd ed.; Baer, G.M., Ed.; 1991; pp. $235-252$.

81. Moore, S.M.; Ricke, T.A.; Davis, R.D.; Briggs, D.J. The influence of homologous vs. Heterologous challenge virus strains on the serological test results of rabies virus neutralizing assays. Biologicals 2005, 33, 269-276. [CrossRef] [PubMed]

82. Lv, X.J.; Ma, X.J.; Wang, L.H.; Li, H.; Shen, X.X.; Yu, P.C.; Tang, Q.; Liang, G.D. Preparation and initial application of a monoclonal antibody specific for a newly discovered conserved linear epitope of rabies virus nucleoprotein. Biomed. Environ. Sci. 2012, 25, 98-103. [PubMed]

83. Wasniewski, M.; Almeida, I.; Baur, A.; Bedekovic, T.; Boncea, D.; Chaves, L.B.; David, D.; De, B.P.; Dobrostana, M.; Giraud, P.; et al. First international collaborative study to evaluate rabies antibody detection method for use in monitoring the effectiveness of oral vaccination programmes in fox and raccoon dog in europe. J. Virol. Methods 2016, 238, 77-85. [CrossRef] [PubMed]

84. Cleaveland, S.; Barrat, J.; Barrat, M.J.; Selve, M.; Kaare, M.; Esterhuysen, J. A rabies serosurvey of domestic dogs in rural Tanzania: Results of a rapid fluorescent focus inhibition test (RFFIT) and a liquid-phase blocking ELISA used in parallel. Epidemiol. Infect. 1999, 123, 157-164. [CrossRef] [PubMed]

85. Fehlner-Gardiner, C.; Rudd, R.; Donovan, D.; Slate, D.; Kempf, L.; Badcock, J. Comparing ONRAB ${ }^{\circledR}$ and Raboral V-RG ${ }^{\circledR}$ oral rabies vaccine field performance in raccoons and striped skunks, New Brunswick, Canada, and Maine, USA. J. Wildl. Dis. 2012, 48, 157-167. [CrossRef] [PubMed] 
86. Gilbert, A.T.; Fooks, A.R.; Hayman, D.T.; Horton, D.L.; Müller, T.; Plowright, R.; Peel, A.J.; Bowen, R.; Wood, J.L.; Mills, J.; et al. Deciphering serology to understand the ecology of infectious diseases in wildlife. Ecohealth 2013, 10, 298-313. [CrossRef] [PubMed]

87. Fry, T.L.; Vandalen, K.K.; Shriner, S.A.; Moore, S.M.; Hanlon, C.A.; Vercauteren, K.C. Humoral immune response to oral rabies vaccination in raccoon kits: Problems and implications. Vaccine 2013, 31, 2811-2815. [CrossRef] [PubMed]

(C) 2017 by the authors. Licensee MDPI, Basel, Switzerland. This article is an open access article distributed under the terms and conditions of the Creative Commons Attribution (CC BY) license (http:/ / creativecommons.org/licenses/by/4.0/). 


\title{
Comparison of a Micro-Neutralization Test with the Rapid Fluorescent Focus Inhibition Test for Measuring Rabies Virus Neutralizing Antibodies
}

\author{
Todd G. Smith ${ }^{1, *}$ and Amy T. Gilbert ${ }^{2}$ \\ 1 Poxvirus and Rabies Branch, Division of High-Consequence Pathogens and Pathology, Centers for Disease \\ Control and Prevention, 1600 Clifton Road Northeast, Atlanta, GA 30329, USA \\ 2 National Wildlife Research Center, US Department of Agriculture, Animal and Plant Health Inspection \\ Service, Wildlife Services, 4101 LaPorte Avenue, Fort Collins, CO 80521, USA; \\ Amy.T.Gilbert@aphis.usda.gov \\ * Correspondence: TGSmith1@cdc.gov; Tel.: +1-404-639-2282
}

Received: 19 May 2017; Accepted: 30 June 2017; Published: 7 July 2017

\begin{abstract}
The rapid fluorescent focus inhibition test (RFFIT) is routinely used in the United States to measure rabies virus neutralizing antibodies (rVNA). RFFIT has a long history of reproducible and reliable results. The test has been modified over the years to use smaller volumes of reagents and samples, but requires a $50 \mu \mathrm{L}$ minimum volume of test serum. To conduct pathogenesis studies, small laboratory animals such as mice are regularly tested for rVNA, but the minimum volume for a standard RFFIT may be impossible to obtain, particularly in scenarios of repeated sampling. To address this problem, a micro-neutralization test was developed previously. In the current study, the micro-neutralization test was compared to the RFFIT using 129 mouse serum samples from rabies vaccine studies. Using a cut-off value of $0.1 \mathrm{IU} / \mathrm{mL}$, the sensitivity, specificity, and concordance of the micro-neutralization test were $100 \%, 97.5 \%$, and $98 \%$, respectively. The geometric mean titer of all samples above the cut-off was $2.0 \mathrm{IU} / \mathrm{mL}$ using RFFIT and $3.4 \mathrm{IU} / \mathrm{mL}$ using the micro-neutralization test, indicating that titers determined using the micro-neutralization test are not equivalent to RFFIT titers. Based on four rVNA-positive hamster serum samples, the intra-assay coefficient of variability was $24 \%$ and inter-assay coefficient of variability was $30.4 \%$. These results support continued use of the micro-neutralization test to determine rabies virus neutralizing antibody titers for low-volume serum samples.
\end{abstract}

Keywords: rabies; virus neutralizing antibodies; diagnostic test; assay development; assay validation

\section{Introduction}

Measurement of rabies virus neutralizing antibody (rVNA) is essential to evaluating pre- or post-exposure prophylaxis and rabies diagnosis in humans and vaccination status in domestic animals [1-3]. The rapid fluorescent focus inhibition test (RFFIT) is one WHO-recommended test for measuring rVNA [3]. The RFFIT is used widely, primarily in the US, due to the standardized and functional results produced [4]. Developed in 1973 as a replacement for the mouse neutralization test, the RFFIT represented a major advance in cost, time, and replacement of animal use [5]. When compared to the mouse neutralization test, the RFFIT was 95\% concordant, 100\% sensitive, and $83 \%$ specific [5]. Over the years, the RFFIT method has been modified to use mouse neuroblastoma cells in place of BHK cells [6], to use a 96-well format similar to the tissue culture serum neutralization test or more widely used fluorescent antibody virus neutralization (FAVN) test [7-9], and to use half the volume of reagents. Despite these modifications, the RFFIT method requires a minimum volume of $50 \mu \mathrm{L}$ of serum per test [10]. 
Kuzmin, et al. (2008) developed a micro-neutralization test based on the RFFIT to measure rVNA in serum samples with limited volume, e.g., from bats [11]. The micro-neutralization test has numerous advantages compared to the standard RFFIT, including the need for only $3 \mu \mathrm{L}$ of serum per test. Additionally, instead of using 8-well, chamber slides, the micro-neutralization test uses 4 -well, Teflon-coated slides, which decreases the reagent content by $\sim 90 \%$ representing a cost savings compared to the traditional RFFIT. Also, the dilutions are simplified starting with $10^{-1}$, and only 10 fields in each well are scored for results rather than 20 fields, representing a time saving compared to the RFFIT. Furthermore, because the first dilution is higher than RFFIT, the micro-neutralization test is less susceptible to cytotoxicity. Overall, the micro-neutralization test is less labor intensive than the Terasaki plate method [12], but similar to the RFFIT, the micro-neutralization test still requires a $20-40 \mathrm{~h}$ incubation period, highly skilled personnel, and appropriate biocontainment and biosafety risk mitigation associated with use of live rabies virus.

The objective of the current study was to compare the rVNA measured in the same test serum using the RFFIT and micro-neutralization test. Mouse serum generated for other rabies immunization experiments was curated for volume and quality. The sample set was run with both tests using the same lots of reagents and rabies virus strain CVS-11. Results were compared based on sensitivity and specificity.

\section{Materials and Methods}

Approved animal use protocols were established with CDC's Institutional Animal Care and Use Committee (protocols 2330SMIMOUC, 2332SMIMOUC, 2622SMIHAMC). For mouse serum, adult female CD-1 mice were purchased from Charles River Laboratories (Wilmington, MA, USA). All animals received experimental or commercial rabies vaccine on day 1. Approximately $0.2 \mathrm{~mL}$ of blood was collected using the submandibular technique on days 0,15 , and 30 . Serum was separated and stored at $\leq-10{ }^{\circ} \mathrm{C}$. After the primary studies were completed, a convenient set of 129 serum samples were selected based on sufficient volume, previous RFFIT result (positive or negative), and lack of cytotoxicity. Cytotoxic samples were excluded because they could not be accurately classified as positive or negative in the RFFIT. Of the convenient sample, 55 had detectable rVNA $(>0.05 \mathrm{IU} / \mathrm{mL})$ and 74 had no detectable rVNA $(<0.05 \mathrm{IU} / \mathrm{mL})$ by RFFIT.

For hamster serum, adult female LVG Syrian hamsters were purchased from Charles River Laboratories (Wilmington, MA, USA). All animals were challenged with rabies virus on day 0 . Some animals received post-exposure prophylaxis with commercial human rabies vaccine and human rabies immune globulin or experimental monoclonal antibody product on day 1, followed by additional doses of vaccine on day 4 and 8 , while some animals received no post-exposure prophylaxis. Approximately $0.2 \mathrm{~mL}$ of blood was collected using the subclavicle technique on days $0,4,8$ and at termination. Serum was separated and stored at $\leq-10^{\circ} \mathrm{C}$. After the primary studies were completed, four serum samples were selected to determine assay variability.

The RFFIT was completed according to a standard protocol [10]. The micro-neutralization test was modified slightly from the previous report [11]. The test was set up in a humidity chamber made from a petri dish and wet paper towel to prevent evaporation from the wells. An amount of $3 \mu \mathrm{L}$ of test serum or standard rabies immune globulin (SRIG, US FDA lot R-3) was serially diluted in $12 \mu \mathrm{L}$ of Dulbecco's minimal essential medium supplemented with $10 \%$ fetal bovine serum in each well of a Teflon-coated, 4-well slide. An amount of $12 \mu \mathrm{L}$ of rabies virus CVS-11 (CDC lot V-404) diluted to $50 \mathrm{FFD}_{50} / \mathrm{mL}(50 \times 50 \%$ fluorescing foci doses $/ \mathrm{mL}$ ) was added to each well. Back titration of the rabies virus CVS-11 and cell-only control were completed in a separate 4-well slide. Slides were incubated $60 \mathrm{~min}$ at $37^{\circ} \mathrm{C}$ with $0.5 \% \mathrm{CO}_{2} .24 \mu \mathrm{L}$ of mouse neuroblastoma cells diluted to approximately $5 \times 10^{5}$ cells $/ \mathrm{mL}$ was added to each well and slides were incubated $20 \mathrm{~h}$ at $37^{\circ} \mathrm{C}$ with $0.5 \% \mathrm{CO}_{2}$. Slides were fixed with acetone for $30 \mathrm{~min}$ at $-20^{\circ} \mathrm{C}$ and stained with FITC-anti-rabies virus antibodies (Fujirebio Diagnostics, Malvern, PA, USA) with additional $0.001 \%$ Evan's Blue for $30 \mathrm{~min}$ at $37^{\circ} \mathrm{C}$ with $0.5 \% \mathrm{CO}_{2}$. Slides were washed twice with $0.1 \mathrm{M} \mathrm{PBS} \mathrm{pH} 7.5$ and observed with a fluorescence 
microscope. In each well, 10 fields at $20 \times$ magnification were scored based on presence/absence of fluorescent foci and endpoint titer was calculated using the Reed-Muench method. Endpoint titers were converted to international units per milliliter $(\mathrm{IU} / \mathrm{mL}$ ) based on comparison to the SRIG diluted at $2 \mathrm{IU} / \mathrm{mL}$.

Results for the same sample from two independent tests were compared. The cut-off of $0.1 \mathrm{IU} / \mathrm{mL}$ was chosen empirically based on approximately $50 \%$ neutralization in the first dilution of the micro-neutralization test. The same cut-off was chosen for RFFIT based on equivalency which is approximately complete neutralization in the first dilution. Sensitivity, specificity, predictive values, and 95\% confidence intervals were calculated using GraphPad Prism v6. The correlation between quantitative titers determined by either test was evaluated using the Pearson test with $\alpha=0.05$. Coefficient of variability was calculated by dividing the standard deviation in IU $/ \mathrm{mL}$ by the mean in $\mathrm{IU} / \mathrm{mL}$.

\section{Results}

Based on the $0.1 \mathrm{IU} / \mathrm{mL}$ cut-off, 127 (98\%) of 129 mouse serum samples tested had concordant results between the two tests. The remaining two samples were above the cut-off based on RFFIT but fell below the cut-off in the micro-neutralization test (Table 1). This results in a sensitivity of $100 \%(\mathrm{CI}=92.6-100 \%)$ and specificity of $97.5 \%(\mathrm{CI}=91.4-99.7 \%)$ for the micro-neutralization test. The positive predictive value was $96 \%(C I=86.3-99.5 \%)$, the negative predictive value was $100 \%$ $(\mathrm{CI}=95.4-100 \%)$, and the false negative rate for the new test was $2.5 \%$.

Table 1. Sensitivity, specificity, as well as positive and negative predictive value of the micro-neutralization test compared to the rapid fluorescent focus inhibition test (RFFIT).

\begin{tabular}{ccccc}
\hline Test & Microneut. ${ }^{\mathbf{1}} \geq \mathbf{0 . 1} \mathbf{~ I U} / \mathbf{m L}$ & Microneut. $<\mathbf{0 . 1} \mathbf{I U} / \mathbf{m L}$ & Total & PPV NPV $^{\mathbf{2}}$ \\
\hline RFFIT $\geq \mathbf{0 . 1} \mathbf{~ I U / m L}$ & 48 & 2 & 50 & $96 \%$ \\
RFFIT $<\mathbf{0 . 1} \mathbf{~ I U} / \mathbf{m L}$ & 0 & 79 & 79 & $100 \%$ \\
Total & 48 & 81 & 129 & \\
SN $_{\mathbf{S}} \mathbf{S P}^{\mathbf{3}}$ & $100 \%$ & $97.5 \%$ & &
\end{tabular}

\footnotetext{
${ }_{1}^{1}$ Micro-neutralization test; ${ }^{2}$ Positive predictive value (PPV), Negative predictive value (NPV); ${ }^{3}$ Sensitivity (SN),
} Specificity (SP).

Using the micro-neutralization test, $37 \%$ of samples were positive for rVNA compared to $39 \%$ with RFFIT. While the number of positive samples in a set may be slightly underestimated, the individual titers of positive samples appear higher using the micro-neutralization test (Figure 1). The geometric mean titer of rVNA positive samples was $3.4 \mathrm{IU} / \mathrm{mL}$ with the micro-neutralization test and $2.0 \mathrm{IU} / \mathrm{mL}$ with the RFFIT. Because of this difference in the individual rVNA titers, the correlation between the two tests was poor $\left(R^{2}=0.55\right)$. 


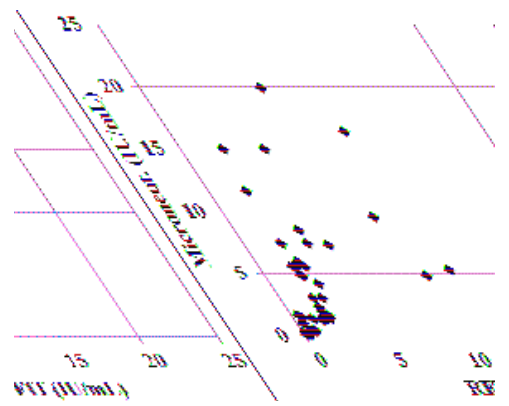

Figure 1. Comparison of rVNA titers (IU/mL) measured by the micro-neutralization test (microneut.) and RFFIT. Rabies virus neutralizing antibody was measure in individual serum samples by the micro-neutralization test (Microneut.) and RFFIT. Positive rVNA titers in IU/mL were plotted on a linear scale. The axis limits exclude four samples that had very high rVNA titers by both tests. The geometric mean titer was $3.4 \mathrm{IU} / \mathrm{mL}$ with the micro-neutralization test compared to $2.0 \mathrm{IU} / \mathrm{mL}$ with the RFFIT.

Intra- and inter-assay coefficient of variability was calculated using $\mathrm{IU} / \mathrm{mL}$ from six statistical replicates, from two biologic replicates, for four rVNA-positive hamster serum samples. The intra-assay coefficient of variability ranged from $21-24 \%$ for the statistical replicates, and the median inter-assay coefficient of variability was $30.4 \%$ for the biologic replicates.

\section{Discussion}

A rabies virus micro-neutralization test is necessary to measure rVNA from small volume samples. The method described herein has been developed over time to meet this need. For purposes of this study, only serum from vaccinated animals was used, which is different, in terms of immune profile, from serum collected from wildlife to estimate prevalence of rabies virus natural infection/exposure. The above comparison to the RFFIT demonstrates that the method has utility for measuring rVNA in samples from vaccinated animals. This will be extremely beneficial in small animal challenge studies validating efficacy of medical countermeasures, where serum volumes are often limited.

Additional validation of the micro-neutralization test for study of natural rabies virus exposure in different taxa, geographic regions, and divergent lyssaviruses is still an important consideration. For purposes of validation, this study would fall under stage one: comparison to a standard test method [13]. Based on the sensitivity and specificity calculated here, $2 \%$ error, and $95 \%$ confidence, a panel of $95 \mathrm{rVNA}$ positive samples, ideally from naturally infected/exposed animals, and $279 \mathrm{rVNA}$ negative samples from the same species, would be required to validate the diagnostic sensitivity and specificity of the assay [13].

Endpoint titers, including for SRIG, were higher in the micro-neutralization test than RFFIT. Paradoxically, the micro-neutralization titers in $\mathrm{IU} / \mathrm{mL}$ were also higher, meaning the endpoint titers of test serum increased more than the endpoint titer of SRIG. This trend holds true even when a subset of 20 samples with rVNA $<1 \mathrm{IU} / \mathrm{mL}$ (RFFIT) is analyzed; although the difference is less for this subset. Because of the difference in individual titers, results from the micro-neutralization test should not be aggregated with results from RFFIT. The differences in titers may be due to differences in the evaporation, contact surface area, or fluid dynamics in the small drop used in the micro-neutralization test. Using a humidity chamber as described in the methods section is recommended to prevent evaporation especially when a large number of samples are being tested. In the future, the method could be further optimized to address the differences in the titers.

The $0.1 \mathrm{IU} / \mathrm{mL}$ cut-off provided high levels of agreement between the micro-neutralization test and RFFIT. Using a higher or lower cut-off of $0.05 \mathrm{IU} / \mathrm{mL}$ or $0.5 \mathrm{IU} / \mathrm{mL}$ resulted in $95 \%$ 
and $93 \%$ concordance, respectively, compared to $98 \%$ concordance at $0.1 \mathrm{IU} / \mathrm{mL}$. Based on these results, the $0.1 \mathrm{IU} / \mathrm{mL}$ cut-off is recommended for determining positive and negative rVNA in the micro-neutralization test.

The coefficient of variability shows that the micro-neutralization test is consistent and reliable for measuring rVNA. The variability is consistent with published variability for the RFFIT of 18-26\% intra-assay and 28-30\% inter-assay [4]. Given the advantages of the micro-neutralization test including sample/reagent sparing and time/labor saving, this assay should be used when the RFFIT is not feasible. Overall, the favorable comparison between the micro-neutralization test and RFFIT supports its continued use for measuring rVNA in small-volume samples.

Acknowledgments: Supported in part by an appointment to the Research Participation Program at CDC administered by the Oak Ridge Institute for Science and Education through an interagency agreement between the U.S. Department of Energy and CDC. Supported in part by a contract between Solution One Industries, Inc. and CDC. Use of trade names and commercial sources are for identification only and do not imply endorsement by the US government. The findings and conclusions in this report are those of the authors and do not necessarily represent the views of their institutions.

Author Contributions: A.G. and T.S. conceived and designed the experiments; T.S. performed the experiments; T.S. analyzed the data; T.S. and A.G. wrote the paper.

Conflicts of Interest: The authors declare no conflicts of interest.

\section{References}

1. Centers for Disease Control and Prevention. Human rabies prevention-United States, 1999. Recommendations of the advisory committee on immunization practices (ACIP). MMWR Morb. Mortal. Wkly. Rep. 1999, 48, 1-21.

2. Brown, C.M.; Slavinski, S.; Ettestad, P.; Sidwa, T.J.; Sorhage, F.E. National Association of State Public Health Veterinarians. Compendium of animal rabies prevention and control, 2016. J. Am. Vet. Med. Assoc. 2016, 248, 505-517. [PubMed]

3. World Health Organization (WHO). WHO Expert Consultation on Rabies: Second Report; WHO: Geneva, Switzerland, 2013.

4. Kostense, S.; Moore, S.; Companjen, A.; Bakker, A.B.; Marissen, W.E.; von Eyben, R.; Weverling, G.J.; Hanlon, C.; Goudsmit, J. Validation of the rapid fluorescent focus inhibition test for rabies virus-neutralizing antibodies in clinical samples. Antimicrob. Agents Chemother. 2012, 56, 3524-3530. [CrossRef] [PubMed]

5. Smith, J.S.; Yager, P.A.; Baer, G.M. A rapid reproducible test for determining rabies neutralizing antibody. Bull. World Health Organ. 1973, 48, 535-541. [PubMed]

6. Smith, J.S.; Yager, P.A.; Baer, G.M. A rapid fluorescent focus inhibition test (RFFIT) for determining rabies virus-neutralizing antibody. In Laboratory Techniques in Rabies, 4th ed.; Meslin, F.X., Kaplan, M.M., Koprowski, H., Eds.; World Health Organization: Geneva, Switzerland, 1996; pp. 181-192.

7. Khawplod, P.; Inoue, K.; Shoji, Y.; Wilde, H.; Ubol, S.; Nishizono, A.; Kurane, I.; Morimoto, K. A novel rapid fluorescent focus inhibition test for rabies virus using a recombinant rabies virus visualizing a green fluorescent protein. J. Virol. Methods 2005, 125, 35-40. [CrossRef] [PubMed]

8. Trimarchi, C.V.; Rudd, R.D.; Safford, M.J. An in vitro virus neutralization test for rabies antibody. In Laboratory Techniques in Rabies, 4th ed.; Meslin, F.X., Kaplan, M.M., Koprowski, H., Eds.; World Health Organization: Geneva, Switzerland, 1996; pp. 193-199.

9. Cliquet, F.; Aubert, M.; Sagne, L. Development of a fluorescent antibody virus neutralisation test (FAVN test) for the quantitation of rabies-neutralising antibody. J. Immunol. Methods 1998, 212, 79-87. [CrossRef]

10. Yager, M.L.; Moore, S.M. The rapid fluorescent focus inhibition test. In Current Laboratory Techniques in Rabies Diagnosis, Research and Prevention; Rupprecht, C., Nagarajan, T., Eds.; Academic Press: San Diego, CA, USA, 2015; Volume 2, pp. 199-214.

11. Kuzmin, I.V.; Niezgoda, M.; Franka, R.; Agwanda, B.; Markotter, W.; Beagley, J.C.; Urazova, O.Y.; Breiman, R.F.; Rupprecht, C.E. Lagos bat virus in Kenya. J. Clin. Microbiol. 2008, 46, 1451-1461. [CrossRef] [PubMed] 
12. Reagan, K.J.; Wunner, W.H.; Wiktor, T.J.; Koprowski, H. Anti-idiotypic antibodies induce neutralizing antibodies to rabies virus glycoprotein. J. Virol. 1983, 48, 660-666. [PubMed]

13. World Organisation for Animal Health. Principles and methods of validation of diagnostic assays for infectious diseases. In OIE Terrestrial Manual; World Oganisation for Animal Health: Paris, France, 2010; pp. 1-18.

(C) 2017 by the authors. Licensee MDPI, Basel, Switzerland. This article is an open access article distributed under the terms and conditions of the Creative Commons Attribution (CC BY) license (http:/ / creativecommons.org/licenses/by/4.0/). 
Article

\title{
Sero-Surveillance of Lyssavirus Specific Antibodies in Nigerian Fruit Bats (Eidolon helvum)
}

\author{
Dinchi A. Tyem ${ }^{1}$, Banenat B. Dogonyaro ${ }^{1,2}$, Timothy A. Woma ${ }^{1}$, Ernest Chuene Ngoepe ${ }^{3}$ and \\ Claude Taurai Sabeta ${ }^{2,3, *}$ \\ 1 National Veterinary Research Institute, P.M.B. 1, Vom-Jos Plateau State, Nigeria; \\ jasminetyem@yahoo.com (D.A.T.); bbdogonyaro@gmail.com (B.B.D); WomaT@up.ac.za (T.A.W.) \\ 2 University of Pretoria, Faculty of Veterinary Sciences, Department of Veterinary Tropical Diseases, \\ P Bag X04, Onderstepoort 0110, South Africa \\ 3 OIE Rabies Reference Laboratory, Agricultural Research Council-Onderstepoort Veterinary Research, \\ Onderstepoort 0110, South Africa; NgoepeE@arc.agric.za \\ * Correspondence: SabetaC@arc.agric.za; Tel.: +27-12-5299439
}

Received: 30 May 2017; Accepted: 4 June 2017; Published: 9 July 2017

\begin{abstract}
The aetiological agent of rabies is a member of the Lyssavirus genus (Rhabdoviridae family, order Mononegavirales). The disease (rabies) is endemic in many parts of Asia and Africa and still remains an important public and veterinary health threat. In Nigeria, there is a dearth of information on the natural infection and/or exposure of bat species to lyssaviruses. Therefore, this study was undertaken to assess the prevalence of rabies virus (RABV) neutralizing antibodies in sera obtained from bats from the central Plateau and North-East Bauchi States in Nigeria. Two hundred serum samples were collected from Nigerian fruit bats from six different locations and tested for anti-RABV antibodies using a commercial blocking ELISA. Of the 200 bat serum samples collected, one batch consisting of 111 samples did not meet the validation criteria and hence was not included in the final analysis. Of the remaining 89 , only three $(3.4 \%)$ contained anti-lyssavirus antibodies, demonstrating a low prevalence of lyssavirus antibodies in the study population. In order to further understand the exposure of bat species to phylogroup II lyssaviruses (Lagos bat virus and Mokola virus), the same panel of samples will be tested for neutralizing antibodies to phylogroup II members, viruses that do not cross-neutralize with members of phylogroup I.
\end{abstract}

Keywords: lyssavirus; rabies; Eidolon helvum; Nigeria; blocking ELISA; phylogroup I; phylogroup II

\section{Introduction}

Rabies is a fatal zoonotic disease and the aetiologic agent belongs to the genus Lyssavirus (Rhabdoviridae family) and order Mononegavirales. Despite rabies being a very old disease, it still commands great global veterinary and public health importance. There are presently fourteen recognised lyssavirus species in the genus and these include: rabies lyssavirus (RABV), Lagos bat lyssavirus (LBV), Mokola lyssavirus (MOKV), Duvenhage lyssavirus (DUVV), European bat 1 lyssavirus (EBLV-1), European bat 2 lyssavirus (EBLV-2), Australian bat lyssavirus (ABLV), Aravan lyssavirus (ARAV), Khujand lyssavirus (KHUV), Irkut lyssavirus (IRKV), West Caucasian bat lyssavirus (WCBV), Bokeloh bat lyssavirus (BBLV), Shimoni bat lyssavirus (SHIBV), and Ikoma lyssavirus (IKOV) [1,2]. Furthermore, two putative lyssavirus species, Lleida bat lyssavirus (LLEBV) [3] and Gannoruwa bat lyssavirus (GBLV) [4], have been identified in bat species and are still awaiting official classification. The viral species of this genus have been further sub-divided into three phylogroups based on their genetic distances, serologic cross-reactivity and/or pathogenicity studies in mouse model [5-7]. 
RABLV is found worldwide, and is responsible for the overwhelming majority of reported animal and human rabies cases [8-10]. Other lyssaviruses appear to have more restricted geographical and host range, with the majority having been isolated from bats with limited public and animal health implications. However, all lyssaviruses tested cause clinical disease indistinguishable from RABLV. In Nigeria, LBV was first isolated from the straw-coloured fruit bat Eidolon helvum in 1956 on Lagos Island [11]. A seroprevalence of $19 \%$ was demonstrated in this species (in Nigeria) by a different research group [12], whereas almost double that seroprevalence (37\%) was observed in the same bat species in Ghana [13]. In contrast, other studies found an even higher seroprevalence, for instance in Kenya (40-67\%), albeit from different bat colonies [14]. In Nigeria and throughout most of the African continent where bat populations are found, the natural infection of bat species with lyssaviruses is either unknown or poorly understood.

\section{Materials and Methods}

Ethical clearance (AEC/02/04/14) was granted by the Animal Ethical Committee (AEC) of the National Veterinary Research Institute, Vom, Nigeria, for the collection of blood samples from bats. Two hundred E. helvum were captured using mist nets from six different roosting sites in the central Plateau and North East Bauchi states of Nigeria with a view to assess the seroprevalence of RABV antibodies in this bat species. The bats were restrained manually and anesthetized with ketamine hydrochloride as described previously [15]. Blood samples were then collected (0.1-1 mL) through the jugular vein using $2 \mathrm{~mL}$ needle and syringe. The blood samples were then transferred into $5 \mathrm{~mL}$ sterile serum separator tubes via cold chain to the laboratory, where all the blood samples were centrifuged at $4000 \mathrm{rpm}$ for 3 minutes, and thereafter serum samples were dispensed into sterile $2 \mathrm{~mL}$ screw capped cryovial tubes and stored at $-80^{\circ} \mathrm{C}$ until required.

This panel of serum samples was tested with an ELISA kit (BioPro rabies ELISA Ab kit, Prague, Czech Republic), a blocking ELISA for serological diagnostic of rabies lyssavirus antibody in serum or plasma of domesticated and wild animals [16]. In brief, the serum samples and controls (rabies positive control serum, rabies control serum 1, rabies control serum 2, rabies control serum 1 and rabies negative control) were diluted two-fold using sample diluent buffer provided in the kit. At least $100 \mu \mathrm{L}$ of each dilution were distributed into the respective well of the plate. Thereafter, the plate was sealed with plate sealer and incubated at $4-8{ }^{\circ} \mathrm{C}$ overnight $(\mathrm{O} / \mathrm{N})$ with gentle shaking on orbital shaker. The plate was washed six times with washing solution using automated washer (BioTek, Winooski, VT, USA) and excess buffer was absorbed on paper towel. The biotinylated anti-rabies antibody was diluted to a working dilution of 1:100 and $100 \mu \mathrm{L}$ was distributed into each well. The plate was covered with a plate sealer and incubated at $37 \pm 2{ }^{\circ} \mathrm{C}$ for 30 minutes with gentle shaking as described before, then washed four times. Excess buffer was removed by tapping on paper towel. The streptavidin peroxidase conjugate was diluted 100 -fold and $100 \mu \mathrm{L}$ was dispensed into each well. The plate was sealed and incubated as previously. The plate was washed four times with washing solution and excess buffer was removed as before. At least $100 \mu \mathrm{L}$ of ready-to-use TMB substrate was added to each well and the plate was incubated at room temperature for 15-30 min, with gently shaking on an orbital shaker away from direct sunlight. Thereafter, the reaction was stopped with $50 \mu \mathrm{L}$ of stop solution per well and the results were read at $450 \mathrm{~nm}$ using an ELISA reader. The optical density (OD) values were expressed as percentage blocking by using the following formula:

$$
\mathrm{PB} \%=[\mathrm{ODNC}-\mathrm{OD} \text { SAMPLE} / \mathrm{OD} \mathrm{NC}-\mathrm{OD} \mathrm{PC}] \times 100
$$

The results were accepted only when the OD of a negative control serum of higher than 1 was obtained and the difference between the means of OD of negative and positive control serum samples was equal or higher than 0.8 . 


\section{Results and Discussion}

Using the set cut-off values (of $40 \%$ and $70 \%$ ) for this ELISA antibody kit, with the latter corresponding to the gold standard method fluorescent antibody virus neutralization test (FAVNT) cut-off value of $0.5 \mathrm{IU} / \mathrm{mL}$, it could be shown that only two serum samples were on the borderline and an equal number just above the cut-off value (Figure 1). Of the 200 serum samples analysed, only 89 met the validation criteria specified by the manufacturer and included for analysis. Three serum samples (sample numbers 2, 24, and 67), i.e., 3.4\% of the study sample, contained lyssavirus-specific antibodies with percentage blockings (PBs) of 70\%, 81\% and $75 \%$ respectively (Figure 1).

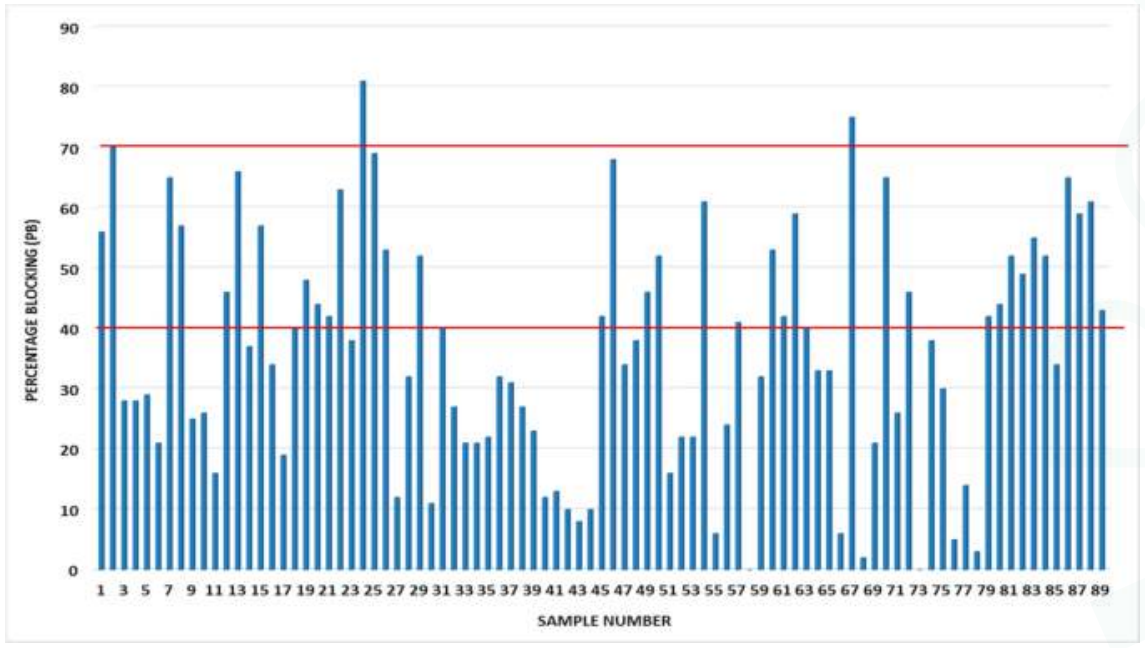

Figure 1. The distribution of percentage blocking values obtained from some of the bat sera obtained from Eidolon helvum from the central Plateau and North East Bauchi States of Nigeria. The red bars are the cut-off values ( $40 \%$ and $70 \%$ ) with the former considered positive for rabies antibodies, and $70 \%$ considered as serum sample with antibody level equal to or higher than $0.5 \mathrm{IU} / \mathrm{mL}$ based on the FAVN test.

The three serum samples were subsequently shown to contain RABV-neutralising antibodies just below the $0.5 \mathrm{IU} / \mathrm{mL}$ cut-off using a laboratory strain of rabies virus (challenge virus standard). The $70 \%$ cut-off value demonstrates adequate seroconversion for international movement of pets using a fluorescent antibody neutralisation test [17]. In order to further understand the exposure of bat species to phylogroup II lyssaviruses (Lagos bat virus and Mokola virus), the same panel of samples (particularly those above $40 \%$ ) can be tested for neutralizing antibodies to phylogroup II members. Data from a study carried out in Ibadan (western Nigeria) in 1990 showed the presence of RABV neutralizing antibodies in the sera of fruit bats [18]. However, given Eidolon helvum has been associated with a reservoir of LBV, it is crucial that the panel of samples be tested against this (LBV) lyssavirus $[12,13]$. These data therefore indicated possible cross-reactivity of antibodies amongst specific phylogroups within the Lyssavirus genus.

Acknowledgments: This work was funded by the National Veterinary Research Institute (NVRI), Vom-Jos Plateau State, Nigeria, and the National Assets Project (P10000029) of Agricultural Research Council-Onderstepoort Veterinary Research (ARC-OVR).

Author Contributions: D.A.T.-collection of samples and performing of experiments; B.B.B.-collection of samples and writing of manuscript; T.A.W.-collection of samples and performing of experiments; E.N-performing of experiments and writing of manuscript; C.T.S.—-supervising postgraduate student and writing manuscript. 
Conflicts of Interest: The authors declare no conflict of interest.

\section{References}

1. ICTV (International Committee on Taxonomy of Viruses). Available online: http://www.ictvonline.org/ virusTaxonomy.asp?bhcp=1 (accessed on 30 May 2017).

2. Marston, D.A.; Ellis, R.J.; Wise, E.L.; Aréchiga-Ceballos, N.; Freuling, C.M.; Banyard, A.C.; Mcelhinney, L.M.; De Lamballerie, X.; Müller, T.; Fooks, A.R.; et al. Complete genome sequence of Lleida bat lyssavirus. Genome Announc. 2017, 5, e01427-16. [CrossRef] [PubMed]

3. Aréchiga, C.N.; Vázquez, M.S.; Berciano, J.M.; Nicolás, O.; Aznar, L.C.; Juste, J.; Rodríguez, N.C.; Aguilar, S.A.; Echevarría, J.E. Novel lyssavirus in bat, Spain. Emerg. Infect. Dis. 2013, 19, 793-795.

4. Gunawardena, P.S.; Marston, D.A.; Ellis, R.J.; Wise, E.L.; Karawita, A.C.; Breed, A.C.; Mcelhinney, L.M.; Johnson, N.; Banyard, A.C.; Fooks, A.R. Lyssavirus in Indian flying foxes, Sri Lanka. Emerg. Infect. Dis. 2016, 22, 1456-1459. [CrossRef] [PubMed]

5. Badrane, H.; Bahloul, C.; Perrin, P.; Noel, T. Evidence of two Lyssavirus phylogroups with distinct pathogenicity and immunogenicity. J. Virol. 2001, 75, 3268-3276. [CrossRef] [PubMed]

6. Hanlon, C.A.; Kuzmin, I.V.; Blanton, J.D.; Weldon, W.C.; Manangan, J.S.; Rupprecht, C.E. Efficacy of rabies biologics against new lyssaviruses from Eurasia. Virus Res. 2005, 111, 44-54. [CrossRef] [PubMed]

7. Kuzmin, I.V.; Mayer, A.E.; Niezgoda, M.; Markotter, W.; Agwanda, B.; Breiman, R.F.; Rupprecht, C.E. Shimoni bat virus, a new representative of the Lyssavirus genus. Virus Res. 2010, 149, 197-210. [CrossRef] [PubMed]

8. Hayman, D.T.S.; Fooks, A.R.; Marston, D.A.; Garcia-R, J.C. The Global Phylogeography of Lyssaviruses-Challenging the 'Out of Africa' hypothesis. PLoS Neglect. Trop. Dis. 2016, 10, e0005266. [CrossRef] [PubMed]

9. Fooks, A.R.; Banyard, A.C.; Horton, D.L.; Johnson, N.; McElhinney, L.M.; Jackson, A.C. Current status of rabies and prospects for elimination. Lancet 2014, 384, 1389-1399. [CrossRef]

10. Hampson, K.; Coudeville, L.; Lembo, T.; Sambo, M.; Kieffer, A.; Attlan, M.; Barrat, J.; Blanton, J.D.; Briggs, D.J.; Cleaveland, S.; et al. Estimating the global burden of endemic canine rabies. PLoS Neglect. Trop. Dis. 2015, 9, e0003786. [CrossRef] [PubMed]

11. Boulger, I.R.; Porterfield, J.S. Isolation of a virus from Nigerian fruit bats. Trans. Roy. Soc. Trop. Med. Hyg. 1958, 52, 421-424. [CrossRef]

12. Dzikwi, A.A.; Kuzmin, I.; Umoh, U.J.; Kwage, J.K.P.; Ahmad, A.A.; Rupprecht, C.E. Evidence of Lagos bat virus circulation among Nigerian fruit bats. J. Wildl. Dis. 2010, 46, 267-271. [CrossRef] [PubMed]

13. Hayman, D.T.S.; Fooks, A.R.; Rowcliffe, J.M.; McCrea, R.; Restif, O.; Baker, K.S.; Horton, D.L.; Suu-Ire, R.; Cunningham, A.A.; Wood, J.L.N. Endemic Lagos bat virus infection in Eidolon helvum. Epidemiol. Infect. 2012, 140, 2163-2171. [CrossRef] [PubMed]

14. Kuzmin, I.V.; Niezgoda, M.; Franka, R.; Agwanda, B.; Markotter, W.; Beagley, J.C.; Urazova, O.Y.; Breiman, R.F.; Rupprecht, C.E. Lagos bat virus in Kenya. J. Clin. Microbiol. 2008, 46, 1451-1461. [CrossRef] [PubMed]

15. Fernandes de Almeida, M.; Alves Martorelli, L.F.; Sodré, M.M.; Arruda Geraldes Kataoka, A.P.; da Rosa, A.R.; de Oliveira, M.L.; Amatuzzi, E. Rabies diagnosis and serology in bats from the State of São Paulo, Brazil. Rev. Soc. Bras. Med. Trop. 2011, 44, 140-145. [CrossRef]

16. Wasniewski, M.; Almeida, I.; Baur, A.; Bedekovic, T.; Boncea, D.; Chaves, L.B.; David, D.; de Benedictis, P.; Dobrostana, M.; Giraud, P.; et al. First international collaborative study to evaluate rabies antibody detection method for use in monitoring the effectiveness of oral vaccination programmes in fox and raccoon dog in Europe. J. Virol. Methods 2016, 238, 77-85. [CrossRef] [PubMed]

17. Cliquet, F.; Aubert, M.; Sagne, L. Development of a fluorescent antibody virus neutralisation test (FAVN test) for the quantitation of rabies-neutralising antibody. J. Immunol. Methods 1998, 212, 79-87. [CrossRef]

18. Aghomo, H.O.; Ako-Nai, A.K.; Oduye, O.O.; Tomori, O.; Rupprecht, C.E. Detection of rabies virus antibodies in fruit bats (Eidolon helvum) from Nigeria. J. Wildl. Dis. 1990, 26, 258-261. [CrossRef] [PubMed]

(C) 2017 by the authors. Licensee MDPI, Basel, Switzerland. This article is an open access article distributed under the terms and conditions of the Creative Commons Attribution (CC BY) license (http:/ / creativecommons.org/licenses/by/4.0/). 


\title{
Lagos Bat Virus Infection Dynamics in Free-Ranging Straw-Colored Fruit Bats (Eidolon helvum)
}

\author{
Richard D. Suu-Ire 1,2,3,7,*, Anthony R. Fooks 4,5, Ashley C. Banyard 4 , David Selden 4 \\ Kofi Amponsah-Mensah ${ }^{1}$, Silke Riesle ${ }^{1,6,7}$, Meyir Y. Ziekah ${ }^{2,3}$, Yaa Ntiamoa-Baidu ${ }^{1}$, \\ James L. N. Wood ${ }^{6}$ and Andrew A. Cunningham ${ }^{7, *}$
}

1 Department of Animal Biology and Conservation Science, University of Ghana, P.O. Box LG 571, Legon, Accra, Ghana; mak2kofi@gmail.com (K.A.-M.); sasr3@cam.ac.uk (S.R.); ynbaidu@ug.edu.gh (Y.N.-B.)

2 Veterinary Services Department, Ministry of Food and Agriculture, P. O. Box M 161, Accra, Ghana; meyir73@gmail.com

3 Wildlife Division of the Forestry Commission, P.O. Box M239, Accra, Ghana

4 Wildlife Zoonoses and Vector-Borne Diseases Research Group, Animal and Plant Health Agency (APHA), Weybridge, Woodham Lane, New Haw, Addlestone, Surrey KT15 3NB, UK; tony.fooks@apha.gsi.gov.uk (A.R.F.); Ashley.Banyard@apha.gsi.gov.uk (A.C.B.); David.Selden@apha.gsi.gov.uk (D.S.)

5 Department of Clinical Infection, Microbiology \& Immunology, Institute of Infection and Global Health, University of Liverpool, Liverpool LP69 7ZX, UK

6 Cambridge Infectious Diseases Consortium, Department of Veterinary Medicine, University of Cambridge, Madingley Road Cambridge CB3 0ES, Cambridge, UK; jlnw2@cam.ac.uk

7 Institute of Zoology, Zoological Society of London, Regent's Park, London NW1 4RY, UK

* Correspondence: suuire@gmail.com (R.D.S.-I.); A.Cunningham@ioz.ac.uk (A.A.C.); Tel.: +233-207347817 (R.D.S.-I.)

Received: 20 May 2017; Accepted: 4 July 2017; Published: 8 July 2017

\begin{abstract}
Bats are key species for ecological function, but they are also reservoirs of zoonotic agents, such as lyssaviruses that cause rabies. Little is known about the maintenance and transmission of lyssaviruses in bats, although the observation of clinically sick bats, both in experimental studies and wild bats, has at least demonstrated that lyssaviruses are capable of causing clinical disease in bat species. Despite this, extensive surveillance for diseased bats has not yielded lyssaviruses, whilst serological surveys demonstrate that bats must be exposed to lyssavirus without developing clinical disease. We hypothesize that there is endemic circulation of Lagos bat virus (LBV) in the straw-coloured fruit bat (Eidolon helvum) in Ghana, West Africa. To investigate this further, longitudinal blood sampling was undertaken quarterly between 2012 and 2014 on wild E. helvum at two sites in Ghana. Serum samples were collected and tested for LBV-neutralizing antibodies using a modified flourescent antibody virus neutralisation (FAVN) assay $(n=294)$ and brains from moribund or dead bats were tested for antigen and viral RNA $(n=55)$. Overall, $44.7 \%$ of the 304 bats sampled had LBV-neutralising antibodies. None of the brain samples from bats contained lyssavirus antigen or RNA. Together with the results of an earlier serological study, our findings demonstrate that LBV is endemic and circulates within E. helvum in Ghana even though the detection of viral infection in dead bats was unsuccessful. Confirmation that LBV infection is endemic in E. helvum in Ghana is an important finding and indicates that the potential public health threats from LBV warrant further investigation.
\end{abstract}

Keywords: bat; rabies; Eidolon helvum; Lagos bat virus; seroprevalence; lyssavirus; Ghana 


\section{Introduction}

Wildlife populations constitute a large and largely undefined reservoir of infectious agents, some of which are zoonotic [1-3]. Infectious pathogens that originate in wild animals have become increasingly important globally, as they have had substantial impacts on human health, agricultural production, wildlife-based economies and wildlife conservation. Bats (Chiroptera) represent a large group of wildlife, comprising $20 \%$ of the 4600 mammalian species recognized to date [4]. Bats have several key ecological functions, including pollination, seed dispersal and insect control [5]. However, bats have also been implicated as the reservoir hosts for numerous emerging infectious diseases. Increasingly, bats have been recognized as important reservoir hosts for viruses that have the potential to cross species barriers to infect humans, domestic and wild mammals $[4,6]$.

Lyssaviruses (family Rhabdoviridae, genus Lyssavirus) are the aetiological agents that cause the disease rabies-an acute, progressive, viral encephalitis that is almost invariably fatal [7]. Most lyssaviruses are carried by bats, but the association of these viruses with bats is complex and poorly understood [8]. Rabies virus (RABV) is found in terrestrial carnivores globally, but it is only found in bats in the Americas, where it is endemic in frugivorous, insectivorous and hematophagous bats [8]. In contrast, the other 13 known lyssavirus species have only been detected in the Old World, predominantly in bat species although infection of terrestrial carnivores has been documented for some lyssavirus species [9]. Globally, the most significant public health and veterinary burden caused by lyssaviruses is dog-mediated transmission of RABV, but instances of other lyssavirus infection of humans or domesticated animals have been reported on rare occasions following spill-over events $[8,10]$.

One bat lyssavirus that has been associated with the infection of terrestrial carnivores is Lagos bat virus (LBV), a virus most commonly associated with infection of African fruit bats. Fruit bats of several species have been identified as reservoir hosts for LBV, with spill-over infections reported in dogs, cats and a mongoose [11-14]. Notably, LBV has never been reported in human cases of rabies or any other case of human meningoencephalitis. Diagnostic tests that can differentiate between lyssaviruses are not available in the majority of rabies endemic areas, therefore clarity surrounding the impact of non-RABV lyssaviruses, such as LBV, is lacking. High seroprevalence against lyssaviruses has been reported in apparently-healthy bats, including for LBV in the straw-colored fruit bat (E. helvum) in Ghana [15]. While the ecology, pathogenesis and pathology of RABV in terrestrial animals and humans is partially understood [7], knowledge on the other lyssavirus species is scant. In this study, investigations into the presence of LBV infection in a natural host, E. helvum, were made through post-mortem sampling of moribund and dead bats as well as through serological assessment of samples for LBV neutralizing antibodies.

\section{Material and Methods}

\subsection{Ethics Statement}

The study was approved by the Institutional Review Board of the Nuguchi Memorial Institute for Medical Research of the University of Ghana (NMIMR-ITB CPN 002/13-14 IORG0000908) and the Ethics Committee of the Zoological Society of London (WLE/0638).

\subsection{Study Sites}

This study was undertaken at two E. helvum roost sites in Ghana, West Africa. The roosts comprised between approximately 3000 to 1,000,000 bats each, depending on year and season. One roost was located in Greater Accra $\left(05^{\circ} 35.192^{\prime} \mathrm{N}, 000^{\circ} 11.053^{\prime} \mathrm{W}\right)$, within the grounds of a large general infirmary (37-Military Hospital) in the center of the city. The other roost was in Tanoboase in the Brong-Ahafo region $\left(07^{\circ} 38^{\prime} \mathrm{N}, 01^{\circ} 11.54^{\prime} \mathrm{W}\right)$, within a protected forest area (Figure 1$)$. The site in Tanoboase, known locally as Tano Sacred Grove, was developed for ecotourism in 1996 and is visited 
by both local and international tourists. The site also hosts an annual Apoo festival (a time of spiritual cleansing held in April-May).

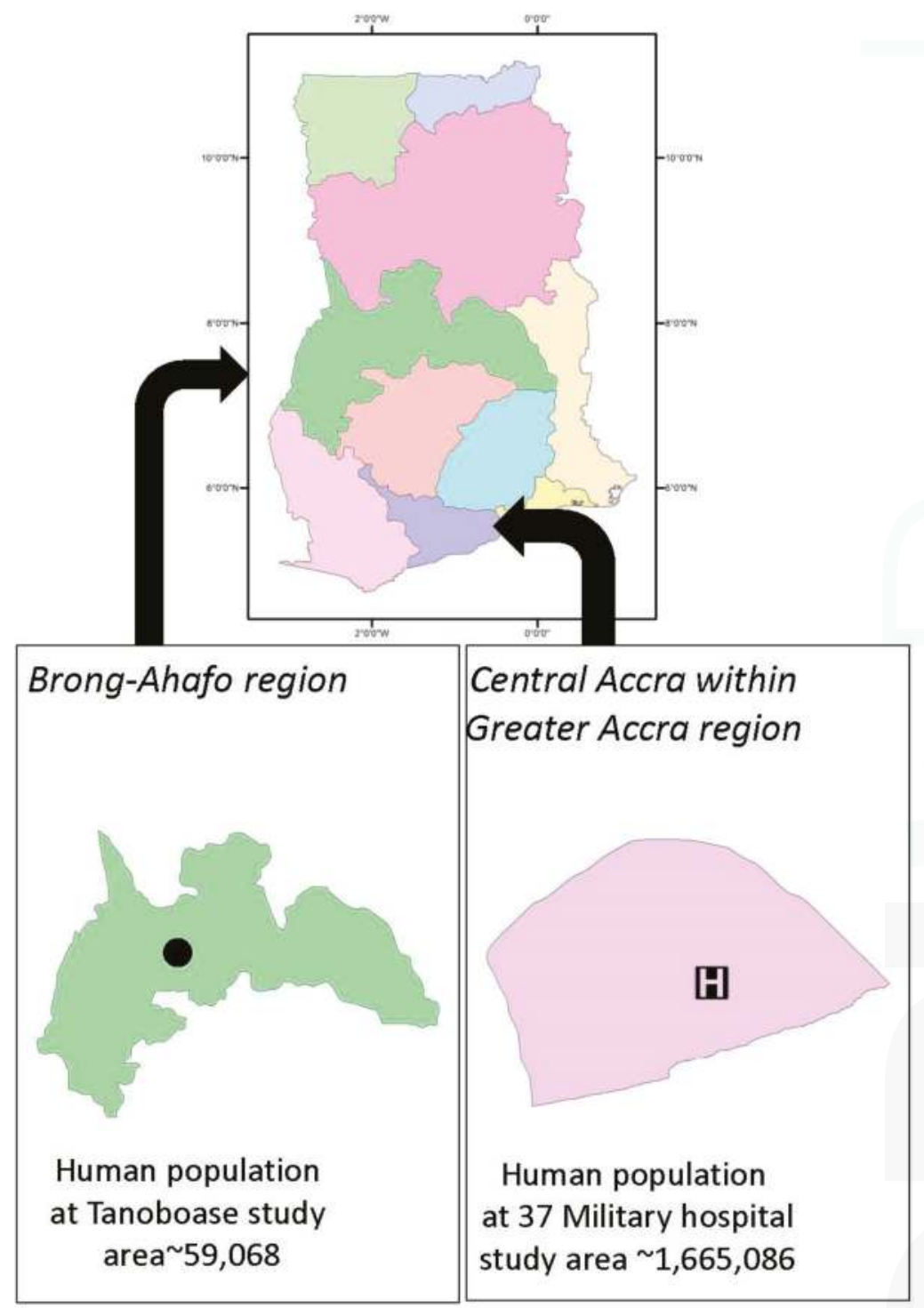

Figure 1. Locations at which wild straw-colored fruit bats (Eidolon helvum) were captured and sampled.

\subsection{Study Design}

Sera Collection for Lagos Bat Virus Antibody Prevalence in Wild Eidolon helvum

Wild bats were captured using mist nets from 2012 to 2014 inclusive, as detailed in Table 1. Sampling in June/July was aimed to correspond with late-stage pregnancy. In July, the majority of the bats in each roost had migrated to alternative, as yet unknown, sites. By November, most 
bats had returned to each roost. Captured bats were housed individually in cloth bags for short time periods before being processed. The sex and sexual maturity of each bat were assessed based on body size (body mass and forearm length were measured routinely) and observation of external genitalia and mammary tissue. Approximately $1 \mathrm{~mL}$ of blood was collected in micro-tubes (SARSTEDT, Germany) from the propatagial vein of each individual, as described previously [15]. Blood samples were centrifuged at $6000 \times g$ for $15 \mathrm{~min}$ and the separated sera were stored at $-70{ }^{\circ} \mathrm{C}$ until required. Each bat was micro-chipped (using the Trovan animal identification system, Electronic Identification Systems, Germany) to enable identification in case of recapture. Bats were released at the site of capture immediately following sampling, after ensuring haemostasis at the site of venipuncture.

Table 1. Sample data collected.

\begin{tabular}{|c|c|c|c|c|c|c|c|}
\hline & \multirow[b]{2}{*}{ Sampling Date } & \multicolumn{3}{|c|}{ 37-Military Hospital } & \multicolumn{2}{|c|}{ Tanoboase } & \multirow{2}{*}{ Totals } \\
\hline & & $10-06-2013$ & 04-09-2013 & $14-07-2014$ & $17-12-2012$ & 01-07-2014 & \\
\hline \multirow{4}{*}{ Age } & Adult & 34 & 87 & 32 & 57 & 26 & 236 \\
\hline & Juvenile & 11 & 6 & 3 & 0 & 2 & 22 \\
\hline & Sub-adult & 0 & 25 & 11 & 0 & 0 & 36 \\
\hline & Not determined & 0 & 1 & 3 & 5 & 1 & 10 \\
\hline \multirow{3}{*}{ Sex } & Male & 34 & 88 & 30 & 33 & 25 & 210 \\
\hline & Female & 11 & 30 & 16 & 24 & 3 & 84 \\
\hline & Unsexed & & 1 & 3 & 5 & 1 & 10 \\
\hline \multirow{2}{*}{ Serostatus } & Positive & 17 & 53 & 24 & 29 & 13 & 136 \\
\hline & Negative & 28 & 66 & 25 & 33 & 16 & 168 \\
\hline
\end{tabular}

\subsection{Collection and Examination of Dead Bats}

Members of the public who frequented the areas under the roosts were asked to report any dead or sick bats they found. Also, during each sampling visit, searches for dead or sick bats were undertaken in the immediate vicinity of the roosts. Sick bats were euthanised using intramuscular ketamine and medetomidine, followed by exsanguination via cardiac puncture. Bat carcasses were stored in a freezer at $-70{ }^{\circ} \mathrm{C}$ until necropsy. At necropsy, a range of tissues, including brain, was collected and stored fixed or frozen for later investigation.

\subsection{Laboratory Investigations}

\subsubsection{Antigen Detection Using the Fluorescent Antibody Test (FAT)}

Fluorescein isothiocyanate (FITC)-conjugated anti-rabies nucleocapsid polyclonal antibody conjugate (Fujirebio Diagnostics, Malvern, PA, USA) was used diluted 1:40 in 0.1 M phosphate buffered saline( PBS) pH 7.2 to stain virus antigen in acetone-fixed impression smears taken from the hippocampus, cerebellum and brain stem of bats found dead or sick (following euthanasia), as described previously [16]. Slides were examined using a fluorescence UV microscope. LBV-infected mouse brain material was used as a positive control for comparison of antigen distribution.

\subsubsection{Detection of LBV-Neutralizing Antibodies (mFAVN)}

The presence of antibodies capable of neutralizing LBV in collected bat sera was assessed using a modified version of the fluorescent antibody virus neutralization assay (mFAVN), as described previously [2,15]. Briefly, lineage B LBV [17] was prepared to a working concentration of 100 tissue culture infective doses (TCID) $)_{50} / 50 \mu \mathrm{L}$. Both negative sera from an unvaccinated dog and positive anti-LBVNig56 rabbit serum samples were used as serological controls for the assay. Each test serum sample was diluted three-fold (starting with a 1:9 dilution) in minimum essential medium (MEM), and incubated with the viral inoculum for $1 \mathrm{~h}$ at $37^{\circ} \mathrm{C}$ before being added to BHK-21 cells in suspension in a 96-well plate. Following incubation for $48 \mathrm{~h}$ at $37^{\circ} \mathrm{C}$, the plates were fixed in $80 \%$ chilled acetone for $20 \mathrm{~min}$, and stained with FITC-labelled anti-rabies polyclonal antibody (Fujirebio Diagnostics, Malvern, PA, USA). Fluorescent foci present in cells infected with LBV were visualized at $488 \mathrm{~nm}$ using 
a fluorescence UV microscope. The lack of accurately-titred control sera meant that all neutralizing antibody levels were expressed as $D_{50}$ values. The $D_{50}$ for each sample is the dilution endpoint at which $50 \%$ of the wells showed the presence of virus. $D_{50}$ values were calculated using the Spearman-Karber method. A serological cut-off was assigned according to neutralization of control sera and a back titration of input virus.

\subsubsection{Detection of LBV RNA Using Molecular Methods}

Total RNA was extracted from brain tissue samples using Trizol (Invitrogen) following the manufacturer's protocol. A pan-lyssavirus SYBR Green real-time (q) RT-PCR [18] and a pan-lyssavirus conventional hemi-nested-RT-PCR [19] were used to determine the presence or absence of viral RNA.

\section{Statistical Analysis}

The chi-squared test was used to investigate if there were significant differences in seroprevalence according to the age, sex and roost location of bats.

\section{Results}

\subsection{LBV Seroprevalence}

Samples taken and data regarding age, sex and serology are detailed in Table 1. A total of 304 bat sera were collected and tested for LBV neutralization antibodies during the sampling periods described. Of the 304 sera tested, $44.7 \%(n=136)$ were considered seropositive (Table 1; Figure 2). This comprised 213 from the 37-Military Hospital in Accra and 91 from the Tanoboase roost site, with 236 adults, 36 sub-adults, 22 juveniles and 10 bats of undetermined age (morphometric data not recorded); 210 males, 84 females and 10 of undetermined sex being tested across the two sites (Table 1). Seroprevalences were high during the three years of sampling $(2012-46.8 \%, n=62 ; 2013-42.7 \%$, $n=164 ; 2014-47.4 \% n=78)$. Of those bats that tested serologically positive, $45.2 \%$ were known to be male $(n=95 / 210)$ while $61.9 \%$ were identified as female $(n=52 / 84)$. Results from samples collected from bats of undetermined sex or age were not included in the statistical analyses. There was no significant difference in the different age groups that tested positive ( $p$-value $=0.78)$ (Table 2). Seroprevalence in adult bats $(0.46, n=236)$ was slightly higher than in the sub-adult and juvenile bats combined $(0.43, n=58)$.

Table 2. Seroprevalence in wild-caught bats by age.

\begin{tabular}{ccc}
\hline & Total Sampled & Total Positive (\% Positive) \\
\hline Adult & 136 & $109(80.15 \%)$ \\
Juvenile & 58 & $25(43.10 \%)$ \\
Total & 294 & $134(45.57 \%)$ \\
\hline
\end{tabular}

In June 2013, two nursing E. helvum dams (ID: 900 and ID: 905) were caught with their pups (ID: 901 and 904, respectively) at the 37-Military Hospital roost site. All four animals were apparently healthy with a good body condition and no outward signs of disease. Following serological assessment, the two mothers were both seronegative with a $D_{50}$ of 5.20 . In contrast, both pups were seropositive with detectable anti-LBV neutralizing antibody $\mathrm{D}_{50}$ of 46.77 and 81.00 for animals 901 and 904, respectively.

Overall, there was no statistically significant difference in seroprevalence between the two sites (Table 1). At 37-Military Hospital, $44.1 \%(n=94 / 213)$ were seropositive (Figure 2a) compared to $46.1 \%$ $(n=42 / 91)$ of bats at Tanoboase (Figure $2 \mathrm{~b})$ (chi-square test $=0.04$; odds ratio $(\mathrm{OR})=1.085$; relative risk $(R R)=1.046 ; p=0.84)$.

To assess potential seasonal variation, an evaluation of seropositivity between the two sites was made for each sampling time. From the total sample set obtained for the two sites, there 
was no statistical significance in the seasonal difference in seroprevalence between the dry season (December-March) and the rainy season (April-November) $(p=0.83)$ (Table 3).

Table 3. Proportion of seroprevalence in wild-caught bats by season.

\begin{tabular}{cccc}
\hline & Positive (+ve) & Negative (-ve) & Total Tested \\
\hline Dry Season & $29(21 \%)$ & $33(20 \%)$ & $62(20 \%)$ \\
Rainy Season & $107(79 \%)$ & $135(80 \%)$ & $242(80 \%)$ \\
Totals & $136(45 \%)$ & $168(55 \%)$ & 304 \\
\hline
\end{tabular}

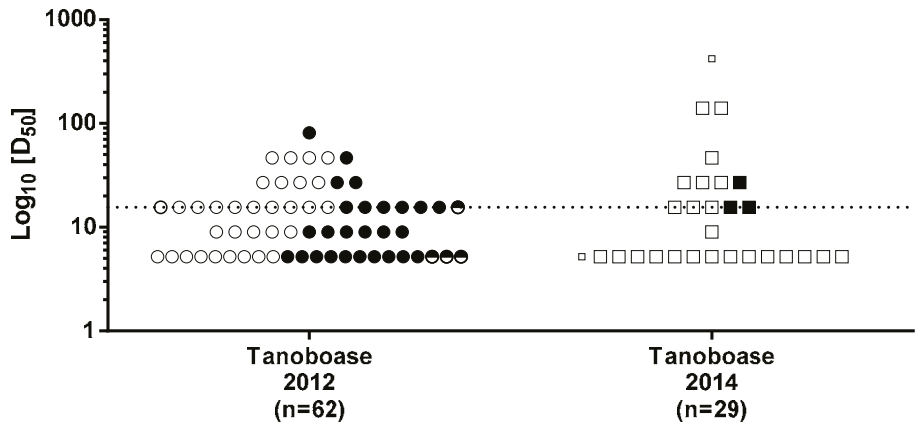

(a)

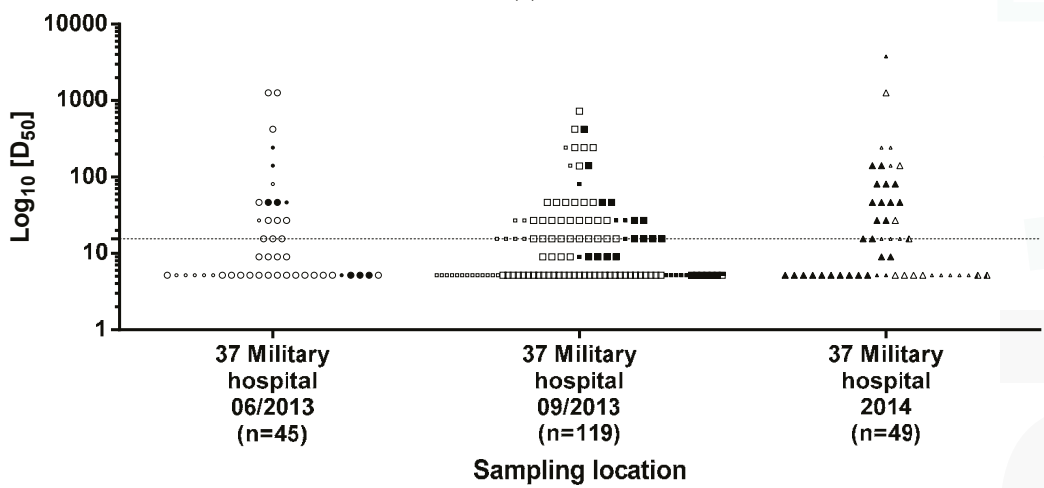

(b)

Figure 2. Serological profiles of straw-colored fruit bats sampled at (a) Tanoboase in the Brong-Ahafo region and (b) at 37-Military Hospital, Greater Accra. Open symbols represent male bats, closed symbols represent female bats; half-filled symbols represent bats of undetermined sex. Smaller symbols represent juvenile or sub-adult bats. The $\mathrm{D}_{50}$ value considered the cut-off for positivity is indicated by a dashed line.

\subsection{Necropsy Findings in E. helvum Bats}

Forty-six bats were examined post-mortem, of which 38 bats had been collected from the 37-Military Hospital roost and eight bats collected from Tanoboase. Thirty-three bats were found dead, while 13 bats were found moribund and were euthanized, following clinical assessment, on welfare grounds (Table 4$)$. Most moribund bats $(n=11)$ had traumatic injuries of unknown origin. All brain samples were negative for lyssavirus antigen and RNA using FAT and the RT-PCRs, respectively. 
Table 4. Necropsy findings in dead/moribund E. helvum bats. All bats found sick were terminated humanely and blood taken as described.

\begin{tabular}{|c|c|c|c|c|}
\hline Bat ID & Location & Date Found & Condition & Comments \\
\hline A1 & 37-Hospital & $20 / 01 / 2013$ & Found dead & N.A.D. * \\
\hline A2 & 37-Hospital & $20 / 02 / 2013$ & Found dead & N.A.D. \\
\hline A3 & 37-Hospital & $20 / 02 / 2013$ & Found dead & N.A.D. \\
\hline A4 & 37-Hospital & $20 / 02 / 2013$ & Found dead & N.A.D. \\
\hline A6 & 37-Hospital & $28 / 10 / 2013$ & Found dead & Very enlarged spleen \\
\hline A5 & Accra Ridge & $29 / 09 / 2013$ & Found dead & Found dead \\
\hline A12 & 37-Hospital & $27 / 11 / 2013$ & Found sick & Paralysed \\
\hline A13 & 37-Hospital & $27 / 11 / 2013$ & Found dead & Fractured right arm \\
\hline A7 & 37-Hospital & $07 / 12 / 2013$ & Found sick & Paralysis \\
\hline A8 & 37-Hospital & $07 / 12 / 2013$ & Found sick & Paralysis \\
\hline A9 & 37-Hospital & $07 / 12 / 2013$ & Found dead & Abscess on neck \\
\hline A10 & 37-Hospital & $10 / 12 / 2013$ & Found dead & N.A.D. \\
\hline A11 & 37-Hospital & $08 / 12 / 2013$ & Found dead & Fractured forearm \\
\hline A14 & 37-Hospital & $11 / 12 / 2013$ & Found dead & Fractured forearm \\
\hline A15 & 37-Hospital & $11 / 12 / 2013$ & Found dead & Severe intestinal, abdominal haemorrhages \\
\hline A16 & 37-Hospital & $11 / 12 / 2013$ & Found dead & Fractured head \\
\hline A17 & 37-Hospital & $13 / 12 / 2013$ & Found sick & Paralysis \\
\hline A18 & 37-Hospital & $13 / 12 / 2013$ & Found dead & N.A.D. \\
\hline A19 & 37-Hospital & $13 / 12 / 2013$ & Found dead & Punctured wing \\
\hline A22 & 37-Hospital & $22 / 12 / 2013$ & Found sick & Paralysis, severe haemorrhages on head \\
\hline A23 & 37-Hospital & $22 / 12 / 2013$ & Found dead & N.A.D. \\
\hline A24 & 37-Hospital & $22 / 12 / 2013$ & Found dead & N.A.D. \\
\hline A20 & 37-Hospital & $03 / 01 / 2014$ & Found dead & N.A.D. \\
\hline A21 & 37-Hospital & $03 / 01 / 2014$ & Found dead & Emaciated carcass \\
\hline A25 & 37-Hospital & $22 / 01 / 2014$ & Found dead & Fractured forearm \\
\hline A26 & 37-Hospital & $22 / 01 / 2014$ & Found dead & Decomposed carcass \\
\hline A27 & 37-Hospital & $22 / 01 / 2014$ & Found dead & N.A.D. \\
\hline A28 & 37-Hospital & $29 / 01 / 2014$ & Found dead & N.A.D. \\
\hline A29 & 37-Hospital & $05 / 02 / 2014$ & Found dead & N.A.D. \\
\hline A30 & 37-Hospital & $12 / 03 / 2014$ & Found dead & N.A.D. \\
\hline A31 & 37-Hospital & $12 / 03 / 2014$ & Found dead & N.A.D. \\
\hline A32 & 37-Hospital & $12 / 03 / 2014$ & Found dead & N.A.D. \\
\hline A33 & 37-Hospital & $12 / 03 / 2014$ & Found dead & N.A.D. \\
\hline A34 & 37-Hospital & $12 / 03 / 2014$ & Found dead & N.A.D. \\
\hline A35 & 37-Hospital & $12 / 03 / 2014$ & Found dead & N.A.D. \\
\hline A36 & 37-Hospital & $06 / 04 / 2014$ & Found sick & Paralysis, emaciated \\
\hline A37 & 37-Hospital & $06 / 04 / 2014$ & Found sick & Paralysis \\
\hline A38 & Achimota & $09 / 07 / 2014$ & Found dead & N.A.D. \\
\hline $\mathrm{T} 1$ & Tanoboase & $22 / 01 / 2013$ & Found dead & N.A.D. \\
\hline $\mathrm{T} 2$ & Tanoboase & $22 / 01 / 2013$ & Found sick & Fractured forearm \\
\hline $\mathrm{T} 3$ & Tanoboase & $22 / 01 / 2013$ & Found sick & Fractured forearm \\
\hline $\mathrm{T} 4$ & Tanoboase & $23 / 01 / 2013$ & Found dead & Multiple body injury \\
\hline $\mathrm{T} 5$ & Tanoboase & $23 / 01 / 2013$ & Found sick & Fractured forearm \\
\hline T6 & Tanoboase & $07 / 03 / 2013$ & Found sick & Weak \\
\hline $\mathrm{T} 7$ & Tanoboase & $07 / 03 / 2013$ & Found sick & Multiple body injury \\
\hline $\mathrm{T} 8$ & Tanoboase & $07 / 03 / 2013$ & Found sick & Weak \\
\hline
\end{tabular}

\section{Discussion}

A total of 304 bat sera was collected and tested for LBV neutralizing antibodies from 2012 to 2014. Of the 304 sera tested, 136 tested positive (seroprevalence: $44.7 \%$ ) (Table 1; Figure 2). Seroprevalences were high during each of the three sampling years $(2012-46.8 \%, n=62 ; 2013-42.7 \%$, $n=164 ; 2014-47.4 \% n=78$ ). These results, taken together with similar LBV serology results reported previously [2], demonstrate the long-term endemic circulation of LBV in the Ghanaian E. helvum population. Previous studies have reported serological evidence of exposure to LBV in different E. helvum populations, including in Nigeria (14-44\% seropositivity; $n=140)$, Ghana (37\% seropositivity; $n=66)$, and Kenya $(40-67 \%$ seropositivity; $n=102)[15,17,18]$. This is the first time a previously-described seropositive population has been re-tested several years later and has been shown 
to maintain a similar level of seroprevalence. The mechanism of maintenance for lyssaviruses in bat species with very high roost numbers and population densities is largely undefined, although several variables including population size, contact rates, species susceptibility, immunological competence, and roost structure may all contribute to virus maintenance via an as-yet-undefined mechanism $[8,20]$.

The size of populations involved within the roosts studied and the movement between defined roosts and other roosting sites that remain undefined during migratory periods may influence virus exposure and hence seropositivity. There was no difference in seroprevalence between the two field sites when assessing data comparing sex and age of sampled bats. However, this species is migratory and individuals may travel long distances to feed [21] perhaps enabling interaction between E. helvum populations and possibly also those of other bat species.

Of the 294 sera from wild-caught bats tested of known age class, 134 (45.5\%) were serologically positive for LBV neutralizing antibodies. There was no significant difference in the seroprevalence detected between the different age groups tested. The slightly higher proportion of seropositive adult bats (0.46) over juvenile bats (0.43) are similar to levels reported in studies addressing serological positivity to RABV in hoary bats (Lasiurus cinereus) [22,23]. The observation of two serologically-positive pups from dams that were serologically negative is unexplained. Maternal antibody transfer is unlikely in the absence of detectable circulating antibodies in the dams. Whilst both dams were seronegative, it is possible that their neutralizing antibodies were below the detection limits of the test applied. The pups might also have acquired the antibodies from other seropositive mothers (through allosuckling) or survived infection and thus acquired immunity.

The effect of migration and coloniality on infection dynamics is not known. Reduced migration and population connectivity has been suggested as a mechanism that could increase the amplitude of seasonal outbreaks and increase the probability for spillover of pathogens to other species, such as human beings [24]. The absence of any seasonal difference in LBV seroprevalence was surprising as increased interactions between bats, and hence an increase in pathogen transmission, might be expected during the dry season in Ghana, when there are increased numbers and an increased population density at the roosting sites. It is possible, though, that the bats have similar aggregation and colonial roosting behaviors during migration as observed during the dry season in Ghana. If so, this would account for the lack of variation in seroprevalence observed in this study.

The current understanding of lyssavirus serological positivity within bat populations is poor. Persistence of neutralizing antibodies to lyssaviruses for longer than 12 months has been described previously $[25,26]$. The long duration of antibodies detected in bats may reflect repeated exposure and may explain the elimination of notable seasonal serological fluctuation in wild-caught bats. Such bats will also influence the epidemiology of an outbreak in the population. From such a small sample set, however, strong conclusions cannot be made and there is a need for a more extensive study to assess serodynamics in bat populations.

The distribution of LBV lineages across Africa is diverse (reviewed in [8]). In Ghana, only serological evidence of LBV has been previously reported, and then only using neutralization assays with lineage B LBV as the test virus [2,15]. The data generated here were also based on using LBV $\mathrm{B}$ as the test virus for neutralization. Future studies might benefit from assessment against all four lineages of LBV as well as against other lyssavirus for the potential detection of cross-neutralizing antibodies. Indeed, interpreting serological responses to lyssaviruses is problematic due to the potential for exposure, and serological responses to, undiscovered virus(es). It is possible that further related lyssaviruses exist, confusing the interpretation of these serological outputs. Nevertheless, numerous bats demonstrated significant neutralizing antibody titres against the test virus. This must indicate prior exposure to an LBV or to an antigenically-related lyssavirus.

Where higher titres are seen, it may indicate repeated exposure to antigenically-similar viruses that drive an anamnestic response. A multiple exposure infection study with rabies virus in bats [26] demonstrated that repeated infection may confer significant immunological memory and reduced susceptibility to RABV infection. It is, therefore, unknown if high seroprevalence is driven by exposure 
to sub-lethal doses of LBV via routes other than biting, such as from aerosol, grooming or food sharing. The significance of lyssavirus seropositivity in bat populations currently remains undefined.

In an attempt to detect live virus in bats at each study site, diseased and dead bats were assessed for the presence of virus antigen and nucleic acid in brain material. Clinical signs observed in moribund bats included paralyses, ataxia, weakness, vocalization and self-urination. The inability to detect LBV antigen or RNA in the brain samples of moribund or dead bats supports previous findings [27] that the infection prevalence of lyssavirus in gregarious colonial bat species is usually less than $1 \%$ of the population. The assays used for molecular detection of viral RNA in the present study are pan-lyssavirus in design and have been assessed to ensure that they are able to detect all lyssaviruses described to date. Many of the necropsied bats were found with evidence of trauma and might have been injured via intra-specific aggression, predators or human hunters; E. helvum is widely hunted in Ghana [28]. Many bats, however, had no evidence indicating possible cause of illness or death. A much larger sample size of dead or moribund bats may improve the chances of detecting infection with LBV or a related lyssavirus. A similar study in Ghana with a much higher sample size $(n=567)$ succeeded in isolating LBV in one E. helvum bat [29].

\section{Conclusions}

A high prevalence of antibodies against Lagos bat virus (LBV) in E. helvum and other bat species was previously demonstrated in Ghana [15,30]. Further follow-up studies confirmed the endemicity of LBV in E. helvum in Ghana [2]. The current study reports continued high antibody prevalence levels that support earlier findings. The high seroprevalence of LBV reported previously and in this study in apparently healthy E. helvum colonies provides evidence of long-term maintenance and circulation of LBV in this bat population. Demonstrating the maintenance of antibody titres within bat populations is important as it indicates that individual bats are being re-exposed to virus, which in turn suggests that bats are shedding virus and are exposing conspecifics. Whilst this perhaps is not surprising, demonstrating what appears to be a stable level of seroprevalence in a population is important. The mechanisms of transmission of bat lyssaviruses remain ill-defined but minimally, the data presented here reiterate that virus continues to circulate within the bat population, which is important in our understanding of the relationship between bats and lyssaviruses.

Ongoing studies have indicated the occurrence of close interactions between chiropteran, domestic animal, and human populations. Current methods used to confirm rabies virus infection in people and terrestrial carnivores are unable to differentiate between different lyssavirus species. As human consumption of bats is practiced in many parts of Ghana [30], the potential for human infection with LBV exists and the invariably fatal outcome of lyssavirus infection poses questions as to the risk from bat populations. Importantly, existing rabies vaccines do not fully protect against some African non-rabies lyssaviruses including LBV, Mokola virus, Shimoni bat lyssavirus, Ikoma lyssavirus and West Caucasian bat virus [31-35]; therefore an understanding of the potential risk of transmission of these viruses to human populations is required. The results presented here are of relevance to public health, although further information is required on LBV infection dynamics within bat populations, potential spillover mechanisms, and bat population dynamics, to further define the risk of human infection.

Acknowledgments: This work was funded by European Union FP7-funded project ANTIGONE (Anticipating the Global Onset of Novel Epidemics) project number 278978.A.R.F., A.C.B. and D.S. were financially supported by the UK Department for Environment, Food and Rural Affairs (Defra), Scottish Government and Welsh Government by grant SV3500, SE0426 and SE0431. A.A.C. was supported by a Royal Society Wolfson Research Merit award. A.R.F., A.A.C. and J.L.N.W. also acknowledge support from The Research and Policy for Infectious Disease Dynamics program of the Science and Technology Directorate, Department of Homeland Security, Fogarty International Center, National Institutes of Health, USA. We thank the staff of the Veterinary Services and Wildlife Division of the Forestry Commission of Ghana for assistance with the sampling of bats in the field. 
Author Contributions: R.D.S.-I., J.L.N.W., Y.N.-B., A.A.C., A.R.F. conceived and designed the experiment; R.D.S.-I., K.A.-M., M.Y.Z., S.R. provided field data; R.D.S.-I., A.C.B., D.S., A.R.F. performed laboratory experiment and analysed data; A.A.C., J.L.N.W., A.C.B., A.R.F., Y.N.-B. revised the manuscript and provided intellectual content; R.D.S.-I. wrote draft and revised the manuscript. All authors have sighted and approved the final manuscript.

Conflicts of Interest: The authors declare no conflict of interest.

\section{References}

1. Daszak, P.; Cunningham, A.A.; Hyatt, A.D. Anthropogenic environmental change and the emergence of infectious diseases in wildlife. Acta Trop. 2001, 78, 103-116. [CrossRef]

2. Hayman, D.T.; Fooks, A.R.; Rowcliffe, J.M.; McCrea, R.; Restif, O.; Baker, K.S.; Horton, D.L.; Suu-Ire, R.D.; Cunningham, A.A.; Wood, J.L.N. Endemic Lagos bat virus infection in Eidolon helvum. Epidemiol. Infect. 2012, 140, 2163-2171. [CrossRef] [PubMed]

3. Jones, K.E.; Patel, N.G.; Levy, M.A.; Storeygard, A.; Balk, D.; Gittleman, J.L.; Daszak, P. Global trends in emerging infectious diseases. Nat. Biotechnol. 2008, 451, 990-994. [CrossRef] [PubMed]

4. Calisher, C.H.; Childs, J.E.; Field, H.E.; Holmes, K.V.; Schountz, T. Bats: Important reservoir hosts of emerging viruses. Clin. Microbiol. Rev. 2006, 19, 531-545. [CrossRef] [PubMed]

5. Taylor, D.A.R.; Kankam, B.O.; Wagner, M.R. The role of fruit bat, Eidolon helvum, in seed dispersal, survival, and germination in Milicia excelsa, a threatened West African hardwood. In Research Advances in Restoration of Iroko as a Commercial Species in West Africa; Cobbinah, J.R., Wagner, M.R., Eds.; Forestry Research Institute of Ghana (FORIG): Kumasi, Ghana, 2000; pp. 29-39.

6. Luis, A.D.; Hayman, D.T.; O'Shea, T.J.; Cryan, P.M.; Gilbert, A.T.; Pulliam, J.R.; Mills, J.N.; Timonin, M.E.; Willis, C.K.; Cunningham, A.A.; et al. A comparison of bats and rodents as reservoirs of zoonotic viruses: Are bats special? Proc. Biol. Sci. 2013, 280, 20122753. [CrossRef] [PubMed]

7. Fooks, A.R.; Banyard, A.C.; Horton, D.L.; Johnson, N.; McElhinney, L.M.; Jackson, A.C. Current status of rabies and prospects for elimination. Lancet 2014, 384, 1389-1399. [CrossRef]

8. Banyard, A.C.; Hayman, D.; Johnson, N.; McElhinney, L.; Fooks, A.R. Bats and lyssaviruses. Adv. Virus Res. 2011, 79, 239-289. [PubMed]

9. Banyard, A.C.; Fooks, A.R. The impact of novel lyssavirus discovery. Microbiol. Aust. 2017, 38, 18-21. [CrossRef]

10. Badrane, H.; Tordo, N. Host switching in lyssavirus history from the Chiroptera to the Carnivora orders. J. Virol. 2001, 75, 8096-8104. [CrossRef] [PubMed]

11. Markotter, W.; Kuzmin, I.; Rupprecht, C.E.; Randles, J.; Sabeta, C.T.; Wandeler, A.I.; Nel, L.H. Isolation of Lagos bat virus from water mongoose. Emerg. Infect. Dis. 2006, 12, 1913-1918. [CrossRef] [PubMed]

12. Foggin, C.M. Atypical rabies virus in cats and a dog in Zimbabwe. Vet. Rec. 1982, 110, 338. [CrossRef] [PubMed]

13. Mebatsion, T.; Cox, J.H.; Frost, J.W. Isolation and characterization of 115 street rabies virus isolates from Ethiopia by using monoclonal antibodies: identification of 2 isolates as Mokola and Lagos bat viruses. J. Infect. Dis. 1992, 166, 972-977. [CrossRef] [PubMed]

14. King, A.; Crick, J. Rabies-related viruses. In Rabies; Campbell, J.B., Charlton, K.M., Eds.; Kluwer Academic Publishers: Boston, MA, USA, 1988; pp. 177-200.

15. Hayman, D.T.; Fooks, A.R.; Horton, D.; Suu-Ire, R.; Breed, A.C.; Cunningham, A.A.; Wood, J.L. Antibodies against Lagos bat virus in megachiroptera from West Africa. Emerg. Infect. Dis. 2008, 14, 926-928. [CrossRef] [PubMed]

16. Dean, D.J.; Abelseth, M.K. Laboratory techniques in rabies: The fluorescent antibody test. Monogr. Ser. World Health Organ. 1973, 23, 73-84.

17. Boulger, L.R.; Porterfield, J.S. Isolation of a virus from Nigerian fruit bats. Trans. R. Soc. Trop. Med. Hyg. 1958, 52, 421-424. [CrossRef]

18. Hayman, D.T.; Johnson, N.; Horton, D.L.; Hedge, J.; Wakeley, P.R.; Banyard, A.C.; Zhang, S.; Alhassan, A.; Fooks, A.R. Evolutionary history of rabies in Ghana. PLoS Negl. Trop. Dis. 2011, 5, e1001. [CrossRef] [PubMed]

19. Heaton, P.R.; McElhinney, L.M.; Lowings, J.P. Detection and identification of rabies and rabies-related viruses using rapid-cycle PCR. J. Virol. Methods 1999, 81, 63-69. [CrossRef] 
20. Kuzmin, I.V.; Niezgoda, M.; Franka, R.; Agwanda, B.; Markotter, W.; Beagley, J.C.; Urazova, O.Y.; Breiman, R.F.; Rupprecht, C.E. Lagos bat virus in Kenya. J. Clin. Microbiol. 2008, 46, 1451-1461. [CrossRef] [PubMed]

21. Fahr, J.; Abedi-Lartey, M.; Esch, T.; Machwitz, M.; Suu-Ire, R.; Wikelski, M.; Dechmann, D.K.N. Pronounced seasonal changes in the movement ecology of a highly gregarious central-place forager, the African straw-coloured fruit bat (Eidolon helvum). PLoS ONE 2015, 10, e138985. [CrossRef] [PubMed]

22. O'Shea, T.J.; Shankar, V.; Bowen, R.A.; Rupprecht, C.E.; Wimsatt, J.H. Do bats acquire immunity to rabies? Evidence from the field. Bat Res. News 2003, 44, 161.

23. Bowen, R.A.; O'Shea, T.J.; Shankar, V.; Neubaum, M.A.; Neubaum, D.J.; Rupprecht, C. Prevalence of neutralizing antibodies to rabies virus in serum of seven species of insectivorous bats from Colorado and New Mexico. J. Wildl. Dis. 2013, 49, 367-374. [CrossRef] [PubMed]

24. Hayman, D.T.S.; Bowen, A.R.; Cryan, P.M.; McCracken, G.F.; O’Shea, T.J.; Peel, A.J.; Gilbert, A.; Webb, C.T.; Wood, J.L.N. Ecology of zoonotic infectious diseases in bats: Current knowledge and future directions. Zoonoses Public Health 2013, 60, 2-21. [CrossRef] [PubMed]

25. Amengual, B.; Bourhy, H.; Lopez-Roig, M.; Serra-Cobo, J. Temporal dynamics of European bat lyssavirus type 1 and survival of Myotis myotis bats in natural colonies. PLoS ONE 2007, 2, e566. [CrossRef] [PubMed]

26. Turmelle, A.S.; Jackson, F.R.; Green, D.; McCracken, G.F.; Rupprecht, C.E. Host immunity to repeated rabies virus infection in big brown bats. J. Gen. Virol. 2010, 91, 2360-2366. [CrossRef] [PubMed]

27. Steece, R.; Altenbach, J.S. Prevalence of rabies specific antibodies in the Mexican free-tailed bat (Tadarida brasiliensis mexicana) at Lava Cave, New Mexico. J. Wildl. Dis. 1989, 25, 490-496. [CrossRef] [PubMed]

28. Kamins, A.O.; Rowcliffe, J.M.; Ntiamoa-Baidu, Y.; Cunningham, A.A.; Wood, J.L.N.; Restif, O. Characteristics and risk perceptions of Ghanaians potentially exposed to bat-borne zoonoses through bushmeat. Ecohealth 2015, 12, 104-120. [CrossRef] [PubMed]

29. Freuling, C.M.; Binger, T.; Beer, M.; Adu-Sarkodie, Y.; Schatz, J.; Fischer, M.; Hanke, D.; Hoffmann, B.; Hoper, D.; Mettenleiter, T.C.; et al. Lagos bat virus transmission in an Eidolon helvum bat colony, Ghana. Virus Res. 2015, 210, 42-45. [CrossRef] [PubMed]

30. Hayman, D.T.; Emmerich, P.; Yu, M.; Wang, L.F.; Suu-Ire, R.; Fooks, A.R.; Cunningham, A.A.; Wood, J.L. Long-term survival of an urban fruit bat seropositive for Ebola and Lagos bat viruses. PLOS ONE 2010, 5, e11978. [CrossRef] [PubMed]

31. Evans, J.S.; Horton, D.L.; Easton, A.J.; Fooks, A.R.; Banyard, A.C. Rabies virus vaccines: Is there a need for a pan-lyssavirus vaccine? Vaccine 2012, 30, 7447-7454. [CrossRef] [PubMed]

32. Badrane, H.; Bahloul, C.; Perrin, P.; Tordo, N. Evidence of two Lyssavirus phylogroups with distinct pathogenicity and immunogenicity. J. Virol. 2001, 75, 3268-3276. [CrossRef] [PubMed]

33. Hanlon, C.A.; Kuzmin, I.V.; Blanton, J.D.; Weldon, W.C.; Manangan, J.S.; Rupprecht, C.E. Efficacy of rabies biologics against new lyssaviruses from Eurasia. Virus Res. 2005, 111, 44-54. [CrossRef] [PubMed]

34. Horton, D.L.; Banyard, A.C.; Marston, D.A.; Wise, E.; Selden, D.; Nunez, A.; Hicks, D.; Lembo, T.; Cleaveland, S.; Peel, A.J.; et al. Antigenic and genetic characterization of a divergent African virus, Ikoma lyssavirus. J. Gen. Virol. 2014, 95, 1025-1032. [CrossRef] [PubMed]

35. Nolden, T.; Banyard, A.C.; Finke, S.; Fooks, A.R.; Hanke, D.; Hoper, D.; Horton, D.L.; Mettenleiter, T.C.; Muller, T.; Teifke, J.P.; et al. Comparative studies on the genetic, antigenic and pathogenic characteristics of Bokeloh bat lyssavirus. J. Gen. Virol. 2014, 95, 1647-1653. [CrossRef] [PubMed]

(C) 2017 by the authors. Licensee MDPI, Basel, Switzerland. This article is an open access article distributed under the terms and conditions of the Creative Commons Attribution (CC BY) license (http:/ / creativecommons.org/licenses/by/4.0/). 


\title{
Pathogenicity and Immunogenicity of Recombinant Rabies Viruses Expressing the Lagos Bat Virus Matrix and Glycoprotein: Perspectives for a Pan-Lyssavirus Vaccine
}

\author{
Joe Kgaladi ${ }^{1}$, Milosz Faber ${ }^{2}$, Bernhard Dietzschold ${ }^{2}$, Louis H. Nel ${ }^{3}$ and Wanda Markotter ${ }^{4, *}$ \\ 1 Centre for Emerging and Zoonotic Diseases, National Institute for Communicable Diseases, \\ National Health Laboratory Service, Sandringham 2193, South Africa; joe.kgaladi@gmail.com \\ 2 Department of Microbiology and Immunology, Thomas Jefferson University, Philadelphia, PA 19107, USA; \\ milosz.faber@jefferson.edu (M.F.); bernhard.dietzschold@jefferson.edu (B.D.) \\ 3 Department of Microbiology and Plant Pathology, Faculty of Natural and Agricultural Sciences, \\ University of Pretoria, Pretoria 0001, South Africa; louis.nel@up.ac.za \\ 4 Centre for Viral Zoonoses, Department of Medical Virology, Faculty of Health Sciences, \\ University of Pretoria, Pretoria 0001, South Africa \\ * Correspondence: wanda.markotter@up.ac.za; Tel.: +27-12-319-2353
}

Received: 30 June 2017; Accepted: 4 August 2017; Published: 9 August 2017

\begin{abstract}
Lagos bat virus (LBV) is a phylogroup II lyssavirus exclusively found in Africa. Previous studies indicated that this virus is lethal to mice after intracranial and intramuscular inoculation. The antigenic composition of LBV differs substantially from that of rabies virus (RABV) and current rabies vaccines do not provide cross protection against phylogroup II lyssaviruses. To investigate the potential role of the LBV matrix protein $(\mathrm{M})$ and glycoprotein $(\mathrm{G})$ in pathogenesis, reverse genetics technology was used to construct recombinant viruses. The genes encoding the glycoprotein, or the matrix and glycoprotein of the attenuated RABV strain SPBN, were replaced with those of LBV resulting in SPBN-LBVG and SPBN-LBVM-LBVG, respectively. To evaluate the immunogenicity of the LBV G, the recombinant RABV SPBNGAS-LBVG-GAS was constructed with the LBV G inserted between two mutated RABV G genes (termed GAS). All the recombinant viruses were lethal to mice after intracranial (i.c.) inoculation although the pathogenicity of SPBNGAS-LBVG-GAS was lower compared to the other recombinant viruses. Following intramuscular (i.m.) inoculation, only SPBN-LBVM-LBVG was lethal to mice, indicating that both the M and G of LBV play a role in the pathogenesis. Most interestingly, serum collected from mice that were inoculated i.m. with SPBNGAS-LBVG-GAS neutralized phylogroup I and II lyssaviruses including RABV, Duvenhage virus (DUVV), LBV, and Mokola virus (MOKV), indicating that this recombinant virus has potential to be developed as a pan-lyssavirus vaccine.
\end{abstract}

Keywords: rabies; vaccines; Africa; lyssavirus; pathogenesis; recombinant viruses

\section{Introduction}

The Lyssavirus genus consists of 14 viral species and three putative species, grouped into three phylogroups [1-3]. While all members of the lyssavirus genus are capable of causing a fatal encephalitic disease, rabies virus (RABV) in phylogroup I is responsible for most human and animal rabies cases and is globally distributed. Other lyssavirus species have a more restricted distribution, with Lagos bat lyssavirus (LBV), Mokola lyssavirus (MOKV), Duvenhage lyssavirus (DUVV), Shimoni bat lyssavirus (SHIBV) and Ikoma lyssavirus (IKOV) exclusively identified from Africa. LBV is associated with Pteropodidae bat species [4-6] and although no human infections have been reported to date, 
fatal spill-over into dogs [7,8], cats [5] and a mongoose [9] have been reported. Although case reports of LBV are limited, pathogenicity studies in mice have indicated that the virus is pathogenic to mice when inoculated via the intramuscular (i.m.) and intracranial (i.c.) route with distinct pathogenicity profiles observed between different LBV lineages $[6,10,11]$.

The lyssavirus genome codes for five proteins; the nucleo- $(N)$, phospho- $(P)$, matrix- $(M)$, glyco $(G)$ and RNA polymerase protein (L) and their cooperative effect in pathogenesis have been shown [12-15]. Gene exchange between RABV strains with different pathogenicity profiles has been performed in previous studies mostly focusing on the $G$ protein [13,16-20]. Different pathogenic mechanisms have been linked to this protein, including interaction with the cell surface molecules, p75 neurotropin receptor [21,22], nicotinic acetylcholine receptor [23] and neural cell adhesion molecule [24], to facilitate binding and entry into the cell. Controlled expression levels of the G gene are important to prevent apoptosis of neuronal cells and they allow transport of the virus to the central nervous system [25]. A number of studies have demonstrated that replacement of the $G$ gene from a non-pathogenic RABV strain with that of a pathogenic strain results in a pathogenic RABV strain $[13,16,17,20]$.

Replacement of the $\mathrm{M}$ gene of Ni-CE strain (non-pathogenic both i.c. and i.m.) with that of the Nishigahara strain (pathogenic both i.c. and i.m.) was shown to result in a pathogenic strain when mice were inoculated i.c. [15]. Pulmanausahakul et al. (2008) showed that replacement of both the M and G gene of a non-pathogenic strain with that of a pathogenic strain resulted in increased pathogenicity when compared with replacing only the $G$ gene. Substitution of the $M$ gene alone did not result in a pathogenic strain. In another study, replacement of the M, G, G-L intergenic region and L gene from a pathogenic strain with that of a non-pathogenic strain resulted in a non-pathogenic strain when mice were inoculated i.m., but when only the G, G-L region and L gene were replaced, the virus was pathogenic [12]. The M gene of LBV and MOKV has also been shown to induce apoptosis in vitro in neuroblastoma and HeLa cells [26]. Apoptosis has been reported to be inversely proportional to pathogenicity of RABV $[25,27]$.

The recombinant RABV backbones (non-pathogenic i.m.) were used for interspecies gene or partial gene replacement between RABV and other lyssaviruses in previous studies. Interspecies $G$ protein substitution was performed between a RABV vaccine strain (SAD B19) and European bat lyssavirus type 1 and 2 (EBLV-1 and EBLV-2) [18]. The RABV with an EBLV-1 G protein was shown to cause higher mortality when inoculated i.m. compared to inoculation with a RABV recombinant backbone. Genz et al. (2012) also generated chimeric RABV and EBLV-1 or EBLV-2 G protein in a backbone of RABV (SAD B19). The chimeric G protein consisted of the cytoplasmic tail from RABV while the transmembrane and ectodomain was from the EBLVs. The recombinant viruses had comparable growth kinetics in vitro and were lethal to mice when inoculated i.c. [28]. Interspecies $\mathrm{M}$ protein substitution between the RABV vaccine strain (SAD B19) and EBLVs (EBLV-1 and EBLV-2) were performed and it was shown that the M protein plays a role in intracellular virus accumulation [29]. Although gene exchange between different strains of RABV has been done, no study has performed gene exchange between RABV and LBV [12].

All currently licensed lyssavirus vaccines are based on a RABV backbone. These vaccines have been shown to protect against members of phylogroup I lyssaviruses [30-35]; however, there appears to be no vaccine affording protection against phylogroup II and III lyssaviruses [2,30,36-38]. Mice vaccinated with RABV vaccine produced significantly lower virus-neutralizing antibodies (VNAs) against DUVV when compared to RABV VNAs.

The generation of recombinant viruses using reverse genetics systems has led to the construction of safe and immunogenic rabies vaccines. Recombinants included the introduction of two or three G genes [39-42], mutation of pathogenic domains on the G gene [39,40], deletion of genes required for replication [43] and introduction of inflammatory cytokines [44,45], chemokines [46] and pro-apoptotic [47] genes into the RABV genome. Recombinant RABV vaccines containing two RABV G genes were shown to express high levels of the $G$ protein, and were more immunogenic than parental strains [39,41,42]. To increase the safety of the vaccine, mutations of Asn 194 to Ser and 
Arg 333 to Glu were introduced in the $G$ gene $[39,48,49]$. A recombinant RABV vaccine with three $G$ genes was investigated [40] and the triple $G$ vaccine was shown to be non-pathogenic to juvenile mice, adult mice deficient in some immune functions, and normal adult mice when inoculated via the i.c. route. The recombinant vaccine protected mice against lethal challenge with RABV and also protected mice when administered as post-exposure prophylaxis.

The aim of this study was to determine the importance of the LBV M and G genes in pathogenesis using a recombinant RABV and replacing the $G$ gene, as well as both the $M$ and $G$ gene, with that of LBV. In addition, the pathogenicity and immunogenicity of a RABV backbone with a LBV G gene sandwiched between two RABV G genes was determined. We demonstrate that the RABV backbone can express functional LBV genes, and that both the M and G genes of LBV play a role in pathogenicity. The feasibility of generating a pan-African lyssavirus vaccine that can induce neutralizing antibodies against at least phylogroup I and II lyssaviruses was demonstrated.

\section{Material and Methods}

\subsection{Virus Isolates, Recombinant Viruses and Cell Lines}

The recombinant viruses, SPBN and SPBNGAS-GAS-GAS, were constructed in previous studies [40,50]. The LBVAFR1999 [51,52] was maintained in mouse neuroblastoma (MNA) cells (C-1300). MNA and BSR-T7 (a clone of BHK-21) [53] cells were grown in an atmosphere of $37^{\circ} \mathrm{C}$ and $5 \% \mathrm{CO}_{2}$ using Dulbecco's modified Eagle's medium (DMEM/F12) (Lonza, Verviers, Belgium) supplemented with 10\% fetal calf serum (Lonza, Verviers, Belgium) and 1\% antibiotics (penicillin [100 units $/ \mathrm{mL}]$, streptomycin $[100 \mu \mathrm{g} / \mathrm{mL}]$ and amphotericin B [0.25 $\mu \mathrm{g} / \mathrm{mL}]$ ) (Lonza, Verviers, Belgium).

\subsection{Construction of the Recombinant Viruses}

Total RNA was isolated from LBVAFR1999 cell culture material using TRIzol ${ }^{\circledR}$ reagent (Invitrogen, Carlsbad, CA, USA) according to manufacturer's instructions. To replace the G gene of SPBN with that of the LBVAFR1999, the G gene was amplified from the LBVAFR1999 RNA using Pfu DNA polymerase (Promega, Madison, WI, USA) and the primers LBVXmaI and LBVPacI containing restriction enzyme sites XmaI and PacI respectively (Table 1). The amplified PCR product was digested with XmaI and PacI (New England Biolabs, Ipswich, MA, USA) and then ligated to PSPBN previously digested with $\mathrm{XmaI}$ and PacI. The resulting plasmid was designated pSPBN-LBVG (Figure 1). To replace both the $\mathrm{M}$ and G genes of SPBN with those of the LBVAFR1999, the KpnI site was introduced upstream of the pSPBN-LBVG M gene start signal, through digestion of another pSPBN (that contains the KpnI site) with AvrII and KpnI (New England Biolabs, Ipswich, MA, USA) (Figure 1). The digested fragment was ligated to PSPBN-LBVG previously digested with the same restriction enzymes (AvrII and KpnI). LBVAFR1999 M gene was synthesized (GenScript, Piscataway, NJ, USA) to contain the KpnI and $\mathrm{XmaI}$ restriction enzyme sites. The $\mathrm{M}$ gene was digested with the KpnI and XmaI and then ligated to PSPBN-LBVG previously digested with KpnI and XmaI. The resulting plasmid was designated pSPBN-LBVM-LBVG (Figure 1). To construct the recombinant virus with a LBVAFR1999 G gene sandwiched between two RABV G genes, the G gene was amplified from the LBVAFR1999 RNA using Pfu DNA polymerase (Promega, Madison, WI, USA) and the primers LBVEcoRIBsiWI and LBVXbaIAsiSI (Table 1). The amplified PCR product was digested with BsiWI and AsiSI (New England Biolabs, Ipswich, MA, USA) and then ligated to pSPBNGAS-GAS-GAS previously digested with BsiWI and AsiSI. The resulting plasmid was designated pSPBNGAS-LBVG-GAS (Figure 1). 
Table 1. Primers used for amplification or sequencing of the Lagos bat virus matrix and glycoprotein genes.

\begin{tabular}{|c|c|c|}
\hline Primer & Sequence in $5^{\prime}$ to $3^{\prime}$ Direction * & Gene Targeted \\
\hline LBVXmaI & TATCCCCCCGGGAAGATGAGTCAATTGTTCTCAACC & Ggene \\
\hline LBVPacI (to be used with LBVXmaI) & CCGACCTTAATTAAGGTTAGACACTTGATGTCTCTTTATATG & $\mathrm{G}$ gene \\
\hline LBVEcoRIBsiWI & GCAGAATTCCGTACGAAGATGAGTCAATTGTTCTCAACCTTCAT & $\mathrm{G}$ gene \\
\hline LBVXbaIAsiSI (to be used with LBVEcoRIBsiWI) & TAATCTAGAGCGATCGCCGTTTAGACACTTGATGTCTCTTTATATGA & $\mathrm{G}$ gene \\
\hline $\begin{array}{l}\text { LBV1319F (binds on position } 1319 \text { on the open reading } \\
\text { frame of the LBVAFR1999 G gene, EF547432) }\end{array}$ & CGACTTCGTCGATGTCCACATGCC & G gene \\
\hline $\begin{array}{l}\text { LBV255R (binds on position } 255 \text { on the open reading } \\
\text { frame of the LBVAFR1999 G gene, EF547432) }\end{array}$ & GTTGGTGTATGTGACTGCCTCG & G gene \\
\hline $\begin{array}{l}\text { RabC2121F (to be used with LBV255R [binds on } \\
\text { position } 2121 \text { on the complete genome of RABV, } \\
\text { NC_001542]) }\end{array}$ & CAGTGGAGGCTGAGATCGCTC & M gene \\
\hline
\end{tabular}

SPBN

SPBN-LBVG

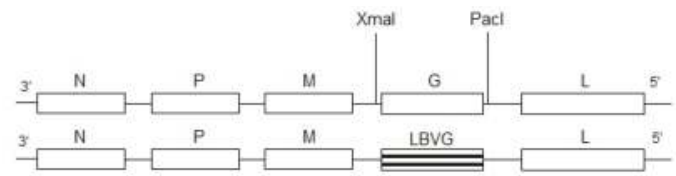

SPBN

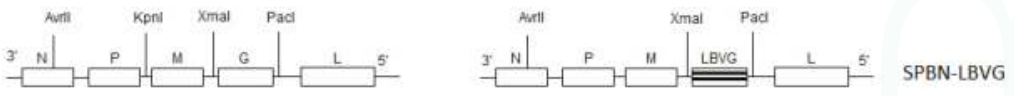

SPBN-LBVM-LBVG
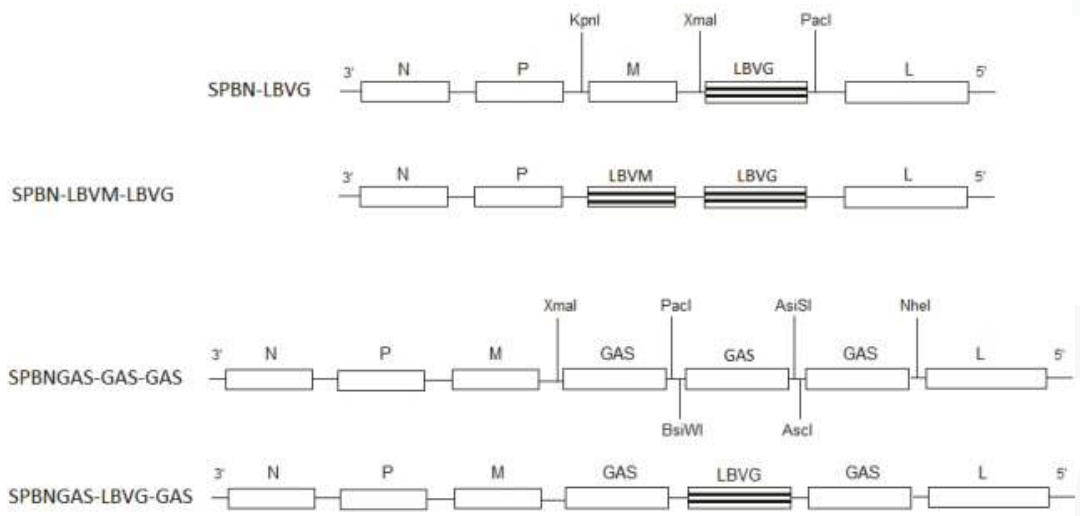

Figure 1. Schematic representation of the construction of recombinant viruses. Restriction enzyme sites are indicated (XmaI, PacI, AvrII, KpnI. BsiWI, AsiSI, NheI and AscI). GAS represents the SPBN G gene with two amino acid substitutions (Asn 194 to Ser and Arg 333 to Glu). The following abbreviations were used: N, nucleoprotein; M, matrix protein; G, glycoprotein; L, RNA-dependent RNA polymerase. LBVM and LBVG represent the LBV $M$ and $G$ gene respectively.

\subsection{Rescue of the Recombinant Viruses}

The recombinant viruses were rescued as described previously [40,50]. Briefly, $250 \mu \mathrm{L}$ of FuGENE (Promega, Madison, WI, USA) in serum-free DMEM (Lonza, Verviers, Belgium) was used to transfect BSR-T7 cells with $10 \mu \mathrm{g}$ of full length plasmids (pSPBN-LBVG, pSPBN-LBVM-LBVG or pSPBNGAS-LBVG-GAS), helper plasmids (5 $\mu \mathrm{g}$ of pTIT-N, $2.5 \mu \mathrm{g}$ of pTIT-P, $2.5 \mu \mathrm{g}$ of pTIT-L, $1 \mu \mathrm{g}$ of pTIT-G) and $2 \mu \mathrm{g}$ of pTIT-T7 (a plasmid expressing the T7 RNA polymerase). Supernatants were transferred onto MNA cells in 12-well plates (Greiner Bio-one, Frickenhausen, Germany) $72 \mathrm{~h}$ post-transfection and incubated in an atmosphere of $37{ }^{\circ} \mathrm{C}$ and $5 \% \mathrm{CO}_{2}$ for $72 \mathrm{~h}$. Positive cells were determined by immunostaining [54] using fluorescein isothiocyanate conjugate (FITC)-labeled RABV 
$\mathrm{N}$ gene specific antibody (Centocor Inc., Malvern, PA, USA). The nucleotide sequence of the inserted genes was confirmed by sequencing as described previously [10].

\subsection{Amplification and Titration of the Rescued Recombinant Viruses}

MNA cells in 6-well plates (Greiner Bio-one, Germany) were infected with supernatant from wells that were positive during transfection and incubated in an atmosphere of $37^{\circ} \mathrm{C}$ and $5 \% \mathrm{CO}_{2}$ for $72 \mathrm{~h}$. The supernatant was harvested and then immunostaining was performed on the plates using FITC-labeled RABV N gene specific antibody (Centocor Inc.). Supernatant from positive wells in the 6-well plates (Greiner Bio-one, Germany) was subsequently amplified in MNA cells in T75 flasks (Corning Incorporated, Corning, NY, USA) and incubated in an atmosphere of $37{ }^{\circ} \mathrm{C}$ and $5 \% \mathrm{CO}_{2}$ for $72 \mathrm{~h}$ to prepare virus stocks. To determine virus yield, MNA cells in 96-well plates (Greiner Bio-one, Frickenhausen, Germany) were infected with ten-fold serial dilutions of the virus stocks and incubated in an atmosphere of $37{ }^{\circ} \mathrm{C}$ and $5 \% \mathrm{CO}_{2}$ for $48 \mathrm{~h}$. All titrations were performed in triplicate. Immunostaining using FITC-labeled RABV N gene-specific antibody (Centocor, Inc.) was performed on the plates and the $50 \%$ tissue culture infectious dose $\left(\mathrm{TCID}_{50}\right)$ was determined according to the method described elsewhere [55].

\subsection{Lagos Bat Virus Glycoprotein Expression by the Recombinant Viruses}

Neutralization of the SPBN-LBVG, SPBN-LBVM-LBVG, SPBNGAS-LBVG-GAS, SPBN (as a negative control) and LBVAFR1999 (positive control) was determined by the rapid fluorescent focus inhibition test (RFFIT) [6,56] using LBV antiserum. This serum was previously collected from bats in South Africa [57] and was found to have virus-neutralizing antibodies (VNAs) against LBV but not against RABV. Four different dilutions (1:10, 1:100, 1:400 and 1:1000) of the serum were used for the neutralization assay. The titer of the challenge viruses used in the neutralization assay was $1 \times 10^{3} \mathrm{FFU} / \mathrm{mL}$. The virus neutralization index $(\mathrm{VNI})$ was calculated by subtracting the virus titer of the untreated challenge virus with the virus titer of the LBV antiserum- treated challenge virus.

\subsection{Single- and Multi-Step Growth Assays}

Single- and multi-step growth assays were performed to determine the growth pattern of the different recombinant viruses. MNA cells in T25 culture flasks were infected with virus inoculums at a multiplicity of infection (MOI) of 2 or 0.01 for the single- and multi-step growth curves respectively, and incubated for $2 \mathrm{~h}$ in an atmosphere of $37{ }^{\circ} \mathrm{C}$ and $5 \% \mathrm{CO}_{2}$. The virus inoculum was removed, the cells were washed three times with $5 \mathrm{~mL}$ of PBS (Lonza, Verviers, Belgium) and then $7 \mathrm{~mL}$ of RPMI (containing $0.2 \%$ bovine serum albumin (BSA)) (Lonza) was added to the flask. At 24, 48, 72 and $96 \mathrm{~h}$ post infection, $100 \mu \mathrm{L}$ of the supernatant was collected and virus titration was performed as described above. The virus titer was expressed as focus-forming units per $\mathrm{mL}(\mathrm{FFU} / \mathrm{mL})$.

\subsection{Experimental Infections of Mice}

Six-week-old mice (Crl:CD1 [ICR]) (Onderstepoort Biological Products, Pretoria, South Africa) were used for experimental infection. The experiments were performed in a biosafety level 3 (BSL-3) laboratory at the Department of Medical Virology, Faculty of Health Sciences, University of Pretoria, South Africa. Ethical approval (EC052-13) for these experiments was granted by the University of Pretoria Animal Ethics Committee and Section 20 approval according to the Animal Disease Act, 1984, was granted by the Department of Agriculture, Forestry and Fishery, South Africa. Mice were housed in a group of five in HEPA-filtered OptiMICE cage units (Animal Care Systems, Centennial, $\mathrm{CO}, \mathrm{USA}$ ). For the pathogenesis study, groups of 4 to 5 mice were inoculated via the i.c. or i.m. (in the hind thigh) route with $5 \times 10^{6} \mathrm{TCID}_{50} / 50 \mu \mathrm{L}$ of virus inoculums (LBVAFR1999, SPBN, SPBN-LBVG, SPBN-LBVM-LBVG, SPBNGAS-LBVG-GAS or SPBNGAS-GAS-GAS) using sterile $1 \mathrm{~mL}$ syringes (Becton Dickinson, Franklin Lakes, NJ, USA). For the vaccine study, 10 mice were vaccinated on day 0 and boosted on day 20 with SPBNGAS-LBVG-GAS via the i.m. (in the hind thigh) route with 
$1 \times 10^{5} \mathrm{TCID}_{50} / 50 \mu \mathrm{L}$ of virus inoculum using sterile $1 \mathrm{ml}$ syringes (Becton Dickinson). Mice were monitored daily for 43 days for the pathogenesis study and 30 days for the vaccine study. Death and clinical signs such as not eating, paralysis, confusion, running in circles, weight loss, ruffled fur and restlessness were recorded daily. The mice were euthanized by i.m. inoculation with a mixture of ketamine (Anaket-V) (35 mg/kg body mass) and xylazine (Chanazine or Rompun) (5 mg/kg body mass) upon development of clinical signs or at the end of the experiment in cases where clinical signs were not observed. Brains were collected and analyzed for the presence of lyssavirus antigen using anti-rabies polyclonal FITC conjugate (Rabies Unit, Onderstepoort Veterinary Institute, Agricultural Research Council, Pretoria, South Africa) in the fluorescent antibody tests (FAT) as described by Dean et al. 1996. Blood was collected in BD Microcontainer ${ }^{\mathrm{TM}}$ (Becton Dickinson) from the saphenous vein using $80 \mu \mathrm{L}$ capillaries (Lasec, Cape Town, South Africa) on days 13 and 28 after primary vaccination. Mice were anesthetized with isoflurane (Piramal Heathcare, India) prior to bleeding. The blood was centrifuged at 13,400 rpm for $5 \mathrm{~min}$, and serum collected in $2 \mathrm{~mL}$ microcentrifuge tubes (Quality Scientific Plastics, San Diego, CA, USA) and stored at $-20{ }^{\circ} \mathrm{C}$ until use.

\subsection{Rapid Fluorescent Focus Inhibition Test (RFFIT)}

Virus-neutralizing antibodies (VNAs) from serum of mice vaccinated with SPBNGAS-LBVG-GAS were determined by a modification of the rapid fluorescent focus inhibition test (RFFIT) $[6,56]$. The following challenge viruses were used: RABV (challenge virus standard [CVS]), LBV (LBVAFR1999), MOKV (252/97) and DUVV (DUVVSA2006). Eight different dilutions were tested: 1:10, $1: 25,1: 65,1: 160,1: 400,1: 1000,1: 2500$ and 1:6100. The VNA titer was indicated as the highest dilution where there was a $50 \%$ reduction in the number of foci. Since there are no reference sera available for LBV, MOKV and DUVV, the VNA titer for RABV were not converted to international units.

\subsection{Statistical Analyses}

For the pathogenesis study, Fisher's exact test $(\mathrm{CI}=95 \%)$ was used to determine the difference in survival between the different groups of mice. For the single- and multi-step growth curves, as well as the vaccine study, statistical analysis was performed using SPSS version 20, licensed to the University of Pretoria. One-way ANOVA was performed followed by Tukey HSD as a post-hoc test.

\section{Results}

\subsection{Confirmation of LBV G Protein Expression by Recombinant Viruses}

A virus neutralization test (RFFIT) using LBV antiserum was employed to ascertain that the LBV G protein is expressed. The neutralization indices tests shown in Table 2 reveal that SPBN-LBVG, SPBN-LBVM-LBVG, SPBNGAS-LBVG-GAS and LBVAFR1999 (positive control) but not SPBN (negative control) were completely neutralized by the LBV anti-serum.

Table 2. Neutralization of recombinant viruses with the different dilutions of the anti-Lagos bat virus serum as determined by the rapid fluorescent focus inhibition test (RFFIT).

\begin{tabular}{ccccc}
\hline \multirow{2}{*}{ Challenge Virus * } & \multicolumn{3}{c}{$\begin{array}{c}\text { Virus Neutralization Index (VNI) } \\
\text { Anti-LBV Serum Dilution }\end{array}$} \\
\cline { 2 - 5 } & $\mathbf{1 : 1 0}$ & $\mathbf{1 : 1 0 0}$ & $\mathbf{1 : 4 0 0}$ & $\mathbf{1 : 1 0 0 0}$ \\
\hline LBV (LBVAFR1999) (positive control) & $10^{3}$ & $10^{3}$ & $10^{3}$ & $10^{0}$ \\
SPBN (negative control) & $10^{0}$ & $10^{0}$ & $10^{0}$ & $10^{0}$ \\
SPBN-LBVG & $10^{3}$ & $10^{3}$ & $10^{3}$ & $10^{0}$ \\
SPBN-LBVM-LBVG & $10^{3}$ & $10^{3}$ & $10^{3}$ & $10^{0}$ \\
SPBNGAS-LBVG-GAS & $10^{3}$ & $10^{3}$ & $10^{0}$ & $10^{0}$ \\
\hline
\end{tabular}

${ }^{*} 10^{3} \mathrm{FFU}$ of each challenge virus was used; ${ }^{\#} \mathrm{VNI}=$ virus titer of untreated challenge virus - virus titer of challenge virus incubated with anti-LBV serum. 

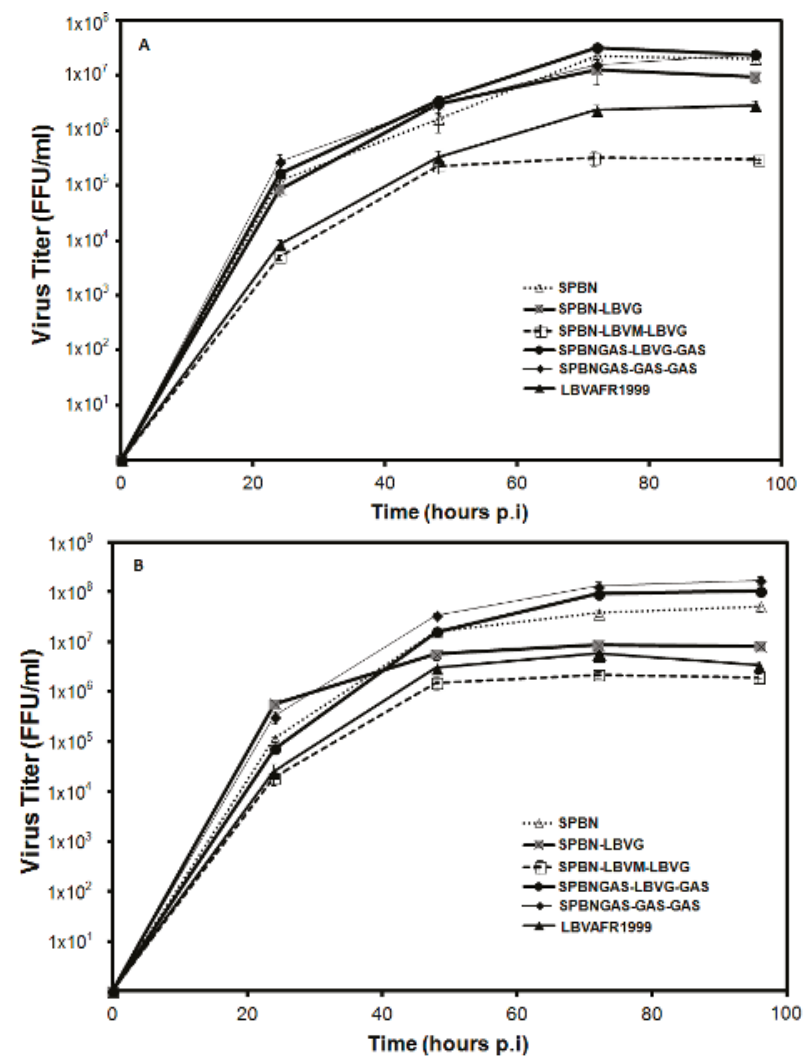

Figure 2. Multi-step (A) and single-step (B) growth curves of recombinant rabies viruses in MNA cells. MNA cells were infected with the recombinant viruses (SPBN, SPBN-LBVG, SPBN-LBVM-LBVG, SPBNGAS-GAS-GAS or SPBNGAS-LBVG-GAS) or LBVAFR1999 at a MOI of 0.01 (A) or a MOI of 2 (B) and incubated at $37^{\circ} \mathrm{C}$. At $24,48,72$ and $96 \mathrm{~h}$ post infection, the recombinant viruses were harvested and titration was performed. Data represent the mean of triplicate experiments.

\subsection{In Vitro Growth of Recombinant Viruses in MNA Cells}

Viral replication rate has been linked to pathogenicity of the virus [12,13]. We investigated the growth kinetics of recombinant RABVs in which the $G$ only or $M$ and $G$ genes were replaced with corresponding LBV genes (Figure 2). Multi-step growth curves (Figure 2A) showed that SPBN and SPBNGAS-GAS-GAS had the highest growth rate followed by SPBN-LBVG and SPBNGAS-LBVG-GAS. While there was no statistically-significant difference between the growth rate of these viruses $(p>0.05)$, the growth rate of SPBN-LBVM-LBVG was lower than that of the other viruses including LBVAFR1999. The single-step growth curves yielded similar results, with SPBNGAS-GAS-GAS, SPBNGAS-LBVG-GAS and SPBN producing the highest titers, and SPBN-LBVM-LBVG and LBVAFR1999 again producing the lowest titers (Figure 2B). SPBN-LBVG also produced a lower titer, however it was still higher than that of SPBN-LBVM-LBVG.

\subsection{Pathogenicity of Recombinant Viruses in Mice}

The ability of various recombinant viruses to cause lethal encephalitis in mice was compared. Virus infection of the brain was confirmed postmortem by FAT. All viruses, except 
SPBNGAS-GAS-GAS, caused mortality in mice after i.c. inoculation and all the mice that died exhibited signs of rabies including walking in circles, hind leg paralysis, weight loss and ruffled fur. The mortality rate ranged from $0 \%$ to $100 \%$ (Figure 3 and Table 3). Mice inoculated with LBVAFR1999 and SPBN-LBVM-LBVG had the highest mortality rate $(100 \%)$ while those inoculated with SPBNGAS-LBVG-GAS had the lowest mortality rate (20\%). After i.m. inoculation of recombinant viruses, only LBVAFR1999 and SPBN-LBVM-LBVG caused mortality (Figure 4). The rates were 40\% for LBVAFR1999 and 20\% for SPBN-LBVM-LBVG with incubation periods of 16 and 14 days, respectively. These results show that both the $\mathrm{M}$ and $\mathrm{G}$ proteins of LBV play a role in the pathogenesis of LBV.

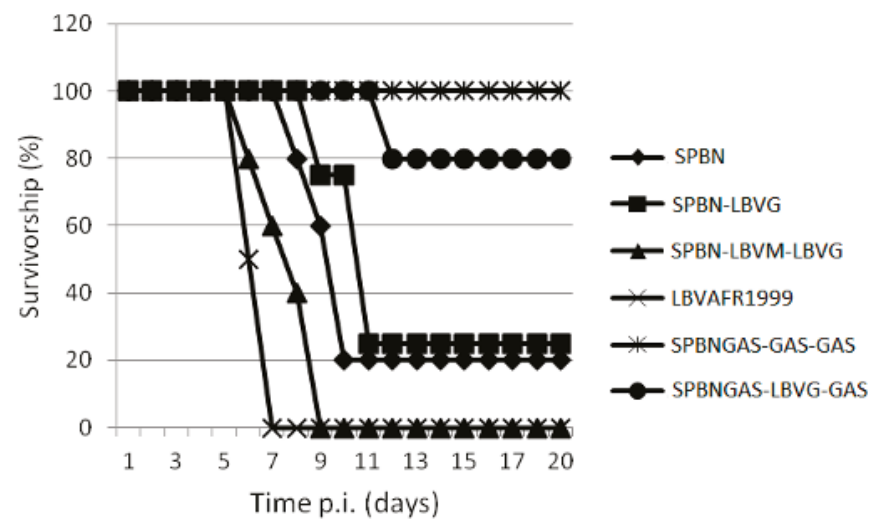

Figure 3. Pathogenicity of SPBN, SPBN-LBVG, SPBN-LBVM-LBVG, LBVAFR1999, SPBNGAS-GAS-GAS and SPBNGAS-LBVG-GAS in mice. Groups of (Crl:CD1 [ICR]) mice were inoculated via the i.c. route with $5 \times 10^{6} \mathrm{TCID}_{50} / 50 \mu \mathrm{L}$ of virus. The groups consisted of 5 mice except for SPBN-LBVG and LBVAFR1999 which consisted of 4 mice per group. The experiment was terminated after 43 days, but no clinical signs were observed 12 days post-infection.

Table 3. Intracranial experimental infections of mice with recombinant viruses.

\begin{tabular}{cccc}
\hline \multirow{2}{*}{ Virus } & Mean Incubation Period, s.d. and Range of Incubation Periods (Days) & $\begin{array}{c}\text { Number of Mice that Died per } \\
\text { Group of Mice Inoculated i.c. }\end{array}$ \\
\cline { 2 - 3 } & Mean and s.d. & Range & $4 / 4(100 \%)$ \\
LBVAFR1999 & $6.5 \pm 0.58$ & $6-7$ & $4 / 5(80 \%)$ \\
SPBN & $9.25 \pm 0.96$ & $8-10$ & $3 / 4(75 \%)$ \\
SPBN-LBVG & $10.33 \pm 1.15$ & $9-11$ & $5 / 5(100 \%)$ \\
SPBN-LBVM-LBVG & $7.8 \pm 1.30$ & $6-9$ & $0 / 5(0 \%)$ \\
SPBNGAS-GAS-GAS & - & - & $1 / 5(20 \%)$ \\
SPBNGAS-LBVG-GAS & $12 \pm$ NA & 12 & \\
\hline
\end{tabular}

$\mathrm{N} / \mathrm{A}=$ no s.d. since only one mouse died; s.d. = standard deviation; i.c. = intracranial. 


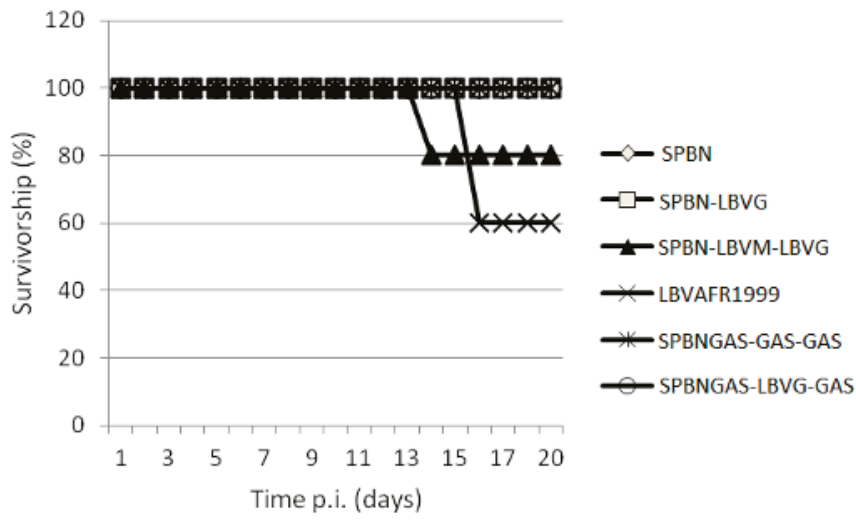

Figure 4. Pathogenicity of SPBN, SPBN-LBVG, SPBN-LBVM-LBVG, LBVAFR1999, SPBNGAS-GAS-GAS and SPBNGAS-LBVG-GAS in mice. Groups of 5 (Crl:CD1 [ICR]) mice were inoculated via the i.m. route with $5 \times 10^{6} \mathrm{TCID}_{50} / 50 \mu \mathrm{L}$ of virus. The experiment was terminated after 43 days, but no clinical signs were observed 16 days post infection.

\subsection{VNA Response of Mice Vaccinated with SPBNGAS-LBVG-GAS}

For primary vaccination (Table 4), VNA titers against LBV and MOKV were significantly lower $(p<0.05)$ compared to RABV (with the exception of VNA titer for RABV and LBV at day 28, where there were no significant differences). There was no significant difference $(p>0.05)$ in VNA titer between RABV and DUVV (Table 4). Booster vaccination resulted in significantly higher $(p<0.05)$ VNA titers against all challenge viruses used. This VNA analysis demonstrates that SPBNGAS-LBVG-GAS can induce cross-reactive antibodies capable of neutralizing different lyssaviruses.

Table 4. Virus neutralizing antibodies in mice vaccinated with SPBNGAS-LBVG-GAS as determined by the rapid fluorescent focus inhibition antibody test (RFFIT).

\begin{tabular}{|c|c|c|c|c|c|c|c|c|}
\hline \multirow{2}{*}{ Mouse No. } & \multicolumn{2}{|c|}{$\begin{array}{l}\text { Neutralization Dilution * } \\
\text { (RABV-CVS) }\end{array}$} & \multicolumn{2}{|c|}{$\begin{array}{l}\text { Neutralization Dilution * } \\
\text { (DUVVSA2006) }{ }^{\#}\end{array}$} & \multicolumn{2}{|c|}{$\begin{array}{l}\text { Neutralization Dilution * } \\
\text { (LBVAFR1999) }{ }^{*}\end{array}$} & \multicolumn{2}{|c|}{$\begin{array}{l}\text { Neutralization Dilution * } \\
\text { (MOKV252/97) }\end{array}$} \\
\hline & Day 13 & Day 28 & Day 13 & Day 28 & Day 13 & Day 28 & Day 13 & Day 28 \\
\hline Mouse 1 & $1: 400$ & $1: 2500$ & $1: 160$ & $1: 1000$ & $1: 160$ & $1: 1000$ & $1: 65$ & $1: 400$ \\
\hline Mouse 2 & $1: 160$ & $1: 2500$ & $1: 65$ & $1: 400$ & $1: 65$ & $1: 400$ & $1: 10$ & $1: 160$ \\
\hline Mouse 3 & $1: 1000$ & $1: 6100$ & $1: 400$ & $1: 2500$ & $1: 400$ & $1: 6100$ & $1: 160$ & $1: 1000$ \\
\hline Mouse 4 & $1: 400$ & $1: 1000$ & $1: 400$ & $1: 1000$ & $1: 160$ & $1: 400$ & $1: 65$ & $1: 400$ \\
\hline Mouse 5 & $1: 400$ & $1: 2500$ & $1: 160$ & $1: 1000$ & $1: 65$ & $1: 400$ & $1: 25$ & $1: 400$ \\
\hline Mouse 6 & $1: 400$ & $1: 1000$ & $1: 160$ & $1: 1000$ & $1: 160$ & $1: 1000$ & $1: 65$ & $1: 400$ \\
\hline Mouse 7 & $1: 160$ & $1: 1000$ & $1: 65$ & $1: 1000$ & $1: 65$ & $1: 400$ & $1: 25$ & $1: 400$ \\
\hline Mouse 8 & $1: 400$ & $1: 2500$ & $1: 400$ & $1: 2500$ & $1: 160$ & $1: 1000$ & $1: 65$ & $1: 400$ \\
\hline Mouse 9 & $1: 400$ & $1: 2500$ & $1: 400$ & $1: 1000$ & $1: 160$ & $1: 1000$ & $1: 160$ & $1: 1000$ \\
\hline Mouse 10 & 1:1000 & 1:6100 & $1: 400$ & 1:6100 & $1: 400$ & 1:2500 & 1:160 & $1: 1000$ \\
\hline Range & $1: 160-1: 1000$ & $1: 1000-6100$ & $1: 65-1: 400$ & $1: 400-1: 6100$ & $1: 65-1: 400$ & $1: 400-1: 6100$ & $1: 10-1: 160$ & $1: 400-1: 1000$ \\
\hline
\end{tabular}

\section{Discussion}

The successful rescue of RABV recombinant viruses expressing LBV proteins, indicates that RABV genes can interact with the LBV M and G genes, similar to previous studies $[18,28,29,58]$. Finke et al. (2010) and Marston et al. (2013) showed that EBLV-1 and EBLV-2 genes can interact with RABV genes by respectively performing replacement of the $M$ and $G$ genes from RABV with those from EBLV-1 or EBLV-2. In addition to these studies, Genz et al. (2012) replaced the transmembrane and ectodomain of RABV G protein with those of EBLV-1 or EBLV-2. Neutralization of SPBN-LBVG, SPBN-LBVM-LBVG and SPBNGAS-LBVG-GAS with LBV antiserum confirmed that the LBV G protein 
is expressed by these recombinant viruses. Failure of the same serum to neutralize SPBN shows that the VNAs were directed against the LBV G protein [59,60]. A G gene-deleted RABV (SAD $\triangle G$ ) was previously shown to be unable to spread in vivo and in vitro, and also failed to produce infectious virus particles when passaged in cells that were not transfected with the plasmid expressing the $G$ protein [61,62]. The SAD $\Delta G$ was also shown to be non-pathogenic when inoculated i.c. [62] and in addition, the $\mathrm{M}$ gene-deleted RABV had a reduced viral titer by about 500000 -fold [63]. The spread of SPBN-LBVG and SPBN-LBVM-LBVG in cells that were not transfected with the relevant exchanged genes also indicated that the recombinant viruses functionally expressed these genes. Western blotting could not be used to determine LBV M and G genes expression because of the lack of suitable antibodies directed against these proteins.

All the viruses in this study, except for SPBNGAS-GAS-GAS, were pathogenic to mice after i.c. inoculation (Table 3), and LBVAFR1999 and SPBN-LBVM-LBVG infection resulted in 100\% mortality. The $20 \%$ mortality rate observed with SPBNGAS-LBVG-GAS compared to $0 \%$ mortality of SPBNGAS-GAS-GAS indicated that the non-pathogenic RABV G (GAS) genes were not dominant over the pathogenic phenotype of the LBV G gene. Previously, it was shown that i.c. inoculation of mice with a double-G gene recombinant virus (SPBNGAK-GAK) resulted in 70\% mortality [48]. However, when one of the G genes was made non-pathogenic (by mutation of Lys 194 to Asn), the recombinant virus only caused $10 \%$ mortality to mice, indicating dominance of the non-pathogenic $G$ over the pathogenic $\mathrm{G}$ gene [48]. This indicates that in addition to multiple $\mathrm{G}$ genes that result in over-expression and therefore reduced pathogenicity [25], the pathogenic domains of the G genes must be eliminated. Inoculation of the viruses into mice i.m. showed that only LBVAFR1999 and SPBN-LBVM-LBVG were pathogenic. In contrast, the SPBN-LBVG was not pathogenic despite expressing the G gene from a pathogenic LBV. It was previously shown that replacement of a non-pathogenic RABV G gene with that of a pathogenic RABV results in a pathogenic RABV, but with reduced pathogenicity compared to the parental strain $[13,16,18]$. In other studies, replacement of a non-pathogenic RABV G gene with a pathogenic RABV did not result in a pathogenic strain [16,64]. Replacement of a $G$ gene from a non-pathogenic RABV (SN-10) with the G gene from a number of street RABV variants (pathogenic i.m.) resulted in a non-pathogenic RABV strain when inoculated i.m. to mice $[16,64]$, as also confirmed in our study where the SPBN-LBVG was non-pathogenic after i.m inoculation. Replacement of both the $\mathrm{M}$ and $\mathrm{G}$ gene of a non-pathogenic RABV with that of a pathogenic RABV was shown to result in increased pathogenicity as compared to the replacement of only the $G$ gene, indicating the importance of the M gene in pathogenicity $[12,13]$. In our study, the SPBN-LBVM-LBVG was pathogenic i.m. while the SPBN-LBVG was non-pathogenic, which is in agreement with the previous studies indicating the role of the $\mathrm{M}$ gene in pathogenicity $[12,13,15]$.

Differences in recombinant virus growth was determined in MNA cells by multi-step and single-step growth curves. SPBN and SPBN-LBVG showed the same growth rate in the multi-step growth curve, indicating that the LBV G gene is able to interact optimally with the RABV M gene during encapsidation and budding. Notably, LBVAFR1999 and SPBN-LBVM-LBVG produced the lowest viral titers during single- and multi-step growth kinetics, which is in agreement with previous findings that pathogenic RABV strains have lower replication rates than non-pathogenic strains $[12,13,48]$. This, thought to be one of the mechanisms by which lyssaviruses evade the host defense mechanisms, is consistent with our finding that only the LBVAFR1999 and SPBN-LBVM-LBVG were pathogenic when inoculated i.m. in mice. The single-step growth curve indicated no significant $(p>0.05)$ difference between SPBN, SPBNGAS-LBVG-GAS and SPBNGAS-GAS-GAS. These viruses maintained higher titers in both the single- and multi-step growth curves, indicating that insertion of multiple $G$ genes and the LBVAFR1999 G gene did not negatively influence the growth of SPBNGAS-LBVG-GAS and SPBNGAS-GAS-GAS.

By replacing the $M$ and $G$ genes between laboratory-adapted SPBN and the wild-type LBVAFR1999 isolate, we have attempted to address the importance of the M and G genes in the pathogenicity of LBV. Our results emphasize again that the G protein is important in pathogenicity 
of lyssaviruses, and that there is a cooperative effect of other lyssavirus genes as shown by increased pathogenicity when both the SPBN M and G genes were replaced by those of LBV.

The SPBNGAS-LBVG-GAS produced high levels of VNAs against RABV and DUVV 13 days post-primary vaccination in mice and the level was comparable to that produced by vaccination with SPBNGAS-GAS-GAS (data not shown). In previous studies, SPBNGAS-GAS-GAS produced high levels of RABV VNA and protected mice against lethal challenge with RABV, therefore suggesting that SPBNGAS-LBVG-GAS will offer the same level of protection $[39,40]$. In addition, SPBNGAS-LBVG-GAS also produced high levels of VNAs capable of cross-neutralizing DUVV. Although serum from RABV-vaccinated mice has already been shown to cross-neutralize DUVV [30] the VNA titers against DUVV were significantly lower than those against RABV. In our study, the DUVV VNA titers induced by SPBNGAS-LBVG-GAS were not significantly different from the RABV VNA titers $(p>0.05)$. Previous studies on cross-reactivity of RABV vaccines to other phylogroup I lyssaviruses indicated that a vaccine derived from the Pasteur virus (PV) strain protected mice from EBLV-1 challenge, while vaccines derived from Pitman-Moore (PM) and LEP-Flury (LEP) strains failed to protect mice against EBLV-1 infection [31]. However, in another study, a vaccine derived from the PM strain was shown to produce VNA that neutralize EBLV-1 and protect mice against lethal challenge [35]. This indicates that different strains from the same lyssavirus species can result in different protection levels.

Mice vaccinated with SPBNGAS-LBVG-GAS also produced VNAs against LBV and MOKV although the titers were significantly lower $(p<0.05)$ compared to RABV, with the exception of VNA titer of RABV and LBV at day 28 , where no significant difference was observed. MOKV VNA titers were significantly lower $(p<0.05)$ than LBV VNA titers on day 13 . Previous studies did report cross-neutralization between MOKV and LBV [30,65,66]; however, the titer was always higher when the $G$ protein of the challenge virus was identical to the $G$ protein of vaccine. Cross-neutralization against SHIBV was not tested in this study but it is likely that cross-neutralization will occur with other phylogroup II viruses when SPBNGAS-LBVG-GAS is used as vaccine [38]. Booster vaccination resulted in significantly higher $(p<0.05)$ VNA titer against all challenge viruses used. Mice were not challenged in this study; however, the high VNA titer produced by SPBNGAS-LBVG-GAS especially after booster vaccination indicates that this recombinant vaccine will likely protect mice against lethal challenge with RABV, LBV, MOKV and DUVV. VNA titer is regarded to be an important factor in protecting against virus challenge and can be correlated with survival, but this will have to be confirmed in challenge studies in mice in the future [67].

In future studies, the expression of LBV G should be increased by changing the gene order of the LBV G gene or by insertion of an additional G gene to determine if the level of LBV and MOKV VNA increases without booster vaccination. Although VNA titers against LBV and MOKV were lower compared to RABV and DUVV during primary vaccination, the significant increase in VNA titer after booster vaccination warrants further investigation of the efficacy of SPBNGAS-LBVG-GAS to protect against phylogroup II lyssaviruses.

Acknowledgments: This work was supported by the National Institutes of Health grant ROIAI093666 (to M.F.), National Research Foundation, South Africa (UID 85786) and International Foundation for Science. J. Kgaladi's $\mathrm{PhD}$ studies were supported by a freestanding bursary from the National Research Foundation, South Africa, the Poliomyelitis Research Foundation and the University of Pretoria study abroad bursary program. DUVVSA2006 isolate was kindly provided by the Centre for Emerging and Zoonotic Diseases, National Institute for Communicable Diseases (National Health Laboratory Service), Sandringham, South Africa. LBVAFR1999 was kindly provided by Florence Cliquet from Agene Francaise de Sécurité Sanitaire des Aliments, France. Dana Curtis and Keith Schutsky (Thomas Jefferson University, USA) are acknowledged for their technical assistance.

Author Contributions: J. Kgaladi, W. Markotter, L.H. Nel, M. Faber and B. Dietzschold conceived and designed the experiments. J. Kgaladi performed the experiments and analyzed the data. W. Markotter, L.H. Nel, M. Faber and B. Dietzschold contributed reagents/materials/analysis tools. J. Kgaladi, W. Markotter, L.H. Nel, M. Faber and B. Dietzschold wrote the paper.

Conflicts of Interest: The authors declare no conflict of interest. 


\section{References}

1. Dietzgen, R.G.; Calisher, C.H.; Kurath, G.; Kuzmin, I.V.; Rodriguez, L.L.; Stone, D.M.; Tesh, R.B.; Tordo, N.; Walker, P.J.; Wetzel, T. Family Rhabdoviridae. In Virus Taxonomy: Ninth Report of the International Committee on Taxonomy of Viruses; King, A.M.Q., Adams, M.J., Carstens, E.B., Lefkowitz, E.J., Eds.; Elsevier: San Diego, CA, USA, 2011; pp. 654-681.

2. Banyard, A.C.; Fooks, A.R. The impact of novel lyssavirus discovery. Mcrobiol. Aust. 2017, 38, 17-21. [CrossRef]

3. ICTV. Available online: http://ictvonline.org/virusTaxonomy.asp/ (accessed on 15 June 2017).

4. Markotter, W.; Kuzmin, I.; Rupprecht, C.; Nel, L. Phylogeny of Lagos bat virus: Challenges for lyssavirus taxonomy. Virus Res. 2008, 135, 10-21. [CrossRef] [PubMed]

5. Swanepoel, R. Rabies. In Infectious Diseases of Livestock: With Special Reference to Southern Africa; Coetzer, J.A.W., Tustin, R.C., Eds.; Oxford University Press: Cape Town, South Africa, 2004; pp. 1123-1182.

6. Kuzmin, I.V.; Niezgoda, M.; Franka, R.; Agwanda, B.; Markotter, W.; Beagley, J.C.; Urazova, O.Y.; Breiman, R.F.; Rupprecht, C.E. Lagos bat virus in Kenya. J. Clin. Microbiol. 2008, 46, 1451-1461. [CrossRef] [PubMed]

7. Mebatsion, T.; Cox, J.H.; Frost, J.W. Isolation and characterization of 115 street rabies virus isolates from Ethiopia by using monoclonal antibodies: Identification of 2 isolates as Mokola and Lagos bat viruses. J. Infect. Dis. 1992, 166, 972-977. [CrossRef] [PubMed]

8. Markotter, W.; Van Eeden, C.; Kuzmin, I.; Rupprecht, C.; Paweska, J.; Swanepoel, R.; Fooks, A.; Sabeta, C.; Cliquet, F.; Nel, L. Epidemiology and pathogenicity of African bat lyssaviruses. Dev. Biol. 2008, 131, 317-325.

9. Markotter, W.; Kuzmin, I.; Rupprecht, C.E.; Randles, J.; Sabeta, C.T.; Wandeler, A.I.; Nel, L.H. Isolation of Lagos bat virus from water mongoose. Emerg. Infect. Dis. 2006, 12, 1913. [CrossRef] [PubMed]

10. Kgaladi, J.; Nel, L.H.; Markotter, W. Comparison of pathogenic domains of rabies and African rabies-related lyssaviruses and pathogenicity observed in mice. Onderstepoort J. Vet. Res. 2013, 80, 1-13. [CrossRef] [PubMed]

11. Markotter, W.; Kuzmin, I.V.; Rupprecht, C.E.; Nel, L.H. Lagos bat virus virulence in mice inoculated by the peripheral route. Epidemiol. Infect. 2009, 137, 1155-1162. [CrossRef] [PubMed]

12. Faber, M.; Pulmanausahakul, R.; Nagao, K.; Prosniak, M.; Rice, A.B.; Koprowski, H.; Schnell, M.J.; Dietzschold, B. Identification of viral genomic elements responsible for rabies virus neuroinvasiveness. Proc. Natl. Acad. Sci. USA 2004, 101, 16328-16332. [CrossRef] [PubMed]

13. Pulmanausahakul, R.; Li, J.; Schnell, M.J.; Dietzschold, B. The glycoprotein and the matrix protein of rabies virus affect pathogenicity by regulating viral replication and facilitating cell-to-cell spread. J. Virol. 2008, 82, 2330-2338. [CrossRef] [PubMed]

14. Tao, L.; Ge, J.; Wang, X.; Zhai, H.; Hua, T.; Zhao, B.; Kong, D.; Yang, C.; Chen, H.; Bu, Z. Molecular basis of neurovirulence of flury rabies virus vaccine strains: Importance of the polymerase and the glycoprotein R333Q mutation. J. Virol. 2010, 84, 8926-8936. [CrossRef] [PubMed]

15. Shimizu, K.; Ito, N.; Mita, T.; Yamada, K.; Hosokawa-Muto, J.; Sugiyama, M.; Minamoto, N. Involvement of nucleoprotein, phosphoprotein, and matrix protein genes of rabies virus in virulence for adult mice. Virus Res. 2007, 123, 154-160. [CrossRef] [PubMed]

16. Dietzschold, B.; Schnell, M.J. New approaches to the development of live attenuated rabies vaccines. Hybrid. Hybridomics. 2002, 21, 129-134. [CrossRef] [PubMed]

17. Morimoto, K.; Foley, H.D.; McGettigan, J.P.; Schnell, M.J.; Dietzschold, B. Reinvestigation of the role of the rabies virus glycoprotein in viral pathogenesis using a reverse genetics approach. J. Neurovirol. 2000, 6, 373-381. [CrossRef] [PubMed]

18. Marston, D.A.; McElhinney, L.M.; Banyard, A.C.; Horton, D.L.; Núñez, A.; Koser, M.L.; Schnell, M.J.; Fooks, A.R. Interspecies protein substitution to investigate the role of the lyssavirus glycoprotein. J. Gen. Virol. 2013, 94, 284-292. [CrossRef] [PubMed]

19. Masatani, T.; Ito, N.; Shimizu, K.; Ito, Y.; Nakagawa, K.; Sawaki, Y.; Koyama, H.; Sugiyama, M. Rabies virus nucleoprotein functions to evade activation of the RIG-I-mediated antiviral response. J. Virol. 2010, 84, 4002-4012. [CrossRef] [PubMed]

20. Ito, N.; Takayama, M.; Yamada, K.; Sugiyama, M.; Minamoto, N. Rescue of rabies virus from cloned cDNA and identification of the pathogenicity-related gene: Glycoprotein gene is associated with virulence for adult mice. J. Virol. 2001, 75, 9121-9128. [CrossRef] [PubMed] 
21. Langevin, C.; Jaaro, H.; Bressanelli, S.; Fainzilber, M.; Tuffereau, C. Rabies virus glycoprotein (RVG) is a trimeric ligand for the $\mathrm{N}$-terminal cysteine-rich domain of the mammalian p75 neurotrophin receptor. J. Biol. Chem. 2002, 277, 37655-37662. [CrossRef] [PubMed]

22. Tuffereau, C.; Benejean, J.; Blondel, D.; Kieffer, B.; Flamand, A. Low-affinity nerve-growth factor receptor (P75NTR) can serve as a receptor for rabies virus. EMBO J. 1998, 17, 7250-7259. [CrossRef] [PubMed]

23. Lentz, T.L.; Burrage, T.G.; Smith, A.L.; Crick, J.; Tignor, G.H. Is the acetylcholine receptor a rabies virus receptor? Science 1982, 215, 182-184. [CrossRef] [PubMed]

24. Thoulouze, M.-I.; Lafage, M.; Schachner, M.; Hartmann, U.; Cremer, H.; Lafon, M. The neural cell adhesion molecule is a receptor for rabies virus. J. Virol. 1998, 72, 7181-7190. [PubMed]

25. Morimoto, K.; Hooper, D.C.; Spitsin, S.; Koprowski, H.; Dietzschold, B. Pathogenicity of different rabies virus variants inversely correlates with apoptosis and rabies virus glycoprotein expression in infected primary neuron cultures. J. Virol. 1999, 73, 510-518. [PubMed]

26. Kassis, R.; Larrous, F.; Estaquier, J.; Bourhy, H. Lyssavirus matrix protein induces apoptosis by a TRAIL-dependent mechanism involving caspase-8 activation. J. Virol. 2004, 78, 6543-6555. [CrossRef] [PubMed]

27. Préhaud, C.; Lay, S.; Dietzschold, B.; Lafon, M. Glycoprotein of nonpathogenic rabies viruses is a key determinant of human cell apoptosis. J. Virol. 2003, 77, 10537-10547. [CrossRef] [PubMed]

28. Genz, B.; Nolden, T.; Negatsch, A.; Teifke, J.-P.; Conzelmann, K.-K.; Finke, S. Chimeric rabies viruses for trans-species comparison of lyssavirus glycoprotein ectodomain functions in virus replication and pathogenesis. Berl. Munch. Tierarztl. Wochenschr. 2012, 9, 219-227.

29. Finke, S.; Granzow, H.; Hurst, J.; Pollin, R.; Mettenleiter, T.C. Intergenotypic replacement of lyssavirus matrix proteins demonstrates the role of lyssavirus M proteins in intracellular virus accumulation. J. Virol. 2010, 84, 1816-1827. [CrossRef] [PubMed]

30. Badrane, H.; Bahloul, C.; Perrin, P.; Tordo, N. Evidence of two Lyssavirus phylogroups with distinct pathogenicity and immunogenicity. J. Virol. 2001, 75, 3268-3276. [CrossRef] [PubMed]

31. Lafon, M.; Bourhy, H.; Sureau, P. Immunity against the European bat rabies (Duvenhage) virus induced by rabies vaccines: An experimental study in mice. Vaccine 1988, 6, 362-368. [CrossRef]

32. Malerczyk, C.; Selhorst, T.; Tordo, N.; Moore, S.; Müller, T. Antibodies induced by vaccination with purified chick embryo cell culture vaccine (PCECV) cross-neutralize non-classical bat lyssavirus strains. Vaccine 2009, 27, 5320-5325. [CrossRef] [PubMed]

33. Hanlon, C.A.; Kuzmin, I.V.; Blanton, J.D.; Weldon, W.C.; Manangan, J.S.; Rupprecht, C.E. Efficacy of rabies biologics against new lyssaviruses from Eurasia. Virus Res. 2005, 111, 44-54. [CrossRef] [PubMed]

34. Jallet, C.; Jacob, Y.; Bahloul, C.; Drings, A.; Desmezieres, E.; Tordo, N.; Perrin, P. Chimeric lyssavirus glycoproteins with increased immunological potential. J. Virol. 1999, 73, 225-233. [PubMed]

35. Brookes, S.; Parsons, G.; Johnson, N.; McElhinney, L.; Fooks, A. Rabies human diploid cell vaccine elicits cross-neutralising and cross-protecting immune responses against European and Australian bat lyssaviruses. Vaccine 2005, 23, 4101-4109. [CrossRef] [PubMed]

36. Nel, L.H. Vaccines for lyssaviruses other than rabies. Expert Rev. Vaccines 2005, 4, 533-540. [CrossRef] [PubMed]

37. Horton, D.L.; Banyard, A.C.; Marston, D.A.; Wise, E.; Selden, D.; Nunez, A.; Hicks, D.; Lembo, T.; Cleaveland, S.; Peel, A.J. Antigenic and genetic characterization of a divergent African virus, Ikoma lyssavirus. J. Gen. Virol. 2014, 95, 1025-1032. [CrossRef] [PubMed]

38. Kuzmin, I.V.; Mayer, A.E.; Niezgoda, M.; Markotter, W.; Agwanda, B.; Breiman, R.F.; Rupprecht, C.E. Shimoni bat virus, a new representative of the Lyssavirus genus. Virus Res. 2010, 149, 197-210. [CrossRef] [PubMed]

39. Faber, M.; Pulmanausahakul, R.; Hodawadekar, S.S.; Spitsin, S.; McGettigan, J.P.; Schnell, M.J.; Dietzschold, B. Overexpression of the rabies virus glycoprotein results in enhancement of apoptosis and antiviral immune response. J. Virol. 2002, 76, 3374-3381. [CrossRef] [PubMed]

40. Faber, M.; Li, J.; Kean, R.B.; Hooper, D.C.; Alugupalli, K.R.; Dietzschold, B. Effective preexposure and postexposure prophylaxis of rabies with a highly attenuated recombinant rabies virus. Proc. Natl. Acad. Sci. USA 2009, 106, 11300-11305. [CrossRef] [PubMed]

41. Hosokawa-Muto, J.; Ito, N.; Yamada, K.; Shimizu, K.; Sugiyama, M.; Minamoto, N. Characterization of recombinant rabies virus carrying double glycoprotein genes. Microbiol. Immunol. 2006, 50, 187-196. [CrossRef] [PubMed] 
42. Tao, L.; Ge, J.; Wang, X.; Wen, Z.; Zhai, H.; Hua, T.; Zhao, B.; Kong, D.; Yang, C.; Bu, Z. Generation of a recombinant rabies Flury LEP virus carrying an additional $G$ gene creates an improved seed virus for inactivated vaccine production. Virol. J. 2011, 8, 1-7. [CrossRef] [PubMed]

43. Cenna, J.; Hunter, M.; Tan, G.S.; Papaneri, A.B.; Ribka, E.P.; Schnell, M.J.; Marx, P.A.; McGettigan, J.P. Replication-deficient rabies virus-based vaccines are safe and immunogenic in mice and monhuman primates. J. Infect. Dis. 2009, 200, 1251-1260. [CrossRef] [PubMed]

44. Faul, E.J.; Wanjalla, C.N.; McGettigan, J.P.; Schnell, M.J. Interferon- $\beta$ expressed by a rabies virus-based HIV-1 vaccine vector serves as a molecular adjuvant and decreases pathogenicity. Virology 2008, 382, 226-238. [CrossRef] [PubMed]

45. Wen, Y.; Wang, H.; Wu, H.; Yang, F.; Tripp, R.A.; Hogan, R.J.; Fu, Z.F. Rabies virus expressing dendritic cell-activating molecules enhances the innate and adaptive immune response to vaccination. J. Virol. 2011, 85, 1634-1644. [CrossRef] [PubMed]

46. Zhao, L.; Toriumi, H.; Wang, H.; Kuang, Y.; Guo, X.; Morimoto, K.; Fu, Z.F. Expression of MIP-1 $\alpha$ (CCL3) by a recombinant rabies virus enhances its immunogenicity by inducing innate immunity and recruiting dendritic cells and B cells. J. Virol. 2010, 84, 9642-9648. [CrossRef] [PubMed]

47. Pulmanausahakul, R.; Faber, M.; Morimoto, K.; Spitsin, S.; Weihe, E.; Hooper, D.C.; Schnell, M.J.; Dietzschold, B. Overexpression of cytochrome $\mathrm{C}$ by a recombinant rabies virus attenuates pathogenicity and enhances antiviral immunity. J. Virol. 2001, 75, 10800-10807. [CrossRef] [PubMed]

48. Faber, M.; Faber, M.-L.; Li, J.; Preuss, M.A.; Schnell, M.J.; Dietzschold, B. Dominance of a nonpathogenic glycoprotein gene over a pathogenic glycoprotein gene in rabies virus. J. Virol. 2007, 81, 7041-7047. [CrossRef] [PubMed]

49. Faber, M.; Faber, M.-L.; Papaneri, A.; Bette, M.; Weihe, E.; Dietzschold, B.; Schnell, M.J. A single amino acid change in rabies virus glycoprotein increases virus spread and enhances virus pathogenicity. J. Virol. 2005, 79, 14141-14148. [CrossRef] [PubMed]

50. Schnell, M.J.; Mebatsion, T.; Conzelmann, K.-K. Infectious rabies viruses from cloned cDNA. EMBO J. 1994, 13, 4195. [PubMed]

51. ProMED-mail. Rabies, bat-France. ProMED-mail 199990813.1401. Available online: http://www.promedmail.org (accessed on 15 June 2017).

52. Aubert, F.A. Rabies in individual countries: France. Rabies Bulletin Europe [serial on the internet]. Available online: http:/ / www.who-rabiesbulletin.org/ (accessed on 15 June 2017).

53. Sato, M.; Maeda, N.; Yoshida, H.; Urade, M.; Saito, S.; Miyazaki, T.; Shibata, T.; Watanabe, M. Plaque formation of herpes virus hominis type 2 and rubella virus in variants isolated from the colonies of BHK21/WI-2 cells formed in soft agar. Arch. Virol. 1977, 53, 269-273. [CrossRef] [PubMed]

54. Dean, D.J.; Abelseth, M.K.; Atanasiu, P. The fluorescent antibody test: p 89-85. In Laboratory Techniques in Rabies, 4th ed.; Meslin, F.-X., Kaplan, M.M., Koprowski, H., Eds.; World Health Organization: Geneva, Switzerland, 1996; pp. 157-174.

55. Reed, L.J.; Muench, H. A simple method of estimating fifty per cent endpoints. Am. J. Epidemiol. 1938, 27, 493-497. [CrossRef]

56. Smith, J.S.; Yager, P.A.; Baer, G.M. A rapid fluorescent focus inhibition test (RFFIT) for determining rabies virus neutralizing antibody. In Laboratory Techniques in Rabies; Meslin, F.-X., Kaplan, M.M., Koprowski, H., Eds.; World Health Organization: Geneva, Switzerland, 1996; pp. 189-192.

57. McCulloch, S.D. Barcoding of South African bat species and evaluation of their natural exposure to lyssaviruses. Master's Thesis, University of Pretoria, Pretoria, South Africa, 2013.

58. Mebatsion, T.; Schnell, M.J.; Conzelmann, K.-K. Mokola virus glycoprotein and chimeric proteins can replace rabies virus glycoprotein in the rescue of infectious defective rabies virus particles. J. Virol. 1995, 69, 1444-1451. [PubMed]

59. Cox, J.H.; Dietzschold, B.; Schneider, L. Rabies virus glycoprotein. II. Biological and serological characterization. Infect. Immun. 1977, 16, 754-759. [PubMed]

60. Dietzschold, B.; Wang, H.; Rupprecht, C.E.; Celis, E.; Tollis, M.; Ertl, H.; Heber-Katz, E.; Koprowski, H. Induction of protective immunity against rabies by immunization with rabies virus ribonucleoprotein. Proc. Natl. Acad. Sci. USA 1987, 84, 9165-9169. [CrossRef] [PubMed]

61. Mebatsion, T.; König, M.; Conzelmann, K.-K. Budding of rabies virus particles in the absence of the spike glycoprotein. Cell 1996, 84, 941-951. [CrossRef] 
62. Etessami, R.; Conzelmann, K.-K.; Fadai-Ghotbi, B.; Natelson, B.; Tsiang, H.; Ceccaldi, P.-E. Spread and pathogenic characteristics of a G-deficient rabies virus recombinant: An in vitro and in vivo study. J. Gen. Virol. 2000, 81, 2147-2153. [CrossRef] [PubMed]

63. Mebatsion, T.; Weiland, F.; Conzelmann, K.-K. Matrix protein of rabies virus is responsible for the assembly and budding of bullet-shaped particles and interacts with the transmembrane spike glycoprotein G. J. Virol. 1999, 73, 242-250. [PubMed]

64. Morimoto, K.; McGettigan, J.P.; Foley, H.D.; Hooper, D.C.; Dietzschold, B.; Schnell, M.J. Genetic engineering of live rabies vaccines. Vaccine 2001, 19, 3543-3551. [CrossRef]

65. Weyer, J.; Kuzmin, I.V.; Rupprecht, C.E.; Nel, L.H. Cross-protective and cross-reactive immune responses to recombinant vaccinia viruses expressing full-length lyssavirus glycoprotein genes. Epidemiol. Infect. 2008, 136, 670-678. [CrossRef] [PubMed]

66. Bahloul, C.; Jacob, Y.; Tordo, N.; Perrin, P. DNA-based immunization for exploring the enlargement of immunological cross-reactivity against the lyssaviruses. Vaccine 1998, 16, 417-425. [CrossRef]

67. Dietzschold, B.; Kao, M.; Zheng, Y.M.; Chen, Z.Y.; Maul, G.; Fu, Z.F.; Rupprecht, C.E.; Koprowski, H. Delineation of putative mechanisms involved in antibody-mediated clearance of rabies virus from the central nervous system. Proc. Natl. Acad. Sci. USA 1992, 89, 7252-7256. [CrossRef] [PubMed]

(C) 2017 by the authors. Licensee MDPI, Basel, Switzerland. This article is an open access article distributed under the terms and conditions of the Creative Commons Attribution (CC BY) license (http:/ / creativecommons.org/licenses/by/4.0/). 
Article

\title{
Protection Against CNS-Targeted Rabies Virus Infection is Dependent upon Type-1 Immune Mechanisms Induced by Live-Attenuated Rabies Vaccines
}

\author{
Aurore Lebrun ${ }^{1}$, Samantha Garcia ${ }^{1}$, Jianwei Li ${ }^{1}$, Rhonda B. Kean ${ }^{1}$ and D. Craig Hooper ${ }^{1,2, *}$ \\ 1 Department of Cancer Biology, Thomas Jefferson University, Philadelphia, PA 19017, USA; \\ aurore.lebrun@jefferson.edu (A.L.); samantha.garcia@jefferson.edu (S.G.); jianwei.li@jefferson.edu (J.L.); \\ rhonda.kean@jefferson.edu (R.B.K.) \\ 2 Department of Neurological Surgery, Thomas Jefferson University, Philadelphia, PA 19017, USA \\ * Correspondence: DouglasC.Hooper@jefferson.edu; Tel.: +1-215-503-1774
}

Received: 17 May 2017; Accepted: 29 June 2017; Published: 4 July 2017

\begin{abstract}
Rabies remains a major public health issue worldwide, especially in developing countries where access to medical care can represent a real challenge. While there is still no cure for rabies, it is a vaccine-preventable disease with pre- and post-exposure prophylaxis regimens approved by the World Health Organization (WHO). However, many rabies-exposed individuals have limited access to vaccines and virus-neutralizing antibodies approved for post-exposure prophylaxis. Unfortunately, any delay in the administration of these reagents can have lethal consequences. This highlights the need to develop cost-effective immunological reagents with a greater window of efficacy. Live-attenuated vaccine strains of rabies virus presents a potential treatment in filling this gap. We show here that immunization with live-attenuated vaccines provide long-lasting rabies immunity, superior to the protection induced by inactivated vaccines. In the absence of an immunostimulatory adjuvant, vaccination with multiple doses of inactivated rabies virus induces a type- 2 immune response. This type of immunity is highly effective at inducing neutralizing antibody but has limited efficacy in clearing the virus from central nervous system (CNS) tissues. In contrast, a single infection with live-attenuated rabies vaccine safely drives a type- 1 immune response, associated with both the production of a neutralizing antibody and the clearance of wild-type rabies virus from CNS tissues. These results indicate that live-attenuated rabies strains have the potential to be more effective in post-exposure prophylaxis than conventional inactivated vaccines.
\end{abstract}

Keywords: rabies; vaccine; type-1 immunity; type-2 immunity

\section{Introduction}

Rabies is a central nervous system (CNS) disease, nearly always fatal for humans and most mammals, caused by host infection with the rabies virus (RABV). RABV is a single-stranded, negative sense, neurotropic RNA virus that belongs to the Lyssavirus genus of the Rhabdoviridae family [1]. Despite advances in the control of animal reservoirs and in human prophylaxis, rabies still accounts for over 60,000 human deaths worldwide, with most cases recorded in Asia and Africa [2]. Although incurable once clinical symptoms appear [3], rabies is largely preventable through mass vaccination of dogs in rabies-enzootic regions, which aims to eliminate the virus at its source [4], or via the use of anti-rabies biologics in humans after exposure [5]. Since Pasteur's development of the first rabies vaccine in 1885, rabies prevention has evolved in two directions: pre- and post-exposure (PEP) prophylaxis. Pre-exposure prophylaxis, which involves a series of three or more intramuscular (i.m.) injections of inactivated rabies vaccine at 0,7 , and 28 days [6,7], is given only to at-risk populations 
such as veterinarians, laboratory workers, and travelers to rabies endemic regions [8]. PEP, which consists of proper wound cleaning, immunization with an inactivated rabies vaccine, and injection of rabies immunoglobulins at the site of infection [8], is effective at preventing the development of the disease when administered to the patient within a short window after exposure to a suspected rabid animal [9].

Unfortunately, a large number of rabies-exposed patients fail to receive adequate PEP, primarily in resource-poor countries, largely due to the high cost or unavailability of rabies vaccine or rabies immunoglobulins [10]. The difficulties of rabies management in animal reservoirs and the inability to follow World Health Organization recommendations for PEP best practice in under-developed countries drives the need to improve the availability of safe, cost-effective rabies reagents [11]. Foremost among these advancements are both the use of human monoclonal rabies virus neutralizing antibodies in replacement of serum-based antibodies and new vaccine approaches that provide the critical, safe, and rapid induction of long-lasting immunity. The use of adjuvants in combination with inactivated RABV vaccines or infection with live-attenuated RABV vaccine strains are two strategies that may more rapidly induce rabies immunity, although it is now known that the nature of the immune response is also an important consideration. We previously reported that the outcome of RABV infection of neural tissues is dependent upon two key processes: (1) the early control of virus replication by IFN- $\gamma$-promoted innate immune mechanisms [12,13]; and (2) virus clearance from CNS tissue by the infiltration of immune effectors and the local production of virus-neutralizing antibodies (VNA) [14]. A rabies-specific immune response biased toward type-1 immunity (Th1 CD4 T cell response) is critical for both of these processes [15].

The present study is aimed at evaluating the efficacy in mice of live-attenuated RABV vaccine strains in triggering long-lasting immunity and protection against challenge with lethal wild-type RABV via routes distal from and proximal to the CNS. Several vaccine and wild-type RABV strains were used in various mice strains to take into account genetic variability in immunity. The immune response to live-attenuated RABV was compared to inactivated $\mathrm{RABV}$, which more closely resembles current approved vaccines for humans [5]. We found that live-attenuated RABV strains consistently outperform inactivated vaccine strains, including a current commercial vaccine IMOVAX ${ }^{\circledR}$, in the induction of protection against challenge with a lethal RABV. We show that this is largely due to differences in the class of immune response elicited: type- 1 by live-attenuated RABV, and type- 2 by inactivated RABV.

\section{Materials and Methods}

\subsection{Mice and Study Approval}

C57BL/ 6 and Swiss Webster mice (6 to 8 weeks of age) were purchased from Jackson Laboratory (Bar Harbor, ME, USA) and Taconic Biosciences (Germantown, NY, USA), respectively. All animals were monitored for survival and blood samples were collected at various times post-infection for serum antibody titers. All procedures were conducted in accordance with Public Health Service Policy on Humane Care and Use of Laboratory Animals under protocols approved by the Institutional Animal Care and Use Committee of Thomas Jefferson University (Animal Welfare Assurance Number A3085-01).

\subsection{Virus and Vaccine Strains}

SPBN Double GAS (GG) and SPBN Triple GAS (GGG), recombinant RABV vaccines containing two or three copies of a mutated glycoprotein, respectively, were developed as previously described [16,17]. Both the dog rabies virus 4 (DRV4) and the silver-haired bat rabies virus 17 (SHBRV-17) are highly pathogenic RABV strains of dog and bat origins. These lethal viruses were isolated from the brains of human victims and propagated in suckling mice brain [18]. The challenge virus standard F3 (CVS-F3) is an antibody escape-attenuated mutant, of dog origin, that differs from 
its parental strain by a single point mutation in its glycoprotein in position 333 [19]. IMOVAX ${ }^{\circledR}$ is a licensed human diploid cell vaccine (Sanofi Pasteur, Swiftwater, PA, USA) prepared from the Pitman-Moore strain of RABV grown on MRC-5 human diploid cell cultures, in use in the USA since $1980[20,21]$.

\subsection{Virus Inactivation}

IMOVAX ${ }^{\circledR}$ is a commercially available vaccine inactivated with beta-propiolactone (BPL), an alkylating agent reacting with nucleic acids and proteins, widely used for the inactivation and increased safety of biological reagents such as viruses [22]. In some experiments, IMOVAX ${ }^{\circledR}$ was reconstituted according to manufacturer's directions and stored at either $25^{\circ} \mathrm{C}$ or $40{ }^{\circ} \mathrm{C}$ for three weeks prior to use. The live-attenuated vaccine strains used in this study were inactivated either by exposing the virus to UV radiation for 45 minutes or by treatment with BPL (1:100 dilution) overnight at $4{ }^{\circ} \mathrm{C}$.

\subsection{Immunization and Challenge of Mice}

A variety of immunization strategies were used and are detailed in each figure legend. Briefly, mice were immunized with $1 \times 10^{5}-1 \times 10^{8}$ focus-forming units (f.f.u.) of live-attenuated or inactivated (f.f.u. determined before inactivation) RABV via intramuscular (gastrocnemius, i.m.g., $50 \mu \mathrm{L}$ ), intranasal (i.n., $10 \mu \mathrm{L}$ ) or intracranial (i.c., $5 \mu \mathrm{L}$ ) routes. Mice immunized with IMOVAX ${ }^{\circledR}$ received 0.125-0.25 International Units (IU) of rabies antigen. Mice were challenged at 21-63 days post-immunization with $1 \times 10^{3}-1 \times 10^{5}$ f.f.u. lethal RABV via one of the same routes as immunization.

\subsection{Neutralizing Antibody (VNA)Titer and Serum Antibody Isotyping}

Virus neutralizing antibody (VNA) titer was evaluated by the rapid fluorescent focus inhibition test as previously described [23]. The antibody isotypes were determined by ELISA using UV-inactivated Evelyn-Rokitnicki-Abelseth (ERA) virus as coating antigen and mouse-specific total IgG, IgG1, and IgG2a secondary antibodies, as described previously [24].

\subsection{StatisticalAnalysis}

Statistical significance of survival rates or IgG levels were compared with a one-way ANOVA followed by the Bonferroni multiple comparison test. Graphs were created and statistical analysis was performed using GraphPad Prism 5.0 software (La Jolla, CA, USA). Statistically significant differences between groups are denoted as follows: ${ }^{*} p \leq 0.01,{ }^{* *} p \leq 0.005$, and ${ }^{* * *} p \leq 0.001$.

\section{Results}

\subsection{Live-Attenuated $R A B V$ are Protective and Stable at Room Temperature}

Current human anti-rabies vaccines are inactivated to improve both the safety for the host and the stability of the preparation. However, multiple doses are required for sufficient immunity. While live-attenuated rabies vaccines are capable of inducing a strong immune response with a single dose, the limitations most often cited for their use are safety and stability. Here we show that IMOVAX ${ }^{\circledR}$, a commercial BPL-inactivated vaccine, either freshly reconstituted or stored at $25{ }^{\circ} \mathrm{C}$ or $40{ }^{\circ} \mathrm{C}$ for three weeks, is fully protective (100\% survival) in immunocompetent mice against an i.m. challenge with the lethal DRV4 virus (Figure 1a). The protection against DRV4 challenge was conferred by the induction of a strong rabies-specific humoral response following immunization with the IMOVAX ${ }^{\circledR}$ vaccine, as evidenced by high levels of circulating IgG antibodies (Figure 1b) and VNAs (Figure 1c). As expected, mice immunized with a fresh preparation of the live-attenuated GG virus resulted in $100 \%$ survival after DRV4 challenge, while only $20 \%$ of the mice survived when the animals were immunized with the vaccine stored at $40{ }^{\circ} \mathrm{C}$ (Figure 1d). However, we found that the live-attenuated GG strain stored at room temperature $\left(25^{\circ} \mathrm{C}\right)$ for three weeks retained sufficient activity to provide full protection against the wild-type DRV4 challenge (Figure 1d). Analysis of the peripheral humoral 
response of mice infected with GG stored at $25^{\circ} \mathrm{C}$ shows that rabies-specific IgGs (Figure 1e) and VNAs (Figure 1f) were both produced. While the VNA titer was lower than that elicited by fresh GG vaccine, it is likely responsible for animal survival, as administration of GG virus stored at $40^{\circ} \mathrm{C}$ failed to elicit rabies-specific antibody production (Figure 1e,f) or protect against DRV4 challenge (Figure 1d).

(a)

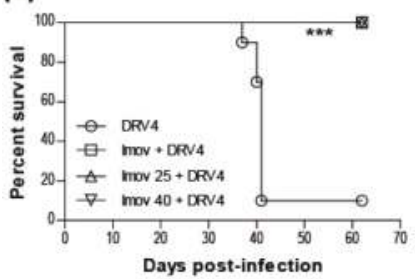

(d)

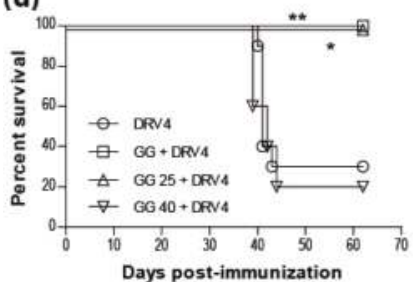

(b)

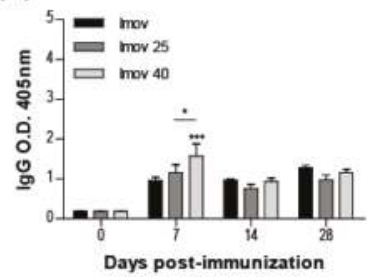

(e)

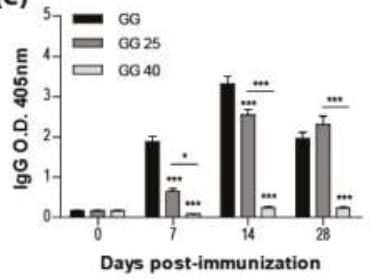

(c)

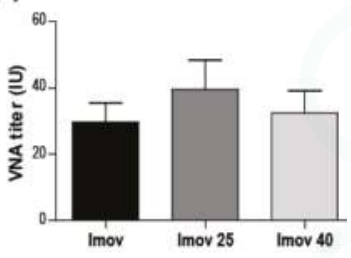

(f)

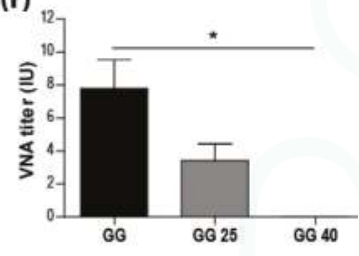

Figure 1. Live-attenuated RABV vaccines, stored at room temperature, retain sufficient infectivity to induce fully protective immunity. Swiss Webster mice were immunized with 0.25 IU of IMOVAX ${ }^{\circledR}$ (a) or $1 \times 10^{5}$ f.f.u. of GG (d) i.m.g. stored at various temperatures then challenged 30 days later with $1 \times 10^{5}$ f.f.u. of DRV4 i.m.g. and monitored for survival. Data are expressed as percent survival ( $n=5-10$ per group). (b,e) Virus-specific Ab response for total IgG was determined by ELISA at 7, 14 and 28 d.p.i. for all groups (dilution 1:40). (c,f) VNA titer at 28 d.p.i. was determined by the rapid fluorescence focus inhibition test, as described in Materials and Methods. Data are expressed as mean \pm SEM of international unit (IU). Statistically significant differences between groups are denoted as follows: * $p \leq 0.01 ;{ }^{* *} p \leq 0.005 ;{ }^{* * *} p \leq 0.001$.

\subsection{IMOVAX ${ }^{\circledR}$ Induces a Mixed Th1/Th2 Immune Response}

In addition to the long-established requirement for VNA, we have previously reported that the bias of the immune response is critical for the clearance of RABV from CNS tissues. We speculate that the bias of the immune response elicited by vaccination is also of importance for long-term protection. As previously reported and seen here, vaccination with RABV inactivated by UV or BPL induces a response producing significantly more IgG1 than IgG2a antibodies (Figure 2a). This is characteristic of a type-2 immune response. We therefore expected the IMOVAX ${ }^{\circledR}$ vaccine, which is BPL-inactivated, to induce the production of IgG1 antibodies. However, both IgG1 and IgG2a RABV-specific antibodies are seen after vaccination with $\operatorname{IMOVAX}^{\circledR}$ (Figure $2 \mathrm{~b}$ ), indicating that the response has mixed type-1 and type- 2 characteristics.

\subsection{Addition of Adjuvant to Inactivated Vaccine does not Promote Protection}

The mixed type-1/-2 response observed following immunization with the IMOVAX ${ }^{\circledR}$ vaccine raises questions about how this inactivated vaccine preparation stimulates Th1 cells. Is there a component with qualities resembling an adjuvant? These immunostimulatory reagents are extensively used for vaccination and have occasionally been reported to promote type- 1 immunity. However, we show here that vaccination with UV-inactivated CVS-F3 RABV in Freund's complete adjuvant (CFA) does not protect mice from subsequent challenge with the lethal DRV4 virus (Figure 3a). The use of 
CFA in the vaccine evidently did not change the type-2 bias of the response as reflected by the higher levels of RABV-specific IgG1 antibodies produced (Figure 3b).

(a)

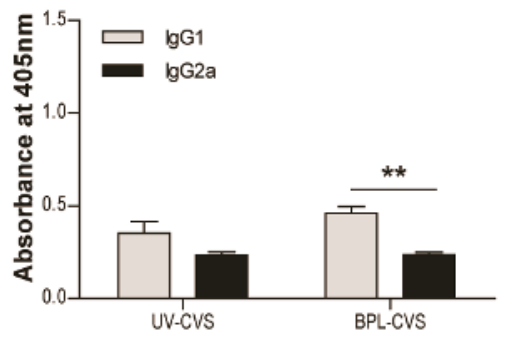

(b)

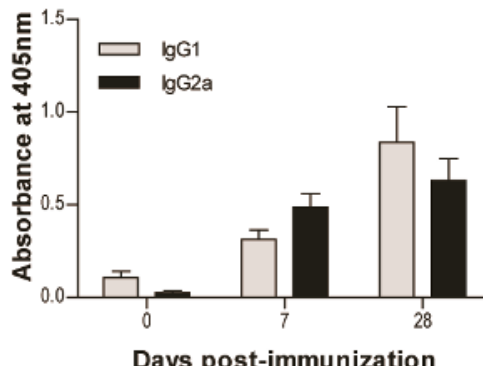

Days post-immunization

Figure 2. IMOVAX ${ }^{\circledR}$ is protective through the induction of a mixed Th1/Th2 immune response. Virus-specific $\mathrm{Ab}$ isotype was determined by ELISA 10 days following immunization with either $1 \times 10^{5}$ f.f.u. of UV- or BPL-inactivated CVS-F3 RABV (a) or $0.25 \mathrm{IU}$ of IMOVAX ${ }^{\circledR}(\mathbf{b})$. Results are expressed as mean absorbance \pm SEM in OD (dilution 1:20). Statistically significant differences between groups ( $n=5-10$ per group) are denoted as follows: ${ }^{* *} p \leq 0.005$.

(a)

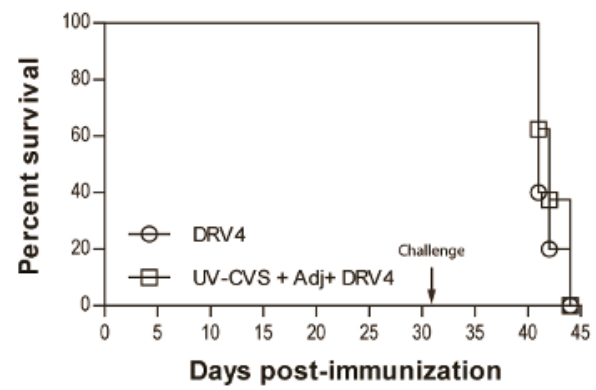

(b)

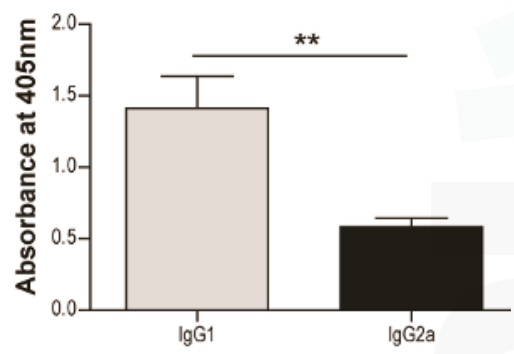

Figure 3. Adding adjuvant to UV-inactivated RABV does not induce protection. (a) C57BL/6 mice were immunized with $5 \times 10^{7}$ f.f.u. of UV-CVS-F3 mixed with CFA adjuvant, i.m.g. then challenged 31 days later with $1 \times 10^{5}$ f.f.u. of DRV4 i.n. and monitored for survival. Data are expressed as percent survival. (b) Virus-specific Ab isotyping was determined by ELISA 24 days post-immunization. Results are expressed as mean absorbance \pm SEM in OD (dilution 1:50). Statistically significant differences between groups ( $n=10$ per group) are denoted as follows: ${ }^{* *} p \leq 0.005$.

\subsection{Vaccination Efficacy is Dictated by the Immunization Regimen and the Challenge Route}

The survival of non-immunized mice infected with the SHBRV-17 RABV differs greatly according to the route of infection, with 33\%, 50\%, and 100\% mortality, for i.m.g (Figure 4a), i.n. (Figure 4b), and i.c. (Figure 4c) routes, respectively. However, regardless of the route of infection, immunization with a single dose of the live CVS-F3 RABV conferred superior protection $(90 \%-100 \%$ survival) against SHBRV-17 challenge 21 days later than immunization with the UV-inactivated CVS-F3 (Figure 4, top panels). The difference in protection against i.n. and i.c. immunization/challenge with SHBRV-17 persisted for at least 63 days post-immunization with survival of i.m.g., i.n., and ic. 
immunized/challenged mice respectively at $100 \%, 50 \%$, and $87.5 \%$ for those vaccinated with live CVS-F3 RABV, versus $87.5 \%, 12.5 \%$, and $37.5 \%$ for animals that had received UV-inactivated CVS-F3 (Figure 4, bottom panel).
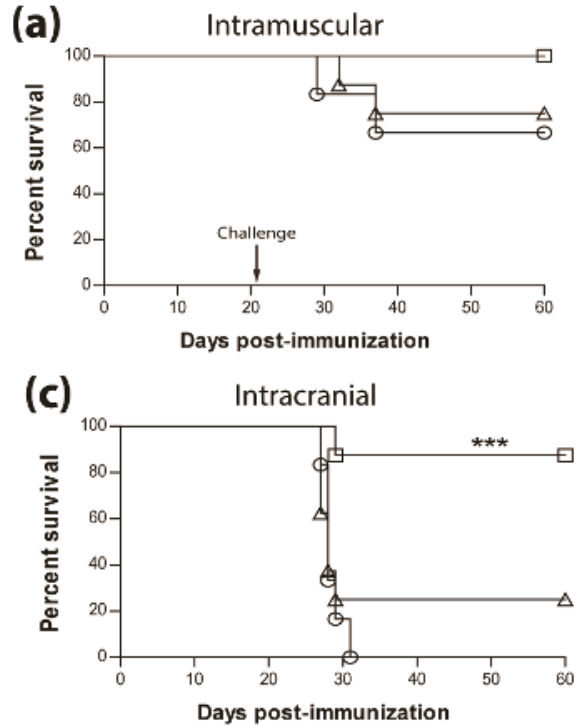

(e)

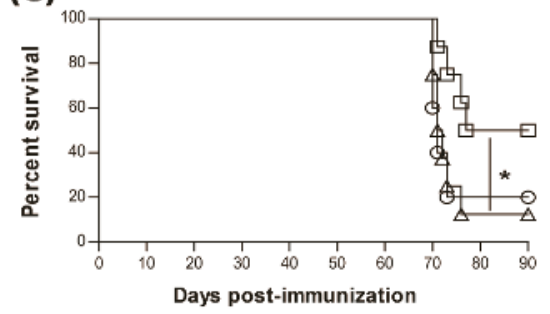

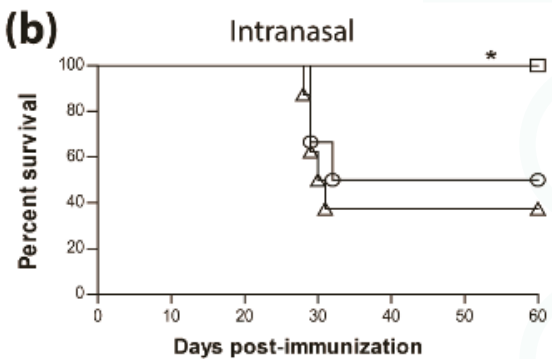

(d)

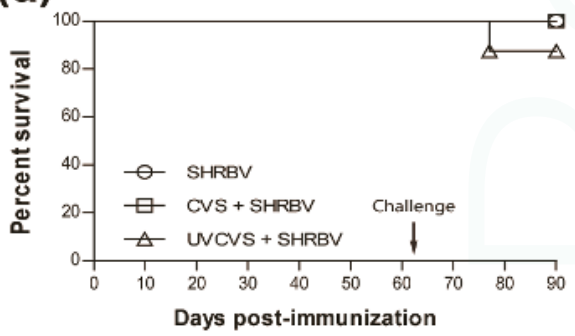

(f)

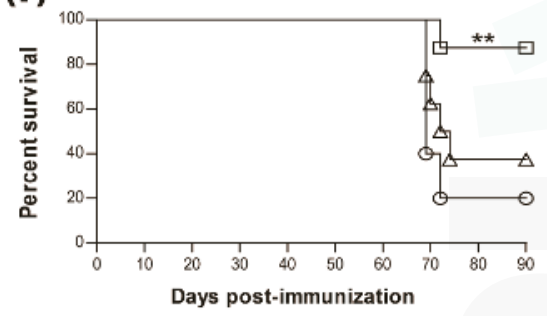

Figure 4. Single immunization with live-attenuated vaccine confer superior long-lasting protection against wild-type virus challenge. Swiss Webster mice were either mock-immunized or immunized with $1 \times 10^{5}$ f.f.u. of live-attenuated CVS-F3 or $1 \times 10^{8}$ f.f.u. of inactivated CVS-F3 (UV-CVS-F3) then challenged 21 (top row) or 63 (bottom row) days later with $1 \times 10^{4}$ f.f.u. of SHBRV-17 virus and monitored for survival. Data are expressed as percent survival ( $n=10$ per group). Animals were immunized either (a,d) intramuscularly in the gastrocnemius, $(\mathbf{b}, \mathbf{e})$ intranasally or $(\mathbf{c}, \mathbf{f})$ intracranially, then challenged with the corresponding route. Statistically significant differences between groups are denoted as follows: ${ }^{*} p \leq 0.01{ }^{* *} p \leq 0.005 ;{ }^{* * *} p \leq 0.001$.

\subsection{Type-1 Immunity is Critical for Protection AgainstWild-Type RABVInfection}

The results presented above as well as in our previous publications (e.g. reference [15]) indicate that a type-1 immune response is important in dealing with wild-type RABV that reaches the CNS. This is further illustrated in Figure 5a, where immunization with live-attenuated, but not UV-inactivated, RABV efficiently protects against i.n. infection with wildtype DRV4 RABV (80\% versus $20 \%$ survival). This is despite the production of levels of RABV-specific, type-2-associated IgG1 antibodies in the latter that are higher than the levels of type-1 IgG2a in mice that were vaccinated with the live-attenuated virus (Figure 5b). To determine if the prior induction of a type-2 immune 
response to $\mathrm{RABV}$ interferes with the induction of a more protective type- 1 response, mice that received UV-inactivated RABV were boosted with the virus in a live-attenuated format. Survival from an i.n. challenge with DRV4 was improved (from $20 \%$ to $50 \%$ ) but did not reach the level (80\%) of mice that were both primed and boosted with live-attenuated RABV (Figure $5 \mathrm{c}$ ). A change in the bias of RABV-specific serum antibodies from IgG1>IgG2a to IgG2a>IgG1 was seen when animals immunized with UV-inactivated RABV were boosted with the live-attenuated virus (compare Figure 5b,d).

\section{(a)}

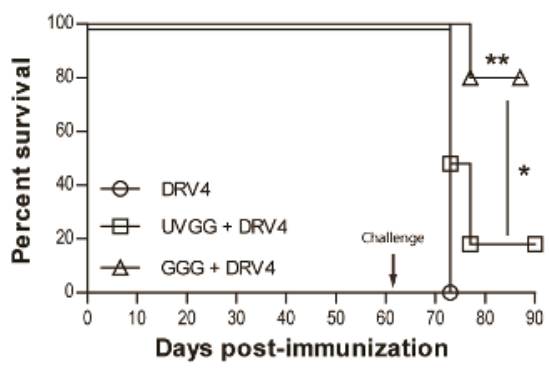

(c)

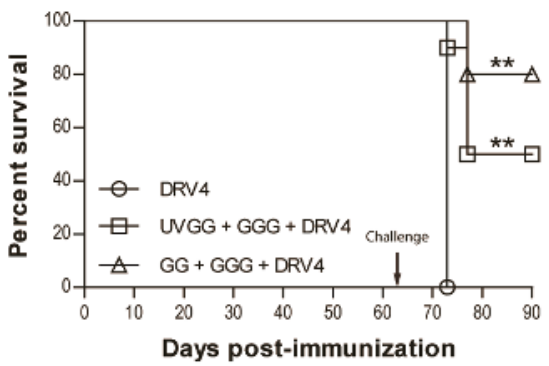

(b)

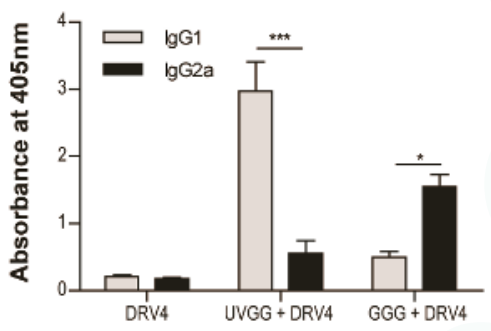

(d)

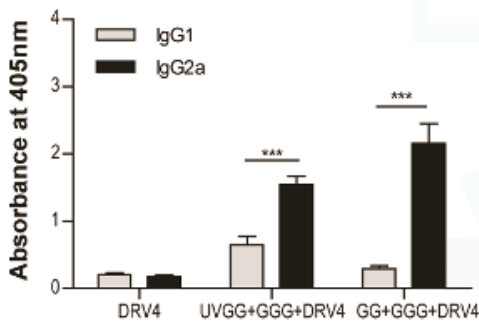

Figure 5. Live-attenuated RABV are protective through the induction of type- 1 immunity. C57BL/6 mice were (a) immunized with 3 doses of $1 \times 10^{6}$ f.f.u. of UV-GG or $1 \times 10^{5}$ f.f.u. of GGG i.m.g.; (c) immunized with $1 \times 10^{6}$ f.f.u. of UV-GG or $1 \times 10^{7}$ f.f.u. of GG followed by a boost of $1 \times 10^{5}$ f.f.u. of GGG 28 days later. All animals were then challenged 63 days later with $1 \times 10^{5}$ f.f.u. of DRV4 i.n. and monitored for survival. Data are expressed as percent survival ( $n=10$ per group). (b,d) Virus-specific $\mathrm{Ab}$ isotyping was determined by ELISA 42 days after immunization. Results are expressed as mean absorbance \pm SEM in OD (dilution 1:20). Statistically significant differences between groups $\left(n=10\right.$ per group) are denoted as follows: ${ }^{*} p \leq 0.01 ;{ }^{* *} p \leq 0.005 ;{ }^{* * *} p \leq 0.001$.

\section{Discussion}

As we previously reported, immunocompetent mice can clear attenuated RABV infection from brain tissues through the local activity of both humoral and cellular type-1 immune mechanisms $[14,15,25]$. Immune effector delivery across the blood-brain barrier (BBB) proves to be particularly important as this does not happen during wild-type RABV infection [24,26]. IFN- $\gamma$, a major product of type-1 immunity, is evidently important in RABV clearance from brain tissues through: (i) its induction of type-I interferons that control virus replication [13]; (ii) its contribution to the non-inflammatory changes in BBB function that promote immune cell infiltration [27]; and (iii) its role in driving the local production of VNA [14], which ultimately eliminates the virus from CNS tissues [25]. While the delivery of immune effectors across the BBB is a critical step, the type of immune 
cells delivered into CNS tissues is also important. CD4 ${ }^{+}$Th2 cells reach CNS tissues during attenuated RABV infection but are evidently non-functional in this environment [15].

The current study reinforces the importance of type- 1 immunity in rabies, not merely in the clearance of attenuated RABV but also in the prevention of wild-type RABV infection. Immunization with inactivated RABV induces a type-2 response with high levels of serum RABV-specific antibody but limited protection from an i.n. challenge dose of highly pathogenic DRV4, regardless of whether the inactivated vaccine is administered with CFA. The use of a live vaccine following initial immunization with a killed vaccine induces the production of IgG2a antibodies that are associated with type- 1 immunity and improves protection against an i.n. DRV4 challenge, but not to the extent provided by the use a live-attenuated vaccine alone. A comparison of the efficacy of immunization with live-attenuated versus inactivated RABV using the lethal SHBRV provides further insight into the differences in vaccination efficacy. SHBRV administered i.m. in the gastrocnemius is only mildly pathogenic, but lethal for around $80 \%$ of mice infected either i.n. or i.c. Infection with the live-attenuated CVS-F3 strain significantly improved survival of mice infected with SHBRV i.n. or i.c., while survival following immunization with inactivated CVS-F3 is only marginally improved in animals challenged i.c. It is also noteworthy that the superior protection against i.n. or i.c. challenge conferred by immunization with live-attenuated virus is consistent, independent of the mouse strain studied (C57BL/ 6 and Swiss Webster) and the RABV strains used for immunization (GG, GGG, CVS-F3) or challenge (DRV4, SHBRV-17).

Currently, rabies vaccines approved for human use are all produced with inactivated, cell culture-derived RABV. As expected, the commercial IMOVAX ${ }^{\circledR}$ vaccine, consisting of BPL inactivated Pitman-Moore RABV [21], protects 100\% of mice against i.m. challenge with DRV4 in the gastrocnemius. While inactivated virus is expected to induce a predominant type-2 response, as shown here for UV-inactivated CVS-F3 and GG as well as beta-propiolactone-inactivated CVS-F3 viruses, IMOVAX ${ }^{\circledR}$ was found to induce the production of RABV-specific antibodies, reflecting a more mixed type- 1 plus type- 2 response. These data support the predominance of type- 1 immunity protection, once triggered, over type- 2 immune responses during viral infection. Previously, it has been reported that $B$ cell hybridomas, produced from the peripheral blood mononuclear cells (PBMC) of human donors vaccinated with Rabivac ${ }^{\mathrm{TM}}$ (Behringwerke, Marburg, FRG), another vaccine based on inactivated Pitman-Moore RABV, largely elaborate IgG1 and IgG3 rabies VNA [28], reflecting type-1 immunity in humans. This suggests the possibility that either the virus strain or some element of the manufacturing process results in products with some type-1 immunostimulatory properties which are not present in the UV or beta-propiolactone-inactivated viruses studied here. We consider that the capacity to stimulate RABV-specific type-1 immunity is an important basis for an effective rabies vaccine.

Prior work in mice has concluded that adjuvant use with inactivated vaccine enhances immune protection against i.m. challenge with pathogenic RABV [29]. While it is expected that an adjuvant would enhance the immune response, we did not find that the use of CFA with UV-inactivated RABV improved the survival of mice challenged with DRV4 i.n. This suggests that the immune response elicited by inactivated RABV is unable to prevent virus spread in the CNS. It has also been found that rabies immunoglobulin must be administered in conjunction with inactivated vaccine to achieve $100 \%$ survival post-exposure [30]. Our finding that live-attenuated RABV vaccines are more effective in the induction of protection against i.n. and i.c. challenge with wild-type RABV provides an explanation as to why GGG [16] and other highly attenuated RABV such as ERAg333 [31] are effective in post-exposure regimens in the absence of added rabies VNA [16]. Infection with GGG would rapidly induce the IFN- $\gamma$-dependent immune mechanisms capable of preventing wild-type virus replication and trigger the processes that promote immune effector activity in CNS tissues. Thus, treatment with live-attenuated GGG can contain the virus until sufficient antibody production is elicited to mediate virus clearance. As supported by the current data and prior reports of the failure of late stage PEP [9], administration of an inactivated vaccine, and VNA is likely to only be effective if wild-type RABV has not yet reached CNS tissues. Based on the current data, a similar consideration holds for an 
immunized individual that is exposed to wild-type RABV by a means that introduces the virus in close proximity to the CNS. Pre-existing type-1 rabies immunity would be expected to be protective, but not a type-2 response.

While our data support, in principle, the use of live-attenuated RABV vaccines as alternatives to the inactivated preparations currently used for pre- and post-exposure rabies prophylaxis, there are several considerations for its use. Cost-effectiveness is likely to be excellent as considerably less virus and only a single dose is required to induce strong immunity. However, inactivated RABV are quite stable at different temperatures and live viruses are less so, unless prepared by a vaporization method [32]. Nevertheless, as found in this study, our live-attenuated RABV strain can retain sufficient infectivity to induce fully protective immunity after three weeks at $25^{\circ} \mathrm{C}$ without additional processing. In addition to efficacy, safety is the most important prerequisite for the use of a live attenuated virus in vaccination. In this regard, the GGG variant is a good candidate. This vaccine strain was reverse engineered [33] to increase the amount of the immunogenic glycoprotein expressed during infection [34]. GGG has proven nonpathogenic even for developmentally immunocompromised baby mice [16], and does not spread extensively into nervous system tissue [35]. Nevertheless, GGG infection induces immune mechanisms that can clear wildtype RABV from CNS tissues [36] and can be used to establish long-term protection against a wildtype RABV exposure targeting the CNS. Historically, vaccines such as the measles,mumps and rubella (MMR), based on live-attenuated viruses, have proven to be most effective with the benefits far outweighing potential risks. The safety of live-attenuated RABV vaccines in animal models has been well established. For example, GG has been found to be safe and effective in a target species [37]. The transition of live-attenuated RABV vaccines from animals to humans may be driven by the understanding that therapeutic intervention after the virus has entered peripheral nerves requires a type- 1 immune response.

Acknowledgments: This work was supported by National Institutes of Health GrantsAI083045 and AI093369 to D.C.H. Grant NCI 5 P30 CA056036 from the National Cancer Institute to the Sidney Kimmel Cancer Center provided support for the Laboratory Animal Facility Shared Resource used in the study.

Author Contributions: D.C.H. conceived and designed the experiments; J.L., S.G. and R.B.K. performed the experiments; A.L. and D.C.H. analyzed the data; A.L. and S.G. contributed reagents/materials/analysis tools; A.L. and D.C.H wrote the paper.

Conflicts of Interest: The authors declare no conflict of interest.

\section{References}

1. Afonso, C.L.; Amarasinghe, G.K.; Banyai, K.; Bao, Y.; Basler, C.F.; Bavari, S.; Bejerman, N.; Blasdell, K.R.; Briand, F.X.; Briese, T.; et al. Taxonomy of the order mononegavirales: Update 2016. Arch. Virol. 2016, 161, 2351-2360. [CrossRef] [PubMed]

2. Hampson, K.; Coudeville, L.; Lembo, T.; Sambo, M.; Kieffer, A.; Attlan, M.; Barrat, J.; Blanton, J.D.; Briggs, D.J.; Cleaveland, S.; et al. Estimating the global burden of endemic canine rabies. PLoS Neglect. Trop. Dis. 2015, 9, e0003709.

3. Crowcroft, N.S.; Thampi, N. The prevention and management of rabies. BMJ 2015, 350, g7827. [CrossRef] [PubMed]

4. Wallace, R.M.; Undurraga, E.A.; Blanton, J.D.; Cleaton, J.; Franka, R. Elimination of dog-mediated human rabies deaths by 2030: Needs assessment and alternatives for progress based on dog vaccination. Front. Vet. Sci. 2017, 4, 9. [CrossRef] [PubMed]

5. World Health Organization. Who Expert Committee on Biological Standardization; World Health Organization: Geneva, Switzerland, 2007; pp. 1-340.

6. Dodet, B.; Durrheim, D.N.; Rees, H. Rabies: Underused vaccines, unnecessary deaths. Vaccine 2014, 32, 2017-2019. [CrossRef] [PubMed]

7. Pichon, S.; Guinet-Morlot, F.; Minutello, M.; Donazzolo, Y.; Rouzier, R.; Chassard, D.; Fitoussi, S.; Hou, V. A serum-free, purified vero cell rabies vaccine is safe and as immunogenic as the reference vaccine verorab for pre-exposure use in healthy adults: Results from a randomized controlled phase-ii trial. Vaccine 2013, 31, 2295-2301. [CrossRef] [PubMed] 
8. Keates, L. Rabies vaccines: WHO position paper-recommendations. Vaccine 2010, 28, 7140-7142.

9. Wilde, H. Failures of post-exposure rabies prophylaxis. Vaccine 2007, 25, 7605-7609. [CrossRef] [PubMed]

10. Shantavasinkul, P.; Wilde, H. Postexposure prophylaxis for rabies in resource-limited/poor countries. Adv. Virus Res. 2011, 79, 291-307. [PubMed]

11. Wilde, H.; Lumlertdacha, B.; Meslin, F.X.; Ghai, S.; Hemachudha, T. Worldwide rabies deaths prevention-A focus on the current inadequacies in postexposure prophylaxis of animal bite victims. Vaccine 2016, 34, 187-189. [CrossRef] [PubMed]

12. Barkhouse, D.A.; Faber, M.; Hooper, D.C. Pre- and post-exposure safety and efficacy of attenuated rabies virus vaccines are enhanced by their expression of IFN-gamma. Virology 2015, 474, 174-180. [CrossRef] [PubMed]

13. Barkhouse, D.A.; Garcia, S.A.; Bongiorno, E.K.; Lebrun, A.; Faber, M.; Hooper, D.C. Expression of interferon gamma by a recombinant rabies virus strongly attenuates the pathogenicity of the virus via induction of type 1 interferon. J. Virol. 2015, 89, 312-322. [CrossRef] [PubMed]

14. Hooper, D.C.; Phares, T.W.; Fabis, M.J.; Roy, A. The production of antibody by invading B cells is required for the clearance of rabies virus from the central nervous system. PLoS Neglect. Trop. Dis. 2009, 3, e535. [CrossRef] [PubMed]

15. Lebrun, A.; Portocarrero, C.; Kean, R.B.; Barkhouse, D.A.; Faber, M.; Hooper, D.C. T-bet is required for the rapid clearance of attenuated rabies virus from central nervous system tissue. J. Immunol. 2015, 195, 4358-4368. [CrossRef] [PubMed]

16. Faber, M.; Li, J.; Kean, R.B.; Hooper, D.C.; Alugupalli, K.R.; Dietzschold, B. Effective preexposure and postexposure prophylaxis of rabies with a highly attenuated recombinant rabies virus. Pro. Natl. Acad. Sci. USA 2009, 106, 11300-11305. [CrossRef] [PubMed]

17. Li, J.; McGettigan, J.P.; Faber, M.; Schnell, M.J.; Dietzschold, B. Infection of monocytes or immature dendritic cells (DCS) with an attenuated rabies virus results in DC maturation and a strong activation of the nfkappab signaling pathway. Vaccine 2008, 26, 419-426. [CrossRef] [PubMed]

18. Dietzschold, B.; Morimoto, K.; Hooper, D.C.; Smith, J.S.; Rupprecht, C.E.; Koprowski, H. Genotypic and phenotypic diversity of rabies virus variants involved in human rabies: Implications for postexposure prophylaxis. J. Hum. Virol. 2000, 3, 50-57. [PubMed]

19. Dietzschold, B.; Wunner, W.H.; Wiktor, T.J.; Lopes, A.D.; Lafon, M.; Smith, C.L.; Koprowski, H. Characterization of an antigenic determinant of the glycoprotein that correlates with pathogenicity of rabies virus. Proc. Natl. Acad. Sci. USA 1983, 80, 70-74. [CrossRef]

20. Manning, S.E.; Rupprecht, C.E.; Fishbein, D.; Hanlon, C.A.; Lumlertdacha, B.; Guerra, M.; Meltzer, M.I.; Dhankhar, P.; Vaidya, S.A.; Jenkins, S.R.; et al. Human Rabies Prevention-United States, 2008: Recommendations of the Advisory Committee On Immunization Practices; MMWR. Morbidity and Mortality Weekly Report; Recommendations and Reports/Centers for Disease Control: Atlanta, GA, USA, 2008; 57, pp. 1-28.

21. Food and Drug Administration: Imovax. Available online: https://www.fda.gov/BiologicsBloodVaccines/ Vaccines/ApprovedProducts/ucm180097.htm (accessed on 4 April 2017).

22. Perrin, P.; Morgeaux, S. Inactivation of DNA by beta-propiolactone. Biologicals 1995, 23, 207-211. [CrossRef] [PubMed]

23. Wiktor, T.J.; Macfarlan, R.I.; Foggin, C.M.; Koprowski, H. Antigenic analysis of rabies and mokola virus from Zimbabwe using monoclonal antibodies. Dev. Biol. Stand. 1984, 57, 199-211.

24. Phares, T.W.; Kean, R.B.; Mikheeva, T.; Hooper, D.C. Regional differences in blood-brain barrier permeability changes and inflammation in the apathogenic clearance of virus from the central nervous system. J. Immunol. 2006, 176, 7666-7675. [CrossRef] [PubMed]

25. Hooper, D.C.; Morimoto, K.; Bette, M.; Weihe, E.; Koprowski, H.; Dietzschold, B. Collaboration of antibody and inflammation in clearance of rabies virus from the central nervous system. J. Virol. 1998, 72, 3711-3719. [PubMed]

26. Roy, A.; Phares, T.W.; Koprowski, H.; Hooper, D.C. Failure to open the blood-brain barrier and deliver immune effectors to central nervous system tissues leads to the lethal outcome of silver-haired bat rabies virus infection. J. Virol. 2007, 81, 1110-1118. [CrossRef] [PubMed] 
27. Phares, T.W.; Fabis, M.J.; Brimer, C.M.; Kean, R.B.; Hooper, D.C. A peroxynitrite-dependent pathway is responsible for blood-brain barrier permeability changes during a central nervous system inflammatory response: TNF-alpha is neither necessary nor sufficient. J. Immunol. 2007, 178, 7334-7343. [CrossRef] [PubMed]

28. Champion, J.M.; Kean, R.B.; Rupprecht, C.E.; Notkins, A.L.; Koprowski, H.; Dietzschold, B.; Hooper, D.C. The development of monoclonal human rabies virus-neutralizing antibodies as a substitute for pooled human immune globulin in the prophylactic treatment of rabies virus exposure. J. Immunol. Methods 2000, 235, 81-90. [CrossRef]

29. Zhang, Y.; Zhang, S.; Li, L.; Hu, R.; Lin, H.; Liu, H.; Liu, F.; Shao, H.; Liu, Y. Ineffectiveness of rabies vaccination alone for post-exposure protection against rabies infection in animal models. Antivir. Res. 2016, 135, 56-61. [CrossRef] [PubMed]

30. Zhang, Y.; Zhang, S.; Li, W.; Hu, Y.; Zhao, J.; Liu, F.; Lin, H.; Liu, Y.; Wang, L.; Xu, S.; et al. A novel rabies vaccine based-on toll-like receptor 3 (TLR3) agonist pika adjuvant exhibiting excellent safety and efficacy in animal studies. Virology 2016, 489, 165-172. [CrossRef] [PubMed]

31. Wu, X.; Franka, R.; Henderson, H.; Rupprecht, C.E. Live attenuated rabies virus co-infected with street rabies virus protects animals against rabies. Vaccine 2011, 29, 4195-4201. [CrossRef] [PubMed]

32. Smith, T.G.; Siirin, M.; Wu, X.; Hanlon, C.A.; Bronshtein, V. Rabies vaccine preserved by vaporization is thermostable and immunogenic. Vaccine 2015, 33, 2203-2206. [CrossRef] [PubMed]

33. Morimoto, K.; McGettigan, J.P.; Foley, H.D.; Hooper, D.C.; Dietzschold, B.; Schnell, M.J. Genetic engineering of live rabies vaccines. Vaccine 2001, 19, 3543-3551. [CrossRef]

34. Morimoto, K.; Hooper, D.C.; Spitsin, S.; Koprowski, H.; Dietzschold, B. Pathogenicity of different rabies virus variants inversely correlates with apoptosis and rabies virus glycoprotein expression in infected primary neuron cultures. J. Virol. 1999, 73, 510-518. [PubMed]

35. Schutsky, K.; Curtis, D.; Bongiorno, E.K.; Barkhouse, D.A.; Kean, R.B.; Dietzschold, B.; Hooper, D.C.; Faber, M. Intramuscular inoculation of mice with the live-attenuated recombinant rabies virus trigas results in a transient infection of the draining lymph nodes and a robust, long-lasting protective immune response against rabies. J. Virol. 2013, 87, 1834-1841. [CrossRef] [PubMed]

36. Li, J.; Ertel, A.; Portocarrero, C.; Barkhouse, D.A.; Dietzschold, B.; Hooper, D.C.; Faber, M. Postexposure treatment with the live-attenuated rabies virus (RV) vaccine trigas triggers the clearance of wild-type RV from the central nervous system (CNS) through the rapid induction of genes relevant to adaptive immunity in CNS tissues. J. Virol. 2012, 86, 3200-3210. [CrossRef] [PubMed]

37. Vos, A.; Kretzschmar, A.; Ortmann, S.; Lojkic, I.; Habla, C.; Muller, T.; Kaiser, C.; Hundt, B.; Schuster, P. Oral vaccination of captive small Indian mongoose (Herpestes auropunctatus) against rabies. J. Wildl. Dis. 2013, 49, 1033-1036. [CrossRef] [PubMed]

(C) 2017 by the authors. Licensee MDPI, Basel, Switzerland. This article is an open access article distributed under the terms and conditions of the Creative Commons Attribution (CC BY) license (http:/ / creativecommons.org/licenses/by/4.0/). 


\title{
In Vivo Efficacy of a Cocktail of Human Monoclonal Antibodies (CL184) Against Diverse North American Bat Rabies Virus Variants
}

\author{
Richard Franka ${ }^{1, *}$, William C. Carson ${ }^{1}$, James A. Ellison ${ }^{1}$, Steven T. Taylor ${ }^{2}$, Todd G. Smith ${ }^{1}$, \\ Natalia A. Kuzmina ${ }^{3}$, Ivan V. Kuzmin ${ }^{3}$, Wilfred E. Marissen ${ }^{4}$ and Charles E. Rupprecht ${ }^{5}$ \\ 1 Centers for Disease Control and Prevention, 1600 Clifton Rd, Atlanta, GA 30333, USA; \\ ioy8@cdc.gov (W.C.C.); hio6@cdc.gov (J.A.E.); ire2@cdc.gov (T.G.S.) \\ 2 East Tennessee State University, James H. Quillen College of Medicine, Johnson City, TN 37614, USA; \\ staylor.trevor@gmail.com \\ 3 University of Texas Medical Branch, 301 University Blvd, Galveston, TX 50555, USA; \\ natakuzmina@yandex.ru (N.A.K.); ivkuzmin@yandex.ru (I.V.K.) \\ 4 Crucell Holland BV, Archimedesweg 4, 2333 CN Leiden, The Netherlands; wmarissen@hotmail.com \\ 5 LYSSA LLC, Cummings, GA 30040, USA; charles_rupprecht@yahoo.com \\ * Correspondence: rfranka@cdc.gov; Tel.: +1-404-263-9810
}

Received: 3 July 2017; Accepted: 12 September 2017; Published: 20 September 2017

\begin{abstract}
Following rabies virus (RABV) exposure, a combination of thorough wound washing, multiple-dose vaccine administration and the local infiltration of rabies immune globulin (RIG) are essential components of modern post-exposure prophylaxis (PEP). Although modern cell-culture-based rabies vaccines are increasingly used in many countries, RIG is much less available. The prohibitive cost of polyclonal serum RIG products has prompted a search for alternatives and design of anti-RABV monoclonal antibodies (MAbs) that can be manufactured on a large scale with a consistent potency and lower production costs. Robust in vitro neutralization activity has been demonstrated for the CL184 MAb cocktail, a 1:1 protein mixture of two human anti-RABV MAbs (CR57/CR4098), against a large panel of RABV isolates. In this study, we used a hamster model to evaluate the efficacy of experimental PEP against a lethal challenge. Various doses of CL184 and commercial rabies vaccine were assessed for the ability to protect against lethal infection with representatives of four distinct bat RABV lineages of public health relevance: silver-haired bat (Ln RABV); western canyon bat (Ph RABV); big brown bat (Ef-w1 RABV) and Mexican free-tailed bat RABV (Tb RABV). $42-100 \%$ of animals survived bat RABV infection when CL184 (in combination with the vaccine) was administered. A dose-response relationship was observed with decreasing doses of CL184 resulting in increasing mortality. Importantly, CL184 was highly effective in neutralizing and clearing Ph RABV in vivo, even though CR4098 does not neutralize this virus in vitro. By comparison, $19-95 \%$ survivorship was observed if human RIG (20 IU $/ \mathrm{kg}$ ) and vaccine were used following challenge with different bat viruses. Based on our results, CL184 represents an efficacious alternative for RIG. Both large-scale and lower cost production could ensure better availability and affordability of this critical life-saving biologic in rabies enzootic countries and as such, significantly contribute to the reduction of human rabies deaths globally.
\end{abstract}

Keywords: bat viral diseases; monoclonal antibody; immune globulin; lyssavirus; post-exposure prophylaxis; rabies; vaccine; zoonosis

\section{Introduction}

Rabies is an acute progressive encephalitis caused by lyssaviruses. Despite significant progress in our understanding of rabies pathobiology and epidemiology, and major advancements in the 
development of safe and effective biologics for disease prevention, this neglected zoonosis causes approximately 60,000 human deaths annually [1,2]. Although dogs are the major global reservoir for rabies virus (RABV), bats are responsible for the majority of human rabies fatalities in the Americas, Australia and Western and Central Europe. Regardless of the source of viral exposure, human rabies is preventable with proper wound care, prompt administration of modern vaccine and rabies immune globulin (RIG) [3,4]. Over the past several decades, post-exposure prophylaxis (PEP) schedules have evolved, encompassing fewer doses of both intramuscular (i.m.) as well as dose-sparing intradermal (i.d.) routes for administration of inactivated vaccine in as few as four doses. However, in the absence of licensed, commercially available, live-attenuated rabies vaccines, administration of RIG remains a critical component of PEP when inactivated vaccines are used $[3,5]$.

Current commercially available human and equine RIGs (HRIG, ERIG) are produced via pooling of human or equine plasma from immunized donors. Such production processes are associated with significant costs as well as with a possibility for transmission of potential bloodborne pathogens. Low-scale manufacturing, coupled with prohibitive cost, renders these immune globulins virtually unavailable for a majority of the population at risk in rabies-enzootic countries such as Asia and Africa, where the demand is the highest. New approaches, such as the use of hybridoma and humanization technologies, as well as use of single chain and VHH single domain antibodies, allow for cell culture or microbial expression systems production of monoclonal antibodies (MAbs), a promising alternative to polyclonal RIG with reduced risks for transmission of pathogens and large-scale production for a reduced cost. An inherent disadvantage of any MAb, however, is the specificity/affinity to a single binding epitope on a viral protein and consequently a diminished breadth of neutralizing activity for certain virus variants with amino acid substitutions that prevent MAb binding $[5,6]$.

The concept of using a cocktail of at least two MAbs, which target distinct, non-overlapping epitopes and that do not compete for binding to the RABV glycoprotein, as a potential alternative to RIG in PEP, has been widely accepted by the scientific community and also endorsed by WHO [3,7-10]. CL184 is a cocktail of two human MAbs (CR57 and CR4098), produced in human PER.C6 ${ }^{\circledR}$ cells. CL184 meets the criteria of binding to different epitopes (CR57 to epitope I, CR4098 to IIIa) and does not engender competition for the binding to RABV glycoprotein [8,11]. Previously, CR57, CR4098 and CL184 were evaluated in vitro against a panel of 26 distinct RABV isolates of public health and veterinary significance [12]. Although CR57 alone did not neutralize a south central skunk RABV and big brown bat RABV (Eptesicus fuscus western lineage 1, Ef-w1); and CR4098 alone did not neutralize mongoose RABV from South Africa, big brown bat RABV (Eptesicus fuscus eastern lineage 1, Ef-e1) or western canyon bat (Parastrellus hesperus from Arizona) [8], it was shown that the combination of these two MAbs, CL184, did provide neutralization of all 26 tested RABV isolates [12], as well as neutralization of an additional panel of $18 \mathrm{RABV}$ isolates (reported in this manuscript, Table 1). Furthermore, it was shown retrospectively that the lack of neutralization was related to epitope mutations introduced during cell culture amplification of the primary RABV isolates in the case of the south-central skunk RABV and the western canyon bat (Ph) RABV from Arizona (previously unpublished results). During one in vivo experiment, CL184, in combination with vaccine, protected hamsters against a lethal challenge with canine RABV, when administered $24 \mathrm{~h}$ after exposure, which was comparable with the results obtained for HRIG. In addition, CL184 was similar to HRIG in demonstrating a lack of interaction with vaccine [12]. These results suggested that CL184 could be an efficacious alternative to RIG as a part of rabies PEP. 
Table 1. Breadth of in vitro neutralization of HRIG, CL184 and its components against selected RABV isolates not covered by previous publications [12].

\begin{tabular}{ccccc}
\hline Lyssaviruses & HRIG & CR57 & CR4098 & CL184 \\
\hline Cow/dog, Sri Lanka & + & + & + & + \\
Dog, China 2005 & + & + & + & + \\
Dog, China (RV342) & + & + & + & + \\
Dog, India (I 148) & NT & NT & NT & + \\
Dog, India (I 151) & + & + & + & + \\
Dog, India (I 155) & + & + & + & NT \\
Dog, Philippines & + & + & + & + \\
Dog, Philippines (231/002) & + & + & + & NT \\
Dog, Tunisia & + & + & + & + \\
Human/dog, UK ex India & NT & NT & NT & + \\
Human/wolf, Russia Siberia (RVHN) & + & + & + & + \\
Mongoose, South Africa & + & + & - & + \\
Raccoon dog, Russia/Far East & + & + & + & + \\
Skunk, south central (SK4384) & + & + & + & + \\
Bat, Lasiurus borealis, TN (tn132) & NT & NT & NT & + \\
Bat, Lasiurus borealis, TN (tn269) & NT & NT & NT \\
Bat, Lasiurus borealis, VA (VA399) & NT & NT & NT & + \\
Bat, Lasiurus cinereus, TN & NT & NT & NT & + \\
\hline
\end{tabular}

* Imogam (Sanofi Pasteur); + indicates neutralization; NT—not tested.

Given the public health importance and the diversity of bat RABV present in the Americas, as well as the frequency and distribution of isolates with mutations in the MAb binding epitopes [13], the objective of this study was to evaluate the efficacy of CL184 against selected distinct bat RABV variants from North America (including those having a critical mutation in the MAb-binding site on the viral glycoprotein). The work was done using an animal model to compare vaccine protection using standard PEP (that included HRIG and commercial rabies vaccines) against those using CL184 in substitution for HRIG.

\section{Materials and Methods}

\subsection{Animals and Viruses}

Two-month-old female Syrian hamsters (Mesocricetus auratus), weighing approximately 100-120 g, were obtained from commercial suppliers and held for acclimation for 3-7 days upon arrival before use. Four different RABV isolates, representatives of distinct bat-associated RABV lineages (Figure 1), were used as a challenge in PEP experiments. An Eptesicus fuscus Ef-w1 RABV (A09-2400L), $10^{6.1} 50 \%$ mouse intracerebral lethal doses $\left(\mathrm{MICLD}_{50}\right) / 50 \mu \mathrm{L}$, was isolated from the salivary glands of a naturally infected gray fox (Urocyon cinereoargenteus) in Arizona. A Parastrellus hesperus RABV (Ph 3860 RABV, A07-0449), $10^{4}$ MICLD $_{50} / 50 \mu \mathrm{L}$, was isolated from the salivary glands of a naturally infected western canyon bat from Arizona. A Lasionycteris noctivigans RABV (WA Ln RABV, A04-0723 and A12-6377), $10^{6} \mathrm{MICLD}_{50} / 50 \mu \mathrm{L}$, was isolated from the salivary glands of a naturally infected silver-haired bat from Washington. A Tadarida brasiliensis RABV (Tb RABV, A14-3368 and TX3368), approximately $10^{5} \mathrm{TCID}_{50} / 100 \mu \mathrm{L}$, was isolated from the brain of a naturally infected Mexican free-tailed bat from Texas. All the original isolates were amplified in cell culture or following i.c. challenge in mice. The titer of viruses was determined in mouse neuroblastoma cell culture and expressed in the 50\% tissue culture infectious doses (TCID 50 ) or focus forming units (FFU) as well as via titration in mice $\left(M_{I C L D}\right)_{50}$ and relative pathogenicity was determined in naive Syrian hamsters prior to experimental prophylaxis. Only RABV isolates that produced at least $75 \%$ mortality in this model were selected for further experiments with a sample size determined accordingly. All animal handling and experimental procedures were undertaken in compliance with CDC Institutional Animal Care and Use Committee guidelines (protocols \#1593FRAHAMC and 2266FRAHAMC). 


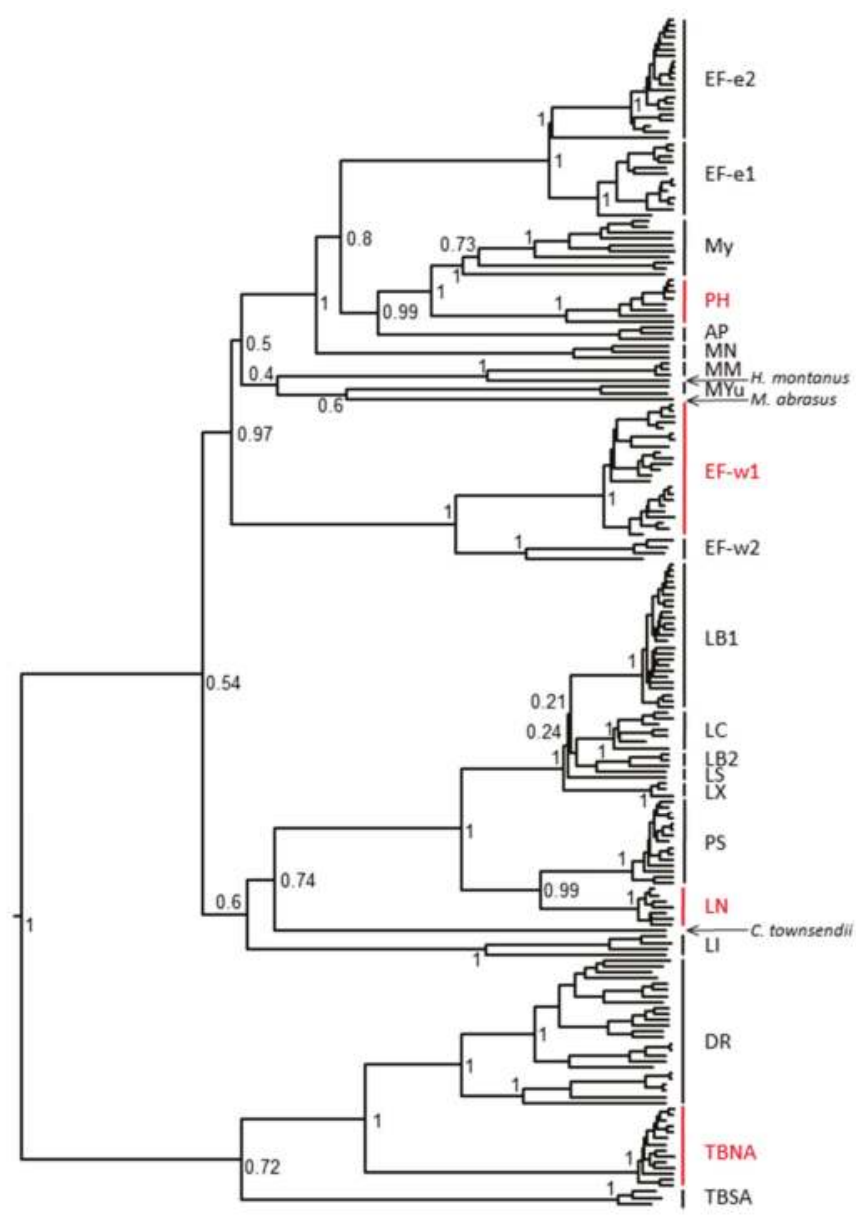

Figure 1. Phylogenetic relationship of rabies virus isolates used in this study with other representatives of bat RABV lineages. RABV used in this study are highlighted in red (PH-Parastrellus hesperus, Ef-w1-E. fuscus western lineage 1, LN-Lasionycteris noctivagans, TBNA-Tadarida brasiliensis North America).

\subsection{Biologics}

A volume of $50 \mu \mathrm{L}$ of the commercial inactivated human diploid cell vaccine (HDCV), Imovax ${ }^{\circledR}$ (Sanofi Pasteur, Lyon, France) or purified chicken embryo cell vaccine (PCECV), RabAvert ${ }^{\circledR}$ (Novartis Vaccines, Marburg, Germany; for Tb groups), with a minimum potency of $2.5 \mathrm{IU} / \mathrm{mL}$ was administered via the intramuscular (i.m.) route, according to the Essen (on days 0, 3, 7, 14 and 28) or modified Essen (on days $0,3,7$ and 14 ) regimen. In addition, $50 \mu \mathrm{L}\left(20 \mathrm{IU} / \mathrm{kg}\right.$ ) of HRIG (Imogam ${ }^{\circledR}$ Rabies-HT (Sanofi Pasteur, $150 \mathrm{IU} / \mathrm{mL}$ )) or 6, 12, 16, 18 or $24 \mu \mathrm{g} / \mathrm{kg}$ of CL184 (mixture of CR57 and CR4098 in 1:1 protein ratio) was administered i.m. into the site of virus inoculation at day 0 .

In all of our experiments, the amount of MAbs administered was expressed in $\mu \mathrm{g} / \mathrm{kg}$ as opposed to IU $/ \mathrm{kg}$ standardly indicated for polyclonal RIG products. HRIG is a polyclonal product consisting of many non-specific proteins with a very small fraction of rabies-specific antibodies, and hence correlation between protein concentration $(\mu \mathrm{g} / \mathrm{kg}$ ) and rabies virus specific neutralization $(\mathrm{IU} / \mathrm{kg})$ could not easily be established. In contrast, cell cultures producing only one anti-rabies MAb combined 
with protein purification techniques result in highly purified MAb devoid of other contaminants. Hence, such antibodies can be accurately quantified and thus dosed on basis of $\mu \mathrm{g} / \mathrm{kg}$, thereby excluding dosing variability as a result of inconsistency in potency measurements.

\subsection{Experimental Design}

The calculations of group sample sizes for each individual RABV isolate were based on statistical analysis and taking into account the mortality of naïve (non-treated) hamsters during preliminary experiments. To achieve the statistical power required to demonstrate the potential added benefit of tested biologics, we selected a cutoff in mortality of $\geq 75 \%$. If mortality was $100 \%$ in RABV-challenged hamsters (via a titration experiment), a group size of 12 animals was considered adequate and selected for consequent experiments. If, however, the mortality of naïve animals was $<100 \%$ but $>75 \%$, a group size of 21 animals was selected as adequate for comparative non-inferiority non-clinical experiments.

\subsection{Model Validation/Post-Exposure Prophylaxis (PEP) Initiation Determination}

Prior to the evaluation of PEP efficacy, determination of the PEP initiation window was conducted. Approximately two-month-old female Syrian hamsters ( $n=12$ or 21) were assigned randomly to experimental groups and infected into the left gastrocnemius muscle with an expected lethal dose of RABV (Ef-w1 RABV, Ph 3860, WA Ln, Tb RABV, based upon prior observations; unpublished data). Thereafter, PEP was initiated 2, 6 or $24 \mathrm{~h}$ following the challenge. On days 0 (set as the day of PEP initiation), 3, 7, 14, +/ - 28 the animals received a dose of rabies vaccine (HDCV for Ef-w1, Ph and WA Ln; and PCECV for Tb) applied into the right gastrocnemius muscle. In addition, HRIG at a dose of $20 \mathrm{IU} / \mathrm{kg}$ was administered at the initiation of PEP into the same i.m. location as virus challenge. For comparison, besides a control (PBS only) group, a vaccine-only group was included with the same time windows of PEP initiation. Monitoring was the same as below for efficacy experiments.

\subsection{Evaluation of the Efficacy of HRIG/Vaccine versus CL184/Vaccine during PEP}

Female Syrian hamsters ( $n=12$ or 21 ) were assigned randomly to experimental groups and infected in the left gastrocnemius muscle with a lethal dose of RABV. Timeline for challenge and initiation of PEP, as well as viral dose used, were selected based on the model validation experiments and prior experimental data regarding particular virus pathobiology in hamster model. The PEP was initiated $24 \mathrm{~h}$ (Ln, Ph and Ef-w1 RABV) or $2 \mathrm{~h}$ post infection (p.i.) (Tb RABV). On days 0, 3, 7, 14, and 28 the animals received a dose of rabies vaccine. In addition, $50 \mu \mathrm{L}$ of HRIG at $20 \mathrm{IU} / \mathrm{kg}$ or $50 \mu \mathrm{L}$ of different doses of CL184 at (6,12 or $16 \mu \mathrm{g} / \mathrm{kg}$ for Ln, Ph and Ef-w1 RABV or 12, 18 and $24 \mu \mathrm{g} / \mathrm{kg}$ for $\mathrm{Tb}$ RABV), were administered i.m. at the site of virus inoculation on day 0 . The animals were followed for 45 days and their clinical signs were monitored. All animals developing any specific signs of rabies were euthanized immediately according to an IACUC approved clinical score. Brains were removed at necropsy and subjected to detection of rabies virus antigens by the direct fluorescent antibody (DFA) test, as described below. Similarly, all animals surviving at the end of the experimental period were euthanized and their brains examined for the presence of RABV antigens.

\subsection{Laboratory Methods}

\subsubsection{Direct Fluorescent Antibody (DFA) Test}

The RABV antigens were detected in brain samples using the DFA test [14] with a fluorescein-isothiocyanate (FITC)-conjugated anti-RABV MAb (Fujirebio Diagnostics, Inc., Malvern, PA, USA).

\subsubsection{Rapid Fluorescent Focus Inhibition Test (RFFIT)}

The rapid fluorescent focus inhibition test (RFFIT) was performed according to a standard, previously described protocol [15]. 
2.6.3. Reverse Transcription Polymerase Chain Reaction (RT-PCR), Hemi-Nested RT-PCR (hnRT-PCR) and Sequencing

To confirm identity of RABV in central nervous system (CNS) tissue of euthanized animals with the initial inoculum and to identify any potential selection of escape mutations, total RNA was extracted from the CNS tissue samples using TRIZol reagent (Ambion, Carlsbad, CA, USA) according to the manufacturer's recommendations. The RT-PCR was performed as described elsewhere [16]. The RT-PCR products were purified and subjected to direct sequencing on an ABI 3730 DNA Sequencer (Applied Biosystems, Carlsbad, CA, USA). The complete and partial nucleotide G gene sequences were assembled and converted into amino acid sequences using the Bio Edit program, v.7 (Ibis Biosciences, Carlsbad, CA, USA) [17]. Amino acid sequences of the aligned MAb binding epitopes were compared across the dataset.

\subsection{Statistical Analysis}

Kaplan-Meier survival curves were calculated in the Statistical Analysis Software (SAS, version 9.2. SAS Institute Inc., Cary, NC, USA). The log-rank test was used to test differences between group survival distributions. The null hypothesis of identical survival functions was rejected at $p<0.05$. GraphPad Prism, version 7 (GraphPad Software, La Jolla, CA, USA) was used to create survival curve graphs.

\section{Results}

\subsection{Neutralization of Selected RABV Isolates In Vitro}

An additional set of 18 RABV isolates of public health importance from Africa, Asia and Americas were tested for neutralization to complement the initial panel of $26 \mathrm{RABV}$ isolates [12]. Twelve of the isolates were tested with CR57, CR4098, and HRIG (Imogam), and all isolates were neutralized with the exception of one, South Africa mongoose RABV, which was not neutralized by CR4098 (Table 1). This RABV isolate contains a N336D mutation in its glycoprotein which explains the observed lack of neutralization (data not shown). Further, 16 of 18 RABV isolates were tested and were shown to be efficiently neutralized by CL184 (Table 1).

\subsection{Model Validation/PEP Initiation Window}

In the experiments dedicated to the determination of PEP initiation window, survivorship of hamsters in control (placebo) groups was $8.3 \%$ for the Ln RABV, $0 \%$ for the Ph RABV, and $16.7 \%$ for the Ef-w1 RABV challenge. In contrast, in the vaccine-only group with PEP initiated $6 \mathrm{~h}$ p.i. the survivorship was $16.7 \%, 4.8 \%, 8.3 \%$, whereas with PEP initiated 24 h p.i. it was $25 \%, 19 \%, 16.7 \%$ for these viruses, respectively (Table 2, Figure 2).

When HRIG + HDCV were administered $6 \mathrm{~h}$ p.i., $83.3 \%, 57 \%$ and $75 \%$ of experimental animals survived in the Ln RABV, Ph RABV, Ef-w1 RABV groups, respectively. Similarly, 83.3\%, 66.7\% and 91.7\% of animals survived challenge with the Ln RABV, Ph RABV and Ef-w1 RABV, respectively, when HRIG and vaccine were administered $24 \mathrm{~h}$ p.i.

In the experiment with the Tb RABV, $0 \%$ survivorship was observed in the control as well as in the vaccine-only and in the HRIG + PCECV groups when biologics were administered $2 \mathrm{~h}$ p.i. (Table 2, Figure 2). 
Table 2. Validation of animal model and postexposure prophylaxis (PEP) initiation ( $p$-values based on log-rank Mantel-Cox test, comparing CL184 with standard PEP regimen 20IU/kg HRIG/vaccine).

\begin{tabular}{|c|c|c|c|c|c|c|c|c|}
\hline \multirow[b]{2}{*}{ Group } & \multicolumn{8}{|c|}{ Survival after 45 days observation } \\
\hline & $\operatorname{Ln}(\%)$ & $p$-Value * & $\mathrm{Ph}(\%)$ & $p$-Value & Ef-w1 (\%) & $p$-Value & $\operatorname{Tb}(\%) \ddagger$ & $p$-Value \\
\hline Control (PBS only) & 8.3 & - & 0 & - & 16.7 & - & 0 & - \\
\hline Vaccine only, 6 h p.i. & 16.7 & 0.9984 & 4.8 & 0.5224 & 8.3 & 0.0023 & 0 & 0.8619 \\
\hline Vaccine only, 24 h p.i. & 25 & 0.5174 & 19 & 0.6200 & 16.7 & 0.3391 & NA & \\
\hline HRIG/vaccine, 6 h p.i. & 83.3 & $\begin{array}{l}0.0002 \\
0.0007\end{array}$ & 57 & $\begin{array}{l}<0.0001 \\
<0.0001\end{array}$ & 75 & $\begin{array}{l}0.0005 \\
0.0002\end{array}$ & 0 & $\begin{array}{l}0.3901 \\
0.3161\end{array}$ \\
\hline HRIG/vaccine, 24 h p.i. & 83.3 & $\begin{array}{c}<0.0001 \\
0.0023\end{array}$ & 66.7 & $\begin{array}{c}<0.0001 \\
0.0002\end{array}$ & 91.7 & $\begin{array}{c}<0.0001 \\
0.0001\end{array}$ & NA & - \\
\hline
\end{tabular}

* $p$-Value for vaccine-only group is comparison to control; HRIG/vaccine groups, first $p$-value is comparison to control group and second is comparison to vaccine-only group. (Ph—Parastrellus hesperus, Ef-w1-Eptesicus fuscus western lineage 1 , Ln—Lasionycteris noctivagans, Tb-Tadarida brasiliensis North America). ${ }^{\ddagger}$ Groups challenged with $\mathrm{Tb}$ RABV were administered PEP at $2 \mathrm{~h}$ p.i. with PCECV vaccine.
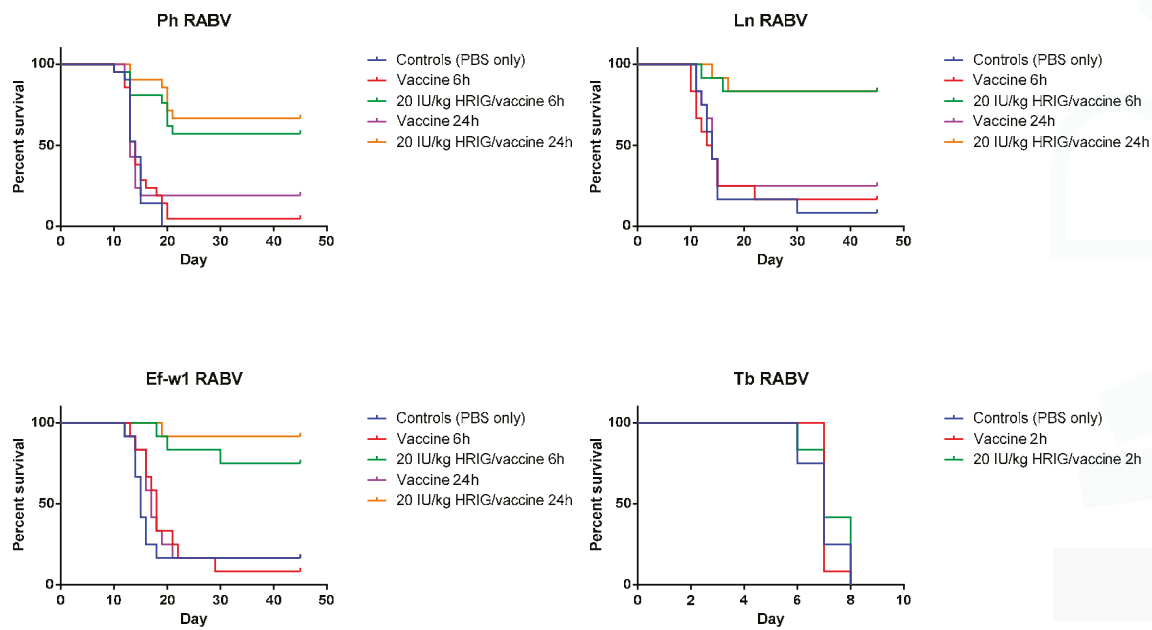

Figure 2. Validation of model and PEP initiation-Kaplan-Meier survival curves for Syrian hamsters after infection with bat rabies viruses. Hamsters ( $n=12$ or 21 per group) infected with the indicated RABV isolate 2, 6, or $24 \mathrm{~h}$ prior to intervention, received PEP consisting of either vaccine only (HDCV or PCECV) or vaccine in combination with $20 \mathrm{IU} / \mathrm{kg}$ HRIG.

\subsection{Evaluation of the Efficacy of HRIG/Vaccine versus CL184/Vaccine during PEP}

In the experimental evaluation of the efficacy of biologics when administered $24 \mathrm{~h}$ p.i., Ln RABV, HRIG $(20 \mathrm{IU} / \mathrm{kg})+$ rabies vaccine $(\mathrm{HDCV})$ resulted in $58 \%$ survival, whereas survival of animals in groups treated with $6 \mu \mathrm{g} / \mathrm{kg}, 12 \mu \mathrm{g} / \mathrm{kg}$, or $16 \mu \mathrm{g} / \mathrm{kg}$ of CL184, $42 \%, 50 \%$ and $67 \%$ survived, respectively (Table 3, Figure 3). In a mock-control group and in the vaccine-only group, $11 \%$ and $25 \%$ of experimental animals, respectively, survived the challenge.

In the experiment where a Ph RABV isolate was used, administration of HRIG $(20 \mathrm{IU} / \mathrm{kg})+$ HDCV resulted in 19\% survival whereas survival in groups treated with $6 \mu \mathrm{g} / \mathrm{kg}, 12 \mu \mathrm{g} / \mathrm{kg}$ and $16 \mu \mathrm{g} / \mathrm{kg}$ of CL184 was $57 \%, 48 \%$ and $57 \%$, respectively (Table 4, Figure 3). In contrast, survivorship of $17 \%$ and $0 \%$ was observed in the mock-control and in the vaccine-only group, respectively, following Ph RABV challenge. 
Table 3. Evaluation of the efficacy of CL184/vaccine during PEP ( $p$-values based on log-rank Mantel-Cox test, comparing CL184 with standard PEP regimen 20 IU/kg HRIG/vaccine).

\begin{tabular}{|c|c|c|c|c|c|c|c|c|}
\hline \multirow[b]{2}{*}{ Groups } & \multicolumn{8}{|c|}{ Survival after 45 Days Observation } \\
\hline & $\operatorname{Ln}(\%)$ & $p$-Value * & $\mathrm{Ph}(\%)$ & $p$-Value & Ef-w1 (\%) & $p$-Value & $\mathrm{Tb} \ddagger(\%)$ & $p$-Value \\
\hline Control (PBS only) & 11.1 & - & 16.7 & - & 33.3 & - & 0 & - \\
\hline Vaccine only & 25 & 0.3630 & 0 & 0.0034 & 38.1 & 0.8464 & 8.3 & 0.6668 \\
\hline $20 \mathrm{IU} / \mathrm{kg}$ HRIG/vaccine & 58.3 & $\begin{array}{l}0.0430 \\
0.1477\end{array}$ & 19 & $\begin{array}{l}0.8705 \\
0.0003\end{array}$ & 95.2 & $\begin{array}{l}<0.0001 \\
<0.0001\end{array}$ & 66.7 & $\begin{array}{l}0.0007 \\
0.0006\end{array}$ \\
\hline $24 \mu \mathrm{g} / \mathrm{kg}$ CL184/vaccine & NA & - & NA & - & NA & - & 100 & 0.0319 \\
\hline $18 \mu \mathrm{g} / \mathrm{kg}$ CL184/vaccine & NA & - & NA & - & NA & - & 83.3 & 0.3959 \\
\hline $16 \mu \mathrm{g} / \mathrm{kg}$ CL184/ vaccine & 66.7 & 0.5951 & 57.1 & 0.0177 & 100 & 0.3173 & NA & - \\
\hline $12 \mu \mathrm{g} / \mathrm{kg}$ CL184/ vaccine & 50 & 0.8931 & 47.6 & 0.0699 & 95.2 & 0.9862 & 66.7 & 0.9483 \\
\hline $6 \mu \mathrm{g} / \mathrm{kg}$ CL184/ vaccine & 41.7 & 0.5257 & 57.1 & 0.0062 & 85.7 & 0.2847 & NA & - \\
\hline
\end{tabular}

$* p$-Value for vaccine-only group is comparison to control; HRIG/vaccine groups, first $p$-value is comparison to control group and second is comparison to vaccine-only group; CL184/vaccine groups is comparison to HRIG/vaccine group. (Ph-Parastrellus hesperus, Ef-w1-Eptesicus fuscus western lineage 1, Ln-Lasionycteris noctivagans, $\mathrm{Tb}-$ Tadarida brasiliensis North America). ${ }^{\ddagger}$ PCECV vaccine was used for Tb group while HDCV for Ef-w1, Ph and WA Ln.

Ph RABV (24h PEP)

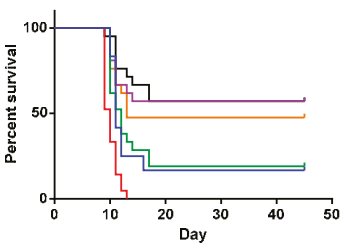

Ef-w1 RABV (24h PEP)

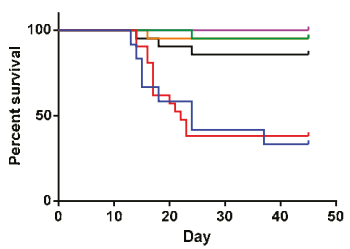

Ln RABV (24h PEP)
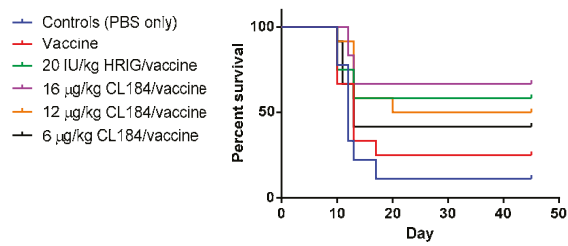

- Controls (PBS only)

- Vaccine

- 20 IU/kg HRIG/vacsine

- $16 \mu \mathrm{\mu g} / \mathrm{kg} \mathrm{CL} 184 / \mathrm{vaccine}$

- $12 \mu \mathrm{g} / \mathrm{kg}$ CL184/vaccine

- 6 ug $/ \mathrm{kg}$ CL184/vaccine

Figure 3. Evaluation of the efficacy of CL184/vaccine during PEP-Kaplan-Meier survival curves for Syrian hamsters after infection with bat rabies viruses. Hamsters ( $n=12$ or 21 per group) infected with a RABV isolate 2 or $24 \mathrm{~h}$ prior to intervention received PEP as outlined in Materials and Methods. Hamsters received $20 \mathrm{IU} / \mathrm{kg}$ HRIG or CL184 at a dosage of 6, 12 or $16 \mu \mathrm{g} / \mathrm{kg}$ for the Ln, Ph and Ef-w1 RABV or CL184 at a dosage of 12,18 and $24 \mu \mathrm{g} / \mathrm{kg}$ for the Tb RABV.

Table 4. Bat RABV isolates used in the animal studies.

\begin{tabular}{ccccc}
\hline RABV Isolate & $\begin{array}{c}\text { CR57 Epitope } \\
\mathbf{( 2 2 6 - 2 3 1 )}\end{array}$ & $\begin{array}{c}\text { CR4098 Epitope } \\
\mathbf{( 3 3 0 - 3 3 8 )}\end{array}$ & $\begin{array}{c}\text { CR57 } \\
\text { Neutralization }\end{array}$ & $\begin{array}{c}\text { CR4098 } \\
\text { Neutralization }\end{array}$ \\
\hline Bat, Lasionycteris noctivagans & KLCGVP & KSVRTWNEV & Yes & Yes \\
Bat, Parastrellus hesperus & KLCGVP & KSVRTWNET * & Yes & No \\
Bat, Eptesicus fuscus w1 lineage $\$$ & KLCGVP & KSIRTWNEI ‡ & Yes & Yes \\
Bat, Tadarida brasiliensis & KLCGVS & KSVRTWNEI & Yes & Yes \\
\hline
\end{tabular}

* Ph 3860 RABV isolate used in our study has I338T mutation in CR4098 epitope precluding its neutralization by that particular MAb. We used this mutation (resulting from cell culture passage) as a model to test CL184 in vivo against virus which is not neutralized in vitro by one MAb from the cocktail. $¥$ Although some naturally-occurring Eptesicus fuscus Ef isolates have N336D mutation in the antigenic site III precluding neutralization of CR4098, we have not had that particular isolate available for in vivo experiments. Our isolate with N336 was neutralized by both CR57 and CR4098. ${ }^{\S}$ Isolated from gray fox, Urocyon cinereoargenteus. 
Combination of HRIG + HDCV resulted in 95\% survivorship when administered $24 \mathrm{~h}$ p.i. with the Ef-w1 RABV variant, whereas administration of $6 \mu \mathrm{g} / \mathrm{kg}, 12 \mu \mathrm{g} / \mathrm{kg}$ and $16 \mu \mathrm{g} / \mathrm{kg}$ of CL184, in combination with HDCV, resulted in $86 \%, 95 \%$ and $100 \%$ survivorship, respectively (Figure 3). A survivorship of $33 \%$ and $38 \%$ was observed in the mock-control and in the vaccine-only groups, respectively, for this virus (Table 3, Figure 3).

When PEP was initiated $2 \mathrm{~h}$ p.i. with Tb RABV, $67 \%$ of animals survived in the HRIG + PCECV group, whereas administration of $12 \mu \mathrm{g} / \mathrm{kg}, 16 \mu \mathrm{g} / \mathrm{kg}$ and $24 \mu \mathrm{g} / \mathrm{kg}$ of CL184, in combination with PCECV resulted in $67 \%, 83 \%$ and $100 \%$ survivorship, respectively (Figure 3). A survivorship of $0 \%$ and $8 \%$ was observed in the mock-control and the vaccine-only group.

\subsection{Sequence Analyses of the Original Inoculum and Virus Detected in CNS of Experimental Animals}

When $\mathrm{G}$ nucleotide sequences of the original $\mathrm{Ph} 3860$ isolate and its cell culture passages were compared to each other, it was confirmed that the first cell culture passage contained a mix of two variants, I338 and T338 (within the CR4098 binding epitope) and that consensus sequences of viral populations from further cell culture passages demonstrated solely the T338 variant. Virus recovered from the infected hamsters (following experimental challenge) resulted in a detection of either I338, or T338, or both phenotypes irrespective of biologics used in PEP and in the mock-control groups. All other output viruses matched the input virus demonstrating CL184 did not select for escape mutations. Phylogenetic relationship of Ph 3860 as well as other bat RABV isolates used in this study to other relevant bat RABV viruses is depicted in Figure 1 and relevant epitopes for virus variants used in this experiment are shown in Table 4.

\section{Discussion and Conclusions}

The scarcity of conventional RIG prompted research and development of alternatives. Multiple MAbs and their combinations have been evaluated in vitro and in vivo during the past decade as potential replacements for RIG (e.g., SO57 [7]; CR57, CR4098, [8,9,12]; RAB1 [18]; E559.9.14, 1112-1, 62-71-3, M727-5-1, and M777-16-3 [19]; RVC20-RVC58 [3,10,20]).

A common denominator for all individual MAbs is their limited breadth of neutralization, inevitably resulting in the inability of one MAb to neutralize the entire spectrum of RABV variants. However, as previous in vivo experiments of $[8,11]$ have demonstrated, this can be compensated by a combination of two MAbs, which bind to non-overlapping epitopes.

Our study has shown that in cases of severe exposures to bat RABV (i.e., high virus doses delivered intramuscularly), administration of either HRIG or CL184, is critical for rapid peripheral neutralization and clearance of rabies virus. In both mock-control (placebo) and inactivated rabies vaccine-only groups, the mortality of $62-100 \%$ was observed (Tables 3 and 4 ). In contrast, CL184, when administered in a dose $\geq 6 \mu \mathrm{g} / \mathrm{kg}$ in combination with vaccine, provided a significant benefit compared to vaccine alone.

In addition, the efficacy of CL184 plus vaccine in a dose $\geq 12 \mu \mathrm{g} / \mathrm{kg}$ was not inferior when compared to PEP consisting of HRIG (20 IU/kg) and rabies vaccine (HDCV), with 50-67\% of experimental animals surviving a Ln RABV challenge, 48-57\% surviving Ph RABV challenge, $95-100 \%$ surviving Ef-w1 challenge, and $67-100 \%$ surviving a Tb RABV challenge (Table 4, Figure 3 ).

Importantly, our experiments have shown that CL184 is efficacious against challenge with $\mathrm{Ph}$ RABV, which was not neutralized in vivo by the MAb CR4098, a component of the CL184 cocktail, given the mutation I338T (Tables 1, 2 and 4; Figure 3). Of note, this mutation was introduced during cell culture amplification of the primary Ph RABV isolate as indicated by G gene sequencing of a series of virus stocks. Epitope mutations might result either from adaptation of the primary RABV isolates to cell culture as shown in the case of south central skunk RABV (Rupprecht, Marissen, personal communication). Alternatively, both sequence variants might be present in the original field isolate in different proportions. Although initially described as a result of selection of CVS rabies strain mutants following culture with neutralizing anti-glycoprotein antibodies [21], our study demonstrated that the 
I338T mutation affecting neutralization could also occur as a result of amplification in cell culture or in the laboratory rodent model without antibody-mediated selection pressure. Of note, 338T did not appear in consensus sequences of 10 natural Ph RABV isolates (data not shown). The Ph 3860 virus with the predominant I338T substitution served as a good model to assess the in vivo efficacy of CL184 given that it was not neutralized in vitro by one of the cocktail MAbs.

Natural occurrence of RABV with mutation(s) in the MAb binding epitope is, however, critical for the assessment of the adequacy of a particular MAb or cocktail of MAbs to be used as PEP in a particular geographic area. Sequencing of epitopes has been shown to be a reliable predictor of MAb neutralization capacity in vitro and in vivo. As previously described [13], the binding epitope for CR57 is relatively conserved with only one isolate/sequence exception (frequency $0.1 \% ; 1 / 1042$, Chinese dog, SE Asia-2), the K226M substitution, shown to preclude binding (data not shown). However, this reported mutation is more likely to be a sequence error rather than representing a true natural isolate, as in more than 175 Chinese RABV isolates no critical mutation in the CR57 epitope was observed (data not shown). Although the frequency of substitutions precluding neutralization of MAb CR4098 in antigenic site III is higher (N336D, 63/1042, 6\%, including besides others big brown bat (Eptesicus fuscus) RABV from North America), our study showed that combining CR57 and CR4098 in a cocktail can effectively neutralize virus in vivo even if one of those MAbs does not neutralize it in vitro. Of note, CR4098 was still shown to bind to RABV glycoprotein harboring an N336D mutation [8] which could facilitate viral clearance in vivo. In addition, in neutralization experiments using a natural big brown bat (Eptesicus fuscus) RABV isolate harboring a N336D mutation, complete neutralization by CR4098 at $15 \mu \mathrm{g} / \mathrm{mL}$ was observed (data not shown). Overall, these findings emphasize the importance of WHO recommendations requiring inclusion of at least two MAbs [3] with non-overlapping epitopes in biologics for PEP as well as a need for continuous surveillance for natural occurrence of RABV isolates with mutations which may preclude MAb binding.

Although effective concentration of immune globulin in the circulation of individual experimental animals was not measured during the observation period, mortality and survivorship data demonstrated a dose effect, with lower Mab doses resulting in higher mortality.

Virulence of different RABV variants influences the efficacy of PEP. As demonstrated in this study, viruses which are more pathogenic in a particular model (e.g., Tb RABV) and possibly spread more rapidly towards the CNS, require an earlier initiation of PEP (2 hours p.i.) as compared to other viruses, for which PEP initiated 6 or $24 \mathrm{~h}$ p.i. still seemed to provide an adequate prophylactic effect within the hamster model (Table 4). Although pathogenesis is dependent on route, viral dose, host species and proximity the exposure site to the CNS, further studies may elucidate differences in the kinetics of peripheral neuronal entry and axonal spread of various RABVs.

In this study, the efficacy of CL184, when administered in a dose $\geq 12 \mu \mathrm{g} / \mathrm{kg}$ in combination with a commercial inactivated rabies vaccine, was not inferior to PEP consisting of HRIG and the same vaccine. As such, CL184 presents a promising, non-inferior alternative for RIG during rabies PEP. Large scale and lower cost production of MAbs could ensure availability and affordability of this critical life-saving biologic in rabies enzootic countries and would significantly contribute to the reduction of human rabies deaths globally.

Acknowledgments: Research work was supported by cooperative research agreement between Centers for Disease Control and Prevention and Crucell.

Author Contributions: Richard Franka was a primary investigator and together with Charles Rupprecht and Wilfred Marissen conceived and designed the experiments; Richard Franka, William C. Carson, James A. Ellison, Steven T. Taylor, Todd G. Smith, Natalia A. Kuzmina, Ivan V. Kuzmin and Charles E. Rupprecht performed the experiments; Richard Franka, Todd G. Smith, Natalia A. Kuzmina, Ivan V. Kuzmin, Wilfred E. Marissen and Charles E. Rupprecht analyzed the data; all authors contributed to writing of the manuscript.

Conflicts of Interest: The authors declare no conflict of interest. The findings and conclusions in this report are those of the authors and do not necessarily represent the views of the Centers for Disease Control and Prevention. 


\section{References}

1. Lozano, R.; Naghavi, M.; Foreman, K.; Lim, S.; Shibuya, K.; Aboyans, V.; Abraham, J.; Adair, T.; Aggarwal, R.; Ahn, S.Y.; et al. Global and regional mortality from 235 causes of death for 20 age groups in 1990 and 2010: A systematic analysis for the Global Burden of Disease Study 2010. Lancet 2012, 380, 2095-2128. [CrossRef]

2. Hampson, K.; Coudeville, L.; Lembo, T.; Sambo, M.; Kieffer, A.; Attlan, M.; Barrat, J.; Blanton, J.D.; Briggs, D.J.; Cleaveland, S.; et al. Estimating the global burden of endemic canine rabies. PLoS Negl. Trop. Dis. 2015, 16, e0003709.

3. World Health Organization. WHO Expert Consultation on Rabies, Second Report. 2013. Available online: http:/ /apps.who.int/iris/bitstream/10665/85346/1/9789240690943_eng.pdf (accessed on 29 August 2016).

4. Franka, R.; Wu, X.; Jackson, F.R.; Velasco-Villa, A.; Palmer, D.P.; Henderson, H.; Hayat, W.; Green, D.B.; Blanton, J.D.; Greenberg, L.; et al. Rabies virus pathogenesis in relationship to intervention with inactivated and attenuated rabies vaccines. Vaccine 2009, 27, 7149-7155. [CrossRef] [PubMed]

5. Habel, K.; Koprowski, H. Laboratory data supporting the clinical trial of antirabies serum in persons bitten by a rabid wolf. Bull. World Health Organ. 1955, 13, 773-779. [PubMed]

6. Nagarajan, T.; Marrisen, W.E.; Rupprecht, C.E. Monoclonal antibodies for the prevention of rabies: Theory and clinical practice. Antib. Technol. J. 2014, 4, 1-12. [CrossRef]

7. Prosniak, M.; Faber, M.; Hanlon, C.A.; Rupprecht, C.E.; Hooper, D.C.; Dietzschold, B. Development of a cocktail of recombinant-expressed human rabies virus-neutralizing monoclonal antibodies for postexposure prophylaxis of rabies. J. Infect. Dis. 2003, 188, 53-56. [CrossRef] [PubMed]

8. Bakker, A.B.; Marissen, W.E.; Kramer, R.A.; Rice, A.B.; Weldon, W.C.; Niezgoda, M.; Hanlon, C.A.; Thijsse, S.; Backus, H.H.; De Kruif, J.; et al. Novel human monoclonal antibody combination effectively neutralizing natural rabies virus variants and individual in vitro escape mutants. J. Virol. 2005, 79, 9062-9068. [CrossRef] [PubMed]

9. De Kruif, J.; Bakker, A.B.; Marissen, W.E.; Kramer, R.A.; Throsby, M.; Rupprecht, C.E.; Goudsmit, J. A human monoclonal antibody cocktail as a novel component of rabies postexposure prophylaxis. Annu. Rev. Med. 2007, 58, 359-368. [CrossRef] [PubMed]

10. World Health Organization. WHO Consultation on a Monoclonal Antibody Cocktail for Rabies Post-Exposure Treatment. Available online: http://www.who.int/rabies/resources/WHO_consultation_ on_RMAC_for_rabies_PEP/en/ (accessed on 15 August 2017).

11. Marissen, W.E.; Kramer, R.A.; Rice, A.; Weldon, W.C.; Niezgoda, M.; Faber, M.; Slootstra, J.W.; Meloen, R.H.; Clijsters-Van der Horst, M.; Visser, T.J.; et al. Novel rabies virus-neutralizing epitope recognized by human monoclonal antibody: Fine mapping and escape mutant analysis. J. Virol. 2005, 79, 4672-4678. [CrossRef] [PubMed]

12. Goudsmit, J.; Marissen, W.E.; Weldon, W.C.; Niezgoda, M.; Hanlon, C.A.; Rice, A.B.; De Kruif, J.; Dietzschold, B.; Bakker, A.B.; Rupprecht, C.E. Comparison of an anti-rabies human monoclonal antibody combination with human polyclonal anti-rabies immune globulin. J. Infect. Dis. 2006, 193, 796-801. [CrossRef] [PubMed]

13. Kuzmina, N.A.; Kuzmin, I.V.; Ellison, J.A.; Rupprecht, C.E. Conservation of binding epitopes for monoclonal antibodies on the rabies virus glycoprotein. J. Antivir. Antiretrovir. 2013, 5, 37-43. [CrossRef]

14. Dean, D.J.; Abelseth, M.K.; Athanasiu, P. The fluorescent antibody test. In Laboratory Techniques in Rabies, 4th ed.; Meslin, F.X., Kaplan, M.M., Koprowski, H., Eds.; World Health Organization: Geneva, Switzerland, 1996; pp. 88-95.

15. Smith, J.S.; Yager, P.A.; Baer, M. A rapid fluorescent focus inhibition test (RFFIT) for determining rabies virus-neutralizing antibody. In Laboratory Techniques in Rabies, 4th ed.; Meslin, F.X., Kaplan, M.M., Koprowski, H., Eds.; World Health Organization: Geneva, Switzerland, 1996; pp. 181-191.

16. Trimarchi, C.V.; Smith, J.S. Diagnostic evaluation. In Rabies, 1st ed.; Jackson, A.C., Wunner, W.H., Eds.; Academic Press: New York, NY, USA, 2002; pp. 307-349.

17. Hall, T.A. BioEdit: A user-friendly biological sequence alignment editor and analysis program for Windows 95/98/NT. Nucleic Acids Symp. Ser. 1999, 41, 95-98. 
18. Sloan, S.E.; Hanlon, C.; Weldon, W.; Niezgoda, M.; Blanton, J.; Self, J.; Rowley, K.J.; Mandell, R.B.; Babcock, G.J.; Thomas, W.D., Jr.; et al. Identification and characterization of a human monoclonal antibody that potently neutralizes a broad panel of rabies virus isolates. Vaccine 2007, 25, 2800-2810. [CrossRef] [PubMed]

19. Müller, T.; Dietzschold, B.; Ertl, H.; Fooks, A.R.; Freuling, C.; Fehlner-Gardiner, C.; Kliemt, J.; Meslin, F.X.; Franka, R.; Rupprecht, C.E.; et al. Development of a mouse monoclonal antibody cocktail for post-exposure rabies prophylaxis in humans. PLoS Negl. Trop. Dis. 2009, 3, e542. [CrossRef]

20. De Benedictis, P.; Minola, A.; Rota Nodari, E.; Aiello, R.; Zecchin, B.; Salomoni, A.; Foglierini, M.; Agatic, G.; Vanzetta, F.; Lavenir, R.; et al. Development of broad-spectrum human monoclonal antibodies for rabies post-exposure prophylaxis. EMBO Mol. Med. 2016, 8, 407-421. [CrossRef] [PubMed]

21. Seif, I.; Coulon, P.; Rollin, P.E.; Flamand, A. Rabies virulence: Effect on pathogenicity and sequence characterization of rabies virus mutations affecting antigenic site III of the glycoprotein. J. Virol. 1985, 53, 926-934. [PubMed]

(c) 2017 by the authors. Licensee MDPI, Basel, Switzerland. This article is an open access article distributed under the terms and conditions of the Creative Commons Attribution (CC BY) license (http:/ / creativecommons.org/licenses/by/4.0/). 


\title{
The Imperative of Palliation in the Management of Rabies Encephalomyelitis
}

\author{
Mary J. Warrell ${ }^{1, *}$, David A. Warrell ${ }^{2}$ and Arnaud Tarantola ${ }^{3}$ \\ 1 Oxford Vaccine Group, University of Oxford, Centre for Clinical Vaccinology \& Tropical Medicine, \\ Churchill Hospital, Old Rd, Headington, Oxford, OX3 7LJ, UK \\ 2 Nuffield Department of Clinical Medicine, University of Oxford, John Radcliffe Hospital, \\ Oxford, OX3 9DW, UK; david.warrell@ndm.ox.ac.uk \\ 3 Institut Pasteur de Nouvelle-Calédonie, BP 61 - 98845 Nouméa cedex, New Caledonia; \\ atarantola@pasteur.nc \\ * Correspondence: Mary.warrell@ndm.ox.ac.uk
}

Received: 8 September 2017; Accepted: 28 September 2017; Published: 4 October 2017

\begin{abstract}
The aim of this review is to guide clinicians in the practical management of patients suffering from rabies encephalomyelitis. This condition is eminently preventable by modern post-exposure vaccination, but is virtually always fatal in unvaccinated people. In the absence of any proven effective antiviral or other treatment, palliative care is an imperative to minimise suffering. Suspicion of rabies encephalomyelitis depends on recognising the classic symptomatology and eliciting a history of exposure to a possibly rabid mammal. Potentially treatable differential diagnoses must be eliminated, notably other infective encephalopathies. Laboratory confirmation of suspected rabies is not usually possible in many endemic areas, but is essential for public health surveillance. In a disease as agonising and terrifying as rabies encephalomyelitis, alleviation of distressing symptoms is the primary concern and overriding responsibility of medical staff. Calm, quiet conditions should be created, allowing relatives to communicate with the dying patient in safety and privacy. Palliative management must address thirst and dehydration, fever, anxiety, fear, restlessness, agitation, seizures, hypersecretion, and pain. As the infection progresses, coma and respiratory, cardiovascular, neurological, endocrine, or gastrointestinal complications will eventually ensue. When the facilities exist, the possibility of intensive care may arise, but although some patients may survive, they will be left with severe neurological sequelae. Recovery from rabies is extremely rare, and heroic measures with intensive care should be considered only in patients who have been previously vaccinated, develop rabies antibody within the first week of illness, or were infected by an American bat rabies virus. However, in most cases, clinicians must have the courage to offer compassionate palliation whenever the diagnosis of rabies encephalomyelitis is inescapable.
\end{abstract}

Keywords: rabies; encephalomyelitis; palliation; diagnosis; treatment

\section{Introduction}

The primary aim of this review is to re-emphasise the humanitarian role of palliative treatment in the compassionate care of patients with rabies encephalomyelitis, who have no chance of recovery. We provide practical details of this management and summarise the clinical and laboratory evidence leading to the fateful diagnosis of rabies encephalomyelitis.

Rabies infection following bites by dogs and other terrestrial mammals is eminently preventable by full modern post-exposure treatment, but if this opportunity has been missed and the virus has infected the nervous system, the condition is almost always fatal in unvaccinated people. Two children bitten by bats in the USA, only one of whom had received rabies post-exposure vaccination, have recovered from rabies encephalomyelitis to live independent lives [1,2]. Another person, who was 
bitten by a dog in Turkey and was incompletely vaccinated, also recovered [3]. However, most rabies patients given expert intensive care have either died in the acute phase or have survived for varying periods of time, but with incapacitating neurological impairment. [4,5]. In the absence of any proven effective antiviral or other treatment, how should clinicians manage patients with this appalling disease, particularly in poorer countries, where dog rabies is endemic?

The practical management of patients in this dire situation has been neglected, while thousands of patients continue to die each year after terrible suffering. For example, in India, 12,700 symptomatically identifiable furious rabies deaths occur annually, $41 \%$ in children under the age of 15 years [6]. However, patients dying of paralytic or dumb rabies are much more difficult to diagnose clinically and therefore to enumerate. No practical advice about the clinical management of rabies patients is available in dog rabies-endemic areas, where palliative care is the best and only option. As a result, clinicians presented with the occasional rabies patient have been forced to improvise. They feel unable to cope with the unpredictable, sometimes agitated, behaviour typical of 'furious' rabies encephalomyelitis. As a result, patients have been abandoned in isolated rooms and bound to their beds. The hydrophobic spasms of furious rabies are associated with feelings of terror and great agitation, and some patients may become aggressive [7]. Relatives needing an opportunity to ask questions and comfort the victim are also neglected, and patients may be sent home to families who are unable to deal with their distressing symptoms and are frightened of being infected themselves.

\section{Clinical Recognition of Rabies Encephalomyelitis}

The incubation period may be highly variable, but is usually 20-60 days after the bite exposure. Itching or other paraesthesiae at the site of the healed bite wound are common prodromal symptoms. However, many patients present with non-specific fever, headache, myalgia, fatigue, sore throat, gastrointestinal symptoms, irritability, anxiety, insomnia, or even hallucinations and may be referred to a wide variety of specialists. Correct diagnosis depends on taking a full history that may reveal the possibility of exposure to a potentially rabid mammal.

Usually within a week, the disease progresses to either furious or paralytic rabies encephalomyelitis [8]. Furious rabies is the commoner and more easily recognisable form. Hydrophobic spasms are pathognomonic and may be the only physical sign in the early stages. Growing thirst forces patients to ask for water, but attempts to drink, the sound of a tap running, or the mere mention of water, a draught of air (aerophobia), touching the palate, bright lights or loud noises may provoke powerful, jerky contractions of the diaphragm and accessory muscles of inspiration, sometimes with gripping retrosternal pain suggesting oesophageal spasms. There is no evidence of the laryngeal spasms and upper airway obstruction implied in some accounts [9]. At the end of the attack, the patient may convulse and become contorted into a position of transient opisthotonos. Patients describe a feeling of terror that they are unable to explain, associated with the spasms. Many die of respiratory or cardiac arrest during these episodes [10]. Phases of extreme excitement, aggression, anxiety, or hallucinations are interspersed with lucid intervals, during which patients may fully comprehend their appalling predicament. Other features include fever, meningism, cranial nerve lesions, autonomic nervous system overactivity (labile temperature, blood pressure, pulse rate, sweating, hypersalivation, lacrimation), cardiac tachyarrhythmias, myocarditis, dramatic polyuria due to diabetes insipidus, haematemesis from Mallory-Weiss oesophageal tears, and hypersexuality. Even with intensive care, patients soon become comatose and may die within a few days or survive for many weeks or months.

The more insidious paralytic or 'dumb' form of the disease is far less distinctive and consequently less often recognised [11-13]. It is characteristic of vampire bat-transmitted rabies and some cases of failed postexposure vaccination. Prodromal symptoms are followed by paraesthesiae, fever, and flaccid paralysis, starting in the bitten limb and then ascending with fasciculations [14], sensory symptoms, sphincter dysfunction, and terminal bulbar and respiratory paralysis. Hydrophobic spasms and 
excitation are usually absent. Even without supportive care, these patients may survive as long as 30 days [11].

If rabies is suspected, every effort should be made to eliminate potentially-treatable differential diagnoses, including encephalopathies caused by other viruses, bacteria including rickettsia, fungi, parasites, drugs, toxins, and psychotic states [15]. This point is exemplified by the case of an agitated teenage girl admitted to hospital with a diagnosis of acute psychosis. She then became drowsy and developed seizures and phobic spasms. Rabies encephalitis was diagnosed, but when she was referred to another hospital in coma, investigations revealed $P$. falciparum. After treatment for cerebral malaria, she recovered fully [16]. Conversely, however, among 133 children dying of central nervous system infections in Malawi, $10.5 \%$ had unsuspected rabies encephalitis confirmed at post-mortem. Three $(11.5 \%)$ of 26 of the fatal cases originally diagnosed as cerebral malaria were in fact due to rabies [17].

\section{Confirmation of Suspected Rabies}

This is important to stop the search for a potentially-treatable condition, to decide on a clinical management plan, to warn others possibly infected by the same animal but unvaccinated, and to offer pre-exposure prophylaxis to relatives and caregivers. Positive diagnoses also contribute to public health surveillance, and guide prevention. However, in most countries with enzootic dog rabies, the diagnosis of human rabies is rarely feasible. Animal testing laboratories are scarce and usually found only in major cities. With advances in techniques, the diagnosis could be made at a remote laboratory, or possibly on a post-mortem needle necropsy by a rapid test on-site [18-21]. Clinicians must be made aware of the possibilities and provide adequate specimens for testing.

\subsection{Intravitam Confirmation of Human Rabies Encephalitis (Table 1)}

The diagnosis of rabies can be made by isolation of virus, identification of antigen or, in unvaccinated patients, antibody detection. First, it is important to find out from the local rabies reference laboratory which tests they can perform, which samples to take, whether to store them in a fridge or frozen, and how to package and send them. Isolation of the virus in tissue culture or by inoculation of suckling mice confirms the diagnosis with high specificity but lower sensitivity than other methods. It is also less technically demanding, uses cheaper reagents, and is the method of choice.

Positive results are most likely during the first week of illness, from saliva, throat, trachea or eye swabs, brain biopsy samples, and CSF. Viraemia has not been detected.

Rabies diagnosis is most commonly made by a variety of reverse transcription polymerase chain reaction (RT-PCR) tests on saliva, skin biopsy or CSF, but this is possible only in specialist laboratories [22]. Remote testing can be very successful. A reverse-transcription hemi-nested polymerase chain reaction (RT-hnPCR) gave excellent results in Cambodia, Madagascar, Senegal, and France when performed on a skin biopsy specimen taken any time after the onset of symptoms, or from at least three successive saliva samples from each patient [23].

A direct immunofluorescent antibody (IFA) test rapidly confirms antigen in frozen sections of skin biopsies taken from a hairy area, usually the nape of the neck [19,24-26]. False positives have not been reported. Unfortunately, this test is rarely performed. The corneal smear IFA test is very insensitive, and the results are unreliable $[19,26]$.

In unvaccinated patients, detection of rabies neutralising antibody is diagnostic. This might appear in the second week of illness, but patients often die before generating any antibody response. In vaccinated people, very high and rising levels of antibody in the serum, and especially in the CSF, suggest the diagnosis [1,2].

The two validated serological methods, the fluorescent antibody neutralization test (FAVN) and the rapid fluorescent focus inhibition test (RFFIT), are technically demanding. Commercial ELISA kits are simpler but do not always correlate with the standard tests. Direct IF antibody methods are unreliable at low levels as cross-reactions occur with other viruses [27]. 
Table 1. Samples and methods recommended for rabies diagnosis in patients

\begin{tabular}{|c|c|c|}
\hline Sample & Purpose & Method \\
\hline $\begin{array}{l}\text { Full thickness skin } \\
\text { punch biopsy, including hair } \\
\text { follicles } \ddagger\end{array}$ & Antigen detection & $\begin{array}{l}\text { IFA test on frozen vertical section }{ }^{+} \\
\text {RT- PCR }\end{array}$ \\
\hline $\begin{array}{l}\text { Saliva }{ }^{\star} \text { or throat swab } \\
\text { Tears } \\
\text { CSF }\end{array}$ & $\begin{array}{l}\text { Virus isolation } \\
\text { and } \\
\text { Antigen detection }\end{array}$ & $\begin{array}{l}\text { Tissue culture } \\
\text { Mouse inoculation test } \\
\text { RT- PCR }\end{array}$ \\
\hline Serum & Neutralising antibody test & $\begin{array}{l}\text { Presence of antibody is diagnostic } \\
\text { in unvaccinated patients } \\
\text { Take sample on admission to save } \\
\text { for comparison } 7 \text { days later }\end{array}$ \\
\hline CSF & Neutralising antibody test & Test in parallel with serum \\
\hline $\begin{array}{l}\text { Brain post-mortem: } \\
\text { Needle necropsy } \mathbb{I} \\
\text { or } \\
\text { Autopsy sample brain stem \& } \\
\text { cerebellum }\end{array}$ & $\begin{array}{l}\text { Virus isolation } \\
\text { and } \\
\text { Antigen detection }\end{array}$ & $\begin{array}{l}\text { Tissue culture } \\
\text { Mouse inoculation test } \\
\text { IFA test on impression smear }{ }^{\circ} \\
\text { RT- PCR }\end{array}$ \\
\hline $\begin{array}{l}\ddagger \text { Highest positivity rate; }{ }^{\dagger} \mathrm{rab}^{\star} \\
\text { immunofluorescence (IFA) test; }{ }^{\star} \\
\text { is confirmed; }{ }^{\mathbb{I}} \text { necropsies are tak } \\
\text { superior orbital fissure; via the nos } \\
\text { in children; }{ }^{\circ} \text { alternative: a direct } \mathrm{r} \\
\text { light microscopy. }\end{array}$ & $\begin{array}{l}\text { tigen seen in nerve twiglets } \\
\text { sample for antigen detection, } \\
\text { h a long biopsy needle via th } \\
\text { gh the ethmoid bone; through } \\
\text { nmunohistochemical test with }\end{array}$ & $\begin{array}{l}\text { round the base of hair follicles by } \\
\text { peat daily at least } x 3 \text {, until a diagnosis } \\
\text { nedial canthus of the eye through the } \\
\text { e foramen magnum or open fontanelles } \\
\text { iotinylated monoclonal antibodies and }\end{array}$ \\
\hline
\end{tabular}

\subsection{Postmortem Diagnosis}

All the methods mentioned above may be used to confirm the diagnosis postmortem, especially if the clinical illness was very short. Brain samples offer the best chance of successful postmortem diagnosis. These can be obtained without a full necropsy examination (Table 1). Other encephalitides or cerebral malaria may also be diagnosed from brain tissue.

In any part of the world, but especially where there are cultural or religious objections to delayed burial or a full autopsy that includes craniotomy, post-mortem needle necropsy is a most useful technique for obtaining brain samples from anterior or posterior fossae and brain stem [28] (Table 1). The usual diagnostic technique is the direct IFA test as used on animals [29]. A local veterinary laboratory may be helpful if the test is done routinely. If no IF microscope is available, the alternative is a direct rapid immunohistochemical test (dRIT) using biotinylated monoclonal antibodies and light microscopy.

Rabies rapid antigen immunodiagnostic test (RIDT) lateral flow kits are being developed for animal testing in the field [20] and could also be used with human brain samples.

\section{Care of Patients with Confirmed Rabies Encephalomyelitis}

In a disease as agonising and terrifying as rabies encephalomyelitis, alleviation of distressing symptoms is the primary concern and overriding responsibility of medical staff. However, in many clinics and hospitals across rabies endemic areas of the world, patients suspected of having rabies are deemed to be untreatable. They are either sent home with their relatives without advice or drugs or are isolated and sometimes abandoned in a remote part of the health facility and denied any medical attention. These practices ignore the fundamental precept that a doctor's responsibility is to relieve suffering even if there is no expectation of cure. 


\subsection{Accommodation}

To avoid provoking hydrophobic or aerophobic spasms, calm, quiet conditions should be created, ideally in a dimly-lit, draught-free, single-bedded room. Restraining the patient in bed can be attempted initially with loose and comfortable ties and cot-sides, and ultimately by adequate sedation. Relatives must be able to communicate with the dying patient with dignity, in safety and privacy, according to their cultural and religious traditions. Other visitors should be restricted, including hospital staff not directly involved in management. However, frequent monitoring is needed so that patients can be given adequate supportive treatment.

\subsection{Protection of Staff, Relatives, and Other Patients}

Although there is no virologically documented instance of person-to-person rabies transmission, patients' saliva and secretions may contain the virus, and so they should be isolated, and their relatives and medical attendants protected with gloves, masks, and gowns, reassured, and offered pre-exposure vaccination. Objects, such as utensils, contaminated with patients' saliva or other secretions should be thoroughly washed with soap, or detergent.

\subsection{Thirst/Dehydration}

Hydrophobic patients cannot tolerate drinking, while those with paralytic rabies often cannot swallow. As a result, these patients may become dehydrated and desperately thirsty. Some may be able to eat fruit such as bananas and suck citrus fruits to combat thirst, and their lips and tongue may be moistened with a damp sponge or flannel. Treatment demands a secure intravenous (iv) line, ideally a catheter rather than a needle. The iv site should be immobilised by splinting. Isotonic $5 \%$ glucose, $0.9 \%$ saline, or Hartmann's (Ringer's lactate) solution (of sodium chloride, sodium lactate, potassium chloride, and calcium chloride) can be used as appropriate. Other possible routes for parenteral rehydration, depending upon available skills and equipment, include intraperitoneal, intraosseous, subcutaneous (sc), or intrarectal (proctoclysis).

\subsection{Fever}

Since physical methods such as tepid sponging and fanning are intolerable to most patients with furious rabies, antipyretic drugs are necessary to control fever. Aspirin, ibuprofen or diclofenac, and paracetamol (acetaminophen) can be given by non-oral routes, such as iv, im, or intrarectal (Table 2). Many patients have evidence of a generalised inflammatory response (e.g. peripheral neutrophil leucocytosis) as a cause for fever [7,8]. However, when the fever is central (neurogenic) in origin, antipyretics may be ineffective. Drugs that have proved effective in individual cases of central hyperthermia include baclofen, bromocriptine, amantadine, dantrolene, and propranolol, but these are unlikely to be widely available in developing countries [30].

\subsection{Anxiety, Fear, Restlessness, Agitation, Seizures-Use of Sedatives and Tranquillisers}

Benzodiazepines are drugs of choice as they are usually available and are on the World Health Organization's list of essential medicine [31]. They are used widely in daily clinical practice in most places and can be administered by various routes (Table 2). Diazepam can be given in the same doses intramuscularly (im) (which may be painful), intravenously (iv), or intrarectally. Although this is a fatal condition, it is important to avoid depressing respiration by giving the diazepam too rapidly by iv injection. Diazepam will alleviate the patient's suffering, while giving the family time to adjust and consider the possibility of taking them home to die, if that is their personal or cultural preference [32]. This can be achieved by giving a slow injection $(0.5 \mathrm{ml} / \mathrm{min}$, which is $2.5 \mathrm{mg} / \mathrm{min})$ of diazepam. The same doses of diazepam given intrarectally may be useful if the family wish to take the patient home. 
Midazolam, an alternative benzodiazepine, has a much shorter half-life. When given im, sc, or iv, it should be 'titrated' against the patient's clinical condition, which must be assessed frequently. Small doses are injected im at frequent intervals or by continuous iv infusion using an electric syringe.

A study of 45 patients in Manila identified their principal distressing symptoms and signs as hydrophobia, aggression, hyperexcitability, aerophobia, disorientation, hypervigilance, difficulty swallowing, hallucination, hypersalivation, anxiety/fear, seizure activity, and restlessness/agitation [33]. Anxiety/fear and restlessness/agitation were relieved by giving either haloperidol alone or diazepam alone, while a combination of the two was also effective against aggression/disorientation/hallucinations. Hypersalivation, hydrophobia and aerophobia were not affected by these treatments. Adult dosages were: haloperidol $5 \mathrm{mg}$ sc or im every hour for at least three doses or until the patient became calm, then haloperidol $5 \mathrm{mg}$ sc or im every 4 or 6 hourly and as needed; and diazepam $20 \mathrm{mg}$ im every $2 \mathrm{~h}$. Haloperidol can also be given by sc injection or infusion and diazepam intrarectally and by iv injection, but only under strict supervision. A patient with rabies encephalomyelitis in Wisconsin, USA, developed neuroleptic malignant syndrome that was attributed to haloperidol [34], but this is too rare a complication of treatment with drugs like haloperidol and chlorpromazine to contraindicate their use in likely-fatal disease. If none of these drugs is available, other possibilities include lorazepam (im, slow iv) or barbiturates (slow iv).

Table 2. Drugs for the palliative management of patients with confirmed or strongly suspected rabies encephalomyelitis that are included in the WHO Model List of Essential Medicines 20th List (March 2017) and WHO Model List of Essential Medicines for Children 6th List (March 2017). http://www.who.int/medicines/publications/essentialmedicines/en/ Recommended doses are taken from https://www.bnf.org/products/bnf-online/ and https://bnfc.nice.org.uk/.

\begin{tabular}{|c|c|c|c|c|}
\hline Indication & Drug & $\begin{array}{c}\text { Route of } \\
\text { administration }\end{array}$ & Dose: adult & Dose: paediatric \\
\hline \multirow[t]{3}{*}{ Fever } & paracetamol & $\begin{array}{c}\text { iv infusion over } 15 \\
\text { minutes } \\
\text { intrarectal }\end{array}$ & $\begin{array}{l}1 \mathrm{~g} \text { every } 4-6 \mathrm{~h}, \\
\text { maximum } 4 \mathrm{~g} / 24 \mathrm{~h} \\
1 \mathrm{~g} \text { every } 4-6 \mathrm{~h}, \\
\text { maximum } 4 \mathrm{~g} / 24 \mathrm{~h}\end{array}$ & $\begin{array}{c}125-500 \mathrm{mg} \text { every } \\
4-6 \mathrm{~h}\end{array}$ \\
\hline & ibuprofen & intrarectal & $300-400$ mg 6-8 hrly & \\
\hline & aspirin & intrarectal & $\begin{array}{l}450-900 \mathrm{mg} 4 \text { hrly, } \\
\text { maximum } 3.6 \mathrm{~g} / \text { day }\end{array}$ & \\
\hline \multirow{5}{*}{$\begin{array}{l}\text { Anxiety, } \\
\text { agitation, } \\
\text { seizures }\end{array}$} & \multirow[t]{2}{*}{ diazepam } & iv (slow! caution!) & $\begin{array}{l}10 \mathrm{mg} \text { in } 3-5 \text { minutes, } \\
\text { repeated } 1-4 \text { hrly }\end{array}$ & $\begin{array}{c}0.1-0.3 \mathrm{mg} / \mathrm{kg} \text { in } 3-5 \\
\text { min, repeated } 1-4 \text { hrly } \\
\text { to provide } 2.4-12 \\
\mathrm{mg} / \mathrm{kg} / 24 \mathrm{~h}\end{array}$ \\
\hline & & $\begin{array}{l}\text { im (painful!) } \\
\text { intrarectal }\end{array}$ & $\begin{array}{l}20 \mathrm{mg} 2 \text { hrly } \\
10 \mathrm{mg} 1-4 \text { hrly }\end{array}$ & $\begin{array}{l}0.1-0.3 \mathrm{mg} / \mathrm{kg} 1-4 \text { hrly } \\
0.1-0.3 \mathrm{mg} / \mathrm{kg} 1-4 \text { hrly }\end{array}$ \\
\hline & lorazepam & $\begin{array}{c}\text { im or slow iv } \\
\text { injection into large } \\
\text { vein (slow! caution!) }\end{array}$ & $\begin{array}{c}\text { 25-50 microg/kg } 6 \\
\text { hrly }\end{array}$ & 25-50 microg/kg 6 hrly \\
\hline & \multirow[t]{2}{*}{ midazolam } & $\begin{array}{c}\text { im } \\
\text { iv or sc injection } \\
\text { sc infusion }\end{array}$ & $\begin{array}{c}0.08-0.2 \mathrm{mg} / \mathrm{kg} \\
\text { repeated } 1-4 \mathrm{hrly} \\
2.5 \mathrm{mg} \text { hrly } \\
10-30 \mathrm{mg} \text { over } 24 \mathrm{~h} \\
\text { by pump }\end{array}$ & $\begin{array}{c}0.07-0.1 \mathrm{mg} / \mathrm{kg} \\
\text { repeated } 1-4 \text { hrly }\end{array}$ \\
\hline & & intrarectal & & $\begin{array}{c}\text { 300-500 microg 1-4 } \\
\text { hrly }\end{array}$ \\
\hline \multirow{3}{*}{$\begin{array}{l}\text { Anxiety, } \\
\text { agitation }\end{array}$} & \multirow[t]{2}{*}{ haloperidol } & im or sc injection & $\begin{array}{l}5 \mathrm{mg} \text { hourly until } \\
\text { calm, then } 4 \text { or } 6 \text { hrly } \\
\text { and when necessary }\end{array}$ & $\begin{array}{c}\text { age } 1 \text { month-12 y: } \\
25-85 \text { microg } / \mathrm{kg} / 24 \mathrm{~h}\end{array}$ \\
\hline & & iv or sc infusion & $5-15 \mathrm{mg} / 24 \mathrm{~h}$ & $12-18$ y: $1.5-5 \mathrm{mg} / 24 \mathrm{~h}$ \\
\hline & chlorpromazine & $\begin{array}{l}\text { deep im } \\
\text { intrarectal }\end{array}$ & $\begin{array}{l}25-50 \mathrm{mg} / 6-8 \text { hrly } \\
100 \mathrm{mg} / 6-8 \text { hrly }\end{array}$ & 500 microg/kg 6-8 hrly \\
\hline \multirow{2}{*}{ Hypersecretion } & \multirow{2}{*}{$\begin{array}{c}\text { hyoscine } \\
\text { (scopolamine) } \\
\text { hydrobromide }\end{array}$} & sc or iv injection & 400 microg 4 hrly & 10 microg $/ \mathrm{kg} 4-8$ hrly \\
\hline & & sc infusion & $1.2-2 \mathrm{mg} / 24 \mathrm{~h}$ & $40-60$ microg $/ \mathrm{kg} / 24 \mathrm{~h}$ \\
\hline \multirow{2}{*}{ Pain } & morphine & $\begin{array}{l}\text { slow iv, sc or im } \\
\text { intrarectal }\end{array}$ & $\begin{array}{c}10 \mathrm{mg} 4 \text { hrly } \\
15-30 \mathrm{mg} 4 \text { hrly }\end{array}$ & 100 microg $/ \mathrm{kg}$ \\
\hline & fentanyl & transdermal patch & $\begin{array}{l}\text { 12-25 microg/h } \\
\text { every } 72 \mathrm{~h}\end{array}$ & $12 \mathrm{microg} / \mathrm{h}$ every $72 \mathrm{~h}$ \\
\hline
\end{tabular}




\subsection{Hypersecretion (Salivation, Lacrimation, Sweating)}

This may be reduced by anti-muscarinic anticholinergic drugs, such as hyoscine (scopolamine) hydrobromide, that block parasympathetic secretory activity.

\subsection{Pain}

There is a role for opioids and other powerful analgesics, when they are available, to relieve pain and suffering in rabies victims. Morphine can be given iv, sc, im, or intrarectally, and fentanyl transdermally by patch, which may be especially valuable for terminal management of patients after they have returned home.

As the infection progresses, coma and respiratory, cardiovascular, neurological, endocrine, or gastrointestinal complications will eventually ensue. When the diagnosis is clear, palliative care is the only compassionate strategy for treating previously unvaccinated patients infected by dogs or other terrestrial mammals.

At this stage, neuronal infection will be widespread. Animal experiments show that, even if cells are cleared of the virus, abnormal gene expression remains. Alterations in some neuronal functions would be permanent [35].

\section{The Likelihood of Recovery Will Vary According to the Origin of Infecting Virus and Whether the Patient Has Been Vaccinated}

In the Americas, all bat rabies viruses are rabies genotype/species 1, but are genetically distinct from the classic rabies viruses of terrestrial mammals in the same group [36]. Recovery from encephalomyelitis has been seen in two patients infected by these American insectivorous bat strains that may be less pathogenic in man. Rabies-related lyssaviruses, which infect bats in the rest of the world, show clinical signs similar to classical rabies viruses. Rabies viruses from dogs and other terrestrial mammals have been rapidly fatal in unvaccinated patients.

In patients who have had some rabies vaccine before the onset of symptoms, the progression of the disease can be more gradual. The surprising case of a man bitten by a dog in Turkey and incompletely vaccinated, and who developed rabies, is reported to have shown signs of spontaneous recovery with decreasing hydrophobia, beginning on his second day in hospital. Rabies antibody was present when first tested within a week of the onset of symptoms. He had had supportive treatment but no specialised intensive care and returned to normal life as a shepherd [3].

This case suggests that keeping the patient in hospital with simple clinical management does not prevent recovery if the patient's immunity is able to control the infection. In contrast, ITU treatment of patients who were vaccinated before the onset of symptoms can prolong the illness, but without any signs of spontaneous improvement, and leave them with severe persistent neurological deficits.

\section{A Dilemma Arises when Expert ITU Facilities are Available}

The decision whether or not to give intensive care relies on confirming the diagnosis in patients at an early stage before they have developed signs of overt clinical rabies, and rapidly testing the neutralising antibody level. If there is a history of an insectivorous bat bite in the Americas, ITU therapy may be considered. However, the diagnosis of rabies might be made only at a terminal stage or post-mortem, because the patients were unaware of any exposure, especially contact with a bat.

Analysis of clinical data leads to the conclusion $[37,38]$ that, if rabies is diagnosed in a previously-vaccinated patient infected by a dog, the relatives must be made aware of the fact that, although intensive care can prolong life, the patient is most unlikely ever to regain full consciousness and will be left with multiple disabilities [39]. It is therefore wise to decide against intensive care for unvaccinated patients infected by a terrestrial mammal in routine clinical practice. This also applies to previously-vaccinated patients with clear signs of rabies who fail to show a rapid steep increase 
in neutralising antibody levels and early signs of improvement. Progression of the disease despite intensive care indicates that palliation rather than intervention is the better course of action.

Recovery from rabies is extremely rare and associated with the presence of neutralising antibody in the blood and also in the CSF.

ITU therapy could therefore be considered if patients:

1. have been vaccinated previously;

2. develop rabies antibody within the first week of illness;

3. were infected by an American bat rabies virus (see above), especially if they present early.

Alleviating symptoms and signs of respiratory, cardiac, and other complications demands expert ITU management. The aim is to maintain homeostasis until the endogenous antibody and probably cellular immunity generated by the patient inhibits viral replication and clears virus from neurological tissue by unknown mechanisms [1,2].

If the diagnosis were initially in doubt and intensive care has already been started, the pressure to continue may be difficult to resist. However, clinicians should be confident in recognising that the disease is beyond recovery, stop aggressive interventions, and begin palliative care to avoid the patient's and their relatives' suffering further.

Striving to keep patients alive without a reasonable prospect of restoring them to a good quality of life would be considered unethical.

\section{Antiviral Therapy?}

At present, there is no specific antiviral agent or other therapy to kill or neutralise rabies virus in the brain. The 'Milwaukee' protocol gave rise to much hope but has proved no more effective than expert ITU therapy alone [38]. Several antiviral or immunotherapeutic methods have been suggested or tried $[40,41]$. One of these, favipiravir, a purine analogue, was effective against other ssRNA viruses. It showed some suppression of street rabies virus replication in vitro, but this effect may vary with different neuroblastoma cell lines. When used in mice as oral post-exposure prophylaxis an hour after inoculation as an alternative to rabies immunoglobulin, it reduced mortality and the titre of virus in the brain when the highest dose of $300 \mathrm{mg} / \mathrm{kg} /$ day was used. If favipiravir was delayed, starting four days post-inoculation or at the onset of symptoms, there was no effect on mouse mortality [42]. A similar study of favipiravir given to mice soon after inoculation showed no effect on mortality [43].

In the future, however, more effective treatment of rabies encephalitis may become possible. A promising method is injection of an attenuated rabies virus intrathecally, or perhaps iv injection of neutralising antibody, if the blood brain barrier can be bypassed by intraventricular administration [41], or breached pharmacologically $[44,45]$. Such apparently drastic therapy would be ethical for some sufferers of this fatal infection, but should be undertaken only when there is evidence of effectiveness in animals, and in an ethical and specialised research setting.

Hospitalization often provides little palliative care in developing countries. To correct this deficiency, clear practical guidelines based on recent relevant literature should be made available on national and international websites. The WHO and the World Medical Association are in a good position to promote this compassionate policy.

\section{Prophylaxis}

Rabies vaccine prophylaxis has been $100 \%$ successful if pre-exposure immunisation is followed by post-exposure booster vaccination.

Although there are no confirmed cases of rabies transmitted to caregivers, hospital staff and the patients' relatives will be reassured by the protection afforded by vaccination. Giving rabies vaccine intradermally (id) at multiple sites induces rapid seroconversion, which has been known for decades [46]. To complete a pre-exposure course, a second dose im or id should be given at least seven days later [47]. 
Giving pre-exposure vaccination to children living in dog rabies-endemic areas would be ideal, but is unaffordable. Pre-exposure vaccination is recommended for anyone, especially children living in dog rabies-endemic areas, if they have access to and can afford it. Vials of vaccine can be shared economically between groups, e.g. families, if injected id [47]. A new syringe and needle must be used for each person. For the vaccinee, this is an insurance against having to pay for full post-exposure vaccination and RIG if exposed for the rest of their lives. If exposure does occur in subsequent years, only wound washing and im or id booster post-exposure vaccination, requiring one or two clinic visits, are needed [47]. Intradermal inoculation of rabies vaccine is not accepted by some authorities, in which case the national protocols should be followed.

\section{Conclusion}

Rabies encephalomyelitis inflicts on its sufferers one of the most agonising deaths imaginable [48] Unfortunately, the inescapably fatal outcome has discouraged medical staff from active management of patients with rabies encephalomyelitis, distracting them from the imperative of humane palliative care. Consideration of the terminal care of rabies patients has been long delayed and deserves formal attention to minimize the suffering of those dying of this terrible disease. Clinicians must have the courage to offer compassionate palliation whenever the diagnosis is evident.

Conflicts of Interest: The authors declare no conflict of interest.

\section{References}

1. Hattwick, M.A.W.; Weis, T.T.; Stechschulte, C.J.; Baer, G.M.; Gregg, M.B. Recovery from rabies: a case report. Ann. Intern. Med. 1972, 76, 931-942. [CrossRef] [PubMed]

2. Willoughby, R.E., Jr.; Tieves, K.S.; Hoffman, G.M.; Ghanayem, N.S.; Amlie-Lefond, C.M.; Schwabe, M.J.; Chusid, M.J.; Rupprecht, C.E. Survival after treatment of rabies with induction of coma. N. Engl. J. Med. 2005, 352, 2508-2514. [CrossRef] [PubMed]

3. Karahocagil, M.K.; Akdeniz, H.; Aylan, O.; Sünnetçioğlu, M.; Ün, H.; Yapici, K.; Baran, A.İ. Complete recovery from clinical rabies: case report. Turk. Klin. J. Med. Sci. 2013, 33, 547-552.

4. Mani, R.S. Human rabies survivors in india: an emerging paradox? PLoS Negl. Trop. Dis. 2016, 10, e0004774.

5. Jackson, A.C. Human rabies: a 2016 update. Curr. Infect. Dis. Rep. 2016, 18, 38. [CrossRef] [PubMed]

6. Suraweera, W.; Morris, S.K.; Kumar, R.; Warrell, D.A.; Warrell, M.J. Deaths from symptomatically identifiable furious rabies in India: a nationally representative mortality survey. PLoS Negl. Trop. Dis. 2012, 6, e1847. [CrossRef] [PubMed]

7. Warrell, D.A.; Davidson, N.M.; Pope, H.M.; Bailie, W.E.; Lawrie, J.H.; Ormerod, L.D.; Kertesz, A.; Lewis, P. Pathophysiologic studies in human rabies. Am. J. Med. 1976, 60, 180-190. [CrossRef]

8. Warrell, D.A. The clinical picture of rabies in man. Trans. R. Soc. Trop. Med. Hyg. 1976, 70, 188-195. [CrossRef]

9. Mahadevan, A.; Suja, M.S.; Mani, R.S.; Shankar, S.K. Perspectives in diagnosis and treatment of rabies viral encephalitis: insights from pathogenesis. Neurotherapeutics 2016, 3, 477-492. [CrossRef] [PubMed]

10. Dupont, J.R.; Earle, K.M. Human rabies encephalitis. A study of forty-nine fatal cases with a review of the literature. Neurology 1965, 11, 1023-1034. [CrossRef]

11. Hurst, E.W.; Pawan, J.L. An outbreak of rabies in Trinidad without history of bites, and with the symptoms of acute ascending myelitis. Caribb. Med. J. 1959, 21, 11-24. [CrossRef]

12. Dumb rabies. Lancet 1978, 2, 1031-1032. [CrossRef]

13. Chopra, J.S.; Banerjee, A.K.; Murthy, J.M.; Pal, S.R. Paralytic rabies: a clinico-pathological study. Brain 1980, 103, 789-802. [CrossRef] [PubMed]

14. Phuapradit, P.; Manatsathit, S.; Warrell, M.J.; Warrell, D.A. Paralytic rabies: some unusual clinical presentations. J. Med. Assoc. Thai. 1985, 68, 106-110.

15. Tarantola, A.; Goutard, F.; Newton, P.; de Lamballerie, X.; Lortholary, O.; Cappelle, J.; Buchy, P. Estimating the burden of Japanese encephalitis virus and other encephalitides in countries of the Mekong region. PLoS Negl. Trop. Dis. 2014, 8, e2533. [CrossRef] [PubMed] 
16. Mudiyanselage, M.H.; Weerasinghe, N.P.; Pathirana, K.; Dias, H. Misdiagnosis of cerebral malaria initially as acute psychotic disorder and later as human rabies: a case report. BMC. Res. Notes. 2016, 9, 400. [CrossRef] [PubMed]

17. Mallewa, M.; Fooks, A.R.; Banda, D.; Chikungwa, P.; Mankhambo, L.; Molyneux, E.; Molyneux, M.E.; Solomon, T. Rabies encephalitis in malaria-endemic area, Malawi, Africa. Emerg. Infect. Dis. 2007, 3, 136-139. [CrossRef] [PubMed]

18. Mani, R.S.; Madhusudana, S.N. Laboratory diagnosis of human rabies: recent advances. Sci. World J. 2013, 569-712. [CrossRef] [PubMed]

19. Duong, V.; Tarantola, A.; Ong, S.; Meya, C.; Choeung, R.; Ly, S.; Bourhy, H.; Dussart, P.; Buchy, P. Laboratory diagnostics in dog-mediated rabies: an overview of performance and a proposed strategy for various settings. Int. J. Inf. Dis. 2016, 46, 107-114. [CrossRef]

20. Léchenne, M.; Naïssengar, K.; Lepelletier, A.; Alfaroukh, I.O.; Bourhy, H.; Zinsstag, J.; Dacheux, L. Validation of a rapid rabies diagnostic tool for field surveillance in developing countries. PLoS Negl. Trop. Dis. 2016, 10, e0005010. [CrossRef] [PubMed]

21. Eggerbauer, E.; de Benedictis, P.; Hoffmann, B.; Mettenleiter, T.C.; Schlottau, K.; Ngoepe, E.C.; Sabeta, C.T.; Freuling, C.M.; Müller, T. Evaluation of six commercially available rapid immunochromatographic tests for the diagnosis of rabies in brain material. PLoS Negl. Trop. Dis. 2016, 10, e0004776. [CrossRef] [PubMed]

22. Dacheux, L.; Wacharapluesadee, S.; Hemachudha, T.; Meslin, F.X.; Buchy, P.; Reynes, J.M. More accurate insight into the incidence of human rabies in developing countries through validated laboratory techniques. PLoS Negl. Trop. Dis. 2010, 4, e765. [CrossRef] [PubMed]

23. Dacheux, L.; Reynes, J.M.; Buchy, P.; Sivuth, O.; Diop, B.M.; Rousset, D.; Rathat, C.; Jolly, N.; Dufourcq, J.B.; Nareth, C; i et al. A reliable diagnosis of human rabies based on analysis of skin biopsy specimens. Clin. Inf. Dis. 2008, 47, 1410-1417. [CrossRef] [PubMed]

24. Bryceson, A.D.M.; Greenwood, B.M.; Warrell, D.A. Demonstration during life of rabies antigen in humans. J. Infect. Dis. 1975, 131, 71-74. [CrossRef] [PubMed]

25. Blenden, D.C.; Creech, W.; Torres-Anjel, M.J. Use of immunofluorescence examination to detect rabies virus antigen in the skin of humans with clinical encephalitis. J. Infect. Dis. 1986, 154, 698-701. [CrossRef] [PubMed]

26. Warrell, M.J.; Looareesuwan, S.; Manatsathit, S.; White, N.J.; Phuapradit, P.; Vejjajiva, A.; Hoke, C.H.; Burke, D.S.; Warrell, D.A. Rapid diagnosis of rabies and post-vaccinal encephalitides. Clin. Exp. Immunol. 1988, 71, 229-234. [PubMed]

27. Rudd, R.J.; Appler, K.A.; Wong, S.J. Presence of cross-reactions with other viral encephalitides in the indirect fluorescent-antibody test for diagnosis of rabies. J. Clin. Microbiol. 2013, 51, 4079-4082. [CrossRef] [PubMed]

28. Marsden, P.D. Needle autopsy. Rev. Soc. Bras. Med. Trop. 1997, 30, 161-162. [CrossRef] [PubMed]

29. Stear, M.J. OIE manual of diagnostic tests and vaccines for terrestrial animals (mammals, birds and bees). Parasitology 2005, 130, 727. [CrossRef]

30. Savage, K.E.; Oleson, C.V.; Schroeder, G.D.; Sidhu, G.S.; Vaccaro, A.R. Neurogenic fever after acute traumatic spinal cord injury: a qualitative systematic review. Global. Spine. J. 2016, 6, 607-614. [CrossRef] [PubMed]

31. World Health Organization. WHO model lists of essential medicines: 20th list, 2017. Available online: http:/ / www.who.int/medicines/publications/essentialmedicines/20th_EML2017.pdf?ua=1 (accessed on 28 September 2017).

32. Tarantola, A.; Crabol1, Y.; Mahendra, B.J.; In, S.; Barennes, H.; Bourhy, H.; Peng, Y.; Ly, S.; Buchy, P. Caring for rabies patients in developing countries-the neglected importance of palliative care. Trop. Med. Internat. Health 2016, 21, 564-567. [CrossRef] [PubMed]

33. Marsden, S.C.; Cabanban, C.R. Rabies: a significant palliative care issue. Prog. Palliat. Care 2006, 14, 62-67. [CrossRef]

34. Kazmierczak, J. Rabies in Wisconsin. MMWR 2011, 60, 1164-1166.

35. Gomme, E.A.; Wirblich, C.; Addya, S.; Rall, G.F.; Schnell, M.J. Immune clearance of attenuated rabies virus results in neuronal survival with altered gene expression. PLoS Pathog. 2012, 8, e1002971. [CrossRef] [PubMed]

36. Páez, A.; Nũñez, C.; García, C.; Bóshell, J. Molecular epidemiology of rabies epizootics in Colombia: evidence for human and dog rabies associated with bats. J. Gen. Virol. 2003, 84, 795-802. [CrossRef] [PubMed] 
37. Hemachudha, T.; Sunsaneewitayakul, B.; Desudchit, T.; Suankratay, C.; Sittipunt, C.; Wacharapluesadee, S.; Khawplod, P.; Wilde, H.; Jackson, A.C. Failure of therapeutic coma and ketamine for therapy of human rabies. J Neurovirol. 2006, 12, 407-409. [CrossRef] [PubMed]

38. Zeiler, F.A.; Jackson, A.C. Critical appraisal of the Milwaukee protocol for rabies: this failed approach should be abandoned. Can. J. Neurol. Sci. 2016, 43, 44-51. [CrossRef] [PubMed]

39. Jackson, A.C. Recovery from rabies: a call to arms. J. Neurol. Sci. 2014, 339, 5-7. [CrossRef] [PubMed]

40. Appolinario, C.M.; Jackson, A.C. Antiviral therapy for human rabies. Antivir. Ther. 2015, 20, 1-10. [CrossRef] [PubMed]

41. Warrell, M.J.; White, N.J.; Looareesuwan, S.; Phillips, R.E.; Suntharasamai, P.; Chanthavanich, P.; Riganti, M.; Fisher-Hoch, S.P.; Nicholson, K.G.; Manatsathit, S.; et al. Failure of interferon alfa and tribavirin in rabies encephalitis. B. M. J. 1989, 299, 830-833. [CrossRef]

42. Yamada, K.; Noguchi, K.; Komeno, T.; Furuta, Y.; Nishizono, A. Efficacy of favipiravir (t-705) in rabies postexposure prophylaxis. J. Infect. Dis. 2016, 213, 1253-1261. [CrossRef] [PubMed]

43. Virojanapirom, P.; Lumlertdacha, B.; Wipattanakitchareon, A.; Hemachudha, T. T-705 as a potential therapeutic agent for rabies. J. Infect. Dis. 2016, 214, 502-503. [CrossRef] [PubMed]

44. Baer, G.M.; Shaddock, J.H.; Williams, L.W. Prolonging morbidity in rabid dogs by intrathecal injection of attenuated rabies vaccine. Infect. Immun. 1975, 12, 98-103. [PubMed]

45. Gnanadurai, C.W.; Huang, C.T.; Kumar, D.; Fu, Z.F. Novel approaches to the prevention and treatment of rabies. Int. J. Virol. Stud. Res. 2015, 3, 8-16. [PubMed]

46. Turner, G.S.; Aoki, F.Y.; Nicholson, K.G.; Tyrrell, D.A.; Hill, L.E. Human diploid cell strain rabies vaccine. Rapid prophylactic immunisation of volunteers with small doses. Lancet 1976, 1, 1379-1381. [CrossRef]

47. World Health Organization. WHO Expert Consultation on Rabies: Second report. WHO Technical Report Series 2013, 982, 1-139. Available online: http://apps.who.int/iris/bitstream/10665/85346/1/9789240690943_eng.pdf (accessed on 28 September 2017).

48. Thomas, L. The Lives of a Cell: Notes of a Biology Watcher; Viking Press: New York, NY, USA, 1974.

(C) 2017 by the authors. Licensee MDPI, Basel, Switzerland. This article is an open access article distributed under the terms and conditions of the Creative Commons Attribution (CC BY) license (http:/ / creativecommons.org/licenses/by/4.0/). 
MDPI AG

St. Alban-Anlage 66

4052 Basel, Switzerland

Tel. +41616837734

Fax +41 613028918

http://www.mdpi.com

Tropical Medicine and Infectious Disease Editorial Office

E-mail: tropicalmed@mdpi.com

http://www.mdpi.com/journal/tropicalmed

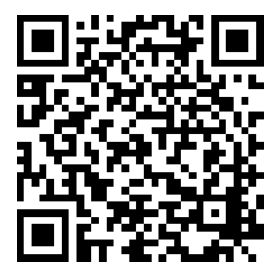



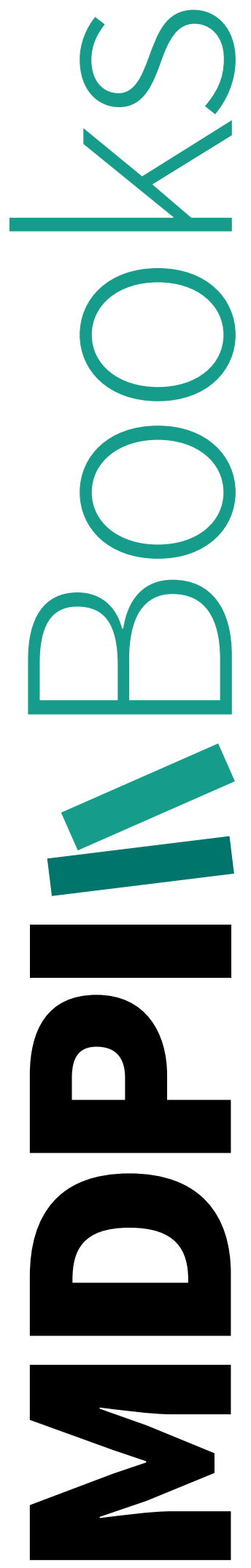


\section{MDPI AG}

St. Alban-Anlage 66

4052 Basel

Switzerland

Tel: +41 616837734

Fax: +41 613028918 